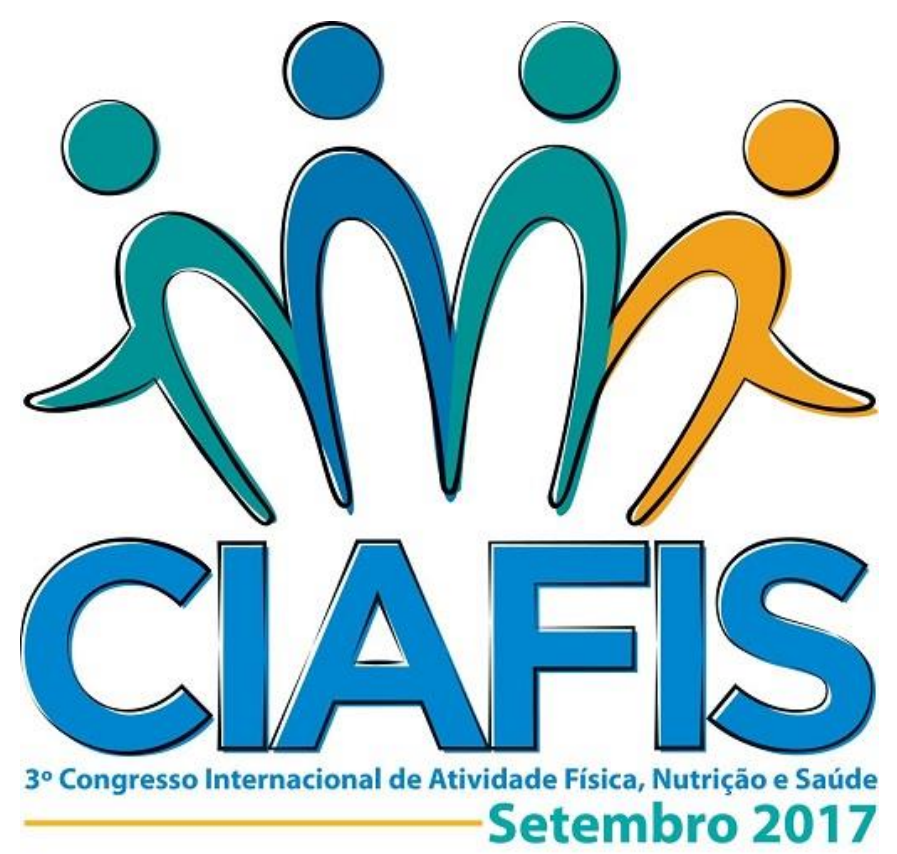

\title{
CIAFIS - Congresso Internacional de Atividade Física, Nutrição e Saúde
} 19, 20, 21, 22 e 23 de setembro de 2017

Os trabalhos publicados no presente suplemento foram submetidos à apreciação da Comissão Científica do Congresso Internacional de Atividade Física, Nutrição e Saúde - "CIAFIS", realizado nos dias 19, 20, 21,22 e 23 de setembro de 2017 na Universidade Tiradentes em Aracajú, Sergipe, Brasil. O conteúdo dos artigos é única e exclusivamente da responsabilidade dos seus autores. A Comissão Científica do CIAFIS não assume qualquer tipo de responsabilidade pelas opiniões e afirmações expressas pelos autores. É permitida a reprodução parcial dos textos e sua utilização sem fins comerciais, desde que devidamente citada a fonte/referência.

O $3^{\circ}$ Congresso Internacional de Atividade Física, Nutrição e Saúde proporcionou discussão, reflexão e prática acerca das bases teórico-metodológicas dirigidas às intervenções na área de Atividade Física, Nutrição e Saúde. Reflexões sobre o processo de envelhecimento, bem como os aspetos do envelhecer com saúde e qualidade de vida foram abordados no evento.

O envelhecimento é um fenômeno natural, universal, irreversível e não ocorre de forma simultânea e igualitária nos seres humanos. Envelhecer faz parte da vida e, visto a luz dos conhecimentos atuais, nada é possível para fazer alterar este processo. Atualmente, o envelhecimento constitui um dos temas de maior interesse da sociedade devido à transição epidemiológica que o mundo está apresentando. Diante disso, procurar respostas sobre quais são as mudanças que ocorrem nesse período, quais são as causas e as consequências são os desafios da ciência com o objetivo de retardar esse processo.

Para melhor compreensão da relação entre envelhecimento e saúde, uma abordagem multidimensional deve ser considerada, levando em consideração os aspectos biológicos, físicos, psicológicos, econômicos e sociais. Além disso, a qualidade de vida passa a ser um aspecto importante por atender as demandas de saúde da sociedade.

Tais discussões realizadas servirão para subsidiar uma análise crítica sobre a atuação dos profissionais da saúde, no Brasil e no Estado de Sergipe. É inadiável, portanto, que os acadêmicos e os professores de todas as áreas do conhecimento, conscientizem-se de que é necessário atualização e capacitação constante.

Aracaju, setembro de 2017.

Nara Michelle Moura Soares

Presidente do Comitê Científico 


\section{Content Index}

\section{motricidade 2017, vol. 13, S2 \\ http://dx.doi.org/10.6063/motricidade. 14077}

\section{Págs. Editorial}

1 Longevity, Health and Quality of Life Marzo Edir Da Silva-Grigoletto

\section{Original Articles}

2 Hemodynamic responses and physical perceptions how indicators of adequacy of abdominal test protocols for women in middle and old age: a pilot study Cláudia Eliza Patrocínio de Oliveira, Osvaldo Costa Moreira, Dihogo Gama de Matos, Eveline Torres Pereira, Sylvia C. C. Franceschini, Nádia S. L. da Silva, Leonice Aparecida Doimo

12 Does emphasis on speeds of execution modify the markers of muscle damage and neuromuscular parameters?

Yuri de Almeida Campos, Hiago Leandro Rodrigues de Souza, Osvaldo Costa Moreira, Sandro Fernandes da Silva

21 Influence of sex, school system and body mass index on the physical activity patterns of adolescents during the school period

Sabrina Fontes Domingues, João Carlos Bouzas Marins, Sílvia Eloiza Priore, Claúdia Eliza Patrocínio de Oliveira, Osvaldo Costa Moreira, Paulo Roberto dos Santos Amorim

31 Factors associated with lower limb strength and agility in the elderly Josiene de Oliveira Couto, Izabella Cristina da Silva Santos, Andressa Melo Alves, Nara Michelle Moura Soares, Gilberto Santos Morais Júnior, Danilo Barbosa Morais, Roberto Jerônimo dos Santos Silva

42 Psychological and physiological effects of music time during walking performed by overweight and obese women

Aldo Coelho Silva, Sandro dos Santos Ferreira, Ragami Chaves Alves, Lucio Follador, Erick Doner Santos de Abreu Garcia, Vinícius Ferreira dos Santos Andrade, Sergio Gregorio da Silva

52 Association between violent behavior and sports practice in adolescents from Aracaju and Metropolitan Region

Mona Gizelle Dreger de Oliveira, Kenia Rejane de Oliveira Batista, Felipe Souza Nery, Josiene de Oliveira Couto, Nara Michelle Moura Soares, Roberto Jerônimo dos Santos Silva

61 Assessment of Brazilian jiu-jitsu related injuries by severity, type and area Adonai Pinheiro Barreto, Walderi Monteiro da Silva, Natanael Sena Santos, Dihogo Gama de Matos, Diego José Lopes de Lima, Marcelo Danillo dos Santos, Alexandre Reis P. Ferreira, Raphael Fabrício de Souza, Andres Armas Alejo, Felipe J Aidar

66 Acute cardiovascular response of a vertical techniques training session Carla Fabiane dos Santos Lemos, Victor Matheus Santos do Nascimento, Layanne de Oliveira Barros, Luís Paulo de Souza Gomes, Nara Michelle Moura Soares

72 Effects of resistance training the spasticity of the upper limb paretic of individuals with sequels of stroke

Aristela de Freitas Zanona, Felipe J. Aidar,Lais Araujo Andrade, Ana Camila Nobre de Lacerda Brito, Dharah Puck Cordeiro Ferreira, Dihogo Gama de Matos, Raphael Fabricio de Souza

Burnout syndrome in physical education teachers

Guadalupe de Moraes Santos Silva, Daianne Cardinalli Rêgo, Camila Moura Ferreira Vorkapic, Marcos Bezerra de Almeida, Afrânio de Andrade Bastos 
86 Effects of a multicomponent training protocol on functional fitness and quality of life of physically active older women

Albernon Costa Nogueira, Antônio Gomes de Resende Neto, José Carlos Aragão Santos, Leandro Henrique Albuquerque Brandão, Leury Max da Silva Chaves, Luan Morais Azevêdo, Cauê V. La Scala Teixeira, Gilmar Webber Senna, Marzo Edir Da Silva-Grigoletto

94 Influence of physical activity levels on the self-esteem of female students Martha Maria Viana de Bragança, Alfonso Salguero del Valle, Sara Márquez Rosa, Elizabeth Carpio-Rivera, Afrânio de Andrade Bastos, Robélius De Bortoli, Olga Molinero González

101 Topological properties and dynamics of nets game shown by france and portugal in the final of european soccer cup 2016

Juan Manuel Martín-González, Rómulo Díaz-Díaz, Eduardo Ramos-Verde, Enrique ArriazaArdiles, Marzo Edir Da Silva-Grigoletto, Juan Manuel García-Manso

113 Weight training along with the use of nandrolone decanoate does not alter the quantity of adipose tissues in rats

Odilon Abrahin, Wiliane Nery Santos, Rejane Pequeno Rodrigues, Roberto Jerônimo dos Santos Silva, José Aderval Aragão, Felipe J. Aidar, Anderson Carlos Marçal

119 Anthropometric profile of basketball athletes by game position, competition level and competition ranking: a cross-sectional study

Petrus Gantois, Gledson Tavares de Amorim Oliveira, Breno Guilherme de Araújo Tinoco Cabral, Paulo Henrique Duarte do Nascimento, Felipe J. Aidar, Gilmário Ricarte Batista

127 Analysis of two different types of circuit training in the determinants of gait ability in elderly women

Leandro Henrique Albuquerque Brandão, Leury Max da Silva Chaves, José Carlos AragãoSantos, Albernon Costa Nogueira, Marta Silva Santos, Juan Ramón Heredia, Guillermo Peña, Antônio Gomes de Resende Neto, Marzo Edir Da Silva-Grigoletto

137 Effects of resistance exercise on posterior muscles of rats chronically treated with dexamethasone

Andressa Pâmela Pires de Siqueira, Jymmys Lopes dos Santos, Silvan Silva de Araújo, Emerson Ticona Fioretto, Vera Lúcia Corrêa Feitosa, Anderson Carlos Marçal

143 Evaluation of physical activity level, life quality and cardiovascular risk in amputees served in the basic health units of Aracaju-SE

Izabel Cristina de Oliveira Lima, Mylena Maria Salgueiro Santana, Marco Antonio Prado Nunes, Genilde Gomes de Oliveira, Géssica Uruga Oliveira, Luma Soares Lustosa, Jader Pereira de Farias Neto, Walderi Monteiro da Silva Junior

149 Anthropometric evaluation, BMI and Physical Fitness in different levels of maturation in scholars from the Jequié's City - BA, Brazil

Carlos Alberto de Oliveira Borges, Martha Maria Viana de Bragança, Alfonso Salguero del Valle, Olga Molinero González, André Luiz Carneiro, Dihogo Gama de Matos, Marcelo Danillo Matos dos Santos, Raphael Fabrício de Souza, Andres Armas Alejo, Felipe J. Aidar

158 Influence of biological maturation on the body mass index of young soccer players

Wallas Carlos Silva Oliveira, Alan Navarro Couto, Matheus Henrique Fonseca Santos, Valdicleide Teixeira Santos, Fabiana Medeiros de Almeida Silva

164 Association of instruments of functional evaluation of the lumbar spine with the international classification of functioning, disability and health

Luana Caroline Dantas Pereira; Saulo da Cunha Machado; Mylena Maria Salgueiro Santana; Géssica Uruga Oliveira; Luma Soares Lustosa; Walderi Monteiro Da Silva Júnior; Marzo Edir Da Silva Grigolleto; Jader Pereira de Farias Neto

174 Relationship between personality and pre-competitive cortisol level in bodybuilding athletes

Licia Cerqueira Ferreira, Felipe J. Aidar, Dihogo Gama de Matos, Mauro Lucio Mazini Filho, Gabriela Rezende de Oliveira Venturini, Nelson Sousa

181 Effects of high-intensity functional and endurance training on neuromuscular performance and body fat of young individuals with overweight and obesity Marta Silva Santos, Antônio Gomes de Resende Neto, Gilmar Werber Senna, Jeferson Viana, Raquel Simões Mendes Netto, Marzo Edir Da Silva-Grigoletto 


\section{Review Articles}

192 Cardiorrespiratory tests of field in elderly: a systematic review Gabriela Rezende de Oliveira Venturini, Paulo de Tarso Veras Farinatti, Nádia Souza Lima da Silva1de Almeida Silva 


\title{
Longevidade, Saúde e Qualidade de Vida
}

\author{
Longevity, Health and Quality of Life
}

Marzo Edir Da Silva-Grigoletto ${ }^{1 *}$

Os avanços científicos e tecnológicos têm colaborado sobremaneira para a prevenção e controle de doenças e para a promoção da saúde, contribuindo positivamente para o aumento da longevidade. Por outro lado, viver mais não significa viver melhor, visto que a manutenção de uma boa qualidade de vida depende de inúmeros fatores, com destaque para o estilo de vida adotado. Portanto, o desenvolvimento de estratégias que valorizem a adoção de um estilo de vida fisicamente ativo e uma alimentação adequada às necessidades da vida diária passa a ser um grande desafio, sobretudo, para pesquisadores e profissionais da saúde, na busca por um envelhecimento saudável, com autonomia funcional e cognitiva.

Neste sentido, a multidimensionalidade do processo de envelhecimento requer projetos de natureza multi e interdisciplinar que tenham como foco principal a busca de soluções viáveis, a partir de uma visão holística e de uma análise integrativa e inclusiva que transcende as perspectivas disciplinares. Logo, constituir grupos de trabalho e de intervenção com essas características torna-se uma tarefa bastante árdua e de alta complexidade.
Nesse contexto, o papel das instituições de ensino, dos eventos científicos e das comunidades científicas parece ser determinante para a produção de soluções efetivas capazes de impactar positivamente na vida dos idosos, de modo que os anos adicionais sejam vividos com qualidade e dignidade. Na maioria das vezes, com o ritmo acelerado de vida que a sociedade moderna nos impõe é difícil parar e prestar atenção nos importantes sinais que recebemos do nosso organismo, como estresse, depressão, cansaço excessivo e marcas de um envelhecimento precoce. Todavia, uma mudança de atitude é necessária e, independentemente da nossa vontade, devemos nos convencer de que o envelhecimento é inevitável e, desse modo, precisamos nos preparar para enfrentar os desafios próprios desta etapa da vida, buscando preservar as capacidades funcional e cognitiva, com vistas a preservação da autonomia. A terceira idade vai chegar, e envelhecer com saúde deve ser a nossa grande meta de vida. Se você ainda não está convencido, aproveite esse momento para refletir sobre suas atitudes e promover as mudanças necessárias para viver com mais saúde e qualidade de vida.

\footnotetext{
${ }^{1}$ Universidade Federal de Sergipe,UFS, São Cristóvão, Sergipe, Brasil.

* Autor correspondente: Rua Napoleão Dórea, 165, Apt 03, Residencial Ana Carolina, Bairro Atalaia CEP: 49037-460, Aracaju- SE. E-mail: pit_researcher@yahoo.es
} especificado em contrário e nos conteúdos retirados de outras fontes bibliográficas. 


\title{
Hemodynamic responses and physical perceptions how indicators of adequacy of abdominal test protocols for women in middle and old age: a pilot study
}

\author{
Cláudia Eliza Patrocínio de Oliveira ${ }^{1,2}$, Osvaldo Costa Moreira1,3, Dihogo Gama de Matos ${ }^{4}$, \\ Eveline Torres Pereira ${ }^{1}$, Sylvia C. C. Franceschini ${ }^{7}$, Nádia S. L. da Silva ${ }^{5}$, Leonice Aparecida \\ Doimo ${ }^{1,6}$
}

ARTIGO ORIGINAL | ORIGINAL ARTICLE

\begin{abstract}
The purpose of this study was to evaluate the hemodynamics responses and physical perceptions how indicators of adequacy of test protocols for abdominal strength in middle-age and older women. Five women, $>45$ years of age, physically active were studied. Tests performed were: partial flexion of the trunk and $7.6 \mathrm{~cm}$ sliding and reach; partial flexion of the trunk with hands on thighs; partial flexion of the trunk and hands on arms; partial flexion of the trunk and hands on elbows, and partial flexion of the trunk with a $12 \mathrm{~cm}$ sliding hand reach. The first two tests were performed in the supine position with the feet flat on the ground while the others with feet on a bench (hinged knee in $90^{\circ}$ ). We measured: heart rate (HR) and blood pressure (BP), during and after the performance of the protocols; blood pressure (BP), before and immediately after each procedure; perceived exertion of the abdominal muscles, and musculoskeletal pain. Our results indicate the inadequacy of the five abdominal test protocols, especially those performed with feet on the bench, was found for these tests when used in women older than 45 years. In conclusion, only two individuals had valid attempts and minor reports of musculoskeletal pain in the cervical and lumbar spine.

Keywords: Women, Aging, Abdominal muscles, Health.
\end{abstract}

\section{INTRODUCTION}

Regular physical exercise has been linked to minimizing the deleterious effects of aging in adults and elderly individuals, being a fundamental part of health promotion and disease prevention programs (ACSM, 2011). There is evidence that certain components of musculoskeletal fitness, such as the strength of abdominal muscles, have a predictive relationship with mortality. There is a significantly higher risk of mortality for men and women who have low abdominal strength (Artero et al., 2012).

In order to assess functional capacity in terms of performance, batteries for assessing functional fitness were developed (Clark, 1989; Rickli \& Jones, 1999; Dantas \& Vale, 2004); however, none of these batteries are focused on evaluation of abdominal strength despite the importance that muscle group plays for elderly's health.

This inadequacy of the above batteries can be due to various aspects such as: a) inadequate abdominal-specific tests for this population; b) inability to perform the test due to the physiological changes of aging that prevent the proper execution of the abdominal test, such as loss of strength as well as spinal and abdominal apoptosis; c) fear of evaluator in applying physical tests whose physiological responses are unknown in the older person d) lack of standardization for performance evaluation of the elderly population. Thus, the most appropriate abdominal test protocol for individuals of middle and old age has not been determined and nor have the

\footnotetext{
${ }^{1 \cdot}$ Institute of Biomedicine, University of Leon, Leon, Spain

2. Department of Physical Education, Federal University of Viçosa, Campus Viçosa, Viçosa, Minas Gerais, Brazil

${ }^{3}$ Institute of Biological Sciences and Health, Federal University of Viçosa, Campus Florestal, Florestal, Minas Gerais, Brazil

4. Department of Nutrition and Health - Federal University of Viçosa, Campus Viçosa, Viçosa, Minas Gerais, Brazil

${ }^{5}$ Institute of Physical Education and Sports, Rio de Janeiro State University, Rio de Janeiro, Brazil

6. Department of Education, University of the Air Force, Rio de Janeiro, Brazil

*Corresponding author: Departamento de Educação Física, Universidade Federal de Viçosa. Avenida PH Rolfs S/N, Campus Universitário, Viçosa-MG, 36570-000. Email: cpatrocinio@ufv.br
} 
cardiovascular, perceived exertion, and musculoskeletal pain responses to this test.

Given the above, this study aimed to evaluate the hemodynamic responses and physical perceptions how indicators of adequacy of abdominal test protocols used in women of middle and old age.

\section{Participants}

\section{METHODS}

The sample was intentional, nonprobabilistic, consisting of women participating in a community project of gymnastics for elderly. The criteria for participation were: to present previous medical certificate, participate in the project at least for a year, three times per week, experience in performing abdominal exercises, not hypertensive, do not use beta blockers and neither have back and hip problems. Initially, the research objectives, procedures and dynamics of implementation of the five abdominal tests used in the study were explained. Among the participants, only five women reached the end of the study, with all the variables collected. For those who agreed to participate, they signed an informed consent. All procedures were approved by the Ethics Committee on Human Research of the Federal University of Viçosa, according to Resolution 466/2012 of the National Ethics Committee - CONEP, the National Health Council, in accordance with the ethical principles expressed in the Declaration of Helsinki.

A day before the beginning of application of the abdominal tests, the women's who agreed to participate responded to an anamnesis, signed the consent form and became familiar with metronome, used in cadenced abdominal tests. After that day, each participant attended the collection site for five consecutive days, and every day (except the last), when was drawn which abdominal exercise they would perform. No warm-up before the execution of each test was allowed. The collection was individual, in a reserved place in the morning and performed by the same evaluator.

On the first day of abdominal tests, body mass (kg) and height (cm) (ISAK, 2011) measurements were collected to calculate the body mass index (BMI) and also waist circumference measurement (ISAK, 2011).

HR was continuously monitored using a heart rate monitor (Polar, model S610) during the performance of each abdominal test protocol and during recovery, which lasted one minute after the completion of exercise. Maximum heart rate (HRmax) was estimated using Tanaka, Monahan and Seals formula (Tanaka, Monahan and Seals, 2001), where HRmax $=208.75-(0.73 \mathrm{x}$ age $)$. Resting heart rate (HRrest) was measured prior to the first test, immediately following a tenminute supine rest period. The training heart rate (THR) for each individual was calculated using Karvonen formula (U.S. Department of Health and Human Services, 1996) where THR $=$ HRrest $+\%$ (HRmax -HRrest). Intensities between 60 and $80 \%$ of heart rate reserve were considered to be the lower and upper acceptable limits for the purpose of verification of the level of cardiac stress during each test (ACSM, 2011).

Blood pressure was measured before and one minute after each test according to the procedures of the VI Brazilian Guidelines on Hypertension (SBC, 2010). In order to maintain standardization, all participants had their blood pressure measured in the right arm. Blood pressure was measured with an aneroid sphygmomanometer, (Premium), and stethoscope using auscultation.

The cardiorespiratory effort in each abdominal test was assessed by the Borg scale (Borg, 1982) of 20 points. Prior to the examination, the researcher gave clear information concerning the rating procedure and the range of the scale. At the end of the abdominal test, the participants were asked by the researcher to score the intensity on the Borg scale.

The perception of musculoskeletal pain was measured by the question "Did you feel pain when performing abdominal exercise?". To evaluate pain intensity, we used a Likert scale, validated for the Brazilian population (Lamarca \& Monteiro da Silva, 2001) and adapted for the purposes of this study. The scale has five possible answers: " $0=$ I did not feel anything", " 1 =It only hurt a little," "2 = It hurt more or less", "3 = It really hurt" and "4 = It hurt too much."In this 


\section{4 | CEP Oliveira, OC Moreira, DG Matos, ET Pereira, SCC Franceschini, NSL Silva, LA Doimo}

study, the intensity of pain was dichotomized into "no or low intensity" (scores0 and 1)and "medium or high intensity" (scores2 to 4 ).
Each volunteer performed 5 abdominal test protocols, according to Table 1 .

Table 1

Abdominal test protocols with respective duration, feet position, form of execution and number of repetitions.

\begin{tabular}{|c|c|c|c|c|}
\hline Protocols/tests & $\begin{array}{l}\text { Duration } \\
\text { (min) }\end{array}$ & $\begin{array}{c}\text { Feet } \\
\text { Position }\end{array}$ & Execution & $\begin{array}{l}\text { Number of } \\
\text { repetitions }\end{array}$ \\
\hline $\begin{array}{l}\text { Protocol } 1 \text { - partial flexion } \\
\text { of the trunk and sliding } \\
\text { hands } 7.6 \mathrm{~cm} \text { (Robertson } \\
\& \text { Magnusdottir, 1987) }\end{array}$ & 1 & $\begin{array}{l}\text { On the } \\
\text { ground }\end{array}$ & $\begin{array}{l}\text { From the extremity of the } \\
\text { middle fingers, set } 7.6 \mathrm{~cm} \text { on the } \\
\text { ground; in the initial position, } \\
\text { flex the trunk and slide hands on } \\
\text { the ground trying to reach the } \\
7.6 \mathrm{~cm} \text { mark. }\end{array}$ & $\begin{array}{l}\text { Higher number } \\
\text { repetitions }\end{array}$ \\
\hline $\begin{array}{l}\text { Protocol 2-partial flexion } \\
\text { of the trunk and hands } \\
\text { on thighs (Sidnei \& Jetté, } \\
\text { 1990) }\end{array}$ & 6 & $\begin{array}{l}\text { On the } \\
\text { ground }\end{array}$ & $\begin{array}{l}\text { With knees bent between } 120- \\
140^{\circ} \text {; set a mark on the top edge } \\
\text { of the patella. From the initial } \\
\text { position, flex the trunk and slide } \\
\text { hands on thighs until they touch } \\
\text { the mark held on the knees. }\end{array}$ & $\begin{array}{l}\text { Cadenced test; } 20 \\
\text { repetitions/min; } \\
\text { maximum } \\
\text { repetitions }\end{array}$ \\
\hline $\begin{array}{l}\text { Protocol 3-partial flexion } \\
\text { of the trunk and hands } \\
\text { on arms (Plowman \& } \\
\text { Meredith, 2013) }\end{array}$ & 5 & $\begin{array}{l}\text { On the } \\
\text { bench }\end{array}$ & $\begin{array}{l}\text { From the initial position, flex } \\
\text { the trunk until your elbows } \\
\text { touch the thighs. }\end{array}$ & $\begin{array}{l}\text { Cadenced test; } 20 \\
\text { repetitions/min; } \\
\text { maximum } \\
\text { repetitions. }\end{array}$ \\
\hline $\begin{array}{l}\text { Protocol 4- partial flexion } \\
\text { of the trunk and hands } \\
\text { on elbows (Knudson \& } \\
\text { Johnston, 1985) }\end{array}$ & 2 & $\begin{array}{l}\text { On the } \\
\text { bench }\end{array}$ & $\begin{array}{l}\text { From the initial position, flex } \\
\text { the trunk until your elbows } \\
\text { touch the anterior part of thighs. }\end{array}$ & $\begin{array}{l}\text { Higher number } \\
\text { repetitions }\end{array}$ \\
\hline $\begin{array}{l}\text { Protocol 5-partial flexion } \\
\text { of the trunk and sliding } \\
\text { hands } 12 \mathrm{~cm} \text { (Sidnei \& } \\
\text { Jetté, 1990) }\end{array}$ & 6 & $\begin{array}{l}\text { On the } \\
\text { bench }\end{array}$ & $\begin{array}{l}\text { From the extremity of the } \\
\text { middle fingers, set } 12 \mathrm{~cm} \text { on the } \\
\text { ground; in the initial position, } \\
\text { flex the trunk and slide hands on } \\
\text { the ground trying to reach the } 12 \\
\text { cm mark. }\end{array}$ & $\begin{array}{l}\text { Cadenced test; } 20 \\
\text { repetitions/min; } \\
\text { maximum } \\
\text { repetitions }\end{array}$ \\
\hline
\end{tabular}

Protocols 2, 4 and 5 does not mention criteria of test interruption. Thus, the loss of pace dictated by metronome or performer's fatigue were criteria for it. Figures 1 illustrates initial and final position of each protocol.

\section{Statistical analysis}

The data were tested for normality using the Shapiro Wilk test. Data from the five protocols were reported as median, minimum and maximum values. The Friedman test to compare repeated measures was applied. The association between variables was assessed using the Spearman correlation test. For comparison of systolic and diastolic blood pressure pre-and post-test, the Wilcoxon test was used. For all analyses, we adopted a significance level of $\mathrm{p}<0.05$.

\section{RESULTS}

Participants were 57-66 years of age (median of $58 \mathrm{yrs}$ ) with a median body weight of $69.8 \mathrm{~kg}$ (59.6 to $80.0 \mathrm{~kg}$ ) and height of 1.53 meters (1.50 to 1.59 meters). Regarding performance, only valid attempts according to established criteria were counted. Valid attempts were only completed for tests 1 and 2: in test 1 only one participant completed a successful attempt, and in Test 2 only three participants completed valid attempts. For other protocols there were no valid attempt observed.

Results for perceived exertion, perceived abdominal effort and musculoskeletal pain of the lumbar and cervical spine are presented in Table 2. 
Protocol 1 (Robertson \& Magnusdottir, 1987)
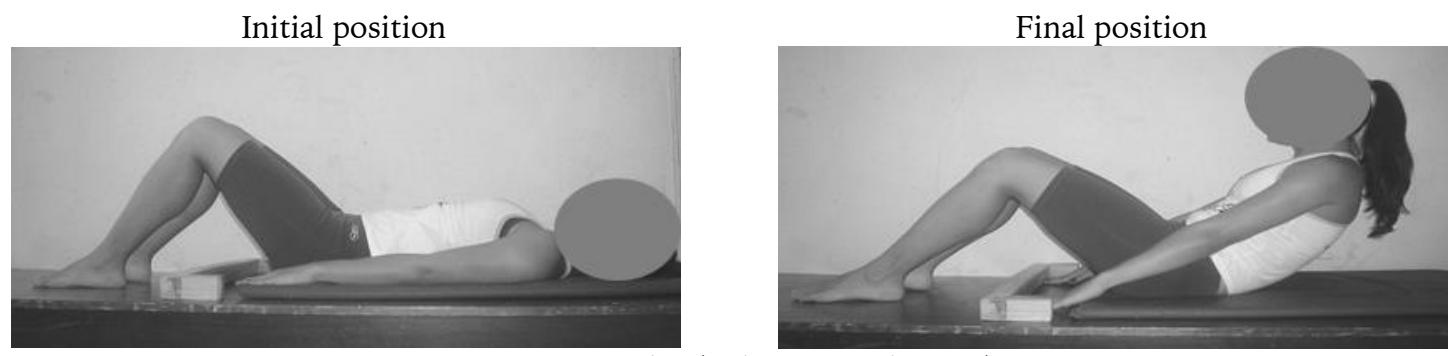

Protocol 2 (Sidnei \& Jetté, 1990)

Initial position

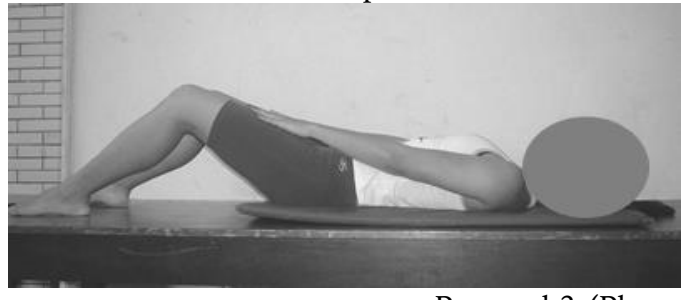

Final position

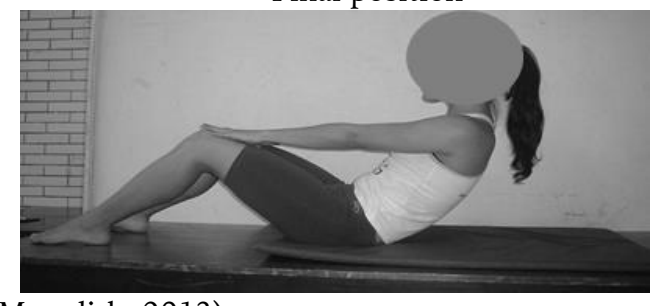

Protocol 3 (Plowman \& Meredith, 2013)

Initial position

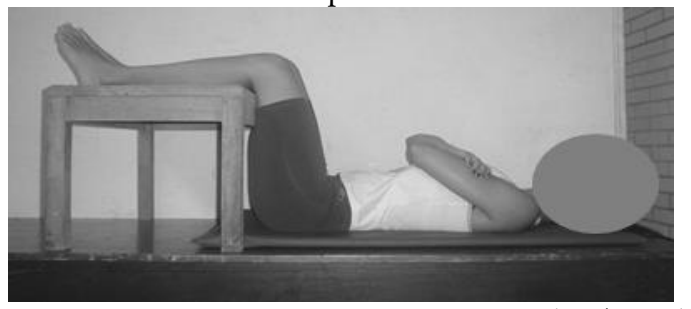

Final position

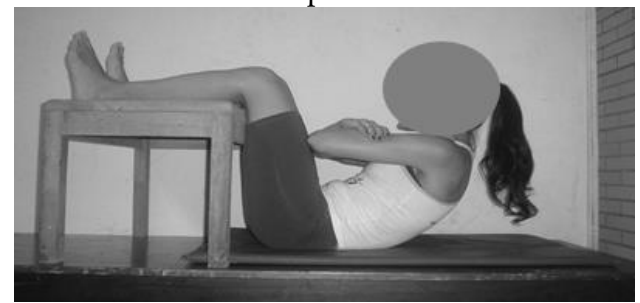

Initial position

Protocol 4 (Knudson \& Johnston, 1985)

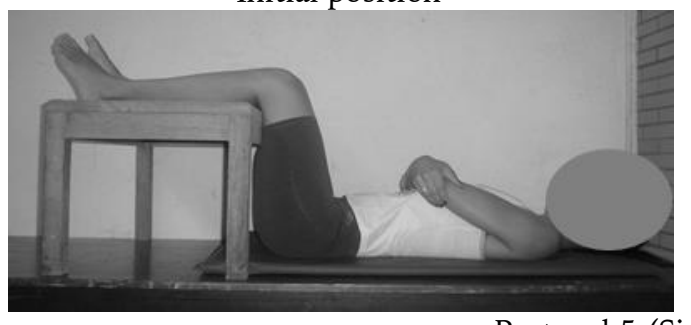

Final position

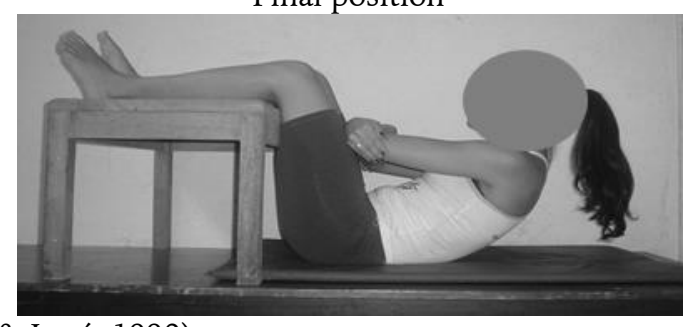

Protocol 5 (Sidnei \& Jetté, 1990)

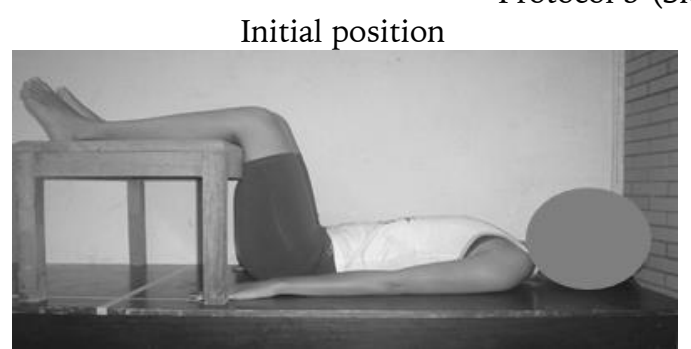

Final position

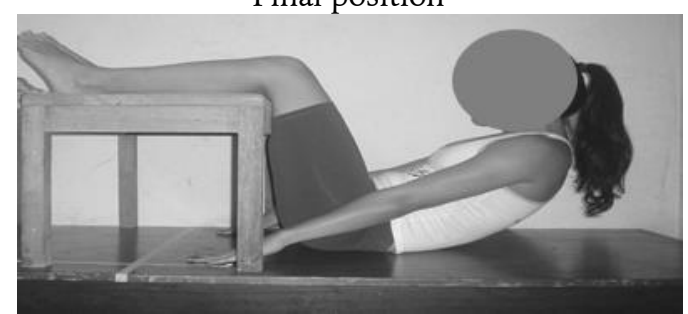

Figure 1. Illustrative pictures of initial and final positions of the five abdominal test protocols used. 
Table 2

Description of the results of overall perceived exertion of exercise, perceived exertion of abdominal muscles, and musculoskeletal pain (cervical and lumbar spine).

\begin{tabular}{|c|c|c|c|c|c|c|}
\hline \multirow[b]{2}{*}{ Protocol } & \multicolumn{3}{|c|}{ RPE (Borg, 1992) } & \multirow{2}{*}{$\begin{array}{c}\text { RPE } \\
\text { abdominal } \\
\text { (Med) }\end{array}$} & \multirow{2}{*}{$\begin{array}{l}\text { Perception of neck } \\
\text { pain }(\%)\end{array}$} & \multirow{2}{*}{$\begin{array}{c}\text { Perception of low back } \\
\text { pain (\%) }\end{array}$} \\
\hline & Med & Mín & Max & & & \\
\hline 1 & 11 & 9 & 14 & 3 & 20 & 0 \\
\hline 2 & 13 & 11 & 15 & 3 & 20 & 0 \\
\hline 3 & 14 & 12 & 16 & 4 & 100 & 20 \\
\hline 4 & 15 & 12 & 18 & 4 & 80 & 20 \\
\hline 5 & 13 & 11 & 13 & 4 & 40 & 20 \\
\hline
\end{tabular}

Note: Med: median values; Min: minimum value; Max: maximum value; PSE: perceived exertion. Total range for the Borg scale is 6-20. Total range for the abdominal RPE test is $0-4$.

Table 3

Resting heart rate, calculated maximum heart rate and calculated training heart rate (60 and80\%).

\begin{tabular}{llll}
\hline Variable & Med & Min & Máx \\
\hline HR $_{\text {rest }}(\mathrm{bpm})$ & 65 & 61 & 80 \\
$\mathrm{HR}_{\max }(\mathrm{bpm})$ & 167 & 161 & 168 \\
$60 \%$ HRT (bpm) & 125 & 123 & 132 \\
$80 \%$ HRT (bpm) & 146 & 150 & 142 \\
\hline
\end{tabular}

Note: HRrest: resting heart rate; HRmax: maximal heart rate; HRT: heart ratetraining; Med: median value; Min:minimum value; Max:maximum value.

Cardiac response data are presented in Table 3 for the median values of resting heart rate, maximum calculated HR, and training HR: used for monitoring exercise intensity during each test.

Data for heart rates taken pre, immediately after, and one minute after exercise are presented in Table 4.

Table 4

Heart rates pre-and post-exercise.

\begin{tabular}{lccc}
\hline Protocol & $\begin{array}{c}\text { HR pre-test } \\
\text { (bpm) } \\
\text { Med (Mín- } \\
\text { Máx) }\end{array}$ & $\begin{array}{c}\mathrm{HR}_{\text {obt }}(\mathrm{bpm}) \\
\text { Med (Mín- } \\
\text { Máx) }\end{array}$ & $\begin{array}{c}\mathrm{HR}_{\text {rec }}(\mathrm{bpm}) \\
\text { Med (Mín- } \\
\text { Máx) }\end{array}$ \\
\hline 1 & $78(62-95)$ & $93(83-105)$ & $90(80-93)$ \\
2 & $83(67-80)$ & $90(87-93)$ & $78(76-81)$ \\
3 & $78(70-81)$ & $87(83-89)$ & $74(68-88)$ \\
4 & $80(62-82)$ & $95(88-105)$ & $74(64-94)$ \\
5 & $69(61-83)$ & $80(73-90)$ & $68(60-89)$ \\
\hline
\end{tabular}

Note: HRobt: heart rate obtained immediately after completion of the protocol; HRrec: heart rate at the end of 1 min. of recovery; Med: median values; Min: minimum value; Max: maximum value

Analyzing the potential risk of cardiovascular overload in more detail, the abdominal exercise sessions appear to be safe, since no participants reached an assessed HR corresponding to $60 \%$ of THR. The cardiovascular stimulation appeared to be minimal with weak load, since the observed increases in both HR and blood pressure were minimal.
Median heart rate during the tests is presented in Figure 2. The deflection at the end of each line represents the heart rate after one minute of recovery.

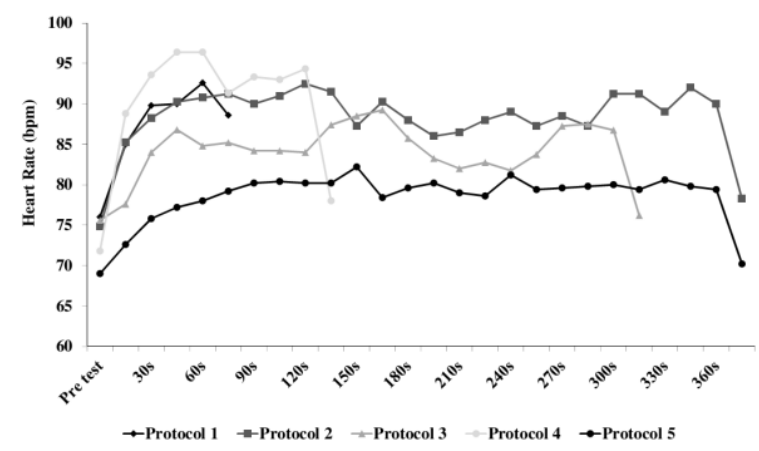

Figure 2. Median heart rate for each test.

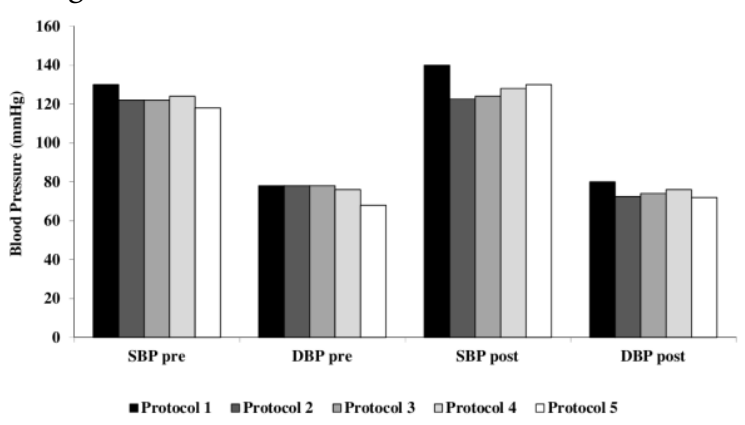

Figure 3. Systolic and diastolic blood pressure (SBP and DBP) before and after each test.

None of the abdominal test protocols resulted in a statistically significant difference when subjected to the Wilcoxon test $(\mathrm{p}>0.05)$ in terms 
of change in systolic and diastolic pressure (Figure 3). Pre-test HR was within normal limits. The changes in HR during the execution of each protocol were also such that exercise HR remained within normal limits (Figure 2).

\section{DISCUSSION}

The present study was conducted to evaluate the adequacy of abdominal test protocols for women of middle and old age, according to performance, cardiovascular response, perceived exertion and musculoskeletal pain.

The sample of women studied performed valid attempts only for protocols 1and 2, based on criteria established for these protocols. Among the factors that may explain the very low performance of the participants can be then onspecificity of tested protocols for the age group, the position of execution, the biomechanics required for execution, and metabolic demands of the test. In the literature, there is a lack of specific abdominal test protocols for seniors, although there is consensus that strengthening the abdominal muscles is extremely important for this stratum of the population (Artero et al., 2012).

Another factor that may be vital for the performance of protocols 3,4 and 5 is the position in which these protocols are performed as compared to those in fitness classes, with feet on a bench or chair for these protocols, which does not allow a comfortable position. This lack of comfort is corroborated by reports of pain sensation, especially in the cervical spine. Additionally, in biomechanical terms, the abdominal muscles are responsible for flexion of the trunk in the first third of this range of motion (approximately 30 degrees), represented by the loss of contact of the shoulder blades with the ground, while the lumbar spine remains supported on the ground (Yoo, 2015). Thus, for the correct performance of protocols 3, 4 and 5, this ideal angle is exceeded, imposing a stress on the abdominal muscles and also on the hip flexors, beyond that experienced in activities of daily living as well as in fitness classes (Ko, Jung \& Bae, 2014).
Metabolic demands of the evaluated test protocols can also impact on performance, since protocols 1 and 4 require as many repetitions as possible within 1 and 2 minutes, respectively, giving them characteristics of power tests requiring a predominance of anaerobic energy production (Riviera-Brown \& Frontera, 2012). Protocols 2, 3 and 5 were designed to contain characteristics of endurance exercises (RivieraBrown \& Frontera, 2012) because they are performed at a set pace over a relatively long period of time (5 or 6 minutes). The energy required to perform Protocols 2, 3, and 5 is therefore usually derived more from oxidative metabolism than from anaerobic (Riviera-Brown \& Frontera, 2012). However, since the participants could not perform a single successful attempt in protocols 3 and 5 , it might be that the tested participants lacked the anaerobic power to yield a single execution of these tasks.

Given that with aging there is a decline in muscle mass and greater preservation of slow twitch (Lee, Lee \& Kim, 2015; Krutki, Ciechanowicz-Kowalczyk, Lochyński \& Celichowski, 2013) muscle fibers, older individuals might be expected to perform better on tests requiring physical strength than on those emphasizing muscle power. Tests emphasizing strength might then be emphasized when attempting to evaluate positive exercise capacity in elderly. However, power tests have the merit of indirectly assessing the degree of loss of fasttwitch fibers: such tests could be used to evaluate the need for anaerobic power training to maintain the individual's functional capacity (Clark, 1989).

Protocols 3 and 4 require the participant to touch, with the rear face of the hand or elbow, the anterior thigh. This entails an inadequate flexion of the cervical spine, projecting the chin toward the chest, and triggers unnecessary contraction of muscles supporting the head and neck. In this study, pain sensation reports assessing these protocols corroborate with the above statements. During these tests, there is intense isometric contraction of muscles such as the sternocleidomastoid and trapezius, leading to the sensation of pain, which was a common factor for test interruption. Still, due to the position of the 
hands resting on arms or elbows, relative to the size of the lever formed by the arms in these protocols, these positions do not significantly alter the results because there is no change in the size of the lever arm because the axis of motion remains the same.

During testing, the distance that fingers/hands travel led in Protocol 5 did not even approached the required mark $(12 \mathrm{~cm})$ for any of the participants. If the participants were to reach the required mark, the angle of the trunk would surpass the ideal angle to work the muscles of the rectus abdominals, which is $30^{\circ}$ of flexion relative to the ground (Monfort-Pañego, Vera-García, Sánchez-Zuriaga \& Sarti-Martínez, 2009). However, the position of the feet during this test (and also in protocols 3 and 4) minimizes the action of the hip flexors. Thus, to achieve the required mark, the assessed should have strong trunk and hip flexion capability. In addition, in protocols 1 and 5, which uses the sliding of the fingers next to the trunk, there is a tendency toward an intense flexion of the cervical spine with the chin touching the chest. This motion is physiologically incorrect and can result in pain and injury.

With advancing age, the cartilaginous tissue has decreased water content and increased noncollagenous substances (Hwang \& Kim, 2015). This is reflected in a stiffening of the joints: a determining factor to reduce flexibility. This reduction probably also affects the spinal joints, decreasing the degree of flexion of those joints, requiring higher levels of strength to move the sternum toward the pelvis. This aspect is probably reflected in the high perceived exertion ratings reported for protocols 3 and 4 .

For RPE, assessed by the Borg scale (Borg, 1982), the median and maximum values were higher for protocols 3 and 4 than the other ones. Similar results were obtained for the perception of the abdominal muscles work and referred pain in the cervical and lumbar region. This indicates that the participants experienced protocols 3 and 4 as the most difficult, subjectively, which supports the finding that neither of these protocols could be performed successfully. By analyzing the score of abdominal work, it is noted that the same effort was reported for the five protocols. However, the protocols 3,4 and 5 showed higher reports of pain in the cervical and lumbar regions, which are responsible for the troublesome test interruption for some assessed. The elevated position of the legs (knees at 90 degrees) in protocols 3,4 and 5 virtually eliminates the action of the hip flexors, requiring the strength to bend the spinal column being taken exclusively by the abdominal muscles. The absence of abdominal practice in that position (in fitness programs for this audience the position of the feet elevated is not usual) probably resulted in inadequate levels of abdominal strength. Concomitantly, there is a higher requirement of flexor muscles of the cervical spine. Together, these aspects may have contributed to the largest musculoskeletal reports of referred pain, especially in the cervical region.

As can be seen in Figure1, heart rate responses during the tests were within the normal range. For tests with power characteristics (1 and 4), we observed a rapid increase in HR and, in protocol 1 , HR rose until the end of the test and decreased only at the end of it. In Protocol 4, HR showed variability, increasing in the first minute, followed by a reduction after the first 1.5 minutes of the test. Peak HR for protocols 1 and 4 were 116 and $111 \mathrm{bpm}$, respectively, the highest values among all tests.

In tests characterized as endurance, differences in HR behavior were also observed, although there was an overall tendency to steady state. During the exercises, HR was higher for protocol 2 (median $89 \mathrm{bpm}$ ), while protocols 3 and 5 resulted in median HR of 84 and $79 \mathrm{bpm}$, respectively. The peak HR were 106, 104 and 96 bpm for protocols 2, 3 and 5, respectively. The small sample size does not allow statistical inferences about the different behavior between the protocols, but some observations can be made, such as a generally low cardiac demand. This low cardiac demand can be explained by the low muscle mass involved and low peak effort (Riviera-Brown \& Frontera, 2012).

The recovery heart rates of the tested participants could be used as an indication of cardiorespiratory fitness. Endurance testing, which lasted 5 and 6 minutes in protocols 2,3 and 5 , resulted in median HR decreases of 12,10 and 
9 bpm, respectively, one minute after the termination of exercise. The HR decreases in protocols 1 and 4 were 5 and $16 \mathrm{bpm}$, respectively. The decrease in HR for the studied sample was therefore within the range recommended by the American College of Cardiology and the American Heart Association (AHA, 2002) for HR recovery in the first minute after exercise. This is indicative of a relatively good fitness of the studied group.

Cardiovascular tolerance to strength training is achieved provided that the appropriate criteria for training prescription are met. Correct breathing techniques should also be performed, always avoiding the Valsalva maneuver (Adams et al., 2014). There is a direct relationship between intrathoracic pressure caused by the Valsalva maneuver, and the responses of SBP, DBP, cardiac output and stroke volume while performing resistance exercises (Adams et al., 2014). The amplitude of SBP, DBP and HR responses also relates to the amount of muscle mass involved during resistance exercises and the amount of occluded intra-musculature vasculature due to mechanical compression (Moreira, et al., 2016; Jesus et al., 2013). According to the recommendations set out by several authors (Cavaggioni et al., 2015; Perry et al., 2014), whose guidelines for resistance training include normal breathing throughout the exercise and the existence of a warm-up and cooldown period, HR and systemic BP are expected to increase only slightly above resting values during the performance of resistance training. Thus, there should not be large increases in HR, SBP and DBP when the elderly perform generalized physical activities and/or specific strength work, since all safety guidelines are followed (Foley \& Bowen, 2014). The lack of significant changes in HR, SBP and DBP in the current study corroborates these points.

Another important aspect to be considered when choosing a test is the generalizability of the test so it can be implemented to assess large populations. The best tests would therefore be those that require minimal equipment, implementation costs, facilities, and training of evaluators.
The current study highlighted the inadequacy of the five abdominal test protocols to test performance in older women. This inadequacy refers more to biomechanical aspects of the tests rather than cardiorespiratory aspects. The deficiencies of the test were related to several factors, including the required length of some of the tests, the body movements required (initial positions and final) for valid attempts, and the overall strength required to properly perform the tests. The correct and complete body movement was most often not achieved due to changes in body structure resulting from aging such as sarcopenia and increased osteoarthritis. The intensity of musculoskeletal referred pain, especially in the cervical region, also interrupted some tests.

There were limitations in the present study such as controlling the workload and musculoskeletal pain perceived by the participants, which could result in measurement errors. However, the choice of tests was based on the low-cost, the possibility of reproduction by other groups of researchers, and the availability of the tests based on the environment in most Community Centers. In addition, the sample size was also a limiting factor, since a larger number of subjects would allow more consistent conclusions. However, the option for a small sample size was due to our limited knowledge of the anticipated cardiovascular responses and the types of discomforts that would result from the abdominal test protocols.

\section{CONCLUSION}

Despite the small sample size, this study demonstrated the inadequacy of the five abdominal test protocols, especially protocols 3 , 4 and 5 , when using the number of valid attempts as the criteria for evaluating the strength of the abdominal muscles. Successful performance of the protocols with a low level of musculoskeletal referred pain in the cervical and lumbar spine was achieved only in protocols 1and 2. With respect to cardiorespiratory parameters, all participants remained in a safe zone (not at risk) for blood pressure, heart rate and perceived exertion. Among the protocols tested, protocols 1 and 2 
were the best for application in adults and elderly public; however, the sample size of this study is insufficient to make definitive statements of safety for this population.

\section{Acknowledgements:}

Conselho Nacional de Desenvolvimento Científico e Tecnológico - CNPq for doctoral scholarship provided to Claudia Eliza Patrocínio de Oliveira and Coordenação de Aperfeiçoamento de Pessoal de Nivel Superior - CAPES for the doctoral scholarship provided to Osvaldo Costa Moreira.

Conflict of interests:

Nothing to declare.

\section{Funding:}

Fundação de Amparo a Pesquisa do Estado de Minas Gerais (FAPEMIG) for funding the publication of this work.

\section{REFERENCES}

Adams J, Schmid J, Parker RD, Coast JR, Cheng D, Killian AD (2014). Comparison of force exerted on the sternum during a sneeze versus during low-, moderate-, and high-intensity bench press resistance exercise with and without the valsalva maneuver in healthy volunteers. Am J Cardiol. 113(6): 1045-8.

American College of Cardiology/American Heart Association (2002). ACC/AHA 2002 guideline update for exercise testing: summary article: a report of the American College of Cardiology/American Heart Association Task Force on Practice Guidelines (Committee to Update the 1997 Exercise Testing Guidelines). Circulation. 106(14): 1883-92.

American College of Sports Medicine (2011). Quantity and Quality of Exercise for Developing and Maintaining Cardiorespiratory, Musculoskeletal, and Neuromotor Fitness in Apparently Healthy Adults: Guidance for Prescribing Exercise. Med Sci Sports Exerc. 43(7):1334-59.

Artero EG, Lee DC, Lavie CJ, España-Romero V, Sui X, Church TS (2012). Effects of muscular strength on cardiovascular risk factors and prognosis. $J$ Cardiopulm Rehabil Prev. 32(6):351-8.

Borg GA (1982). Psychophysical bases of perceived exertion. Med Sci Sports Exerc. 14(5): 377-381.

Cavaggioni L, Ongaro L, Zannin E, Iaia FM, Zoeng KI, Alberti G (2015). Effects of different core exercises on respiratory parameters and abdominal strength. J Phys Ther Sci. 27(10): 324953.
Clark BA (1989). Tests for fitness in older adults. AAHPERD Fitness Task Force. JOPERD, 60(3): 66-71.

Dantas EHM, Vale RGS (2004). GDLAM's protocol of functional autonomy evaluation. Fit Perf J. 3(3): 175-82.

Foley M, Bowen B (2014). Comparison of metabolic cost and cardiovascular response to stair ascending and descending with walkers and canes in older adults. Arch Phys Med Rehabil. 95(9): 174249.

Hwang HS, Kim HA (2015). Chondrocyte Apoptosis in the Pathogenesis of Osteoarthritis. Int J Mol Sci. 16(11): 26035-54.

International Society for the Advancement of Kinanthropometry (ISAK) (2011). International standards for anthropometric assessment. Adelaid: National Library of Australia.

Jesus RC, Moreira OC, Oliveira CE, Doimo LA, Monteiro WD (2013). Cardiovascular response in three different resistance exercises to the deltoid muscle. Bioscience J. 29(6): 2077-84.

Knudson D, Johnston D (1995). Validity and reliability of a bench Trunk-curl test of abdominal endurance. J Strength Cond Res, 9: 165-69.

Ko DS, Jung DI, Bae SY (2014). Effect of lumbar stabilization exercises on the balance ability of patients with stroke: a systematic review. J Phys Ther Sci. 26(12): 1993-6.

Krutki P, Ciechanowicz-Kowalczyk I, Lochyński D, Celichowski J (2013). Effect of aging on properties of motor unit action potentials in the rat medial gastrocnemius muscle. $J$ Electromyogr Kinesiol. 23(5): 1150-7.

Lamarca GA, Monteiro da Silva AM (2001). Escala likert de dor para crianças: um estudo preliminar de validação. In: Anais do $5^{\circ}$ Simpósio Brasileiro e Encontro Internacional sobre Dor. São Paulo: Lemos Editorial.

Lee HC, Lee ML, Kim SR (2015). Effect of exercise performance by elderly women on balance ability and muscle function. J Phys Ther Sci. 27(4): 98992.

Monfort-Pañego M, Vera-García FJ, Sánchez-Zuriaga D, Sarti-Martínez MA (2009). Electromyographic studies in abdominal exercises: a literature synthesis. J Manipulative Physiol Ther. 32(3): 232244.

Moreira OC, Faraci LL, de Matos DG, Mazini Filho ML, da Silva SF, Aidar F (2016). Cardiovascular responses to unilateral, bilateral and alternating limb resistance exercise performed using different body segments. J Strength Cond Res. [Epub ahead of print]. (Accessed at 11/02/2016). Available in: http://www.ncbi.nlm.nih.gov/pubmed/2638212 8.

Perry BG, Mündel T, Cochrane DJ, Santos JA, Cotter JD, Lucas SJ (2014). The cerebrovascular response to graded Valsalva maneuvers while standing. Physiol Rep. 2(2): e00233. 
Plowman SA, Meredith MD (Eds.) (2013). Fitnessgram/Activitygram Reference Guide. 4th Ed. Dallas, TX: The Cooper Institute.

Rikli RE, Jones CJ (1999). Developmental and validation of a functional fitness test for community-residing older adults. J Aging Phys Act. 7: 129-61.

Rivera-Brown AM, Frontera WR (2012). Principles of exercise physiology: responses to acute exercise and long-term adaptations to training. PMER. 4(11): 797-804.

Robertson LD, Magnusdottir H (1987). Evaluation of criteria associated with abdominal fitness testing. Res Q Exerc Sport, 58: 355-9.

Sidnei K, Jetté M (1990). The partial curl-up to assess abdominal endurance: age and sex standards. Sports Training Med Rehabil, 2: 47-56.
Sociedade Brasileira de Cardiologia (SBC)/Sociedade Brasileira de Hipertensão/ Sociedade Brasileira de Nefrologia (2010). VI Diretrizes Brasileiras de Hipertensão. Arq Bras Cardiol. 95(supl.1): 1-51.

Tanaka H, Monahan KD, Seals DR (2001). Agepredicted maximal heart rate revisited. $J$ Am Coll Cardiol. 37: 153-56.

U.S. Department of Health and Human Services (1996). Physical activity and health: a report of the surgeon general - at a glance. Atlanta: U.S. Department os Health and Human Services, Centers for disease control and prevention, National center for chronic disease prevention and health promotion.

Yoo WG (2015). Effect of thoracic movementmediated training on back pain and trunk range of motion in a patient with lower back pain. J Phys Ther Sci. 27(8): 2665-6.

All content of Journal Motricidade is licensed under Creative Commons, except when otherwise specified and in content retrieved from other bibliographic sources. 


\title{
Does emphasis on speeds of execution modify the markers of muscle damage and neuromuscular parameters?
}

\author{
Yuri de Almeida Campos ${ }^{1,2}$, Hiago Leandro Rodrigues de Souza ${ }^{1,3}$, Osvaldo Costa \\ Moreira ${ }^{1,4,5}$, Sandro Fernandes da Silva ${ }^{1 *}$
}

ARTIGO ORIGINAL | ORIGINAL ARTICLE

\begin{abstract}
The study investigated the influence of different speeds of muscle actions on the volume of repetitions, muscle fatigue and delayed-onset muscle soreness (DOMS). The study included 9 women. At first, was performed the anthropometric measurements and evaluation of maximum dynamic force through the 1RM test; At second, the volunteers performed three sets with $60 \%$ of $1 \mathrm{RM}$ with the highest number of repetitions possible, emphasizing the concentric phase of the movement $(\mathrm{CP})$; at third, the same was executed with emphasis on the eccentric phase of the movement (EP); at fourth, the same procedure was done without emphasis on any stage of the movement (CoP). At the end of each set of each protocol was added the maximum volume of repetitions (MVR), collected the fatigue index, and DOMS was evaluated in the intervals of 24, 48 and 72 hours. In the DOMS, EP protocol showed significant difference compared to other protocols in all intervals. The MVR in EP showed a smaller number of repetitions $(34,77)$ opposite the other protocols. We conclude that the accomplishment of protocols that emphasize the eccentric actions should be done with caution, because it's responses can lead at to loss on volume, increase DOMS and affect the performance.

Keywords: Resistance Training, Fatigue, Muscle Strength, Muscle Contraction.
\end{abstract}

\section{INTRODUCTION}

One of the possible study paths of human movement by the perspectives of physiology and biomechanics could occur through the stretchshortening cycle in skeletal muscle. It is well established in the scientific literature that such a cycle, when performed repeatedly, is responsible for causing muscle damage (Chapman, Newton, Sacco, \& Nosaka, 2006), with some factors related to stretch-shortening cycle can interfere with the magnitude of this muscle damage, such as range of motion, the type of muscle action and the force generated during movement (Libardi et al., 2013).

In particular, the type of muscle action is a factor that directly affects the magnitude of muscle damage, and in muscle stretching / eccentric action (EA), this factor would have a major interference in muscle damage, while in muscle shortening / concentric action (CA), the magnitude of this damage would be reduced (Blazevich, Cannavan, Coleman, \& Horne, 2007). Thus the scientific community has turned to study the magnitude of muscle damage caused by different muscle actions on muscle adaptations (Carvalho et al., 2015; Moore, Young, \& Phillips, 2012), seeking to demystify the existing controversy regarding the benefits and harms of different emphases of resistance training (RT) in each one of muscle actions (CA and EA) (Bird, Tarpenning, \& Marino, 2005).

The stimulation of eccentric exercise (EE) in untrained subjects induces muscle injuries generating a myofibrillar degradation, it affects

\footnotetext{
${ }^{1}$ Studies Research Group in Neuromuscular Responses, GEPREN, University of Lavras, Lavras, Brazil

${ }^{2}$ Postgraduate Stricto Sensu Program of the Faculty of Physical Education and Sports, FAEFID, University of Juiz de Fora, Juiz de Fora, Brazil

${ }^{3}$ Postgraduate Stricto Sensu Program in Physical Education, University of Triangulo Mineiro, Uberaba, Brazil

${ }^{4}$ Institute of Biomedicine, University of León, León, Spain

${ }^{5}$ Institute of Biological Science and Health, University of Viçosa, Florestal, Brazil

* Autor correspondente: Studies Research Group in Neuromuscular Responses, Department of Physical Education, University of Lavras, Câmpus Universitário, P. O. Box: 3037, CEP: 37200-000, Lavras/MG, Brazil. E-mail: reiclauy@hotmail.com
} 
the range of motion, increase delayed-onset muscle soreness (DOMS) and some blood markers of muscle damage (Candia-Luján, Fernández, \& Moreira, 2014; Chen \& Nosaka, 2006; Choi, 2014). Other studies have confirmed the $\mathrm{EE}$ as a potent inducer of muscle injury, especially when compared to concentric stimulation (Choi et al., 2012; Hody, Rogister, Leprince, Laglaine, \& Croisier, 2013). Indirect markers such as DOMS, limb circumference, and muscle strength, have been used to establish the magnitude of EE as muscle injury inductor (de Barros Berton et al., 2012; de Souza-Teixeira \& de $\mathrm{Paz}, 2012$ ).

Some studies have attempted to elucidate the effects of each of the muscle actions (EA and CA) in the TR parameters, especially in muscle strength and volume of repetitions, investigations clarify that the eccentric strength compared to the concentric shows a conservation of power 20\% higher (Farthing \& Chilibeck, 2003; Roig et al., 2010). The mechanisms that regulate the advantage of EA originally seem to be neural, because, it was demonstrated that they generate a greater stimulation to the motor cortex during maximum voluntary contraction (MVC) (Hortobágyi \& Maffiuletti, 2011; Son, Lee, \& Kim, 2014). Moreover, mechanical and cell stimulation that are involved in the EA include regulators of muscle stiffness both active and passive (Hortobágyi \& Maffiuletti, 2011).

Another line of investigation has sought to clarify the difference of muscle damage caused by different speeds of execution $\mathrm{EE}$, in which the results indicate that the $\mathrm{EE}$ executed faster appears to induce a greater muscle damage (Ellwanger, Brentano, \& Kruel, 2007; Shepstone et al., 2005). However, the role of the speed of execution of muscle actions in the RT is not fully constituted, since few studies have assessed the effect of the speed of muscle actions in certain RT control variables such as volume of sets, number of repetitions, maximum load, muscle work, range of motion and muscle damage (Buitrago, Wirtz, Yue, Kleinoder, \& Mester, 2013), which are extremely important to be controlled for efficient exercise prescription and is safe for the individual who performs it. Besides, Carpinelli, Otto, and Winett (2004), after performing a critical analysis of the ACSM Position Stand on Resistance Training, attest that there is insufficient evidence to support the superiority of a particular speed in the results produced by the $\mathrm{RT}$, requiring greater deepening studies so that it can be clarified the role of this variable on the effects induced by RT (Buitrago et al., 2013; Carpinelli et al., 2004).

In addition to the questions abovementioned regarding the generated strength, speed of execution and muscle damage generated, after the stimulation in each of the contractions, literature still needs further clarification about the acute effect of different muscle actions on control parameters of training such as the volume of repetitions, muscle fatigue and DOMS.

Therefore, this study aimed to investigate the influence of different speeds of muscle actions on the volume of repetitions, muscle fatigue and DOMS.

Participants

The sample consisted of nine female volunteers $(22 \pm 1.8$ years; $1.71 \pm 3.96 \mathrm{~m}$; 68.3 $\pm 12.94 \mathrm{~kg} ; 32.12 \pm 6.30 \%$ fat). All volunteers were familiar with the proposed exercise and had minimum experience of six months in resistance training, and while participating in this research should not use medicines that could interfere in the responses of the variables, besides not possessing bone-joint injuries or acute infectious processes. The study excluded all individuals who had precedents of bone and/or muscle injuries that could compromise the total or partial performance of the movement. All volunteers read and signed the Informed Consent (IC) and the study was approved by the local institutional Ethical Committee for Human Experiments and were performed in accordance with the Declaration of Helsinki.

\section{Instruments and Procedures}

The exercise smith machine squat was used with, in which each participant was standing 
positioned, just below the bar, aligning vertically. He is holding the bar next to the shoulders, on the trapeze, and aligned his feet and knees with the hip joint. Then, they moved their hips backwards and bent their knees until it was achieved a range of $90^{\circ}$ (controlled with the aid of digital goniometer GN360 of Miotec $\left.{ }^{\circledR}\right)$. The volunteers should perform three sets. In each set, it was performed as many repetitions as possible until concentric failure with $60 \%$ of maximum load. The rest interval between sets was 90 seconds. To control the speed of contraction during the exercises it was used the software Metronome Plus 2.0.0.5 software ${ }^{\circledR}$.

For full control of the protocols, the assessments were conducted by the same researchers. The volunteers underwent a familiarization process, where they performed the speeds prescribed for each protocol three times, with a total of nine familiarization visits.

The subjects were assessed at four different moments, in which from the 2 nd time, there was a randomization to determine the exercises that would be executed. Each of the four moments of the assessments occurred with seven days (168 hours) of interval between them, according to the following determinations:

A) At first the volunteers read and signed the IC form and were told about the procedures that would be adopted during the research. Then they were sent to the anthropometric measurements where the weight-in, height measurement, and assessment of body composition were done. Just after it was performed the assessment of the maximum dynamic strength through the 1RM test in order to determine the load that would be used during the study;

B) At second the volunteers were asked to perform three sets of exercise emphasizing the concentric phase of the movement, concentric protocol (CP), being determined 30 radians per second (3 seconds) for the concentric action and 90 radians per second (1 second) for the eccentric action (3/CA for $1 /$ EA)
C) At third the volunteers were asked to perform three sets of exercise with emphasis on the eccentric phase of the movement, eccentric Protocol (EP) being determined 90 radians per second (1 second) for the concentric action and 30 radians per second (3 seconds) for the eccentric action (1/CA for 3EA);

D) At fourth the volunteers were asked to perform three sets of the exercise with a balance between the times of muscle actions, control protocol (CoP), being determined 45 radians per second (2 seconds) for the concentric action and 45 radians per second (2 seconds) for the eccentric action (2/AC for 2/AE).

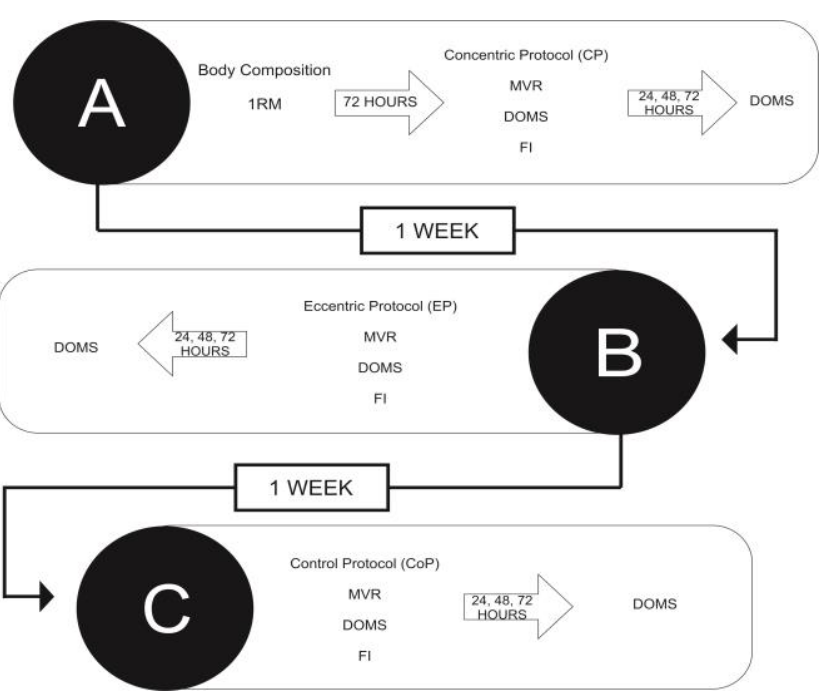

Figure 1. Investigation outline

Maximum Volume of Repetitions (MVR) and Fatigue Index (FI)

In the analysis of the maximum volume of repetitions (MVR) was held the sum of the maximum number of repetitions performed in each set of each protocol. To identify the strength loss rate in each protocol was used as the fatigue index (FI) the equation proposed by Sforzo and Touey (1996):

$$
\mathrm{FI}=\left[\left(\mathrm{TS}\left({ }_{\text {set } 1}\right)-\mathrm{TS}\left({ }_{\text {set } 3}\right)\right) / \mathrm{TS}\left({ }_{\text {set } 1}\right)\right] \times 100 \%
$$

Where FI $=$ Fatigue index and TS $=$ Total Strength (lifted load $\mathrm{x}$ number of repetitions performed during the sets). 


\section{Delayed-onset Muscle Soreness (DOMS)}

To evaluate the DOMS was used Visual Analogue Scale (VAS), which expresses pain from a continuous line with numerical values ranging from zero (0) and ten (10), in which the initial value is assigned to "no pain "and the final value is assigned to" unbearable pain". The assessed is instructed to demarcate the line of VAS value related to his perception of pain.(Price, Bush, Long, \& Harkins, 1994; Price, McGrath, Rafii, \& Buckingham, 1983) The scale was applied to the subjects after the accomplishment of each protocol, again being applied in the interval of 24, 48 and 72 hours (Philippou, Koutsilieris, \& Maridaki, 2012; Umbel et al., 2009).

Assessment of Maximum Dynamic Strength (1RM):

For analysis of maximum dynamic strength it was performed the one repetition maximum 1RM test, following the recommendations (Brown \& Weir, 2001), where volunteers should respect the following procedures:

A) The subjects were instructed to complete a set of 4 repetitions at $60 \%$ of $1 \mathrm{RM}$ estimated load, one set of three repetitions at $70 \%$ of $1 \mathrm{RM}$ estimated, a set of 2 repetitions at $80 \%$ of $1 \mathrm{RM}$ estimated, and a repetition $90 \%$ of 1 RM estimated, from then it started trying the 1RM, being the maximum number of 5 attempts to identify the 1RM load. Between sets and attempts it has been observed a three minutes interval (Brown \& Weir, 2001).

\section{Statistical analysis}

Data analysis was performed based on the statistical comparison of means and standard deviations. In order to verify the the distribution of the sample it was adopted the Shapiro-Wilk normality test. To compare the data between concentric, eccentric and control protocols it was used ANOVA for repeated measures, with posthoc Scheffe. As for the comparison of variables between the same group, it was used the statistical nonparametric Wilcoxon test, to check the effect size of the sample it was adopted Cohen's D test. As statistical evidence it was adopted the significance value of $\mathrm{p}<0.05$ for all tests.

\section{RESULTS}

In table 1, we presented the anthropometric data for characterization of the sample.

In Table 2, we verified DOMS in two forms of analysis, the first refers to the behavior of each protocol in the interval of 72 hours. In the CP there was significant difference in the DOMS between 24-72 hours and between 48 and 72 hours, and the greatest sensation of pain was reported after 24 hours $(3.56 \pm 1.23)$ and the lowest in the 72 hours after stimulation (1.44 \pm 0.52 ). In the EP, significant differences were found in the DOMS between 24 and 72 hours and between 48 and 72 hours and observed an increase in pain after 48 hours $(5.00 \pm 1.22)$. When performing the CoP, significant difference was also observed between the intervals 24-72 and 48-72, with the greater DOMS caused by this protocol after 24 hours $(2.44 \pm 0.72)$.

The second analysis refers to the behavior between the protocols at three intervals of time (24, 48 and 72 hours). At the 24-hour interval the EP was significantly higher than the CoP. When analyzing the interval of 48 hours we found significant differences between all protocols, where the EP was the one which caused the higher DOMS. The latter interval studied was 72 hours, in which we found significant differences between all protocols and, again, the higher DOMS reported was in the EP.

Table 1

Anthropometric Characteristics of the Sample.

\begin{tabular}{cccccc}
\hline $\mathrm{N}$ & $\begin{array}{c}\text { Age } \\
\text { (Years) }\end{array}$ & $\begin{array}{c}\text { Height } \\
(\mathrm{m})\end{array}$ & $\begin{array}{c}\text { Weight } \\
(\mathrm{Kg})\end{array}$ & BMI & $\begin{array}{c}\text { Body Fat } \\
(\%)\end{array}$ \\
\hline 9 & $22 \pm 1.8$ & $1.71 \pm 3.96$ & $68.3 \pm 12.94$ & $23.63 \pm 5.45$ & $32.12 \pm 6.30$ \\
\hline
\end{tabular}


Table 2.

Comparison DOMS in the interval of 72 hours at diferente protocols.

\begin{tabular}{|c|c|c|c|c|c|c|c|}
\hline Contraction & $\mathrm{n}$ & & Interval & & & p-value & \\
\hline & \multirow{4}{*}{9} & 24 Hours & 48 Hours & 72 Hours & $24-48$ & $24-72$ & $48-72$ \\
\hline $\mathrm{CP}$ & & $3.56 \pm 1.23^{\mathrm{a}}$ & $3.33 \pm 1.22^{\text {b.h.i }}$ & $1.44 \pm 0.52^{\mathrm{k} . \mathrm{l}}$ & 0.52 & 0.01 & 0.01 \\
\hline EP & & $4.44 \pm 1.50^{\text {c.g }}$ & $5.00 \pm 1.22^{\mathrm{d} . \mathrm{j}}$ & $2.89 \pm 1.36^{\mathrm{m}}$ & 0.31 & 0.03 & 0.01 \\
\hline $\mathrm{CoP}$ & & $2.44 \pm 0.72^{\mathrm{e}}$ & $2.11 \pm 0.78$ & $0.22 \pm 0.05$ & 0.08 & 0.01 & 0.01 \\
\hline \multirow{3}{*}{$\mathrm{p}$-value } & CP-EP & 0.31 & 0.01 & 0.01 & - & - & - \\
\hline & CP-CoP & 0.16 & 0.08 & 0.04 & - & - & - \\
\hline & EP-CoP & 0.01 & 0.01 & 0.01 & - & - & - \\
\hline
\end{tabular}

Note: CP: concentric protocol; EP: eccentric protocol; CoP: control protocol; a- significant difference in CP protocol between 24 and 72 hours; b- significant difference in CP protocol between 48 and 72 hours; c- significant difference in protocol EP between 24 and 72 hours; d- significant difference in protocol EP between 48 and 72 hours; e- significant difference in CoP protocol between 24 and 72 hours; $\mathrm{f}$ - significant difference in CoP protocol between 48 and 72 hours; g- significant difference between $\mathrm{EP}$ and CoP Protocol in the interval of 24 hours; h- significant differences between $\mathrm{CP}$ and EP protocol in the interval of 48 hours; i- significant differences between $\mathrm{CP}$ and $\mathrm{CoP}$ protocol in the interval of 48 hours; $j$ - significant differences between the $\mathrm{EP}$ and $\mathrm{CoP}$ protocol in the interval of 48 hours; $\mathrm{k}$ - significant difference between $\mathrm{EP}$ and $\mathrm{CP}$ protocol in the interval of 72 hours; 1- significant difference between the $\mathrm{CP}$ and $\mathrm{CoP}$ protocol in the interval of 72 hours; $\mathrm{m}$ - significant difference between EP and CoP protocol in the interval of 72 hours.

Table 3 presents the data of maximum volume of repetitions (MVR). No significant difference was found in the MVR between the protocols used in the study. When analyzing the intra protocols data it was found that in the $\mathrm{CP}$ and CoP there was significant difference in MNRs1 $\mathrm{x}$ MNRs2 and MNRs1 x MNRs3 variable, while in

Table 3

Comparison of number of repetitions. maximum volume of repetitions and fatigue index in different protocols.

\begin{tabular}{|c|c|c|c|c|c|c|c|}
\hline \multirow{2}{*}{ Variables } & $\mathrm{n}$ & & Contraction & & & p-value & \\
\hline & \multirow{5}{*}{9} & $\mathrm{CP}$ & EP & CoP & CP-EP & CP-CoP & EP-CoP \\
\hline $\mathrm{MNR}_{s 1}$ & & $14.55 \pm 2.31^{\text {a.b }}$ & $13.00 \pm 2.87^{c}$ & $15.88 \pm 3.58^{\text {d.e }}$ & 0.55 & 0.64 & 0.14 \\
\hline $\mathrm{MNR}_{\mathrm{s} 2}$ & & $12.11 \pm 2.42$ & $11.44 \pm 2.60$ & $12.66 \pm 2.39$ & 0.85 & 0.89 & 0.58 \\
\hline $\mathrm{MNR}_{\mathrm{s} 3}$ & & $12.55 \pm 1.87$ & $10.33 \pm 2.44$ & $13.11 \pm 4.31$ & 0.32 & 0.92 & 0.17 \\
\hline MVR & & $39.22 \pm 5.35$ & $34.77 \pm 6.68$ & $41.66 \pm 9.32$ & 0.44 & 0.78 & 0.15 \\
\hline \multirow{3}{*}{ p-value } & $\mathrm{MNR}_{\mathrm{s} 1}$ & 0.02 & 0.09 & 0.01 & - & - & - \\
\hline & $\mathrm{MNR}_{\mathrm{s} 2}$ & 0.04 & 0.02 & 0.02 & - & - & - \\
\hline & $\mathrm{MNR}_{\mathrm{s} 3}$ & 0.59 & 0.12 & 0.88 & - & - & - \\
\hline
\end{tabular}

Note: MNRs1- Maximum repetitions performed in $1^{\text {st }}$ set; MNRs2- Maximum repetitions in $2^{\text {nd }}$ set; MNRs3- Maximum repetitions performed in $3^{\text {rd }}$ set; MVR - Sum of Number of Repetitions of 3 sets; CP - concentric protocol; EP - eccentric protocol $\mathrm{CoP}$ - control protocol. a- significant difference in $\mathrm{CP}$ protocol between $1^{\text {st }}$ and $2^{\text {nd }}$ set; b- significant difference in $\mathrm{CP}$ protocol between $1^{\text {st }}$ and $2^{\text {nd }}$ set; c- significant difference in EP protocol between $1^{\text {st }}$ and $2^{\text {nd }}$ set; $d$ - significant difference in CoP protocol between the $1^{\text {st }}$ and $2^{\text {nd }}$ set; e- significant difference in CoP protocol between $1^{\text {st }}$ and $2^{\text {nd }}$ set.

Table 4

Comparison Fatigue Index (FI) in diferente protocols.

\begin{tabular}{|c|c|c|c|c|c|c|c|}
\hline \multirow{2}{*}{ Variables } & $\mathrm{n}$ & & ontractiol & & & $\mathrm{p}$ & \\
\hline & \multirow{2}{*}{9} & $\mathrm{CP}$ & EP & CoP & CP-EP & CP-CoP & EP-CoP \\
\hline FI (\%) & & $-12.16 \%$ & $-19.25 \%$ & $-17.62 \%$ & 0.68 & 0.77 & 0.97 \\
\hline \multirow{3}{*}{ Difference(\%) } & $\mathrm{CP} \times \mathrm{EP}$ & - & $-7.08 \%$ & - & - & - & - \\
\hline & $\mathrm{CP} \times \mathrm{CoP}$ & - & - & $-5.45 \%$ & - & - & - \\
\hline & EP x CoP & - & - & $1.63 \%$ & - & - & - \\
\hline
\end{tabular}




\section{DISCUSSION}

The current study aimed to investigate the influence of different speeds of muscle actions on the DOMS, the MVR and the FI. One of the main findings of this study was to identify that the movement with emphasis on the eccentric phase causes a higher DOMS, it shows a reduction in MVR and a higher FI.

In the DOMS was found significant difference between the EP and the other protocols in the intervals of 48 and 72 hours. Recently, studies have shown that the emphasis on the eccentric action causes an increase in DOMS 24 and 48 hours after eccentric stimulation (Rezaei et al., 2014). Even corroborating with our results, an investigation compared the DOMS between the concentric and eccentric actions and detected a greater DOMS in the eccentric phase of the movement (Umbel et al., 2009). The literature recognizes that the acute effect of performing eccentric muscle actions causes disturbances in the sarcolemma and inflammatory responses, that are manifested by markers of muscle damage such as creatine kinase (CK), lactate dehydrogenase (LDH) and DOMS (Falvo, Schilling, Bloomer, \& Smith, 2009; FernandezGonzalo et al., 2011; Hody et al., 2013). Thus, the increase in DOMS found after performing the EP, meets to what the scientific literature claims. This may indicate that the exercises done with speed of execution that prioritizes the eccentric movement causes an increase in DOMS, to cause an increase in muscle microlesions as well reported in the literature (Hollander et al., 2007; Torres, Pinho, Duarte, \& Cabri, 2013).

When focusing on the results of repetitions, we verified that there is no significant decrease in all protocols, but it is possible to notice a tendency to performing fewer repetitions in the $\mathrm{EP}$, both in repetitions performed in each set as in total volume of repetitions. The literature demonstrates that even in cyclical efforts emphasizing the eccentric phase occurs a decrease in muscle work capacity (Black \& Dobson, 2013) and the same happens in the performance of vertical jumps (Wirth, Keiner, Szilvas, Hartmann, \& Sander, 2015). The eccentric stimulation induces to a decreased range of motion in response to localized muscle pain, which can be a response to the increase of CK in the blood (Newton, Sacco, Chapman, \& Nosaka, 2013). Recent investigations have observed loss of strength, muscle power and increased muscle soreness after performing a set of eccentric exercise (Fernandez-Gonzalo et al., 2011), as well as the reduction of the number of repetitions during the eccentric stimulus at different loads work (Kelly et al., 2015).

EP presented a higher FI when compared to other protocols, these data confirm previous findings that report a drop in mechanical performance of muscle actions (Eches, Ribeiro, Nascimento, \& Cyrino, 2013). This decrease in the number of repetitions especially in EP, seems to be due to a functional impairment of muscle that is related to an increased enzyme activity of DOMS markers such as CK and LDH, besides a smaller range of motion (Paulsen, Mikkelsen, Raastad, \& Peake, 2012; Philippou et al., 2012), and may be related more to exercise intensity than properly the CE (Barroso, Roschel, Gil, Ugrinowitsch, \& Tricoli, 2011).

The literature is still lacking in using functional markers as maximum, maximum repetitions, maximum volume of repetitions and fatigue index, as parameter to the acute responses to eccentric training, and the muscle power has been demonstrated as a reliable marker to assess the acute effects of EC (Fernandez-Gonzalo et al., 2011), however studies abovementioned the decrease found in the total volume of replications after $\mathrm{CE}$ becomes an effective indirect response when associated with markers of muscle damage and metabolites and also with the electromyographic activity in response to EC (Gonzalez- Izal, Cadore, \& Izquierdo, 2014). Thus, it is possible to hypothesize that the maximum repetition, volume of repetitions and the fatigue index may represent an interesting strategy to check the acute responses to the EC.

The current study showed some limitations, such as lack of control of biochemical markers of muscle damage, which could help further elucidate the findings, as well as the small 
number of subjects in the sample, due to the attempt to homogenize, at maximum, the group of individuals analyzed regarding the age and characteristics (physical, physiological and environmental) that could interfere with the results of the study.

\section{CONCLUSIONS}

Based on the results found, it is possible to conclude that performing exercise protocols with speeds of movement that emphasizes different muscle actions affects the DOMS, shows a tendency to decrease the number and total volume of repetitions, as well as in FI when the speed of movement emphasizes eccentric actions. Thus, it is possible to appreciate that training programs that use speeds of movement that emphasize the eccentric actions should be performed with caution, because the regulatory mechanisms, of this muscle action can cause major losses in TF parameters (number and volume of repetitions), increasing the DOMS, which could affect performance.

\section{Acknowledgements: \\ The authors wish to thank the Fundação de Amparo a Pesquisa do Estado de Minas Gerais (FAPEMIG) for funding this project.}

\section{Conflict of interests:}

Nothing to declare.

\section{Funding:}

Nothing to declare.

\section{REFERENCES}

Barroso, R., Roschel, H., Gil, S., Ugrinowitsch, C., \& Tricoli, V. (2011). Efeito do número e intensidade das ações excêntricas nos indicadores de dano muscular. Revista Brasileira de Medicina do Esporte, 17, 401-404.

Bird, S. P., Tarpenning, K. M., \& Marino, F. E. (2005). Designing resistance training programmes to enhance muscular fitness. Sports medicine, 35(10), 841-851.

Black, C. D., \& Dobson, R. M. (2013). Prior Eccentric Exercise Augments Muscle Pain and Perception of Effort During Cycling Exercise. The Clinical journal of pain, 29(5), 443-449.

Blazevich, A. J., Cannavan, D., Coleman, D. R., \& Horne, S. (2007). Influence of concentric and eccentric resistance training on architectural adaptation in human quadriceps muscles. Journal of Applied Physiology, 103(5), 1565-1575.

Brown, L. E., \& Weir, J. P. (2001). ASEP procedures recommendation i: accurate assessment of muscular strength and power. Journal of Exercise Physiology Online, 4(3), 1-21.

Buitrago, S., Wirtz, N., Yue, Z., Kleinoder, H., \& Mester, J. (2013). Mechanical load and physiological responses of four different resistance training methods in bench press exercise. Journal of Strength and Conditioning Research, 27(4), 1091-1100. doi: 10.1519/JSC.0b013e318260ec77

Candia-Luján, R., Fernández, J. A. D. P., \& Moreira, O. C. (2014). ¿ Son efectivos los suplementos antioxidantes en la disminución del dolor muscular tardío? Una revisión sistemática. Nutrición Hospitalaria, 31 (1), 32-45.

Carpinelli, R. N., Otto, R. M., \& Winett, R. A. (2004). A critical analysis of the ACSM position stand on resistance training: insufficient evidence to support recommended training protocols. Journal of Exercise Physiology Online, 7(3), 1-60.

Carvalho, T., Crisp, A., Lopes, C., Crepaldi, M., Calixto, R., Pereira, A., . . . Verlengia, R. (2015). Effect of eccentric velocity on muscle damage markers after bench press exercise in resistance-trained men. Gazzetta Medica Italiana, 174(3), 105-111.

Chapman, D., Newton, M., Sacco, P., \& Nosaka, K. (2006). Greater muscle damage induced by fast versus slow velocity eccentric exercise. International Journal of Sports Medicine, 27(8), 591598.

Chen, T., \& Nosaka, K. (2006). Effects of number of eccentric muscle actions on first and second bouts of eccentric exercise of the elbow flexors. Journal of Science and Medicine in Sport, 9(1), 57-66.

Choi, S. J. (2014). Differential susceptibility on myosin heavy chain isoform following eccentric-induced muscle damage. Journal of Exercise Rehabilitation, 10(6), 344-348.

Choi, S. J., Lim, J.-Y., Nibaldi, E. G., Phillips, E. M., Frontera, W. R., Fielding, R. A., \& Widrick, J. J. (2012). Eccentric contraction-induced injury to type I, IIa, and IIa/IIx muscle fibers of elderly adults. Age, 34(1), 215-226.

de Barros Berton, R. P., Libardi, C. A., Conceição, M. S., Bonganha, V., Nogueira, F. R. D., ChaconMikahil, M. P. T., . . . Madruga, V. A. (2012). Dano muscular: resposta inflamatória sistêmica após ações excêntricas máximas. Revista Brasileira de Educação Física e Esporte, 26 (3), 367-374.

de Souza-Teixeira, F., \& de Paz, J. (2012). Eccentric Resistance Training and Muscle Hypertrophy. Journal of Sports Medicine and Doping Studies, 1, 1-5. 
Eches, E. H. P., Ribeiro, A. S., Nascimento, M. A., \& Cyrino, E. S. (2013). Desempenho motor em séries múltiplas até a falha concêntrica. Motriz, 19(3), 43-48.

Ellwanger, R. B., Brentano, M. A., \& Kruel, L. F. M. (2007). Efeito da utilização de diferentes velocidades do treino de força em marcadores indiretos de lesão muscular. Revista Brasileira de Educação Física e Esporte, 21 (4), 259-270.

Falvo, M. J., Schilling, B. K., Bloomer, R. J., \& Smith, W. A. (2009). Repeated bout effect is absent in resistance trained men: an electromyographic analysis. Journal of Electromyography and Kinesiology, 19(6), e529-e535.

Farthing, J. P., \& Chilibeck, P. D. (2003). The effects of eccentric and concentric training at different velocities on muscle hypertrophy. European Journal of Applied Physiology, 89(6), 578-586.

Fernandez-Gonzalo, R., Bresciani, G., de SouzaTeixeira, F., Hernandez-Murua, J. A., JimenezJimenez, R., Gonzalez-Gallego, J., \& de Paz, J. A. (2011). Effects of a 4-week eccentric training program on the repeated bout effect in young active women. Journal of Sports Science \& Medicine, 10(4), 692-699.

Gonzalez-Izal, M., Cadore, E. L., \& Izquierdo, M. (2014). Muscle conduction velocity, surface electromyography variables, and echo intensity during concentric and eccentric fatigue. Muscle $\mathcal{E}$ nerve, 49(3), 389-397.

Hody, S., Rogister, B., Leprince, P., Laglaine, T., \& Croisier, J. L. (2013). The susceptibility of the knee extensors to eccentric exercise-induced muscle damage is not affected by leg dominance but by exercise order. Clinical Physiology and Functional Imaging, 33(5), 373-380.

Hollander, D. B., Kraemer, R. R., Kilpatrick, M. W., Ramadan, Z. G., Reeves, G. V., Francois, M., . . . Tryniecki, J. L. (2007). Maximal eccentric and concentric strength discrepancies between young men and women for dynamic resistance exercise. The Journal of Strength \& Conditioning Research, $21(1), 37-40$.

Hortobágyi, T., \& Maffiuletti, N. A. (2011). Neural adaptations to electrical stimulation strength training. European Journal of Applied Physiology, 111 (10), 2439-2449.

Kelly, S. B., Brown, L. E., Hooker, S. P., Swan, P. D., Buman, M. P., Alvar, B. A., \& Black, L. E. (2015). Comparison of concentric and eccentric bench press repetitions to failure. The Journal of Strength and Conditioning Research, 29(4), 1027-1032. doi: 10.1519/JSC.0000000000000713

Libardi, C. A., Nogueira, F. R., Vechin, F. C., Conceição, M. S., Bonganha, V., \& ChaconMikahil, M. P. T. (2013). Acute hormonal responses following different velocities of eccentric exercise. Clinical Physiology and Functional Imaging, 33(6), 450-454.
Moore, D. R., Young, M., \& Phillips, S. M. (2012). Similar increases in muscle size and strength in young men after training with maximal shortening or lengthening contractions when matched for total work. European Journal of Applied Physiology, 112(4), 1587-1592.

Newton, M. J., Sacco, P., Chapman, D., \& Nosaka, K. (2013). Do dominant and non-dominant arms respond similarly to maximal eccentric exercise of the elbow flexors? Journal of Science and Medicine in Sport, 16(2), 166-171.

Paulsen, G., Mikkelsen, U. R., Raastad, T., \& Peake, J. M. (2012). Leucocytes, cytokines and satellite cells: what role do they play in muscle damage and regeneration following eccentric exercise. Exercise Immunology Reveveiw, 18(1), 42-97.

Philippou, A., Koutsilieris, M., \& Maridaki, M. (2012). Changes in kinematic variables at various muscle lengths of human elbow flexors following eccentric exercise. Journal of Muscle Research and Cell Motility, 33(3-4), 167-175.

Price, D. D., Bush, F. M., Long, S., \& Harkins, S. W. (1994). A comparison of pain measurement characteristics of mechanical visual analogue and simple numerical rating scales. Pain, 56(2), 217226.

Price, D. D., McGrath, P. A., Rafii, A., \& Buckingham, B. (1983). The validation of visual analogue scales as ratio scale measures for chronic and experimental pain. Pain, 17(1), 45-56.

Rezaei, M., Ebrahimi-Takamjani, I., Jamshidi, A. A., Vassaghi-Gharamaleki, B., Hedayatpour, N., \& Havaei, N. (2014). Effect of eccentric exerciseinduced muscle damage on electromyographyic activity of quadriceps in untrained healthy females. Medical Journal of the Islamic Republic of Iran, 28, 154.

Roig, M., MacIntyre, D. L., Eng, J. J., Narici, M. V., Maganaris, C. N., \& Reid, W. D. (2010). Preservation of eccentric strength in older adults: evidence, mechanisms and implications for training and rehabilitation. Experimental Gerontology, 45(6), 400-409.

Sforzo, G. A., \& Touey, P. R. (1996). Manipulating Exercise Order Affects Muscular Performance During a Resistance Exercise Training Session. The Journal of Strength and Conditioning Research, 10(1), 20-24.

Shepstone, T. N., Tang, J. E., Dallaire, S., Schuenke, M. D., Staron, R. S., \& Phillips, S. M. (2005). Shortterm high-vs. low-velocity isokinetic lengthening training results in greater hypertrophy of the elbow flexors in young men. Journal of Applied Physiology, 98(5), 1768-1776.

Son, J., Lee, D., \& Kim, Y. (2014). Effects of involuntary eccentric contraction training by neuromuscular electrical stimulation on the enhancement of muscle strength. Clinical Biomechanics, 29(7), 767-772. 
Torres, R., Pinho, F., Duarte, J. A., \& Cabri, J. M. (2013). Effect of single bout versus repeated bouts of stretching on muscle recovery following eccentric exercise. Journal of Science and Medicine in Sport, 16(6), 583-588.

Umbel, J. D., Hoffman, R. L., Dearth, D. J., Chleboun, G. S., Manini, T. M., \& Clark, B. C. (2009). Delayed-onset muscle soreness induced by low- load blood flow-restricted exercise. European Journal of Applied Physiology, 107(6), 687-695.

Wirth, K., Keiner, M., Szilvas, E., Hartmann, H., \& Sander, A. (2015). Effects of Eccentric Strength Training on Different Maximal Strength and Speed-Strength Parameters of the Lower Extremity. The Journal of Strength and Conditioning Research, 29(7), 1837-1845. doi: 10.1519/JSC.0000000000000528

(c) (1) (8) All content of Journal Motricidade is licensed under Creative Commons, except when otherwise specified and in content retrieved from other bibliographic sources. 


\title{
Influence of sex, school system and body mass index on the physical activity patterns of adolescents during the school period
}

\author{
Sabrina Fontes Domingues ${ }^{1 *}$, João Carlos Bouzas Marins¹, Sílvia Eloiza Priore ${ }^{2}$, Claúdia Eliza \\ Patrocínio de Oliveira ${ }^{1}$, Osvaldo Costa Moreira ${ }^{3}$, Paulo Roberto dos Santos Amorim ${ }^{1}$ \\ ARTIGO ORIGINAL | ORIGINAL ARTICLE
}

\begin{abstract}
The objective of this study was to identify the influence of sex, school system and Body Mass Index (BMI) on the intensity of physical activities (PA) performed during the school period and to evaluate the contribution of this time to the achievement of the recommended physical activity from moderate to vigorous (RPAMV). 10-year-old schoolchildren were evaluated in Viçosa/Brazil. Body mass, stature and movements each 5 seconds were measured in 5 consecutive days with the ActiGraphGT3X accelerometer. The movements were classified in sedentary ( $\leq 100$ counts $/ \mathrm{min}$ ), light (between 101 and 2295 counts/min), moderate (between 2296 and 4011 counts $/ \mathrm{min}$ ) and vigorous ( $\geq 4012$ counts $/ \mathrm{min}$ ). Descriptive statistics, Student's $t$ test for independent samples and linear regression were used. The sex was a predictor in sedentary, moderate, vigorous and moderate to vigorous PA and BMI in light and vigorous activities. The school system was associated only with light PA. It was concluded that the boys were more active and less sedentary, mainly in moderate to vigorous PA. In the private school there was more time of light activities. The BMI showed direct association with light activities and inverse with vigorous. The school period contributed with $16 \%$ (10 minutes) of the RPAMV.

Keywords: Child, Movement, Accelerometer.
\end{abstract}

\section{INTRODUCTION}

Physical inactivity is a behavior that, when initiated in childhood or adolescence, tends to remain during adulthood becoming more difficult to be modified (Moraes et al., 2009). Therefore, childhood has been considered an important period of life in the acquisition and establishment of habits related to energy balance (Fisher, Hill, Webber, Purslow, \& Wardle, 2011), since the need to encourage children to become more physically active is evident (Lanningham-Foster et al., 2008).

Currently there is a reduction in the practice of physical activity (PA) since adolescence (Mota et al., 2005; Pawlowski, Andersen, TjørnhøjThomsen, Troelsen, \& Schipperijn, 2015), with indications that a greater risk of being inactive affects the girls (Fernandes \& Strum, 2011). On the other hand, it seems to be a general agreement that boys are more involved in moderate and vigorous PA (MVPA) (Dolinsky, Brouwer, Evenson, Siega-Riz, \& Østbye, 2011;
Mota, Santos, Guerra, Ribeiro, \& Duarte, 2003; Page et al., 2005; Pate, Pfeiffer, Trost, Ziegler, \& Dowda, 2004; Patnode et al., 2010; Vale, Silva, Santos, Soares-Miranda, \& Mota, 2010).

The regular practice of MVPA in school-age children has been associated with improvements in both physical and mental health conditions, as well as improvements in physical fitness and body weight control, as well as an indication of the adoption of a healthy lifestyle in the adulthood (Strong et al., 2005). In this sense, a single moderate PA session before, during and after school brings benefits in acute brain function, cognition, and school performance in children and youth (Bangsbo et al., 2016).

Some authors (Fernandes \& Strum, 2011; Frömel, Svozil, Chmelík, Jakubec, \& Groffik, 2016) point out that PA time during the school period is essential in reaching the 60-minute of MVPA daily practice recommendations (Services., 2010; Strong, et al., 2005), however, most school-age youth are still unable to reach

\footnotetext{
${ }^{1}$ Department of Physical Education - Federal University of Viçosa, Campus Viçosa, Viçosa, Minas Gerais, Brazil

${ }^{2}$ Department of Nutrition and Health, Federal University of Viçosa, Campus Viçosa, Viçosa, Minas Gerais, Brazil

${ }^{3}$ Institute of Biological Sciences and Health, Federal University of Viçosa, Campus Florestal, Florestal, Minas Gerais, Brazil

* Corresponding author: Departamento de Educação Física, Universidade Federal de Viçosa. Avenida PH Rolfs S/N, Campus Universitário, Viçosa-MG, 36570-000. Email: cpatrocinio@ufv.br
} 
them (Caetano, Albuquerque, Nascimento, Mendes, \& Amorim, 2016; Carson, Cliff, Janssen, \& Okely, 2013; Faria, Canabrava, \& Amorim, 2013; Patnode, et al., 2010; Pawlowski, et al., 2015), during school hours and leisure time (Nilsson et al., 2009).

Therefore, the present study aimed to identify the contribution of factors such as sex, school and Body Mass Index (BMI) in the practice of PA performed at different intensities during the school period, as well as evaluate the contribution of this period in reaching the PA daily recommended for children and adolescents.

\section{METHODS}

This is a cross-sectional epidemiological study carried out with 10-year-old schoolchildren from the 5th grade of elementary school, belonging to public (municipal and state) and private school of the city of Viçosa/Brazil.

The estimated population of the city of Viçosa/Brazil by the Brazilian Institute of Geography and Statistics (IBGE, 2010) is approximately 72,200 inhabitants, of which 1.146 are enrolled in the 5th grade of schooling, therefore the proportion of students in this age group for the population (maximum prevalence rate) Is $1.58 \%$.

The sample size was calculated according to the equation proposed by Lwanga and Lemeshow (Lwanga \& S., 1991): in which $\mathrm{n}=\mathrm{PxQ} /(\mathrm{E} / 1,96) 2$, where $\mathrm{n}=$ minimum sample size required; $\mathrm{P}=$ highest prevalence rate; $\mathrm{Q}=$ 100-P; E = tolerated sample margin for error. Considering the total number of students in the age group to be studied, the total number of the population and a standard error of $2 \%$ with a confidence interval of $98 \%$, it was estimated that a minimum sample of 150 students would be necessary for probabilistic proof.

\section{Sample}

The procedure for the selection of the schools participating in the study was based on data provided by the City Department of Education of Viçosa/Brazil, where information was obtained on the number of municipal, state and private schools in the city that offered the 5th grade of elementary school in 2011.

It was verified that this city council counts on 33 schools located in the urban zone and rural area, that attend to that year of schooling, of which eighteen are municipal $(n=489)$, eight are state $(\mathrm{n}=457)$, seven are private $\mathrm{N}=200)$. We excluded 13 schools that had less than 20 students with 10 years of age enrolled in the 5 th grade of elementary school. 15 of the remaining 20 schools were selected by simple random sampling, so that the ratio between municipal, state and private schools was respected. In addition, these were stratified according to the geographic region of the city (north, south, east or west). Of these, 4 schools were excluded from the sample because they refused to participate in the study.

From the eleven remaining schools, a list of students enrolled in the fifth grade of elementary school was requested, totaling 600 potential volunteers. Due to the limited number of accelerometers, 20 children in each school were selected, respecting the sex segmentation, in up to two classes per school, and these should meet the following inclusion criteria to be considered eligible to participate in this study: to be 10 years old during the period of data collection, to be present in the classroom on the day of the participants' draw and to present the Informed Consent Form fulfilled and signed with the consent of the persons responsible until the first day of data collection. The chronological age of the students was determined in a centesimal manner, using the date of birth and the day of data collection.

The number of students evaluated per school ranged from 8 to 20 , with a mean of 13 , totaling 177. Twenty-seven schoolchildren were excluded because they presented insufficient data or because of failure to register, leaving a total of 150 (Figure 1), of which 80 were female $(53 \%)$ and 70 male (47\%) (Table 1).

The present study was registered and approved by the Ethics Committee in Research with Human Beings of the Federal University of Viçosa under the $n^{\circ} 027 / 2010$. 


\section{Instruments}

A portable digital scale (Soehnle, Germany), with a precision of $100 \mathrm{~g}$ and a $130 \mathrm{~kg}$ capacity, and a portable stadiometer fixed to the wall compact model type (Sanny ${ }^{\circledR}$ Medical, model SN-4010) with an accuracy of $0.1 \mathrm{~cm}$ and a length of $210 \mathrm{~cm}$, were used to record the anthropometric measures body mass $(\mathrm{kg})$ and height $(\mathrm{cm})$ respectively.

The GT3X tri-axial accelerometer (Actigraph, USA) was used to evaluate the vertical, horizontal and vector acceleration of body movements.

\section{Procedures}

BMI was determined from the anthropometric measurements to classify the nutritional status of the participants according to the World Health Organization (WHO, 2007). The anthropometric measurements were performed according to Lohman et al. (1988) the day before PA monitoring.

The measurement of physical activity was determined from the detected accelerations which were filtered, converted to numerical values, and subsequently summed in a specific range of recording time interval called "epoch". The record of the movement count in each epoch represents the intensity of the activities performed during that period of time stored in memory. These records were performed every 5 seconds, since this interval has been considered sensitive, accurate and effective to evaluate the spontaneous, intermittent and highly transient PA expressed through the movements performed by the children (Vale, et al., 2010).

Participants were instructed on the care of the use of the equipment, which were set in the hip of each volunteer through an adjustable elastic belt. This procedure was performed immediately upon arrival at the school, withdrawing them before leaving, in order to evaluate the entire school period for five consecutive weekdays, without interfering with the activities performed.

The familiarization with accelerometers was performed on the day of anthropometric measurements, which data were disregarded to minimize the Hawthorne effect, a general scientific procedure, where the observation process changes the observed phenomenon (Corder, Ekelund, Steele, Wareham, \& Brage, 2008), since the students could move more through the first contact with the equipment, overestimating the intensity of the movements performed. Each child used the same accelerometer (identified by serial number) on each day of data collection to avoid possible variations between devices.

At the end of each school stay, accelerometers were connected through an interface to a notebook to perform data download and conversion of records every five seconds at 1minute intervals using the software ActiLife version 4. 0 (Pensacola, FL, USA) and the average movements per minute were calculated. From these results, was obtained the general average of the number of movements performed during the evaluated days, individually and overall, using the Microsoft Office Excel 2007 program.

The evaluators were monitored throughout the school period by the researcher responsible for this study, with the purpose of recording, in a Control Sheet, the time of the beginning and the end of classes, the observations of active behavior patterns and sedentary and/or eventual changes in the routine of the children, in order to facilitate the understanding of the data obtained through accelerometry.

The time of delay of the arrival in the school or of anticipation of the time of exit of the schoolchildren was excluded from the general calculation of the amount of movements accomplished. The means of monitoring for collection days and duration were 4.2 days for 260 minutes per day (4 hours and 20 minutes). As some schools showed differences in the total time of the school period, the results of the total number of movements were divided by the length of stay (in minutes) in each school, these being expressed in count/min.

In the present study, PA counts thresholds were used to determine the amount of time that students engaged in sedentary $(\leq 100$ counts/min), light (101 to 2295 counts/min), moderate (2296 to 4011 counts/min) or vigorous 
( $\geq 4012$ counts/min) PA (Evenson, Catellier, Gill, Ondrak, \& McMurray, 2008), as recent studies (Romanzini, Petroski, \& Reichert, 2012; Trost, Loprinzi, Moore, \& Pfeiffer, 2011) have found that these thresholds presented good to moderate generality for the identification of sedentary, moderate and vigorous PA in children and adolescents when compared to other thresholds.

\section{Statistical analysis}

Data analysis was performed using descriptive statistics (absolute and relative frequency, mean, standard deviation, minimum and maximum) for the general data. The Kolmogorov - Smirnov test was used to test normality and Student 's t - test for independent samples in order to identify any differences between the sex.

Five linear regression models were created to verify the contribution of the independent variables sex (including the binary variables: female and male), school system (considering the binary variables: public and private) and BMI, at the time of PA in the intensities sendentary (Model 1), light (model 2), moderate (model 3), vigorous (model 4 ), and moderate to vigorous (model 5). In case of heteroscedasticity, this was corrected from a pondering matrix of White's robust standard errors.

The level of significance was 5\% ( $\mathrm{p}<0.05)$. Statistical analyzes were performed with STATA ${ }^{\circledR}$ software - Data Analysis and Statistical Software version 11.0 (Stata Corp LP, College Station, TX, USA).

\section{RESULTS}

Table 1 shows the characterization of the sample $(n=150)$ regarding sex, school and BMI in absolute and relative values.

The anthropometric characteristics, the number of movements performed and their classifications, and the time engaged in PA in different intensities (sedentary, light, moderate, vigorous and MVPA) were presented as mean and standard deviation in table 2 .

Table 1

Profile of the students of the fifth grade of elementary school in Viçosa/Brazil.

\begin{tabular}{lccc}
\hline & Female & Male & Total \\
\hline Sex & $80(53 \%)$ & $70(47 \%)$ & $150(100 \%)$ \\
School & & & \\
Public & $59(39 \%)$ & $49(33 \%)$ & $108(72 \%)$ \\
Private & $21(14 \%)$ & $21(14 \%)$ & $42(28 \%)$ \\
BMI & & & \\
Low weight & $4(5 \%)$ & $5(7 \%)$ & $9(6 \%)$ \\
Eutrophy & $55(69 \%)$ & $44(63 \%)$ & $99(66 \%)$ \\
Overweight & $16(20 \%)$ & $12(17 \%)$ & $28(19 \%)$ \\
Obesity & $5(6 \%)$ & $9(13 \%)$ & $14(9 \%)$ \\
\hline
\end{tabular}

In the models 1,3 and 5 , the independent variables were responsible for explaining only $7.21 \%, 21.09 \%$ and $20.80 \%$ of the average time of practice of sedentary, moderate and moderate to vigorous PA, respectively, performed during the school period, presenting statistical significance only for the sex variable (Table 3 ).

Yet in model 2, the independent variables explain $11.11 \%$ of the variance of the time of practice of light PA, being the evaluated variables school and BMI considered predictors of the time of practice of PA performed in these intensities.

Considering the model 4 , it is possible to verify that the variables sex and BMI elucidated $11.72 \%$ of the variance of the practice time of vigorous PA obtained during the period of permanence in the school, being considered as predictors variables of the time of practice of PA.

Sex was associated with sedentary, moderate, vigorous and moderate to vigorous movements. In contrast, the school was only associated with light intensity movements. However, BMI was associated with light and vigorous intensities. 
Table 2

Description of the characteristics of the students of the 5th grade of elementary school in Viçosa/Brazil.

\begin{tabular}{|c|c|c|c|c|c|c|c|c|c|}
\hline & \multicolumn{3}{|c|}{ Female } & \multicolumn{2}{|c|}{ Male } & \multicolumn{4}{|c|}{ Total } \\
\hline & Mean \pm SD & Min. & Max. & Mean \pm SD & Min. & Max. & Mean \pm SD & Min. & Max. \\
\hline $\begin{array}{l}\text {-Body } \\
\text { Mass }(\mathrm{kg})\end{array}$ & $37.09 \pm 8.52$ & 22.30 & 68.50 & $35.89 \pm 9.09$ & 24.10 & 67.50 & $36.53 \pm 8.78$ & 22.30 & 68.50 \\
\hline -Estature (m) & $1.46 \pm 0.07$ & 1.30 & 1.63 & $1.43 \pm 0.65^{* *}$ & 1.28 & 1.59 & $1.44 \pm 0.69$ & 1.28 & 1.63 \\
\hline $\begin{array}{l}\text {-BMI }(\mathrm{kg} / \mathrm{m} 2) \\
\text {-TPAP (min) }\end{array}$ & $17.37 \pm 3.04$ & 11.95 & 27.44 & $17.43 \pm 3.36$ & 12.47 & 29.90 & $17.40 \pm 3.19$ & 11.95 & 29.90 \\
\hline Sedentary & $162.62 \pm 25.91$ & 101.80 & 225.00 & $150.17 \pm 29.67^{*}$ & 85.40 & 210.00 & $156.78 \pm 28.34$ & 85.40 & 225.00 \\
\hline Light & $90.34 \pm 26.56$ & 27.40 & 151.00 & $98.05 \pm 28.69^{* * *}$ & 42.00 & 170.00 & $93.96 \pm 27.75$ & 27.40 & 170.00 \\
\hline Moderate & $6.21 \pm 3.81$ & 0.25 & 15.20 & $10.43 \pm 4.34^{* * *}$ & 1.20 & 19.33 & $8.19 \pm 4.57$ & 0.25 & 19.33 \\
\hline Vigorous & $1.05 \pm 1.06$ & 0.00 & 4.80 & $2.05 \pm 2.11^{* * *}$ & 0.00 & 11.40 & $1.52 \pm 1.71$ & 0.00 & 11.40 \\
\hline MVPA & $7.26 \pm 4.50$ & 0.25 & 17.40 & $12.48 \pm 5.78^{*}$ & 1.40 & 29.40 & $9.71 \pm 5.75$ & 0.25 & 29.40 \\
\hline
\end{tabular}

Note: $\mathrm{p}<0,01 ;{ }^{* *} \mathrm{p}<0,05 ;{ }^{* * *} \mathrm{p}<0,001$, for comparison between male and female; SD: standard deviation; Min: minimum; Max: maximum; BMI: body mass index; MVPA: moderate to vigorous physical activity; TPAP: time of physical activity practice.

Table 3

Results of the regression analysis to predict the time of practice of PA (minutes) in defined intensities by students of 10 years old during the school period.

\begin{tabular}{lccccc}
\hline & Sedentary & Light & Moderate & Vigorous & MVPA \\
& $\beta(\mathrm{SE})$ & $\beta(\mathrm{SE})$ & $\beta(\mathrm{SE})$ & $\beta(\mathrm{SE})$ & $\beta(\mathrm{SE})$ \\
\hline \multirow{2}{*}{ - constant } & $185,7447^{* * *}$ & $59,7772^{* * *}$ & $5,9380^{*}$ & $2,5244^{* * *}$ & $8,4622^{*}$ \\
& $(13,8478)$ & $(12,2065)$ & $(1,9118)$ & $(0,6772)$ & $(2,4461)$ \\
\hline - dummy sex & $-12,4672^{*}$ & 7,0529 & $4,1958^{* * *}$ & $1,0166^{* * *}$ & $5,2123^{* * *}$ \\
Male & $(4,5324)$ & $(4,2907)$ & $(0,6720)$ & $(0,2750)$ & $(0,8615)$ \\
\hline - dummy school & $-0,7796$ & $14,9308^{*}$ & $-0,2914$ & $-0,3095$ & $-0,6012$ \\
Private & $(4,9657)$ & $(4,7679)$ & $(0,7467)$ & $(0,2903)$ & $(0,8114)$ \\
\hline - BMI & $-1,3251$ & $1,5364^{* *}$ & 0,0162 & $-0,0806^{* *}$ & $-0,0643$ \\
& $(0,7952)$ & $(0,6780)$ & $(0,1061)$ & $(0,0357)$ & $(0,1357)$ \\
\hline $\mathrm{r}^{2}$ & 0,0721 & 0,1111 & 0,2109 & 0,1172 & 0,2080 \\
\hline
\end{tabular}

Notes: $\mathrm{p}<0,01{ }^{* *} \mathrm{p}<0,05 ;{ }^{* * *} \mathrm{p}<0,001$ for comparison between the different levels of physical activity; BMI: Body Mass Index; $\beta$ : regression coefficient; SE: standard error; The regression models of sedentary, moderate, vigorous PA and MVPA presented heteroscedasticity, which was corrected from a pondering matrix of White's robust standard error.

\section{DISCUSSION}

In the present study, the sex variable was considered as an isolated predictor in the performance of sedentary moderate and moderate to vigorous PA, and as a predictor associated with BMI in vigorous intensity. However, only the school variables and BMI were associated as predictors in the practice of light PA.

Regarding sex, this seems to be a determining factor in the time engaded in PA performed at school since this variable was associated with all intensities, except for light activities (Table 3) according to the results obtained by Pate et al. (Pate, et al., 2004).

From the mean values of PA practice time presented in Table 3, it was found that the fact that the child is a male indicates that the child performs, on average, $12.46 \pm 4.53$ minutes less sedentary activities $(\mathrm{p}<0.01)$ compared to a female child, in addition performs $4.19 \pm 0.67$ minutes of moderate activity $(\mathrm{p}<0.001)$ and 1.01 \pm 0.27 minutes of vigorous activity.

The results (table 2) confirm this difference between the sex, especially regarding the time engaged in MVPA in school, in agreement with the findings of Nilsson et al. (Nilsson, et al., 2009) when evaluating Danish, Portuguese, Norwegian and Estonian children of 9 years old.

It was also observed that boys practice, on average, $5.21 \pm 0.86$ minutes more of MVPA in comparison to girls during the school period ( $\mathrm{p}$ $<0.001$ ). These results corroborate previous findings (Dolinsky, et al., 2011; Mitchell et al., 2009; J. Mota, et al., 2003; Page, et al., 2005; Pate, et al., 2004; Patnode, et al., 2010; Vale, et al., 2010). 
Higher males values (Table 2) for the time of participation in MVPA are in line with the results observed in children in the United States $(7.8 \pm$ 0.7 and $7.0 \pm 0.7$ minutes/hour) (Pate, et al., 2004), Denmark $(49.0 \pm 25.0$ and $29.0 \pm 18.0$ minutes), Portugal $(38.0 \pm 22.0$ and $26.0 \pm 14.0$ minutes), Norway $(58.0 \pm 27.0$ and $44.0 \pm 19.0$ minutes), Estonia $(46.0 \pm 23.0$ and $35.0 \pm 17.0$ minutes) (Nilsson, et al., 2009) and in New Zealand (17.0 \pm 10.0 and $11.0 \pm 7.0$ minutes/day) (Taylor et al., 2011) during the school period $(7.8 \pm 0.7$ and $7.0 \pm 0.7$ minutes / hour), as well as in the United Kingdom (13.7 \pm 3.7 and $9.4 \pm 4.1$ minutes) (Page, et al., 2005) over the school days $(152.57 \pm 79.39$ and 87.41 \pm 56.16 counts/min, respectively).

Pate et al. (2004) report that socio-cultural and environmental aspects such as the type of entertainment performed by the boys, who usually engage in more intense activities, with greater body contact and in larger groups of children, as well as the fact that the girls receive less incentive from their teachers and colleagues to practice MVPA during the school period, may justify the difference presented in the results between the sex, accordingly to our findings, although Patnode et al. (2010) report in their study that there was no correlation between the time engaged in MVPA between boys and girls and family support in both sex.

Although the literature is very restricted with regard to active time in school, some authors have reported the difference between the sex in the time dedicated to MVPA, especially during Physical Education classes (Jennings-Aburto et al., 2009) e and in school playgrounds (Amorim, Faria, Canabrava, \& Domingues, 2012; Faria, et al., 2013; Jennings-Aburto, et al., 2009; Pawlowski, Andersen, J., \& Schipperijn, 2016 ; Taylor, et al., 2011). However,, Fromel et al. (2016) emphasize that on physical education days both boys and girls perform more PA. Pawlowski et al. (2016) observed in Denmark that during break time the girls spent most of their time in the school building because of the lack of attraction of the outdoor facilities and the school yard; In order to avoid the competitive soccer matches in the field, while the boys dominated this activity, which reinforces the boys choice for more active activities.

On the other hand, when analyzing the school and its association with the time of PA during the school period, significance was verified only in light intensity $(\mathrm{p}<0.01)$, indicating that the student belonging to a private school is engaged in light activities during $14.93 \pm 4.76$ minutes ( $\mathrm{p}$ $<0.01$ ) more, when compared to the student belonging to the public school system. Although, in the present study, it appears that this variable did not influence the time of practice of PA at other intensities, Pate et al. (2004) state that the level of PA of children varies greatly between schools and that characteristics such as the school or the school system have a greater influence on the level of PA than the personal and demographic characteristics.

Cherobin e Palma (2014) also observed that the fact that student belonging to a certain educational system (public or private) influences their physical activity profile in some aspects (motorized transportation to school, restricted and ample space to entertain, participation in physical education classes and also outside, daily time practicing sports, daily time in the computer \nternet during the weekend, daily time playing with the friends), in which public school students, in the majority, practice these activities only at school.

The BMI showed an association with the time of practice of light and vigorous intensity PA, and the increase of one unit in the BMI of the sample corresponds to an increase of $1.53 \pm 0.67$ minutes of light activities $(\mathrm{p}<0.05)$ and a reduction of $0.08 \pm 0.03$ minutes of vigorous activities $(\mathrm{p}<0.05)$ throughout the school period. The results of the present study differ from the findings of Treuth et al. (2009), who performed a prospective analysis of girls in the 6th to 8th grade, in which there is an increase in sedentary activity over the period evaluated, but without association with the changes in BMI or the percentage of fat. Pawlowski et al. (2015) suggest that girls and obese children are less physically active. 
It is unclear whether high BMI rates result in reduced PA levels or if low PA levels induce high body mass indexes, but scientific evidence supports the hypothesis that obese children are less physically active than their non-obese counterparts (Mcmanus, Chu, $\mathrm{Yu}, \& \mathrm{Hu}, 2011$; Page, et al., 2005). In addition, it is suspected that the PA patterns presented by obese children can contribute substantially to maintain their obesity status (Page, et al., 2005). However, the rise of sedentary behavior (Mitchell, et al., 2009) and the decline of PA (Pate, et al., 2004) appear to be determinants of increased overweight and childhood obesity (Treuth, et al., 2009).

Conversely, with a prospective study, Fisher et al. (2011) concluded that a longer time engaged in MVPA was associated with lower adiposity indexes (including BMI), regardless of total PA time or sedentary time. Considering these premises, the need for health education in the perspective of increased levels of PA and reduction of sedentary behaviors for children from the earliest ages becomes evident.

The evaluation of MVPA has been the focus of research as a level of intensity capable of improving the health of individuals (Robertson, Stewart-Brown, Wilcock, Oldfield, \& Thorogood, 2011). In this sense, Fromel et al. (2016) e Mota et al. (2003) indicate that the school seems to be an important place for the engagement in MVPA.

The mean time of practiced MVPA in this study was $9.71 \pm 5.75$ minutes. Mean values higher than these, but still low in relation to the recommended ones, were reported by Fisher et al.(Fisher, et al., 2011), 12 minutes in a study of 280 English children; by Dolinsky et al. (2011), 14.9 minutes, when evaluating 337 American students from 2 to 5 years old; and by Patnode et al. (2010), 21.4 minutes, when investigating 294 young Americans from 10 to 17 years old. Nevertheless, even after implementing an intervention program with active intervals of PA throughout the school period, Wadsworth et al. (Wadsworth, Robinson, Beckham, \& Webster, 2012) obtained mean values between 5 and 15 minutes of the minimum required of 60 minutes of daily MVPA, surpassing the initial values recorded by them, but still far below the daily recommendations.

Considering that epidemiological evidence points to a reduction in PA among young people during adolescence (Mota, et al., 2003; Pawlowski, et al., 2015) and that until adulthood individuals tend to spend even more time engaged in sedentary behavior (Mitchell, et al., 2009; Treuth, et al., 2009), the risks of obesity may become increasingly prominent, in addition to increasing the chances of developing chronic diseases such as diabetes, hypertension, colon and endometrial cancer, depression and anxiety, and impairment of the muscles and bones (Treuth, et al., 2009) which makes very worrying the results presented of the time of involvement in MVPA, since only $16 \%$ of the daily recommendations of PA for children and adolescents were reached during the school period.

This panorama highlights the need for emergency care in the promotion of childhood PA, as more active children tend to be more active adults (Wadsworth, et al., 2012) and because the health-related benefits also depend on the increased time engaged in MVPA (Mitchell, et al., 2009). In addition, attempts to implement active PA intervals during the school day have contributed significantly to the rise in MVPA practice time (Wadsworth, et al., 2012).

Considering that the children of the present study spend a good part of their school day time seated and in sedentary activities (in average 156 minutes) (Table 2), the occasions that allow the practice of PA in this environment are limited to the daily break time of 15 to 30 minutes and Physical Education classes from 35 to 50 minutes once or twice a week, which are recognized as potential opportunities to reach the daily MVPA recommendations (Services., 2010; Strong, et al., 2005).

Interventions involving changes in the physical structure of schools, incentives for an active learning environment and promotion of PA during classes, replacing the tables and chairs of a traditional classroom by balls and vertical workstations, have provided interesting results at 
the levels of PA reached by schoolchildren of 10 years old during the school period (LanninghamFoster, et al., 2008). In addition, some approaches in school such as creating parks and playgrounds, are effective strategies to increase the practice of PA for children and adolescents (Bangsbo, et al., 2016).

In view of the low rates of MVPA, both in active time and in classroom time, it is suggested that intervention programs and incentive policies be implemented during the school period, in order to make children more active, either in Physical Education classes, recreation, or even active breaks during the school day and/or participating in extracurricular activities projects that enable the practice of sports and leisure activities in order to maximize the reach of 60 minutes daily of MVPA recommended for children and adolescents, whereas a single moderate PA session before, during, and after school results in benefits in the acute brain function, cognition, and school performance for children and adolescents (Bangsbo, et al., 2016).

Some limitations of this study should be recognized. As the present sample was restricted to the cohort of 10-year-old students, the behaviors verified here should not be extrapolated to other age ranges, such as childhood or adolescence. Because of the lack of studies specifically related to the length of school period, comparing the results presented here with others that used different methods of assessing PA and sedentary lifestyle, as well as cutoff points or the setting of different movement count thresholds, may result in a disparity between the results. We also recognize that the inclusion of other variables in the analysis models could reveal intervening factors in the students' behavior, such as the maturational stage and the seasonality, which were not measured due to operational limitations.

\section{CONCLUSIONS}

From the results found in the present study it is possible to conclude that during the school period there is a predominance of sedentary activities, that sex is a predictor of the practice of physical activity at all intensities, except for the light ones; with females being more sedentary than males. Regarding the educational system, it was concluded that the students of the private school were engaged in PAs for a longer time only of light intensity, in comparison to the students of the public school system. BMI is also a predictor of physical activity practice, being inversely associated with activities of vigorous intensity and directly with activities of light intensities. In addition, it is noted that the school period presents little contribution to the achievement of the daily recommended of physical activities for children and teenagers.

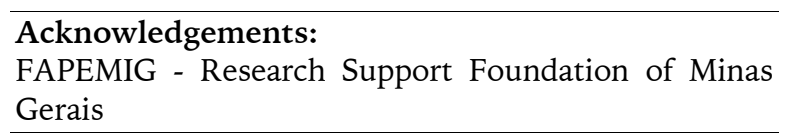

Conflict of interests:

Nothing to declare.

Funding:
FAPEMIG - Research Support Foundation of Minas
Gerais

\section{REFERENCES}

Amorim, P. R. S., Faria, F. R., Canabrava, K. L., \& Domingues, S. F. (2012). Nível e intensidade da atividade física de crianças durante o recreio escolar. Motricidade, 8(2), 331-338.

Bangsbo, J., Krustrup, P., Duda, J., Hillman, C., Andersen, L., \& al., W. M. e. (2016). The Copenhagen Consensus Conference 2016: children, youth, and physical activity in schools and during leisure time. Br J Sports Med, 1-2.

Caetano, I. T., Albuquerque, M. R., Nascimento, F. R., Mendes, E. L., \& Amorim, P. R. S. (2016). Análise do comportamento sedentário de escolares por sexo, tipo de escola e turno escolar. R. bras. Ci. e Mov, 24(1), 16-26.

Carson, V., Cliff, D. P., Janssen, X., \& Okely, A. D. (2013). Longitudinal levels and bouts of sedentary time among adolescente girls. BMC Pediatrics, 13(1), 173.

Cherobin, I. A., \& Palma, M. S. (2014). Perfil de atividade física de escolares provenientes de diferentes redes de ensino e cidades do Rio Grande do Sul. R. bras. Ci. e Mov, 22 (4), 77-87.

Corder, K., Ekelund, U., Steele, R. M., Wareham, N. J., \& Brage, S. (2008). Assessment of physical 
activity in younth. Journal of Applied Physiology, 105(3), 977-987.

Dolinsky, D. H., Brouwer, R. J., Evenson, K. R., SiegaRiz, A. M., \& Østbye, T. (2011). Correlates of Sedentary Time and Physical Activity Among Preschool-Aged Children. Prev Chronic Dis, 8(6), $1-14$.

Evenson, K. R., Catellier, D. J., Gill, K., Ondrak, K. S., \& McMurray, R. G. (2008). Calibration of two objective measures of physical activity for children. J Sports Sci. , 26(14), 1557-1565. doi: 10.1080/02640410802334196.

Faria, F. R., Canabrava, K. L., \& Amorim, P. R. S. (2013). Nível de Atividade Física durante o recreio escolar em escola pública e particular. $R$. bras. Ci. e Mov, 21 (1), 90-97.

Fernandes, M. M., \& Strum, R. (2011). The role of school physical activity programs in child body mass trajectory. Journal of Physical Activity $\mathcal{E}$ Health, 8(2), 174-181.

Fisher, A., Hill, C., Webber, L., Purslow, L., \& Wardle, J. (2011). MVPA is associated with lower weight gain in 8-10 year old children: a prospective study with 1 year follow-up. PLoS One, 6(4), e18576. doi: 10.1371/journal.pone.0018576

Frömel, K., Svozil, Z., Chmelík, F., Jakubec, L., \& Groffik, D. (2016). The Role of Physical Education Lessons and Recesses in School Lifestyle of Adolescents. J Sch Health, 86(2), 143151. doi: 10.1111/josh.12362.

IBGE. (2010). Contagem populacional 2010. Rio de Janeiro.

Jennings-Aburto, N., Nava, F., Bonvecchio, A., Safdie, M., González-Casanova, I., Gust, T., \& ., R. J. (2009). Physical activity during the school day in public primary schools in Mexico City. Salud Publica Mex, 51 (1), 141-147.

Lanningham-Foster, L., Foster, R. C., Mccrady, S. K., Manohar, C. U., Jensen, T. B., Mitre, N. G., . . . Levine, J. A. (2008). Changing the school environment to increase physical activity in children. Obesity (Silver Spring), 16(8), 18491853.

Lohman, T. G., Roche, A. F., \& Martorell, R. (1988). Anthropometric standardization reference manual. Champaign, Illinois: HumanKinectis.

Lwanga, S. K., \& S., L. (1991). Sample size determination in health studies. A pratical manual. Geneva.

Mcmanus, A. M., Chu, E. Y. W., Yu, C. C. W., \& Hu, Y. (2011). How children move: activity pattern characteristics in lean and obese chinese children. Journal of Obesity, 2011 (1), 1-6.

Mitchell, J. A., Mattocks, C., Ness, A. R., Leary, S. D., Pate, R. R., Dowda, M., . . Riddoch, C. (2009). Sedentary behaviour and obesity in a large cohort of children. Obesity (Silver Spring), 17(8), 15961602.

Moraes, A. C. F., Fernandes, C. A. M., Elias, R. G. M., Nakashima, A. T. A., Reichert, F. F., \& Falcão, M. C. (2009). Prevalência de inatividade física e fatores associados em adolescentes. Rev Assoc Med Bras, 55(5), 523-528.

Mota, J., Santos, P., Guerra, S., Ribeiro, J. C., \& Duarte, J. (2003). A. patterns of daily physical activity during school days in children and adolescents. American Journal of Human Biology, 15 (1), 547-553.

Mota, J., Silva, P., Santos, M. P., Ribeiro, J. C., Oliveira, J., \& Duarte, J. A. (2005). Physical activity and school recess time: Differences between the sexes and the relationship between children's playground physical activity and habitual physical activity. Journal of Sports Sciences, 23 (3), 269-275.

Nilsson, A., Anderssen, S. A., Andersen, L. B., Froberg, K., Riddoch, C., Sardinha, L. B., \& Ekelund, U. (2009). Between- and within-day variability in physical activity and inactivity in 9- and 15-yearold European children. Scandinavian Journal of Medicine \& Science in Sports, 19(1), 10-18.

Page, A., Cooper, A. R., Stamatakis, E., Foster, L. J., Crowne, E. C., Sabin, M., \& Shield, J. P. H. (2005). Physical activity patterns in nonobese and obese children assessed using minute-by-minute accelerometry. International Journal of Obesity, 29(1), 1070-1076.

Pate, R. R., Pfeiffer, K. A., Trost, S. G., Ziegler, P., \& Dowda, M. (2004). Physical activity among children attending preschools. Pediatrics, 114(5), 1258-1263.

Patnode, C. D., Lytle, L. A., Erickson, D. J., Sirard, J. R., Barr-Anderson, D., \& Story, M. (2010). The relative influence of demographic, individual, social, and environmental factors on physical activity among boys and girls. International Journal of Behavioral Nutrition and Physical Activity, 7(1), 79.

Pawlowski, C. S., Andersen, H. B., J., T., \& Schipperijn, J. (2016 ). Children's Physical Activity Behavior during School Recess: A Pilot Study Using GPS, Accelerometer, Participant Observation, and GoAlong Interview. PLoS One, 11 (2), e0148786. .

Pawlowski, C. S., Andersen, H. B., Tjørnhøj-Thomsen, T., Troelsen, J., \& Schipperijn, J. (2015). Space, body, time and relationship experiences of recess physical activity: a qualitative case study among the least physical active schoolchildren. BMC Public Health, 16, 16.

Robertson, W., Stewart-Brown, S., Wilcock, E., Oldfield, M., \& Thorogood, M. (2011). Utility of accelerometers to measure physical activity in children attending an obesity treatment intervention. Journal of Obesity, 2011 (1).

Romanzini, M., Petroski, E. L., \& Reichert, F. F. (2012). Limiares de acelerômetros para a estimativa da intensidade da atividade física em crianças e adolescentes: uma revisão sistemática. Revista Brasileira de Cineantropometria \& Desempenho Humano, 14(1), 101-113.

Services., U. D. o. A. a. U. S. D. o. H. a. H. (2010). Dietary Guidelines for Americans, 2010. 
Washington, DC: U.S.: Government Printing Office.

Strong, W. B., Malina, R. M., Blimkie, C. J., Daniels, S. R., Dishman, R. K., Gutin, B., . . . Trudeau, F. (2005). Evidence based physical activity for school-age youth. The Journal of Pediatrics, 146(6), 732-737.

Taylor, R. W., Farmer, V. L., Cameron, S. L., MeredithJones, K., Williams, S. M., \& Mann, J. (2011). School playgrounds and physical activity policies as predictors of school and home time activity. International Journal of Behavioral Nutrition and Physical Activity, 8(1), 38.

Treuth, M. S., Baggett, C. D., Pratt, C. A., Going, S. B., Elder, J. P., Charneco, E. Y., \& Webber, L. S. (2009). A longitudinal study of sedentary behavior and overweight in adolescent girls. Obesity (Silver Spring), 17(5), 1003-1008.
Trost, S. G., Loprinzi, P. D., Moore, R., \& Pfeiffer, K. A. (2011). Comparison of accelerometer cut points for predicting activity intensity in youth. Medicine and Science in Sports and Exercise, 43(7), 1360-1368.

Vale, S., Silva, P., Santos, R., Soares-Miranda, L., \& Mota, J. (2010). Compliance with physical activity guidelines in preschool children. Journal of Sports Sciences, 28(6), 603-608.

Wadsworth, D. D., Robinson, L. E., Beckham, K., \& Webster, K. (2012). Break for Physical Activity: Incorporating Classroom-Based Physical Activity Breaks into Preschools. Early Childhood Education Journal, 39(6), 391-395.

WHO, W. H. O., \& (2007). The WHO Reference 2007: growth reference data for 5 - 19 years. WHO: Programmes and Projects

(c) () () All content of Journal Motricidade is licensed under Creative Commons, except when otherwise specified and in content retrieved from other bibliographic sources. 


\title{
Factors associated with lower limb strength and agility in the elderly
}

\author{
Josiene de Oliveira Couto ${ }^{1}$, Izabella Cristina da Silva Santos ${ }^{1}$, Andressa Melo Alves ${ }^{1}$, Nara \\ Michelle Moura Soares ${ }^{2}$, Gilberto Santos Morais Júnior ${ }^{1}$, Danilo Barbosa Morais ${ }^{1}$, Roberto \\ Jerônimo dos Santos Silva ${ }^{*}$
}

ARTIGO ORIGINAL | ORIGINALARTICLE

\begin{abstract}
This study aims to verify the factors associated with strength and agility in the elderly. The sample consisted of 224 elderly individuals aged $70.59 \pm 6.3$ years. The socioeconomic level and physical activity level were observed from previously validated instruments. Anthropometric indexes were calculated and lower limb strength and agility tests were applied. Binary Logistic Regression with robust estimator was used, with significance level of $5 \%$. It was verified that the factors that were associated to the best agility performance were: age $(\mathrm{OR}=6.3,95 \% \mathrm{CI}=2.6-15.25)$, educational level $(\mathrm{OR}=0.34,95 \% \mathrm{CI}=0.15-0.76)$ and physical activity level $(\mathrm{OR}=2.86,95 \% \mathrm{CI}=1.32-6.16)$. However, for the best lower limb strength performance, the associated factors were reported physical limitation $(\mathrm{OR}=0.41,95 \% \mathrm{CI}=0.20-0.82)$ and physical activity level $(\mathrm{OR}=0.43,95 \% \mathrm{CI}=0.21-0.86)$. It was concluded that younger elderly individuals, with higher educational level and physically active perform well in the neuromotor agility variable. However, elderly individuals with reported physical limitation and with low physical activity levels presented good lower limb strength performance.

Keywords: Aging, Functional Fitness, Neuromotor Fitness
\end{abstract}

\section{INTRODUCTION}

Globally, there is a projection that the elderly population segment will more than triple by 2100, increasing from 901 million in 2015 to 3.1 billion by 2100 (DESA, 2015). In Brazil it will not be different, and official data have pointed out that this is the fastest growing segment of the population, with a $4 \%$ increase per year between 2012 and 2022, and that there should be an increase of over 50 million of the population over 60 years in the period from 2000 to 2060 (Borges, Campos \& Silva, 2015).

The increasing aging of the population is directly related to the demographic transition, which is characterized by a decrease in the birth rate and increase in life expectancy, which has created new challenges for government agencies, especially by changing the age pyramid and the need for the development of policies to improve the health of the elderly population (Vasconcelos \& Gomes, 2012).

This change of the age pyramid has given rise to wide debates related to variables that condition the lifestyle of the Brazilian elderly population, since with the advancement of age, a reduction in the physical activity levels of this population has been observed, leading to a consequent decrease of physical fitness (Closs \& Schwanke, 2012; Farinatti, 2016).

From the health intervention point of view, the concern to preserve and increase physical fitness of elderly individuals is of fundamental importance for their insertion and maintenance in society, mainly due to the clear perception that the reduction of the main determinants of functional fitness such as strength, agility and flexibility, will lead to limitations on the functionality of their activities of the daily living (Jacob Filho, 2006).

\footnotetext{
${ }^{1}$ Federal University of Sergipe, São Cristóvão, Brazil

${ }^{2}$ Tiradentes University, Aracaju, Brazil

* Corresponding author: Núcleo de Pesquisa em Aptidão Física, Saúde e Desempenho de Sergipe-NUPAFISE, Departamento de Educação Física, Universidade Federal de Sergipe, Campus Universitário Prof. José Aloísio de Campos - Av. Mal. Rondon s/n. Bairro Jd. Rosa Elze. CEP: 49100-000. São Cristóvão/SE, Brasil. Email: rjeronimoss@ufs.br
} 
Elderly people with a high decline in lower limb strength are more prone to falls, and may have as a consequence fractures, disability and even death (Cho, Bok, Kim, \& Hwang, 2012; Santos \& Griep, 2013). In addition, agility is a component that is linked to a better efficiency in the performance of daily activities. The decline of these determinants will cause a compromise of functionality in the activities of the daily living (Ferreira \& Gobbi, 2003).

Therefore, reduction of strength and agility leads to decreased ability to perform activities of the daily living, loss of autonomy, dependence and decline in the quality of life of this population (Milanović et al., 2013).

Thus, assessing the strength and agility levels in the elderly is of fundamental importance in view that this information can serve as a tool to characterize the profile of elderly individuals, to promote actions in public health aimed at preventing, remedying or mitigating associated factors aiming at maintaining the autonomy of elderly individuals (Campos, Almeida, Campos, \& Bogutchi, 2016).

In view of the above, the aim of this study was to analyze the factors associated with the strength and agility variables in elderly individuals in the Municipality of Cedro de São João - SE.

\section{METHOD}

This is a descriptive research with crosssectional design. According to Thomas and Nelson (2002), the descriptive research has the objective of describing the set of information presented by the sample, and the cross-sectional design is characterized by the collection of data in a single moment.

\section{Participants}

The population was composed of elderly individuals aged 60-93 years, living in the municipality of Cedro de São João - SE and registered in the Unified Health System of the municipality. The sampling process was carried out from the periodic visits made to the homes of individuals by Community Health Agents, who invited them to voluntarily participate in the study. Associated with these visits, there were meetings in the Basic Health Units of the municipality in order to invite elderly individuals to participate in the study.

The sample consisted of 233 elderly people enrolled in the municipal and federal coverage system, HIPERDIA, a program whose objective is the follow - up of people with hypertension and / or diabetes mellitus treated in the outpatient network of the Unified Health System - SUS.

For the sample selection, the inclusion criteria were: to be registered in the Basic Attention Information System - SIAB and to be 60 years or older. As exclusion criteria, the presence of physical or mental weakness, which impaired answering the questionnaires applied or that made physical tests impossible, as well as those with questionnaires that did not answer important questions such as gender, age and those who did not fill $50 \%$ of questionnaires.

\section{Instruments}

The instrument used for data collection was compiled from three validated questionnaires added of sample characterization information to estimate anthropometric indexes (AI) and the tests that estimated strength and agility were applied according to the Functional Fitness Test FFT (Rikli \& Jones, 1999), as in table 1.

\section{Procedures}

Before data collection, Community Health Agents of the municipality were trained for familiarization and clarification regarding the application of questionnaires and tests.

Data collection took place in two stages. The first was individually performed at the residence of individuals to explain the research objectives, being asked to sign the Free and Informed Consent Form, according to the Declaration of Helsinky (World, 1964) and Brazilian Legislation. Following, questions of individual and socio demographic characterization were applied in the form of interviews, the socioeconomic questionnaire and physical activity level. At that moment, a schedule was made for the next stage. 
In the second stage, physical evaluation was performed in the following sequence: height, body mass, abdomen and hip circumference, and later the sitting and standing and raising and walking tests were applied.

The research was approved by the Research Ethics Committee of the Federal University of Sergipe, under the approval number CAAE0213.0.107.000-11.

\section{Statistical analysis}

Descriptive analysis, Wald chi-square and confidence interval $(95 \% \mathrm{CI})$ were used to interpret data. Binary logistic regression model was developed from the identification of variables that in a bivariate analysis obtained $\mathrm{p}<0.20$. These variables were grouped in an adjusted model, favoring the identification of explanations regarding the outcome. Whenever necessary, for a better understanding of results, the inverse odds ratio $(1 / \mathrm{OR})$ was used to try to explain associations, mainly due to the easy understanding of this measure. Throughout the analysis, significance level of $p \leq 0.05$ was considered. The statistical treatment was performed in the SPSS software version 23.

\section{RESULTS}

A total of 233 participants were interviewed; nine were excluded, two of them being $<60$ years old and seven due to incomplete questionnaires, and the sample was composed of 224 subjects.

The sample consisted of elderly men and women, $66.5 \%$ women aged $\leq 70$ (52\%), presenting low socioeconomic level (47.1\%) and low educational level (68.3\%) (Table 2).

Table 3 shows that for the multivariate analysis, younger elderly individuals were five times as likely of having good agility in relation to the older ones. Regarding the educational level, for a better understanding, the analysis of the inverse odds ratio ( 1 / OR) was used, thus, it was verified that individuals with higher educational level were twice likely to have good agility when compared to less educated elderly subjects.

Table 3 also shows that regarding physical activity level, it was observed that active individuals were almost three times as likely of having good agility.

Analyzing Table 4 and the inverse odds ratios, it could be observed that individuals who reported having physical limitation are two and a half times as likely to present low strength levels compared to those who did not report physical limitation. Accordingly, it was found that elderly individuals with low physical activity levels were twice as likely to have better lower limb strength levels.

When the adjusted model was observed, it was verified that the significant variables presented some variations in the odds, but the condition verified in the univariate model was confirmed, in which younger subjects with high educational level and physically active are more likely to have good agility and those who reported physical limitation and who have low physical activity levels presented better strength levels. 
Table 1

Analytical matrix for characterization and categorization of variables used in the study.

\begin{tabular}{|c|c|c|}
\hline Variable & Cutoff point & Characterization \\
\hline \multirow{2}{*}{ Age group } & $\leq 70$ & \multirow{2}{*}{$\begin{array}{c}\text { The median age distribution was used to categorize } \\
\text { this variable. }\end{array}$} \\
\hline & $>70$ & \\
\hline \multirow{3}{*}{$\begin{array}{l}\text { Socioeconomic } \\
\text { level }\end{array}$} & High & \multirow{3}{*}{$\begin{array}{l}\text { Socioeconomic level was assessed using the CCEB } \\
\text { questionnaire, from the sum of the points obtained, } \\
\text { participants were classified into the following } \\
\text { socioeconomic levels: High (A1, A2, B1, B2), } \\
\text { Intermediate }(\mathrm{C} 1, \mathrm{C} 2) \text { and Low }(\mathrm{D}, \mathrm{E}) \text {. }\end{array}$} \\
\hline & Intermediate & \\
\hline & Low & \\
\hline \multirow[b]{2}{*}{ Educational level } & $\leq 4$ years & \multirow{2}{*}{$\begin{array}{c}\text { It was dichotomized using the item educational } \\
\text { level of the CCEB questionnaire. Being considered } \\
\text { up to } 4 \text { years (item 1) and more than } 4 \text { years (items } \\
2,3,4 \text { and 5). }\end{array}$} \\
\hline & $>4$ years & \\
\hline \multirow[t]{2}{*}{ BMI } & $\begin{array}{l}\text { Normal weight/low } \\
\text { weight }\end{array}$ & \multirow{2}{*}{$\begin{array}{l}\text { It was dichotomized using as cutoff point: normal } \\
\text { weight }(\leq 24.9 \ldots \mathrm{kg} / \mathrm{m} 2) \text { and overweight }(>25 \\
\mathrm{kg} / \mathrm{m} 2) .\end{array}$} \\
\hline & Overweight/high risk & \\
\hline \multirow[b]{2}{*}{$\mathrm{AC}$} & Low risk & \multirow{2}{*}{$\begin{array}{l}\text { It was dichotomized considering low risk women } \\
\text { with } \mathrm{AC}<80 \mathrm{~cm} \text { and men with } \mathrm{AC}<94 \text { and with } \\
\text { high risk women with } \mathrm{AC}>80 \mathrm{~cm} \text { and men with } \\
\qquad \mathrm{AC}>94 \mathrm{~cm} .\end{array}$} \\
\hline & High risk & \\
\hline \multirow{2}{*}{ WtHR } & Low risk & \multirow{2}{*}{$\begin{array}{c}\text { It was dichotomized with cutoff point of } \mathrm{WtHR} \geq \\
0.80 \mathrm{~cm} \text { for women and } \geq 0.95 \mathrm{~cm} \text { for men. }\end{array}$} \\
\hline & High risk & \\
\hline \multirow{2}{*}{$\begin{array}{l}\text { Reported } \\
\text { physical } \\
\text { limitation }\end{array}$} & Yes & \multirow{2}{*}{$\begin{array}{l}\text { Do you have any physical or motor limitations that } \\
\text { prevent you from developing your daily activities? }\end{array}$} \\
\hline & No & \\
\hline \multirow{2}{*}{ Smoking } & Yes & \multirow{2}{*}{$\begin{array}{c}\text { Do you smoke or have smoked regularly? If so, how } \\
\text { long? }\end{array}$} \\
\hline & No & \\
\hline \multirow{2}{*}{ Alcohol } & Yes & \multirow{2}{*}{$\begin{array}{c}\text { Did you make or use alcohol regularly? If so, how } \\
\text { long? }\end{array}$} \\
\hline & No & \\
\hline \multirow[b]{2}{*}{ PAL } & Active & \multirow{2}{*}{$\begin{array}{c}\text { It was dichotomized considering active "active and } \\
\text { very active" and low levels "insufficiently active and } \\
\text { sedentary" }\end{array}$} \\
\hline & LPAL & \\
\hline \multirow{2}{*}{$\begin{array}{l}\text { Sitting and } \\
\text { standing }\end{array}$} & Good & \multirow{2}{*}{$\begin{array}{l}\text { The distribution median was used to categorize this } \\
\text { variable because there is no classification by criteria } \\
\text { that classifies these variables in Brazil. }\end{array}$} \\
\hline & Poor & \\
\hline \multirow{2}{*}{$\begin{array}{l}\text { Raising and } \\
\text { walking }\end{array}$} & Good & \multirow{2}{*}{$\begin{array}{l}\text { The distribution median was used to categorize this } \\
\text { variable because there is no classification by criteria } \\
\text { that classifies these variables in Brazil. }\end{array}$} \\
\hline & Poor & \\
\hline
\end{tabular}


Table 2

Characteristics of the elderly population living in the municipality of Cedro de São João SE.

\begin{tabular}{|c|c|c|c|}
\hline Variable & $\mathrm{n}$ & $\%$ & IC95\% \\
\hline & 224 & 100 & \\
\hline \multicolumn{4}{|l|}{ Sex } \\
\hline Female & 149 & 66,5 & \multirow{2}{*}{$0,27-0,39$} \\
\hline Male & 75 & 33,5 & \\
\hline \multicolumn{4}{|l|}{ Age group } \\
\hline$\leq 70$ & 116 & 52 & \multirow{2}{*}{$0,41-0,54$} \\
\hline$>70$ & 107 & 48 & \\
\hline \multicolumn{4}{|c|}{ Socioeconomic level } \\
\hline High & 15 & 6,7 & \multirow{3}{*}{$0,41-0,54$} \\
\hline Intermediate & 103 & 46,2 & \\
\hline Low & 105 & 47,1 & \\
\hline \multicolumn{4}{|c|}{ Educational level } \\
\hline$\leq 4$ years & 153 & 68,3 & \multirow{2}{*}{$0,25-0,37$} \\
\hline$>4$ years & 71 & 31,7 & \\
\hline \multicolumn{4}{|l|}{ BMI } \\
\hline Normal weight & 45 & 22,4 & \multirow{2}{*}{$0,71-0,83$} \\
\hline Overweight & 156 & 77,6 & \\
\hline \multicolumn{4}{|l|}{ AC } \\
\hline Low risk & 54 & 26,9 & \multirow{2}{*}{$0,66-0,79$} \\
\hline High risk & 147 & 73,1 & \\
\hline \multicolumn{4}{|l|}{ WtHR } \\
\hline Low risk & 13 & 6,5 & \multirow[t]{2}{*}{$0,90-0,96$} \\
\hline High risk & 188 & 93,5 & \\
\hline \multicolumn{4}{|c|}{ Reported physical limitation } \\
\hline Yes & 94 & 42 & \multirow[t]{2}{*}{$0,35-0,48$} \\
\hline No & 130 & 58 & \\
\hline \multicolumn{4}{|l|}{ Smoking } \\
\hline Yes & 48 & 21,4 & \multirow[t]{2}{*}{$0,16-0,26$} \\
\hline No & 176 & 78,6 & \\
\hline \multicolumn{4}{|l|}{ Alcohol } \\
\hline Yes & 27 & 12,1 & \multirow[t]{2}{*}{$0,07-0,16$} \\
\hline No & 197 & 87,9 & \\
\hline \multicolumn{4}{|l|}{ PAL } \\
\hline Active & 122 & 54,5 & \multirow[t]{2}{*}{$0,38-0,52$} \\
\hline LPAL & 102 & 45,5 & \\
\hline \multicolumn{4}{|c|}{ Sitting and standing } \\
\hline Good & 74 & 47,7 & \multirow[t]{2}{*}{$0,39-0,55$} \\
\hline Poor & 81 & 52,3 & \\
\hline \multicolumn{4}{|c|}{ Raising and walking } \\
\hline Good & 94 & 61,4 & \multirow[t]{2}{*}{$0,53-0,69$} \\
\hline Poor & 59 & 38,6 & \\
\hline
\end{tabular}


36 | JO Couto, ICS Santos, AM Alves, NMM Soares, GS Morais Junior, DB Morais, RJS Silva

Table 3

Gross and adjusted Odds Ratio (OR) for association between independent variables and better agility performance in the elderly.

\begin{tabular}{|c|c|c|c|c|c|c|c|}
\hline \multirow{4}{*}{ Variables } & \multirow{4}{*}{ Categories } & \multicolumn{6}{|c|}{ Odds ratio } \\
\hline & & \multirow{2}{*}{\multicolumn{2}{|c|}{ Gross }} & \multirow{2}{*}{\multicolumn{3}{|c|}{ Adjusted }} & \multirow{3}{*}{$p \leq 0.05$} \\
\hline & & & & & & & \\
\hline & & OR & IC95\% & & OR & IC95\% & \\
\hline \multicolumn{8}{|l|}{ Sociodemographic } \\
\hline Sex & $\begin{array}{c}\text { Female } \\
\text { Male }\end{array}$ & 0,45 & $\begin{array}{c}0,22-0,90 \\
1\end{array}$ & 0,26 & 0,42 & $\begin{array}{c}0,15-1,19 \\
1\end{array}$ & 0,104 \\
\hline Age group & $\begin{array}{l}\leq 70 \\
>70\end{array}$ & 5,4 & $\begin{array}{c}2,53-11,51 \\
1\end{array}$ & $<0,001$ & 6,3 & $\begin{array}{c}2,6-15,25 \\
1\end{array}$ & $<0,001$ \\
\hline $\begin{array}{c}\text { Socioeconomic } \\
\text { level }\end{array}$ & $\begin{array}{c}\text { High } \\
\text { Intermediate } \\
\text { Low }\end{array}$ & $\begin{array}{l}0,59 \\
0,92\end{array}$ & $\begin{array}{c}0,17-2,06 \\
0,47-1,79 \\
1\end{array}$ & 0,468 & & & \\
\hline Educational level & $\begin{array}{l}\leq 4 \text { years } \\
>4 \text { years }\end{array}$ & 0,42 & $\begin{array}{c}0,21-0,83 \\
1\end{array}$ & 0,013 & 0,34 & $\begin{array}{c}0,15-0,76 \\
1\end{array}$ & 0,009 \\
\hline \multicolumn{8}{|l|}{ Anthropometric } \\
\hline BMI & $\begin{array}{c}\text { Normal weight } \\
\text { Overweight }\end{array}$ & 1,22 & $\frac{0,54-2,72}{1}$ & 0,628 & & & \\
\hline $\mathrm{AC}$ & $\begin{array}{c}\text { Low risk } \\
\text { Risk }\end{array}$ & 2,05 & $\begin{array}{c}0,97-4,36 \\
1\end{array}$ & 0,6 & 1,56 & $\begin{array}{c}0,57-4,25 \\
1\end{array}$ & 0,379 \\
\hline WtHR & $\begin{array}{c}\text { Low risk } \\
\text { Risk }\end{array}$ & 0,97 & $\begin{array}{c}0,22-4,22 \\
1\end{array}$ & 0,969 & & & \\
\hline \multicolumn{8}{|l|}{ Behavioral } \\
\hline Physical limitation & $\begin{array}{l}\text { No } \\
\text { Yes }\end{array}$ & 1,86 & $\begin{array}{c}0,91-3,77 \\
1\end{array}$ & 0,085 & 1,76 & $\begin{array}{c}0,73-4,22 \\
1\end{array}$ & 0,204 \\
\hline $\begin{array}{l}\text { Alcoholic } \\
\text { beverages }\end{array}$ & $\begin{array}{l}\text { No } \\
\text { Yes }\end{array}$ & 0,72 & $\begin{array}{c}0,27-1,86 \\
1 \\
\end{array}$ & 0,5 & & & \\
\hline Tobacco & $\begin{array}{l}\text { No } \\
\text { Yes }\end{array}$ & 0,59 & $\begin{array}{c}0,26-1,35 \\
1\end{array}$ & 0,215 & & & \\
\hline $\begin{array}{c}\text { Physical activity } \\
\text { level }\end{array}$ & $\begin{array}{c}\text { Active } \\
\text { Low level }\end{array}$ & 2,86 & $\begin{array}{c}1,40-5,85 \\
1\end{array}$ & 0,004 & 2,86 & $\begin{array}{c}1,32-6,16 \\
1\end{array}$ & 0,007 \\
\hline
\end{tabular}

$\mathrm{BMI}=$ Body mass index; $\mathrm{AC}=$ Abdomen circumference; $\mathrm{WtHR}=$ Waist $/$ hip ratio. 
Table 4

Neuromotor Variables in the Elderly $\mid \mathbf{3 7}$

Gross and adjusted Odds Ratio (OR) for association between independent variables and better performance of lower limb strength in the elderly.

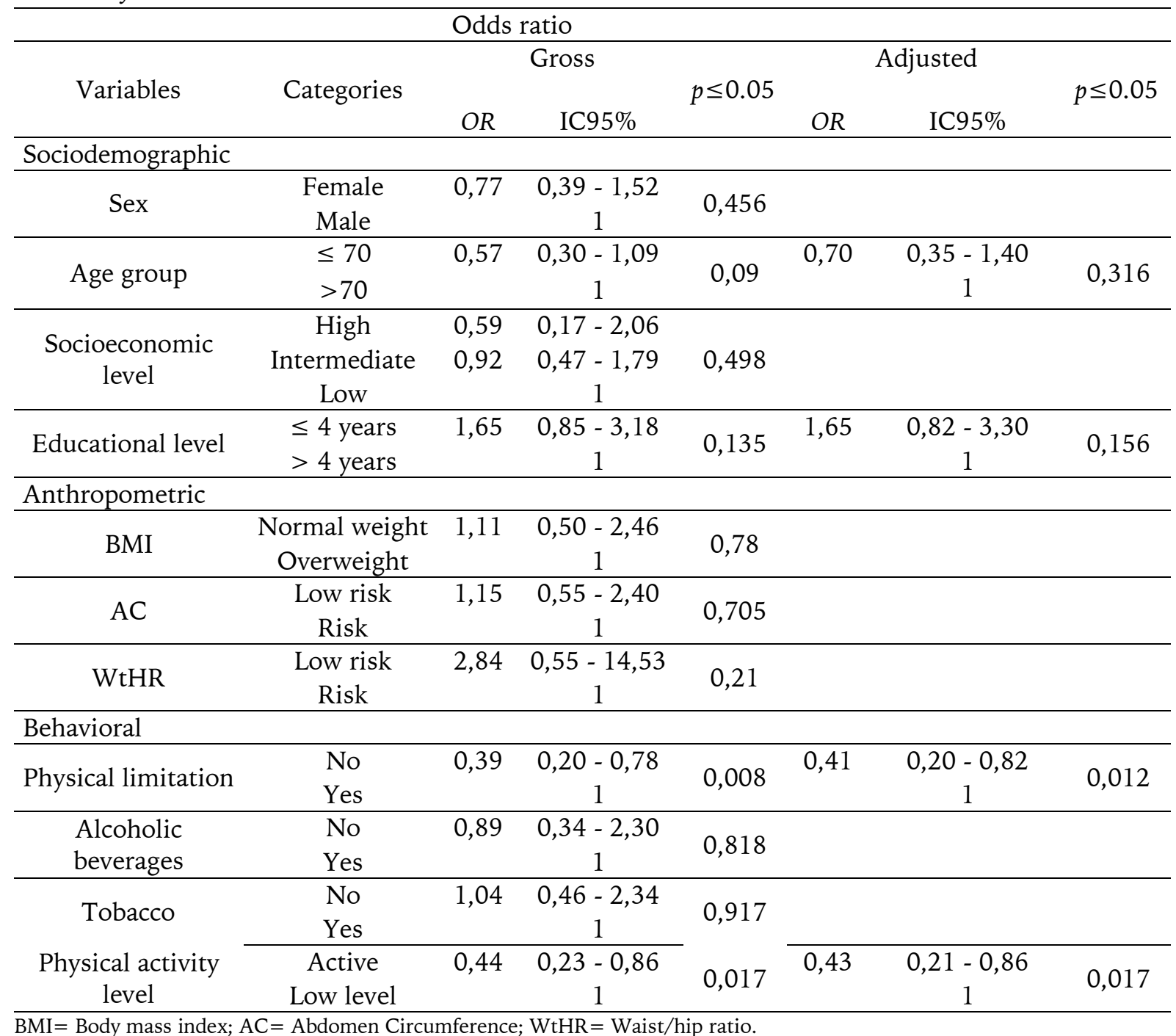

\section{DISCUSSION}

As main results, the multivariate analysis showed that there was an association between age group, educational level and physical activity level with good performance of elderly subjects in the neuromotor agility variable. Regarding the good performance of lower limb strength, there was an association between reported physical limitation and physical activity level.

Younger elderly individuals $(\leq 70)$ were five times as likely to perform well in the agility variable. Studies aimed at agility using the same test used by the present survey have concluded that the best performance in agility is identified in groups of elderly people classified as "younger" (Nunes \& Santos, 2009; Maciel, Quaresma, Barbosa, \& Souza, 2015). These findings can be explained by the fact that, with advancing age, there is a reduction in physical fitness levels and neuromotor capacity (Mendonca, PezaratCorreia, Vaz, Silva, \& Heffernan, 2016). 
The inverse odds ratio indicated that older adults with higher educational level were twice as likely to have better performance in the neuromotor agility variable. Studies that have evaluated performance in daily life activities that require agility have found that the best performance in these activities was observed in groups of older adults with higher educational level (Rosa, Benício, Latorre, \& Ramos, 2003; Assis et al.., 2014).

As for the anthropometric indexes, no association was found with neuromotor variables. In this perspective, Roncato, Galarza, Freire, Tiggemann, \& Dias (2014) evaluated the relationship between body composition, lower limb strength and functional capacity using anthropometric indexes and functional tests, and verified no association between lower limb strength and BMI.

On the other hand, a study by Gonçalves, Guimarães, Souza, Ferreira, \& Mainenti (2015) that aimed to analyze the relationship between body composition and functional autonomy in the elderly, using another instrument of evaluation, electrical bioimpedance, found a correlation between higher body adiposity level decrease in functional capacity.

The findings of the present study identified that the body composition itself has no association with neuromotor variables in the elderly, but it is noteworthy that metabolic disorders are associated with high body adiposity levels and the onset of chronic noncommunicable diseases, and can interfere in the neuromotor fitness in the elderly (Freitas et al., 2012; da Silva, Barros, da Silva, \& Ferreira, 2014).

Regarding the reported physical limitation, elderly subjects who reported this condition were twice as likely to have good strength levels. However, studies that have verified lower limb strength using the same instrument applied in this research, found that the best performance in lower limb strength levels was in the group of elderly people who did not report physical limitation or history of falls (Cho, Bok, Kim, \& Hwang, 2012; Santos et al., 2013).
Due to the reported physical limitation, the results may have been influenced, since low strength levels are associated with physical limitation and consequent episodes of falls (Streit, Mazo, Virtuoso, Menezes, \& Gonçalves, 2012).

In the findings of the present study, there was no association between use of alcoholic beverages, cigarette and strength and agility variables. Accordingly, in the study by VirtuosoJúnior, Tribess, Menezes, Meneguci, \& Sasaki, (2016) aimed to analyze the association between behavioral and sociodemographic aspects related to health and functional disability in elderly people from different regions of Brazil found no association between the use of cigarettes and alcoholic beverages with functional disability.

Regarding the physical activity level, active individuals had better performance in the agility test; however, in the strength test, they presented worse performance. In this sense, the study by Ono, Schneider, Confortin, \& d'Orsi, (2015) that evaluated the prevalence and relationship between functional deficiency and health-related aspects in the elderly identified that being physically active in leisure reduces the likelihood of presenting some functional deficiency. However, in the study by Ferreira, Ferreira, \& Escobar, (2015) who investigated the prevalence and factors associated with impairment and functional capacity found no association between physical activity level and functional capacity.

It is noteworthy that even with this contradiction in the outcomes, it is known that physical activity helps maintaining muscle strength, agility and intrinsic factors that are linked to the preservation of neuromotor fitness (World Health Organization [WHO], 2010).

The inverse odds ratio indicated that older adults with higher educational level are twice as likely to have better performance in the neuromotor agility variable. Studies that have evaluated performance in daily life activities that require agility have found that the best performance in these activities is perceived in groups of individuals with higher educational 
level (Rosa, Benício, Latorre, \& Ramos, 2003; Assis et al., 2014).

\section{CONCLUSIONS}

This study showed that younger elderly individuals with higher educational level and active have better performance in the neuromotor agility variable. However, individuals who reported physical limitation and low physical activity levels presented higher lower limb strength levels.

These findings highlight the importance of community programs that encourage the practice of physical exercise by the population studied, considering that high physical activity levels are presented as a protection and remediation factor for the maintenance of functional capacity in the elderly.

\section{Acknowledgments:}

Foundation for Research and Innovation Support of Sergipe - FAPITEC; Institutional Program for Scientific Initiation Scholarships - PIBIC / CNPq / UFS, PPSUS / CNPq / FAPITEC

\section{Conflict of interests:}

Nothing to declare.

\begin{tabular}{l}
\hline Funding: \\
PIBIC/CNPq/UFS \\
PIBIC/PPSUS/FAPITEC/Sergipe
\end{tabular}

\section{REFERÊNCIAS}

Amaral, J. F., Castro, E. A. D., Doimo, L. A., Silva, M. V. D., Júnior, N., \& Marques, J. (2015). Mudanças no desenvolvimento temporal da força em mulheres de diferentes faixas etárias. Revista Brasileira de Medicina do Esporte, 21(1), 70-74. doi: 10.1590/1517-8692

Assis, V. G., Marta, S. N., Conti, M. H. S., Gatti, M. A. N., Simeão S. F. A. P., \& Vitta A. (2014). Prevalência e fatores associados à capacidade funcional de idosos na Estratégia Saúde da Família em Montes Claros, Minas Gerais, Brasil. Revista Brasileira de Geriatria e Gerontologia.[online], 17(1), 153-63.

Associação Brasileira de Empresas de Pesquisa (2013). Critério de Classificação Econômica Brasil. Disponível a partir de http://www.abep.org/criterio-brasil. Acesso: 08/05/17.
Borges G. M., Campos M. B., Silva L. G. C. (2015). Transição da estrutura etária no Brasil: oportunidades e desafios para a sociedade nas próximas décadas. In: ERVATTI L.R; BORGES G. M; JARDIM A. P. Mudança Demográfica no Brasil no início do século XXI: Subsídios para as projeções da população. Rio de Janeiro: Instituto Brasileiro de Geografia e Estatística, p. 138-151.

Brito, T. A., Fernandes, M. H., da Silva Coqueiro, R., de Jesus, C. S., \& Freitas, R. (2014). Capacidade funcional e fatores associados em idosos longevos residentes em comunidade: estudo populacional no Nordeste do Brasil. Fisioterapia e Pesquisa, $21(4)$, 308-313. doi: 10.590/18092950/11556021042014

Campos, A. C. V., Almeida, M. H. M., Campos, G. V., \& Bogutchi, T. F. (2016). Prevalência de incapacidade funcional por gênero em idosos brasileiros: uma revisão sistemática com metanálise. Revista Brasileira de Geriatria e Gerontologia, 19(3). doi: 10.1590/180998232016019.150086

Cho, K. H., Bok, S. K., Kim, Y. J., \& Hwang, S. L. (2012). Effect of lower limb strength on falls and balance of the elderly. Annals of Rehabilitation Medicine, 36(3), 386-393. doi: 10.5535/arm.2012.36.3.386

Closs, V. E., \& Schwanke, C. H. A. (2012). A evolução do índice de envelhecimento no Brasil, nas suas regiões e unidades federativas no período de 1970 a 2010. Revista Brasileira de Geriatria e Gerontologia, 15(3), 443-458. doi: $10.1590 /$ S1809-98232012000300006

da Silva, I. A., Barros, D. D., da Silva, V. C., \& Ferreira, E. A. A. P. (2014). Antropometria na avaliação da obesidade abdominal e risco de doenças. Revista Brasileira de Educação e Saúde, 4(1).

DESA, U.N. (2015). World population prospects: the 2015 revision. Population Division of the Department of Economic and Social Affairs of the United Nations Secretariat, New York.

dos Santos, R. L., \& Virtuoso Júnior, J. S. (2008). Confiabilidade da versão brasileira da escala de atividades instrumentais da vida diária. Revista Brasileira em Promoção da Saúde, 21(4).

Farinatti, P. (2016). A prática regular de atividades físicas e o envolvimento social da pessoa idosa. Revista Brasileira de Geriatria e Gerontologia, 19(5), 721-722.

Ferreira, C. V., Ferreira, C. G., \& Escobar, R. V. (2015). Relação entre envelhecimento ativo, risco de queda e perfil funcional de idosos. Revista Equilíbrio Corporal e Saúde, 4(2). doi: 10.17921/2176-9524.2012v4n2p\%25p

Ferreira, L., \& Gobbi, S. (2003). Agilidade geral e agilidade de membros superiores em mulheres de terceira idade treinadas e não treinadas. Revista Brasileira de Cineantropometria e Desempenho Humano, 5(1), 46-53. 
Fidelis, L. T., Patrizzi, L. J., \& Walsh, I. A. P. D. (2013). Influência da prática de exercícios físicos sobre a flexibilidade, força muscular manual e mobilidade funcional em idosos. Revista Brasileira de Geriatria e Gerontologia, 16(1), 109-16.

Fiedler, M. M., \& Peres, K. G. (2008). Capacidade funcional e fatores associados em idosos do Sul do Brasil: um estudo de base populacional. Cadernos de Saúde Pública, 24(2), 409-415.

Freitas, R. S., Fernandes, M. H., Coqueiro, R. D. S., Reis Júnior, W. M., Rocha, S. V., \& Brito, T. A. (2012). Capacidade funcional e fatores associados em idosos: estudo populacional. Acta Paulista Enfermagem, 25(6), 933-9.

Gonçalves, B. L., Guimarães, F. S., Souza, M. L. L. D., Ferreira, A. D. S., \& Mainenti, M. R. M. (2015). Association among body composition, muscle performance and functional autonomy in older adults. Fisioterapia em Movimento, 28(1), 49-59.

Jacob Filho, W. (2006). Atividade física e envelhecimento saudável. Revista Brasileira de Educação Física Esp, 20(5), 73-77.

Maciel, E., Quaresma, F. R. P., Barbosa, T. C., \& Souza, G. S. (2015). Avaliação da aptidão física funcional e a percepção da qualidade de vida de idosos praticantes de atividade física. Amazônia: Science \& Health, 3(2), 8-15.

Marfell-Jones, M. J., Stewart, A. D., \& de Ridder, J. H. (2006). International standards for anthropometric assessment.

Matsudo, S., Araújo, T., Matsudo, V., Andrade, D., Andrade, E., Oliveira, L. C., \& Braggion, G. (2012). Questionário Internacional De Atividade Física (Ipaq): Estupo De Validade E Reprodutibilidade No Brasil. Revista Brasileira de Atividade Física \& Saúde, 6(2), 5-18.

Matsudo, S. M., Matsudo, V. K., Barros Neto, T. L. D., \& Araújo, T. L. D. (2003). Evolução do perfil neuromotor e capacidade funcional de mulheres fisicamente ativas de acordo com a idade cronológica. Revista Brasileira de Medicina do Esporte, 9(6), 365-76.

Matsudo, S. M. M. (2009). Envelhecimento, atividade física e saúde. BIS. Boletim do Instituto de Saúde (Impresso), (47), 76-79.

Matsudo, S. M., Matsudo, V. K., \& de Barros Neto, T. L. (2000). Impacto do envelhecimento nas variáveis antropométricas, neuromotoras e metabólicas da aptidão física. Revista Brasileira de Ciência e Movimento, 8(4), 21-32.

Mendonca, G. V., Pezarat-Correia, P., Vaz, J. R., Silva, L., \& Heffernan, K. S. (2016). Impact of Aging on Endurance and Neuromuscular Physical Performance: The Role of Vascular Senescence. Sports Medicine, 1-16.

Milanović, Z., Pantelić, S., Trajković, N., Sporiš, G., Kostić, R., \& James, N. (2013). Age-related decrease in physical activity and functional fitness among elderly men and women. Clinical
Interventions in Aging, 8, 549-556. doi: 10.2147/CIA.S44112

Mundial, A. M. (1964). Declaração de Helsinque. Princípios éticos para a pesquisa em seres humanos. Helsinque.

Nunes, M. E., \& Santos, S. (2009). Avaliação funcional de idosos em três programas de atividade física: caminhada, hidroginástica e Lian Gong. Revista Portuguesa de Ciências do Desporto, 9(2-3), 150159.

Ono, L. M., Schneider, I. J. C., Confortin, S. C., \& d' Orsi, E. (2015). Paid Work and Physical Activity Preserve Functional Capacity in Elderly People: EpiFloripa Study. Gerontology and Geriatric Medicine, 1, 2333721415608022.

Rikli, R. E., \& Jones, C. J. (1999). Functional fitness normative scores for community-residing older adults, ages 60-94. Journal of Aging and Physical Activity, 7(2), 162-181.

Roma, M. F. B., Busse, A. L., Santarem, J. M., Melo, A. C. D., Kong, J., Jacob Filho, W., \& Betoni, R. A. (2013). Efeitos das atividades físicas resistida e aeróbia em idosos em relação à aptidão física e à funcionalidade: ensaio clínico prospectivo. Einstein (Säo Paulo), 11(2), 153-157.

Roncato, M., Galarza, E., Freire, B., Tiggemann, C. L., \& Dias, C. P. (2014). Correlação da força e composição corporal com a capacidade funcional em mulheres idosas. Revista Brasileira de Ciência e Movimento, 22(1), 122-130. doi: 10.18511/0103-1716/rbcm. v22n1p122-130

Rosa, T. E. D. C., Benício, M. H. D. A., Latorre, M. D. R. D. D., \& Ramos, L. R. (2003). Fatores determinantes da capacidade funcional entre idosos. Revista de Saúde Pública, 37(1), 40-48.

Santos, M. I. P. O., \& Griep, R. H. (2013). Capacidade funcional de idosos atendidos em um programa do SUS em Belém (PA). Ciência \& Saúde Coletiva, 18(3), 753-761. doi: 10.1590/S14138123201300030002

Santos, R. G. D., Tribess, S., Meneguci, J., Bastos, L. L. D. G., Damião, R., \& Virtuoso Júnior, J. S. (2013). Força de membros inferiores como indicador de incapacidade funcional em idosos. Motriz Revista Educação Física (Impr.), 19(3, supl), 35-42. doi: 10.1590/S1980-65742013000700006

Streit, I. A., Mazo, G. Z., Virtuoso, J. F., Menezes, E. C., \& Gonçalves, E. (2012). Aptidão física e ocorrência de quedas em idosos praticantes de exercícios físicos. Revista Brasileira de Atividade Física \& Saúde, 16(4), 346-352.

Tiggemann, C. L., Dias, C. P., Noll, M., Schoenell, M. C. W., \& Kruel, L. F. M. (2013). Envelhecimento e treinamento de potência: aspectos neuromusculares e funcionais. Journal of Physical Education, 24(2), 295-304. doi: 10.4025/reveducfis. v24i2. 15725

Thomas, J. R, \& Nelson J. K. (2002). Métodos da pesquisa em Educação Física. Porto Alegre: Artmed ( $3^{\mathrm{a}}$ ed.). 
Vasconcelos, A. M. N., \& Gomes, M. M. F. (2012). Transição demográfica: a experiência brasileira. Epidemiologia e Serviços de Saúde, 21(4), 539548. doi: 10.5123/S1679-49742012000400003

Virtuoso Júnior, J. S., \& Guerra, R. O. (2011). Incapacidade funcional em mulheres idosas de baixa renda. Revista Ciência \& Saúde Coletiva, 16(5).
Virtuoso-Júnior, J. S., Tribess, S., Menezes, A. S., Meneguci, J., \& Sasaki, J. E. (2016). Fatores associados à incapacidade funcional em idosos brasileiros. Revista Andaluza de Medicina del Deporte.

World Health Organization. (2010). Recomendaciones mundiales sobre actividad física para la salud.

cc) (i) (5) All content of Journal Motricidade is licensed under Creative Commons, except when otherwise specified and in content retrieved from other bibliographic sources. 


\title{
Psychological and physiological effects of music time during walking performed by overweight and obese women
}

\author{
Aldo Coelho Silva ${ }^{1}$, Sandro dos Santos Ferreira ${ }^{1}$, Ragami Chaves Alves ${ }^{1}$, Lucio Follador ${ }^{1}$, \\ Erick Doner Santos de Abreu Garcia ${ }^{1}$, Vinícius Ferreira dos Santos Andrade ${ }^{1}$, Sergio \\ Gregorio da Silva ${ }^{*}$
}

ORIGINAL ARTICLE

\begin{abstract}
The aim of this study was to investigate if music tempi has an effect on women during self-selected pace walking. Sixteen women (mean $\pm \mathrm{SD}$, age $42.1 \pm 5.0$ years, height $157.1 \pm 7.3 \mathrm{~cm}$, body weight $80.1 \pm$ $10.8 \mathrm{~kg}$, BMI $\left.32.5 \pm 4.7 \mathrm{~kg} / \mathrm{m}^{2}, \mathrm{VO}_{2 \text { peak }} 24.6 \pm 4.3 \mathrm{ml} / \mathrm{kg} \cdot \mathrm{min} .^{-1}\right)$ volunteered and performed three different sessions: walking without music, walking with medium tempo music, and walking with fast tempo music. Rating Perceived Exertion, BRUMS, and K4b2 were used to measure perceived exertion, mood state, and physiological response, respectively. Results showed that medium and fast tempo music can reduce perceived exertion $(p=0.01)$ and improvemood state $(p<0.05)$, respectively. Furthermore, music altered CHO contribution $(p=0.04)$ andhad a tendency to affect FAT $(p=0.05)$ contribution during exercise. With regard to ergogenic effect, the results showed that music does not influence the pace of activity. In conclusion, this study suggests that music can have psychological and physiological effects, but these effects depend on the tempo of music.

Keywords: perceived exertion, walking at self-selected pace, outdoor environment
\end{abstract}

\section{INTRODUCTION}

In recent decades, the number of studies that investigate the effect of music during physical exercise has increased. Music has been suggested to be able to provide physiological, psychological, and ergogenic effects(Karageorghis \& Priest, 2012). In terms of ergogenic effects, music seems to increase exercise time during aerobic or resistance exercises, as well as affect self-selected pace(Crust \& Clough, 2006; Lee \& Kimmerly, 2016; Lima-Silva et al., 2012; Yamashita, Iwai, Akimoto, Sugawara, \& Kono, 2006). Concerning the psychological effect, music can positively affect several dimensions of mood state and perceived exertion during the activity (Brownley, McMurray, \& Hackney, 1995; Silva, Ferreira, Alves, Follador, \& da Silva, 2016). With regard to the physiological effect, music seems to be capable of affecting heart rate and lactate production(Terry, Karageorghis, Saha, \&
D'Auria, 2012; Waterhouse, Hudson, \& Edwards, 2010).

For music to have a motivational effect and to positively affect physical exercise, four variables modulate this aspect: rhythmicity, musicality, cultural impact, and association(Karageorghis, Terry, \& Lane, 1999). In a hierarchical way, musical time seems to be the most important aspect with regard to the motivational aspect of music(Priest \& Karageorghis, 2008). In addition to the variables that influence the motivational qualities of music, variables related to physical exercise prescription exist, such as intensity and volume, to verify the effect of music during exercise. In general, high-intensity exercise seems to be unaffected by the use of music(Dyer \& Mckune, 2013). By contrast, light- and moderate-intensity exercises seem to be positively affected by music. Another important methodological point is the study sample. In general, studies use elite athletes, highly active

\footnotetext{
${ }^{1}$ Universidade Federal do Paraná, Curitiba, Brasil

* Corresponding author: Centro de Pesquisa em Exercício e Esporte, Departamento de Educação Física, Universidade Federal do Paraná, Campus Jardim Botânico - Bairro Jardim Botânico. Rua Coração de Maria, 92, CEP: 80210132. Curitiba/PR, Brasil. E-mail: sergiogregorio@ufpr.br
} 
individuals, active individuals, and sedentary individuals. A common factor for these subjects is the normal body mass index (BMI), neglecting the possible effect of BMI on performance and physiological and psychological responses during physical exercise.

To reduce or minimize the effects of obesity or being overweight, regular physical activity has been an important strategy in maintaining and controlling body weight(Donnelly et al., 2009). However, during walking, individuals with higher BMI have higher oxygen uptake $\left(\mathrm{VO}_{2}\right)$ and increased perceived exertion compared with individuals with normal BMI(Ekkekakis \& Lind, 2006). In this way, people who are overweight or have obesity expend more energy than individuals with normal BMI. In fact, the physiological responses may be influenced by BMI possibly because of the low level of cardorespiratory fitness presented by individuals with high BMI(Mattsson, Larsson, \& Rössner, 1997). The way exertion is perceived is considered one of the main factors that contribute to the practice of physical exercise. Therefore, the intensity of exertion during exercise may be a limiting factor for continued exercise (Perri et al., 2002). However, findings on the degree to which music can affect the responses resulting from physical exercise in this population are limited in the literature.

The objective of this study was to verify the effects of music tempi on the performance and psychological and physiological responses of women who are overweight or have obesity. In line with previous studies, we expected that women would improve their pace, and their physiological and psychological responses would be affected by music during walking (Almeida et al., 2015; Dyer \& Mckune, 2013).

\section{Participants}

Women from a stretching program at the Municipal Secretary of Sports and Leisure of Curitiba City were invited to participate in this study. Sixteen women (mean \pm SD, age: $42.1 \pm$ 5.0 years, height: $157.1 \pm 7.3 \mathrm{~cm}$, body mass:
$80.1 \pm 10.8 \mathrm{~kg}$, BMI: $32.5 \pm 4.7 \mathrm{~kg} / \mathrm{m}^{2}, \mathrm{VO}_{2 \text { peak}}$ : $24.6 \pm 4.3 \mathrm{ml} / \mathrm{kg} \cdot \mathrm{min}^{-1}$ ) volunteered to participate in this study. Inclusion criteria were: exercise less than 30 minutes on most days of the week, BMI above of $25 \mathrm{~kg} / \mathrm{m}^{2}$, stable body mass (less than a $2.5 \mathrm{~kg}$-change during the last three months), does not have cardiovascular disease, and negative answers to all questions on the Physical Activity Readiness Questionnaire. Participants signed an informed consent form after receiving verbal and written explanations of the experimental procedures and the possible risks involved in this study, which was approved by the Ethics Committee of the Federal University of Paraná (CAAE. 33836614.1.0000.0102).

\section{Experimental design}

All participants reported to the laboratory on four different days. During the first day, selection, anthropometric measurements, and an incremental test were conducted. In the following days, all participants walked at a self-selected pace in an outdoor environment under three trials: walking with medium tempo music (MT), walking with fast tempo music (FT), or walking without music (NM). The trials were performed following a randomized design and with $48 \mathrm{~h}$ between trials to prevent any residual effects of fatigue from the previous exercise activity. During the experimental trials, any information about the music tempo was used. All participants were asked to refrain from physical exercise $24 \mathrm{~h}$ before each visit and from consuming coffee, energy drinks, or pharmacological resources that contain caffeine $3 \mathrm{~h}$ before the trial(Ahrens, Crixell, Lloyd, \& Walker, 2007). All trials were conducted on the same day. The percent relative humidity of air (\%) was $51.2 \pm 0.9,51.5 \pm 0.8$, and $51.2 \pm 0.9$ for NM, MT, and FT, respectively. The temperature (degree Celsius, $\mathrm{C}^{\circ}$ ) was $22.5 \pm$ $3.2,22.2 \pm 3.3$, and $23.0 \pm 2.5$, for NM, MT, and FT, respectively. No differences in ambient temperature or humidity were observed. The device K4b2 provided the data. 


\section{Instruments}

Body weight $\left(\mathrm{kg}\right.$, Toledo scale ${ }^{\mathrm{TM}}$, São Paulo, Brazil) and height $\left(\mathrm{cm}\right.$, Sanny stadiometer ${ }^{\mathrm{TM}}$, São Paulo, Brazil) were measured according to the technique described by Lohman, Roache, and Martorell (1992). The weight and height were utilized to calculate the BMI $\left(\mathrm{BMI}=\mathrm{kg} / \mathrm{m}^{2}\right)$.

Performance was measured according to traveled distance during 30 minutes of walking and shown as $\mathrm{m} / \mathrm{s}$. The scale of6-20 - RPE(Borg, 1982), measured the perceived exertion. This instrument consists of a15-point scale, with scores ranging from6 ("minimal effort") to 20 ("maximum effort"). We asked the participants to scale their overall perceived exertion based on cardiopulmonary word, breathlessness, and muscle discomfort. During the incremental test, high and low perceptual anchors for the rating perceived exertion were measured. The RPE was measured at 5th, 10th, 15th, 20th, 25th, and 30th minute by displaying a version of Borg's RPE scale and the participant indicating their response by pointing to the numerical descriptor.

The Brunel Mood Scale (Rohlfs et al., 2008)measured the mood state. The Brunel Mood Scale or BRUMS has 24 items and is divided into 6 subscales: anger, tension, vigor, confusion, depression, and fatigue. Each mood descriptor is rated on a 5-point Likert scale, where 0 means "Not at all" and 4 means "Extremely." This scale takes less than 2 minutes to complete and has been used extensively (Leite et al., 2013; Rotta, Rohlfs, \& Oliveira, 2014). The BRUMS produces answers for separate subscales with specific moods and an overall measure labeled as total mood disturbance, which is calculated by adding all negative factors and subtracting vigor. With regard to a specific mood, the percentage change from the pre- to the postexercise moment was used. The BRUMS was completed five minutes before walking started and five minutes after walking ended.

With regard to physiological measures, heart rate was measured by the incremental test and by using a heart rate monitor in the experimental trials (Polar Electro Oy, Kempele, Finland). The carbon dioxide output $\left(\mathrm{VCO}_{2}\right), \mathrm{VO}_{2}$, minute ventilation $\left(\mathrm{V}_{\mathrm{E}}\right)$, respiratory frequency (Rf), total energy expenditure, percentage of fat (\%FAT), and carbohydrate $(\% \mathrm{CHO})$ contribution were measured throughout the test by using a breathby-breath gas analyzer (Cosmed, $\mathrm{K}_{4} \mathrm{~b}^{2}$, Rome, Italy). The respiratory exchange ratio (RER) was calculated from the following formula: $\mathrm{VCO}_{2} / \mathrm{VO}_{2}$. The total energy expenditure was calculated assuming that one liter of oxygen $\left(\mathrm{O}_{2}\right)$ corresponds to five kilocalories -kcal- (Smith \& Hill, 1991). The \%FAT and \%CHO were provided by Cosmed K4b2 software 7.4b. This software accurately measures $\mathrm{VO}_{2}$ and estimates kcal over a wide range of metabolic rates in adults(McLaughlin, King, Howley, Bassett Jr, \& Ainsworth, 2001). During the incremental test, physiological responses were obtained every minute, and during the trials, an average of five minutes was used for comparison between groups (01:00-05:00, 06:00-10:00, 11:00-15: 00, 16:00-20:00, 21:00-25:00, and26:00-30:00).

\section{Incremental test}

All the participants performed an incremental test on a treadmill (XFit-7 model, London, UK). Participants started the protocol at a velocity of $2.7 \mathrm{~km} \cdot \mathrm{h}^{-1}$ and a slope of $10 \%$. Every three minutes, exercise intensity was raised by increasing the velocity and slope until the participants were exhausted(Bruce, 1971). Oxygen up take was measured throughout the test through a gas analyzer. Calibration of the device followed the manufacturer's recommendations prior to each test session. A heart rate monitor measured the heart rate throughout the test. The perceived exertion was measured each minute during all test. The $\mathrm{VO}_{2 \text { peak }}$ was considered the greatest oxygen up take achieved during the last 30 seconds of the test, and the peak heart rate $\left(\mathrm{HR}_{\text {peak }}\right)$ was defined as the highest value obtained from the HR recordings during the incremental test.

\section{Music selection}

Two music tempi were used in this study: fast (ranging between 140 and 145 beats per minute) and medium (ranging between 115 and 120 beats 
per minute). The participants elaborated a list with their three preferred artists(Karageorghis, Jones, \& Stuart, 2008). The playlist used the three most mentioned artists, with three fast tempo songs and three medium tempo songs from each artist. The music was played in random order.

\section{Procedures}

After being equipped with a device for the analysis of physiological variables, the participants warmed up for three minutes. In trials with music, the participants wore headphones after warming up, and the device played the playlist randomly (fast or medium music tempo). In the NM trial, the participants used the headphones without any sound. The participants were instructed to walk at their preferred rate (Dishman, Farquhar, \& Cureton, 1994). Then, after30 minutes, the participants performed "cool down" activities for three minutes. We conducted the trials individually to avoid the effect of social interaction.

\section{Statistical Analyses}

The Shapiro-Wilk test was used to analyze the data distribution. Descriptive analysis used mean central tendency (mean) and variability analysis (standard deviation, SD and standard error of the mean, sem.). To verify the difference on $\% \mathrm{VO}_{2 \text { peak }}$, $\% \mathrm{HR}_{\text {peak }}$, and perceived exertion, analysis of variance (ANOVA) with two-way repeated measures (time $\mathrm{x}$ trial) was performed. ANOVA with one-way repeated measures was used to compare walking velocity $(\mathrm{m} / \mathrm{s}), \quad \mathrm{VCO}_{2}$ ( $\mathrm{mL} / \mathrm{min}), \mathrm{V}_{\mathrm{E}}(\mathrm{L} / \mathrm{min}), \mathrm{Rf}$ (breaths per minute), RER, \%CHO, \%FAT, kcal, and mood state across the three different trials. The GreenhouseGeisser epsilon was corrected when the assumption of sphericity was violated. When a difference was detected, Bonferroni's post-hoc test was utilized. Partial eta squared $\left(\mathrm{n}_{\mathrm{p}}{ }^{2}\right)$ was applied to estimate the size of effects. For the non-parametric date, the Wilcoxon test was performed. A significance level of $p<0.05$ was set for all analyses. IBM Statistical Package for Social
Sciencesversion21.0 (IBM Corp., Armonk, NY, USA) for Windows was used.

\section{RESULTS}

The women's RPE were influenced by music $\left(\mathrm{F}_{2,30}=4.717 ; p=0.017 ; \eta_{\mathrm{p}}{ }^{2}=0.239\right)$. The RPE was lower during the MT trial than that during the NM trial at three points during the session $(\min 20, p=0.00 ; \min 25, p=0.00 ; \min 30, p=$ $0.00)$. No differences in RPE were observed between NM and FT trials. Moreover, time has affected the RPE $\left(F_{2.750,41.245}=20.669 ; p=0.000\right.$; $\left.\eta_{\mathrm{p}}{ }^{2}=0.579\right)$. Overall, there were increases in the last minutes in comparison to the initial minutes (Figure 1). In the NM and MT, minute 30 was higher than minutes 5,10 , and $15(p=0.01)$, as well as minute 10 was lower than minute 25 ( $p=$ 0.02 ), and 30 were higher than minutes 5,10 and $15(p=0.00)$. In the MT, minute 5 was lower than minutes 25 and $30(p=0.03)$. In the FT, minutes 5 was lower than all subsequent time points $(p=0.01)$ and 10 was lower than minutes 25 and $30(p=0.01)$. However, there was no interaction between factors $\left(\mathrm{F}_{4.784,71.753}=1.321\right.$; $\left.p=0.266 ; \eta_{\mathrm{p}}^{2}=0.081\right)$. With regard to mood state, reductions were observed in depression $(p=$ $0.02)$, tension $(p=0.04)$, and confusion $(p=$ $0.02)$ during FT trial and in anger $(p=0.03)$ during NM trial from pre- to post-exercise (Table $1)$.

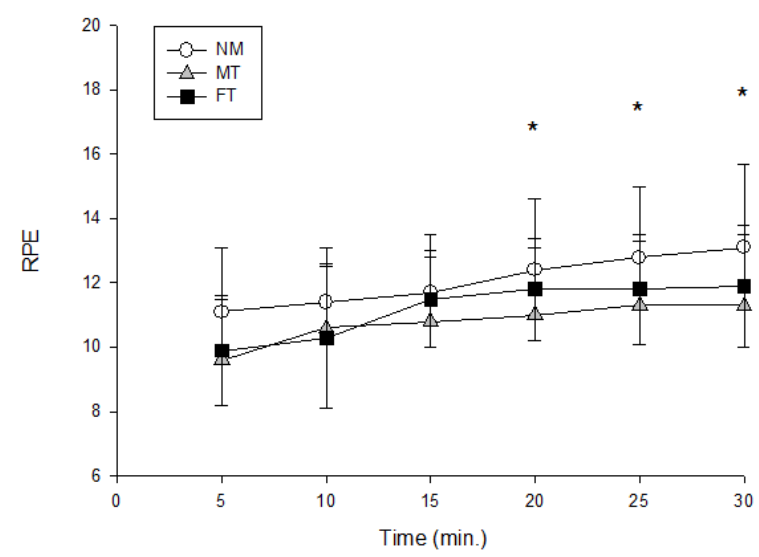

Figure 1. Perceptual response (mean \pm sem) of walking at self-selected pace with MT, FT, and NM. Note: * indicates a difference between NM and MT trials $(p<0.05)$. 
Music tempi did not change most of the physiological responses exhibited by the women (Table 2). No inter-trial differences were observed in the $\operatorname{RER}\left(\mathrm{F}_{2,30}=0.779 ; p=0.468\right.$; $\left.\mathrm{\eta}_{\mathrm{P}}{ }^{2}=0.049\right), \mathrm{V}_{\mathrm{E}}\left(\mathrm{F}_{2,30}=0.136 ; p=0.874 ; \mathrm{\eta}_{\mathrm{P}}{ }^{2}=\right.$ $0.009)$, Rf $\left(\mathrm{F}_{2,30}=0.437 ; p=0.650 ; \eta_{\mathrm{p}}{ }^{2}=0.028\right)$, $\% \mathrm{VO}_{2 \text { peak }} \quad\left(\mathrm{F}_{1.419,21.287}=0.526 ; p=0.538 ; \eta_{\mathrm{p}}^{2}=\right.$ $0.034), \% \mathrm{HR}_{\text {peak }}\left(\mathrm{F}_{4.032,0.477}=0.585 ; p=0.676\right.$; $\left.\eta_{\mathrm{p}}{ }^{2}=0.038\right)$ and energy expenditure $\left(\mathrm{F}_{2,30}=0.977\right.$; $\left.p=0.388 ; \quad \eta_{\mathrm{p}}{ }^{2}=0.061\right)$.In addition, the $\% \operatorname{FAT}\left(\mathrm{F}_{2,30}=3.298 ; p=0.051 ; \eta_{\mathrm{p}}^{2}=0.180\right)$ tended but was not different between trials. Moreover, a verified difference in $\% \mathrm{CHO}\left(\mathrm{F}_{2,30}=\right.$ 3.326; $\left.p=0.049 ; \mathrm{\eta}_{\mathrm{p}}{ }^{2}=0.181\right)$ was observed, with lower values during the FT trial than during the NM trial (Figure 2). No verified difference was found between other trials.

The average walking speed (Figure 3 ) was not affected by music tempo $\left(\mathrm{F}_{2,30}=0.330 ; p=0.722\right.$; $\left.\eta_{\mathrm{p}}{ }^{2}=0.022\right)$, with values being similar between $\mathrm{NM}, \mathrm{MT}$, and FT trials $(1.44 \pm 0.04,1.46 \pm 0.04$, and $1.45 \pm 0.03 \mathrm{~m} / \mathrm{s}$, respectively).

Table 1

Profile of mood state values in NM, MT, and FT pre- and post-exercise (mean $\pm S D$ ).

\begin{tabular}{lllllll}
\hline & & Pre-exercise & \multicolumn{3}{c}{ Post-exercise } \\
& NM & MT & FT & NM & MT & FT \\
\hline Fatigue & $2.9 \pm 2.7$ & $1.7 \pm 1.7$ & $3.1 \pm 3.0$ & $3.7 \pm 3.5$ & $2.3 \pm 3.1$ & $3.5 \pm 3.0$ \\
Tension & $2.0 \pm 2.2$ & $1.8 \pm 1.6$ & $2.7 \pm 2.5$ & $1.3 \pm 2.1$ & $1.3 \pm 1.8$ & $1.5 \pm 2.0^{*}$ \\
Vigor & $8.2 \pm 3.3$ & $8.5 \pm 3.3$ & $7.6 \pm 2.9$ & $8.3 \pm 3.8$ & $9.4 \pm 3.5$ & $8.3 \pm 3.3$ \\
Anger & $0.7 \pm 1.0$ & $0.4 \pm 0.7$ & $0.9 \pm 1.4$ & $0.3 \pm 0.7^{*}$ & $0.3 \pm 1.5$ & $0.3 \pm 1.2$ \\
Confusion & $0.5 \pm 1.0$ & $0.3 \pm 0.8$ & $1.1 \pm 1.4$ & $0.0 \pm 0.2$ & $0.2 \pm 0.6$ & $0.5 \pm 1.2^{*}$ \\
Depression & $0.6 \pm 0.9$ & $03 \pm 0.6$ & $1.3 \pm 2.7$ & $0.6 \pm 1.5$ & $0.3 \pm 0.6$ & $0.5 \pm 1.9^{*}$ \\
TMD & $-1.3 \pm 8.0$ & $-2.7 \pm 6.6$ & $2.1 \pm 7.7$ & $-1.7 \pm 8.5$ & $-4.5 \pm 7.3$ & $-1.9 \pm 8.7$ \\
\hline
\end{tabular}

Note. $\mathrm{FT}=$ fast tempo music; $\mathrm{MT}=$ medium tempo music; $\mathrm{NM}=$ no music; $\mathrm{TMD}=$ total mood disturbance; ${ }^{*}=$ difference from pre-exercise.

Table 2.

Physiological and psychophysical responses while walking at a self-selected pace during different trials.

\begin{tabular}{lccc}
\hline Variable & $\mathrm{NM}$ & $\mathrm{MT}$ & $\mathrm{FT}$ \\
\hline $\mathrm{RER}$ & $1.0 \pm 0.0$ & $1.0 \pm 0.0$ & $1.0 \pm 0.0$ \\
$\mathrm{~V}_{\mathrm{E}}(\mathrm{L} / \mathrm{min})$ & $41.7 \pm 1.6$ & $41.1 \pm 2.0$ & $40.9 \pm 1.8$ \\
$\mathrm{Rf}($ breath/min) & $36.4 \pm 1.4$ & $36.5 \pm 1.3$ & $37.1 \pm 1.6$ \\
$\% \mathrm{VO}_{\text {2peak }}$ & $58.0 \pm 13.4$ & $55.3 \pm 13.9$ & $56.2 \pm 14.3$ \\
$\% \mathrm{HR}_{\text {peak }}$ & $75.6 \pm 11.3$ & $74.2 \pm 10.3$ & $74.6 \pm 11.6$ \\
Energy expenditure (Kcal) & $156.5 \pm 20.3$ & $157.4 \pm 19.1$ & $162.7 \pm 21.3$ \\
\hline Note: \%HR peak & percentage of peak of heart rate; $\% \mathrm{VO}_{2 \text { peak }}=$ percentage of peak rate of oxygen uptake; Kcal = kilocalorie; RER \\
respiratory quotient; $\mathrm{Rf}=$ breath per minute; $\mathrm{V}_{\mathrm{E}}=$ minute ventilation.
\end{tabular}

\section{DISCUSSION}

The objective of the study was to evaluate the effects of music tempi on psychological and physiological responses and performance during walking by women who were overweight or have obesity at a self-selected pace intensity. The main outcomes were that listening to music with medium tempo during workouts can reduce the perceived exertion and that fast tempo music can affect mood state. Moreover, music did not affect most physiological responses; an exception is that the percentage of $\mathrm{CHO}$ contribution and music tempo did not influence the performance measure.
With regard to the rating of perceived exertion, this study found that medium tempo music reduces perceived exertion. In fact, previous studies showed that music affects perceptual responses during exercise, reducing the RPE(Potteiger, Schroeder, \& Goff, 2000; Terry et al., 2012). One possible explanation is attention processing, during which the afferent nerve impulses to the central nervous system through put are limited, while music might prevent the physiological feedback associated with physical exertion(Tenenbaum, 2001). Indeed, music seems to have the potential to affect attentional focus during exercise at a self- 
selected pace; this condition could explain the shift of attention from an external influence, thereby reducing the RPE(Silva et al., 2016). However, the exercise intensity controls the influence of music in terms of afferent feedback. At higher intensities, the physiological path ways seem to dominate information processing, while at moderate intensity, external routes, such as the use of music, can be processed in parallel (Tenenbaum, 2001). Considering that all trials were performed at the moderate or heavy domain, the perceived exertion should have been affected by music during two trials, yet this effect was not observed. However, a change in perceived exertion was observed only between NM and MT. One possible reason the RPE is not lower in FT than in NM may be the exposure time. (Karageorghis, Jones, \& Low, 2006) suggest that continuous exposure to fast music time can reduce motivation, thereby leading to bored omand annoyance. Fast tempo music can also increase the total mood disturbance and tension(Dyer \& Mckune, 2013). These changes in psychological responses could change how the participants perceived the exercise.

With regard to mood state, we verified the effect of fast tempo music on depression, tension, and confusion, and we found that it seems to positively affect mood state(Bruner, 1990; Västfjäll, 2002). Interestingly, we did not verify the effect of medium tempo music on mood state. By contrast, we observed a change in the anger state during the NM trial. Similar toBiagini et al. (2012) and Dyer and Mckune (2013), we verified the effect of music on tension. However, unlike the cited authors, we verified a reduction from pre-exercise to post-exercise. We could consider several differences between the results. First is the sample that was studied. We studied women who are overweight or have obesity, who may have different psychological responses because of their higher depressive symptoms(Fassino, Leombruni, Pierò, Abbate-Daga, \& Rovera, 2003; Tanco, Linden, \& Earle, 1998). Another aspect is the environment. Our study was conducted in an outdoor environment with high external validity. Recently, environment has been verified to influence mood during physical activity(Song et al., 2014). In this sense, we can postulate that the environment per se, not music, may have influenced the mood response.

The absence of the effect of music on most physiological responses has been shown in the field of physical exercise, although the same studies presented the effects of music(Karageorghis et al., 2013; Lim, Karageorghis, Romer, \& Bishop, 2014; Nakamura, Pereira, Papini, Nakamura, \& Kokubun, 2010). We observed a lower contribution of $\mathrm{CHO}$ and a tendency for the higher contribution of FAT during FT than during NM. These differences in physiological responses may be due to modulations in the activation of the autonomic system. A dominant sympathetic activity may change the use of substrates, such as carbohydrates and fats(Nonogaki, 2000). Exercise itself is able to increase sympathetic activity; the use of music also seems to achieve this increase(Jia, Ogawa, Miura, Ito, \& Kohzuki, 2016; Nichols, 2015). Although this information may postulate the possible cause of the alteration in the contribution of nutrients, our methodology is unable to affirm that these alterations can be due to the autonomic activity. We suggest that future studies analyze the responses of the autonomic nervous system during physical exercise with the use of music. With regard to music tempo, few studies investigated its effects on physiological responses. Unlike our study, Birnbaum, Boone, and Huschle (2009)found a higher $\mathrm{VO}_{2}$ on the exercise performed with fast tempo music compared with trials with low tempo music and without music. Almeida et al. (2015) found no effect of music tempo (90 and $140 \mathrm{bpm})$ at $\% \mathrm{HR}_{\max }$ and $\% \mathrm{VO}_{2 \max }$ during walking performed by healthy women. Dyer and Mckune (2013)also found no effect of music tempo $(140,120$, and $100 \mathrm{bpm})$ on the $\% \mathrm{VO}_{2 \text { peak }}$, $\mathrm{HR}$, and RER in well-trained cyclists. Potteiger et al. (2000)found similar results, and no change in HR was observed in any of the trials (fast beats, classical music, self-selected music, and no music) for 20 minutes at $70 \% \mathrm{VO}_{2 \text { peak }}$ on a cycle ergometer. These contradictory results may be 
due to the experimental design used in each study. Features such as music selection (motivational music, neutral music, different tempo, favorite music, stimulating music, sedative music, classical music), the type of task (cycle ergometer, treadmill, dynamometer), level of subject's fitness, and exercise prescription (volume and intensity) make comparing studies.

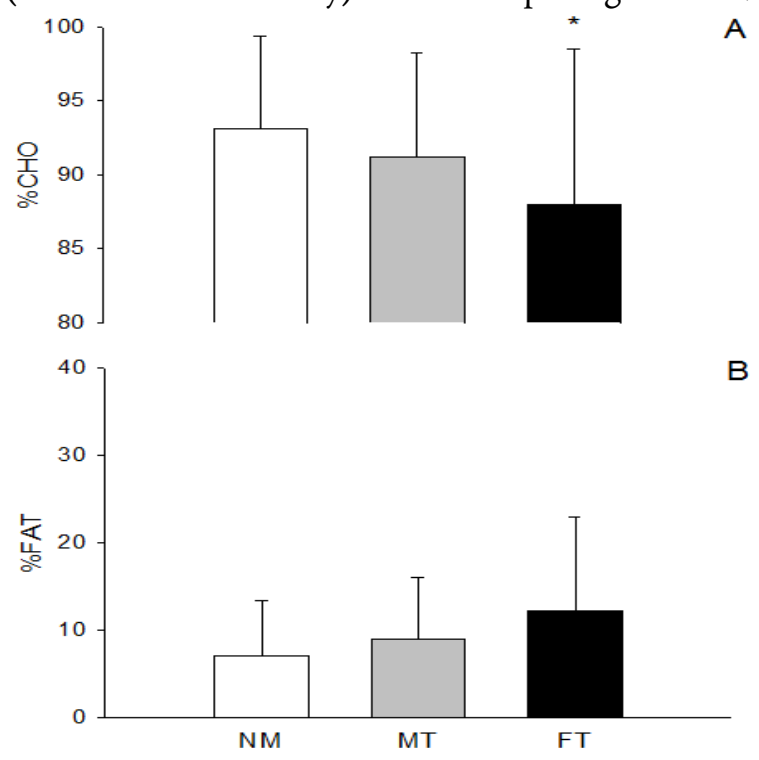

Figure 2. A) Percentage of carbohydrate contribution (mean \pm sem) and; B), percentage of fat contribution (mean \pm sem.) during walking at selfselected pace with NM, MT, and FT. Note: * indicates a difference from the control group $(p<0.03)$.

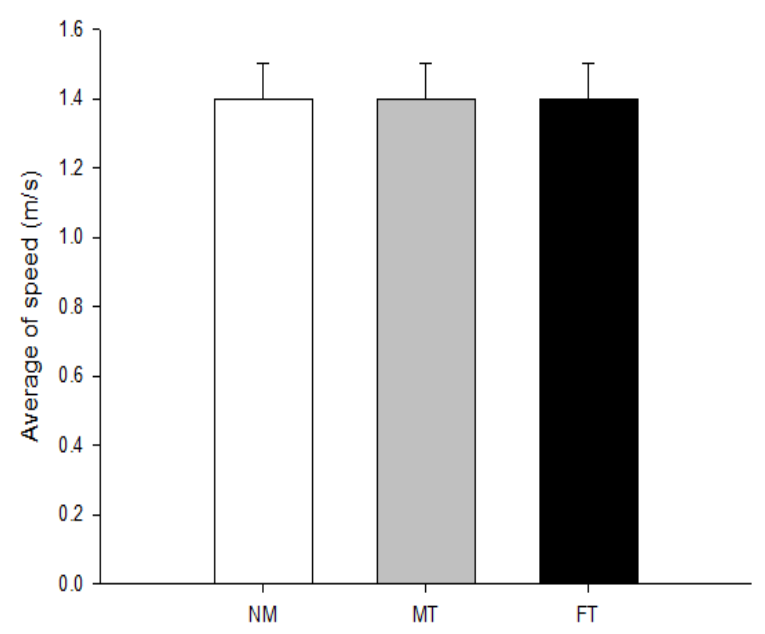

Figure 3. Average of speed (mean \pm sem.) during walking at a self-selected pace at NM, MT, and FT.

Our results demonstrate that music does not change the walking speed regardless of music tempo. Previous studies found the ergogenic effect of music during exercise prescribed in a certain percentage of $\mathrm{HR}$ and $\mathrm{VO}_{2}$ or under an imposed RPE(Karageorghis et al., 2006; Yamashita et al., 2006). Karageorghis et al. (2009) reported greater distance with the use of music at an imposed intensity of $75 \%$ of the maximum heart rate reserve. Similarly, Elliott, Carr, and Savage (2004) reported extensive work output with the use of music at an imposed intensity of "13" on the Borg scale. Although several studies indicate the effect of music on performance, this effect is dependent on the exercise intensity. At higher intensities, music seems to have little or no effect on performance (Dyer \& Mckune, 2013; Tenenbaum et al., 2004). Studies on self-selected pace intensity during walking and the use of music are scarce. Music affects the perception of effort during MT; thus, this group would be expected to increase its pace considering that the perception of effort is one of the mediators of the pace of activity (Abbiss, Peiffer, Meeusen, \& Skorski, 2015). However, this change did not occur. An important detail to consider is that other factors contribute in the regulation of pace, such as knowledge of task duration, remaining distance, and motivation(Edwards \& Polman, 2013; St Gibson et al., 2006). The participants in our study have knowledge of the remaining distance and were not motivated to alter their pace. Together, these situations may have influenced the pace of activity. At a self-selected pace, when the subjects are free to select their exercise intensity, the use of music cannot effectively increase the performed work, as confirmed by the same walking speed and energy expenditure in all trials. The use of music during exercise without knowledge of task time should be used in future designs.

Considering that walking is the most popular activity among adults of all ages (Hardman, 1999)and given the increasing trend in the number of women with obesity(Flegal, KruszonMoran, Carroll, Fryar, \& Ogden, 2016), our results can have important practical applications. Our results can help health professionals to prescribe exercises for this population, 
elaborating strategies that manipulate the way the participants perceive the exercise and determining what could help address the important factor of adherence to exercise(Ekkekakis, 2009). Moreover, with regard to the importance of mood state on mental health, especially among people with obesity(Kanning \& Schlicht, 2010; Paluska \& Schwenk, 2000), our results show an effective strategy of affecting mood state during exercise. Our findings may contribute to advances in some areas, such as the study of music and perceived exertion and the promotion of exercise among women who are overweight or have obesity. In practical terms, health professionals can use this information as a tool for the development of a stimulus that is positively perceived and leads to adherence to physical exercise among women who are overweight or have obesity. For future studies, we suggest designs that use accurate instruments to measure activities in the brain area and its association with perceived exertion during exercise with the use of music. Given the relevance of these results, another suggestion is the investigation of different groups, such as children and adolescents with obesity considering that this population has a tendency to increase.

\section{CONCLUSION}

Findings show that at moderate exercise intensity, external stimuli can modulate psychological responses. Medium tempo music can lower perceived exertion, and fast tempo music can affect the moods of individuals who are overweight or have obesity. However, music does not influence physiological response and performance. Although music may be an important ergogenic aid in other conditions, its use is seemingly ineffective at improving the selfselected walking pace of individuals who are overweight or have obesity.

\footnotetext{
Acknowledgments:

This work was supported by Coordenação de Aperfeiçoamento de Pessoal de Nível Superior (Aldo Coelho Silva).
}

\section{Conflict of Interests:}

Nothing to declare

\section{Funding:}

Nothing to declare

\section{REFERENCES}

Abbiss, C, Peiffer, J, Meeusen, R, \& Skorski, S. (2015). Role of Ratings of Perceived Exertion during SelfPaced Exercise: What are We Actually Measuring? Sports Medicine, 45(9), 1235-1243.

Ahrens, J. N., Crixell, S. H., Lloyd, L. K., \& Walker, J. L. (2007). The physiological effects of caffeine in women during treadmill walking. The Journal of Strength \& Conditioning Research, 21 (1), 164-168.

Almeida, F. A. M., Nunes, R. F. H., Ferreira, S. S., Krinski, K, Elsangedy, H. M., Buzzachera, C. F., . . da Silva, S. G. (2015). Effects of musical tempo on physiological, affective, and perceptual variables and performance of self-selected walking pace. Journal of Physical Therapy Science, 27(6), 1709-1712.

Biagini, Matthew S, Brown, Lee E, Coburn, Jared W, Judelson, Daniel A, Statler, Traci A, Bottaro, Martim, ... Longo, Nick A. (2012). Effects of selfselected music on strength, explosiveness, and mood. The Journal of Strength \& Conditioning Research, 26(7), 1934-1938.

Birnbaum, Larry, Boone, Tommy, \& Huschle, Beth. (2009). Cardiovascular responses to music tempo during steady-state exercise. Journal of Exercise Physiology Online, 12 (1), 50-57.

Borg, G. A. (1982). Psychophysical bases of perceived exertion. Medicine \& Science in Sports \& Exercise, 14(5), 377-381.

Brownley, K. A., McMurray, R. G., \& Hackney, A. C. (1995). Effects of music on physiological and affective responses to graded treadmill exercise in trained and untrained runners. International Journal of Psychophysiology, 19(3), 193-201.

Bruce, R. A. (1971). Exercise testing of patients with coronary heart disease. Principles and normal standards for evaluation. Annals of Clinical Research, 3(6), 323.

Bruner, G. C. (1990). Music, mood, and marketing. The Journal of Marketing, 54(4), 94-104.

Crust, L., \& Clough, P. J. (2006). The influence of rhythm and personality in the endurance response to motivational asynchronous music. Journal of Sports Sciences, 24(2), 187-195.

Dishman, R. K., Farquhar, R. P., \& Cureton, K. J. (1994). Responses to preferred intensities of exertion in men differing in activity levels. Medicine \& Science in Sports \& Exercise, 26(6), 783790. 
Donnelly, J. E., Blair, S. N., Jakicic, J. M., Manore, M. M., Rankin, J. W., \& Smith, B. K. (2009). American College of Sports Medicine Position Stand. Appropriate physical activity intervention strategies for weight loss and prevention of weight regain for adults. Medicine \& Science in Sports \& Exercise, 41 (2), 459-471.

Dyer, B. J., \& Mckune, A. J. (2013). Effects of music tempo on performance, psychological, and physiological variables during 20KM cycling in well-trained cyclists. Perceptual \& Motor Skills, 117(2), 484-497.

Edwards, A. M., \& Polman, R. C. J. (2013). Pacing and awareness: brain regulation of physical activity. Sports Medicine, 43 (11), 1057-1064.

Ekkekakis, P. (2009). Let Them Roam Free? Sports Medicine, 39(10), 857-888.

Ekkekakis, P., \& Lind, E. (2006). Exercise does not feel the same when you are overweight: the impact of self-selected and imposed intensity on affect and exertion. International Journal of Obesity, 30(4), 652-660.

Elliott, D., Carr, S., \& Savage, D. (2004). Effects of motivational music on work output and affective responses during sub-maximal cycling of a standardized perceived intensity. Journal of Sport Behavior, 27(2), 134.

Fassino, S., Leombruni, P., Pierò, A., Abbate-Daga, G., \& Rovera, G. G. (2003). Mood, eating attitudes, and anger in obese women with and without binge eating disorder. Journal of Psychosomatic Research, 54(6), 559-566.

Flegal, K. M., Kruszon-Moran, D., Carroll, M. D., Fryar, C. D., \& Ogden, C. L. (2016). Trends in Obesity Among Adults in the United States, 2005 to 2014. JAMA, 315(21), 2284-2291.

Hardman, A. E. (1999). Physical activity, obesity and blood lipids. International Journal of Obesity $\mathcal{E}$ Related Metabolic Disorders, Suppl3, S64-71.

Jia, T., Ogawa, Y., Miura, M., Ito, O., \& Kohzuki, M. (2016). Music Attenuated a Decrease in Parasympathetic Nervous System Activity after Exercise. PloS one, 11 (2), e0148648.

Kanning, M., \& Schlicht, W. (2010). Be active and become happy: an ecological momentary assessment of physical activity and mood. Journal of Sport and Exercise Psychology, 32 (2), 253-261.

Karageorghis, C. I., Hutchinson, J. C., Jones, L., Farmer, H. L., Ayhan, M. S., Wilson, R. C., . . . Bailey, S. G. (2013). Psychological, psychophysical, and ergogenic effects of music in swimming. Psychology of Sport and Exercise, 14(4), 560-568.

Karageorghis, C. I., Jones, L., \& Low, D. (2006). Relationship between exercise heart rate and music tempo preference. Research Quarterly for Exercise and Sport, $77(2), 240-250$.

Karageorghis, C. I., Jones, L., \& Stuart, D. . (2008). Psychological effects of music tempi during exercise. International Journal of Sports Medicine, 29(7), 613-619.

Karageorghis, C. I., Mouzourides, D. A., Priest, D., Sasso, T. A., Morrish, D. J., \& Walley, C. L. (2009). Psychophysical and ergogenic effects of synchronous music during treadmill walking. Journal of Sport and Exercise Psychology, 31(1), 1836.

Karageorghis, C. I., \& Priest, D. (2012). Music in the exercise domain: a review and synthesis (Part I). International Review of Sport and Exercise Psychology, 5(1), 44-66.

Karageorghis, C. I., Terry, P. C., \& Lane, A. M. . (1999). Development and initial validation of an instrument to assess the motivational qualities of music in exercise and sport: The Brunel Music Rating Inventory. Journal of Sports Sciences, 17(9), 713-724.

Lee, S., \& Kimmerly, D. (2016). Influence of music on maximal self-paced running performance and passive post-exercise recovery rate. Journal of Sports Medicine and Physical Fitness, 56 (1-2), 39-48.

Leite, G. S., Amaral, D. P., Oliveira, R. S., Oliveira Filho, C. W., Mello, M. T., \& Brandão, M. R. F. (2013). Relação entre estados de humor, variabilidade da frequência cardíaca e creatina quinase de para-atletas brasileiros. Revista da Educação Física / UEM, 24(1), 33-40.

Lim, H. B. T., Karageorghis, C. I., Romer, L. M., \& Bishop, D. T. (2014). Psychophysiological effects of synchronous versus asynchronous music during cycling. Medicine \& Science in Sports $\mathcal{E}$ Exercise, 46(2), 407-413.

Lima-Silva, A. E., Silva-Cavalcante, M. D., Pires, F. O., Bertuzzi, R., Oliveira, R. S., \& Bishop, D. (2012). Listening to music in the first, but not the last 1.5 $\mathrm{km}$ of a $5-\mathrm{km}$ running trial alters pacing strategy and improves performance. International Journal of Sports Medicine, 33(10), 813-818. doi: 10.1055/s0032-1311581

Lohman, T. J., Roache, A. F., \& Martorell, R. (1992). Anthropometric standardization reference manual. Medicine $\&$ Science in Sports \& Exercise, 24(8), 952.

Mattsson, E., Larsson, U. E., \& Rössner, S. (1997). Is walking for exercise too exhausting for obese women? International Journal of Obesity \& Related Metabolic Disorders, 21 (5), 380-6.

McLaughlin, J. E., King, G. A., Howley, E. T., Bassett Jr, D. R., \& Ainsworth, B. E. (2001). Validation of the COSMED K4 b2 portable metabolic system. International Journal of Sports Medicine, 22 (4), 280284.

Nakamura, P. M., Pereira, G., Papini, C. B., Nakamura, F. Y., \& Kokubun, E. (2010). Effects of preferred and nonpreferred music on continuous cycling exercise performance. Perceptual \& Motor Skills, 110(1), 257-264.

Nichols, T. W. (2015). Music as Medicine: The Science of How Music Can Help Induce Sleep, Relieves 
Anxiety and Pain in Patients. Journal of Biomusical Engineering, 3(1), 1000110.

Nonogaki, K. (2000). New insights into sympathetic regulation of glucose and fat metabolism. Diabetologia, 43(5), 533-549.

Paluska, S. A., \& Schwenk, T. L. (2000). Physical activity and mental health. Sports Medicine, 29(3), 167-180.

Perri, M. G., Anton, S. D., Durning, P. E., Ketterson, T. U., Sydeman, S. J., Berlant, N. E., . . . Martin, A. D. (2002). Adherence to exercise prescriptions: effects of prescribing moderate versus higher levels of intensity and frequency. Health Psychology, 21(5), 452-8.

Potteiger, J. A., Schroeder, J. M., \& Goff, K. L. (2000). Influence of music on ratings of perceived exertion during 20 minutes of moderate intensity exercise. Perceptual \& Motor Skills, 91 (3 Pt 1), 848854.

Priest, D., \& Karageorghis, C. I. (2008). A qualitative investigation into the characteristics and effects of music accompanying exercise. European Physical Education Review, 14(3), 347-366.

Rohlfs, I. C. P. M., Rotta, T. M., Luft, C. B., Andrade, A., Krebs, R. J., \& Carvalho, T. (2008). A Escala de Humor de Brunel (Brums): instrumento para detecção precoce da síndrome do excesso de treinamento. Revista Brasileira de Medicina do Esporte, 14(3), 176-181.

Rotta, T. M., Rohlfs, I. C. P. M., \& Oliveira, W. F. (2014). Aplicabilidade do Brums: estados de humor em atletas de voleibol e tênis no alto rendimento. Revista Brasileira de Medicina do Esporte, 20(6), 424-428.

Silva, A. C., Ferreira, S. S., Alves, R. C., Follador, L., \& da Silva, S. G. . (2016). Effect of music tempo on attentional focus and perceived exertion during selected self-paced walking. International Journal of Exercise Science, 9(4), 536-544.

Smith, J. C., \& Hill, D. W. (1991). Contribution of energy systems during a Wingate power test. British Journal of Sports Medicine, 25(4), 196-199.
Song, C., Ikei, H., Igarashi, M., Miwa, M., Takagaki, M., \& Miyazaki, Y. (2014). Physiological and psychological responses of young males during spring-time walks in urban parks. Journal of Physiological Anthropology, 33(1), 8. doi: 10.1186/1880-6805-33-8

St Gibson, A. C., Lambert, E. V., Rauch, L. H. G., Tucker, R., Baden, D. A., Foster, C., \& Noakes, T. D. (2006). The role of information processing between the brain and peripheral physiological systems in pacing and perception of effort. Sports Medicine, 36(8), 705-722.

Tanco, S., Linden, W., \& Earle, T. (1998). Well-being and morbid obesity in women: A controlled therapy evaluation. International Journal of Eating Disorders, 23(3), 325-339.

Tenenbaum, G. (2001). A social-cognitive perspective of perceived exertion and exertion tolerance. Handbook of Ssport Psychology, 2(1), 810-820.

Tenenbaum, G., Lidor, R., Lavyan, N., Morrow, K., Tonnel, S., Gershgore, A., . . J Johnson, M. (2004). The effect of music type on running perseverance and coping with effort sensations. Psychology of Sport and Exercise, 5(2), 89-109.

Terry, P. C., Karageorghis, C. I., Saha, A. M., \& D'Auria, S. (2012). Effects of synchronous music on treadmill running among elite triathletes. Journal of Science and Medicine in Sport, 15(1), 5257.

Västfjäll, D. (2002). Emotion induction through music: A review of the musical mood induction procedure. Musicae Scientiae, 5(1 suppl), 173-211.

Waterhouse, J. P., Hudson, P., \& Edwards, B. (2010). Effects of music tempo upon submaximal cycling performance. Scandinavian Journal of Medicine $\mathcal{E}$ Science in Sports, 20(4), 662-669.

Yamashita, S., Iwai, K., Akimoto, T., Sugawara, J., \& Kono, I. (2006). Effects of music during exercise on RPE, heart rate and the autonomic nervous system. Journal of Sports Medicine and Physical Fitness, 46(3), 425-430. 


\title{
Association between violent behavior and sports practice in adolescents from Aracaju and Metropolitan Region
}

\author{
Mona Gizelle Dreger de Oliveira ${ }^{1}$, Kenia Rejane de Oliveira Batista ${ }^{1}$, Felipe Souza Nery ${ }^{2,3}$, \\ Josiene de Oliveira Couto ${ }^{1}$, Nara Michelle Moura Soares ${ }^{3}$, Roberto Jerônimo dos Santos \\ Silva ${ }^{*}$
}

ORIGINAL ARTICLE

\begin{abstract}
This study aimed to verify the association between sports practice and violent behavior in adolescents. The study included 2248 adolescents (mean age $=16.3, \mathrm{SD}=1.10$ years) regularly enrolled in public high schools of Aracaju and Metropolitan Region. To characterize violent behavior, adolescents were asked about involvement in fights in the last 30 days, according to YRBS-2007. A logistic regression model was used to estimate the crude and adjusted Odds Ratio (OR) in addition to their respective Confidence Intervals $(95 \%$ $\mathrm{CI})$, assuming a $5 \%$ error. There was higher likelihood of violent behavior among males (OR $=3.0,95 \%$ CI 2.3-3.9), individuals reporting alcohol beverage consumption (OR $=2.5,95 \% \mathrm{CI} 1.9-3.3)$ and cigarette consumption ( $\mathrm{OR}=2.6,95 \%$ CI $1.7-4.0)$. In addition, it was observed that sports practice increases by $40 \%$ the likelihood of violent behavior when compared to individuals who do not practice sports (OR = 1.4; $95 \%$ CI $1.1-1.8$ ). It was concluded that there is strong evidence of the relationship between violent behavior and sports practice in high school students from Aracaju and Metropolitan Region.

Keywords: Sport, Violence, Adolescent.
\end{abstract}

\section{INTRODUCTION}

According to the World Health Organization (1995), adolescence is the period between 10 and 19 years of age in which major biopsychosocial transformations occur. Such transformations contribute to greater exposure of adolescents to health risk behaviors. Feijó and Oliveira (2001) reported that these behaviors make reference to the exposure to situations that can harm the physical and psychological health of adolescents.

Health monitoring in childhood and adolescence is a relevant point due to the increase of unhealthy behaviors in this phase (Farias Júnior et al., 2009). Some studies conclude that health risk behaviors acquired in this age group can be maintained throughout life (GECKOVA et al., 2001; Pena et al., 2016). These studies may contribute to preventive health practices for young people and subsidize public intervention policies, leading to the reduction of unhealthy behaviors among adolescents (BRASIL, 2004).
The World Health Organization (2002) establishes that some risk behaviors are determinant for a third of deaths worldwide. Among these behaviors, consumption of tobacco, alcohol and other drugs, in addition to irregular diets, low levels of physical activity and violent behavior stand out.

In this context, it is worth mentioning that violence is one of the main public health problems worldwide. When violence practiced by young people is concerned, it becomes one of the most visible forms in society. Youth violence directly affects the entire social context of victims, their families, friends and the community itself. For causing not only death, but diseases, disability and changes in the quality of life, violence is a problem that generates high costs to health services, causing a distortion of the real function of the service (World Health Organization, 2002).

Researchers indicate that the greater the number of risk factors for the health of

\footnotetext{
${ }^{1}$ Federal University of Sergipe, São Cristovão, Brazil

${ }^{2}$ National School of Public Health, Fiocruz, Rio de Janeiro, Brazil

${ }^{3}$ Tiradentes University, Aracaju, Brazil

* Corresponding author: Núcleo de Pesquisa em Aptidão Física Saúde e Desempenho de Sergipe, Cidade Universitária "Prof. José Aloísio de Campos", Av. Mal. Rondon s/n. CEP: 409100-000. São Cristovão/SE, Brasil. E-mail: rjeronimoss@ufs.br
} 
adolescents, the greater the likelihood of involvement in violent behavior. In addition, the authors point out that there is a gender difference in violence-related behaviors, since girls suffer more from family problems or impaired relationships with parents, while boys suffer from effects on involvement with other behaviors such as use and sell drugs, commit non-violent criminal offenses, and engage in other forms of non-violent delinquency. In addition, involvement in various types of violent behavior is influenced by risk factors from multiple domains, whether demographic, environmental, or behavioral (Saner \& Ellickson, 1996).

In 2011, in Aracaju / SE, an association was observed between violent behavior, smoking and alcohol consumption, regardless of gender. Girls who reported using cigarettes are 2 times more likely to get into a fight. The same likelihood was found for girls who reported alcohol consumption. However, boys who reported cigarette use were 1.5 times more likely to get into a fight, maintaining the proportion for boys who reported alcohol consumption (Silva et al., 2014).

In an attempt to revert scenarios such as this, several institutions have provided activities for young people to exercise values such as "nonviolence", mutual respect, and opportunities for growth through education (Castro, 2001; Instituto de Segurança Pública, 2015; Moreira, 2009; Rolim, 2008). It was also verified that, among the preventive actions more frequently developed, the activities that stand out are those that use as a base the use of sports, art, culture and leisure; however, programs that have a rigorous evaluation that proves the effectiveness of their actions are scarce (Instituto de Segurança Pública, 2015).

Lately, youth violence related to sports has been neglected or ignored, when it should be treated with concern and attention. These authors have argued that non-acceptance of violence within sports culture may partly explain why the phenomenon of violence in sports is not recognized as a public health problem (Fields, Collins, \& Comstock, 2010).
In view of the differences among authors about the true relationship between sports practice and violence among young people, the current study is relevant in the field of Public Health, as it will serve as a basis for broadening the discussion about the way violent actions of these young people in sports are analyzed.

Based on the above, this study aims to analyze the association between sports practice and the determinants of violent behavior in adolescents from Aracaju and Metropolitan Region, State of Sergipe, Brazil.

\section{Sample}

\section{METHOD}

This is a cross-sectional, school-based epidemiological study of adolescents of both sexes from public schools in the city of Aracaju and Metropolitan Region. In the observed region, the 2011 School Census was considered, with a total of 13,373 students enrolled.

The conglomerate sampling technique was divided into two stages. In the first stage, the High School units of each municipality were considered, with enrollments above 350 students. At this stage, 19 schools met the established criteria. In the second stage, the sample was stratified by the Teaching Unit. Conglomerate was defined by the classroom (the average number of students was 32.62 per classroom, respecting the proportionality of grades by School Unit, classes and shifts).

After stratification, the "n" calculated for each School Unit was divided by 32.62 , identifying the number of classes that should be drawn by Unit, respecting the proportionality by school grades.

For the sample calculation, a sample error of 3 percentage points and prevalence of the observed behavior of $50 \%$ were adopted, with design effect of 2.0. In addition, there was an increase of $20 \%$ in order to compensate for possible losses.

Inclusion criteria were: to be regularly enrolled in high schools of the teaching units chosen to participate in the study; to have minimum age of 13 and maximum of 18 years; to have the Informed Consent Form (TCLE) signed 
by parents or guardians; and to be present on the day of data collection. Exclusion criteria were: to have completed less than $50 \%$ of the instrument and not to have filled fundamental questions such as sex and age.

\section{Instruments}

Data collection took place in three months, from July to September 2011. Each selected Teaching Unit was visited twice. The questionnaire developed by ABEP (Brazilian Association of Research Companies, 2010) was used to define economic class and education level of parents or guardians. Socioeconomic levels were grouped into the following strata: "High" ("A1", "A2", "B1" and "B2") and "Low" ("C1" and "C2"). Maternal educational level was dichotomized into "Up to eight years of study" and "More than eight years of study".

For the identification of violent behavior, the responses of the YRBS-2007 questionnaire, validated for Brazil by Guedes and Lopes (Guedes \& Lopes, 2010), were analyzed from question number 14 (During THE LAST 12 MONTHS, how many times have you got involved in a (fight)?). Responses to violent behavior were classified as "never" or "once or more." Regarding risk behavior, responses for cigarettes, alcohol, marijuana consumption and sports practice were classified as "yes" or "no".

\section{Procedures}

Data collection was performed in September 2011 in 18 schools in the study region, in the afternoon and morning shifts. For the application of the instrument, evaluators were previously trained in order to standardize all procedures related to obtaining data.

\section{Statistical analysis}

For data analysis, a logistic regression model was adopted to estimate crude and adjusted Odds Ratio (OR), in addition to their Confidence Intervals (CI). Only variables that presented statistical significance in the bivariate analyses were considered in the adjustment of the hierarchical model structured in two levels.

The first level included the socioeconomic and demographic variables (sex, age, socioeconomic level, maternal educational level) and the second level included variables that characterize the health risk behaviors of adolescents (sports practice, hours watching TV, alcohol consumption, smoking, marijuana use). The possibility of confusion and interaction was considered in the specific analysis study. Significance level of $5 \%(\mathrm{p} \leq 0.05)$ was used in all analyses. All procedures were performed using SPSS software version 19.0 for Windows.

This study was approved by the Research Ethics Committee of the Federal University of Sergipe (CEP / UFS) under CAAE number 5724.0.000.107-10, attesting that it was in accordance with the Brazilian Legislation for Research on Human Beings.

\section{RESULTS}

A total of 2,259 adolescents were included, of which approximately $2 / 3(62.2 \%)$ were female. The mean age was $16.3 \pm 1.10$ years $(95 \% \mathrm{CI}$ : 16.25 - 16.34), ranging from 13 to 18 years, with predominance of adolescents aged over 15 years $(73.7 \%)$ and attending the first grade of high school (47.3\%). Of the total, $84.8 \%$ did not work and $76.1 \%$ were considered of low socioeconomic level (Table 1).

A considerable number of mothers of adolescents had up to eight years of schooling $(61.7 \%)$. In addition, approximately $70 \%$ reported spending more than two hours watching TV.

Regarding risk behavior and lifestyle, variables predicting violent behavior, $38.4 \%$ consumed alcoholic beverages, $6.6 \%$ had smoking habit, $2.4 \%$ used marijuana, $3.5 \%$ used other drugs and $42.3 \%$ of adolescents practiced sports. Of the total number of adolescents, it was observed that $16.5 \%$ had at least one violent behavior. 
Table 1

Percentage distribution of socioeconomic and demographic variables of adolescents from public schools of Aracaju, Sergipe, in the year 2012.

\begin{tabular}{|c|c|c|c|}
\hline Variables & $\mathrm{n}$ & $\%$ & IC95\% \\
\hline \multicolumn{4}{|l|}{ Sex } \\
\hline Female & 1.377 & 62,2 & $0,36-0,40$ \\
\hline Male & 836 & 37,8 & \\
\hline \multicolumn{4}{|l|}{ Age } \\
\hline$\geq 15$ years & 586 & 26,3 & $0,72-0,76$ \\
\hline$<15$ years & 1.646 & 73,7 & \\
\hline \multicolumn{4}{|l|}{ High school grade } \\
\hline 1st & 1.052 & 47,3 & $1,69-1,76$ \\
\hline 2nd & 731 & 32,8 & \\
\hline $3 \mathrm{rd}$ & 443 & 19,9 & \\
\hline \multicolumn{4}{|l|}{ Work } \\
\hline No & 1.872 & 84,8 & $0,14-0,17$ \\
\hline Yes & 335 & 15,2 & \\
\hline \multicolumn{4}{|l|}{ Socioeconomic level } \\
\hline High & 525 & 23,9 & $0,22-0,26$ \\
\hline Low & 1.673 & 76,1 & \\
\hline \multicolumn{4}{|l|}{ Maternal educational level } \\
\hline Up to eight years of schooling & 1321 & 61,7 & $0,36-0,40$ \\
\hline More than eight years of schooling & 820 & 38,3 & \\
\hline \multicolumn{4}{|l|}{ Time watching TV } \\
\hline More than 2 hours & 1.482 & 69,1 & $0,67-0,71$ \\
\hline Up to 2 hours & 662 & 30,9 & \\
\hline \multicolumn{4}{|l|}{ Consumption of alcoholic beverages } \\
\hline No & 1.383 & 61,6 & $0,36-0,40$ \\
\hline Yes & 862 & 38,4 & \\
\hline \multicolumn{4}{|l|}{ Smoking habit } \\
\hline No & 2.100 & 93,4 & $0,06-0,08$ \\
\hline Yes & 148 & 6,6 & \\
\hline \multicolumn{4}{|l|}{ Habit of smoking marijuana } \\
\hline No & 2.190 & 97,6 & $0,02-0,03$ \\
\hline Yes & 27 & 2,4 & \\
\hline \multicolumn{4}{|l|}{ Sports practice } \\
\hline No & 1.287 & 57,7 & $0,40-0,44$ \\
\hline Yes & 944 & 42,3 & \\
\hline \multicolumn{4}{|l|}{ Violent behavior } \\
\hline Never & 1.884 & 83,5 & $0,15-0,18$ \\
\hline One or more times & 372 & 16,5 & \\
\hline
\end{tabular}

There was a statistically significant correlation between violent behavior and predictor variables: gender, socioeconomic level, alcohol consumption, smoking habit, marijuana use and sports practice. Men showed higher frequency of involvement in fights (60.6\%) when compared to women (39.4\%) (Data not shown), and $26.4 \%$ and $10.5 \%$ of men and women, respectively, presented violent behavior (Table 2).
The age group considered to be the most prevalent for violent behavior was for individuals aged over 15 years, as well as for those with high socioeconomic level. Of individuals who reported using alcohol, approximately $26 \%$ had been involved in fights, while $10.8 \%$ of those who reported not using alcohol had had this behavior.

This proportional difference in violent behavior was also observed in the comparison 
between adolescents who reported smoking (41.2\% violent behavior of the total number of smokers) and those who did not have this habit (14.9\% violent behavior of all non-smokers), as well as those making use of marijuana (50\% violent behavior of the total users) and not users (15.8\% violent behavior of the total nonusers) (Table2).

Table 2

Percentage distribution and p-value of the Spearman correlation coefficient ( $\rho$ ) of socioeconomic and demographic variables, lifestyle and risk behavior of adolescents from public schools of Aracaju according to violent behavior, Sergipe, 2012.

\begin{tabular}{|c|c|c|c|c|}
\hline \multirow{3}{*}{ Variables } & \multicolumn{4}{|c|}{ Violent behavior (involvement in fights) } \\
\hline & Never & One or more times & Total & \multirow{2}{*}{$p$-value ${ }^{\mathrm{I}}$} \\
\hline & n (\%) & $\mathrm{n}(\%)$ & $\mathrm{N}$ & \\
\hline \multicolumn{5}{|l|}{ Sex } \\
\hline Female & $1.233(89,5 \%)$ & $144(10,5 \%)$ & 1.377 & $<0,001$ \\
\hline Male & $615(73,6 \%)$ & $221(26,4 \%)$ & 836 & \\
\hline \multicolumn{5}{|l|}{ Age } \\
\hline$\geq 15$ years & $484(82,6 \%)$ & $102(17,4 \%)$ & 586 & 0,464 \\
\hline$<15$ years & $1.381(83,9 \%)$ & $265(16,1 \%)$ & 1.646 & \\
\hline \multicolumn{5}{|l|}{ Socioeconomic level } \\
\hline Low & $1.421(84,9 \%)$ & $252(15,1 \%)$ & 1.672 & 0,001 \\
\hline High & $415(79 \%)$ & $110(21 \%)$ & 525 & \\
\hline \multicolumn{5}{|l|}{ Time watching TV } \\
\hline Up to 2 hours & $559(84,4 \%)$ & $103(15,6 \%)$ & 662 & 0,428 \\
\hline More than 2 hours & $1.231(83,1 \%)$ & $251(16,9 \%)$ & 1.482 & \\
\hline \multicolumn{5}{|c|}{ Consumption of alcoholic beverages } \\
\hline No & $1.234(89,2 \%)$ & $149(10,8 \%)$ & 1.383 & $<0,000$ \\
\hline Yes & $639(74,1 \%)$ & $223(25,9 \%)$ & 862 & \\
\hline \multicolumn{5}{|l|}{ Smoking habit } \\
\hline No & $1.788(85,1 \%)$ & $312(14,9 \%)$ & 2.100 & $<0,000$ \\
\hline Yes & $87(58,8 \%)$ & $61(41,2 \%)$ & 148 & \\
\hline \multicolumn{5}{|l|}{ Habit smoking marijuana } \\
\hline No & $1.844(84,2 \%)$ & $346(15,8 \%)$ & 2.190 & $<0,000$ \\
\hline Yes & $27(50 \%)$ & $27(50 \%)$ & 54 & \\
\hline \multicolumn{5}{|l|}{ Sports practice } \\
\hline No & $1.122(87,2 \%)$ & $165(12,8 \%)$ & 1.287 & $<0,000$ \\
\hline Yes & $739(78,3 \%)$ & $205(21,7 \%)$ & 944 & \\
\hline
\end{tabular}

Note: ${ }^{\text {I }}$ p-value of the Spearman Correlation Coefficient. ${ }^{\text {II }}$ socioeconomic classes classified as: low, represented by classes $\mathrm{Cl}$, $\mathrm{C} 2$, D and E; high, represented by classes A2, B1 and B2.

In the crude analysis, it was observed that the likelihood of violent behavior in men was 3.1 (95\% CI: 2.4 - 3.9) times the likelihood of the same behavior in women. There was 50\% (95\% CI: $20 \%$ - 90\%) more likelihood of violent behavior in individuals of high socioeconomic level. In relation to the use of alcoholic beverages, the likelihood of violent behavior was higher when compared to those who did not consume alcohol (OR $=2.9,95 \%$ CI: 2.3-3.6), and was higher for those who had smoking habit (OR = 4; 95\% CI: 2.8 - 5.7) and used marijuana (OR = 5.3, 95\% CI: 3.1 - 9.2). Regarding sports, it was observed that practicing sports increased violent behavior in 90\% (95\% CI: 50\% - 140\%) when compared to individuals who did not practice sports (Table 3 ).

The adjusted analysis showed loss of significance in relation to the socioeconomic level and the habit of consuming marijuana. However, being male (OR 3.0, 95\% CI 2.3-3.9), using alcohol (OR 2.5, 95\% CI 1.9-3.3), smoking (OR 2.6; 95\% CI $1.7-4.0$ ) and practicing sports (OR 1.4; $95 \%$ CI 1.1 - 1.8) were risk factors for involvement in fights (Table3). 
Table 3

Gross and adjusted Odds Ratio, and respective 95\% CI, referring to the analysis of association between risk behavior (involvement in fights) and socioeconomic and demographic variables, lifestyle and risk behavior of adolescents from public schools of Aracaju, Sergipe, 2012.

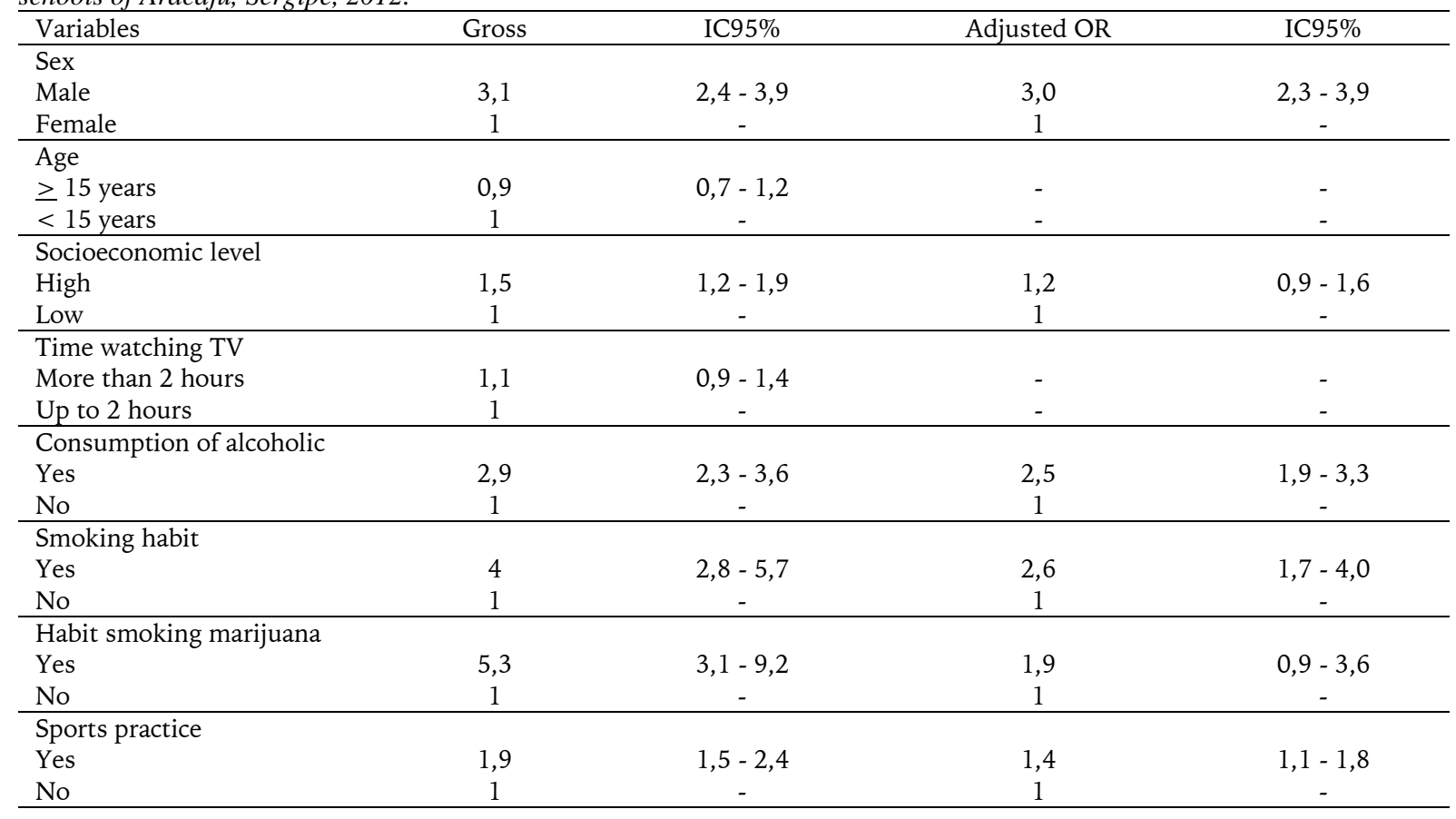

\section{DISCUSSION}

In society in general there seems to be a consensus that sports practice is a strong protective factor for violent behavior; however, in scientific studies, there is still no clear relationship between sports practice and violence.

The findings presented in this study indicate that in adolescents from Aracaju / SE and Metropolitan Region, there is a positive association between sports practice and violent behavior, as well as evidence of an epidemiological risk profile associated with males, alcohol consumption and smoking.

Burton and Marshall (2005) conducted an investigation with 14-year-old students and found a positive correlation between participation in sports and involvement in aggressive behavior. For these authors, these results suggest that participation in sports is a possible risk factor and not a protective factor.

A study aimed at verifying the risk behaviors in students who participated in school sports activities found that these adolescents presented at least one health risk behavior, including aggression and victimization by bullying (Johnson \& McRee, 2015).

The relationship between violence and collective sports in the USA between 1994 and 2001 was studied. Among the three sports modalities most practiced by adolescents, football presented a significant and positive relation with violence, different from baseball and basketball, also verifying that athletes practicing football had a greater risk of entering into a serious violent event when compared to non-athletes (Kreager, 2007).

As for individual sports, it was also identified that adolescents who practiced wrestling presented aggressive behavior similar to that of adolescents practicing football when compared to non-athletes (Kreager, 2007).

Ingestion of alcoholic beverages as a risk factor for violent behavior was also observed in other studies. In Australia, for example, between 2002 and 2012, the authors pointed out that, although no direct relationship between sports participation and violent behavior in young adults was observed, it was observed that those 
who practiced sports and excessive consumption of alcoholic beverages were associated with higher likelihood of being involved in fights (Scholes-Balog, Hemphill, Kremer, \& Toumbourou, 2016).

In this sense, in a meta-analysis performed with 11 studies, Sønderlund et al. (2014) identified significant relationships between alcohol consumption, sports practice and aggression and / or violence. According to this review, evidence suggests that alcohol consumption and the occurrence of a number of negative consequences, including violence and aggression, are greater in sports populations than in non-sports populations.

On the other hand, Terry-Mcelrath, O'malley, and Johnston (2011) have shown that physical exercise is not associated with higher prevalence of use of various substances (alcohol, cigarette, tobacco, marijuana and steroids) in elementary and high school students. In contrast, the participation of the school athletic team had mixed results with the use of these substances. In addition, the results were stable over time.

In a study carried out in the United Kingdom, it was observed that adolescents who had a greater participation in organized activities consumed less amount of alcohol when compared with adolescent transgressors. Although young transgressors are less likely to participate in organized activities, participation in a team sport has been associated with less drinking (Hallingberg, Moore, Morgan, Bowen, $\&$ van Goozen, 2015).

Contrasting the findings of this study, Spruit et al. (2016) found no significant association between sports participation and juvenile delinquency; in this sense, the authors suggest that there is no global relationship between sports practice and the level of violent behavior among adolescents.

In Greece, it was observed that sports practice was related to behaviors of health promotion.

However, this study showed low positive association between sports practice and violence in sport-related events (Papaioannou, Karastogiannidou, \& Theodorakis, 2004).
Hartmann and Depro (2006) emphasize that, as studies have been carried out, there is no way to affirm that sports practice is responsible for reducing or increasing violent behavior in adolescents, since the authors argue that evaluations, studies with comparative groups and the use of more consistent methodologies could contribute to improve the strength of scientific evidence, since studies are based on observational surveys, which impairs causal relationship.

Thus, according to Hartmann and Depro (2006), there is a need for longitudinal surveys in which the relationship between sports and violent behavior are considered as direct observation variables, since studies that identify these relationships have cross-sectional nature, making it difficult to establish a causal relationship.

Although there is evidence of the relationship between sports practice, ethnicity and violent behavior (Taliaferro, Rienzo, \& Donovan, 2010), the present study has as limitation the fact that it did not analyze race / color differences in relation to violent behavior in adolescents from Aracaju, Sergipe.

In addition, due to self-reported measures, there is a concern with the reliability of measures, since there is a possibility of concealment of information, especially those related to the consumption of illicit drugs and violent actions due to the fear of censorship actions; thus longitudinal or cohort studies should be conducted, in which the relationship between sports practice and violent behavior can be observed, facilitating the verification of the causal relationship between these two variables.

\section{CONCLUSION}

It was concluded that there is strong evidence of the relationship between violent behavior and sports practice in high school students from Aracaju and Metropolitan Region. It was also suggested that male adolescents, individuals who consumed alcoholic beverages and those who had smoking habits are more likely to exhibit this type of behavior. 
There are no studies in the Brazilian scientific literature that have evaluated this theme in order to verify the factors associated with violent behavior and sports practice. Thus, further studies should investigate how these sports practices are being oriented.

Although we understand that leisure time can be considered a risk factor for violent behavior in adolescents and the importance of adequate occupation of this time, including sports practice, it is recommended a better planning in the execution of activities that will be performed by adolescents, favoring a better understanding of the sport phenomenon as a practice, and the elaboration of strategies to reduce violent behavior among adolescents who practice these activities.

\section{Acknowledgments:}

Nothing to declare

\section{Conflict of interests:}

Nothing to declare

\begin{tabular}{l}
\hline Funding: \\
Foundation for Research and Technological Innovation \\
Support of the State of Sergipe (Fapitec).
\end{tabular}

\section{REFERENCES}

Associação Brasileira de Empresas de Pesquisa. ABEP. (2010). Critério de Classificação Econômica Brasil 2010. Retrieved from http://www.abep.org.

BRASIL. MINISTÉRIO DA SAÚDE. SECRETARIA DE VILILÂNCIA EM SAÚDE. DEPARTAMENTO DE ANÁlISE DE SITUAÇÃO DE SAÚDE. (2004). Saúde Brasil 2004: uma análise da situação de saúde. Retrieved from http://bvsms.saude.gov.br/bvs/publicacoes/sau de_brasil_2004.pdf

Burton, J. M., \& Marshall, L. A. (2005). Protective factors for youth considered at risk of criminal behaviour: does participation in extracurricular activities help? Criminal Behaviour and Mental Health, 15(1), 46-64. https://doi.org/10.1002/cbm.36

Castro, M. G. (2001). Cultivando vida, desarmando violências: experiências em educação, cultura, lazer, esporte e cidadania com jovens. Unesco; Brasil Telecom; W. K. Kellogg Foudation. Retrieved from http://bases.bireme.br/cgi-
bin/wxislind.exe/iah/online/?IsisScript =iah/iah .xis\&src $=$ google \&base $=$ LILACS\&lang $=p \&$ next Action $=\operatorname{lnk} \&$ exprSearch $=758955$ \&indexSearch $=$ ID

Farias Júnior, J. C. de, Nahas, M. V., Barros, M. V. G. de, Loch, M. R., Oliveira, E. S. A. de, Bem, M. F. L. de, \& Lopes, A. da S. (2009). Comportamentos de risco à saúde em adolescentes no Sul do Brasil: prevalência e fatores associados. Retrieved from http://iris.paho.org/xmlui/handle/123456789/9 857

Feijo, R. B., \& Oliveira, E. A. de. (2001). Comportamento de risco na adolescência. Retrieved from http://www.lume.ufrgs.br/handle/10183/54698

Fields, S. K., Collins, C. L., \& Comstock, R. D. (2010). Violence in youth sports: hazing, brawling and foul play. British Journal of Sports Medicine, 44(1), 32-37. https://doi.org/10.1136/bjsm.2009.068320

GECKOVA, A., TUINSTRA, J., PUDELSKY, M., KOVAROVA, M., VAN DIJK, J. P., GROOTHOFF, J. W., \& POST, D. (2001). Selfreported health problems of Slovak adolescents. Journal of Adolescence, 24(5), 635-645. https://doi.org/10.1006/jado.2001.0422

Guedes, D. P., \& Lopes, C. C. (2010). Validation of the Brazilian version of the 2007 Youth Risk Behavior Survey. Revista de Saúde Pública, 44(5), 840-850. https://doi.org/10.1590/S003489102010000500009

Hallingberg, B., Moore, S., Morgan, J., Bowen, K., \& van Goozen, S. H. M. (2015). Adolescent male hazardous drinking and participation in organised activities: Involvement in team sports is associated with less hazardous drinking in young offenders. Criminal Behaviour and Mental Health, 25(1), 28-41. https://doi.org/10.1002/cbm.1912

Hartmann, D., \& Depro, B. (2006). Rethinking SportsBased Community Crime Prevention: A Preliminary Analysis of the Relationship Between Midnight Basketball and Urban Crime Rates. Journal of Sport and Social Issues, 30(2), 180-196. https://doi.org/10.1177/0193723506286863

Instituto de Segurança Pública (RJ). (2015). Dossiê criança e adolescente 2015. Retrieved from http://arquivos.proderj.rj.gov.br/isp_imagens/U ploads/DossieCriancaAdolescente2015.pdf

Johnson, K. E., \& McRee, A.-L. (2015). Health-risk behaviors among high school athletes and preventive services provided during sports physicals. Journal of Pediatric Health Care: Official Publication of National Association of Pediatric Nurse Associates \& Practitioners, 29(1), 17-27. https://doi.org/10.1016/j.pedhc.2014.05.007

Kreager, D. A. (2007). Unnecessary Roughness? School Sports, Peer Networks, and Male Adolescent Violence. American Sociological Review, $72(5)$,

705-724. 
$60 \mid$ MGD Oliveira, KRO Batista, FS Nery, JO Couto, NMM Soares, RJS Silva

https://doi.org/10.1177/000312240707200503

Moreira, B. S. (2009). Linguagem Corporal: Formas Negociadas Contra Agressões Do Meio. Quaestio: Revista de Estudos Em Educação, 8(1).

ORGANIZAÇÃO MUNDIAL DA SAÚDE; KRUG, Etienne G. (2002). Relatório mundial sobre violência e saúde. Retrieved from https://www.opas.org.br/wpcontent/uploads/2015/09/relatorio-mundialviolencia-saude.pdf

Papaioannou, A., Karastogiannidou, C., \& Theodorakis, Y. (2004). Sport involvement, sport violence and health behaviours of Greek adolescents. European Journal of Public Health, $14(2)$, $168-172$. https://doi.org/10.1093/eurpub/14.2.168

Pena, G. das G., Mendes, J. C. L., Silveira, A. P. da, Martins, T. C. R., Vieira, R. G., Silva, S. e, ... Silva, R. R. V. (2016). Comportamentos de risco para a saúde de adolescentes da rede pública de ensino. Adolesc. Saúde (Online), 36-50.

Rolim, M. (2008). Mais educação, menos violência: caminhos inovadores do programa de abertura das escolas públicas nos fins de semana. Retrieved from http://bibliotecadigital.puccampinas.edu.br/services/ebooks/178542por.pdf

Saner, H., \& Ellickson, P. (1996). Concurrent risk factors for adolescent violence. Journal of Adolescent Health, 19(2), 94-103. https://doi.org/10.1016/1054-139X(96)001310

Scholes-Balog, K. E., Hemphill, S. A., Kremer, P. J., \& Toumbourou, J. W. (2016). Relationships Between Sport Participation, Problem Alcohol Use, and Violence: A Longitudinal Study of Young Adults in Australia. Journal of Interpersonal
Violence, $31(8)$ 1501-1530. https://doi.org/10.1177/0886260514567962

Silva, R. J., Santos, N. D., Soares, N. M. M., Cabral de Oliveira, A., C\&\#xe9, N., \& sar. (2014). Factors Associated with Violent Behavior among Adolescents in Northeastern Brazil. The Scientific World Journal, 2014, e863918. https://doi.org/10.1155/2014/863918

Sønderlund, A. L., O’Brien, K., Kremer, P., Rowland, B., Groot, F. D., Staiger, P., ... Miller, P. G. (2014). The association between sports participation, alcohol use and aggression and violence: A systematic review. Journal of Science and Medicine in Sport, 17(1), 2-7. https://doi.org/10.1016/j.jsams.2013.03.011

Spruit, A., Vugt, E. van, Put, C. van der, Stouwe, T. van der, \& Stams, G.-J. (2016). Sports Participation and Juvenile Delinquency: A Meta-Analytic Review. Journal of Youth and Adolescence, 45(4), 655-671. https://doi.org/10.1007/s10964-0150389-7

Taliaferro, L. A., Rienzo, B. A., \& Donovan, K. A. (2010). Relationships between youth sport participation and selected health risk behaviors from 1999 to 2007. The Journal of School Health, 80(8), 399-410. https://doi.org/10.1111/j.17461561.2010.00520.x

Terry-McElrath, Y. M., O’Malley, P. M., \& Johnston, L. D. (2011). Exercise and Substance Use Among American Youth, 1991-2009. American Journal of Preventive Medicine, 40(5), 530-540. https://doi.org/10.1016/j.amepre.2010.12.021

World Health Organization. (1995). Physical Status: The Use and Interpretation of Anthropometry. Retrieved from http://apps.who.int/iris/bitstream/10665/3700 3/1/WHO_TRS_854.pdf 


\title{
Assessment of Brazilian jiu-jitsu related injuries by severity, type and area
}

\author{
Adonai Pinheiro Barreto ${ }^{1,2}$, Walderi Monteiro da Silva2,3, Natanael Sena Santos ${ }^{4}$, Dihogo \\ Gama de Matos ${ }^{5}$, Diego José Lopes de Lima ${ }^{6}$, Marcelo Danillo dos Santos ${ }^{2,5}$, Alexandre Reis \\ P. Ferreira ${ }^{5}$, Raphael Fabrício de Souza ${ }^{4,7}$, Andres Armas Alejo ${ }^{2,5}$, Felipe J Aidar ${ }^{2,5,7,8}$ \\ ARTIGO ORIGINAL | ORIGINALARTICLE
}

\begin{abstract}
Brazilian jiu-jitsu (Bjj) is a martial art that uses falls and joint locks to submit an opponent. The objective of this present article is to determine the incidence and describe the most common types and severity of injuries in $\mathrm{Bjj}$ athletes, related to their level of practice. We evaluated 126 male athletes $(26,0 \pm 7,93)$, at the University Hospital, Department of Orthopedic Surgery and Physical Therapy at Federal University of Sergipe. Regarding their belt levels we had the following data: blue (33,3\%), purple $(20,6 \%)$, white $(22,2 \%)$, black $(13,6 \%)$ e brown $(10,3 \%)$. The mean years of practicing was $5,77 \pm 5,07$, and the mean frequency of training days were 4,82 $\pm 1,70$ per week with training sessions of $2,4 \pm 1$ hour long, each. An inclusion criterion was a minimum of 2 years experience in Bjj. The difference was not statistically significant in frequency of practices among the groups categorized by belt rank. Ligament sprain was the most frequent injury found, ranging from mild to severe. These lesions occurred most often during practice than during tournaments. The most frequent sites of injuries were shoulder and knee.

Keywords: Brazilian jiu-jitsu; Sports injuries; Martial Arts.
\end{abstract}

\section{INTRODUTION}

Brazilian jiu-jitsu is a modern combat martial art that uses takedowns and joint locks to submit an opponent. (Scoggin et al, 2014; Jones et al, 2012; Andreato et al, 2015)

Nonetheless, during practice and tournaments, it has been reported several musculoskeletal injuries, where Pinto et al (2004) reported a high incidence of articular lesions among fighters. On top of that, Jensen et al (2017), reported that Brazilian jiu-jitsu is a practice with an increased risk of damage to the joint segment.

Within the same though, person-to-person combat sports, notably the ones requiring most full contact, such as BJJ, Judo and collegiate wrestling, end up leading to more physical exhaustion proportioning the development of more orthopedic-related injuries. (Agel et al 2007, Jarret et al 1998, Pasque \& Hewett 2000, Snook 1982, Llinás et al, 2016; Jensen et al, 2017) However, more sustainable medical literature is needed regarding combat sports-related injuries. (Jarret et al 1998, Pasque \& Hewett 2000, Scoggin et al, 2014; Drury et al, 2017)

Thus, the objective of this present study was to evaluate the most common types and severity of injuries in Bjj athletes, related to their level of practice and belt rank.

\footnotetext{
${ }^{1}$ Department of Orthopedics of the University Hospital of the Federal University of Sergipe, Aracaju, SE, Brazil.

${ }^{2}$ Graduate Program in Physical Education, Federal University of Sergipe.

${ }^{3}$ Department of Physical Therapy, Hospital Universitário Federal University of Sergipe, Aracaju, SE, Brazil.

${ }^{4}$ Student of Medicine, Federal University of Sergipe, São Cristóvão-SE, Brazil.

${ }^{5}$ Performance Study Group, Sports, Paralympic Sports and Health, GEPEPS, Federal University of Sergipe, UFS, São Cristovão, Sergipe, Brazil.

${ }^{6}$ Department of Orthopedics and Traumatology, University Hospital of Taubaté, Taubaté, SP, Brazil

${ }^{7}$ Department of Physical Education, Federal University of Sergipe, São Cristóvão, Sergipe, Brazil.

${ }^{8}$ Graduate Program in Master and Doctorate's level in Physiology Science, Federal University of Sergipe, UFS, São Cristovão, Sergipe, Brazil, Florianópolis, Brasil

* Corresponding author: Department of Physical Education, Federal University of Sergipe, São Cristóvão, Sergipe, Brazil. E-mail: fjaidar@gmail.com
} 


\section{METHODS}

We evaluated 126 Brazilian jiu-jitsu male athletes $(26,0 \pm 7,93)$. The consults took place at University Hospital, Department of Orthopedic Surgery and Physical Therapy at Federal University of Sergipe. Most of them were blue belt $(33,3 \%)$, followed by white belt $(22,2 \%)$, purple belt $(20,6 \%)$, black belt $(13,6 \%)$ and brown belt $(10,3 \%)$. The mean years of practicing was $5,77 \pm 5,07$, and the mean frequency was 4,82 $\pm 1,70$ days of training per week with training sessions of 2,4 \pm 1 hour long, each.

As criterion of inclusion, it was required a minimum of two years experience of practice. All participants were evaluated by a board certified orthopedic surgeon, including the history of the present illness to verify the existence of orthopedic related injuries, history of previous lesions, mechanism and setting of the last injury, if caused by self or not, severity and previous treatments.

We followed a specific protocol regarding ethics in research with humans according to resolution $\mathrm{n}^{\mathrm{o}} 466$, from $12 / 12 / 2012$ of the Health National Department, enforced research laws involving humans, in agreement with ethic principals from the Helsinki's Declaration (1964, modified in 1975, 1983, 1989, 1996, 2000 and 2008), of "World Medical Association".

The athletes gave their were oral and written consent.

Table 1

Injury Severity Scale

\begin{tabular}{lc}
\hline Severity & Time away from practice \\
\hline Mild & No missing time \\
Mild to moderate & 1 to 2 days \\
Moderate & Up to 2 weeks \\
Moderate to severe & 2 to 4 weeks \\
Severe & Hospitalization or more \\
& than 4 weeks \\
\hline
\end{tabular}

Source: Birrer (1996)

\section{Instruments}

From the severity stand point, we categorized according to the International Injuries Registration Severity Scale cited by Birrer (1996), stratified as mild, mild to moderate, moderate, moderate to severe and severe. (Table 1).

\section{Procedures}

All of our data were obtained based on the demand of the Department of Orthopedic Surgery and Physical Therapy at Federal University of Sergipe. Our department is a reference in orthopedic and trauma care to athletes in many modalities in Sergipe, such as full contact sports, volleyball, gymnastics, soccer, etc.

\section{Statistics}

The statistical analyses were performed using the Statistical Package for the Social Science (SPSS), version 22.0, including the measures of mode, median, mean \pm standard deviation $(\mathrm{M} \pm \mathrm{SD})$. In order to verify the variable normality, it was utilized the Kolmogorov Smirnov test Kolmogorov Smirnov, considering the sample size. We used ANOVA (two way), Post Hoc of Bonferroni, to check the possible differences among groups split by age. To measure the size of effect, it was utilized the Cohen $\mathrm{f} 2$ test, with scores ranging from 0,02 a 0,15 as little effect, 0,15 a 0,35 as moderate and more than 0,35 as great (Grissom e Kim 2005). (p < 0,05)

\section{RESULTS}

Table 2 summarizes the correlation between the frequency of practice and experience by belt level. Table 3 represents the severity, setting, area and type of injury stratified by belt level in Bjj athletes.

Table 2

Hours of practice in a week and experience by belt level in BJJ athletes (Mean $\pm S D)$

\begin{tabular}{lcccc}
\hline Belt level & Hours/week & Experience & $\mathrm{p}$ & $f^{2}$ Cohen \\
\hline White & $10,26 \pm 10,25$ & $1,46 \pm 0,79$ & 0,096 & 0,152 \\
Blue & $11,91 \pm 8,80$ & $3,94 \pm 2,12$ & 0,931 & 0,012 \\
Purple & $13,40 \pm 6,42$ & $6,34 \pm 2,90$ & 0,084 & 0,132 \\
Brown & $10,54 \pm 5,74$ & $9,77 \pm 5,02$ & 0,123 & 0,091 \\
Black & $14,29 \pm 7,18$ & $15,18 \pm 3,76$ & 0,054 & 0,149 \\
\hline
\end{tabular}


Table 2

Type, severity, setting and site of injury correlated to the belt level in Bjj athletes.

\begin{tabular}{|c|c|c|c|c|}
\hline Level & Type & Severity & Setting & Area \\
\hline White & Sprain & Mild/severe & Practice & Shoulder/knee \\
\hline Blue & Sprain & Mild/severe & Practice & Shoulder/knee \\
\hline Purple & Sprain & Mild/severe & Practice & Shoulder/knee \\
\hline Brown & Sprain & Mild/severe & Practice & Shoulder/knee \\
\hline Black & Sprain & Mild/severe & Practice & Shoulder/elbow \\
\hline
\end{tabular}

\section{DISCUSSION}

From the training hours stand point, our data showed that despite of the lack of difference between subjects in different belt ranks, black belt athletes tend to practice longer hours than less experienced fighters. Nevertheless, all subjects demonstrated a mean practicing time of 10 to 14 hours a week.

Some authors report that more experienced athletes is more prone of having injuries caused by their practice (Oliveira et al 2010, Rainey 2009), and that makes them more vulnerable of having worse injuries and chronic lesions. On the other hand, Rainey et al (2009) found just the opposite relation among MMA fighters. Less experienced athletes showed a larger number of combat-related injuries than more experienced ones. This relationship between experience and number of injuries has been described very often. (Lystad et al 2015, 2013, Buse 2006, Barroso et al 2011, Ramos et al 2015)

Confirming our study, some authors have shown a high rate of injuries (70-82\%) during practicing sessions. (Buse 2006, Loosemore et al 2006)

Barsottini et al (2006) described an incidence of $71 \%$ of orthopedic injuries during practicing. At the same time, Corso CO \& Gress FAG, (2012) reported that $90 \%$ of fighters have been injured during a practice session of Bjj. Oliveira et al., (2010) agreed with those authors saying that most of the lesions occurs on a practice setting.

Regarding the area of injuries, severity and type, our study demonstrates mild or severe, mostly ligament sprains and the most common affected sites are shoulder and knees, excepted for black belts where the location changes to shoulder and elbows. Other lesions that might be caused by practicing $\mathrm{Bjj}$ are contusion, dislocation, fracture and muscle strain. Studies show that the most frequent injury is ligament tear (sprain) affecting $61,5 \%$ of athletes, meanwhile the least frequent lesion is muscular distension affecting $2,6 \%$ of them. (Souza et al 2011) McPherson \& Pickett (2010) assessed 46 Brazilian jiu-jitsu fighters where most of them presented with ligament sprain. Oliveira et al., (2010) realized most of the subjects evaluated had shown dislocation injuries, as opposed to the small number of fractures $(5,26 \%)$ among black belt athletes. Guedes (2009), has also assessed the most common lesions and he has found a $52 \%$ rate of dislocation, followed by ligament sprain $(21 \%)$ and fracture $(21,1 \%)$.

From the body area wise, the most prevalent locations were the shoulder $(21,7 \%)$ and knee $(20,5 \%)$ followed by hand, ankle, elbow, foot and wrist. It is also remarkable that the upper extremity has been more affected by it (52\%). Scoggin et al. (2004), had described as the elbow the most prevalent location for lesions. Kreiswirth et al. (2014), had obtained in their study, $64,5 \%$ of the injuries at the upper extremity, involving the elbow and knee. Baffa \& Barros (2002) highlighted the knee as the most frequent location of injuries in the body with $37,5 \%$. The shoulder joint was the most prevalent (16,7\%) of injuries by Corso et al., (2012)

\section{CONCLUSION}

We observed no statistically difference between the frequency of practicing in between the groups categorized by belt level.

Ligament sprain was the most prevalent lesion found, mostly mild or severe. Regarding the setting where the injuries had occurred, practice sessions were where it happened the most in 
comparison to tournaments. And the body regions most affected by lesions were shoulder and knee.

\section{Acknowledgments: \\ Nothing to declare}

Conflict of interests:

Nothing to declare

\section{Funding:}

Nothing to declare

\section{REFERENCES}

Agel J, Ransone J, Dick R, Oppliger R, Marshall SW. (2007) Descriptive epidemiology of collegiate men's wrestling injuries: National Collegiate Athletic Association Injury Surveillance System, 1988-1989 through 2003-2004. J Athl Train. 42, 303-10.

Andreato LV, Julio UF, Gonçalves PVL, Conti EJV, Hardt F, Franzói MSM, Oliveira SC, Franchini E. (2015) Brazilian Jiu-Jitsu Simulated Competition Part II: Physical Performance, Time-Motion, Technical-Tactical Analyses, and Perceptual Responses. Journal of Strength and Conditioning Research. 29(7), 2015-2025.

Baffa AP, Barros JEA. (2002) As principais lesões no jiu-jitsu. Fisioter. Bras. 3, 377-81.

Barroso BG, Silva JMA, Garcia AC, Ramos NCO, Martinelli MO, Resende VR, Júnior AD, Santili C. (2011) Lesões Musculoesqueléticas em Atletas de Luta Olímpica. Acta Ortop Bras. 19(2), 98-101.

Barsottini D, Guimarães A, Morais P. (2006) Relação entre técnicas e lesões em praticantes de judô. Revista Brasileira de Medicina do Esporte, 12(1), 5660.

Birrer RB. (1996) Trauma epidemiology in the martial arts. The results of an eighteen-year international survey. Am J Sports Med. 24(6 Suppl), S72-9.

Buse GJ. (2006) No holds barred sport fighting: a 10 year review of mixed martial arts competition. $\mathrm{Br}$ J Sports Med. 40, 169-172.

Corso CO, Gress FAG. (2012) Lesões no jiu-jítsu. Rev. Acta Brasileira do Movimento Humano, 2(3), 11-20.

Drury BT, Lehman, TP, Rayan G. (2017) Hand and Wrist Injuries in Boxing and the Martial Arts. Hand Clinics. 33(1), 97-106.

Grindstaff TL, Potach DH. (2005) Prevention of common wrestling injuries. Strength Cond J. 28, 20-8.

Grissom RJ e Kim JJ (2005). Effect sizes for research: A broad practical aproach. Psycology Press: New York.

Guedes RC. (2009) Prevalência de lesões de punho e mão em atletas praticantes de jiu-jitsu. Trabalho de conclusão de curso (graduação), Universidade do Extremo Sul Catarinense. Criciúma.

Jarret GJ, Orwin JF, Dick RW. (1998) Injuries in collegiate wrestling. Am J Sports Med. 26, 674-80.

Jensen AR, Maciel RC, Petrigliano FA, Rodriguez, JP, Brooks AG. (2017) Injuries Sustained by the Mixed Martial Arts Athlete. Sports Health: A Multidisciplinary Approach. 9(1), 64-69.

Jones N, Ledford E. (2012) Strengh and Conditioning for Brazilian Jiu jitsu. Strengh and Conditioning Journal. 34(2), 60-69.

Kreiswirth EM, Myer GD, Rauh MJ. (2014) Incidence of injury among male Brazilian jiujitsu fighters at the World Jiu-Jitsu No-Gi Championship 2009. J Athl Train. 49(1), 89-94.

Llinás PJ, Serrano RF, Barrera LQ, Noguera JCQ, Cano JPM. (2016) Sports injuries and ill-health episodes in the Cali 2013 World Game. BMJ Open Sport Exerc Med. 2(1), e000072.

Loosemore M, Lightfoot J, Palmer-Green D, Gatt I, Bilzon J, Beardsley C. (2015) Boxing injury epidemiology in the Great Britain team: a 5-year surveillance study of medically diagnosed injury incidence and outcome. Br J Sports Med. 49, 11001107.

Lystad RP, Graham PL, Poulos RG. (2015) Epidemiology of training injuries in amateur taekwondo athletes: a retrospective cohort study. Biol Sport. 32, 213-218.

Lystad RP, Graham PL, Poulos RG. (2013) Exposureadjusted incidence rates and severity of competition injuries in Australian amateur taekwondo athletes: a 2-year prospective study. Br J Sports Med. 47, 441-446.

McPherson M, Pickett W. (2010) Characteristics of martial art injuries in a defined Canadian population: a descriptive epidemiological study. BMC Public Health. 10,795.

Oliveira EG,Oliveira RRC, Silva KAF. (2010) Prevalência e incidência de lesões em atletas participantes do campeonato open de jiu-jitsu da cidade de catalão-go realizado em agosto de 2010. Saúde CESUC.

Pasque CB, Hewett TE. (2000) A prospective study of high school wrestling injuries. Am J Sports Med. 28(4), 509-15.

Pinto AMD, Ferreira CAA, Costa FCH. (2004) Incidência de lesões traumáticas em praticantes de Jiu-Jitsu em uma academia do estado do Rio de Janeiro. Rev Bras Med Esporte. 10(1), 5-11.

Rainey CE. (2009) Determining the prevalence and assessing the severity of injuries in mixed martial arts athletes. N Am J Sports Phys Ther. 4(4), 190-9.

Ramos SMP, Oliveira AS. (2015) Lesões em Atletas de Judô: Revisão Sistemática. Corpussci, 11(2), 46-54.

Scoggin JF, Brusovanik G, Izuka BH, Zandee van Rilland E, Geling O, Tokumura S. (2014) Assessment of injuries during Brazilian jiu-jitsu competition. Orthop J Sports Med. 2(2), 2325967114522184 
Snook GA. (1982) Injuries in intercollegiate wrestling. A 5-year study. Am J Sports Med. 10, 142-4.

Souza JMC,Faim FT,Nakashima IY,Altruda CR,Medeiros WM,Silva FR. (2011) Lesões no
Karate Shotokan e no Jiu-Jitsu - Trauma Direto Versus Indireto. Rev Bras Med Esporte. 17(2), 107110.

(c) () () All content of Journal Motricidade is licensed under Creative Commons, except when otherwise specified and in content retrieved from other bibliographic sources. 


\title{
Acute cardiovascular response of a vertical techniques training session
}

\author{
Carla Fabiane dos Santos Lemos ${ }^{1 *}$, Victor Matheus Santos do Nascimento ${ }^{1}$, Layanne de \\ Oliveira Barros ${ }^{1}$, Luís Paulo de Souza Gomes ${ }^{1}$, Nara Michelle Moura Soares ${ }^{1}$
}

\begin{abstract}
Abseiling has become a radical sport that can be practiced anywhere, as long as the necessary safety is provided. Websites that offer the technique report that practicing it requires the minimum age of eight years. The objective this study was to verify the response of BP, HR and DP in individuals practicing abseiling. The sample consisted of 15 asymptomatic individuals aged $24( \pm 7)$ years, with no prior experience in the technique. Individuals with positive PAR-Q and those using medications that altered the physiological responses during the tests were excluded. Data were evaluated through descriptive statistics and through ANOVA, analysing the significant differences through Bonferroni post-hoc. About $80 \%$ of participants presented mild to moderate hypertension and $20 \%$ of individuals had optimal to normal-high $\mathrm{BP}$ on the descent. In pre-exercise, an increase in all variables $(\mathrm{p}<0.001)$ was observed, in relation to the previous moment. In post-exercise, there was a reduction of all data $(7-21 \%)$ in relation to pre-exercise, and only HR increased 7\%, demonstrating significance for SBP and DBP ( $p<0.001)$. The reduction of these variables in the post-exercise is related to the stress relief of the physiological system, which increased due to physical effort.

Keywords: Abseiling, cardiovascular changes, training
\end{abstract}

\section{INTRODUCTION}

Abseiling is the technique practiced in descending using ropes meaning to bring and to recover (NAZARI, 2007). Before being a sport, it emerged as a technique used by speleologists to search for caves and to access inaccessible places, and is currently considered a radical sport (FIGUEIRÔA, 2007).

The vertical technique was first used in 1879 during the conquest of the Petit Dru in France (NAZARI, 2007). For being a risky activity, cotton ropes have been replaced by specialized and more resistant equipment. It can now be practiced anywhere, providing it is safe and according to the individual's level of ability (MCLAREN, 2006). However, it is imperative to choose a trained, experienced professional with knowledgeable on the site to assist in case of accidents. It is also fundamental to check the equipment, since its quality will protect the individual's integrity (RABELLO, 2003).
Websites that offer the technique report that the minimum age to practice it is only eight years (MOREIRA, 2008). However, there is a gap regarding the physiological conditions of the individual, among them, blood pressure, heart rate and some cardiovascular diseases.

The evidence indicates that between the years of 2000 and 2006, there was a tenfold increase in the number of accidents in relation to the 1990s (ASSOCIAÇÃO BRASILEIRA DE RAPEL DO RIO DE JANEIRO, 2010). However, it is not known if some of these accidents may have occurred due to a lack of physical fitness.

Considering the increase of cardiovascular accidents in physical activity and the fact that abseiling is a sport that involves risks to physical integrity, it is necessary to observe the cardiovascular behavior of individuals who adopt the sport as sporadic practice in order to try to reduce the number of accidents.

The literature points out as a criterion of inclusion in sport only the age, leaving a gap

\footnotetext{
${ }^{1}$ Tiradentes University, Aracaju, Brazil

* Corresponding author: Laboratório de Biomotricidade Humana, Coordenação de Educação Física, Universidade Tiradentes, Campus Farolândia - Bairro Farolândia. CEP: 49032-490. Aracaju/SE, Brazil. E-mail: carla_fabiane.tec.alimentos@hotmail.com
} 
between other criteria that should be adopted. The evidence also indicates that the systematized physical activity assists in the physiological conditioning of the individual, and may be an alternative to supply the debt of sporadic practice. Thus, the aim of this study was to verify the response of blood pressure (BP), heart rate (HR) and double-product (DP) in individuals practicing vertical techniques.

\section{METHODS \\ Sample}

The subjects of this study were 15 individuals of both genders (four women), aged $24( \pm 7$ ) years, participants of the Tribo da Serra group. The sample of this study was selected in a nonprobabilistic and intentional way. Exclusion criteria were positive PAR-Q (SHEPHARD, 1988) and use of medications that could alter physiological responses during the tests.

The sample participated in a vertical techniques training session lasting 4 hours. In order to compose it, individuals should not have participated, at any other time, in vertical techniques training, regardless of whether they participated in other activities, such as: trekking, hikking, rafting, parachuting and others. Participants should not have family history of hypertension, cardiac arrhythmias or bradycardia.

These individuals were part of classes of the theoretical course on the technique and were not adapted to training. However, this study did not evaluate the level of physical activity of subjects.

The group has an internal regiment, where it is a duty of members and guests to sign a free and informed consent form, informing them of the hazards involved in the activity, even though all participants were informed and clarified about the risks involved in the experiment, being invited to sign a consent form, in accordance with Law 196/96.

The project was submitted to the Ethics Committee for Research with Human Beings of the University Hospital of the Federal University of Sergipe and was approved under protocol No. $31 / 2009$.

\section{Procedures}

Data collected were age, gender, anamnesis, PAR-Q, HR, BP and DP. Blood pressure assessment to measure cardiac status was compared to reference values suggested by the British Hypertension Society Guidelines IV (2004) (WILLIAMS et al., 2004).

Evaluations were carried out in three different moments: a) before descent, b) when "clipped" to the apparatus, positioned for descent and, c) after having completed it. Positive Physical Activity Readiness Questionnaire (PAR-Q) corresponds to at least one positive response among the seven items presented. This positive affirmation would bring the individual to a medical evaluation. Data collection was performed in only one training session, scheduled according to group availability.

Before performing the training, individuals were given instructions on how they should proceed and then HR and BP were checked (by a digital TechLine ${ }^{\circledR}$ device), and then participants were asked to complete the course. At the end of the course, another evaluator recorded the information and reassessed BP and HR. Finally, the double-product was calculated by multiplying the systolic blood pressure by the heart rate.

\section{Statistical analysis}

Data were evaluated through descriptive statistics with mean, standard deviation, maximum and minimum and through ANOVA, analyzing significant differences through Bonferroni post-hoc. The statistical analysis of data was observed through the Statistical Package for the Social Science software (SPSS) version 15 for Windows. A significance level of $5 \%$ was adopted.

\section{RESULTS}

Initially, it is necessary to demonstrate the characteristic of the sample by descriptive statistics. Data obtained were the results of anamnesis, which identified age, gender, presence of stress, smoking habit, use of medications and PAR-Q. Thus, $47 \%$ of individuals reported frequent stress. All subjects 
reported being asymptomatic in relation to diseases such as diabetes, stroke, hypertension, coronary diseases and others, not users of betablockers, not smokers and with no family history of cardiovascular diseases.

It is worth mentioning that $80 \%$ of individuals had mild to moderate hypertension and $20 \%$ of individuals presented optimal to normal high blood pressure on the descent, according to reference values suggested by the British Hypertension Society Guidelines IV (2004), as summarized in table 1 .

Table 1

Comparison of blood pressure levels of individuals participating in vertical techniques training according to the British Hypertension Society

\begin{tabular}{lcccc}
\hline Category & SBP $(\mathrm{mmHg})$ & DBP $(\mathrm{mmHg})$ & $\mathrm{N}_{(\mathrm{c})}$ & $\mathrm{N}_{(\mathrm{t})}(\%)$ \\
\hline Optimal BP & $<120$ & $<80$ & 1 & 3 \\
Normal BP & $<130$ & $<85$ & 1 & $(20)$ \\
Normal-high BP & $130-139$ & $85-89$ & 1 & 12 \\
\hline HD 1 (mild) & $140-159$ & $90-99$ & 9 & $(80)$ \\
HD 2 (moderate) & $160-170$ & $100-109$ & 2 & 1 \\
HD 3 (severe) & $=180$ & $=110$ & 109
\end{tabular}

BP - Blood pressure; SBP - Systolic blood pressure; DBP - Diastolic blood pressure, HD - Hypertension degree, $\mathrm{N}_{(c)}-$ number of individuals per category, $\mathrm{N}_{(\mathrm{t})}$ - total number of individuals per category

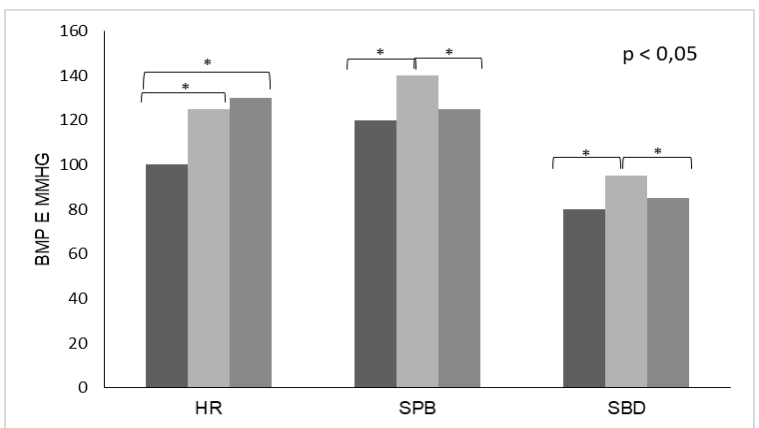

Graph 1. Comparison of HR, SBP and DBP at the three moments of evaluation

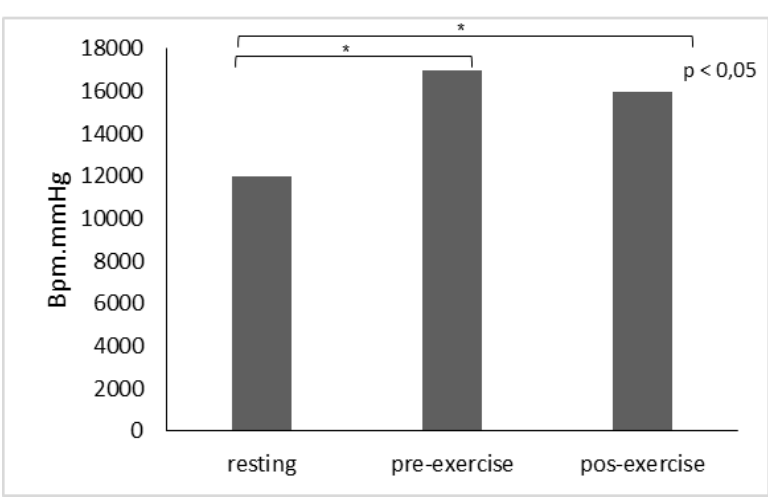

Graph 2. Comparison of DP at the three moments of evaluation

In pre-exercise, there was an increase in all variables $(\mathrm{p}<0.001)$, in relation to rest (Graph 1). In post-exercise, there was a reduction of all data $(7-21 \%)$, compared to pre-exercise, and only HR increased by $7 \%$, demonstrating significance for all variables $(p=0.0001)$. In general, HR and
DP (Graph 2) were increased by 25\% ( $\mathrm{p}=$ $0.0001)$, reducing DBP (8\%) and maintaining SBP.

It was detected through the Bonferroni post hoc that in HR and DP, there was no difference between pre- and post-exercise. However, SBP and DBP did not detect difference between rest and post-exercise.

\section{DISCUSSION}

The aim of this study was to verify the blood pressure, heart rate and double-product response in individuals practicing vertical techniques, whose concern is justified by the cardiovascular alteration in individuals submitted to nonphysiological stress. In this sense, it presents limitations inherent to cross-sectional studies. Although the results identify pseudoassociations, they do not characterize cause and effect relationships, they only represent a segment of the population, without, however, identifying factors that led to the observed results.

The study showed that most individuals had elevated blood pressure on the descent. This sharp rise, according to Negrão et al. (2001), is due to adrenaline and noradrenaline hormones that accelerate the depolarization of the AS nodule, causing the heart to beat faster 
(chronotropic effect), increasing the pressure in arteries and also increasing the myocardial contractility (inotropic effect) with the objective of regulating the amount of blood with each beat. In addition, this sympathetic stimulation affects blood flow, producing vasoconstriction and elevating HR, along with the parasympathetic action (ALMEIDA and ARAÚJO, 2003).

The chronotropic response reported by Negrão et al. (2001) is an excellent indicator of health during exercise (ALMEIDA, 2003), since values that do not reach $85 \%$ of the maximum predicted HR for age are considered heart failure. This anomaly is present in $11 \%$ to $26 \%$ of healthy middle-aged adults (DE ALMEIDA, 2007).

Data also showed an elevation in HR that can be attributed to non-physiological emotional stress. According to Lima et al. (2012), the increase in heart rate during exercise is mainly mediated by the sympathetic nervous system, whose action allows the release of catecholamines and increase in the permeability of sodium and calcium in the heart muscle. Curtis and O'Keefe (2002) stated that sympathetic activation usually occurs in response to emotional stress, but the body is prepared to respond to physical training, since the increase in sympathetic tonus that occurs with exercise is physiological and raises the physical work capacity. Increased non-physiological stress, as shown in our study, increases the risk of cardiovascular events, thus, normal sympathetic physiological activation promotes physical conditioning and cardiovascular prognosis (PONTES et al., 2010). In the initial transient of the exercise, there is a reduction of the cardiac vagal activity and subsequent increase of the adrenergic stimulation, increasing $\mathrm{HR}$ (DE ALMEIDA, 2007). In the final transient, that is, in the post-exercise recovery, an inverse pathway of the autonomic action can be observed, restoring vagal activity (especially in the initial 30 s) (IMAI et al., 1994), and then a reduction of sympathetic influence.

HR may have increased due to the predominance of static force during exercise. The sustained contraction of isometric exercise compromises blood and oxygen supply to contracting muscle tissue, and thus, HR increases linearly with increased need for higher oxygen consumption (GANDEVIA and HOBBS, 1990). According to Figueiredo (2016), exercise intensity control can monitor cardiovascular stress, and provide important information on the level of adaptation of loads.

The literature on the subject is scarce, which led to restrictions in the comparison of results. In this context, Figueiredo (2002) carried out a research with individuals of university age with the objective of evaluating the way in which abseiling induces stress in a $20-\mathrm{m}$ wall descent. The somatic anxiety presented high values, and HR presented a rise before the descent. An interesting aspect was the possibility of performing the laboratory analysis of noradrenaline concentrations before and after the activity. The serum increase observed in this neurotransmitter proves the stress through the activation of sympathetic SN translated by the increased serotonin.

Despite the 133-m height of abseiling descent and in addition to evaluating only the acute cardiovascular response to training, our data corroborate the results of Figueiredo (2002), regarding the HR behavior. The study by Figueiredo (2002) does not make it clear if individuals who performed the training had prior experience on the technique, which makes a differential mark in our research. The fact that they do not have prior experience can generate greater stress and promote a more effective increase in cardiovascular variables (MACE, CARROLL and EASTMAN, 1986). It is worth mentioning that the present study presented some limitations, among them we can emphasize that it was not possible to evaluate the anxiety level or the serum concentration of hormones during the abseiling descending. However, we considered that blood dosage prior to the descending event could become a further determinant of increased stress in individuals. 


\section{CONCLUSION}

Within the intrinsic and extrinsic limitations and characteristics of this study, our findings allow us concluding that: a) at the peak of the descent, HR, BP and DP values increased substantially; b) the reduction of these variables in relation to the arrival may be related to the stress relief of the physiological system, with the exception of HR, which was elevated due to physical effort, by controlling the descent speed from muscular contractions, often of high static component.

It should be recommended that individuals, when engaging in the practice of vertical training, should perform physical and functional assessments to minimize the risk of cardiovascular events. However, the adoption of an inclusion criterion in the technique becomes necessary, given the number of accidents reported in literature. Further studies including larger numbers of individuals and questions about physical activity levels should be conducted.

\section{Acknowledgments:}

Nothing to declare

\section{Conflict of interests:}

Nothing to declare

\section{Funding:}

Nothing to declare

\section{REFERENCES}

Almeida, M.B.; Araújo, C.G.S. (2003) Effects of aerobic training on heart rate. Revista Brasileira de Medicina do Esporte, 9(2), 113-120.

Associação Brasileira De Rapel Do Rio De Janeiro. www.rapelradical.com. [online] [citado $2010 \mathrm{fev}$ 23]. disponível em: url: <http://www.rapelradical.com/html/oquerapel. asp? sessao $=1>$. Acesso em: 28 de agosto De 2017.

Curtis, B. M.; O'keefe, J. H. (2002) Autonomic tone as a cardiovascular risk factor: the dangers of chronic fight or flight. In: Mayo Clinic Proceedings. Elsevier.

De Almeida, M.B. (2007) Frequência cardíaca e exercício: uma interpretação baseada em evidências. Revista Brasileira de Cineantropometria e Desempenho Humano, 9(2), 196-202.

Figueiredo, A.P. (2016) Comportamento da variabilidade da frequência cardíaca em teste com cargas progressivas. Conexão Ciência (Online), 11(1), 107-111.

Gandevia, S.C.; Hobbs, S.F. (1990) Cardiovascular responses to static exercise in man: central and reflex contributions. The Journal of Physiology, 430(1), 105-117.

Figueiredo, A.T.S.D. P. Stresse em actividades de lazer e aventura: avaliação na actividade de rappel. 2002. Dissertação De Mestrado. Disponível Em: $<$ Http://Hdl.Handle.Net/11449/96059>. Acesso Em: 28 de agosto de 2017.

Figueirôa, W.G. (2007) Cavernas: técnicas verticais e autoresgate. ( $1^{\mathrm{a}}$ Ed.) Piracicaba: s.n.

Imai $K 1$, Sato $H$, Hori $M$, Kusuoka $H$, Ozaki $H$, Yokoyama $\mathrm{H}$, Takeda $\mathrm{H}$, Inoue $\mathrm{M}$, Kamada $\mathrm{T}$. (1994) Vagally mediated heart rate recovery after exercise is accelerated in athletes but blunted in patients with chronic heart failure. Journal of The American College Of Cardiology, 24(6), 1529-1535.

Lima, J.R.P.; Oliveira, T.P.; Ferreira-Júnior, A.J. (2012) Pos-exercise cardiovascular autonomic recovery: review of the underlying autonomic mechanisms and clinical and sports relevance. Motricidade, $8(2), 419$.

Mace, R. D.; Carroll, D.; Eastman, C.L. (1986) Effects of stress inoculation training on self-report, behavioural and psychophysiological reactions to abseiling. Journal of Sports Sciences, 4(3), 229-236.

Mclaren, A. J. (2006) Design and performance of ropes for climbing and sailing. Proceedings of the institution of mechanical engineers, Part L: Journal of Materials: Design and Applications, 220(1), $1-12$.

Moreira, L. Rapel. www.bicodocorvo.com.br. [online] sd. [citado $2008 \mathrm{dez}$ 10]. disponível e: <url: www.bicodocorvo.com.br/saude/esporte/rapel> Acesso Em: 20 de agosto de 2017.

Nazari, J. Rapel: (2007) Na Perspectiva Vertical. Lecturas: Educación Física Y Deportes, 2007, 106.

Negrão, C.E.; Rondon, M.U.P.B. (2001) Exercício físico, hipertensão e controle barorreflexo da pressão arterial. Revista Brasileira de Hipertensão, 8(1), 89-95.

Pontes, J.R.F.L.; Prestes, J.; Leite, R.D. (2010) Influência do treinamento aeróbico nos mecanismos fisiopatológicos da hipertensão arterial sistêmica. Revista Brasileira de Ciências do Esporte; 32(2-4), 229-44.

Rabello L. Praticando rafting com segurança. Inema.com.br. [Online] 2003. [Citado $2008 \mathrm{Dez}$ 10] Disponível em: url:< http://inema.com.br/mat/idmat021710.html > Acesso em: 26 de agosto de 2017.

Shephard, R.J. (1988) PAR-Q, Canadian home fitness test and exercise screening alternatives. Sports Medicine, 5(3), 185-195. 
Williams, B.; Poulter, N.R.; Brown, M.J.; Davis, M.; Mcinnes, G.T.; Potter, J.F.; Server, P.S.; Thim, S.Mc. (2004) British Hypertension Society
Guidelines for Hypertension Management 2004 (Bhs-Iv): Summary. BMJ, 328(7440), 634-640.

c) (9) (9) All content of Journal Motricidade is licensed under Creative Commons, except when otherwise specified and in content retrieved from other bibliographic sources. 


\title{
Effects of resistance training the spasticity of the upper limb paretic of individuals with sequels of stroke
}

\author{
Aristela de Freitas Zanona ${ }^{1 *}$, Felipe J. Aidar ${ }^{1,2}$,Lais Araujo Andrade ${ }^{1}$, Ana Camila Nobre de \\ Lacerda Brito ${ }^{3}$, Dharah Puck Cordeiro Ferreira ${ }^{3}$, Dihogo Gama de Matos ${ }^{2}$, Raphael Fabricio \\ de Souza ${ }^{1,2,3}$
}

\begin{abstract}
The objective of the present study was to analyze the effects of a resistance training protocol on the reduction of spasticity of the brachii biceps muscle of the paretic upper limb of individuals after stroke. The sample consisted of nine individuals with stroke diagnosis, with spasticity (any degree) and muscle strength (minimum grade 2), allocated in 3 groups: group 1 (G1) undergoing traditional therapy, group 2 (G2) therapy Associated with a resistance training protocol and group 3 (G3) control. Spasticity (assessed by the modified Ashworth scale) was analyzed; Muscle strength (assessed by the Kendall test) and upper limb function (assessed by the Fulg Meyer scale). Ten sessions of Occupational Therapy were performed, twice a week for 50 minutes. The resisted exercises were performed in 3 sets of 20 repetitions with intervals of 2 minutes. There was an increase in the muscular strength of $\mathrm{G} 2(\mathrm{p}<0,001$; Hedges' $g=5,65)$, decreased spasticity G1 $(p=0,025$; Hedges' $g=17,75)$ and G2 $(p=0,003$; Hedges' $g=2,04)$ and improvement in motor function of $\mathrm{G} 1(\mathrm{p}=0,002$; Hedges' $g=12,52)$ and $\mathrm{G} 2(\mathrm{p}=0,001$; Hedges' $g=5,48)$. Resistance training associated with nutritional therapy to control spasticity is effective in decreasing the sequelae of this condition, increasing the strength and function of the upper limb.

Keywords: Resistance Training; Stroke; Muscular spasticity.
\end{abstract}

\section{INTRODUCTION}

The clinical manifestations of Cerebral Vascular Accident (CVA) occur according to the place of cerebral involvement, generating sensory, motor, perceptual and cognitive alterations. Among the motor deficits are physical deconditioning, muscular weakness, abnormal movement patterns and spasticity that compromise the occupational performance of the individual in the areas of occupation, limiting mainly activities of daily living (ADL) and instrumental activities of daily living (IADL) (Piassaroli, Almeida, Luvizotto, \& Suzan, 2012).

Spasticity is characterized by hypertonia and hyperreflexia, secondary to an increase in the stretch reflex response, directly proportional to the rate of muscular distention, and has as pathophysiological mechanism the imbalance between the inhibitory and facilitative influences of the descending pathways that regulate muscle tone (Lianzaet al., 2001; Winstein et al., 2016). The main disabling potentials of spasticity are related to contractures, stiffness, dislocations, pain, deformities that cause impairment in carrying out the transfer activities and self care. In addition, because it impedes controlled, fast and rhythmic movement of spasticity, and all changes in praxis-motor skills almost always cause people with physical disabilities such as stroke to change their lifestyle, becoming more sedentary (Greve, 1994; Meythaler, 2001; Mayer, 2002).

\footnotetext{
${ }^{1}$ Universidade Federal de Sergipe, Sergipe, Brasil

${ }^{2}$ Performance Study Group, Sports, Paralympic Sports and Health - GEPEPS, Federal University of Sergipe - UFS, São Cristovão, Sergipe, Brazil.

${ }^{3}$ Universidade Federal de Pernambuco, Recife, Brasil

* Autor correspondente: Departamento de Terapia Ocupacional,Universidade Federal de Sergipe, Campus Universitário - Lagarto . Av. Governador Marcelo Déda, 13, Centro. Caixa Postal 476. CEP: 49400-000. Lagarto/SE, Brasil. E-mail: arisz_to@yahoo.com.br
} 
On the other hand, the practice of physical activity can be indicated for these patients, since the improvement in the strength of the trained muscles does not increase the degree of spasticity during the resistance exercise training, a positive relation is suggested between the muscular strength gain and function motor (Falcão, 2008). Muscular strengthening also promotes motor learning translated by the development of neuromotor coordination patterns through the practice of specific action, which has the potential to direct the cerebral reorganization and optimize the functional performance (Shepherd, 2001). In addition to muscular strength, with resistance training, increased joint stability, resistance and posture are considered important variables for the development of ADL (Baldin, 2009).

Although several indications present favorable relations of physical activity to assist the treatment of people with physical disabilities, there are scarce in the literature specific studies of the use of resistance training exercises in order to modulate the spasticity. Thus, the objective of this research was to evaluate the effects of a resistance training protocol combined with conventional therapy to reduce spasticity of the brachii biceps muscle of the paretic upper limb of post-stroke individuals.

\section{METHOD}

This is a randomized clinical trial, with a quantitative approach and longitudinal design. All participants and those responsible for the institutions were informed about the objectives and procedures of the study, confirming their participation through the Free and Informed Consent Form, according to Resolution 466/12 of the National Health Council. Approved by the Research Ethics Committee of the University Hospital of the Federal University of Sergipe (UFS) under the CAEE: 67243717.4.0000.5546.

\section{Participants}

The sample consisted of nine patients of both sexes, with diagnosis of stroke, hemiparetic, with a muscular strength of at least 2 according to the Muscular Strength Test (Kendall, Mccreary, \& Provance, 1995) and any degree of spasticity based on the Ashworth Modified Scale (Bohannon,1987).

Eligibility criteria included patients aged between 18 and 60 years; With diagnosis of Cerebral Vascular Accident proven by International Classification of Diseases ICD; No hearing, vision or speech problems; Were not in rehabilitation care (Physical Therapy, Occupational Therapy and / or Psychology) during the time of collection, in order to avoid confounding variables; Did not present any of the following disorders: degenerative diseases, fibromyalgia, chronic pain, degenerative neuromuscular diseases.

Patients who, after being evaluated by the Fugl-Meyer scale, showed absence of motor or sensitivity in a body dimidio; Patients with mental illness; Severe cognitive deficit (assessed by the Mental State Mini-Exam Scale, score 20 for cutoff point); Patients with herniated disc and patients without medical release for the practice of physical activity. Patients who refused or refused to participate in the study were also excluded, even after signing the Informed Consent Form.

\section{Outcome and Outcome Measure}

The primary endpoint considered at work was spasticity of the brachii biceps muscle, as assessed by the Ashworth Modified Scale. The muscle strength assessed by the Kendall test and the function of the upper limb evaluated by the FuglMeyer Scale are the secondary outcome variables.

The Ashworth Modified Scale was used as the most widely used instrument for assessing spasticity. The passive and velocity movement of the extremity was performed by evaluating the moment of joint amplitude in which resistance to movement arises. The patient was placed in the dorsal decubitus position and oriented to relax during the handling. The result can be measured through an ordinal scale ranging from 0 to 4 , indicating the degree of increase of muscle tone during the execution of the movement. The zero score indicates normal muscle tone response to stretching; 1 Discrete increase in muscle tone, manifested by minimal resistance at the end of the range of motion; $1+$ Discrete increase in muscle tone, manifested by minimal resistance 
through less than half the range of motion; 2 Significant increase in muscle tone through most of the range of motion, but the affected parts are easily moved; 3 Considerable increase in muscle tone hindering passive movement throughout the range of motion; 4 the affected part (or parts) is rigid in flexion or extension (Bohannon, 1987).

The Fugl-Meyer Rating Scale was used to assess motor function after stroke. The evaluation includes items on range of motion, presence of reflexes, motor function, sensitivity, balance, range of motion and pain, in which each item is scored between 0 and 2, (0 absent, 1 partially present, 2 present) totaling 10066 , with respect to the upper end and 34 with respect to the lower end. In this work only, the set of items for the upper limb was used. Depending on the overall score, the patient may be classified as having severe, moderate or mild impairment (Maki, Quagliato, \& Cacho, 2006).

The Kendall test was used to evaluate the biceps muscle strength in the upper limb after stroke. The evaluation was used to determine the ability of the muscle to act in the movement and its ability to provide stability and support. This test is directed to the examination of individual muscles, requiring a professional who has a broad knowledge of the actions of muscles and joints to perform the test. The examiner observed the muscle response to move partially or totally throughout its range of motion against a resistance that was imposed by the examiner or to keep the part in an antigravity position. The patient remained in supine position to avoid body compensation. The result is punctuated from 0 to 5, 5 refers to total or maximum force, 4 moderate force, 3 light force, 2- antigravity force 1- Only muscle contraction; 0- absence of contraction (Kendall et al., 1995).

\section{Study design}

Ten days prior to the start of the protocol, the patients who met the eligibility criteria were assessed for spasticity, muscular strength and functionality by a duly trained evaluator and at the end of the training protocol were reevaluated, with the instruments mentioned above by the same therapist.
There were 10 sessions, 2 sessions / week, 50 minutes each. Patients were randomly assigned to three groups ( $\mathrm{n}=3$ per group): Group 1 (G1) - patients submitted only to the therapeutic protocol to control spasticity; Group 2 (G2) protocol of resistance training associated to the therapeutic protocol to control spasticity; Group 3 (G3) - Control, patients submitted only the initial evaluations and reassessment. These patients were instructed not to perform vigorous exercises but to remain with the daily routine unchanged. No G3 patients were in rehabilitation care or attending gyms or places where resistance exercises were performed.

\section{Therapeutic spasticity control protocol}

The therapeutic protocol to control spasticity was obtained by analyzing the literature on the main techniques to reduce spasticity and were applied by an occupational therapist trained and able to apply the techniques, consisting of the following maneuvers: muscular mobilization of the biceps and triceps brachii ; Articular mobilization of shoulder, elbow and wrist; stretching; Activity of weight transfer to the affected upper limb; Therapeutic heat; Dissociation of pelvic and scapular waists, sensorial reeducation (protocol of sensory supply with different textures on the skin covering the biceps and triceps brachii muscles, besides stimuli to the glabrous skin of the palm), functional activities in closed kinetic chain and use of band Elastic as a perceptual resource to improve the quality of movement (Koninklij Nederlands Genootshap Voor Fysiotherapie, 2004; Winstein et al., 2016).

\section{Resistance Training Protocol}

The application of the resistance training protocol was guided by a Physical Education professional and consisted of resistance exercises of direct thread, concentrated thread and alternating thread. The loads of the exercises were calculated from $40 \%$ to $60 \%$ of the maximum strength. The patients performed 3 sets of 20 repetitions for each exercise, with intervals of 2 minutes between each repetition (Filho, 2006). 


\section{Statistical analysis}

For the statistical analysis of the nominal data the chi-square test was used and for verification of the homogeneity of the sample the Levene test. The Kruskal-Wallis test was used for nonparametric data before and after intervention and intergroup comparison verified the size of the effect with the Hedges'g test. Statistical Package for Social Sciences (SPSS), version $20^{\circledR}$, was used for all statistical analyzes and adopted a level of significance of $5 \%(\mathrm{p}<0,05)$.

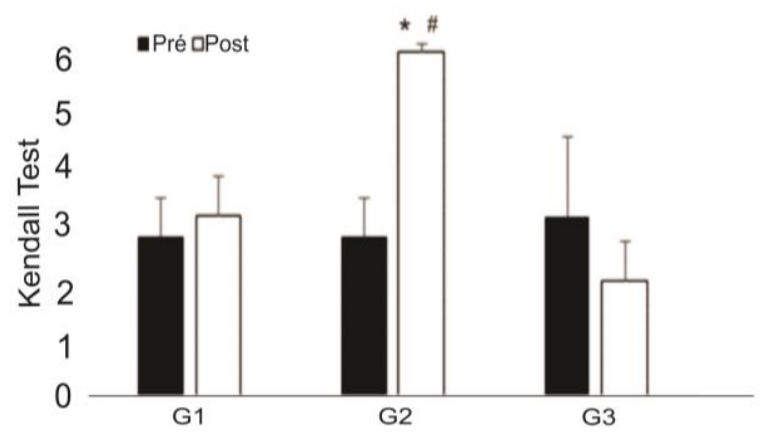

Graph 1. Kendall's muscular function test. ${ }^{*} \mathrm{p}<$ 0,001 (G2 pre test vs G2 post test); \# p < 0,001 (G2 post test vs G1 post test); (G2 post test vs G3 Post test).

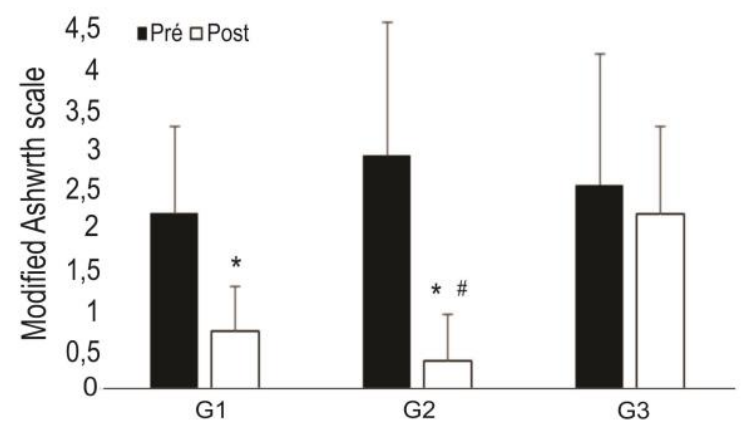

Graph 2. Ashworth modified scale. ${ }^{*} \mathrm{p}<0,05$ (pre test vs post test); \# $\mathrm{p}=0,011$ (G2 post test vs $\mathrm{G} 3$ post test).

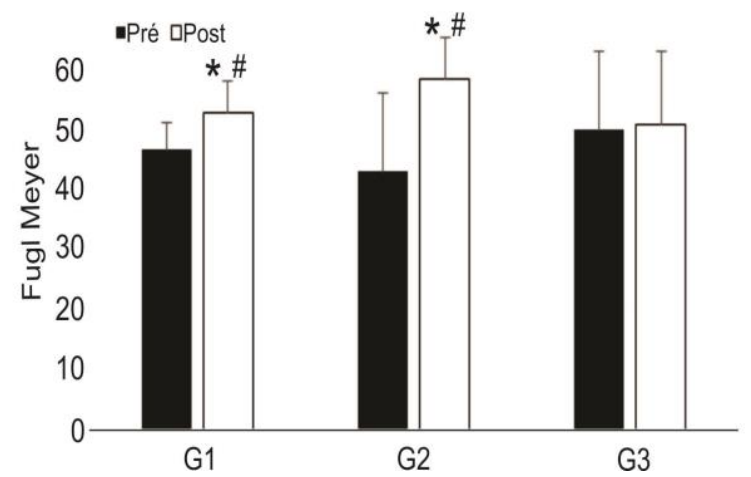

Graph 3. Motor function evaluated by Fugl Meyer. ${ }^{*} \mathrm{p}<0,05$ (pre test vs post test); \# $\mathrm{p}<0,001$ (G1 and G2 post test vs G3 post test).

\section{RESULTS}

The sociodemographic and clinical profile of the individuals affected by stroke was composed of predominantly male patients, age group over 58 years old, full high school, married, type of ischemic stroke with a mean of 4 years of involvement.

\section{Muscle strength, spasticity and motor function}

For muscle strength data, there was intragroup difference after intervention only in group 2 $(\mathrm{p}<0,001$, Hedges' $g=5,65)$. For intergroup analysis it was verified difference between the groups G1 post test and G2 post test $(<0,001$; Hedges' $g=6,36)$; G2 post test and G3 post test $(\mathrm{p}<0,001$; Hedges' $g=3,99)$, and indicative of improvement only in G2 (Graph 1). There was a reduction of spasticity in intragroup comparison in G1 $(\mathrm{p}=0,025$; Hedges' $g=17,75)$ and G2 $(\mathrm{p}=0,003$; Hedges' $g=2,04)$, in the intergroup analysis there was reduction of spasticity in the G2 group when compared to G3 ( $\mathrm{p}=0,011$; Hedges' $g=0,82$ ) (Graph 2). An increase in motor function was observed in both groups in the intragroup comparison of G1 intervention $(\mathrm{p}=0,002$; Hedges' $g=12,52)$ and G2 ( $\mathrm{p}=0,001$; Hedges' $g=5,48$ ), Indicating an increase in motor function in both groups. In the intergroup verification G1 and G2 post, they were greater than $G 3$ post test $(p<0,001)$ (Graph 3).

\section{DISCUSSION}

In Brazil, despite the decline in mortality rates, stroke is still the leading cause of death. The incidence of stroke doubles every decade after 55 years of age, occupying a prominent position among the elderly population. (Pereira et al., 2009).

Regarding the type of stroke, the findings of this research corroborate previous studies (Damata et al., 2016; Piassaroli et al., 2012) in which ischemia is the main form of involvement causing about $80 \%$ of cerebrovascular accidents. The age of the individuals affected in the present study are also in accordance with the literature (Damata et al., 2016).

The increase in muscle strength found in the resistance training group in relation to the other groups and their initial moment may have 
occurred due to the improvement of the muscle's ability to generate force, which is due to the greater recruitment of motor units and the increase in the frequency of That this type of training allows, being the muscular hypertrophy a secondary factor (Teixeira-Salmela, Oliveira, Santana, \& Resende, 2000).

Due to gains in strength, potency and resistance to fatigue that resistance training allows, currently, it has been widely indicated for several age groups of the population, including the elderly, with or without pathology (Kim \& Eng, 2003; Freire et al., 2015).

For the variable Spasticity there was a significant difference between the pretest and post test intervention in G1 and G2. The application of traditional maneuvers alone can gain greater effect when associated with resistance training. Historically, resistance training was applied with caution to hemiparetic patients because it believed that an exacerbation of muscle tone could occur, but with the increase of strength there is also an improvement in the function of the muscle that can as a consequence improve control and motor skills, That is, spasticity can be controlled by motor control gain (Shepherd,2001; Falcão, 2008).

Even with clinical results that indicate that spasticity limits movement, it is estimated that upon return of voluntary function, reliance on spasticity patterns may decrease. Thus, strength training generates a positive impact not only on the musculoskeletal system but also on neuromotor excitation, integrity, connective tissue viability and even a person's sense of wellbeing (Harris\&Watkins, 2001).

Structural and mechanical changes in skeletal muscle also play a role in the genesis of spasticity, a functional change of muscle has an inherent effect of its biomechanical characteristics. The increase in muscle tone is not only caused by reflex activity, but also by intrinsic muscle mechanisms. Passive stiffness (tonic spasticity) can be caused by the alteration of the connective tissue, tendon, joint capsule and intrinsic stiffness of the muscle fiber leading to contracture. The main goal of strength training is to restore the interaction between agonist and antagonist muscles by repetitive movements and specific tasks as a result of the improvement in the neural condition between them, thus reducing the frequency of spastic muscle contractions (Reid, Hamer, Alderson, \& Lloyde, 2010; Logan, 2011).

This research suggests a favorable relation for the improvement of the symptom, optimizing the motor activity. Aerobic / anaerobic training with a weekly frequency can have a positive impact on the different degrees of spasticity (Adams \& Hicks, 2011).

Among the techniques used in traditional therapy, stretching is extremely important in the treatment of spasticity, as it helps to normalize muscle tone, improves soft tissue extensibility, posture and range of motion (Bovend'eerdt, Newman, Barker,Dawes, \& Minelli,2008). Another resource also used was therapeutic heat; Thermotherapy can be used to treat spasticity, since its properties bring benefits such as muscle relaxation, which occurs when temperatures are progressively reached between 38,5 e $40^{\circ} \mathrm{C}$ (Fonseca et al., 2006).

Spasticity can also be triggered when there is a sensory deficit. For this reason a sensory reeducation protocol was included in the conventional therapy sessions. The sensory search, especially in the glabrous skin of the palm, can cause the patient to increase the tone of the intrinsic and extrinsic muscles in order to increase the sensory input. The promotion of this stimulus is an important factor for motor performance optimized after stroke (Schabrun, 2009). Thus, somatosensory stimulation should be included in motor rehabilitation protocols since the basis of all movement is the sensorial information arriving from the peripheral pathways and interpreted in the upper cerebral instances (Winstein et al., 2016).

In relation to the motor function that includes reflex and active motor, synergic movements, active-resistive movement, functional activities of force and precision, coordination and speed, evaluated by the Fugl Meyer Scale, it was identified improvement of these components in both groups G1 and G2. Increased muscle quality may have beneficial effects on the motor capacity of the upper limb (Reidet al., 2010). 
Loss and impairment of sensorimotor function is common after a stroke, especially at the upper end. Deficits in motor function of the upper limb persist even after years of stroke, about $80 \%$ of cases are inability to use arms and hands, and only a small portion of people recover completely from upper limb paresis (Schabrun, 2009; Jeong \& Chon, 2015).

Strengthening is an effective tool in increasing functional motor performance and upper limb muscle size in patients with hemiparesis. In addition, it is a key contributor to improving the ability to perform activities of daily living (Jeong \& Chon, 2015). However, previous studies have also shown that the recovery of arm and hand function was not improved only by resistance training, but required repetitive training oriented to functional tasks associated with different interventions (Jeong \& Chon, 2015).

Thus, a program of physical activity combined with traditional rehabilitation that can meet the needs and interests of the patient, can help him to adapt to his deficiencies, favor his functional, neuropsychological recovery and promote his social integration, maximizing the functionality (Baldin, 2016).

\section{CONCLUSION}

Improvement in muscle strength gain, motor function, and the considerable decrease in spasticity of hemiparetic patients with Cerebral Vascular Stroke (CVA) sequelae can be observed after a therapeutic program combined with resistance training based on the specificity of each subject. Therefore, it is suggested that the clinical picture be stabilized and this individual be referred to rehabilitation centers with multiprofessional care.

Further studies with a larger number of patients and use of evaluation equipment that may be more sensitive to changes in spasticity and muscle strength such as load cell and $\mathrm{H}$ reflex analysis by electromyography are suggested.

\section{Acknowledgments:}

Nothing to declare
Conflict of interests:

Nothing to declare

\section{Funding: \\ Nothing to declare}

\section{REFERENCES}

Adams, M. M., \&Hicks, A. L. (2011). Comparison of the effects of body-weight-supported treadmill training and tilt-table standing on spasticity in individuals with chronic spinal cord injury. The Journal Of Spinal Cord Medicine. 34(5), 488-494.

Baldin, A. D. (2009). Atividadefísica e acidente vascular cerebral. Rev. Com. Ciência, Campinas, 109.

Bohannon, R. W., \&Smith, M. B. (1987) A confiabilidade interavaliadores do Modified Ashworth Scale, de espasticidade muscular. Phisical Therapy, 67, 207.

Bovend'eerd, T. T. J., Newman, M., Barker, K., Dawes, H., Minelli, C., \&Wade, D. T. (2008). Efeitos do alongamentonaespasticidade: umasistemática. Arch Phys Med Rehabil, 89, 32-40.

Damata, S. R. R, Formiga, L. M. F., Araújo, A. K. S., Oliveira, E. R. A., Oliveira, A. K. S., \&Formiga, R. C. F. (2016).Perfil epidemiológico dos idosos acometidos por acidente vascular cerebral. Revista Interdisciplinar, 9(1), 107-117.

Falcão, L. K. C. (2008). Intervenções de fortalecimento muscular após o acidente vascular cerebral: umarevisão. Pós-Graduação em Fisioterapia Neurofuncional da Universidade Tuiuti do Paraná.

Freire, B., Dias, C., Oliveira, L., Goulart, N., Lemos, F., Becker, J., Gomes, I., \&Vaz, M. F. (2015) Rate of force development and torque production assessment in spastic stroke survivors. Brazilian Journal of Kinanthropometry and Human Performance, 17(3), 328-336.

Filho, W. J. (2006). Atividadefísica e envelhecimentosaudável. Rev. bras. Educ. Fís. Esp. 20, 73-77.

Fonseca, A. P. C.,Jakaitis, F., D'Andreia-Greve, J. M., Pavan, K., Lourenção, M. I. P., Gal, P. L. M., \&Lianza, S. (2006). AssociaçãoBrasileira de MedicinaFísica e Reabilitação. Espasticidade: Tratamento por Meio de Medicina Física. Projeto Diretrizes Associação Médica Brasileira e Conselho Federal de Medicina.

Greve, J. A. (1994). Fisiopatologia e avaliaçãoclínica da espasticidade. Rev. Hosp. Clin. Fac. Med. 49, 141-4.

Harris, B. A., \&Watkins, M. P. (2001). AdaptaçõesaoTreinamento de Força. In: Frontera, W. R., Dawson, D. M., Slovik, D. M. ExercícioFísico e Reabilitação. São Paulo: Artmed,

Konin klijk Nederlands Genootschap Voor Fysiotherapie (KNGF). (2004) Royal Dutch Society for Physical Therapy. Amsterdã: KNGF

Kendall, F. P., Mccreary, E. K.,\&Provance, P. G. (1995). Músculos: provas e funções. 4. ed. São Paulo: Manole. 
Kim, C. M.,\&Eng, J. J. (2003). The relationship of Lower-Extremity muscle torque locomotor performance in people with stroke. Phys Ther, 83(1), 49-57.

Jeong, S. W.,\& Chon, S. C. H. (2015). Effects of a novel forced intensive strengthening technique on muscle size and upper extremity function in a patient with chronic stroke. J. Phys. Ther. Sci. 27(11), 3607-3611.

Lianza, S.,Pavan, K., Lourenço, A. F., Fonseca, A. P., Leitão, A. V., Musse, C. A. I., Santos, C. A., Masiero, D., Quagliato, E., Fonseca, F. G. A., Granero, L. H. M., Gianni, M. A. C., Gal, P. L. M., Rosetto, R., Belizzi, D., Greve, J. M. D.,\&Sposito, M. M. M. (2001) Diagnóstico e tratamento da espasticidade. Projeto Diretrizes. Associação Médica Brasileira e Conselho Federal de Medicina. São Pauo: Sociedade Brasileira de Medicina Física e Reabilitação.

Logan, L. R. (2011). Rehabilitation techniques to maximize spasticity management. Topics In Stroke Rehabilitation. 18(3), 203-211.

Mayer, N. H. (2002). Clinicophysiologic concepts of spasticity and motor dysfunction in adults with an upper motoneuron lesion. Muscle \& Nerve, 6 (1), 11.

Meythaler, J. M. Conceito de hipertoniaespástica. (2001). Phys Med Clin Rehab. 12 (4), 725-32.

Pereira, A. B. G., Gama, A. B. C. N., Alvarenga, H., Pereira, J., Silva, R.,\& Barbosa, M. T. S. (2009). Prevalência de acidente vascular cerebral emidosos no Município de Vassouras, Rio de Janeiro, Brasil, através do rastreamento de dados do ProgramaSaúde da Família. Cad. SaúdePública, 25(9), 1929-1936.
Piassaroli, C. A. P., Almeida, G. C., Luvizotto, J. C., \& Suzan, A. B. B. M. (2012). Modelos de ReabilitaçãoFisioterápicaemPacientesAdultos com Sequelas de AVC Isquêmico. Rev. Neurociências, 20(1), 128-137.

Reid, S., Hamer, P., Alderson, J. \& Lloyd, D. (2010). Neuromuscular adaptations to eccentric strength training in children and adolescents with cerebral palsy. Developmental Medicine And Child Neurology. 52(4), 358-363.

Maki, T., Quagliato, E. M. A. B.,\&Cacho, E. W. A. (2006). Estudo de confiabilidade da aplicação da escala de fugl-meyer no brasil. Rev. bras. fisioter. 10(2), 177-183.

Schabrun, S. M., \&Hilier, S. (2009). Evidence for the retraining of sensation after stroke: A systematic review. Clinical Rehabilitations, 23(1), 27-39.

Shepherd, R. (2001). Exercise and training to optimize functional motor performance in stroke in stroke: driving Neural Reorganization?Neural Plasticity, 8 (1-2), 121-129.

Teixeira-Salmela, L. F., Oliveira, E. S. G., Santana, E. G. S., \&Resende, G. P. (2000) Efeitos do treinamento de fortalecimento muscular e condicionamentofísicoemvariáveistemporais,

cinemáticas e cinéticasdurante a marchaempacientes com AVC crônico. J. Rehabil. Med. 33 (2), 53-60.

Winstein, C. J., Stein, J. Arena, R., Bates, B., Cherney, L. R., Cramer, S. C., Deruyter, F., Eng, J. J., Fischer, B. Harvey, R. L., Lang, C. E., MacKayLyons, M., Ottenbacher, K. J., Pugh, S., Reeves, M. J., Richards, L. G., Stiers, W., \&Zorowitz, R. D. (2016). Guidelines for Adult Stroke Rehabilitation and Recovery. Stroke Aha Journal, $18,20-33$. 


\title{
Burnout syndrome in physical education teachers
}

\author{
Guadalupe de Moraes Santos Silva ${ }^{1}$, Daianne Cardinalli Rêgo ${ }^{2}$, Camila Moura Ferreira \\ Vorkapic $^{3}$, Marcos Bezerra de Almeida ${ }^{2}$, Afrânio de Andrade Bastos ${ }^{2 *}$
}

ORIGINAL ARTICLE

\begin{abstract}
Physical education teachers play a decisive role in the school environment, and mental illness may make it impossible to achieve efficiency in their social role, then the main objective of this study is to verify the presence of Burnout Syndrome in physical education teachers of public schools in Sergipe. For this, a sociodemographic survey and the Maslach Burnout Inventory (MBI) were used, and for the analysis of the data collected, the Cronbach's alpha was used to determine the internal consistency of the inventory, whereas the Mann-Whitney and Kruskal-Wallis tests were applied to compare the variables. The presence of a moderate level of Burnout Syndrome in a sample of 164 physical education teachers was verified. The results showed significant differences $(\mathrm{p} \leq 0.05)$ in the Depersonalization dimension between the genderes (female, mean 13.18; male, mean 14.99) and time of practicing (more than 30 years, $\mathrm{p}=0.017$ ). It is concluded that the sample did not present extreme cases of Burnout, but the identifiers found in the three dimensions point to a beginning of development of the syndrome.

Keywords: Occupational stress, Burnout syndrome, professor of physical education, sport.
\end{abstract}

\section{INTRODUCTION}

Work is a set of tasks, relationships, responsibilities, incentives and rewards in a given physical and social context (Nascimento, Folle, Rosa, \& Both, 2016). Through the work of teachers, the school can promote its goal of promoting the construction of certain knowledge (Davis, Steele, Bozick, Williams, Turner, Miles et al., 2014).

When we imagine a classroom, we can observe the teaching work, susceptible to many activities, demands and pressures; this social role is leaving several professionals ill (Araujo, Godinho, Reis, \& Almeida, 2006). The interactive process expected in a school environment aims at enabling the learner to understand their role in the construction of knowledge. In order to make the classroom a place where the teacher is the articulator and everyone becomes active, the teacher needs to be in a healthy condition to be efficient (Martins, 1997).
Burnout Syndrome or Occupational Exhaustion Syndrome mainly affects professions whose tension and stress are evident (Moreira, Farias \& Nascimento, 2009) and professionals who work directly with the public (Tironi, 2005). It is a set of psychological symptoms suffered by the worker, evidenced by emotional exhaustion, low level of achievement and high level of stress (Nascimento, Folle, Rosa \& Both, 2016).

Burnout was found to be prevalent among Physical Education teachers (Both, Nascimento, Petroski, Ramos, Donegá, Lemos et al 2006; Gomes, Borges, \& Nascimento, 2007; Moreira, Collet, Farias, \& Nas-cimento, 2008; Nogueira, 2005; Santini \& Molina Neto, 2005). However, the studies do not show the dimensions that cause the syndrome. The Maslach and Jackson syndrome $(1981,1986)$ and Maslach and Leiter (1999) are composed of three central elements: low professional achievement, depersonalization and emotional exhaustion.

\footnotetext{
${ }^{1}$ Faculdade São Luís de França, Aracaju, SE, Brasil

${ }^{2}$ Universidade Federal de Sergipe, São Cristóvão, SE, Brasil

${ }^{3}$ Universidade Tiradentes, Aracaju, SE, Brasil

* Autor correspondente: Professor do Departamento de Educação Física e do Programa de Pós-graduação em Educação Física, Universidade Federal de Sergipe, Cidade Univiversitária Prof. José Aloísio de Campos, Av. Marechal Rondon, s/n, Jd. Rosa Elze, CEP 49100-000. São Cristóvão/SE, Brasil. E-mail: afranioufs@gmail.com.
} 
Considering that, according to Andrews (1993), Physical Education teachers are subject to four forms of stress: personal pressures, general pressures, problems related to teaching, problems specific to the profession. Teachers of physical education being affected by Burnout Syndrome allow social interactions to suffer a breakdown in the construction and transformation of knowledge that, due to social interactions, conquer spaces and new meanings in society and group activities (Martins, 1997), since the student is constituted as a human being by the relationships he establishes with others.

The existence of a disease promotes prejudgment in the personal, social and professional life of the individual. In this way, the objective of this paper is to investigate the presence of Burnout Syndrome in Physical Education teachers from public schools of a state in the Brazilian Northeast, characterizing the sociodemographic and labor profile. Moreover, the research aims to identify the causative dimensions of the syndrome, evaluating the intensity and comparing Burnout symptomatology with the teacher's profile.

\section{METHOD}

This is a cross-sectional, descriptive study, with a quantitative approach, and it started in 2012, after approval by the Ethics Committee for Research in Human Beings of the Federal University of Sergipe-UFS, and authorization by the Bureau of Education of Sergipe (SEED / SE).

\section{Participants}

The sampling was carried out by groups, due to the existence of 10 regional boards in the State of Sergipe, and included 164 Physical Education teachers of both genders, effective and active in the first semester of 2013 in state public schools who voluntarily consented to participate by signing the Informed Consent Term (TCLE).

The sample consisted mainly of female participants $(51.82 \%)$, who declared themselves married (61.58\%); $36.58 \%$ of them have worked for 10 to 19 years and $35.97 \%$ have done so for 20 to 29 years; in relation to the workload,
$46.34 \%$ dedicate between $180 \mathrm{~h}$ and $200 \mathrm{~h}$ monthly to the work activity.

\section{Measures}

The instruments used for data collection were: (i) sociodemographic survey, which aims to identify the profile of the participants for the variables gender, marital status, workload and length of service in the profession; and (ii) the Maslach Burnout Inventory (MBI) (Maslach \& Jackson, 1981), a self-assessment questionnaire validated in Brazil by the Group of Studies and Research on Stress and Burnout (GEPEBB) (Benevides-Pereira, 2002).

The MBI consists of 22 items in a 7-point Likert scale, divided into three dimensions or subscales: emotional exhaustion (EE), depersonalization (DP) and low professional achievement (PA). In this study, the definition of cutoff points by size was based on percentiles (25 and 75), as described in table 1, following the MBI application manual (Maslach \& Jackson, 1981).

Table 1

Categorizing the Dimensions of Burnout Syndrome

\begin{tabular}{lccc}
\hline \multicolumn{4}{c}{ Dimensions } \\
\hline Level & EE & DP & PA \\
Low & 0 a 14 & 0 a 6 & 36 a 48 \\
Moderate & 15 a 40 & 7 a 22 & 13 a 35 \\
High & 41 a 54 & 23 a 30 & 0 a 12 \\
\hline Source: (Maslach \& Jackson, 1981)
\end{tabular}

A low level of Burnout is reproduced in low scores on the dimensions of emotional exhaustion and depersonalization, and high scores on personal achievement. The moderate level of Burnout is represented by average values in the scores of the three dimensions. The high level of Burnout, however, translates into high scores for the dimensions of emotional exhaustion and depersonalization, and low scores on personal achievement.

\section{Procedures}

The application of the questionnaires was carried out by the researcher in charge and by a team of applicators, previously trained. The 
researchers-applicators received in the training sessions: a folder containing guidelines for application of the instruments, application and registration form, official letter and the SEED / Se statement (to be delivered to the managers of the teaching units), the TCLE, the sociodemographic survey and MBI.

\section{Statistical Analysis}

For the data analysis, a descriptive evaluation of the data (mean, standard deviation and percentage) was carried out to characterize the sample and to identify the Burnout Syndrome scores. Also, the distribution of the data was assessed using the Kolmogorov-Smirnov test in order to verify normality and to justify the use of non-parametric tests. The Cronbach's $\alpha$ coefficient was calculated to test the internal consistency of MBI in the three dimensions of Burnout syndrome. The results of the calculation of Cronbach's $\alpha$ showed that the Emotional Exhaustion $(\alpha=0.78)$, Depersonization $(\alpha=$ $0.71)$ and Low Professional Achievement $(\alpha=$ 0.70) presented high consistency, according to the reliability classification proposed by Freitas and Rodrigues (2005).

Burnout Syndrome scores in its three MBI dimensions were related to the variables gender, marital status, workload and length of service of the profession, using the Mann-Whitney and Kruskal-Wallis tests, with $\mathrm{p} \leq 0.05$. These tests were performed using the statistical program SPSS in its 16.0 version.

\section{RESULTS}

The results will be presented by answering the following questions: how are the dimensions of the Burnout in the sample? Is there a difference between the dimensions of the syndrome and the gender of the participants? And between the dimensions of teachers' marital status? Is there a statistically significant difference among the dimensions of the syndrome in relation to the professional length of service? What about the monthly workload of the professionals?

The table 2 presents the results in percentage of the dimensions of Burnout Syndrome in teachers, evidencing the presentation of significant difference between the levels obtained.

\section{Table 2}

Percentages of the dimensions of Burnout Syndrome in teachers of the state public schools of Sergipe in the first semester of 2013

\begin{tabular}{llllc}
\hline Dimension & Low & Moderate & High & $\mathrm{p}$ \\
\hline EE & $3.7 \%$ & $78.4 \%$ & $4.2 \%$ & $0.001^{*}$ \\
DP & $1.6 \%$ & $84.2 \%$ & $0.5 \%$ & $0.001^{*}$ \\
PA & $17.9 \%$ & $67.9 \%$ & $0.5 \%$ & $0.001^{*}$ \\
\hline
\end{tabular}

Note: DE: Emotional exhaustion; SD: Depersonalization; PA: Professional achievement. * A statistically significant difference $\mathrm{p} \leq 0.05$

It was possible to observe, in this research, a possible development of Burnout symptoms in the studied sample, as all dimensions presented higher rate in the percentile that characterizes average scores.

As we will see, the tables will show the relation between the variables mentioned before with the dimensions of Burnout: Emotional Exhaustion (EE), Depersonalization (DP) and Low Professional Achievement (PA)

Table 3

Gender in relation to the dimensions of Burnout Syndrome in physical education teachers of the Sergipe state public schools.

\begin{tabular}{lccccc}
\hline Dimension & Gender & $\mathrm{N}$ & Mean & SD & $\mathrm{p}$ \\
\hline \multirow{2}{*}{ EE } & Female & 85 & 27.25 & 8.51 & \multirow{2}{*}{0.281} \\
& Male & 79 & 25.84 & 8.17 & \\
DP & Female & 85 & 13.18 & 3.52 & $0.001^{*}$ \\
& Male & 79 & 14.99 & 3.21 & \\
PA & Female & 85 & 17.35 & 5.25 & \multirow{2}{*}{0.278} \\
& Male & 79 & 18.30 & 5.94 & \\
\hline
\end{tabular}

Note: DE: Emotional exhaustion; SD: Depersonalization; PA: Professional achievement. SD: standard deviation. ${ }^{*}$ A statistically significant difference $\mathrm{p} \leq 0.05$

There was a statistically significant difference in relation to gender in the Depersonalization dimension, in which the men presented higher indices.

The next table demonstrates the Marital Status variable in relation to the dimensions of Burnout.

It was noticed that there was no statistically significant difference. However, the data showed that married physical education teachers present 
higher results regarding Emotional Exhaustion and Depersonalization.

Table 4

Marital status in relation to the dimensions of Burnout Syndrome in physical education teachers of the Sergipe state public schools.

\begin{tabular}{lccccc} 
Dimension & $\begin{array}{c}\text { Marital } \\
\text { Status }\end{array}$ & $\mathrm{N}$ & Mean & SD & $\mathrm{p}$ \\
\hline \multirow{2}{*}{ EE } & Married & 101 & 26.76 & 7.98 & \\
& Single & 48 & 26.21 & 9.09 & 0.929 \\
& Other & 15 & 26.40 & 8.91 & \\
DP & Married & 101 & 14.29 & 3.69 & \\
& Single & 48 & 13.67 & 2.80 & 0.545 \\
& Other & 15 & 13.67 & 4.15 & \\
PA & Married & 101 & 17.79 & 5.61 & \\
& Single & 48 & 17.90 & 5.26 & 0.989 \\
\hline
\end{tabular}

Note: DE: Emotional exhaustion; SD: Depersonalization; PA: Professional achievement. SD: standard deviation. ${ }^{*}$ A statistically significant difference $\mathrm{p} \leq 0.05$

Table 5

Professional length of service in relation to the dimensions of Burnout Syndrome in physical education teachers of the Sergipe state public schools.

\begin{tabular}{|c|c|c|c|c|c|}
\hline Dimension & $\begin{array}{l}\text { Professional } \\
\text { length of } \\
\text { service }\end{array}$ & $\mathrm{N}$ & Mean & SD & $\mathrm{p}$ \\
\hline \multirow{4}{*}{ EE } & $\begin{array}{l}\text { Up to } 9 \\
\text { anos }\end{array}$ & 37 & 25.81 & 8.566 & \multirow{4}{*}{0.284} \\
\hline & $\begin{array}{c}10 \text { to } 19 \\
\text { years }\end{array}$ & 60 & 25.73 & 7.695 & \\
\hline & $\begin{array}{c}20 \text { to } 29 \\
\text { years }\end{array}$ & 59 & 27.25 & 8.531 & \\
\hline & $\begin{array}{l}\text { over } 30 \\
\text { years }\end{array}$ & 8 & 31.25 & 10.403 & \\
\hline \multirow{4}{*}{ DP } & $\begin{array}{l}\text { Up to } 9 \\
\text { anos }\end{array}$ & 37 & 14.46 & 2.433 & \multirow{4}{*}{$0.017^{*}$} \\
\hline & $\begin{array}{c}10 \text { to } 19 \\
\text { years }\end{array}$ & 60 & 13.90 & 3.965 & \\
\hline & $\begin{array}{c}20 \text { to } 29 \\
\text { years }\end{array}$ & 59 & 13.47 & 3.159 & \\
\hline & $\begin{array}{l}\text { over } 30 \\
\text { years }\end{array}$ & 8 & 17.50 & 4.567 & \\
\hline \multirow{4}{*}{ PA } & $\begin{array}{l}\text { Up to } 9 \\
\text { anos }\end{array}$ & 37 & 17.35 & 6.308 & \multirow{4}{*}{0.537} \\
\hline & $\begin{array}{c}10 \text { to } 19 \\
\text { years }\end{array}$ & 60 & 18.37 & 5.517 & \\
\hline & $\begin{array}{c}20 \text { to } 29 \\
\text { years }\end{array}$ & 59 & 17.29 & 5.219 & \\
\hline & $\begin{array}{l}\text { over } 30 \\
\text { years }\end{array}$ & 8 & 19.63 & 5.731 & \\
\hline
\end{tabular}

Note: DE: Emotional exhaustion; SD: Depersonalization; PA: Professional achievement. SD: standard deviation. ${ }^{*}$ A statistically significant difference $\mathrm{p} \leq 0.05$
The table above shows the analysis of the relationship between the professional length of service and the characterizing dimensions of the syndrome.

It is possible to observe that in the category Depersonalization there was a significant difference of the professors who have been in the profession for more than 30 years.

The following representation refers to the variable workload of the teachers surveyed in this study.

Table 6

Workload in relation to the dimensions of Burnout Syndrome in physical education teachers of the Sergipe state public schools.

\begin{tabular}{lccccc}
\hline Dimension & Workload & N & Mean & SD & p \\
\hline \multirow{4}{*}{ EE } & Up to $100 h$ & 43 & 26.14 & 8.571 & \\
& 120 to $125 \mathrm{~h}$ & 42 & 25.79 & 8.420 & 0.612 \\
& 135 to $160 \mathrm{~h}$ & 5 & 30.60 & 4.393 & \\
& 180 to $200 \mathrm{~h}$ & 74 & 26.99 & 8.426 & \\
DP & Up to $100 \mathrm{~h}$ & 43 & 13.30 & 3.370 & \\
& 120 to $125 \mathrm{~h}$ & 42 & 14.62 & 3.076 & 0.336 \\
& 135 to $160 \mathrm{~h}$ & 5 & 13.40 & 5.367 & \\
& 180 to $200 \mathrm{~h}$ & 74 & 14.20 & 3.638 & \\
PA & Up to $100 \mathrm{~h}$ & 43 & 17.91 & 6.331 & \\
& 120 to $125 \mathrm{~h}$ & 42 & 17.48 & 5.597 & 0 \\
& 135 to $160 \mathrm{~h}$ & 5 & 20.40 & 5.030 & \\
& 180 to $200 \mathrm{~h}$ & 74 & 17.77 & 5.233 &
\end{tabular}

Note: DE: Emotional exhaustion; SD: Depersonalization; PA: Professional achievement. SD: standard deviation. ${ }^{*}$ A statistically significant difference $\mathrm{p} \leq 0.05$

In this table, it can be seen that the three dimensions did not show significantly different values, regardless the workload.

\section{DISCUSSION}

As we have seen, there is the possibility of the development of Burnout in the studied sample. It was verified that all dimensions presented higher scores in the percentile that characterizes average scores. This syndrome is triggered slowly (Rey, Extremera \& Pena, 2016), leading us to watch carefully this population.

Another important finding was the statistically significant difference in relation to gender in the Depersonalization dimension. The men presented the highest indices and this may be associated with the fact that women have less difficulty expressing themselves, dealing better with stressful situations at work (Maslach \& 
Jackson, 1981). The study of Benevides-Pereira (2002) and Gil-Monte and Peiró (1997) states that women have high rates of emotional exhaustion (probably due to the accumulation of functions inside and outside home), whereas they rate less in the depersonalization dimension.

In the study by Sinott et al. (2014), the emotional exhaustion dimension is of concern in the teachers investigated, with women having the highest percentages in this dimension (Female, mean 27.25, Male, mean 25.84). The study points to the double journey as a factor that makes the work of women more exhausting.

Regarding the results on the marital status, it was noted that there was no statistically significant difference. Nonetheless, Sampaio (2009) points that people who have stable relationships are less likely to develop Burnout Syndrome, as they have the possibility of sharing with the family/conjugate their daily problems. This environment provides greater sense of comfort and security, sometimes preventing stressors from triggering pathologies. Even though married individuals in our study presented higher scores in EE (mean 26.76) and DP (mean 14.29), this difference was not statistically significant. These higher scores may be related to the marriage time length, which was not considered in our study.

We have noticed higher average scores in all dimensions in teachers with more than 30 years of professional time. In a study by Batista (2010), carried out with teachers from municipal schools in the city of João Pessoa/PB, people with more than 20 years of career were associated with the Depersonalization dimension. They reported feeling distant, unmotivated and without good affective relationships at work. Considering that the problems arising from the Brazilian educational system cause a series of losses to the teachers, it is inferred that the longer the service time, the greater the contact with stressors and the triggering of work-related pathologies.

Dorman (2003) addresses Depersonalization as a direct consequence of the Emotional Exhaustion dimension and lack of interest in work. The work is no longer important and becomes a daily burden, causing greater emotional, physical and psychological wear. Rey, Extremera, Pena (2016) understand that depersonalization occurs when there is an insensitive and impersonal response to the beneficiaries of their care or services. For these authors, this syndrome progresses over time, slowly eroding the motivation and mood of the teacher. Given that social interactions contribute to the construction of knowledge, this lack of importance that can be observed by the teacher interferes with the efficiency of the teachinglearning process (Davis et al., 2014).

As results, it was observed that the three dimensions did not show significantly different values in relation to the dedicated workload. In the research developed by Leite (2007) with professors from public schools of Brasilia, most teachers had a workload of 31 to 40 weekly hours (120 to 160 hours per month). In the study developed with 101 high school teachers, by Tibúrcio and Moreno (2009), the average weekly load was 38.6 hours, ranging from 10 hours to 60 hours. This information analyzed from the results of the study by Carlotto and Palazzo (2006) showed that teachers who work more than 20 hours per week ( 80 hours per month) have a direct association with Emotional Exhaustion. Batista (2010) also found association of this dimension with the number of hours at work, teachers in this sample worked 40 or more hours per week (160 hours or more per month) and reported that work was negatively interfering with personal life and especially in the relationship with the family.

The workload has a significant influence on the mental health of the professionals, once the teachers' work extends to their homes, reducing or taking the time that would be spent with family and leisure. This accumulation of work results in psychotic suffering, emotional exhaustion and depersonalization (VasquesMenezes, Codo, \& Medeiros, 2006). In this way, it is urgent to reflect on the way the school operates, seeking to make it a space where knowledge is socially constructed (Davis et al., 2014). 


\section{CONCLUSIONS}

It is concluded that Physical Education teachers present average Burnout level, with the highest indexes found in the Emotional Exhaustion and Depersonalization dimensions. The professionals are mostly female, but the male and those with more than 30-year career have more worrying results in the depersonalization dimension. No relationship was found between the dimensions of the syndrome and the marital status, as well as the workload of the professional.

Stressors common to the teaching career must be observed so that they do not trigger mental and somatic transverse movements. In this way, we must pay attention to the quality of the work environment, social relations and how these two variables can affect the teacher, because the installation of Burnout occurs slowly and cumulatively.

Acknowledgments:

Nothing to declare

Conflict of interests:

Nothing to declare

Funding:

Nothing to declare

\section{REFERENCES}

Adami, F., \& Vasconcelos, F. de A. G. de. (2008). Obesidade e maturação sexual precoce em escolares de Florianópolis - SC. Revista Brasileira de Epidemiologia, 11(4), 549-560. doi: 10.1590/S1415-790X2008000400004

Andrews, J. (1993). O stress nos professores de Educação Física dos nossos dias: uma perspectiva internacional. Boletim da Sociedade Portuguesa em Educação Física, (7-8), 13-25.

Araujo, T. M. de, Godinho, T. M., Reis, E. J. F. B. dos, \& Almeida, M. M. G. de. (2006). Diferenciais de gênero no trabalho docente e repercussões sobre a saúde. Ciência E Saúde Coletiva, 11(4), 1117-11. doi: 10.1590/S1413-81232006000400032

Batista, J. (2010). Síndrome de Burnout em professores do ensino fundamental: um problema de saúde pública não percebido (Doutorado em Saúde pública). Fundação Oswaldo Cruz, Pernambuco). Recuperado https://www.arca.fiocruz.br/bitstream/icict/105 09/1/752.pdf

Benevides-Pereira, A. (2002). Burnout: Quando o trabalho ameaça o bem-estar do trabalhador. São Paulo, SP: Casa do Psicólogo.

Both, J.; Nascimento, J. V. do; Petroski, E. C.; Ramos, M. H. K. P.; Donegá, A. L.; Lemos, C. A. F.; et al (2006). Qualidade de vida no trabalho percebida por Professores de Educação Física. Revista Brasileira Cineantropometria Desempenho Humano, 8(2), 45-52. Recuperado de https://periodicos.ufsc.br/index.php/rbcdh/artic le/view/3884/16669

Carlotto, M., \& Palazzo, L. (2006). Síndrome de Burnout e fatores associados: um estudo epidemiológico com professores. Caderno de Saúde Pública, 22(5), 17-26. doi: 10.1590/S0102311X2006000500014

Davis, L. M., Steele, J. L., Bozick, R., Williams, M. V., Turner, S., Miles, J. N. V.,...Steinberg, P. S. (2014). How Effective Is Correctional Education, and Where Do We Go from Here? The Results of a Comprehensive Evaluation. RAND Corporation, 1-156. Recuperado de https://www.rand.org/pubs/research_reports/R R564.readonline.html

Dorman, J. (2003). Relationship between school a classroom environment and teacher Burnout: a LISREL analysis. Social Psychology of Education, 6(2), 107-27. doi: 10.1023/A:1023296126723

Freitas, A. L. P.; Rodrigues. S. G. (2005). A avaliação da confiabilidade de questionários: uma análise utilizando o coeficiente alfa de Cronbach. In artigo do XII Simpósio de Engenharia de produção. p. 12. Bauru, SP

Gil-Monte, P., \& Peiró, J. (1997). Desgaste psíquico en el trabajo: el síndrome de quemarse. Madrid: Síntesis.

Gomes, M., Borges, L., \& Nascimento, J. (2007). Ciclos de desenvolvimento profissional e a qualidade de vida de professores de educação física da região sudoeste da Bahia. Revista Brasileira de Educação Física, Esporte, Lazer e Dança, 2(4), 104-114.

Hypolito, Á. M. (1997). Trabalho docente, classe social e relações de gênero. São Paulo: Papirus.

Leite, N. (2007). Síndrome de Burnout e relações sociais no trabalho: um estudo com professores da educação básica (Mestrado em Psicologia, Universidade de Brasília, Brasilia). Recuperado de http://repositorio.unb.br/bitstream/10482/3261 /1/2007 NadiaMariaBeserraLeite.PDF

Martins, J. C. los. (1997). Vygostsky e o papel das interações sociais na sala de aula. Reconhecer $e$ desvendar o mundo. São Paulo: FDE.

Maslach, C., \& Jackson, S. (1981). The measurement of experienced burnout. Journal of Ocuppational Behavior, 2(99), 133. Recuperado de https://smlr.rutgers.edu/sites/default/files/docu ments/faculty staff docs/TheMeasurementofEx periencedBurnout.pdf 
Maslach, C., \& Jackson, S. (1986). Maslach Burnout Inventory. Palo Alto: Consulting Psychologist Press.

Maslach, C., \& Leiter, M. (1999). Trabalho: fonte de prazer ou desgaste? Guia para vencer o estresse na empresa. Campinas, SP: Papirus.

Moreira, H., Cotterta, C., Farias, G., \& Nascimento, J. V. do. (2008). Síndrome de Burnout em professores de Educação Física: um estudo de caso. Revista Efdeportes, 13(123). recuperado de http://www.efdeportes.com/efd123/sindromede-burnout-em-professores-de-educacaofisica.htm

Moreira, H., Farias, G., J, B., \& Nascimento, J. (2009). Qualidade de vida no trabalho e síndrome de burnout em professores de educação física do estado do rio grande do sul, Brasil. Revista Brasileira de Atividade Física E Saúde, 14(2), 1-8. doi: 10.12820/rbafs.v.14n2p115-122

Nascimento, R., Folle, A., Rosa, A., \& Both, J. (2016). Satisfação no trabalho dos professores de educação física da rede municipal de ensino de São José-SC. Journal of Physical Educacion, 27(2740), 1-11. doi: 10.4025/jphyseduc.v27i1.2740

Nogueira, L. (2005). Qualidade de Vida no trabalho do Professor de Educação Física: reflexões sobre as possibilidades de um novo campo de investigação acadêmica. Arquivos em Movimento, 1(1), 75-86. Recuperado de https://revistas.ufrj.br/index.php/am/article/vie $\mathrm{w} / 9051 / 7181$

Rey, L., Extremera, N., \& Pena, M. (2016). Emotional competence relating to perceived stress and burnout in Spanish teachers : a mediator model. PeerJ, 31(4), 1-14. doi: 10.7717/peerj.2087

Sampaio, E. (2009). A sindrome de burnout em professores e alunos do programa de mestrado em ensino de ciências na Amazônia: uma contribuição para formação de professores (Mestrado em Ensino de Ciências, Universidade do Estado do Amazonas, Manaus, Amazonas). Recuperado de http://www.pos.uea.edu.br/data/area/titulado/d ownload/14-7.pdf

Santini, J., \& Molina Neto, V. (2005). A síndrome do esgotamento profissional em professores de educação física: um estudo na rede municipal de ensino de Porto Alegre. Revista Brasileira de Educação Física e Esporte, 19(3), 209-22. doi: 10.1590/S1807-55092005000300004

Sinott, E. C., Afonso, M. da R., Ribeiro, J. A. B., \& Farias, G. O. (2014). Síndrome de Burnout : um estudo com professores de Educação Física. Movimento, 20(2), 519-539. Recuperado de http://www.seer.ufrgs.br/index.php/Movimento /article/view/43226/28915

Tibúrcio, A., \& Moreno, C. (2009). Síndrome de burnout em professores do ensino médio de escolas pertencentes à gerência regional de educação e inovação (gerei) do município de Tubarão (SC). Revista de Gestão Integrada em Saúde do Trabalho e Meio Ambiente, 4(1), 1-14. Recuperado http://producao.usp.br/handle/BDPI/14239

Tironi, M. (2005). A síndrome de burnout em médicos pediatras: um estudo em duas organizações hospitalares (Mestrado em Psicologia, Universidade Federal da Bahia, Salvador). Recuperado de https://pospsi.ufba.br/sites/pospsi.ufba.br/files/ marcia_tironi.pdf

Vasques-Menezes, I., Codo, W., \& Medeiros, L. (2006). Suporte Afetivo e o Sofrimento Psíquico. In Educação Carinho e Trabalho. Petropólis: Ed. Vozes.

Vianna, C. P. (2001). O sexo e o gênero da docência. Cadernos Pagu, 17(18), 81-103. doi:10.1590/S0104-83332002000100003 


\title{
Effects of a multicomponent training protocol on functional fitness and quality of life of physically active older women
}

\author{
Albernon Costa Nogueira ${ }^{1}$, Antônio Gomes de Resende Neto ${ }^{1}$, José Carlos Aragão Santos ${ }^{1}$, \\ Leury Max da Silva Chaves $^{1}$, Luan Morais Azevêdoํㅜ, Cauê V. La Scala Teixeira ${ }^{2}$, Gilmar \\ Webber Senna ${ }^{3}$, Marzo Edir Da Silva-Grigoletto ${ }^{1 *}$
}

\begin{abstract}
The aim of the study was to evaluate the effects of twelve weeks of a multicomponent training program on functional fitness and quality of life in physically active elderly women. Twenty-six women were randomly divided into Multicomponent Training ( $\mathrm{TM}=15,65,60 \pm 5,0,10$ years, $28,50 \pm 5,50 \mathrm{~kg} / \mathrm{m}^{2}$ ) and Control Group $\left(\mathrm{GC}=11,62,5 \pm 5,30\right.$ years, $30,4 \pm 5,90 \mathrm{~kg} / \mathrm{m}^{2}$ ). The TM performed mobility exercises, walking, strength exercises in circuit and intermittent activities. The GC performed mobility exercises and relaxation practices. For both interventions, the frequency was three weekly sessions, in intercalated days, lasting 50 minutes. The functional fitness was evaluated by Senior Fitness battery and quality of life using the WHOQOOL-bref questionnaire. The data were analyzed by ANOVA $2 \times 2$ with post hoc Bonferroni. At the end of the 12 weeks, the TM presented significant differences in relation to the pretest and GC in the Raise and walk, Sit and Raise, Forearm flexion and WHOQOOL tests. In the sit and reach, Reaching behind the back and 6-minute walk tests did not show significant differences between groups. The present TM protocol was effective in improving the functional parameters and quality of life of the elderly. Therefore, it was demonstrated that TM is as a viable option to combat some of the deleterious effects of aging.

Keywords: Aging, Exercise, Daily activities Life style.
\end{abstract}

\section{INTRODUCTION}

Aging is a natural process of the body in which the entire psychobiological system suffers deleterious effects such as gradual reduction of muscle and bone mass, as well as decrease in levels of different physical fitness components such as muscle strength and power, cardiorespiratory fitness, balance and flexibility (Hughes, Wallace and Baar, 2015; Hunter, Pereira and Keenan, 2016). The deleterious effects of aging on physical fitness levels compromise the functional capacity of individuals, which is understood as the physiological competence to perform simple activities of the daily living with independence, safety, autonomy and without excessive fatigue (Rikli and Jones 1999).

Participation in regular physical exercise programs has shown to be one of the most effective interventions to mitigate functional losses due to the aging process, positively contributing to health, quality of life and independence (Westcott, 2012). According to the American College of Sports Medicine (Chodzko-Zajko et al., 2009), physical training programs for the elderly should include aerobic exercises to maintain and / or improve various aspects of the cardiovascular function, strength exercises to compensate loss of muscle mass and strength, balancing exercises to maintain body control and reduce the risk of falls, and flexibility exercises to maintain adequate levels of joint mobility in the structures most commonly used in daily life. The referred positioning considers that multicomponent training (MT) is more likely to provide multisystemic benefits and, currently, several studies have confirmed this efficacy, which is more evident in this type of

\footnotetext{
${ }^{1}$ Program of Post-Graduation in Physical Education of Federal University of Sergipe; Department of Physical Education and Functional Training Research Group, FTG, Federal University of Sergipe, UFS, São Cristóvão, Sergipe, Brazil.

${ }^{2}$ Faculty of Physical Education, Faculty Praia Grande, FPG, Praia Grande, São Paulo, Brasil.

${ }^{3}$ Laboratory of Biosciences of Human Motricity, LABIMH, Program of Post-Graduation in Nursing and Biosciences, PPgEnfBio, Federal University of Rio de Janeiro, UNIRIO, Rio de Janeiro, RJ, Brasil.

* Corresponding author: Rua Napoleão Dórea, 165, Apt 03, Residencial Ana Carolina, Bairro Atalaia CEP: 49037 460, Aracaju-SE. E-mail: pit_researcher@yahoo.es
} 
intervention in relation to training programs that include only one physical fitness component (Liu et al.,2014; Silva-Grigoletto, Brito and Heredia, 2014; Resende-Neto et al., 2016b).

MT consists of a training proposal that aims at the balanced and synergistic improvement of more than one physical fitness component (Colado, Chulvi and Heredia, 2008; Teixeira et al., 2015). For this, different activities (mobility exercises, strength exercises, aerobic exercises, etc.) are applied in the same training session. Particularly in strength exercises, movements similar to daily activities (pushing, pulling, squatting, etc.) are emphasized, which are executed at maximum concentric speed and associated with acceleration, deceleration and stabilization movements, in order to improve neuromuscular efficiency and strength of the trunk region (core) (Heredia, Peña and Moral, 2011). Cadore et al. (2014) found significant increases in handgrip strength, isometric strength and muscle power using a combination of force exercises performed at maximum concentric velocity, balance and gait during 12 weeks in fragile nonagenarians; which findings reflect the importance of using the power component in the training methodology for the elderly.

In this sense, the aim of the present study was to evaluate the effects of 12 weeks of a multicomponent training protocol on the functional fitness and quality of life of physically active older women.

\section{METHOD}

The study has an experimental and longitudinal design, with the purpose of evaluating the degree of change generated by multicomponent training, controlling the action of intervening factors and describing the behavior of variables observed from the intervention (Thomas, Nelson \& Silverman, 2007).

\section{Participants}

Twenty-six women who have been practicing physical exercise in the last three months were randomly assigned into two different groups: Multicomponent Training (MT: $\mathrm{n}=15,65.60 \pm$ 5.10 years, $\left.28.50 \pm 5.50 \mathrm{~kg} / \mathrm{m}^{2}\right)$ and Control Group (CG: $\mathrm{n}=11,62.50 \pm 5.30$ years, $30.40 \pm$ $5.90 \mathrm{~kg} / \mathrm{m}^{2}$ ). Inclusion criteria were: a) female sex; b) age above 60 years; c) be free from situations that may prevent intervention or tests applied. Exclusion criteria were: a) enrollment in another physical activity program; and b) attendance of less than $85 \%$ in the program. After information about the study objectives and procedures to which they would be submitted, volunteers signed the free and informed consent form and the study was approved by the Research Ethics Committee of the Federal University of Sergipe (No. 1.021 .732 / CAAE: 42022915.9.0000.5546), and the experiment complies with the Declaration of Helsinki for research involving human beings.

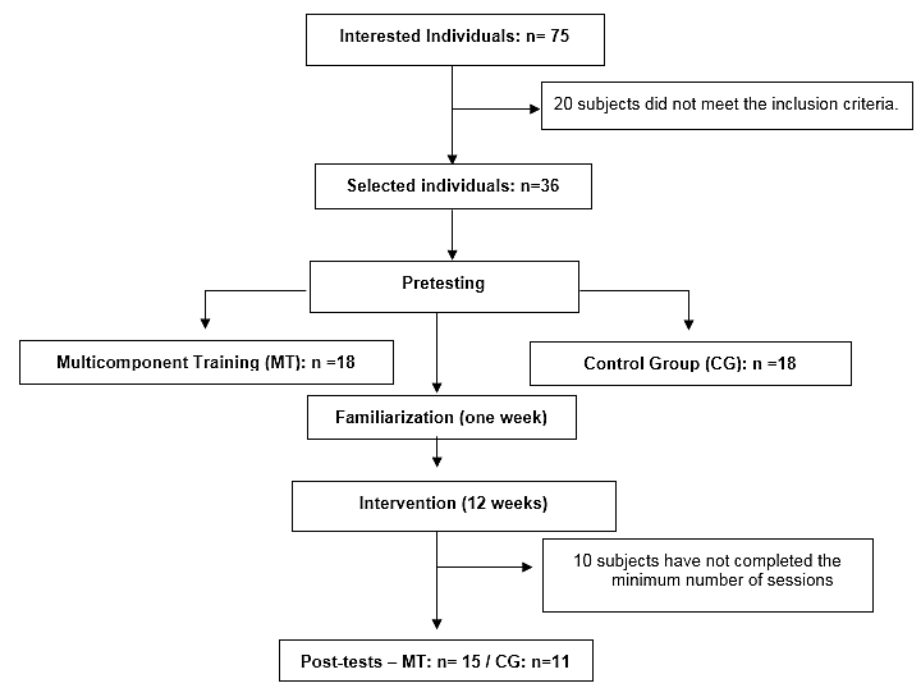

Figure 1. Experimental Design 


\section{Intervention}

The intervention lasted twelve weeks and was practiced in three weekly sessions of approximately 50 minutes on nonconsecutive days, respecting the recovery time between the fortyeight hour sessions. The OMNI-GSE scale (Da Silva-Grigoletto; Viana-Montaner; Heredia, 2013) was used to control the overall training intensity. CG participants performed stretches with submaximal joint amplitude levels and relaxation practices in order to reduce the evasion of this group during the intervention period. MT participants performed training sessions divided into four blocks. In the first block, participants performed five minutes of mobility exercises for major body joints, about five exercises per joint and a series of eight seconds per exercise, as well as general warm-up exercises that included ten free squatting repetitions and ten jumping jack repetitions.

In the second block, MT participants performed fifteen minutes of continuous walking, with values between 6 and 7 on the OMINI-GSE scale, with change of direction through a pre-established distance of eighty-six meters. In the third block, they performed strength exercises on bodybuilding apparatus, in circuit format, composed of eight exercises (stations), two sets of 8 to 12 repetitions, intensity between 7 and 8 on the OMINI-GSE scale, with ratio between stimulus and passive recovery of 30/30 seconds. Exercises were performed aiming at the improvement of movement patterns essential to the activities of the daily living (pushing, pulling and squatting) at maximum concentric speed. The exercises used in the program are described in table 1. Regarding intensity progression, if the volunteer performed more than the maximum number of pre-established repetitions ( $>12$ ), an increase of 5 to $15 \%$ in the external load was performed.

For logistical reasons, in the third block (strength exercises), participants trained in pairs, being supervised by experienced instructors whose responsibility was to maintain the established protocols and ensure an optimal standard of execution, as well as safety and motivation.
In the fourth block, five minutes of high intensity interval training (HIIT) were applied through activities such as tug of war, interval running or aerobic gymnastics, with density of $1 / 1$ and between 8 and 9 on the OMNI-GSE scale in each high-intensity stimulus.

Table 1

Strength exercises performed by the multicomponent training group during the twelve weeks of intervention.

\begin{tabular}{cc}
\hline Week 1 to 6 & Week 7 to 12 \\
\hline Squat smith machine & Back squat \\
Seated row & Seated row \\
Knee flexion machine & Knee extension machine \\
Pulled on high pulley & Pulled on high pulley \\
Leg press $45^{\circ}$ & Abdominal Flexion (Curl \\
& Up) \\
Stiff leg deadlift & One-sided knee flexion \\
Standing plantar flexion & Leg Press $45^{\circ}$ plantar flex- \\
& ion \\
Vertical bench press & Horizontal bench press \\
\hline
\end{tabular}

Note. Exercises were performed at maximum concentric speed, in circuit format, with two passages in each exercise, range of repetitions between 08 and 12 .

\section{Procedures}

The initial evaluation included anamnesis with questions regarding sociodemographic aspects, health characterization, type and quantity of medications used, presence of diseases and physical activity level (report of daily living and work activities). Subsequently, a medical evaluation was carried out to know the current state of the physiological parameters of each individual. Finally, they were submitted to a dietary assessment by means of a 24 -hour recall applied by specialized nutritionists (de Andrade Gomes et al., 2015) to control feeding during the training period.

The test battery was performed in three moments: pre-test (M1); retest after the familiarization week (M2); and after 12 weeks of intervention (M3). The organization of tests was planned so that one test influenced as little as possible in the results of the others, and the evaluations were performed in a single day and in the following order: anthropometric measurements, Questionnaires (Mini Mental State Examination and WHOQOL-Bref) and the Senior Fitness Test battery.

For the anthropometric characterization, body weight $(\mathrm{kg})$ was measured through a scale 
(Lider ${ }^{\circledR}$, P150C, São Paulo, Brazil) with maximum capacity of $150 \mathrm{~kg}$. Height $(\mathrm{cm})$ was determined through a stadiometer (Sanny, ES2030, São Paulo, Brazil).

The Mini Mental State Examination (MMSE) is defined as a cognitive evaluation test, consisting of a score ranging from zero to 30 points that aims to provide data on various cognitive parameters of any geriatric population. The application of this test was used only to characterize the sample.

Quality of life was assessed using the WHOQOL-BREF structured questionnaire (Fleck, Chachamovich \& Trentini, 2006), which values individual perception in different groups and situations. The test consists of 26 questions, including four domains of life: physical, psychological, social and environmental factors. Responses follow the Likert scale (from 1 to 5 ; the higher the score, the better the quality of life).

Functional capacity was verified through the Senior Fitness Test battery proposed by Rikli and Jones (1999), using tests that evaluate physiological attributes (agility / dynamic balance, muscular strength of the lower and upper limbs, and cardiorespiratory capacity) to perform normal daily activities safely and independently, without excessive fatigue:

Bach Stratch: During the test, participant stands on two feet, and the distance between dactiloidals was measured with a ruler (+ or -), while one arm crosses over the other arm under the body, trying to touch the back, this is an important test to measure the flexibility of the scapular girdle, which is paramount for tasks such as putting on a dress, combing hair, scratching or washing the back and putting on a seat belt.

Chair sit-and-reach: Participant is leaning against the chair without armrest, one leg is held at 90 degrees and the other fully extended, the trunk is flexed frontward with hands overlapping and fingers outstretched to reach beyond the tip of the foot, and this distance is measured with a ruler ( + or -$)$, this test proposes to measure the flexibility of the posterior body chain, which is of extreme importance for good gait and adoption of good body posture, also reflecting in mobility tasks like getting in and out of a car and lying down and getting up from the bed.

8-ft up-and-go: Participant is sitting on a chair without armrest and should perform the movement of getting up and walking quickly, but not running, and turn around a cone that will be positioned at a distance of 2.40 meters from the chair. The run time of the test is timed by an evaluator and three repetitions are performed. Such a test is designed to evaluate agility and dynamic balance, an important component for rapid maneuvers, essential in activities such as speeding up to answer the telephone, taking a pan from the stove, or going to the bathroom quickly.

Arm curl: The subject is positioned sitting in a chair without arm support, holding a $3 \mathrm{~kg}$ halter and must perform the flexing movement of the forearm on the arm, repetition is only considered when the elbow is fully extended and flexed completely, this test proposes to measure the strength and resistance of upper limbs that is paramount in domestic activities such as lifting and carrying groceries, carrying bags or equipment, carrying the grandchildren. The total number of runs in 30 seconds is recorded, so the final value will be added to the average of both sides divided by two.

30s -chair stand: Starting from the sitting position in a chair leaning against the wall and without an armrest, the participant with arms folded over the shoulders should in 30 seconds perform as many repetitions as possible, repetition is only considered when there is complete hip extension and the participant touches the gluteal region on the chair, this test is responsible for measuring the strength and resistance of lower limbs, which is paramount for tasks such as transferring to a chair, climbing stairs, moving for a transport and a simple walk. The total number of runs performed in 30 seconds is recorded.

6-min walk: During the test, participants walked for 6 minutes a distance of 50 meters in a rectangle format where along the route, mediumsized cones were placed as a way of signaling and provide a better notion of the space that should be covered. At the end of the 6 minutes, the distance traveled by participants was measured. This 
test aims to evaluate the aerobic resistance, which is paramount in activities such as climbing stairs, traveling long distances, shopping with the family or going out for a walk with friends.

\section{Statistical Analysis}

Data were expressed in descriptive statistics with mean and standard deviation. The sample size was calculated using the $G$ * Power software version 3.1.9.2 (Erdfelder, Faul, \& Buchner, 1996; Kiel, Germany) based on the results obtained by Milton et al. (2008) on the sitting and standing test. The Shapiro-Wilk test was applied to verify the sample normality. The $2 \times 2$ ANOVA was used for comparative analyses between groups at two different times. When necessary, Bonferroni's post hoc was run for multiple comparisons. The significance level was $\mathrm{P} \leq 0.05$. The effect size was calculated through the equation proposed by Cohen (1990), as well as the classification of each result. All statistical procedures were performed in SPSS software version 22.0 (IBM, Inc).

\section{RESULTS}

The average participation rate was 30 sessions of total 36 and the sample loss was ten individuals. MT group had three exclusions, one for medical reasons and two for not complying with all study steps. CG had 7 exclusions, three of them for medical reasons and four for not completing the final evaluation. The results of life quality interventions and applied physical tests are presented in table 3 .

Table 2

Characteristics of Multicomponent Training (MT) and Control Group (CG) participants. Values presented as mean and standard deviation $(M \pm S D)$

\begin{tabular}{ccc}
\hline Variables & MT $(\mathrm{n}=18)$ & CG $(\mathrm{n}=18)$ \\
\hline Age & $65,60 \pm 5,10$ & $62,50 \pm 3,00$ \\
Weigth $(\mathrm{Kg})$ & $65,80 \pm 12,80$ & $72,50 \pm 14,40$ \\
Height $(\mathrm{cm})$ & $152,00 \pm 7,00$ & $154,40 \pm 7,80$ \\
BMI $\left(\mathrm{kg} / \mathrm{m}^{2}\right)$ & $28,50 \pm 5,50$ & $30,40 \pm 5,90$ \\
MEEM & $25,70 \pm 3,60$ & $24,10 \pm 2,80$ \\
\hline
\end{tabular}

Note. No statistically significant differences were found between groups in the pre-test.

Table 3

Effects of twelve weeks of multicomponent training on physical fitness and quality of life of physically active older women.

\begin{tabular}{lccccccc}
\hline \multicolumn{7}{c}{ Tests } & \multicolumn{7}{c}{ MT } & \multicolumn{7}{c}{ CG } & CG & $\Delta \%$ & ES \\
& Pre & Pos & $\Delta \%$ & Pre & Pos & 0.41 \\
Chair sit-and-reach (cm) & $0,6 \pm 7,5$ & $6,5 \pm 7,1^{*}$ & 96 & $-0,8 \pm 8,4$ & $6,8 \pm 7,3^{*}$ & 209 & 0.17 \\
Back Stratch (cm) & $-5,3 \pm 10,7$ & $-0,3 \pm 9,0^{*}$ & 85 & $-6,9 \pm 10,7$ & $-1,0 \pm 7,4^{*}$ & 72 & 0.17 \\
30-s chair stand (rep) & $19,5 \pm 3,4$ & $22,3 \pm 2,9^{* *}$ & 14 & $18,0 \pm 2,6$ & $19,0 \pm 3,4^{*}$ & 5 & 0.97 \\
Arm curl (rep) & $18,2 \pm 3,1$ & $23,0 \pm 2,8^{* *}$ & 26 & $17,5 \pm 3,6$ & $20,6 \pm 2,0^{*}$ & 17 & 1.2 \\
6-min walk (meters) & $533,9 \pm 48,7$ & $563,4 \pm 51,1^{*}$ & 5 & $517,1 \pm 41$ & $549,4 \pm 40,7^{*}$ & 6 & 0.34 \\
8-ft up-and-go (sec) & $5,4 \pm 0,5$ & $4,9 \pm 0,5^{* *}$ & 10 & $5,8 \pm 0,7$ & $5,6 \pm 0,6^{*}$ & 3 & 1.16 \\
WHOQOOL (points) & $98,3 \pm 13,1$ & $101,3 \pm 12,8^{* *}$ & 3 & $86,4 \pm 8,7$ & $89,6 \pm 8,0^{*}$ & 3,7 & 1.46 \\
\hline
\end{tabular}

* Significant difference in relation to pre-test. \# Significant difference between groups. $\Delta \%$ : change percentage from pre- to posttest. $\mathrm{ES}=$ effect size from pre- to post-test. Triv = Trivial; Mod = Moderate; Grand = large.

Twelve weeks after intervention, MT group presented significant differences in relation to CG in quality of life, agility / dynamic balance, lower and upper limb strength. However, in the cardiorespiratory resistance, shoulder and posterior chain flexibility, no significant differences were observed between groups.

\section{DISCUSSION}

The results of the present study demonstrated that both groups showed improvement in all variables analyzed, both in functional fitness and quality of life. However, the MT group showed advantages over CG in 3 of the 6 variables analyzed in functional fitness, in addition to more expressive results in quality of life.

The most evident multisystemic adaptations in MT are justified by the combination of different physical exercises in the same training session. The exercise session organized in distinct blocks followed recommendations previously published by our group (Resende-Neto, Da SilvaGrigolleto, Santos e Cyrino, 2016), which aims, 
besides contemplating different training modalities in a short period of time ( $\sim 1$ hour), applying such modalities in a sequence that allows a gradual increase in intensity and complexity, respecting the particularities of older individuals.

Dynamic stretching exercises performed at maximum range of motion (Block 1) help maintaining adequate levels of joint mobility in the structures most commonly used in everyday activities (De Oliveira et al., 2016) and continuous walking (Block 2) helps maintaining and / or improving various aspects of the cardiovascular function (LaCroix et al., 1996). Endurance exercises respecting functional patterns and stimulating muscular power (Block 3 ) help compensating natural losses resulting from sarcopenia (Borde et al., 2015). HIIT (Block 4) is also an option for improving cardiorespiratory resistance (Milanovic et al., 2015).

Hakkinen et al. (1993) and Izquierdo et al., (1999) demonstrated that elderly subjects submitted to strength training with exercises performed at maximum concentric speed showed a significant increase in muscle mass, strength, power and neuromuscular activation capacity.

However, recent studies have suggested that MT, including strength exercises, may be an interesting strategy to promote multisystemic adaptations in the elderly (Resende-Neto et al., 2016b; Bouaziz et al., 2016), and are more effective than isolated strength training for this purpose (Liu et al., 2014; Resende-Neto, Da SilvaGrigolleto, Santos e Cyrino, 2016).

After 12 weeks of MT in fragile nonagenarians, Cadore et al. (2014) showed a significant improvement in strength and power performance, muscle mass, intramuscular fat infiltration, functional task performance (agility, standing up from a chair, balance, double tasks), in addition to a reduction in the incidence of falls.

Krebs et al. (2007) found greater gait velocity, improved dynamic balance, increased maximal knee torque and improved coordination during the performance of daily activities in an MT group.

Improvement in quality of life can be considered a global result of participation in a physical exercise program aimed at active aging, involving aspects such as lifestyle change, improvement of health and physical and psychological well-being, reduction of diseases and improved social interaction. Aveiro et al. (2004) found that physical training methodologies that aim to increase muscular strength result in beneficial effects on quality of life.

Castro et al. (2009) applied the WHOQOOL questionnaire in elderly MT practitioners (meditation, dance and bodybuilding) and found improvements in quality of life when compared to another group of elderly individuals who performed conventional activities (unicomponent training).

The present research focused on analyzing adaptive responses to a training protocol with emerging particularities in the scientific community, providing important information about the benefits of MT for functional fitness and quality of life in the elderly. Future studies should apply longer-term interventions with greater number of volunteers. We believe that this study may stimulate the development of new studies to confront results, as well as broaden knowledge about the subject and better support practical applications.

\section{CONCLUSIONS}

The MT protocol applied in the present study promoted positive and significant effects on quality of life and important components of physical fitness such as balance, strength, muscular power, aerobic endurance and flexibility in physically active older women. Thus, the present research demonstrates that the combination of different activities (e.g., mobility, strength, power, endurance) and intensities (e.g., moderate, high) in a training session is a fundamental feature in physical training protocols for the elderly aimed at multisystemic adaptations.

\footnotetext{
Acknowledgments:

For the integrants of Functional Training Group by UFS. Thank you, Albanir, Vanessa, Iohana, Letícia, Eduardo, Marta, Alan, Elenilton, Marcely, Jadson, Gabriel, Diego, Rafael e Lucas, for building this pro-ject.
} 
Conflict of interests:

Nothing to declare

\section{Funding:}

Coordenação de Aperfeiçoamento de Pessoal de Nível Superior (Capes).

\section{REFERENCES}

Aveiro, M. C., Navega, M. T., Granito, R. N., Rennó, A. C. M., \& Oishi, J. (2004). Efeitos de um programa de atividade física no equilíbrio e na força muscular do quadríceps em mulheres osteoporóticas visando uma melhoria na qualidade de vida. Rev Bras de Ciência e Movimento, 12(3), 33-8.

Borde, R., Hortobágyi, T., \& Granacher, U. (2015). Dose-response relationships of resistance training in healthy Old adults: a systematic review and meta-analysis. Sports Medicine (Auckland, NZ), 45(12), 1693.

Cadore, E. L., Casas-Herrero, A., Zambom-Ferraresi, F., Idoate, F., Millor, N., Gómez, M., ... \& Izquierdo, M. (2014). Multicomponent exercises including muscle power training enhance muscle mass, power output, and functional outcomes in institutionalized frail nonagenarians. Age, 36(2), 773-785.

Castro, J. C., Bastos, F. A. C., Cruz, T. H. P., Giani, T. S., Ferreira, M. D. A., \& Dantas, E. H. M. (2009). Níveis de qualidade de vida em idosas ativas praticantes de dança, musculação e meditação. Rev Bras Geriatr Gerontol, 12(2), 255-65.

Chodzko-Zajko, W. J., Proctor, D. N., Singh, M. A. F., Minson, C. T., Nigg, C. R., Salem, G. J., \& Skinner, J. S. (2009). Exercise and physical activity for older adults. Medicine $\mathcal{E}$ science in sports $\&$ exercise, 41 (7), 1510-1530.

Colado, J. C., Chulvi, I., \& Heredia, J. R. (2008). Criterios para el diseño de los programas de acondicionamiento muscular desde una perspectiva funcional. Ejercicio físico en salas de acondicionamiento muscular: bases científico-médicas para una práctica segura y saludable. Madrid: Panamericana.

de Andrade Gomes, A., Pereira, R. A., \& Yokoo, E. M. (2015). Caracterização do consumo alimentar de adultos por meio de questionário simplificado: contribuição para os estudos de vigilância alimentar e nutricional. Cadernos Saúde Coletiva, 23(4).

de Oliveira, L. C., de Oliveira, R. G., \& de Almeida Pires-Oliveira, D. A. (2016). Comparison between static stretching and the Pilates method on the flexibility of older women. Journal of bodywork and movement therapies, 20(4), 800-806.

Erdfelder, E., Faul, F., \& Buchner, A. (1996). GPOWER: A general power analysis program. Behavior research methods, instruments, \& computers, 28(1), 1-11.
Fleck, M. P., Chachamovich, E., \& Trentini, C. (2006). Desenvolvimento e validação da versão em Português do módulo WHOQOL-OLD. Revista de Saúde Pública, 40(5), 785-791.

Häkkinen, K., \& Häkkinen, A. (1993). Neuromuscular adaptations during strength training in middleaged and elderly males and females. Journal of Biomechanics, 26(3), 293.

Heredia, J. R., Peña, G., \& Moral, S. (2011). Entrenamiento funcional en Sañudo B y García B (Coordinadores): Nuevas orientaciones para una actividad física saludable en centros de fitness. Editorial Wanceulen.

Hughes, D. C., Wallace, M. A., \& Baar, K. (2015). Effects of aging, exercise, and disease on force transfer in skeletal muscle. American Journal of Physiology-Endocrinology and Metabolism, 309(1), E1-E10.

Hunter, S. K., Pereira, H. M., \& Keenan, K. G. (2016). The aging neuromuscular system and motor performance. Journal of applied physiology, 121(4), 982-995.

Izquierdo, M., Aguado, X., Gonzalez, R., Lopez, J. L., \& Häkkinen, K. (1999). Maximal and explosive force production capacity and balance performance in men of different ages. European Journal of Applied Physiology and Occupational Physiology, 79(3), 260-267.

Krebs, D. E., Scarborough, D. M., \& McGibbon, C. A. (2007). Functional vs. strength training in disabled elderly outpatients. American journal of physical medicine \& rehabilitation, 86(2), 93-103.

LaCroix, A. Z., Leveille, S. G., Hecht, J. A., Grothaus, L. C., \& Wagner, E. H. (1996). Does walking decrease the risk of cardiovascular disease hospitalizations and death in older adults?. Journal of the American Geriatrics Society, 44(2), 113-120.

Liu, C. J., Shiroy, D. M., Jones, L. Y., \& Clark, D. O. (2014). Systematic review of functional training on muscle strength, physical functioning, and activities of daily living in older adults. European Review of Aging and Physical Activity, 11 (2), 95.

Milanovic, Z., Sporis, G., \& Weston, M. (2015). Effectiveness of High-Intensity Interval Training (HIT) and Continuous Endurance Training for $\mathrm{VO}^{\wedge}$ sub $2 \max ^{\wedge}$ Improvements: A Systematic Review and Meta-Analysis of Controlled Trials. Sports medicine, 45(10), 1469.

Milton, D., Porcari, J. P., Foster, C., Gibson, M., \& Udermann, B. (2008). The effect of functional exercise training on functional fitness levels of older adults. Gundersen Lutheran Medical Journal, 5(1), 48.

Resende-Neto AG, Feitosa Neta ML, Santos MS, La Scala Teixeira CV, de Sá CA, Da Silva-Grigoletto ME. Treinamento funcional versus treinamento de força tradicional: efeitos sobre indicadores da aptidão física em idosas pré-frageis. Motricidade . 2016b Sup., Vol. 12 Issue S2, p44-53. 10p.

Resende-Neto, A. G., Da Silva-Grigoletto, M. E., Santos, M. S., \& Cyrino, E. S. (2016). Treinamento 
funcional para idosos: uma breve revisão. Revista Brasileira de Ciência e Movimento, 24(3), 167-177.

Rikli, R. E., \& Jones, C. J. (1999). Development and validation of a functional fitness test for community-residing older adults. Journal of aging and physical activity, 7(2), 129-161.

Silva-Grigoletto, D., Viana-Montaner, B. H., Heredia, J., Mata Ordóñez, F., Peña, G., Brito, C. J., ... \& García-Manso, J. M. (2013). Validación de la escala de valoración subjetiva del esfuerzo OMNIGSE para el control de la intensidad global en sesiones de objetivos múltiples en personas mayores.
Silva-Grigoletto, M. E. D., Brito, C. J., \& Heredia, J. R. (2014). Functional training: functional for what and for whom?. Revista Brasileira de Cineantropometria \& Desempenho Humano, 16(6), 714-719.

Teixeira, C. V. L. S., Evangelista, A. L., Pereira, C. A., \& Da Silva-Grigoletto, M. E. (2015). Short roundtable RBCM: treinamento funcional. Revista Brasileira de Ciência e Movimento, 24(1), 200-206.

Thomas, J. R., Nelson, J. K., \& Silverman, S. J. (2007). Métodos de pesquisa em educação física. Porto Alegre: Editora ArteMed.

Westcott, W. L. (2012). Resistance training is medicine: effects of strength training on health. Current sports medicine reports, 11(4), 209-216.

All content of Journal Motricidade is licensed under Creative Commons, except when otherwise specified and in content retrieved from other bibliographic sources. 


\title{
Influence of physical activity levels on the self-esteem of female students
}

\author{
Martha Maria Viana de Bragança1,2,3,4*, Alfonso Salguero del Valle ${ }^{4,5}$, Sara Márquez Rosa ${ }^{4,5}$, \\ Elizabeth Carpio-Rivera 6 , Afrânio de Andrade Bastos ${ }^{1,2,7}$, Robélius De Bortoli ${ }^{1,3,8}$, Olga \\ Molinero González ${ }^{4,5,9}$
}

\begin{abstract}
The recognition of the beneficial effects of physical exercise from the psychological point of view is an increasingly evident fact. The aim of this study was to verify the influence of physical activity level (PAL) and age on indicators of psychological well-being, such as self-esteem, in female students. A total of 572 girls aged 11-18 years (14.6 \pm 2.1 years) from various schools in the city of León (Spain) participated in the study. The Spanish version of the Four-by-One-Day Physical Activity Questionnaire and the Rosenberg Self-Esteem Scale - RSES were used to collect data. It was observed that, as age increases, the amount of physical activity that students perform decreases. Significant associations were observed between the different age groups and self-esteem and PAL. It was concluded that there is a high prevalence of students with "low" or "very low" physical activity levels; however, age seems to influence self-esteem levels.

Keywords: Motor activity, Adolescent, Mental health, Self-esteem.
\end{abstract}

\section{INTRODUCTION}

The recognition of the beneficial effects of physical exercise in all aspects is an increasingly evident fact, with research being conducted in all countries (Córdoba et al., 2014; Márquez \& González-Boto, 2009; Pescatello et al., 2015). However, although a large amount of publications have shown these effects, there is a high prevalence of low physical activity levels in adolescents, and it is estimated that scientific and technological progress is influencing the population's lifestyle, causing a worrying increase in sedentary behavior (Abajo \& Márquez, 2009).

In this perspective, studies suggest that the adoption of an active lifestyle from an early age will contribute to an adequate prevention and reduction of the incidence of cardiovascular pathologies, metabolic and ischemic diseases, cancer, and diabetes, among others (Córdoba et al., 2014; World Health Organization [WHO], 2010. In addition, studies point out that there is a direct relationship between regular physical activity and psychological health in all age groups (Márquez \& González-Boto, 2009, Salguero, Molinero \& Márquez, 2011, Zurita-Ortega et al., 2016).

Among the age groups, it is verified that psychological health is affected, to a great extent, in adolescence. It is at this stage that physical, social, and psychic transformations begin, which

\footnotetext{
${ }^{1}$ Departamento de Educação Física, Universidade Federal de Sergipe, DEF/UFS.

${ }^{2}$ Núcleo de Pesquisa em Aptidão Física, Saúde e Desempenho de Sergipe/UFS, NUPAFISE.

${ }^{3}$ Laboratório de Pesquisa do Desenvolvimento Cognitivo Humano/UFS, LADEC.

${ }^{4}$ Programa de Doctorado en Ciencias de la Actividad física y el Deporte, Universidad de León, León, España.

${ }^{5}$ Facultad de Ciencias de la Actividad Física y el Deporte e Instituto de Biomedicina, IBIOMED, Universidad de León, León, España.

${ }^{6}$ Escuela de Educación Física y Deportes, Universidad de Costa Rica, EDUFI/UCR.

${ }^{7}$ Programa de Pós-Graduação em Educação Física da Universidade Federal de Sergipe, PPGEF/UFS.

${ }^{8}$ Programa de Pós-Graduação em Ciência da Propriedade Intelectual da Universidade Federal de Sergipe, PPGPI/UFS.

${ }^{9}$ Facultad de Educación, Universidad Autónoma de Chile, Chile.

* Autor correspondente: Núcleo de Pesquisa em Aptidão Física, Saúde e Desempenho de Sergipe, Departamento de Educação Física, Universidade Federal de Sergipe, Cidade Universitária Prof. José Aloisio de Campos, Jardim Rosa Elze. CEP: 49100-000. São Cristóvão/SE, Brasil. E-mail: marthabragancaufs@gmail.com
} 
can directly affect self-esteem, which is closely related to self-concept. Although self-esteem is a general sense of value as a person, that is, a person's assessment of himself that can be positive or negative (Harter, 1988; Rosenberg, 1965), self-concept is the perception, thought, and feeling that each person has on himself related to different domains: physical, behavioral, emotional, cognitive, social (Harter, 1988; Rosenberg, 1979).

In addition, young people feel the need for social approval and believe that they can achieve it through behaviors recommended and accepted by society (Crowne \& Marlowe, 1964). On the other hand, it is also in adolescence where good behaviors and habits of life are developed and when the patterns of healthy behaviors of adults begin to appear, being worth mentioning those related to the practice of physical activity and physical exercise (Gil de Montes, Arruza, Arribas, Irazusta \& Telletxea, 2011).

In fact, analyzing certain aspects that relate physical activity to psychological well-being in different populations, it was observed that regular physical activity promotes a positive impact on mental health, quality of life, reduces stress, promotes changes in emotional states and moods, reduces anxiety and depression levels, improves self-concept and self-esteem, and increases self-efficacy and social approval (Rodríguez-Hernández, Cruz, Feu \& MartínezSantos, 2011; Salguero et al. 2011; Zurita-Ortega et al., 2016).

Regarding age and gender, studies indicate that female adolescents present a decrease in physical activity practice during adolescence and a decrease in Physical Activity Level (PAL) in relation to the advancement of age and when compared to male individuals, which may compromise their psychological health (Cano Garcinuño, Pérez García, Casares Alonso \& Alberola López, 2011; Martinez, Aznar \& Conteras, 2015).

Thus, the aim of this study was to verify the influence of physical activity level and age on indicators of psychological well-being, such as self-esteem, in female students.

\section{METHOD}

\section{Participants}

This is a cross-sectional study with a quantitative approach and the Ethics Committee of the University of León (2007/00066/001) approved the study protocol. A total of 572 female students enrolled in Elementary and High Schools aged 11-18 years, with mean age of 14.6 $( \pm 2.1)$ years, from different schools in the city of León, Spain, participated in the study.

\section{Instruments}

A calibrated scale Seca 703® (Hamburg, Germany) was used to measure the weight of participants.

To evaluate PAL, the Physical Activity Assessment Questionnaire (Cantera-Garde, 1997), Spanish version of the Four-by-One-Day Physical Activity Questionnaire (FBODPAQ Cale, 1993) was used. This instrument makes it possible to record both the physical activity performed on Weekday (WD) and on the Weekend (WE). Regarding WD, daily habits from Monday to Friday were evaluated (before school, during classes, recess, lunch time and after school). In WE, daily habits are evaluated over the weekend (morning, afternoon and evening).

To record the caloric expenditure, the unit of measurement of the metabolic index (mets) was used, which was multiplied by the time spent in each activity in order to obtain the corresponding kilocalories. In this way, it was possible to estimate the total caloric expenditure and to determine PAL, which allowed classifying students into four levels: 1- "very inactive"; 2"inactive"; 3 - "moderately active"; and 4 - "active".

The Rosenberg Self-Esteem Scale (RSES) (Rosenberg, 1965) is among the most widely used and well-known instruments to measure self-esteem. In this study, the Spanish adaptation for adolescents validated by Atienza, Moreno \& Balaguer (2000) was used, which is a scale for the evaluation of global self-esteem whose focus is to measure the feelings of respect and acceptance of oneself. It consists of 10 items, half of them being stated positively and the other half negatively. 
Responses are graded using a 4-point Likert scale, where 1 corresponds to "totally agree" and 4 to "totally disagree". The total score can range from 10 to 40 points.

\section{Procedures}

Initially, contact was made with the management of participating schools. Subsequently, students and their respective parents or guardians, who voluntarily agreed to participate in the survey, were informed of the study's objectives and procedures.

Prior to the application of questionnaires, informed consent was administered, which, in the case of minors, should be signed by parents or guardians. The application of the questionnaires was done in a collective way, according to the ethical principles that prevail in human investigations, as recommended by the Declaration of Helsinki (1964, reformulated in 1975, 1983, 1989, 1996, 2000, 2008 and 2013) of the World Medical Association, and ensured anonymity, privacy and confidentiality. Throughout the time, the team of previously trained researchers was present to help resolve any doubts arising during the administration.

\section{Statistical analysis}

Descriptive statistics (mean and standard deviation) were used to characterize the sample. In order to verify the associations between PAL and variables self-esteem and age, the Pearson's chi-square was used. The significance level was $p$ $\leq 0.05$.

Analyses were performed using SPSS for Windows ${ }^{\circledR}$ software (Chicago, United States), version 21.0.

\section{RESULTS}

To meet the objectives of this research, students were classified into four groups according to PAL (Table 1) obtained from the estimation of the total caloric expenditure. This classification allowed obtaining the corresponding values for the energy expenditure, being possible to estimate the total caloric expenditure and, thus, to classify PAL. The majority of girls presented low PAL.

Table 1

Classification of physical activity levels of students from the estimation of total caloric expenditure

\begin{tabular}{lc}
\hline Physical activity level $\left(\mathrm{kcal}_{\mathrm{kg}}^{-1}\right.$.day & \\
\hline Very inactive $(<33.00)$ & $\mathrm{N}$ \\
Inactive $(33.00$ to 36.99$)$ & $250(43.70 \%)$ \\
Moderately active (37.00 to 39.99) & $68(11.90 \%)$ \\
Active ( $\geq 40.00)$ & $114(19.90 \%)$ \\
\hline Total & $572(100.00 \%)$ \\
\hline
\end{tabular}

The mean age of participants was 14.60 ( \pm 2.1) years, ranging from 11 to 18 years, and were classified by physical activity level and specific age group, according to table 2 .

When analyzing these two variables, PAL and age (Table 2), a statistically significant association was verified, which suggests that age is associated with PAL. In addition, data indicate that, in general, students have low PAL and, as the age increases, the amount of physical activity decreases.

One of the indicators of psychological wellbeing, object of this study, was self-esteem (SE). In order to determine their SE levels, students were classified into two groups: "low selfesteem", including subjects with score below the average of the group, and "high self-esteem", which included all those who scored above average. Then, SE levels were classified in relation to the age group, as shown in Table 3 .

It could be observed (Table 3 ) that there are significant associations between different age groups and SE levels, which indicate that age may affect PAL. It is also possible to observe that the percentage of girls with a high SE level decreases as age increases.

The results reported in Table 4 indicate that no significant association was found between PAL and SE level among students, although there is a trend in increasing the frequency of girls with high SE level as physical activity level increases. 
Table 2

Distribution of physical activity levels according to age groups (years) of students

\begin{tabular}{|c|c|c|c|c|c|}
\hline \multirow{2}{*}{ PAL } & \multicolumn{4}{|c|}{ Age groups (years) } & \multirow{2}{*}{ Total } \\
\hline & $11-12$ & $13-14$ & $15-16$ & $17-18$ & \\
\hline Very inactive & $53(31.70 \%)$ & $62(43.70 \%)$ & $93(52.20 \%)$ & $42(49.40 \%)$ & $250(43.70 \%)$ \\
\hline Inactive & $46(27.50 \%)$ & $27(19.00 \%)$ & $42(23.60 \%)$ & $25(29.40 \%)$ & $140(24.50 \%)$ \\
\hline Moderately active & $28(16.80 \%)$ & $19(13.40 \%)$ & $14(7.90 \%)$ & $7(8.30 \%)$ & $68(11.90 \%)$ \\
\hline Active & $40(24.00 \%)$ & $34(23.90 \%)$ & $29(16.30 \%)$ & $11(12.90 \%)$ & $114(19.90 \%)$ \\
\hline Total & $167(100.00 \%)$ & $142(100.00 \%)$ & $178(100.00 \%)$ & $85(100.00 \%)$ & $572(100.00 \%)$ \\
\hline
\end{tabular}

Statistically significant association for Pearson's chi-square $=25.109$, with $\mathrm{p} \leq 0.003$

Table 3

Distribution of self-esteem levels according to age groups (years) of students

\begin{tabular}{|c|c|c|c|c|c|}
\hline \multirow{2}{*}{ SE } & \multicolumn{4}{|c|}{ Age groups (years) } & \multirow{2}{*}{ Total } \\
\hline & $11-12$ & $13-14$ & $15-16$ & $17-18$ & \\
\hline Low & $52(31.10 \%)$ & $76(53.50 \%)$ & $115(64.60 \%)^{*}$ & $60(70.60 \%)$ & $303(53.00 \%)$ \\
\hline High & $115(68.90 \%)^{*}$ & $66(46.50 \%)$ & $63(35.40 \%)$ & $25(29.40 \%)$ & $269(47.00 \%)$ \\
\hline Total & $167(100.00 \%)$ & $142(100.00 \%)$ & $178(100.00 \%)$ & $85(100.00 \%)$ & $572(100.00 \%)$ \\
\hline
\end{tabular}

* Association statistically significant for Pearson's chi-square $=52.237$, with $\mathrm{p} \leq 0.001$

Table 4

Distribution of self-esteem levels according to the physical activity level of students

\begin{tabular}{|c|c|c|c|c|c|}
\hline \multirow{2}{*}{ SE } & \multicolumn{4}{|c|}{ PAL } & \multirow{2}{*}{ Total } \\
\hline & Very inactive & Inactive & Moderately active & Active & \\
\hline Low & $138(55.20 \%)$ & $73(52.10 \%)$ & $35(51.50 \%)$ & $57(50.00 \%)$ & $303(53.00 \%)$ \\
\hline High & $112(44.80 \%)$ & $67(47.90 \%)$ & $33(48.50 \%)$ & $57(50.00 \%)$ & $269(47.00 \%)$ \\
\hline Total & 250 (100.00\%) & $140(100.00 \%)$ & $68(100.00 \%)$ & $114(100.00 \%)$ & $572(100.00 \%)$ \\
\hline
\end{tabular}

Pearson's chi-square $=1.003$, with $\mathrm{p}=0.80$

\section{DISCUSSION}

Adolescence is a key period in the development of the individual where physical, social and psychological transformations occur, in addition to being a period of transition between childhood and adulthood. In addition, the majority of young people seek psychological wellbeing and social approval, either by their relatives, peers or by everything that makes up their surroundings, and many see the practice of physical-sport activities as a form of recognition and social acceptance, to learn to combine social obligations with values such as solidarity and team spirit, as well as to find their psychological well-being (Gallego, 2014).

The present study verified the influence of PAL and age on SE of female students. The analysis of variables PAL and age made it evident that as age increases, the amount of physical activity performed decreases, evidence also present in the studies of Bragança, Márquez \& Salguero (2015) and Cano Garcinuño et al.
(2011). In this sense, age is a variable that seems to influence PAL (Molinero, Martinez, Garatachea \& Márquez, 2010; Zamarripa Rivera, Ruiz-Juan, López Walle \& Fernandez Baños, 2013), perhaps since academic obligations, insertion in the labor market and increased responsibilities, the desire for independence and freedom increase significantly as age advances.

When psychological well-being is investigated, $\mathrm{SE}$ is one of the indicators used to evaluate it. The determination of SE levels can inform how each one thinks and feels about himself, either positively or negatively.

In the present study, when variables SE and age were verified, it was identified that SE decreases with age, which suggests that age can affect it. Low SE levels may lead to states of discouragement, sadness, leading to depression; therefore, such results may point the direction and purpose of future intervention actions. These results corroborate those obtained by Montes, Escudero \& Martínez (2012), where younger 
individuals (14 years or younger) were those with higher SE levels, as in the study by Salguero et al. (2011). Different results were found by Erol \& Orth (2011), Moreno, Cervelló \& Moreno (2008), and Orth \& Robins (2014), and by longitudinal studies that showed an increase in SE levels after 15 years, with a peak in this growth at $50-60$ years of age, followed by a considerable decrease in old age (Orth, Robins \& Widaman, 2012; Orth, Trzesniewski \& Robins, 2010).

According to Harter (1993), one of the best predictors of SE in women is physical appearance, which can be improved through physical-sporting activities. In this context, studies have shown that physically active individuals and those with high PAL have high self-concept levels (Candel, Olmedilla \& Blas, 2008; Infante, Goñi \& Villarroel, 2011), self-esteem levels (Biddle \& Asare, 2011; Kristjánsson, Sigfúsdóttir \& Allegrante, 2010; Salguero et al., 2011), and physical self-concept (Asghar, Wang, Linde \& Alfermann, 2013; Fernández, Contreras, García \& González, 2010; Reigal, Videra, Martín \& Juárez, 2013).

The results of the present study corroborated those of these studies, since a tendency was observed in the increase of SE as physical activity levels increase. Perhaps the most physically active girls have high SE because physical activity causes an improvement in physical condition and body aesthetics, as well as physical and psychic changes seem to be more balanced with the advancement of age. However, no association was found between these two variables. Perhaps the lack of association between PAL and SE may be related to the lack of motivation or fun of girls when they practice physical activity, since the activity alone would not increase the SE levels of participants (Huang, Norman, Zabinski, Calfas \& Patrick, 2007).

The results of the present study are similar to others that did not find association between participation in physical-sport activities and SE (Fisher, Juszczak \& Friedman, 1996; Molinero et al., 2004). However, studies have found a relationship between girls' self-perceptions and lifestyle with moderate (Gilson, Cooke \&
Mahoney, 2005), or intense physical activity (Strauss, 2001), and others found that psychological well-being is associated with the regular practice of physical activity (Jiménez, Martínez, Miró \& Sánchez, 2008; Salguero et al., 2011).

\section{CONCLUSIONS}

Based on the results obtained, there was a high prevalence of female students with low or very low physical activity levels. In addition, it was observed that physical activity levels and selfesteem progressively decrease as age increases. However, having certain physical activity level is not related to low or high self-esteem, but the age of these students seems to influence self-esteem and physical activity levels. Therefore, older girls will need greater attention in order to plan more specific and effective interventions to address this issue, having in mind the basic and preventive work to be done at a younger age.

In view of the above, it is necessary to seek strategies that increase adherence to physical exercise through intervention programs that stimulate the practice of physical and sports activities in school and out of school, since it may increase the self-esteem and physical activity level of practitioners. In this sense, the role of the school and, in particular, of physical education teachers is fundamental, but the participation of public institutions and municipal sports services is also important.

Acknowledgments:

Nothing to declare

Conflict of interests:

Nothing to declare

\section{Funding:}

Nothing to declare

\section{REFERENCES}

Abajo. S., \& Márquez, S. (2009). Salud y efectos beneficiosos de la actividad física. En S. Márquez 
\& N. Garatachea (Eds.), Actividad física y salud. (313). Madrid: Ediciones Díaz de Santos.

Asghar, E., Wang, X., Linde, K., \& Alfermann, D. (2013). Comparisons between Asian and German male adolescent athletes on goal orientation, physical self-concept, and competitive anxiety. International Journal of Sport and Exercise Psychology, 11(3), 229-243.

Atienza, F. L., Moreno, Y., \& Balaguer, I. (2000). Análisis de la dimensionalidad de la Escala de Autoestima de Rosenberg en una muestra de estudiantes valencianos. Revista de Psicología Universitas Tarraconensis, 22(1-2), 29-42.

Biddle, S. J. H., \& Asare, M. (2011). Physical activity and mental health in children and adolescents: a review of reviews. British Journal of Sports Medicine, 45(11), 886-895. doi:10.1136/886 bjsports2011-090185

Bragança, M., Márquez, S., \& Salguero, A. (2015). Consumo de alcohol, tabaco y otras drogas en chicas en edad escolar: relación con la edad y los niveles de actividad física. Scientia Plena, 11 (12), 1-9. doi: 10.14808/sci.plena.2015.122801

Cale, L. (1993). Monitoring physical activity in children. (Tesis doctoral). Loughborough University of Technology, London, England.

Candel, N., Olmedilla, A., \& Blas, A. (2008). Relaciones entre la práctica de actividad física y el autoconcepto, la ansiedad y la depresión en chicas adolescentes. Cuadernos de Psicología del Deporte, 8(1), 61-77.

Cano Garcinuño, A., Pérez García, I., Casares Alonso, I., \& Alberola López, S. (2011). Determinantes del nivel de actividad física en escolares y adolescentes: estudio OPACA. Anales de Pediatría, 74(1), 15-24. doi:10.1016/j.anpedi.2010.08.009

Cantera-Garde, M. A. (1997). Niveles de actividad física en la adolescencia: estudio realizado en la población escolar de la provincia de Teruel. (Tesis doctoral). Facultad de Medicina, Universidad de Zaragoza, España.

Córdoba, R., Camarelles, F., Muñoz, E., Gómez, J., Díaz, D., Ramírez, J. I., ... Cabezas, C. (2014). Recomendaciones sobre el estilo de vida. Atención Primaria, 46(S4), 16-23.

Crowne, D. P., \& Marlowe, D. (1964). The approval motives: studies in evaluative dependence. New York: Wiley.

Erol, R. Y., \& Orth, U. (2011). Self-esteem development from age 14 to 30 years: a longitudinal study. Journal of Personality and Social Psychology, 101(3), 607-619. doi: $10.1037 / \mathrm{a} 0024299$

Fernández, J. G., Contreras, O. R., García, L. M., \& González, S. (2010). Autoconcepto físico según la actividad físico-deportiva realizada y la motivación hacia ésta. Revista Latinoamericana de Psicología, 42(2), 251-283.

Fisher, M., Juszczak, L., \& Friedman, S. B. (1996). Sports participation in an urban high school: academic and psychologic correlates. Journal of Adolescent Health, 18(5), 329-334.

Gallego, B. (2014). La igualdad de género en la práctica deportiva y su contribución a la educación para la ciudadanía y la democracia. Journal for Educators, Teachers and Trainers, 5(3), 191-203.

Gil de Montes, L., Arruza, J. A., Arribas, S., Irazusta, S., \& Telletxea, S. (2011). The role of organized sports participation during adolescence in adult physical activity patterns. Sport Science Review, 20(5-6), 37-51. doi: 10.1037/a0024299

Gilson, N. D., Cooke, C. B., \& Mahoney, C. A. (2005). Adolescent physical self-perceptions, sport/exercise and lifestyle physical activity. Health Education, 105(6), 437-450.

Harter, S. (1988). Manual for the self-perception profile for adolescentes. Denver: University of Denver.

Harter, S. (1993). Causes and consequences of low self-esteem in children and adolescents. In R. B. Baumeister (Ed.): Self-esteem: the puzzle of low selfregard (pp. 87-116). New York: Plenum Press.

Huang, J. S., Norman, G. J., Zabinski, M. F., Calfas, K., \& Patrick, K. (2007). Body image and self-esteem among adolescents undergoing an intervention targeting dietary and physical activity behaviors. Journal of Adolescent Health, 40(3), 245-251. doi:10.1016/j.jadohealth.2006.09.026

Infante, G., Goñi, A., \& Villarroel, J. D. (2011). Actividad física y autoconcepto, físico y general, a lo largo de la edad adulta. Revista de Psicología del Deporte, 20(2), 429-444.

Jiménez, M. G. Martínez, P., Miró, E., \& Sánchez, A. I. (2008). Bienestar psicológico y hábitos saludables: ¿están asociados a la práctica de ejercicio físico? International Journal of Clinical and Health Psychology, 8(1), 185-202.

Kristjánsson, A. L., Sigfúsdóttir, I. D., \& Allegrante, J. P. (2010). Health behavior and academic achievement among adolescents: the relative contribution of dietary habits, physical activity, body mass index, and self-esteem. Health Education \& Behavior, 37(1), 51-64. doi: $10.1177 / 1090198107313481$

Márquez, S., \& González-Boto, R. (2009). Actividad física y bienestar subjetivo. In S. Márquez \& N. Garatachea (Eds.), Actividad física y salud (pp. 7198). Madrid: Ediciones Díaz de Santos.

Martínez, J., Aznar, S., \& Contreras, O. (2015). El recreo escolar como oportunidad de espacio y tiempo saludable. Revista Internacional de Medicina y Ciencias de la Actividad Física y el Deporte, 15(59), 419-432.

doi: http://dx.doi.org/10.15366/rimcafd2015.59.002

Molinero, O., Martínez, R., Garatachea, N., \& Márquez, S. (2010). Pautas de actividad física de adolescentes españolas: diferencias mediadas por la participación deportiva y el día de la semana. Revista de Psicología del Deporte, 19(1), 103-116.

Molinero, O., Martínez, R., Martín, C. M., Bragança, M., Salguero, A., \& Márquez, S. (2004). 
100 | M Bragança, AS del Valle, SM Rosa, et al.

Autoestima, habilidad física percibida y deseabilidad social en chicas adolescentes: relación con la práctica de actividad física. Acta del $V$ Congreso de la Asociación Española de Ciencias del Deporte, León.

Montes I., Escudero V., \& Martínez J. (2012). Nivel de autoestima de adolescentes escolarizados en zona rural de Pereira, Colombia. Revista Colombiana de Psiquiatria, 41 (3), 485-495.

Moreno, J. A., Cervelló, E., \& Moreno, R. (2008). Importancia de la práctica físico-deportiva y del género en el autoconcepto físico de los 9 a los 23 años. International Journal of Clinical and Health Psychology, 8(1), 171-183.

Orth, U., \& Robins, R. W. (2014). The development of self-esteem. Current Directions in Psychological Science, 23(5), 381-387. doi: $10.1177 / 0963721414547414$

Orth, U., Robins, R. W., \& Widaman, K. F. (2012). Life-span development of self-esteem and its effects on important life outcomes. Journal of Personality and Social Psychology, 102(6), 12711288. doi: $10.1037 / \mathrm{a} 0025558$

Orth, U., Trzesniewski, K. H., \& Robins, R. W. (2010). Self-esteem development from young adulthood to old age: a cohort-sequential longitudinal study. Journal of Personality and Social Psychology, 98(4), 645-658. doi: 10.1037/a0018769

Pescatello, L. S., MacDonald, H. V., Ash, G. I., Lamberti, L. M., Farguhar, W. B., Arena, R., \& Johnson, B. T. (2015). Assessing the existing professional exercise recommendations for hypertension: a review and recommendations for future research priorities. Mayo Clinical Proceedings, 90(6), 801-812.

Reigal, R., Videra, A., Martín, I., \& Juárez, R. (2013). Importancia del autoconcepto físico y la autoeficacia general en la predicción de la conducta de práctica física. Apunts. Educación Física $y$ Deportes, 112(2), 46-51.

Rodríguez-Hernández, A., Cruz, E., Feu, S. \& Martínez-Santos, R. (2011). Sedentarismo, obesidad y salud mental en la población española de 4 a 15 años de edad. Revista Española de Salud Pública, 85(4), 373-382.

Rosenberg, M. (1965). Society and the adolescent selfimage. New Jersey: Princeton University Press.

Rosenberg, M. (1979). Conceiving the self. New York: Basic.

Salguero, A., Molinero, O., \& Márquez, S. (2011). Beneficios psicológicos de un estilo de vida activo. In J. A. Casajús \& G. Vicente-Rodríguez (Coords.), Ejercicio físico y salud en poblaciones especiales. Exernet (pp. 79-99). Madrid: Consejo Superior de Deportes, Subdirección General de Deporte y Salud.

Strauss, R. S. (2001). Psychosocial correlates of physical activity in health children. Archives of Pediatrics and Adolescent Medicine, 155(8), 897-902.

World Health Organization (WHO) (2010). Global recommendations on physical activity for health. Geneva: WHO.

Zamarripa Rivera, J. I., Ruiz-Juan, F., López Walle, J. M., \& Fernandez Baños, R. (2013). Actividad e inactividad física durante el tiempo libre en la población adulta de Monterrey (Nuevo León, México). RETOS. Nuevas Tendencias en Educación Física, Deporte y Recreación, 24, 91-96.

Zurita-Ortega, F., Álvaro-González, J. I., CastroSánchez, M., Knox, E., Muros, J. J., \& VicianaGarófano, V. (2016). The influence of exercise on adolescents self-concept. International Journal of Sport Psychology, 47(1), 67-80. doi: 10.7352/IJSP 


\title{
Topological properties and dynamics of nets game shown by france and portugal in the final of european soccer cup 2016
}

\author{
Juan Manuel Martín-González¹, Rómulo Díaz-Díaz², Eduardo Ramos-Verde², Enrique \\ Arriaza-Ardiles $^{3,4}$, Marzo Edir Da Silva-Grigoletto ${ }^{5}$, Juan Manuel García-Manso ${ }^{2,3}$

\begin{abstract}
This paper explains some of the descriptive and organizational parameters underlying the theory of complex networks to understand how football team players interact, taking the pass as a reference. We analyze the offensive phase of the final of Euro 2016 football, which pitted France and Portugal teams. We used different strategies to determine the degree of interaction between the components of the analyzed teams. Specifically, we analyzed the effective number of passes and the number of peers with which each player is related; likewise, the geodesic distance and eccentricity. All within the basic descriptive parameters.

As organizational parameters, we consider the degree of centrality, levels of clustering and intermediation game values. Each of these parameters allows us to represent the play structure, examine the individual role of each player individually and understand the collective operation of the team. The results prove that the superiority in the different parameters within the game does not always guarantee a favorable marker. Keywords: Complexity, Football, Passes, Organizational parameters, descriptive parameters.
\end{abstract}

\section{INTRODUCTION}

The methodological strategies used have undergone a significant change in recent years. They have also incorporated the non-linear analysis of information in the reports provided to the people who have to use it to improve and optimize the specific work of training or matches.

One of the progressing analysis strategies in recent years is the interpretation of the game from the perspective of complex systems and, especially, using complex networks. Complex networks described many systems in nature. Topologically, they are graphs adding dynamic characteristics, necessary to study applying specific mathematical algorithms.

Although the first structured analysis based on this methodology dates from the 70s (Gould \& Gatrell, 1979), the most systematic application and with more different objectives is quite recent, when this last decade, it has joined the group of tools used by specialists although using different criteria in the study of specific matches, teams or tournaments (Cintia, Rinzivillo, \& Pappalardo; Clemente et al., 2015; Cotta, Mora, Merelo, \& Merelo-Molina, 2013; Duch, Waitzman, \& Amaral, 2010; Gama, Couceiro, Dias, \& Vaz, 2015; Grund, 2012; Onody \& de Castro, 2004; Pena \& Touchette, 2012; Sarangi \& Unlu, 2010). Although the proposal of many quantitative measures of complex networks in recent years, not all are easy to understand, calculate and use in football analysis and, specifically, to evaluate a network of passes. The pass is a fundamental technical element when attacking in football. It is to control the game and look how to get the goal. Usually, the teams with most passes often have more chances of goal but there are important aspects to consider. Playing to pass the ball is within the reach of many but passing the ball with meaning is within the reach of very few teams. However, only if close to the area, there are high chances of getting a favorable option to get a goal. Near the opposing goal, we can search or cause the opponent's failure and have a chance

\footnotetext{
${ }^{1}$ Department of de Physics of University of Las Palmas de Gran Canaria. Spain.

${ }^{2}$ Department of Physical Education of the University of Las Palmas de Gran Canaria. Spain

${ }^{3}$ Advanced Studies Center, CEA, University of Playa Ancha, Valparaiso, Chile.

${ }^{4}$ Facultad de Ciencias de la Actividad Física y el Deporte. University of Viña del Mar, Chile.

${ }^{5}$ University Program of Physical Education, Federal University Sergipe, San Cristobal, Brazil

* Corresponding author: Facultad de Ciencias de la Actividad Física y Del Deporte Campus Universitario de Tafira

S/N CP. 350017. Universidad de Las Palmas de Gran Canaria E-mail: eduardo.ramos@ulpgc.es
} 
to score. For these reasons, when it comes to studying football, the analysis of the passes network becomes important.

The objective of this paper is to analyze the football final of the European Soccer Cup 2016 of the National Teams from the perspective of networks, trying to explain the topology, dynamics and evolution both teams used in the game and trying to understand the reasons the final result is based.

\section{Sample}

We started from the official reports published by UEFA (http://uefa.com/uefaeuro/) and by Wyscout (https://wyscout.com), and the viewing and discussion of the video of the game once the tournament was over. Specifically, the passes performed by each team and the game network they generate were used as a reference parameter. The values of the player he was substituted were added to carry out the analysis in the case of the substituted players.

\section{Procedures}

We will use two types of indicators or parameters for the quantitative analysis of the network: the basic descriptive parameters and the organizational parameters of the network. These indicators will be used individually or collectively according to the needs of the study.

Although individual, the descriptive parameters were used to evaluating the topological characteristics of the interconnection network (passes and receptions) and its spatial location. The starting parameter was always the number of nodes in the network (players). In each case, the weight (degree) of each player was determined, as well as the number and type of connections (intermediation and proximity) with other players and the distance that each player presents for the rest of the team's components. The organizational parameters used were those of centrality (closeness, grouping or clustering, betweenness or intermediation and transitivity). The latter will be used to explain the dynamics of the game and its organization on the field.

\section{Descriptive parameters}

They are the simplest to evaluate since they are the number of connections of each player with their teammates in a unidirectional or bidirectional way. The density indicates the proportion of existing connections to the possible ones. In the case of soccer, they can be calculated in a simple way by dividing the number of existing relations (passes of a team) among all the possible ones (total of passes of the match or maximum value of the tournament). We also analyzed the density of passes of the team relating the total of triangulations in the totality of possible triangulations. We also divide the total number of passes a team or each player performs in each game by the total minutes of the game.

These parameters can be established from the gross interconnection values (higher value will indicate greater relationship) but they need more information to know the greater or lesser ease with these connections are generated. To know the length of the paths players use to connect, it was necessary to determine the distance between two nodes, the radius, the diameter and the average length.

In any case, the concept of distance should not be confused with length, defined in the networks as the average of the distances between all pairs of nodes. We will understand that the distance between two players is defined as the number of links of the shortest path connecting them. We must consider that the distance between players is calculated on the inverse value of the passes. That is, if $i$ and $j$ are two neighboring players, so for example, player i gives 30 passes to player $\mathrm{j}$, the distance between $\mathrm{i}$ and $\mathrm{j}$ will be: $\mathrm{dij}=1 / 30$. That is, the greater the number of passes between them, the closer two players are placed.

The diameter or the radius should not be confused with distance. Both values are born from the eccentricity $(\mathrm{Ecc})$. The eccentricity of a node is the longest path (between the shortest) to another node in the network when the path is between two nodes and no node is visited more than once. Thus, it shows its link with the periphery. The nodes with less eccentricity are 
more central and their value is determined by the following algorithm:

$$
\operatorname{Ecc}(i)=M_{d} \text { of maximum }(i) ;
$$

Where $M_{d}$ is the distance matrix.

As it happens with the concept of proximity, the eccentricity value represents measures of centrality (we will talk later), but inverse.

The diameter is defined as the shortest maximum path between any pair of players measured by the number of links traveled. In our case, it numerically shows the value of maximum eccentricity of the equipment and the lower its value, the greater communication skill of the players of a team. The value of the radius represents just the opposite value, that is, the minimum eccentricity.

The above-described concepts are recommended to be compared to each other for each game since they indicate different things and give specific and individualized information in each case.

\section{Organizational Parameters}

One of the main objectives of a network is to know the characteristics of the players' behaviors within the group and, in this way, to be able to understand the game used in each match. This criterion can be evaluated based on what is known as centrality indexes (for players) or centralization (for the whole team). The concept of centrality is the position of the players in the passes network that the team builds and the concept of centralization is the structure of the network.

Centrality. The measure of centrality tries to capture how certain nodes are important for a given passes network and it informs us of the ability of each player to connect with the rest of his teammates. However, the centrality is not necessarily indicating a level of efficiency.

The most used parameter is the closeness of centrality, which provides a direct measure of how easy it is to reach a specific player of the team. The centrality of a node depends mainly on its distance to other nodes. It can be determined from the geodetic distances average that the player shows within the team. For this reason, centrality values usually correlate well with the number of passes and neighbors. The more a player passes the ball, the greater his value and the smaller his average distance to other players. Therefore, a player will show greater centrality if the maximum value or the sum of the distances are small. Thus, we must know the minimum distances between all the players by adding the paths between them to calculate the centrality. For this study, his value was determined by the following equation (Pena \& Touchette, 2012):

$$
C_{i}=\frac{1}{\sum_{j \neq i} d_{i, j}+\sum_{j \neq i} d_{j, i}}
$$

Clustering. There is no consensus when determining how to calculate the clustering coefficient in sports modalities. In this work, we will use one of the most frequently proposal by Onnela et al., (2005). This procedure is based on the geometric average of the passes that each player performs with the teammates he most related during the game and, in turn, it includes the passes the neighbors perform among themselves:

$$
c_{i}^{c}=\frac{1}{u_{i}\left(u_{i}-1\right)} \sum_{j, k} \frac{\sqrt[3]{A_{i, j} A_{K, j} A_{k, i}}}{\max (A)}
$$

Where $u_{i}=\sum_{j} \varepsilon_{i, j}$ is the number of passes perform by the player $i$, as the reference node.

An interesting parameter of clustering is the coefficient of assortativity. In this case, it is a value that shows the preference of the players of a team to join other similar players in some technical, tactical or positional characteristic. Numerically, it refers to the Pearson correlation coefficient of the degrees between two pairs of connected players. Positive values (assortative network) indicate that there is a correlation with similar weight (nodes with a lot of weight tend to link with very strong nodes), while a negative value (dissasortative network) indicates correlations between nodes of different degree 
(nodes with little weight they are associated with low weight nodes).

$$
\text { Coefficient of assortativity }=\frac{\sum_{j k} j k\left(e_{j} k-q_{j} Q_{k}\right)}{\sigma_{q}^{2}}
$$

Another interesting parameter in this type of networks is known as effectiveness. From the point of view of the networks, we can evaluate it individually (Eff) or collectively (Ec). The Eff shows a grouping relationship with neighboring players and it represents the average value of the inverse of the shorter paths (geodetic) the players are connected. Consequently, the higher this value, the more efficient the player is since the distance (ease of interconnection) is small. Besides to the overall effectiveness level of the equipment, the Ec value also indicates the expansion capacity of the game network and it represents the inverse of the distance. Therefore, the lesser the distance, the more effective the team will be in interconnecting their players. The effectiveness is important because it refers to aspects related to the connectivity of the player in the network, which is not necessarily synonymous with effectiveness in the game, so we can find players who connect very little but are very important in the final behavior.

An interesting grouping value is offered by the transitivity factor. This parameter refers to the frequency of appearance of triangles (triangles to triples) that occur during the game. It indicates us as two players that are related to any other team, but at the same time they can also relate to each other. Consequently, it is a kind of a mean clustering value.

Intermediation. A different concept is the concept of intermediation (betweenness), which is how each player on the team interacts with the closest players (neighbors). The intermediation of a player is represented by the number of shortest paths directed between all the pairs of players with the reference player. It is a measure that favors the players who participate in the game by connecting peers and penalizes those who do not usually include support among team members in their game. From a tactical point of view, a team could look for intermediation scores that are not evenly distributed among all players. Concentrated meditation results indicate a high reliance on few players that are too important for the game, while low intermediation scores indicate a well-balanced step strategy. For their individual determination, the same criteria proposed by López-Peña \& Tuchette (2012) were used:

$$
C_{B}(i)=\frac{1}{90} \sum_{j \neq k \neq i} \frac{n_{j k}^{i}}{g_{j k}}
$$

Transitivity was calculated for the global triangulation of each team. This type of grouping assigns greater weight to the players with the greater centrality of weight.

$$
\text { Transitivity }=\frac{3 \times \text { of triangles }}{\begin{array}{c}
\text { Number of triple connections } \\
\text { connected by vertices }
\end{array}}
$$

\section{DISCUSSION}

\section{Basic Descriptive Parameters}

This match was characterized by the confrontation of two different styles. The French team made a clearly offensive game proposal, while the Portuguese team showed a more conservative game.

The way to the final also has significant differences in both teams. France arrives with six wins (favor-against goals: 13-4) and Portugal comes with four ties and two wins (favor-against goals: 8-5). Portugal needed three extra time to go to the final, which forces it to play 50 minutes more than the French team (Portugal: 628 minutes, France: 573 minutes). In the total of the tournament, both teams have a possession percentage $(52 \%)$, but with different ways of treating the ball (Portugal: 3633 passes - 86\% effectiveness - 4.78 passes/minute, France: 3519 passes - 88\% effectiveness - 4.99 passes/minute). These values undergo modifications in the final game of the tournament.

In this match, France starts with a 1-4-2-3-1 scheme, in which the line of three midfielders is characterized by incorporating players with excellent mobility and ability to associate. This organization in the attack is enhanced by the 
position and profile of a player such as Pogba who usually enlace easily with the most advanced players. They also used a striker as a reference to an offensive game (Giroud) with the intention of rying to fix the midfielder of Portugal. Their offensive capacity was reinforced by the presence of two full-back players with clear attacking vocation and two central defenders with a high creative capacity (381 passes performed) from the moment the team is in possession of the ball.

Portugal initially had a 1-4-3-3 scheme, with the variant to 1-4-4-2. They were possibly seeking to stop the combinative game that France usually showed in this tournament and giving offensive freedom to full-backs (Cristiano and Nani) to execute destabilizing offensive actions. However, an unexpected event causes a significant change in the organization of the team and the way of organizing the game. In complexity, this situation is especially interesting, provoking self-organizing phenomena with emergent capacity, necessary to interpret it in this work. Some facts of these characteristics show the dynamics of the game and, occasionally, generate surprising circumstances (goal, expulsion, injury, change of player, etc.) that alter that dynamic and the functional tendency they had.
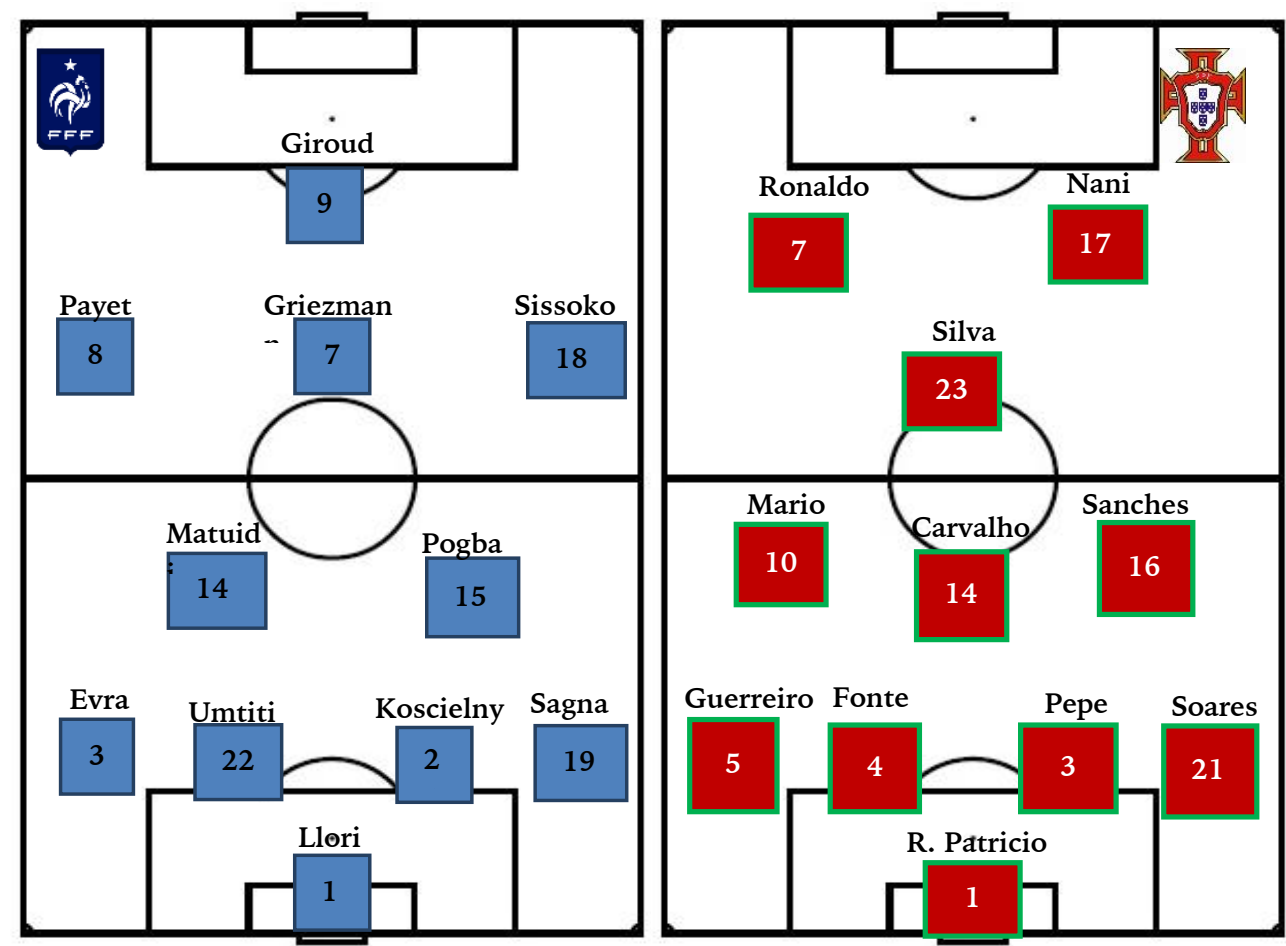

Figure 1. The game system presented by both teams at the beginning of the match.

In the $22^{\text {nd }}$ minute of the first half, the Portuguese player of reference (Ronaldo) is injured and replaced four minutes later. The substitution of Cristiano Ronaldo in the first minutes was the triggering phenomenon that altered the organization and the dynamics of the game during the rest of the match changing (Figure 2) its initial tactical provision (1-4-1-41).

There is no a single mode of organization valid for all cases and it must be adapted to the environment in any circumstance. A large part of the organization processes can be understood as the constant attempt to resolve the tension between the environmental uncertainty and the organizational rationality. The relationship between organization and environment must be conceived as the result of multiple adjustments in which strategy, space and time management, and resources must be coherent and respond to the game situations. In theory, a rational organization should influence levels of uncertainty according to the phase of the game (defense or attack). 


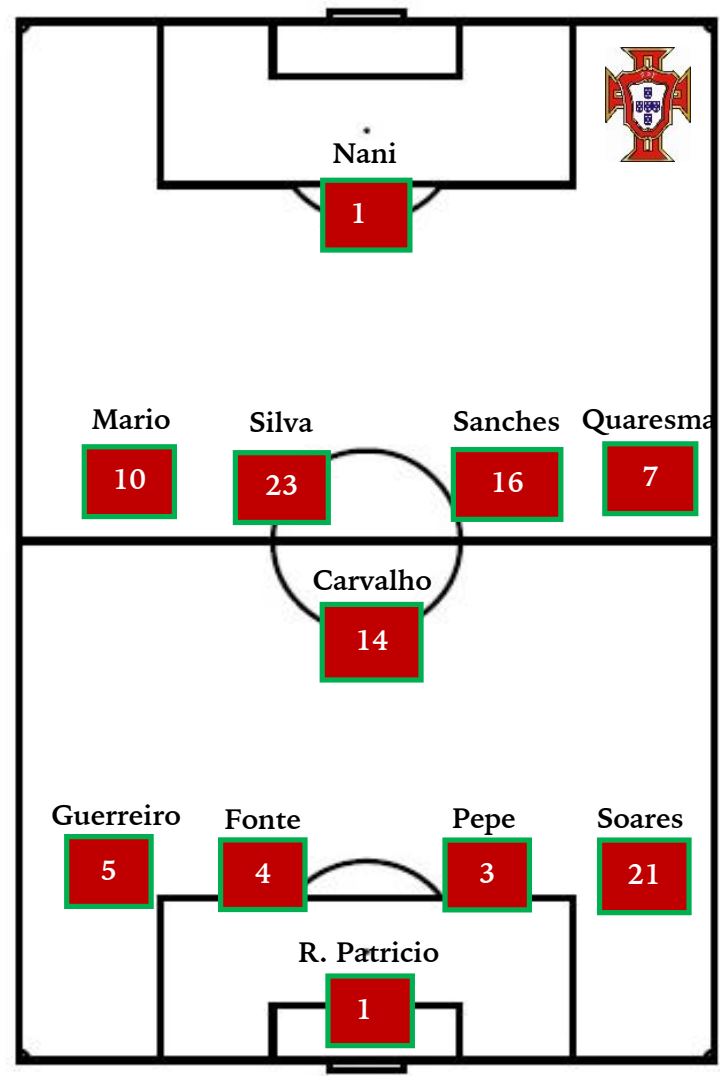

Figure 2. The game system presented by Portugal after replacing Cristiano Ronaldo

The number of effective passes performed by each player and the number of balls he receives is shown in Table 1. It also indicates the number of teammates (neighbors) he performs with this technical action. We must consider that the value of this parameter is a gross indicator of the offensive player participation.

Table 1

Number of neighbors and passes each player of both teams are linked.

\begin{tabular}{|c|c|c|c|c|c|c|c|c|c|c|c|}
\hline \multirow[b]{2}{*}{ Player } & \multicolumn{3}{|c|}{ Portugal } & \multirow[b]{2}{*}{$\mathrm{Pi}$} & \multirow[b]{2}{*}{$\mathrm{Tp}$} & \multicolumn{6}{|c|}{ France } \\
\hline & Vo & $\mathrm{Vi}$ & Po & & & Player & Vo & $\mathrm{Vi}$ & Po & $\mathrm{Pi}$ & $\mathrm{Tp}$ \\
\hline R. Patricio & 8 & 7 & 36 & 19 & 55 & Lloris & 6 & 4 & 19 & 4 & 23 \\
\hline Soares & 8 & 9 & 31 & 41 & 72 & Sagna & 8 & 9 & 48 & 44 & 92 \\
\hline Guerreiro & 9 & 9 & 56 & 59 & 115 & Evra & 8 & 7 & 49 & 49 & 98 \\
\hline Pepe & 10 & 9 & 42 & 34 & 76 & Koscielny & 8 & 9 & 85 & 76 & 161 \\
\hline Fonte & 9 & 9 & 64 & 65 & 129 & Umtiti & 10 & 9 & 115 & 105 & 220 \\
\hline Carvalho & 9 & 10 & 66 & 56 & 122 & Pogba & 10 & 9 & 105 & 97 & 202 \\
\hline Sanches & 10 & 10 & 41 & 53 & 94 & Matuidi & 9 & 10 & 75 & 73 & 148 \\
\hline J. Mario & 10 & 9 & 50 & 47 & 97 & Sissoko & 9 & 10 & 42 & 58 & 100 \\
\hline Silva & 9 & 9 & 54 & 53 & 107 & Payet & 9 & 8 & 48 & 73 & 121 \\
\hline Ronaldo & 9 & 10 & 27 & 33 & 60 & Griezmann & 9 & 9 & 45 & 47 & 92 \\
\hline Nani & 9 & 9 & 29 & 36 & 65 & Giroud & 6 & 8 & 13 & 18 & 31 \\
\hline
\end{tabular}

Note: Vo: neighboring players he passes the ball; Vi: neighboring players he receives the ball; Po: passes he performs; Pi: passes he receives; Tp: Total of actions (passes and receptions).

Neither the gross value of passes nor the centrality represents anything by themselves. They only indicate the weight of each player and the number of neighbors each player connects with the rest of his teammates, but it does not show the way the player interacts with each of its teammates. In this match, France has $20 \%$ more passes (710 passes vs. 575 passes), but no differences are detected in centrality, where the connectivity between players is similar in both teams except in the case of goalkeepers. Rui Patricio is a player with a good ball game with his feet manifested in the high level of centrality that, in part, is justified by the style of playing assumed 
by Portugal, with more delayed positions during most of the match.

From a complexity point of view, it is more interesting to calculate the density of effective passes (644 passes vs. 496 passes). If we take the total of attempted passes as a reference, we see that the density of the gaming network created by France was clearly higher than Portugal ( 0.565 vs. 0.425). Something similar happens when the criteria used were the minutes of possession of each team's ball (12.9 vs. 10.3) or the number of triangulations performed by each of them (11.7 vs. 9.0), indicating a greater associative capacity of the French team.

Beforehand, a greater collective control of the ball should allow a greater number of options for approaching the opposing area, greater shots on the goal and, if the effectiveness is high, there would be a greater number of goals achieved. On the contrary, a lower possession of the ball would mean running more behind the ball, higher levels of fatigue and consequently, less effectiveness in the passes (loss of technical quality) in the final parts of each time. However, this is not fulfilled, at least in part, especially in soccer criterion: win or lose. If we analyze the game in detail, we see that France plays more time in the rival area, having more possession of the ball, kicking more times to the goal (France: 18 total shots, 5 intercepted, 6 pitches out, Portugal: 9 total shots, 1 intercepted, 5 pitches out, 1 goal), but it is less efficient for the goal.
On an individual level, the density of French players also was the difference from their rivals. In the number of total actions, the average connectivity is equal in both teams ( 0.14 actions per player/total passes), but with great differences between some players of the team. The passes and receptions in which each player intervenes are considered as an action. In France, players like Umtiti (0.34), Pogba (0.31) or Koscielny (0.25) have high-density values compared to the best players of the rival team (Fonte: 0.26, Carvalho: 0.24, Guerreiro: 0.23). However, this parameter is insufficient if the minutes played by each player are not considered. In this sense, we see how the density of a player like Payet, who was substituted in the 58th minute, exceeds a high number of teammates (0.64 actions/minute) when related to time (actions/minute).

Another way to determine and assess the connectivity of each player is from the calculation of the geodesic distance of passes and receptions (Do and $\mathrm{Di}$ ). For Portugal team, the lowest interconnection values belong to the players Fonte and Carvalho; that is, those players who need lesser teammates to intervene in the game. In contrast to these values, there are players like Ronaldo and Quaresma who need the previous participation of several teammates to intervene in the game. In the case of France, this situation of low interconnection occurs with Umtiti and Pogba; while Giroud presents similar values.

Table 2

Eccentricity and geodetic distance values are shown by both teams in the final of the Euro Cup 2016

\begin{tabular}{|c|c|c|c|c|c|c|c|}
\hline \multicolumn{4}{|c|}{ Portugal } & \multicolumn{4}{|c|}{ France } \\
\hline Player & Ecc & Do & $\mathrm{D}_{\mathrm{i}}$ & Player & Ecc & Do & $\mathrm{D}_{\mathrm{i}}$ \\
\hline R. Patricio & 0,356 & 1,99 & 2,68 & Lloris & 0,437 & 2,36 & 10,89 \\
\hline Soares & 0,402 & 2,85 & 2,10 & Sagna & 1,000 & 2,46 & 1,82 \\
\hline Guerreiro & 0,254 & 1,74 & 1,91 & Evra & 1,059 & 2,32 & 1,55 \\
\hline Pepe & 0,292 & 2,02 & 2,49 & Koscielny & 1,000 & 2,11 & 1,49 \\
\hline Fonte & 0,289 & 1,56 & 1,74 & Umtiti & 1,000 & 1,93 & 1,35 \\
\hline Carvalho & 0,222 & 1,51 & 1,81 & Pogba & 1,000 & 1,99 & 1,33 \\
\hline Sanches & 0,333 & 2,32 & 1,98 & Matuidi & 1,067 & 2,22 & 1,64 \\
\hline J. Mario & 0,321 & 2.00 & 1,97 & Sissoko & 1,167 & 2,93 & 1,76 \\
\hline Silva & 0,311 & 1,79 & 1,80 & Payet & 1,143 & 2,74 & 1,23 \\
\hline Ronaldo & 0,411 & 2,96 & 2,62 & Griezmann & 1,167 & 2,92 & 1,81 \\
\hline Nani & 0,393 & 2,73 & 2,38 & Giroud & 1,286 & 3,97 & 3,09 \\
\hline Mean & 0.326 & 1.95 & 2.13 & Mean & 1.030 & 2.54 & 2.54 \\
\hline DT & 0.392 & 0.62 & 0.51 & DT & 0.218 & 1.98 & 2.81 \\
\hline
\end{tabular}

Note: Do is the percentage of the distance of passes performed; Di: is the percentage of the distance of passes received 
For the collective analysis, we will use the distance and the average eccentricity, which are simple indicators that explain the connectivity (number and type) of each of the finalist teams. In the case of Portugal, the values of the distance between passes and receptions (defined as the length of the shortest trajectory between players and the matrix, giving us an idea about the capacity two players can interact in the network) do not show large differences between players. This does not happen with France, although in this case, we must consider the distortion value that Lloris causes. This value represents the maximum finite distance to the rest of the players. The value of eccentricity of this player is very high (10.89), which it seems logical if we consider the French team plays preferably attacking the opponent field.

At a collective level, it is interesting to analyze the radius and the diameter of the passes network of each set. The radius shows the minimum eccentricity of the players while the diameter shows the maximum eccentricity of the players. Comparing with physics, its value shows the characteristics of the orbit an object makes in space. If the orbit were circular, the diameter would be twice the radius, but when it is elliptical, that proportion logically changes, which is a usual situation when we apply the theory of networks to soccer.

The ratio between the diameter and the radius $(\mathrm{Dm} / \mathrm{R})$ shows how each team uses the field. The oscillations in both values of the distances the players show affect the surfaces of the game and this, in turn, affect the way in which the team plays. A high value indicates that the team has a more open game with the greater use of the game space, while a low value indicates the opposite, that is, the team closes and shortens the distance between its players. In soccer, the ratio between $\mathrm{Dm} / \mathrm{R}$ almost always exceeds the theoretical maximum value $(\mathrm{Dm} / \mathrm{R}>2)$. Although the playing field is longer than wide, the amplitude of the real game space is usually greater (35-40 meters) than its depth (30-35 meters). During the game, that surface moves from one side of the field to the other, varying its shape, position and surface depending on the circumstances of the game and the team that owns the ball (Castellano \& Álvarez, 2013; Duarte et al., 2013). However, some authors suggest that, during the game, the teams tend to show a less regular and predictable behavior with the increase in variability in the organization and management of the space (Duarte et al., 2013).

Each game has its own peculiarities and values allowing evaluations between matches or teams. In the case of the analyzed match, the differences between teams are evident. France plays more openly than Portugal, concentrated in the midfield (France: $\quad$ Radio $=0.437$, Diameter $=1.286$, Ratio $\mathrm{D} / \mathrm{R}=2.943$ - Portugal: Radio $=0.222, \quad$ Diameter $=0.411, \quad$ Ratio $\mathrm{D} / \mathrm{R}=1.850$ ).

The values that result in each case depend on how the players are in the field and how they interact with each other. The communication between neighboring players allows the team, as a whole, to coordinate and be correct in the field. In this sense, players do not have to control the position and direction of the movements of all teammates, or all their rivals, to read the game correctly and intervene properly in the game. Only the actions of neighboring players (peers or rivals) should be precisely controlled. If this is done correctly, the coordination of all team players will occur automatically. In large part this is the concept of self-organization, understanding it as the process in which some global form of order arises from the local interactions between the components of a system initially, more or less, ordered or disordered.

The team game, the organization, and occupation of the space are similar to the topology and functioning of any complex adaptive system. These systems constantly show emerging behaviors that try to adapt and make the system respond to the changing and specific needs of the environment. To be efficient, its elements (in our case, the players) behave according to previously established basic laws, usually given by the coach, and the ability of the players to self-organize. In soccer, this process is manifested differently. During a game, despite previously established criteria, players always self-organize according to the changes that occur in the environment 
(game), the position of the ball and the score that exists at each moment of the game (won, losing or tying).

The organization and the uncertainty of the game must be based on the necessary position of an emerging order: spontaneous selforganization. But self-organized systems do not show emergent situations if the interactions of their components, locally or globally, do not present observable, evaluable and modifiable behaviors. For this to happen, it is necessary that there is a high level of automation of basic mechanisms, the understanding of the essence of the game, a high degree of interaction between players and the acceptance of the model by all the components. A clear example in this game is analyzed with the injury of Cristiano Ronaldo, where his replacement significantly modified the organization of the team and its form of playing.

\section{Organizational parameters of the game network}

The theory of networks provides parameters of centrality, clustering, and intermediation that helps to explain with enough precision how is the organizational dynamics of the game network.

\section{Centrality}

We can think that a player has greater centrality if he depends less on the rest to communicate with the rest of the team's components. In other words, he does not need many intermediate connections with his peers. From this point of view, a player has more centrality since he is independent. However, centrality is a value of participation but not of effectiveness. To complete this measure, it is convenient to also observe the values of intermediation and proximity. In our case, the values of centrality have a high correlation with the values of eccentricity. Especially total eccentricity $(r=0.87)$ and pass $(r=0.92)$ but not so much with the values of eccentricity in receptions $(r=0.67)$

Table 3

Centrality values

\begin{tabular}{lccclccc}
\hline \multicolumn{2}{c}{ Portugal } & & & \multicolumn{2}{c}{ France } \\
Player & $\mathrm{C}_{\mathrm{o}}{ }^{*} 100$ & $\mathrm{C}_{\mathrm{i}}{ }^{*} 100$ & $\mathrm{C}_{\mathrm{t}}{ }^{*} 100$ & Player & $\mathrm{C}_{\mathrm{o}}^{*} 100$ & $\mathrm{C}_{\mathrm{o}}{ }^{*} 100$ & $\mathrm{C}_{\mathrm{t}}{ }^{*} 100$ \\
\hline R. Patricio & 50,32 & 37,32 & 21,43 & Lloris & 42,36 & 09,18 & 07,55 \\
Soares & 35,04 & 47,61 & 20,18 & Sagna & 40,60 & 54,90 & 23,34 \\
Guerreiro & 57,61 & 52,38 & 27,44 & Evra & 43,06 & 64,48 & 25,82 \\
Pepe & 49,58 & 40,11 & 22,17 & Koscielny & 47,38 & 67,26 & 27,80 \\
Fonte & 64,18 & 57,38 & 30,29 & Umtiti & 51,84 & 74,27 & 30,53 \\
Carvalho & 66,07 & 55,21 & 30,08 & Pogba & 50,30 & 75,45 & 30,18 \\
Sanches & 43,02 & 50,53 & 23,24 & Matuidi & 45,03 & 60,93 & 25,89 \\
J. Mario & 50,01 & 50,86 & 25,22 & Sissoko & 34,14 & 56,91 & 21,34 \\
Silva & 55,78 & 55,68 & 27,86 & Payet & 36,53 & 81,29 & 25,21 \\
Ronaldo & 33,78 & 38,18 & 17,92 & Giroud & 25,22 & 32,39 & 14,18 \\
Nani & 36,64 & 42,10 & 19,59 & Griezmann & 34,22 & 55,11 & 21,11 \\
\hline \multicolumn{1}{c}{ Mean } & 49.28 & 47.94 & 24.13 & Mean & 40.97 & 57.47 & 22.30 \\
\multicolumn{1}{c}{ DT } & 9.28 & 13.53 & 4.31 & DT & 17.50 & 23.21 & 6.90 \\
\hline
\end{tabular}

Note: CP: passes centrality; CR: reception centrality; $C T$ : total centrality.

Each team usually has several players that centralize the circulation of the ball in each subzone of the field. Teams using only one or two main strikers score fewer goals than teams that move the ball more evenly among all team members. A striker indicator in a complex network is given by the value (\%) of centrality. The lower its value, the more efficient the game of the player or the team will be.
In the case of the Europe Cup 2016, there are no big global differences $(\mathrm{Ct})$ but they highlight the existing differences when the passes and the receptions are compared separately. In this sense, France shows lower values but more distributed. On the other hand, Portugal centers the game on players like Carvalho and Fonte, players considered the main strikers of the game of Portugal. However, in both cases, in general, the 
values are not statistically significant (Co: $\mathrm{p}$ $<0.059, \mathrm{TE}=0.28, \mathrm{Ci}: \mathrm{p}<0.166, \mathrm{TE}=0.24)$.

\section{Clustering}

In our case, three clustering indicators have been used (Table 4), showing similar results with high Pearson correlation coefficients among them (Wi vs WEff $=0.90$, Wi vs $\mathrm{Wv}=0.89$ ), indicating the strength of the measure of clustering obtained.

Portugal presented strong offensive clustering in the middle of the field and in the right side of the field with four key players as strikers of these groups (Carvalho: 0.64, Silva: 0.54, Fonte: 0.53, Guerreiro: 0.51), who channeled the game towards the finishing area close to João Mario. Channeling the game on the right side was less frequent. The French team clustering was different in the way and the surface of the field used. Their offensive game was richer, with greater offensive options, strongly organized in the center of the field although important variants towards both sides. We can talk about a strongly interconnected central rectangle where Umtiti (0.35) and Koscielny (0.34) had the most backward zone, while Matuidi (0.36) and Pogba (0.37) were responsible for the circulation of the ball in the creation zone.

Such a tactical arrangement clearly shows the offensive sub-areas that most commonly generate both teams and the way in which players move and interconnect with each other. However, although everything is related to everything, the closest subspaces (clusters) are more related to each other than those more distant. Based on Waldo Tobler's law of geographical simplicity (first law of geography or the principle of spatial autocorrelation), Reggiani \& Nijkamp, (2009) state that regardless of the spatial distribution used, each game subspace must always be related to all the spaces rest. They will achieve it through a specific organization (aggregate organization) sufficiently decentralized (subspaces and clustering) to optimize the game as a whole. Also, distant spaces can be related through preferential nodes in spatial networks similar to those configured in the field of play during the final analyzed.

In soccer as in any other team sport, players must adopt simple rules of the game knowing where to move, slowing down, accelerating, changing direction and using space intelligently for their own benefit and the team. This leads to the appearance or should appear, of areas with a high degree of concentration of links between a group of players. Such groupings vary in number and weight in each team, associating players with specific tactical functions that force an intense relationship between them. Each player has a greater affinity and contact with a certain number of partners than with others (either for technical reasons, such as tactics or purely spatial).

Finding the hub nodes of the game is useful to understand the behavior of multiple natural and/or accidental events generated by this type of networks. We must consider that the existence of more than one striker element makes the system more solid and less vulnerable to external attacks. The key to its functioning must be based, fundamentally, on the attention that each element shows about its neighbors and the understanding of its actions.

Table 4

Values of groupings showed by France and Portugal in the final of the Eurocup of 2016.

\begin{tabular}{|c|c|c|c|c|c|c|c|}
\hline \multicolumn{4}{|c|}{ Portugal } & \multicolumn{4}{|c|}{ France } \\
\hline Player & $W_{i}$ & $W_{v}$ & $W_{E f f}$ & Player & $W_{i}$ & $W_{v}$ & $W_{E f f}$ \\
\hline R. Patricio & 0,394 & 0,256 & 3,296 & Lloris & 0,229 & 0,107 & 3,501 \\
\hline Soares & 0,363 & 0,152 & 3,966 & Sagna & 0,280 & 0,215 & 5,025 \\
\hline Guerreiro & 0,510 & 0,382 & 5,022 & Evra & 0,287 & 0,228 & 5,859 \\
\hline Pepe & 0,402 & 0,254 & 3,995 & Koscielny & 0,341 & 0,464 & 6,617 \\
\hline Fonte & 0,530 & 0,440 & 5,270 & Umtiti & 0,354 & 0,536 & 7,599 \\
\hline Carvalho & 0,644 & 0,406 & 5,559 & Pogba & 0,369 & 0,449 & 7,802 \\
\hline Sanches & 0,415 & 0,268 & 4,741 & Matuidi & 0,357 & 0,317 & 6,883 \\
\hline J. Mario & 0,450 & 0,314 & 4,563 & Sissoko & 0,237 & 0,154 & 5,280 \\
\hline Silva & 0,548 & 0,340 & 5,304 & Payet & 0,265 & 0,181 & 6,425 \\
\hline Ronaldo & 0,349 & 0,168 & 3,520 & Griezmann & 0,257 & 0,169 & 5,450 \\
\hline Nani & 0,374 & 0,170 & 3,781 & Giroud & 0,136 & 0,035 & 3,007 \\
\hline
\end{tabular}

Note: Wi, Wv y WEff: clustering coefficients. 
Based on its associativity (associative coefficient), the global clustering capacity of a team can be established. Its value represents the Pearson's correlation coefficient of the degrees between two pairs of players who connect during the game. In this match, a negative associativity appears in both teams (Portugal: -0.0539, France: -0.1079). Positive values indicate a correlation between nodes with a similar degree, while a negative value indicates correlations of different degrees.

Game intermediation

In a way, soccer is often based on the triangulation of the game and the search and use of efficient pass lines between the players of a team. During the triangulation, the length of the sides changes constantly depending on the game situation to maintain pass lines without opposition or with a difficult interception by the rivals (Gyarmati, Kwak, \& Rodriguez, 2014). This form of the game is based on intermediation. A player whose position is in the communication path between two others shows an important potential for control of communication among his peers. However, we must consider that, as suggested by Freeman \& Freeman (1979), a player may be slightly connected to the rest of the team's components (that is, low-degree centrality) and yet be an essential intermediation player in the relationships of two other components of the team. Therefore, they are players who can influence the group by filtering or distorting the circulation of the ball. In these cases, these players will also be in a better position to ensure the coordination of the game network. The intermediation coefficients used in the study practically tell us the same thing $(r=0.98$ and 0.94 for France and Portugal, respectively) and they explain with great precision what happened in the match (Table 5).

Table 5

Individual interconnection values of the players of the France and Portugal teams in the final of the Eurocup in 2016 using two criteria

\begin{tabular}{lcclcc}
\hline & Portugal & & & France & $\mathrm{B}_{2}$ \\
Player & $\mathrm{B}_{1}$ & $\mathrm{~B}_{2}$ & Player & $\mathrm{B}_{1}$ & 17,83 \\
\hline R. Patricio & 7,76 & 27,72 & Lloris & 4,77 & 19,37 \\
Soares & 0,82 & 5,23 & Sagna & 2,23 & 8,73 \\
Guerreiro & 0,93 & 4,70 & Evra & 1,12 & 9,37 \\
Pepe & 1,38 & 11,27 & Koscielny & 0,11 & 1,50 \\
Fonte & 2,06 & 5,67 & Umtiti & 0 & 0,53 \\
Carvalho & 0 & 0 & Pogba & 0,07 & 0,53 \\
Sanches & 0 & 0 & Matuidi & 1,77 & 11,57 \\
Joa Mario & 0,79 & 3,20 & Sissoko & 0,20 & 1.00 \\
Silva & 0 & 2,17 & Payet & 0,43 & 3,50 \\
Ronaldo & 2,47 & 15,10 & Griezmann & 6,58 & 31,77 \\
Nani & 2,04 & 6,47 & Giroud & & \\
\hline
\end{tabular}

The intermediation in Portugal was executed with a high precision in the center of the field by Calvalho, Sanches, and Silva, changing to players like Fonte and Guerreiro when the offensive game was moved to the left side and towards Cedric and Nani when the players were going to the right of the attack. In the case of France, the intermediation of the players is different, highlighting Pogba, Matuidi, and Umtiti. in these functions

The probability of two players neighboring a third player, being also neighbors of other team members may be more or less elevated depending on the spatial distribution of the players and the game system used. This quality of the game network could be estimated through transitivity. In this case, the transitivity value of the Portuguese team (0.226) was clearly higher than the French team (0.147), which indicates once again the greater location of the offensive Portuguese team against the greater dispersion and openness developed by the French team.

\section{CONCLUSIONS}

Compared to Portugal, the results reveal a clear superiority of France in most of the parameters analyzed. However, the final result of the match was favorable to the Portuguese team, 
which shows that the dominance of the offensive game does not always translate into a favorable result.

Acknowledgments:

Nothing to declare

Conflict of interests:

Nothing to declare

Funding:

Nothing to declare

\section{REFERENCES}

Castellano, J., \& Álvarez, D. (2013). Uso defensivo del espacio de interacción en fútbol. RICYDE. Revista Internacional de Ciencias del Deporte, 9(32), 126136.

Cintia, P., Rinzivillo, S., \& Pappalardo, L. (2015). A network-based approach to evaluate the performance of football teams.

Clemente, F. M., Martins, F. M. L., Kalamaras, D., Oliveira, J., Oliveira, P., \& Mendes, R. S. (2015). The social network analysis of switzerland football team on FIFA world cup 2014. Journal of Physical Education and Sport, 15(1), 136.

Cotta, C., Mora, A. M., Merelo, J. J., \& Merelo-Molina, C. (2013). A network analysis of the 2010 FIFA world cup champion team play. Journal of Systems Science and Complexity, 26(1), 21-42.
Duarte, R., Araújo, D., Folgado, H., Esteves, P., Marques, P., \& Davids, K. (2013). Capturing complex, non-linear team behaviours during competitive football performance. J. Systems Science \& Complexity, 26(1), 62-72.

Duch, J., Waitzman, J. S., \& Amaral, L. A. N. (2010). Quantifying the performance of individual players in a team activity. PloS one, 5(6), e10937.

Gama, J., Couceiro, M., Dias, G., \& Vaz, V. (2015). Small-world networks in professional football: conceptual model and data. European Journal of Human Movement, 35, 85-113.

Gould, P., \& Gatrell, A. (1979). A structural analysis of a game: the Liverpool $\mathrm{v}$ Manchester United Cup Final of 1977. Social Networks, 2(3), 253-273.

Grund, T. U. (2012). Network structure and team performance: The case of English Premier League soccer teams. Social Networks, 34(4), 682-690.

Gyarmati, L., Kwak, H., \& Rodriguez, P. (2014). Searching for a unique style in soccer. arXiv preprint arXiv:1409.0308.

Onody, R. N., \& de Castro, P. A. (2004). Complex network study of Brazilian soccer players. Physical Review E, 70(3), 037103.

Pena, J. L., \& Touchette, H. (2012). A network theory analysis of football strategies. arXiv preprint arXiv:1206.6904.

Reggiani, A., \& Nijkamp, P. (2009). Complexity and spatial networks: in search of simplicity: Springer Science \& Business Media.

Sarangi, S., \& Unlu, E. (2010). Key Players in Teams: A Network Approach Using Soccer Data. 


\title{
Weight training along with the use of nandrolone decanoate does not alter the quantity of adipose tissues in rats
}

\author{
Odilon Abrahin ${ }^{1}$, Wiliane Nery Santos ${ }^{2}$, Rejane Pequeno Rodrigues ${ }^{1}$, Roberto Jerônimo dos \\ Santos Silva², José Aderval Aragão², Felipe J. Aidar², Anderson Carlos Marçal ${ }^{2 *}$
}

ARTIGO ORIGINAL | ORIGINAL ARTICLE

\begin{abstract}
This study aimed to evaluate the effects of nandrolone decanoate on adipose tissues and muscle strength of eutrophic rats undergoing weight training. Twenty-four eutrophic rats were randomly divided into the following four groups: sedentary control (SC), trained control (TC), sedentary nandrolone decanoate (SN), and trained nandrolone decanoate (TN). Strength training was performed using a squat machine (four sets of 12 repetitions; $70 \%$ intensity of $1 \mathrm{RM})$. The SN and TN groups were intraperitoneally administered nandrolone decanoate $(10 \mathrm{mg} / \mathrm{kg} /$ week), whereas the SC and TC groups were intraperitoneally administered a saline solution (0.9\%). The body weight did not significantly differ (SC vs. TC; SN vs. TN). In the one-repetition maximum test (TC vs. ST), the muscle strength increased by $10.8 \%$ and $11.2 \%$ in weeks 6 and 8, respectively. Subcutaneous, retroperitoneal, and periovarian fat did not exhibit significant differences after the intervention. Therefore, nandrolone decanoate concomitantly administered with weight training did not affect muscle strength or the quantity of adipose tissues in eutrophic rats. Keywords: anabolic agents, resistance training, adipose tissues, muscle strength.
\end{abstract}

\section{INTRODUCTION}

Androgenic anabolic steroids (AASs) are synthetic hormones that are derived from testosterone. They exhibit anabolic characteristics that are responsible for the increase in protein synthesis, muscle strength, and muscle volume. Androgenic properties are responsible for the development of male sexual characteristics, namely the appearance of facial and body hair and a deeper voice (Basaria et al., 2001; Abrahin et al., 2013).

AASs were originally developed for therapeutic and treatment purposes for diseases; however, athletes realized the potential benefits of steroids in physical performance, particularly in activities that involved strength and muscle power. The indiscriminate and abusive use of AASs has currently become a public health problem (Sagoe et al., 2014), and the prevalence of their use is increasing in several populations, including female recreational practitioners of physical activity (Elliot et al. 2007; Abrahin et al., 2017).
Abrahin et al. (2017) described the profile of Brazilian women who typically used AASs. The results showed a prevalence of $13.3 \%$ of use, and all users performed weight training with predominantly esthetic goals (i.e., to increase muscle mass and reduce body fat percentage). However, a limited number of scientific studies have evaluated the effects of AASs on adipose tissues in women. Thus, this study aimed to evaluate the effects of nandrolone decanoate on adipose tissues and muscle strength of eutrophic rats undergoing weight training.

\section{METHOD}

\section{Sample}

The research was conducted according to the norms established by the Brazilian National Council for Animal Experimentation Control (CONECA). The experimental protocol was initiated after receiving the approval from the local Committee for Ethics in Animal Research (Case No. 29/2014). Twenty-four eutrophic adult Wistar rats (Rattus norvegicus), weighing between 230 and $250 \mathrm{~g}$, were used.

\footnotetext{
${ }^{1}$ Faculdade Metropolitana de Amazônia, FAMAZ, Belém, Pará, Brazil

${ }^{2}$ Federal University of Sergipe, Graduate Program in Physical Education, São Cristóvão, Sergipe, Brazil

${ }^{*}$ Corresponding author: Departamento de Morfologia, Universidade Federal de Sergipe, Rua Marechal Rondon, s/n, CEP: 49100-000. Aracaju/SE, Brasil.E-mail: acmarcal@yahoo.com.br
} 
They were obtained from the vivarium department. The animals were kept in polypropylene cages that were lined with wood shavings; each cage contained up to five animals. The temperature was maintained between $22^{\circ} \mathrm{C}$ and $24^{\circ} \mathrm{C}$, and brightness was controlled using a 12-h light/dark cycle. Filtered water and feed were administered ad libitum. The rats were identified and weighed from the beginning to the end of the experimental protocol, and each female's estrous cycle was monitored daily.

\section{Procedure}

Injectable nandrolone decanoate of $25 \mathrm{mg}$ doses (Decadurabolin, Organon, Roseland, NJ) were used. They were manufactured in packages that contained one ampoule with $1 \mathrm{ml}$ of injectable solution, with benzyl alcohol and peanut oil as excipients. Healthy female rats with regular estrous cycles were randomly distributed into the following four experimental groups (6 rats/group): sedentary control (SC) group, wherein rats were only administered a saline solution (0.9\%); trained control (TC) group, wherein rats were only administered only a saline solution $(0.9 \%)$ and underwent strength training; sedentary nandrolone decanoate (SN) group, wherein rats were administered nandrolone decanoate at a rate of $10 \mathrm{mg} / \mathrm{kg}$ each week; and trained nandrolone decanoate (TN) group, wherein rats were administered nandrolone decanoate at a rate of $10 \mathrm{mg} / \mathrm{kg}$ each week and underwent strength training.

Nandrolone decanoate were intraperitoneally administered twice a week every other day, alternating with weight training days, at a dose of $5 \mathrm{mg} / \mathrm{kg}$ (for a total of $10 \mathrm{mg} / \mathrm{kg} /$ week). This dose is equivalent to that usually used by athletes (600 mg/week). The SC and SN groups were placed on the exercise machine at the same time as the trained groups ( $\mathrm{TC}$ and $\mathrm{TN}$ ), although the former groups received the same electrical stimuli, they did not perform any specific exercise-related movements.

Strength training was performed according to the model proposed by Tamaki et al. (1992); in the model the rats were wrapped in a tarpaulin (inhibiting the torsion and flexion of their torsos) and were then placed on the squatting machine. An electrical stimulation $(10 \mathrm{~V}, 0.3-\mathrm{s}$ duration plus 2-s intervals) was applied to the tail of the rat via an electrode attached to the tail (ValuTrode, Model CF3200, Axelgaard, Fallbrook, CA) and connected to an electrostimulator (BIOSET, Physiotonus Four, Model 3050, Rio Claro, SP, Brazil) (Rodrigues et al., 2016). As a result, the rats extended their rear legs and lifted the arm of the device with the stipulated load.

The rats performed four sets of 12 repetitions with $70 \%$ intensity, which was established by the one-repetition maximum (1RM) test, with a 60-s interval between the sets. They underwent the training session thrice a week for 8 weeks (total of 24 sessions). Before the training began, the rats underwent adaptation to the equipment for 1 week. The training load and intensity were readjusted every 2 weeks by a new 1RM test until the last week.

All animals were killed $24 \mathrm{~h}$ after the last training session and underwent laparotomy with the incision and removal of the periovarian, retroperitoneal, and subcutaneous fats. They were then placed in a sterile Petri dish to measure their wet weight.

\section{Statistical analysis}

The results are presented as mean \pm standard error. The statistical analysis was performed using Student's t-test for two unpaired samples $(\mathrm{P}<0.05)$; one-way and two-way ANOVA were performed for more than four variables. The Bonferroni post-test was used for both, and $\mathrm{P}$ values of $<0.05$ were considered to be statistically significant.

Table 1

Weight $(g)$ of rats in each experimental group after 8 weeks (one-way ANOVA)

\begin{tabular}{lc}
\hline \multicolumn{1}{c}{ GROUP } & $\begin{array}{c}\text { BODY WEIGHT } \\
\text { (average } \pm \text { SD) }\end{array}$ \\
\hline Sedentary control (SC) & $240.2 \pm 8.9$ \\
Trained control (TC) & $237.2 \pm 11.6$ \\
Sedentary nandrolone decanoate (SN) & $275.7 \pm 10.6^{*}$ \\
Trained nandrolone decanoate (TN) & $281.4 \pm 22.0^{*}$ \\
\hline
\end{tabular}




\section{RESULTS}

All the rats had an initial weight that ranged from 230 to $250 \mathrm{~g}$. Data regarding weight gain are presented in Table 1 and Figure 1. Table 1 shows the body weight of the rats obtained at the end of intervention.

We observed a statistical difference among the groups, with a $14.8 \%$ increase (SC vs. SN) and an $18.6 \%$ increase (TC vs. TN).

A

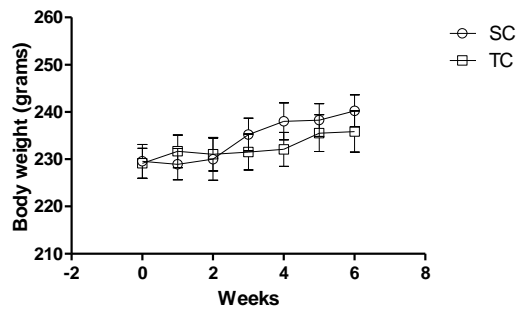

B

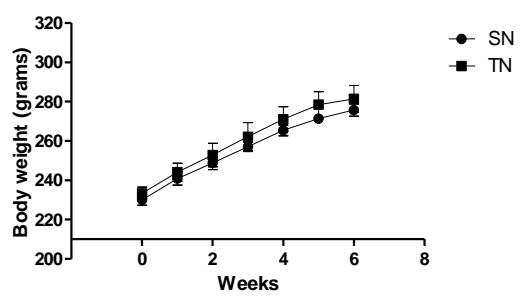

C

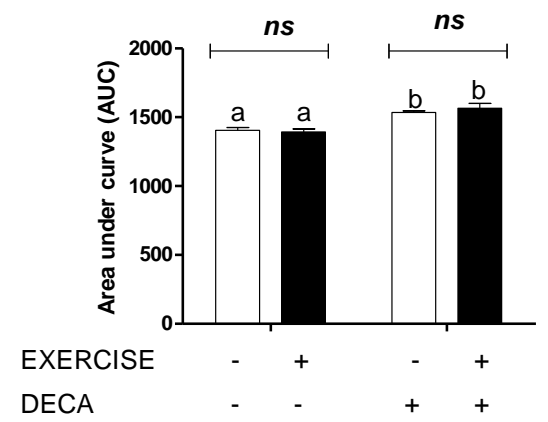

Figure 1. Effects of nandrolone decanoate treatment on body weights of rats undergoing weight training. In $\mathrm{A}$ and $\mathrm{B}$, two-way ANOVA and Bonferroni post-test were used $\left({ }^{*} P<0.05\right)$. In $\mathrm{C}$, one-way ANOVA was used for the analysis between groups (different letters $=$ statistically significant difference; ${ }^{*} P<0.05$ ). (NS, no statistical difference; $n=6$ )

When changes in body weight were assessed between the SC and SN groups (Figure 1A) and between the TC and TN groups (Figure 1B) over time (point-to-point evaluation), no statistically significant difference was detected. These results were similar to those obtained when the area over the curve of body weight evolution with time was calculated (Figure 1C).

The 1RM test was used to determine the effects on the load increase on the rats of the experimental groups.

A

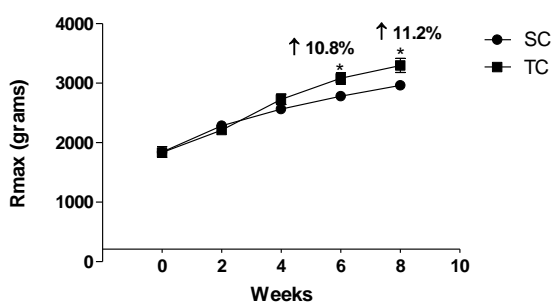

B

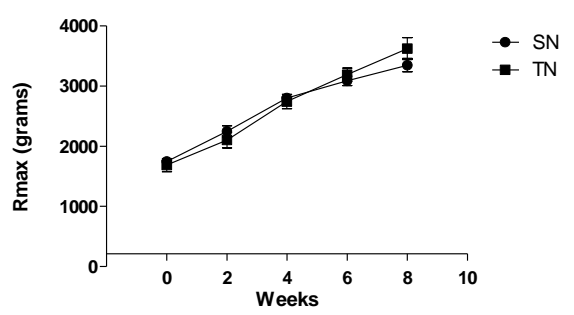

C

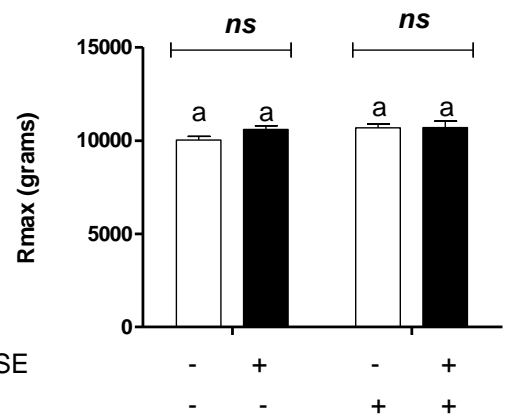

Figure 2. Effects of nandrolone decanoate treatment on maximum strength test when treatment was combined with weight training. Data are presented as mean \pm standard error of the mean. A represents the $\mathrm{SC}$ and TC groups (Bonferroni post-test, ${ }^{*} P<0.05$ ). B represents the $\mathrm{SN}$ and TN groups (Bonferroni posttest, $\left.{ }^{*} P<0.05\right)$. C represents the area over the curve (Student's $t$-test; the same letters $=$ no statistical significance; $P>0.05$ ) (NS, no statistical difference).

After 8 weeks of training, the control rats that underwent strength training had a $10.8 \%$ and $11.2 \%$ increase in strength at weeks 6 and 8 , 
respectively (Figure $2 \mathrm{~A}$ ). Among the rats that were administered nandrolone decanoate, the sedentary and trained rats exhibited no significant differences (Figure 2B). Data in Figures $2 \mathrm{~A}$ and $2 \mathrm{~B}$ were systematized as an area under the curve, which revealed no significant differences among the study groups (Figure 2C).

A

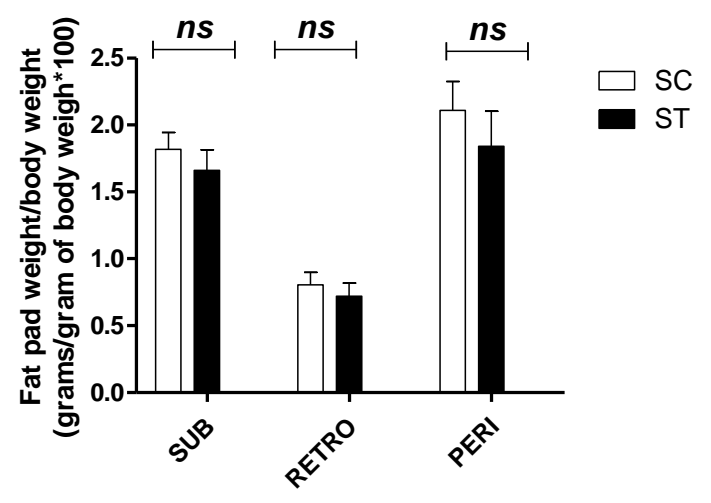

B

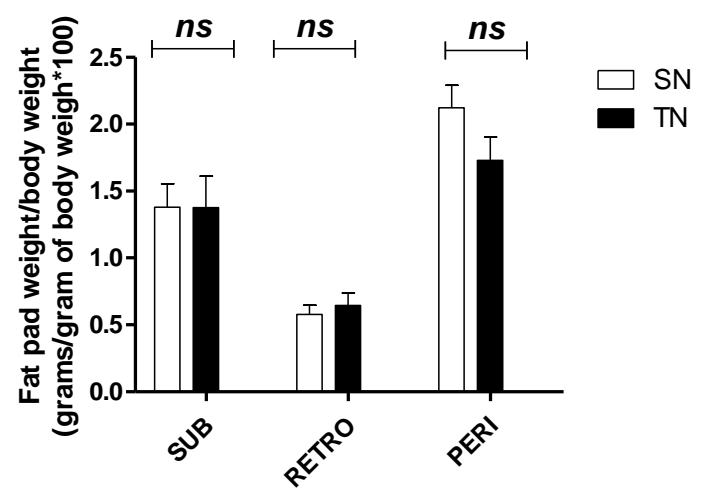

Figure 3. Effects of nandrolone decanoate treatments on adipose tissues when treatment was combined with weight training. The fat contents of SUB, RETRO, and PERI were evaluated. Data are presented as mean \pm standard error of the mean. A represents the $\mathrm{SC}$ and TC groups, and B represents the $\mathrm{SN}$ and TN groups (NS, no significant difference).

The quantities of adipose tissues of the rats in the different experimental groups were evaluated (Figures $3 \mathrm{~A}$ and 3B). To this end, the subcutaneous (SUB), retroperitoneal (RETRO), and periovarian (PERI) fats were dissected and removed during laparotomy. After 8 weeks of weight training, the rats belonging to both the SC and TC groups exhibited no significant differences in adipose tissue quantities in the different body regions (Figure 3A). These results were similar to those observed in the groups administered nandrolone decanoate, i.e., SN and $\mathrm{TN}$ groups (Figure $3 \mathrm{~B}$ ).

\section{DISCUSSION}

Our study results showed that the supraphysiological use of nandrolone decanoate along with weight training did not alter the amount of periovarian, subcutaneous, or retroperitoneal fat in eutrophic rats. In addition, no intergroup changes ( $\mathrm{SN}$ vs. $\mathrm{TN}$ ) were observed with respect to maximal muscle strength performance.

Bhasin et al. (2005) evaluated the effects of different dosages of testosterone enanthate (25, $50,125,300$, or $600 \mathrm{mg}$ per week) on body composition in young and elderly men. The results showed that higher dosages $(125,300$, or $600 \mathrm{mg}$ per week) increased the muscle strength (1RM) and decreased the amount of fat mass in both young and elderly men.

Corroborating the results previously cited, Ribeiro et al. (2011) found that the use of nandrolone decanoate $(10 \mathrm{mg} / \mathrm{kg}$ per week) along with weight training (75\% $1 \mathrm{RM})$ reduced the adipose tissues of male rats. However, in our study, the supraphysiological use of nandrolone decanoate did not reduce the amount of adipose tissues. On the contrary, it is important to note that female rats were used and that differences between the sexes cannot be ruled out.

Kwok et al. (2016) demonstrated that sex is an essential factor for the regulation of lipid quantity and flow, emphasizing that women have a higher amount of adipose tissues. It is important to evaluate the association between phenotype fat the accumulation because some authors report that men have a greater capacity to oxidize fatty acids than women do (Whitaker et al., 2016); however, both men and women continue to accumulate abdominal adiposity as they age.

Bodybuilders who use AASs usually engage in polypharmacy (use of various drugs, including 
stimulants), in addition to diets that aid in reducing adipose tissues and maximizing gains in muscle mass (Spendlove et al., 2015). In light of this factor, a causal association cannot be established; it is not necessarily true that the use of AAS alone along with weight training will drastically reduce the amount of adipose tissues. Various factors likely contribute to the lower fat percentages of such athletes. Therefore, the scientific evidence regarding the supraphysiological use of AAS and adipose tissues, particularly in women, remains limited.

Another finding of our study was that the supraphysiological use of nandrolone decanoate along with weight training did not alter the muscle strength of eutrophic rats because the TN and SN groups presented similar results in the 1RM test. Meanwhile, muscle strength increased in the TC group by $10.8 \%$ and $11.2 \%$ at weeks 6 and 8 , respectively (TC vs. CS).

Bhasin et al. (1996) suggested that supraphysiological doses of testosterone (600 $\mathrm{mg} /$ week, with no weight training) in men for 10 weeks improved the maximal muscle strength as measured in the upper and lower limbs by the 1RM test. Nevertheless, men who used testosterone along with weight training had statistically superior results (training without testosterone vs. training with testosterone). However, in our study, female rats were used, and the volume of exercise was relatively lower, possibly explaining the difference observed in our study.

Thus, further studies are warranted to evaluate the effects of supraphysiological dosages of AAS on adipose tissues, as well as on other tissues and systems in female rats (such as the reproductive system), because these substances have been associated with several adverse effects. It is important to note the prevalence of AAS use is increasing, particularly among women.

\section{CONCLUSIONS}

The use of nandrolone decanoate along with weight training for 8 weeks did not affect the muscle strength or quantity of adipose tissues in eutrophic rats.
Acknowledgments:

Nothing to declare

Conflict of interests:

Nothing to declare

\section{Funding:}

Coordenação de Aperfeiçoamento de Pessoal de Nível Superior (Capes), sob processo número AUXPE PROCAD/NF 110/2010

\section{REFERENCES}

Abrahin, O., Souza, N., Sousa, E., Santos, A. M., Bahrke, M. (2017). Anabolic-androgenic steroid use among Brazilian women: an exploratory investigation. Journal of Substance Use, 22(3), 246-252.

Basaria, S., Wahlstrom, J. T., Dobs, A. S. (2001). Anabolic-androgenic steroid therapy in the treatment of chronic diseases. The Journal of Clinical.

Bhasin, S., Storer, T. W., Berman, N., Callegari, C., Clevenger, B., Phillips, J., Bunnell, T. J., Tricker, R., Shirazi, A., Casaburi, R. (1996). The effects of supraphysiologic doses of testosterone on muscle size and strength in normal men. The New England Journal of Medicine, 335(1), 1-7.

Bhasin, S., Woodhouse, L., Casaburi, R., Singh, A. B., Mac, R. P., Lee, M., Yarasheski, K. E., SinhaHikim, I., Dzekov, C., Dzekov, J., Magliano, L., Storer, T. W. (2005). Older men are as responsive as young men to the anabolic effects of graded doses of testosterone on the skeletal muscle. The Journal of Clinical Endocrinology and Metabolism, 90(2), 678-688.

Elliot, D. L., Cheong, J., Moe, E. L., Goldberg, L. (2007). Crosssectional study of female students reporting anabolic steroid use. Archives of Pediatrics \& Adolescent Medicine, 161(6), 572577.

Kwok, K. H., Lam, K. S., Xu, A. (2016). Heterogeneity of white adipose tissue: molecular basis and clinical implications. Experimental \& Molecular Medicine, 48(3), e215.

Ribeiro, T., Esteves, J. V., Almeida, F. N., Fabricio, G. S., Tófolo L. P., Rinaldi, W., Moraes, S. M. (2011). O uso de decanoato de nandrolona, redução de gordura corporal e ganho de força em ratos wistar. Revista Digital EFDesportes 16(161).

Rodrigues, R. W. P., Abrahin, O., Sousa, E. C., Marçal, A. C. (2016). Efeitos do exercício resistido de alta intensidade em ratos que receberam dexametasona. Revista Brasileira de Medicina do Esporte, 22 (3), 211-215. 
118 | O Abrahin, WN Santos, RP Rodrigues, RJS Silva, JA Aragão, FJA Martins, AC Marçal.

Sagoe, D., Molde, H., Andreassen, C. S., Torsheim, T., \& Pallesen, S. (2014). The global epidemiology of anabolic-androgenic steroid use: a meta-analysis and meta-regression analysis. Annals of Epidemiology, 24(5), 383-398.

Spendlove, J., Mitchell, L., Gifford, J., Hackett, D., Slater, G., Cobley, S., O'Connor, H. (2015). Dietary Intake of Competitive Bodybuilders. Sports Medicine. 45(7), 1041-63

Tamaki, T., Uchiyama, S., Nakano, S. A. (1992). Weight lifiting exercise model for inducing hypertrophy in the hind limb muscles of rats.
Medicine and Science in Sports and Exercise, 24(8), 881-886.

Whitaker, K. M., Choh, A. C., Lee, M., Towne, B., Czerwinski, SA., Demerath, E. W. (2016). Sex differences in the rate of abdominal adipose accrual during adulthood: the fels longitudinal study. International Journal of Obesity, 40(8), 1278-1285.troski, E. L., Pelegrini, A., \& Glaner, M. F. (2012). Reasons and prevalence of body image dissatisfaction in adolescents. Ciência $\mathcal{E}$ Saúde Coletiva, 17(4), 1071-1077. http://doi.org/10.1590/S141381232012000400028

c) (i) (9) All content of Journal Motricidade is licensed under Creative Commons, except when otherwise specified and in content retrieved from other bibliographic sources. 


\title{
Anthropometric profile of basketball athletes by game position, competition level and competition ranking: a cross-sectional study
}

\author{
Petrus Gantois ${ }^{1 *}$, Gledson Tavares de Amorim Oliveira ${ }^{1}$, Breno Guilherme de Araújo Tinoco \\ Cabral $^{1}$, Paulo Henrique Duarte do Nascimento ${ }^{1}$, Felipe J. Aidar ${ }^{2}$, Gilmário Ricarte Batista ${ }^{3}$

\begin{abstract}
Objective: Describe and compare the anthropometric profile of basketball athletes according to their game position, competition level and ranking. Methods: Participants were 189 male basketball athletes competing in the first and second division of the basketball state championship. The anthropometric profile measurements were body mass, height, body fat (skinfold) and somatotype analysis. The athletes were distributed according to their position (guard, forwards and centers), competition level (first and second division) and ranking (semi-finalists) at the competition. Results: The centers presented the highest height and body mass $(\mathrm{p}<0.05)$. The first division athletes in all positions were taller $(\mathrm{p}<0.05)$ than the athletes from the second division. The best-ranked centers from the first division presented less endomorphic components than the best-ranked centers from the second division $(p<0.05)$. Conclusion: In conclusion, the athletes from higher competition level and better ranked presented higher height and less endomorphic components, which is believed to be important characteristics for performance. Therefore, the anthropometric profiles are likely to play a role in athletic performance.

Keywords: Anthropometry; Body composition; Athletic performance; Athletes.
\end{abstract}

\section{INTRODUCTION}

In basketball, the identification of body composition and the somatotype components are essential factors that predict athletic performance (Alejandro, Santiago, Gerardo, Carlos, \& Vicente, 2015). These components are capable to provide indicators of selection and detection of potential athletes (Martín-Matillas et al., 2013) and thus, support coaches to elaborate an optimized training program (Ziv \& Lidor 2009). During a training program, the anthropometric profile (e.g. height, weight and somatotype) provides relevant data that support trainers when picking young athletes (Nikolaidis et al., 2014).

The somatotype is characterized by components of endomorphy (relative adiposity) ectomorphy (linearity) and mesomorphy (muscular development), and, together with body mass, height and body fat percentage, compose the anthropometric profile (Carter, Ackland, Kerr, \& Stapff, 2005; Martín-Matillas et al., 2013). During a basketball game, the athletes are frequently submitted to more than 2.700 actions of intermittent intensity, which involves running, walking, sprinting and jumping (Scanlan; Dascombe; Reaburn 2011). Recently, studies reported the negative effect of high values of body mass and body fat and, consequently high index of endomorphy, on anaerobic performance (e.g. sprinting and jumping) (Nikolaidis et al., 2014; Ribeiro, Mota, Sampaio-Jorge, Morales, \& Leite, 2015). Thus, inappropriate anthropometric profile can limit performance of motor abilities required in a basketball game.

Previous studies with athletes of different team sports indicate that for each position during the game, it is necessary a specifically different body profile (Malousaris et al. 2008; RamosCampo et al. 2014). In basketball, the athletes are distributed in three different positions with specific attributions during the game (guards, forwards and centers). According to scientific literature, significant differences in body composition were reported in function of specific

\footnotetext{
${ }^{1}$ Universidade Federal Do Rio Grande do Norte, Natal, Brasil

2 Universidade Federal de Sergipe; ${ }^{3}$ Universidade Federal da Paraíba

* Corresponding author: Universidade Federal do Rio Grande do Norte, Campus Universitário Lagoa Nova. Caixa Postal 1524. CEP 59078-970. Natal/RN, Brasil E-mail: pgm.gantois@gmail.com
} 
in-game demands, with centers commonly presenting higher body mass, height and body fat in comparison with forwards and guards (Abdelkrim, Chaouachi, Chamari, Chtara, \& Castagna, 2010; Alejandro et al. 2015; PonceGonzález, Olmedillas, Calleja-González, \& Guerra, 2015). Concerning to somatotype, a review-level evidence observed that players in forwards show predominance in mesomorphy, which suggests that this component, together with lower body mass, can contribute in a situation where the players need higher velocity and agility, as in actions of counter attacks (Ziv \& Lidor, 2009). In this sense, it is reasonable to assume that certain parameters of anthropometric profile can aid coaches to define in which position each player should play (Ostojic, Mazic \& Dikic, 2006).

In the last decades, many investigation in regard to athletes anthropometric profile proposed to identify morphologic differences between sports modalities (Bayios, Bergeles, \& Apostolidis, 2006; Gaurav, Singh, \& Singh, 2010), game position (Ostojic et al., 2006; Rivera-Sosa, 2016) and competition level, this last one characterized by team division level (Erčulj, Blas, \& Bračič, 2010) and athlete's category (Abdelkrim et al., 2010). In contrast, it is observed a lack in studies which encompasses athlete's anthropometric profiles and final ranking in a tournament. At one of the few studies with this proposal, Carter, Ackland, Kerr, and Stapff (2005) and Martín-Matillas et al. (2013) investigated the morphologic profile of athletes from the women's basketball world championship according to their competition ranking.

From the studies previously mentioned, there is a lack of studies in the anthropometric profile of men's basketball and competition level and ranking. This information has great relevance to support coaches and trainers to advise young athletes according to their body profile, based on descriptive studies that present the relationship of body profile, competition level and ranking, as well as aiding the prescription of the training program. For such, this study proposes to describe and compare the anthropometric profile of basketball athletes in function of their position, competition level and ranking.

\section{METHODS}

\section{Participants}

The sample was composed of 189 male basketball athletes of 17 teams that compete in the Basketball State Championship of Pernambuco participated in this study. From the 189, 63 athletes were players competing in the first division ( $\mathrm{FD}$, age $=21.1 \pm 5.46$ years $)$ and 126 (age $=28.3 \pm 10.1$ years) were players competing in the second division (SD). All the participants in this study were competing during a period superior to 3 years and were officially registered in the local Federation of Basketball

\section{Study Design}

The present study is descriptive with crosssectional design. To conduct the data collection, it was performed a survey of the teams and quantity of athletes registered to the Basketball State Federation of Basketball of Pernambuco. It was found 204 athletes, participants of the FD and SD of the Basketball State Championship of Pernambuco. Fifteen participants did not accept to participate in the study or did not attend the inclusion criteria of the study; therefore, our sample comprises $92.6 \%$ (189 athletes) of the athletes competing at the Basketball State Championship of Pernambuco. The data collection was performed in two stages, the first moment - the explanation of the study objectives and general procedures - and the second moment - anthropometric evaluations. The data collection was performed in the pre-season, one month before the competition. The procedures were performed in their training center with a previously scheduled visit with athletes and coaches. For study effects, the athletes were distributed according to their position (guards, forwards and centers), competition level, FD versus SD, and by championship ranking, in which were distributed as semi-finalists from FD (SFD) versus semifinalists from the SD (SSD), after the final results. The study was approved by 
the institutional ethics committee of the center of health sciences from the Federal University of Pernambuco (CAE: 0178.0.172.000-10), following the guidelines of data collection for humans, following the resolution of $466 / 12$ from the Brazilian Health Council of 12/12/2012, as well as rigorously respecting the principles of ethic stated at the Declaration of Helsinki. Each subject signed the informed consent.

\section{Anthropometry}

It was assessed the body mass $(\mathrm{kg})$ in an anthropometric scale (Filizola ${ }^{\circledR}$ 110, São Paulo, Brazil) with an accuracy of $0.1 \mathrm{~kg}$ and height through a stenographer (Sanny®, São Bernardo do Campo, Brazil) with an accuracy of $0.1 \mathrm{~cm}$. For each estimate of somatotype, it was used the same procedures outlined at Carter; Heath (1990), being measured the triceps, suprailiac, subscapular and mid-thigh skinfolds with an adipometer (Cescorf ${ }^{\circledR}$, Porto Alegre, Brasil), with an accuracy of $0.1 \mathrm{~mm}$. The body circumferences were performed in the biceps brachii, in point of maximal contraction, and the calf, with an anthropometric tape with an accuracy of $0.1 \mathrm{~cm}$. It was assessed the bone diameter of humerus and femur with a pachymeter (Sanny ${ }^{\circledR}$, São Bernardo do Campo, Brazil) with an accuracy of $0.05 \mathrm{~mm}$. To calculate the corporal density, we used the protocol of Durnin and Womersley (1974), identified by the somatotype of the four skinfolds (biceps, triceps, subscapular and suprailliac). For the estimate of body fat percentage, it was used the equation of Siri (1961). The measures were performed during nighttime and always by the same evaluator. The coefficient of test-retest for each anatomic point exceeded 0.95 and the technical error was inferior to 0.05. All measures followed the standards adopted by the International Society for Advancement in Kinanthropometry (MarfellJones, Stewart, \& Ridder, 2012).

\section{Statistical Analyses}

To verify the data normality, it was used the Shapiro-Wilk test. The data are presented as means and standard deviation. A one-way ANOVA was conducted to compare the dependent variables between position (e.g. guards, forwards and center), competition level (e.g. FD and SD) and ranking (e.g. SFD and SSD). Eta squared partial (partial $\eta^{2}$ ) was used to determine the effect size. When necessary, it was used a Bonferroni post hoc to find significant differences. To assess and compare athletes' somatotype, it was used the calculation of the spatial distance of somatotypes (SDM), proposed by Duquet and Hebbelinck (1977), considering significant values with $S D M \geq 1.00$. The distance is the result of the square root of the sum of squares of the difference obtained by the following equation: $\mathrm{SDM}=\sqrt{ }(\mathrm{IA}-\mathrm{IB})^{2}+(\mathrm{IIA}-$ $\mathrm{IIB})^{2}+(\mathrm{IIIA}-\mathrm{IIIB})^{2}$, where, DES $=$ spatial distance of somatotypes; $\mathrm{I}=$ endomorphy; $\mathrm{II}=$ mesomorphy; III= ectomorphy; $\mathrm{A}$ e $\mathrm{B}=$ indexes of two somatotype to be compared. An analysis of study power post hoc was conducted to determine the achieved power, based on the sample size investigated, assuming and alfa error of 0.05 , and the effect size achieved. Regarding the position, it was achieved a power $>92.5 \%$ for the dependent variables. Regarding the ranking, a power $>84.6 \%$ was achieved and regarding ranking, a power $>80.0 \%$ was achieved. All statistical analyses were performed in the Statistical Package for the Social Sciences (SPSS, version 20) for windows (New York, EUA). $\mathrm{p} \leq 0,05$ was adopted as statistical significance.

\section{RESULTS}

Table 1 presents the descriptions and comparison of athletes' body composition and somatotype in function of their position. 
Table 1

Athletes' body composition and components of somatotype per game position

\begin{tabular}{lcccc}
\hline VARIABLES & $\begin{array}{c}\text { GUARDS } \\
(\mathrm{n}=50)\end{array}$ & $\begin{array}{c}\text { FORWARDS } \\
(\mathrm{n}=79)\end{array}$ & $\begin{array}{c}\text { CENTERS } \\
(\mathrm{n}=60)\end{array}$ & Partial $\eta 2$ \\
\cline { 2 - 5 } Body Mass $(\mathrm{kg})$ & $80.3 \pm 14.1$ & $84.4 \pm 14.4$ & $100.6 \pm 15.7^{\mathrm{b}, \mathrm{c}}$ & 0.240 \\
Height $(\mathrm{cm})$ & $176.1 \pm 7.1^{\mathrm{a}}$ & $183.0 \pm 6.6$ & $193.4 \pm 6.9^{\mathrm{b}, \mathrm{c}}$ & 0.484 \\
\% Fat & $18.0 \pm 5.1$ & $17.0 \pm 4.7$ & $20.1 \pm 5.1^{\mathrm{c}}$ & 0.07 \\
Endomorphy & $3.9 \pm 1.5$ & $3.6 \pm 1.4$ & $4.5 \pm 1.6^{\mathrm{c}}$ & 0.05 \\
Mesomorphy & $4.2 \pm 1.3$ & $3.8 \pm 1.4$ & $3.6 \pm 1.5$ & 0.02 \\
Ectomorphy & $1.7 \pm 1.2^{\mathrm{a}}$ & $2.3 \pm 1.4$ & $2.1 \pm 1.3$ & 0.03 \\
\hline
\end{tabular}

Statistical difference $(p<0.05): a=$ Guards $\mathrm{x}$ Forwards; $\mathrm{b}=$ Guards $\mathrm{x}$ Centers; $\mathrm{c}=$ Forwards $\mathrm{x}$ Centers.

Table 2

Athletes' body composition and components of somatotype per competition level

\begin{tabular}{lcccccc}
\hline \multirow{2}{*}{ VARIABLES } & \multicolumn{2}{c}{ GUARDS } & \multicolumn{2}{c}{ FORWARD } & \multicolumn{2}{c}{ CENTERS } \\
\cline { 2 - 7 } & FD & SD & FD & SD & FD & SD \\
$(\mathrm{n}=16)$ & $(\mathrm{n}=34)$ & $(\mathrm{n}=24)$ & $(\mathrm{n}=55)$ & $(\mathrm{n}=23)$ & $(\mathrm{n}=37)$ \\
\cline { 2 - 7 } Body Mass $(\mathrm{kg})$ & $80.6 \pm 9.5$ & $80.0 \pm 16.1$ & $85.4 \pm 11.5$ & $84.0 \pm 15.6$ & $101.7 \pm 13.3$ & $99.3 \pm 17.4$ \\
Height (cm) & $180.7 \pm 6.6^{*}$ & $173.8 \pm 6.1$ & $186.2 \pm 6.5^{*}$ & $181.6 \pm 6.2$ & $197.9 \pm 5.1^{*}$ & $190.1 \pm 6.1$ \\
\% Fat & $15.6 \pm 3.8^{*}$ & $19.2 \pm 5.2$ & $16.0 \pm 4.4$ & $17.4 \pm 4.9$ & $19.6 \pm 4.4$ & $20.4 \pm 5.3$ \\
Endomorphy & $3.2 \pm 1.1^{*}$ & $4.3 \pm 1.7$ & $3.3 \pm 1.3$ & $3.8 \pm 1.5$ & $3.9 \pm 1.4^{*}$ & $4.8 \pm 1.7$ \\
Mesomorphy & $3.8 \pm 1.3$ & $4.4 \pm 1.2$ & $3.5 \pm 1.4$ & $4.0 \pm 1.4$ & $3.4 \pm 1.22$ & $3.7 \pm 1.6$ \\
Ectomorphy & $2.3 \pm 1.1^{*}$ & $1.4 \pm 1.2$ & $2.5 \pm 1.6$ & $2.2 \pm 1.4$ & $2.5 \pm 0.9$ & $1.8 \pm 1.4$ \\
\hline
\end{tabular}

${ }^{*}$ Statistical difference $(\mathrm{p}<0.05) ; \mathrm{FD}=$ First division; $\mathrm{SD}=$ Second division

Table 3

Athletes' body composition and components of somatotype per ranking

\begin{tabular}{lcccccc}
\hline \multirow{2}{*}{ VARIABLES } & \multicolumn{2}{c}{ GUARDS } & \multicolumn{2}{c}{ FORWARD } & \multicolumn{2}{c}{ CENTERS } \\
\cline { 2 - 7 } & $\begin{array}{c}\text { SFD } \\
(\mathrm{n}=12)\end{array}$ & $\begin{array}{c}\text { SSD } \\
(\mathrm{n}=12)\end{array}$ & $\begin{array}{c}\text { SFD } \\
(\mathrm{n}=14)\end{array}$ & $\begin{array}{c}\text { SSD } \\
(\mathrm{n}=16)\end{array}$ & $\begin{array}{c}\text { SFD } \\
(\mathrm{n}=18)\end{array}$ & $\begin{array}{c}\text { SSD } \\
(\mathrm{n}=18)\end{array}$ \\
\cline { 2 - 7 } $\begin{array}{l}\text { Body } \\
\text { (kg) }\end{array}$ & $84.0 \pm 8.5$ & $78.8 \pm 16.2$ & $84.7 \pm 8.6$ & $86.1 \pm 11.2$ & $101.0 \pm 11.8$ & $105.1 \pm 13.6$ \\
Height (cm) & $183.1 \pm 4.3^{*}$ & $175.7 \pm 7.5$ & $187.6 \pm 5.4^{*}$ & $181.9 \pm 5.8$ & $198.2 \pm 4.6^{*}$ & $190.6 \pm 4.7$ \\
\% Fat & $15.6 \pm 3.7$ & $18.8 \pm 4.6$ & $13.9 \pm 3.5^{*}$ & $17.8 \pm 3.3$ & $18.6 \pm 4.3^{*}$ & $22.1 \pm 3.6$ \\
Endomorphy & $3.2 \pm 1.1$ & $4.5 \pm 1.6$ & $2.6 \pm 0.9^{*}$ & $3.8 \pm 1.9$ & $3.6 \pm 1.1^{*}$ & $3.8 \pm 1.7$ \\
Mesomorphy & $3.6 \pm 1.2$ & $4.7 \pm 1.2$ & $3.2 \pm 1.5$ & $3.9 \pm 1.3$ & $3.1 \pm 0.9$ & $2.4 \pm 1.6$ \\
Ectomorphy & $2.3 \pm 1.0$ & $1.1 \pm 0.9$ & $2.7 \pm 1.7$ & $2.3 \pm 1.3$ & $2.4 \pm 0.8^{*}$ & $2.7 \pm 2.0$ \\
\hline
\end{tabular}

*Statistical difference $(\mathrm{p}<0.05) ; \mathrm{SFD}=$ Semifinalists from first division; $\mathrm{SSD}=$ Semifinalists from second division.

The centers presented higher height $(\mathrm{F}=$ 87.30; $\mathrm{p}<0.001)$ and body mass $(\mathrm{F}=28.78 ; \mathrm{p}>$ 0.001 ) than forwards and guards, and higher body fat than forwards $(F=7.03 ; p=0.001)$. The forwards presented higher height than guards $(F=87.30 ; p<0.001)$. For the components of somatotype, it was observed differences in endomorphy between forwards and centers $(\mathrm{F}=$ 5.42; $\mathrm{p}=0.003$ ), and for ectomorphy between guards and forwards $(\mathrm{F}=2.86 ; \mathrm{p}=0.047)$. Regarding somatotype classification, the guards and forwards were classified as mesomorphendomorph and centers were endomorphmesomorph. When comparing the somatotype between positions, it was not observed statistical differences regarding SDM DES $<1.0$.

Table 2 presents a comparison of anthropometric variables between athletes from FD and SD in function of position. The athletes from FD presented higher height in all positions when compared with their pairs, Guards $(F=$ 13.76; $\mathrm{p}=0.001)$, forwards $(\mathrm{F}=9.12 ; \mathrm{p}=0.003)$ and centers $(F=24.40 ; p<0.001)$; the guards from the FD presented lower body fat than SD $(\mathrm{F}=6.13 ; \mathrm{p}=0.017)$. Regarding somatotype, guards and centers presented differences in endomorphy $(\mathrm{F}=6.29 ; \mathrm{p}=0.016$ and $\mathrm{F}=4.35$; $\mathrm{p}=$ 0.041). The forwards did not present 
differences. The guards were classified as mesomorph-endomorph for FD and endomorphmesomorph for SD; the forwards as mesomorphendomorph for $\mathrm{FD}$ and $\mathrm{SD}$ and centers as endomorph-mesomorph for FD and SD. Regarding somatotype comparison, it was found differences in guards $(\mathrm{SDM}=1.54)$ and centers $(\mathrm{SDM}=1.21)$ relative to their pairs ( $\mathrm{PD}$ versus $\mathrm{SD})$.

Table 3 presents the results of the anthropometric profile of athletes of SFD and SSD groups per position. Significant differences were found in height for SFD in comparison to SSD, guards $(F=5.43 ; p=0.029)$, forwards $(F=$ $7.65 ; \mathrm{p}<0.001)$ and centers $(\mathrm{F}=20.39 ; \mathrm{p}<$ $0.001)$. Forwards and centers SSD presented higher body fat in comparison to SFD $(\mathrm{F}=9.69$; $\mathrm{p}=0.004$ and $\mathrm{F}=7.41 ; \mathrm{p}=0.010)$. For the components of somatotype, it was not observed differences in guards; forwards presented differences for endomorphy $(\mathrm{F}=11.29 ; \mathrm{p}=$ $0.002)$; and the centers for endomorphy $(\mathrm{F}=$ 17.80; $\mathrm{p}<$ 0.001). Regarding somatotype classification, guards were classified as endomorph-mesomorph for SFD and SSD. The forwards were classified as mesomorph for SFD and endomorph-mesomorph for SSD. The centers were classified as endomorph-mesomorph for SFD and endomorph for SSD. Regarding somatotype, it was found differences in forwards $(\mathrm{SDM}=1.81)$ and centers $(\mathrm{SDM}=2.04)$ relative to their pairs (SPD versus SSD).

\section{DISCUSSION}

The main finding of the present study was to characterize distinct anthropometric profiles of players that assumed different position (guards, forwards and centers) in basketball, competition level (FD and SD) and ranking (SFD and SSD). It was observed differences in body composition and somatotype, especially for height. These findings corroborate with previous studies that reported differences in body profile among athletes of different sports modalities, including basketball (Abdelkrim et al., 2010; Nikolaidis \& Ingebriggtsen, 2013; Ramos-Campo et al., 2014; Alejandro et al., 2015).
Regarding the comparison relative to the game position, our findings are similar to other studies presented in the literature, in which is possible to infer that the specific position demand requires a different anthropometric profile, due to the execution of motor actions inherent to that position (Malousaris et al., 2008). A review study conducted by Ziv and Lidor (2009) investigated the anthropometric profile of men's and women's basketball athletes and found that differences in body mass and height are the most frequently reported, especially with regard to gaming attributions. In this sense, investigations conducted by Boone and Bourgois (2013) and Ponce-González, Olmedillas, Calleja-González and Guerra (2015) in elite basketball players corroborated with our findings, confirming that centers display higher height than guards and forwards, as well as higher body mass than guards. From this, it is possible to suggest that these differences in body composition in centers highlight the importance of physical attributes, favoring them in space dispute, mainly on rebound actions and pitches close to the hoop (Ostojic et al., 2006; Ziv \& Lidor, 2009).

Concerning height, it was verified that according to the competition level and ranking in the championship, the athletes, both FD and SD displayed higher height when compared to SD and SSD. Erčulj, Blas, and Bračič, (2010) found that the A division of women's category from the European Basketball Championship presented higher height than athletes from $B$ division and C. Carter et al., (2005) compared four out of five best positioned teams with four out of five worst positioned teams from the Women's World Championship of 1994 and found that the bestpositioned guards and centers were seven and six centimeters taller, respectively. It was expected that the athletes with higher competition level and ranking presented increased height due to the higher demands required, also because this characteristic is associated with other factors, as higher performance, technical performance and tactics. Apparently, height demonstrated to be a parameter that may be used to select and guide 
coaches to choose the athletes' specific functions and position in basketball (Ostojic et al., 2006).

Regarding the somatotype analyses, the SDM did not show differences between player's position, although it was found differences in individual components. The centers presented higher endomorphy components than forwards, while ectomorphy was more prevalent in forwards than guards but no differences in mesomorphy. The similar mesomorphic components suggest that muscle mass may be an important factor for basketball, independent of position, which can contribute in disputes that involve physical contact during the game (Bayios et al., 2006; Martinez, Lopez, Meza, Millan, \& Leon, 2014). A study conducted by Carter et al., (2005) also found differences in somatotype components when assessed the players from the women's basketball World Championship. Regarding the somatotype analyses concerning competition level and ranking, the SDM was different in guards and centers athletes from the FD when compared to SD, as well as forwards and centers from SFD to SSD. In an individual analysis of somatotype components, it was found that endomorphy was responsible for these changes, where SD athletes displayed higher endomorphic components than FD. It is important to highlight that endomorphic components were observed along with the percentage of body fat. According to Wilmore and Costill (1999), the ideal percentage of body fat for basketball athletes should fluctuate between 6 to $15 \%$, but these values were not observed in our study. This data suggests that high endomorphy and percentage of body fat may be associated with reduced athletic performance, mainly in intermittent tasks, which was reported about 1050 movements in a basketball game and that corresponds to movement changes every 2 seconds (Abdelkrim, Fazaa, \& Ati 2007). Reinforcing this concept, the study of MartínMatillas et al., (2013) found a negative relationship between endomorphy and percentage of body fat with athletic performance. In this sense, it is likely that there is a negative influence of endomorphy and body fat on performance variables, and thus, emphasize the influence of assessing these parameters in basketball athletes.

Therefore, the results presented here suggest that according to the game demands and functions, a specific anthropometric profile is needed, and these patterns can aid the process of detection and selection of players for each position. Although the success in sports is the result of the interaction of many aspects, such as technical, tactical and motor, it is likely that the combination of increased height with less percentage of body fat and endomorphy can favor athletic performance. Although our findings can aid coaches and physical trainers to choose and prepare athletes accordingly with their physical profile, this study has some limitation inherent to its cross-sectional design. In this sense, we recommended next studies to conduct a followup design with athlete's body profile and track their performance throughout the competition. Also, it may be interesting to use methods with increased reliability in order to avoid measurement errors.

\section{CONCLUSION}

It is possible to infer that the anthropometric profile is an important component of the athletic performance, and the athletes with higher competition level and better classified in the championship presented increased height and less endomorphy, this in turn, can be an important physical attribute to succeed in basketball. Therefore, our data can favor coaches during the process of selection and orientation of young athletes of basketball, from the point of view of the anthropometric profile, a critical attribute to achieve success in basketball.

Acknowledgments:

Nothing to declare

Conflict of interests:

Nothing to declare 
Funding:

Nothing to declare

\section{REFERENCES}

Abdelkrim, N., Chaouachi, A., Chamari, K., Chtara, M., \& Castagna, C. (2010). Positional role and competitive-level differences in elite-level men's basketball players. Journal of Strength and Conditioning Research, 24(5), 1346-55. doi: 10.1519/JSC.0b013e3181cf7510

Abdelkrim, N., Fazaa, E., \& Ati, E. (2007). Timemotion analysis and physiological data of elite under-19-year-old basketball players during competition. British Journal of Sports Medicine, 41 (2), 69-75. doi: 10.1136/bjsm.2006.032318

Alejandro, V., Santiago, S., Gerardo, V. J., Carlos, M. J., \& Vicente, G. T. (2015). Anthropometric Characteristics of Spanish Professional Basketball Players. Journal Of Human Kinetics, 46(1), 99-106. doi: 10.1515/hukin-2015-0038

Bayios, I., Bergeles, N., \& Apostolidis, N. (2006). Anthropometric, body composition and somatotype differences of Greek elite female basketball, volleyball and handball players. Journal of Sports.

Boone, J., \& Bourgois, J. (2013). Morphological and physiological profile of elite basketball player in Belgium. International Journal of Sports Physiology and Performance, 8, 630-38.

Carter, J. E. L., Ackland, T. R., Kerr, D. a, \& Stapff, a B. (2005). Somatotype and size of elite female basketball players. Journal of Sports Sciences, $23(10)$,

1057-63. doi:10.1080/02640410400023233

Carter, J. E. L., \& Heath, B. H. (1990). Somatotyping: Development and Applications.

Duquet, W., \& Hebbelinck, M. (1977). Application of the somatotype attitudinal distance to the study of group and individual somatotype status and relations. Growth and Development Physique. Academiai Kiado: Budapest.

Durnin, J. V, \& Womersley, J. (1974). Body fat assessed from total body density and its estimation from skinfold thickness: measurements on 481 men and women aged from 16 to 72 years. The British Journal of Nutrition, $32(1), 77-97$.

Erčulj, F., Blas, M., \& Bračič, M. (2010). Physical demands on young elite European female basketball players with special reference to speed, agility, explosive strength, and take-off power. Journal of Strength and Conditioning Research, 24(11), 2970-8.

Gaurav, V., Singh, M., \& Singh, S. (2010). Anthropometric characteristics, somatotyping and body composition of volleyball and basketball players. Journal of Physical Education and Sport Managemen, 1(3), 28-32.
Malousaris, G. G., Bergeles, N. K., Barzouka, K. G., Bayios, I. A., Nassis, G. P., \& Koskolou, M. D. (2008). Somatotype, size and body composition of competitive female volleyball players. Journal of Science and Medicine in Sport, 11 (3), 337-344.

Marfell-Jones, M., Stewart, A., \& Ridder, J. de. (2012). International standards for anthropometric assessment.

Martín-Matillas, M., Valadés, D., HernándezHernández, E., Olea-Serrano, F., Sjöström, M., Delgado-Fernández, M., ... Delgado-Fernández, M. (2013). Anthropometric, body composition and somatotype characteristics of elite female volleyball players from the highest Spanish league. Journal of Sport Science, 32 (January 2014), 37-41.

Martinez, P. Y. O., Lopez, J. A. H., Meza, E. I. A., Millan, E. M. A., \& Leon, R. S. (2014). Somatotype Profile and Body Composition of Players from the Mexican Professional Basketball League. International Journal Of Morphology, 32 (3), 1032-1035. doi:10.4067/S071795022014000300046

Nikolaidis, P. T., Asadi, A., Santos, E. J. A. M., CallejaGonzález, J., Padulo, J., Chtourou, H., \& Zemkova, E. (2014). Relationship of body mass status with running and jumping performances in young basketball players Shortened. Muscles, Ligaments and Tendons Journal, 5(1), 1-5.

Nikolaidis, P. T., \& Ingebrigtsen, J. (2013). Physical and physiological characteristics of elite male handball players from teams with a different ranking. Journal of Human Kinetics, 38(September), 115-124.

Ostojic, S. M., Mazic, S., \& Dikic, N. (2006). Profiling in basketball: physical and physiological characteristics of elite players. Journal of Strength and Conditioning Research, 20(4), 740-4. doi: 10.1519/R-15944.1

Ponce-González, J. G., Olmedillas, H., CallejaGonzález, J., \& Guerra, B. (2015). Physical fitness, adiposity and testosterone concentrations are associated to playing position in professional basketballers. Nutrición Hospitalaria, 31 (6), 26242632. doi:10.3305/nh.2015.31.6.8977

Ramos-Campo, D. J., Martínez Sánchez, F., Esteban García, P., Rubio Arias, J. Á., Bores Cerezal, A., Clemente-Suarez, V. J., \& Jiménez Díaz, J. F. (2014). Body Composition Features in Different Playing Position of Professional Team Indoor Players: Basketball, Handball and Futsal. International Journal of Morphology, 32(4), 13161324. doi: $10.4067 / \mathrm{S} 0717-95022014000400032$

Ribeiro, B., Mota, H., Sampaio-Jorge, F., Morales, A., \& Leite, T. (2015). Correlation between Body Composition and the Performance of Vertical Jumps in Basketball Players. Journal of Exercise Physiology, 18(5), 69-78. doi: 10.5007/1980$0037.2016 \mathrm{v} 18 \mathrm{n} 2 \mathrm{p} 177$

Rivera-Sosa, J. M. (2016). Propiedades 
Antropométricas y Somatotipo de Jugadores de Baloncesto de Diferente Nivel Competitivo. International Journal of Morphology, 34(1), 179-188. doi: $10.4067 /$ S0717-95022016000100026

Scanlan, A., Dascombe, B., \& Reaburn, P. (2011). A comparison of the activity demands of elite and sub-elite Australian men's basketball competition. Journal of Sports Sciences, 29(11), $1153-1160$.

DOI: 10.1080/02640414.2011.582509

Siri, W. E. (1961). Techniques for Measuring Body
Composition: Proceedings of a Conference, Quartermaster Research and Engineering Center, Natick, Massachusetts, January 22-23, 1959.

Wilmore, J. H., \& Costill, D. L. (1999). Physiology of sport and exercise.

Ziv, G., \& Lidor, R. (2009). Physical attributes, physiological characteristics, on-court performances and nutritional strategies of female and male basketball players. Sports Medicine, $39(7)$, 547-568. doi: 10.2165/00007256200939070-00003

All content of Journal Motricidade is licensed under Creative Commons, except when otherwise specified and in content retrieved from other bibliographic sources. 


\section{Analysis of two different types of circuit training in the determinants of gait ability in elderly women}

Leandro Henrique Albuquerque Brandão ${ }^{1 *}$, Leury Max da Silva Chaves ${ }^{1,2}$, José Carlos Aragão-Santos ${ }^{1}$, Albernon Costa Nogueira ${ }^{1}$, Marta Silva Santos ${ }^{1,2}$, Juan Ramón Heredia ${ }^{3}$, Guillermo Peña ${ }^{3}$, Antônio Gomes de Resende Neto ${ }^{1,2}$, Marzo Edir Da Silva-Grigoletto ${ }^{1,2}$ Introduction: Walking ability in the elderly is negatively influenced by the advancing age. Among the ways to attenuate this reduction are the functional and traditional training. However, there is no consensus as to which method is most effective in improving this important skill. AIM: To compare the effects of different physical training on indicators of gait skills in elderly. Methodos: Forty-seven elderly women were randomly divided into three groups: functional training (FT), $n=18$; traditional training (TT), $n=18$; and control group (CG), $n=11$. Four tests were used: a) Time up and go (TUG); b) 30 seconds chair stand (CS); and c) six-minute walk test (6MWT) as well as the Ankle test. Data were analyzed using a $2 \times 3$ ANOVA with SIDAK post hoc test. Results: After of training, FT group presented a difference when compared with the control group $(\mathrm{p} \leq 0,05)$ and the pre-test in the CS $(\Delta \%=30,48 ; \mathrm{p} \leq 0,01)$, TUG $(\Delta \%=21,81 ; \mathrm{p} \leq 0,01)$ e 6 MWT $(\Delta \%=12,38 ; \mathrm{p} \leq 0,01)$. When compared FT and TT, difference was observed in TUG only. There was no difference between groups in the Ankle test. Conclusion: It is concluded that FT group is more effective in improving indicators of gait ability in elderly women.

Keywords: Aging, physical activity, performance, daily activities.

\section{INTRODUCTION}

Aging is understood as a multifactorial and inherent phenomenon, which is installed in human beings throughout their existence (Brandalize et al., 2011), causing exponential reductions in muscle mass, strength and balance (Bierbaum, Peper, Karamanidis, \& Arampatzis, 2010), with consequent loss of autonomy to perform simple daily activities such as walking (do Rosario, da Fonseca Martins, Peixinho, \& Oliveira, 2017), which is associated with physical disability (Rodríguez-Berzal, Durán, Royo, \& Jódar, 2013), increased risk of falls, and increased tendency to death (Studenski et al., 2011). In addition to advancing age, gender is also considered as an independent risk factor for the decline in gait ability. Thus, maintaining adequate functional capacity is an important goal for aging individuals, especially women (Cao, Maeda, Shima, Kurata, \& Nishizono, 2007).
One of the main strategies to change this clinical condition is the application of traditional resistance training (TT), which aims to reduce the risk of falls and increase gait velocity and stability through the increase in muscle strength of lower limbs (Fleck \& Kraemer, 2014). In a study developed with 65- to 79-year-old elderly submitted to 5 months of TT, significant improvements in maximal knee extension strength were observed, followed by improvement in the usual gait speed (Henderson et al., 2016). However, traditional methods commonly performed on bodybuilders are questionable regarding their potential of transference to gait ability (Buchner, Larson, Wagner, Koepsell, \& De Lateur, 1996). In the quest for greater effectiveness, functional training (FT) has emerged as an approach directly focused on the basic functions of the human being, relying on the principle of specific training

\footnotetext{
${ }^{1}$ Universidade Federal de Sergipe, São Cristovão, Brasil

${ }^{2}$ Scientific Sport, Brasil.

${ }^{3}$ International Institute of Physical Exercise and Health Science, Spain

E-mail: leeo.henriquee01@gmail.com
} 
(Resende-Neto, Da Silva-Grigoletto, Santos, \& Cyrino, 2016)

In this context, studies have demonstrated a significant improvement in gait speed after 12 weeks of FT (Giné-Garriga et al., 2010). They have also shown improvements based on the analysis of different strength training methods (Cadore, Rodríguez-Mañas, Sinclair, \& Izquierdo, 2013), indicating that FT or multicomponent training may be the most efficient method to improve gait ability and functionality of elderly individuals. However, other researchers have argumented in a systematic review that there are no differences between the so-called functional and traditional methods when it comes to physical fitness of the elderly (Liu, Shiroy, Jones, \& Clark, 2014). Thus, divergences in the literature regarding the effectiveness of these interventions to promote adaptations in gait components are noticeable, and this hinders a more robust comparison between the protocols used and the responses found.

The results of the present investigation will provide support to health professionals by shedding light on the effects of differentiated training, to elaborate useful and assertive intervention protocols for the elderly population.

Based on an experimental model, the present study sought to comparatively analyze the effects of functional and traditional training on the gait ability of pre-frail elderly women, having the methodological rigor and standardization of intervention protocols, especially with regard to load components, as a differential in relation to previous studies.

\section{Subjects}

\section{METHODS}

This is a randomized controlled clinical trial (Thomas, Nelson, \& Silverman, 2009). The sample consisted of 47 elderly women aged 60 to 79 years, recruited through the distribution of leaflets in the community surrounding the Federal University of Sergipe. In order to be included in the intervention, the participants had to be free of acute osteomioarticular diseases and cardiac instability that could prevents the practice of high-effort exercises, what was checked by a medical professional; participants should also achieve a minimum score of 24 points in the mental health questionnaire, and agree not to participate in any regular physical activity besides the prescribed training. After the training period, participants with an attendance of less than $85 \%$ or who missed three consecutive training sessions were excluded from the analyses.

Table 1

Characteristic of the sample by groups.

\begin{tabular}{lccc}
\hline & $\begin{array}{c}\text { Functional Training } \\
(\mathrm{n}=18)\end{array}$ & $\begin{array}{c}\text { Traditional training } \\
(\mathrm{n}=18)\end{array}$ & $\begin{array}{c}\text { Control group } \\
(\mathrm{n}=11)\end{array}$ \\
\hline Age & $65.60 \pm 5.40$ & $65.60 \pm 5.10$ & $62.50 \pm 3.00$ \\
Weight & $68.90 \pm 12.60$ & $65.80 \pm 12.80$ & $72.50 \pm 14.40$ \\
Height & $154.00 \pm 5.30$ & $152.00 \pm 7.00$ & $154.40 \pm 7.80$ \\
BMI & $29.00 \pm 4.90$ & $28.50 \pm 5.50$ & $30.40 \pm 5.90$ \\
MMHE & $25.20 \pm 2.90$ & $25.70 \pm 3.60$ & $24.10 \pm 2.80$ \\
\hline
\end{tabular}

BMI - Body mass index; MMHE - Mini mental health examination. No significant difference $(\mathrm{p}<0.05)$ was found for any of the variables analyzed in the pretest.

The study was approved by the ethics committee of research with human beings of the institution $\quad\left(\mathrm{n}^{\mathrm{o}} \quad 1,021,732 / \mathrm{CAAE}\right.$ : 42022915.9.0000.5546). The methodological procedures were explained orally and the elderly women agreed to participate voluntarily in the research, signing the free and informed consent form. 


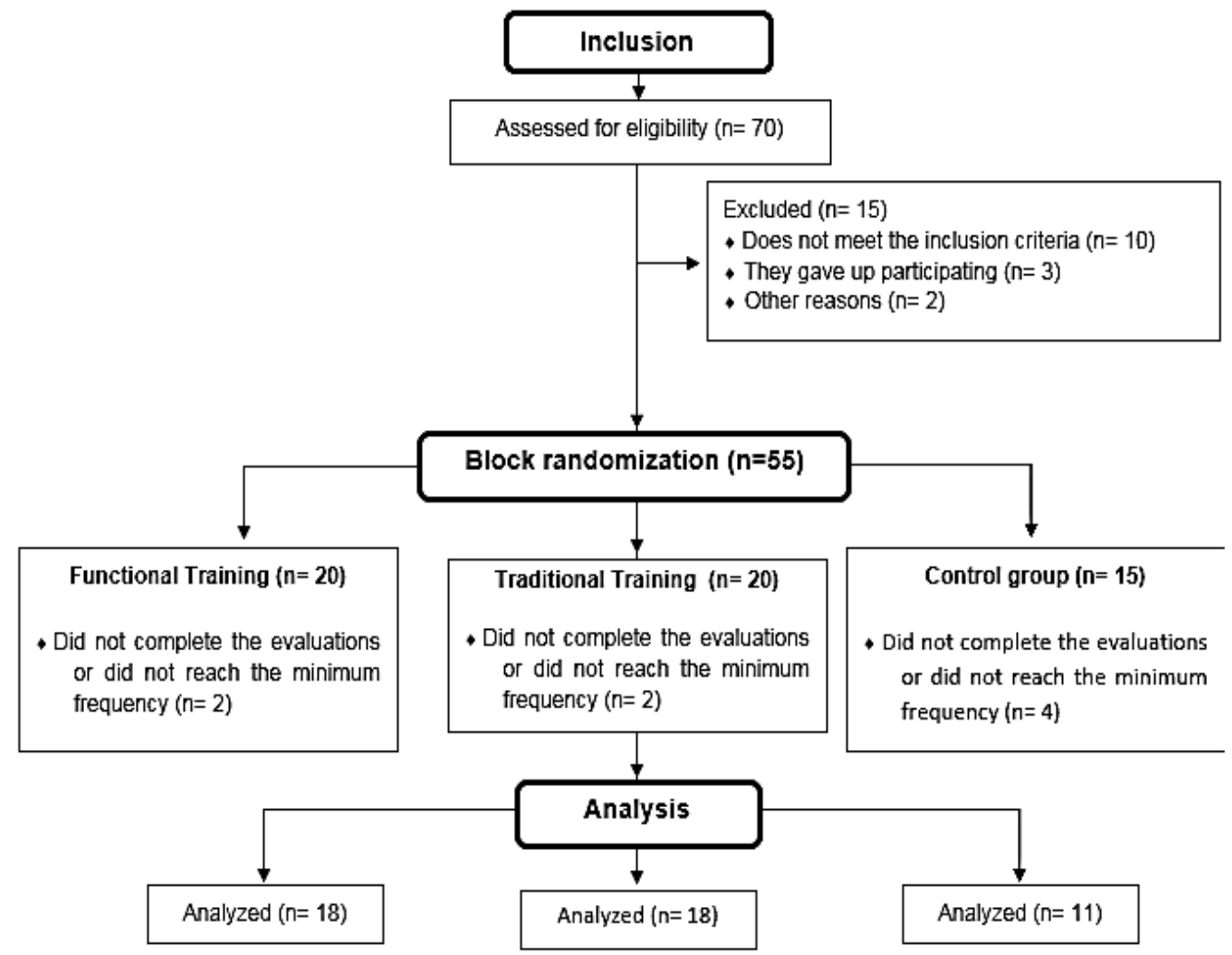

Figure 1. Experimental study design.

\section{Instruments}

The evaluators were blinded as to the intervention performed by the participants. The test battery was performed in three different moments: beginning of the study (M1); retest after two weeks of familiarization (M2) and after 12 weeks of intervention (M3). For all performance tests, participants were verbally encouraged to make their best.

The body weight $(\mathrm{kg})$ was determined through a scale (Lider ${ }^{\circledR}$, P150C, São Paulo, Brazil), with a maximum capacity of $150 \mathrm{~kg}$, for anthropometric characterization. The height $(\mathrm{cm})$ was determined by means of a stadiometer (Sanny, ES2030, São Paulo, Brazil).

The Mini Mental State Examination (MMSE), a cognitive evaluation test with a score ranging from zero to 30 points that provides data on several cognitive parameters of geriatric populations, was also used to better distribute the elderly in the groups.

In order to evaluate the determinants of gait ability, we used the Ankle test, which measures the dorsiflexion of the ankle (Calatayud et al.,
2015). Soon after, the volunteers applied three senior fitness battery tests (Rikli \& Jones, 2013) - Time up and go, 30 seconds and chair stand and six minutes walk test.

Ankle test: Participants began with hands on hips and with one foot in the middle of the longitudinal line right behind the transverse line. The other foot was positioned off the platform with the fingers touching the platform; holding that position, the participants were instructed to perform the maximum ankle dorsiflexion with the goal of touching the knee in the stick put ahead. This maximum reach achieved without losing contact of the heel with the ground was recorded in centimeters and the final result was the mean sum of the right and left sides. The test followed the guidelines described by Calatayud et al. (2015).

Time up and go: The participants began the test by sitting in a chair, with hands on thighs and feet resting on the ground. At the evaluator's signal, the participants were instructed to stand up and walk as fast as possible, without running, circling a cone at a distance of $2.44 \mathrm{~m}$ and then 
return to the starting position. The timer was triggered at the evaluator's signal and again when the participant sat down fully in the chair. After demonstration, an attempt was made for familiarization and after that, two attempts were made. We used the best score (time in seconds).

30 seconds chair stand: The test started from the sitting position and finished in the orthostatic position. At the evaluator's signal, the participants were instructed to stand up and return to the initial position and were encouraged to complete as many repetitions as possible within 30 seconds. Before starting the test, the evaluator demonstrated the exercise and then the participants performed one to three repetitions to become familiar with the task, and then started the test.

Six-minute walk test: Distance walked, walking as fast as possible, in a time of 6 minutes. The rectangular course had a total distance of $45.72 \mathrm{~m}$ and was demarcated by cones every 4.57 $\mathrm{m}$. The participant was advised when 2 minutes and 1 minute were left to the end of the task. At the end of the time, the walk was interrupted and then the distance traveled was measured.

\section{Procedures}

The intervention lasted three months and each session was performed three times a week on alternate days. The OMNI-GSE scale (SilvaGrigoletto et al., 2013) was used to control and standardize the overall internal load of training, based on which participants were asked to choose a score that reflected their perceived degree of effort during and after training.

After the initial evaluations, the individuals in the experimental groups (FT and TT) went through two weeks of familiarization, in which $50 \%$ of the intensity planned for the first session was applied. After that, they completed 36 training sessions.

\section{Functional training}

Participants performed integrated exercises, specific to activities of daily living, each session being divided into four blocks: 1 st (5 minutes): mobility for the main joints (ankle, hip and glenohumeral); 2nd (15 minutes): activities organized in a circuit that required agility, motor coordination and strength through a set of complex sensory motor systems (Box 1); 3rd (25 minutes): integrated multi-articular exercises involving lower and upper limbs, performed at maximum concentric velocity, in addition to specific exercises for the core (Table 2); and 4th (5 minutes): high-intensity intermittent activities.

Table 2

Exercises used in block 2 of functional training.

\begin{tabular}{cc}
\hline Phase 1 (1-18 sessions) & Phase 2 (19-36 sessions) \\
Move up and down step & Jump over the step \\
Alternative waves & Alternative waves \\
Vertical throw & Ground pitch \\
Displacement between cones & Run and jump between the cones \\
Linear agility ladder & Linear agility ladder \\
5 activities, 3 passages, 1' by station, density 1/1 & 5 activities, 3 passages, 1 ' by station, density 2/1. OMINI- \\
OMINI-GSE: 6 a 7. & GSE: 6 a 7. \\
\hline
\end{tabular}

\section{Traditional resistance training}

The participants performed uniplanar and analytical resistive exercises with isolated neuromuscular work. Each session was divided into four blocks: 1 st (5 minutes): mobility for the main joints (ankle, hip and glenohumeral); 2nd (15 minutes): continuous walking (Figure 2); 3rd (25 minutes): predominantly multi-articular, but uniplanar, exercises for upper and lower limbs in bodybuilders and performed at maximum concentric velocity (Table 2); and 4th (5 minutes): high-intensity intermittent activities.

In the 3rd block, all participants trained in doubles and were supervised by experienced physical education professionals whose responsibility was to maintain the established 
protocols and ensure an optimal standard of safety and motivation. Seven experienced instructors per group were responsible for the same exercises in order to standardize the stimuli throughout the intervention period. The addition of external load occurred from a perceived exertion 6 (easy) on the OMINI-GSE scale and with maintenance of 08 to 12 maximum repetitions. In the exercises performed with the own body mass, biomechanical modifications were applied according to the level of comfort and ability of the participant.

Table 3

Exercises used in block 3 of the functional (FT) and traditional (TT) training during 12 weeks.

\begin{tabular}{|c|c|c|c|}
\hline FT (1-18) & TT (1-18) & TF (19-36) & TT (19-36) \\
\hline Deadlift & Squat & Shouldering & Squat \\
\hline (ketlebells) & (Smith) & (Bulgarian bag) & (Free weight) \\
\hline Vertical Pull & Horizontal Pull & Vertical Pull & Horizontal Pull \\
\hline (Suspension tape) & (Articulated paddle) & (Suspension tape) & (Articulated paddle) \\
\hline Sit and stand up & Knee Extension & Goblet Squats & Knee Extension \\
\hline from the bench & $\left(\right.$ Leg press $\left.45^{\circ}\right)$ & (Ketlebells) & (Extending chair) \\
\hline Vertical Push & Vertical Push & Push-ups & Horizontal push \\
\hline (elastic) & (Vertical Bench Press) & (bench of $40 \mathrm{~cm}$ ) & (Bench press) \\
\hline Farm walk & Knee Flexion & Farm walk & One-sided knee \\
\hline (ketlebells) & (Flexor table) & (ketlebells) & flexion (ankle support) \\
\hline $\begin{array}{l}\text { Vertical pull } \\
\quad \text { (elastic) }\end{array}$ & Foward pull down & $\begin{array}{l}\text { Vertical row with } \\
\text { knee elevation } \\
\text { (elastic) }\end{array}$ & $\begin{array}{l}\text { Foward pull down } \\
\text { with neutral footprint }\end{array}$ \\
\hline $\begin{array}{l}\text { Elevation of the } \\
\text { pelvis on the ground } \\
\text { (body weight) }\end{array}$ & $\begin{array}{l}\text { Standing plantar flexion } \\
\text { (body weight) }\end{array}$ & $\begin{array}{l}\text { Elevation of the } \\
\text { pelvis on the ground }\end{array}$ & $\begin{array}{l}\text { Plantar flexion } \\
\left(\text { leg press } 45^{\circ}\right)\end{array}$ \\
\hline $\begin{array}{c}\text { Front plate } \\
\text { (bench of } 40 \mathrm{~cm} \text { ) }\end{array}$ & $\begin{array}{c}\text { Stiff } \\
\text { (barbell and washers) }\end{array}$ & $\begin{array}{l}\text { Front plate } \\
\text { (step) }\end{array}$ & curl up \\
\hline \multicolumn{2}{|c|}{$\begin{array}{c}8 \text { activities, } 2 \text { passages, } 1 \text { ' by station, density } 1 / 1 \text {. } \\
\text { OMINI-GSE: } 8 \text { a } 9 .\end{array}$} & \multicolumn{2}{|c|}{$\begin{array}{c}8 \text { activities, } 2 \text { passages, } 1 \text { ' by station, density } \\
1 / 1 \text {. OMINI-GSE: } 8 \text { a } 9\end{array}$} \\
\hline
\end{tabular}

In the high-intensity intermittent exercises (4th Block), collective activities of executable motor complexity were used, following a density of 30 seconds of work per 30 seconds of transition between the stations and an intensity equivalent to 8-9 in the OMNI-GSE. Here is a description of one of the activities used to achieve this stimulus:

-Interval Run: In a space of 30 meters, the participants were divided into five groups; of these, three formed a column behind a cone and the other two formed another column, at a distance of 20 meters. The working time consisted of traveling this distance with the maximum speed and recovery was achieved while the other participants of the group performed the sprints. The total volume was 8 to 12 sprints per participant.

\section{Control group}

The participants performed cognitive, stretching and relaxation activities during the 50 minutes that comprised the activities of the second, third, and fourth block of the experimental groups. These activities did not require mechanical and/or metabolic stress and were performed only for the purpose of maintaining the sample.

\section{Data analysis}

Data were expressed according to means, standard deviation and percentage of change. Reproducibility of the measurements was evaluated through the Intraclass Correlation Index (ICI), adopting $\geq 0.90$ as acceptance criterion. Homogeneity of the data was tested with the Levene test. Data were analyzed through repeated-measures ANOVA with post-hoc test of SIDAK to check the differences between interventions. They were tabulated and analyzed using the software Statistical Package for the Social Sciences (SPSS), version 22, adopting a significance level of $5 \%(\mathrm{P} \leq 0.05)$. The effect size 
(ES) was calculated using the equation proposed by Cohen (1990), as well as the classification of each result. Sample calculation was performed using the G*Power software version 3.1.9.2 (Erdfelder, Faul, \& Buchner, 1996; Kiel, Germany), considering the sample size with a power of 0.80 for the analyzed variables.

\section{RESULTS}

At the end of the intervention, all groups improved the ankle joint amplitude in the same way (Ankle test) (FT: $\Delta \%=45.33 \mathrm{p}=0.01, \mathrm{ES}=$ 1.60; TT: $\Delta \%=32.46, \mathrm{p}=0.01 \mathrm{ES}=0.80, \mathrm{GC}$ : $\Delta \%=53.96, \mathrm{p}=0.01, \mathrm{ES}=2,10)$, and did not differed significantly from each other (figure 2).

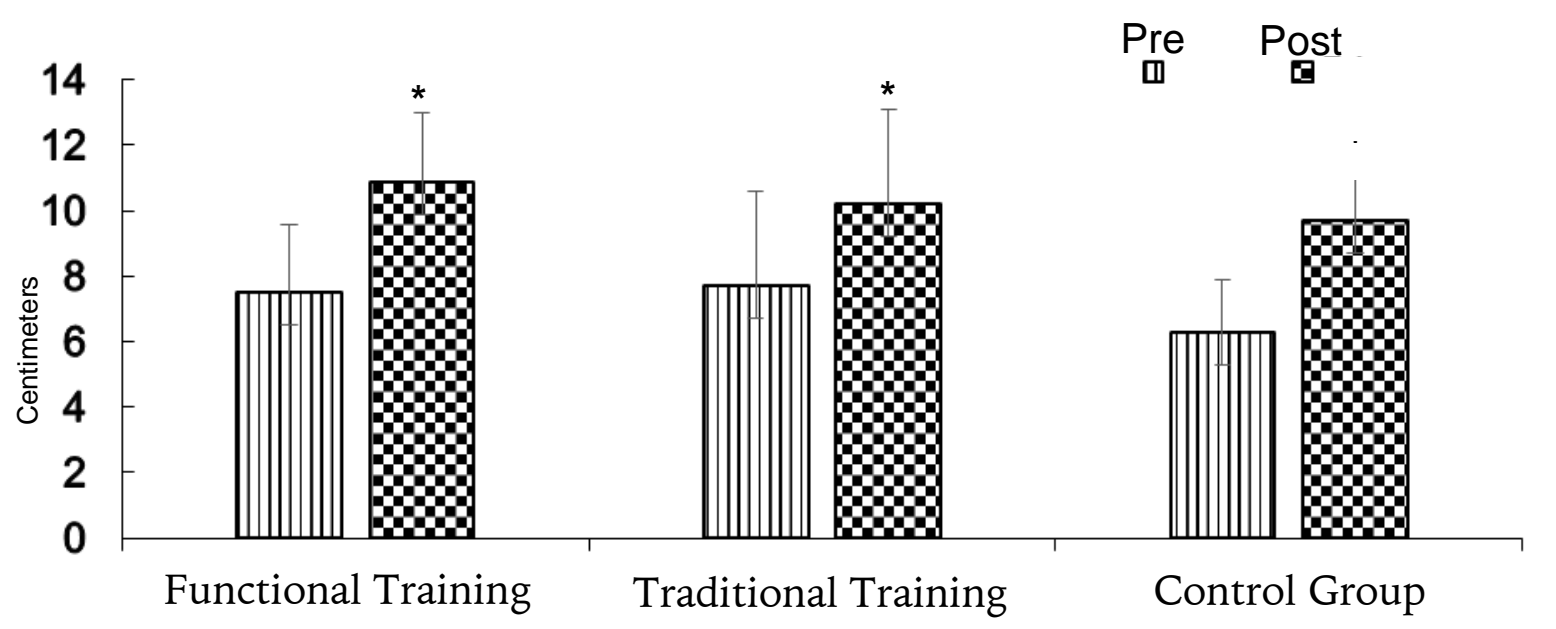

Figure 2. Changes in the range of motion of the ankle joint complex in functional training, traditional training and control group. * Significant difference $(\mathrm{P}<0.05)$ in relation to the pre-test. (a) Significant difference $(\mathrm{P}$ $<0.05)$ in relation to CG. (b) Significant difference $(\mathrm{P}<0.05)$ in relation to TT. (c) Significant difference $(\mathrm{P}<$ $0.05)$ in relation to FT.

As for lower limb strength (30 seconds chair stand), both experimental groups were statistically superior to the CG (FT: $p=0.01$ and TT: $p=0,01)$, but only the FT group presented a significant difference in relation to the pretest (FT: $\Delta \%=30.48, \mathrm{p}=0.01$, ES $=1.60 ; \mathrm{TT}: \Delta \%=$ $14.35 \mathrm{p}=0.13, \mathrm{ES}=0.80$ ) (figure 3 ).

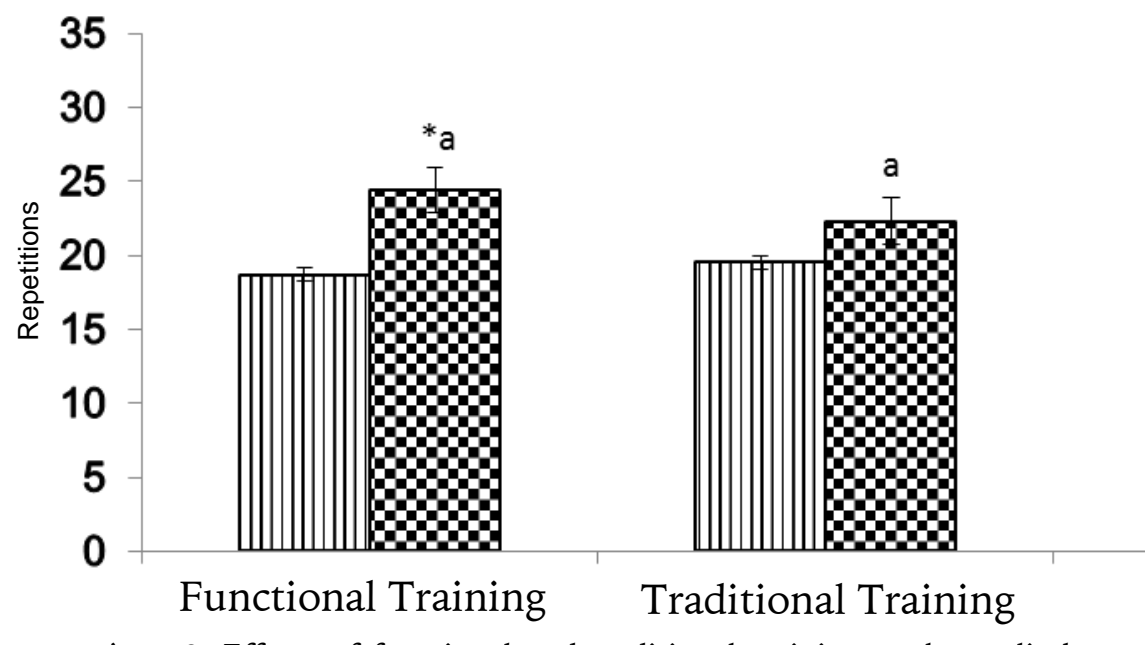
(1) Pre
$\mathbf{\square}$ Post

Figure 3. Effects of functional and traditional training on lower limb strength in the elderly. ${ }^{*}$ Significant difference $(P<0.05)$ in relation to the pre-test. (a) Significant difference $(P<0.05)$ in relation to $C G$. (b) Significant difference $(\mathrm{P}<0.05)$ in relation to TT. (c) Significant difference $(\mathrm{P}<0.05)$ in relation to FT. 
In the dynamic balance/agility, the FT was significantly superior compared to the pretest $(\Delta \%=21.81, \mathrm{p}=0.01, \mathrm{ES}=1.70)$, the TT $(\mathrm{p}=$ $0.01)$ and the CG $(\mathrm{p}=0.01)$. The TT also achieved a significant improvement in this test in relation to the initial values $(\Delta \%=21.81, \mathrm{p}=0.01, \mathrm{ES}=$ $1.00)$ and to the $C G(p=0.01)$ (figure 4$)$.

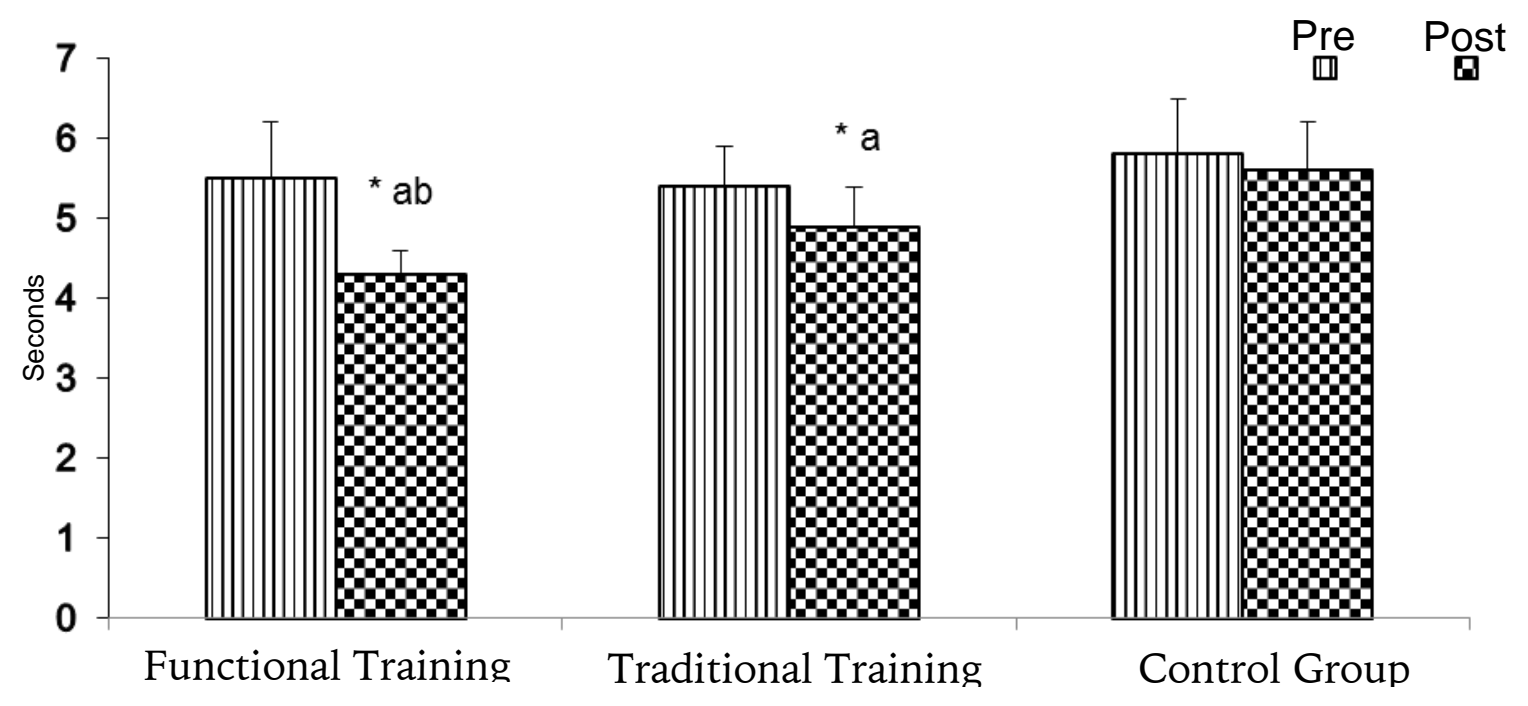

Figure 4. Effect of functional and traditional training on agility and dynamic balance in the elderly. ${ }^{*}$ Significant difference $(P<0.05)$ in relation to the pre-test. (a) Significant difference $(P<0.05)$ in relation to CG. (b) Significant difference $(\mathrm{P}<0.05)$ in relation to TT. (c) Significant difference $(\mathrm{P}<0.05)$ in relation to FT.

The TF presented a statistically significant difference in the cardiorespiratory condition in relation to the initial values $(\Delta \%=12.38, p=$ $0.01, \mathrm{ES}=1.60)$ and to the $\mathrm{CG}(\mathrm{p}=0.04)$. In this capacity, TT presented no statistically significant difference when compared to the pre-test $(\Delta \%$ 5.52, $\mathrm{p}=0.55$, ES $=0.60)$, nor in relation to the $\mathrm{CG}(\mathrm{p}=0.09)$ (figure 5$)$.

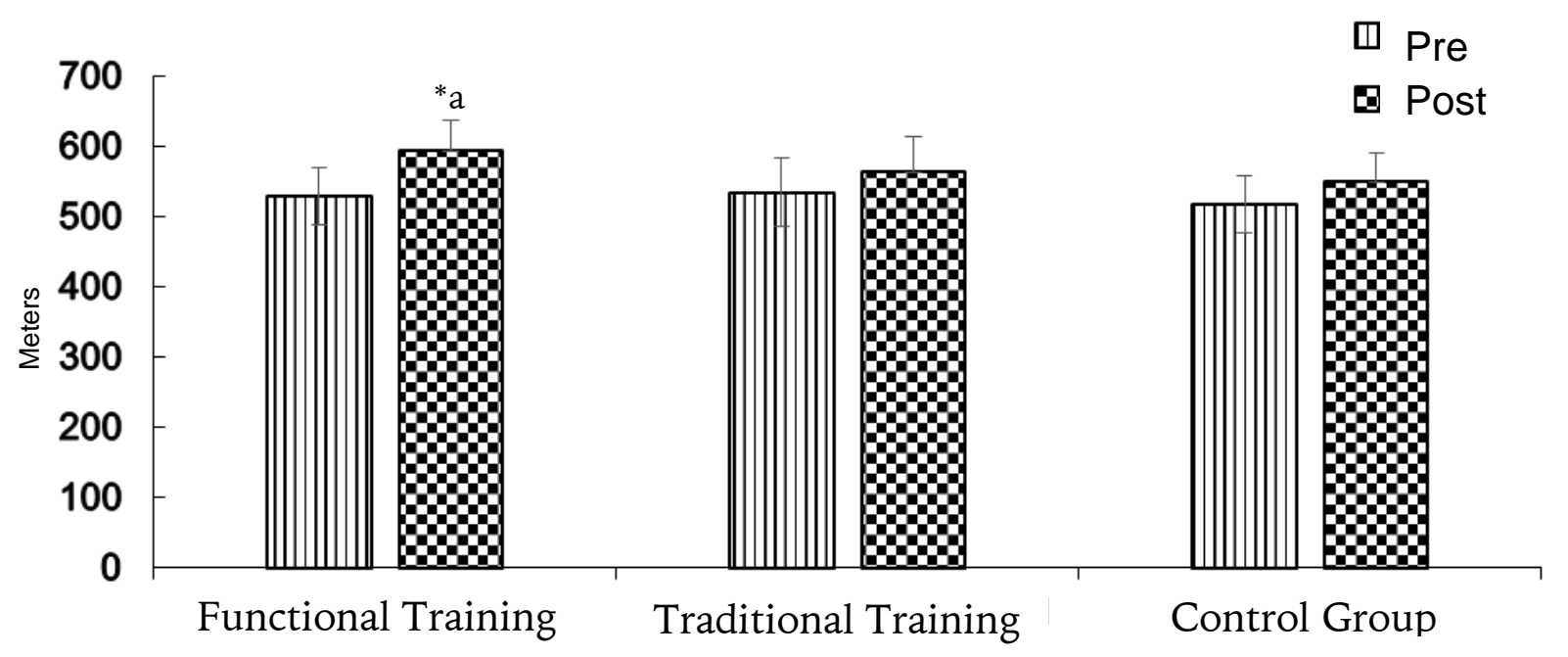

Figure 5. Changes in cardiorespiratory capacity in the experimental groups and in the control group. * Significant difference $(\mathrm{P}<0.05)$ in relation to the pre-test. (a) Significant difference $(\mathrm{P}<0.05)$ in relation to $\mathrm{CG}$. (b) Significant difference $(\mathrm{P}<0.05)$ in relation to TT. (c) Significant difference $(\mathrm{P}<0.05)$ in relation to FT. 


\section{DISCUSSION}

The main findings of the present study demonstrate that although both experimental protocols proved to be efficient to improve gait determinants, FT was superior to the other groups in muscle strength, dynamic agility/balance and cardiorespiratory capacity after twelve weeks of intervention.

Aging is accompanied by a decline in the range of motion due to mechanical and morphological changes in joint structures (Mecagni, Smith, Roberts, \& O'Sullivan, 2000). This joint amplitude is considered an indicator of good muscle and tendon function, as well as good performance in the activities of daily living (do Rosario et al., 2017). An average of 10 centimeters could be observed after intervention in all groups; according to the reference values, this range is ideal for performing daily tasks and reducing the risk of falls (Harris, 1991). We believe that the improvement of this variable in the three groups is related to the specificity of the exercises of the first training block. In the experimental groups, the improvement can also be explained by the execution of multiarticular exercises in great amplitudes of motion, which provoke favorable adaptations to reduce joint stiffness and the firing rate of the muscle spindle (Bloomquist et al., 2013). Regarding the CG, improvement can be attributed to the specificity of the training, since the participants performed activities of flexibility and joint mobility.

Both experimental groups improved muscle strength in the lower limbs (FT: 19.6\%; TT: $4.6 \%$ ), as evidenced by a study of women over 70 years of age (FT: 26\%; TT: 16\%) (Krebs, Scarborough, \& McGibbon, 2007). The adaptations in this variable from the experimental protocols can be explained by neuromuscular changes clearly evidenced in the strength training, either functional or traditional, when used as a tool to attenuate the loss of muscle strength related to senescence (Pinto et al., 2014). FT seems to act by interacting the body structures in a way that causes an important neuromuscular readjustment for the performance of the strength in daily activities. In the present study, these adaptations, even superior to those in the TT, can be explained by neuromuscular and metabolic specificity in the 30 seconds chair test. The greater muscle activation (Schwanbeck, Chilibeck, \& Binsted, 2009), hormone release (Shaner et al., 2014), and the better functional performance (Wirth et al., 2016) of exercises with free weights when compared with guided exercises can also explain the adaptations.

Unstable activities with abrupt direction changes in the FT can stimulate receptors in different systems (somatosensory, vestibular and visual), promoting increased synaesthetic awareness and postural control (Muehlbauer, Gollhofer, \& Granacher, 2015), besides activating stabilizing muscles of the spine with more intensity, so that the conditions of agility, balance and proprioception are developed more efficiently (Lesinski, Hortobágyi, Muehlbauer, Gollhofer, \& Granacher, 2015). Evidence shows that 12 weeks of circuit FT are able to improve between $17 \%$ and $27 \%$ (Giné-Garriga et al., 2010) the dynamic balance and agility in the elderly, both in the case of groups that performed conventional activities, what also indicates the benefits of this type of exercise to the functionality of the elderly. Another important aspect is that multicomponent training protocols with principles similar to the present study seem to be effective in gait performance in the elderly; a recent systematic review showed increases of $7.2 \%$ to $40 \%$ after several programs with these characteristics (Bouaziz et al., 2016).

As for the cardiorespiratory condition, it seems that the metabolic characteristic of the high-intensity interval exercises allied to the circuit and intermittent character present in the FT block promoted changes in the mechanisms responsible for the transport and use of oxygen, such as increased oxidative capacity of the muscle cell, increased glycogen and phosphate degradation and better utilization of intramuscular triglyceride (Jiménez-Pavón \& Lavie, 2017; Romero-Arenas et al., 2013), thus explaining the adaptations that were superior to the TT and GC. Moreover, it is worth mentioning that the walk performed by the TT was of low 
speed, not corresponding to the maximum speed with change of direction in six meters required by the six-minute walk test.

In general, the adaptations shown by the FT are justified by the combination of different physical exercises in the same training session. The organization of the session in distinct blocks followed recommendations directed to functionality previously published by our group (Resende-Neto et al., 2016), which aims, besides contemplating different modalities of training in a short period of time (60 minutes), to apply these modalities in a sequence that allows a gradual increase of intensity and complexity, respecting the particularities of the elderly participants. In this way, we can infer that there was no stagnation of the effects of this training method during the intervention period.

The present research focused on comparing the adaptive responses to the so-called functional training protocols, due to the differences between the characteristics of each intervention and of the tests applied. Although the present study provided important information about the benefits of FT in gait ability determinants among elderly women, future research should use longer interventions and analyze the levels of habitual physical activity for better isolation of intervening factors.

\section{CONCLUSION}

Based on this, we conclude that functional training seems to be more effective than traditional training for improvement of dynamic balance/agility, strength-resistance of lower limbs and cardiorespiratory capacity, considered determinants associated with gait ability in the elderly.

\section{Acknowledgments:}

Nothing to declare

\section{Conflict of interests:}

Nothing to declare

\section{Funding:}

Coordenação de Aperfeiçoamento de Pessoal de Nível Superior (Capes), sob processo número AUXPE PROCAD/NF 110/2010

\section{REFERENCES}

Bierbaum, S., Peper, A., Karamanidis, K., \& Arampatzis, A. (2010). Adaptational responses in dynamic stability during disturbed walking in the elderly. Journal of biomechanics, 43 (12), 2362-2368.

Bloomquist, K., Langberg, H., Karlsen, S., Madsgaard, S., Boesen, M., \& Raastad, T. (2013). Effect of range of motion in heavy load squatting on muscle and tendon adaptations. European journal of applied physiology, 113(8), 2133-2142.

Bouaziz, W., Lang, P. O., Schmitt, E., Kaltenbach, G., Geny, B., \& Vogel, T. (2016). Health benefits of multicomponent training programmes in seniors: a systematic review. International journal of clinical practice, $70(7), 520-536$.

Brandalize, D., de Almeida, P. H. F., Machado, J., Endrigo, R., Chodur, A., \& Israel, V. L. (2011). Efeitos de diferentes programas de exercícios físicos na marcha de idosos saudáveis: uma revisão. Fisioterapia em Movimento, 24(3).

Buchner, D. M., Larson, E. B., Wagner, E. H., Koepsell, T. D., \& De Lateur, B. J. (1996). Evidence for a non-linear relationship between leg strength and gait speed. Age and ageing, 25(5), 386-391.

Cadore, E. L., Rodríguez-Mañas, L., Sinclair, A., \& Izquierdo, M. (2013). Effects of different exercise interventions on risk of falls, gait ability, and balance in physically frail older adults: a systematic review. Rejuvenation research, 16(2), 105-114.

Calatayud, J., Martin, F., Gargallo, P., García-Redondo, J., Colado, J. C., \& Marín, P. J. (2015). The validity and reliability of a new instrumented device for measuring ankle dorsiflexion range of motion. International journal of sports physical therapy, 10(2), 197.

Cao, Z.-B., Maeda, A., Shima, N., Kurata, H., \& Nishizono, H. (2007). The effect of a 12-week combined exercise intervention program on physical performance and gait kinematics in community-dwelling elderly women. Journal of physiological anthropology, 26 (3), 325-332.

do Rosario, J. T., da Fonseca Martins, N. S., Peixinho, C. C., \& Oliveira, L. F. (2017). Effects of Functional Training and Calf Stretching on Risk of Falls in Older People: A Pilot Study. Journal of aging and physical activity, 25(2), 228-233.

Fleck, S. J., \& Kraemer, W. (2014). Designing Resistance Training Programs, 4E: Human Kinetics.

Giné-Garriga, M., Guerra, M., Pagès, E., Manini, T. M., Jiménez, R., \& Unnithan, V. B. (2010). The effect of functional circuit training on physical frailty in 
frail older adults: a randomized controlled trial. Journal of aging and physical activity, 18(4), 401-424.

Harris, G. F. (1991). Analysis of ankle and subtalar motion during human locomotion. Inman's Joints of the Ankle, 2, 75-84.

Henderson, R. M., Leng, X. I., Chmelo, E. A., Brinkley, T. E., Lyles, M. F., Marsh, A. P., \& Nicklas, B. J. (2016). Gait speed response to aerobic versus resistance exercise training in older adults. Aging clinical and experimental research, 1-8.

Jiménez-Pavón, D., \& Lavie, C. J. (2017). Highintensity intermittent training versus moderateintensity intermittent training: is it a matter of intensity or intermittent efforts? In: BMJ Publishing Group Ltd and British Association of Sport and Exercise Medicine.

Krebs, D. E., Scarborough, D. M., \& McGibbon, C. A. (2007). Functional vs. strength training in disabled elderly outpatients. American journal of physical medicine \& rehabilitation, 86(2), 93-103.

Lesinski, M., Hortobágyi, T., Muehlbauer, T., Gollhofer, A., \& Granacher, U. (2015). Effects of balance training on balance performance in healthy older adults: a systematic review and meta-analysis. Sports medicine, 45(12), 1721-1738.

Liu, C.-j., Shiroy, D. M., Jones, L. Y., \& Clark, D. O. (2014). Systematic review of functional training on muscle strength, physical functioning, and activities of daily living in older adults. European Review of Aging and Physical Activity, 11 (2), 95.

Mecagni, C., Smith, J. P., Roberts, K. E., \& O'Sullivan, S. B. (2000). Balance and ankle range of motion in community-dwelling women aged 64 to 87 years: a correlational study. Physical Therapy, 80(10), 1004-1011.

Muehlbauer, T., Gollhofer, A., \& Granacher, U. (2015). Associations between measures of balance and lower-extremity muscle strength/power in healthy individuals across the lifespan: a systematic review and meta-analysis. Sports medicine, 45(12), 1671-1692.

Pinto, R. S., Correa, C. S., Radaelli, R., Cadore, E. L., Brown, L. E., \& Bottaro, M. (2014). Short-term strength training improves muscle quality and functional capacity of elderly women. Age, 36(1), 365-372.

Resende-Neto, A. G., Da Silva-Grigoletto, M. E., Santos, M. S., \& Cyrino, E. S. (2016). Treinamento funcional para idosos: uma breve revisão. Revista Brasileira de Ciência e Movimento, 24(3), 167-177.

Rikli, R. E., \& Jones, C. J. (2013). Development and validation of criterion-referenced clinically relevant fitness standards for maintaining physical independence in later years. The Gerontologist, 53 (2), 255-267.

Rodríguez-Berzal, E., Durán, L. A., Royo, I. A., \& Jódar, X. A. (2013). Entrenamientos funcionales frente a específicos en la prevención de caídas en las personas mayores. Apunts. Medicina de l'Esport, 48(180), 153-164.

Romero-Arenas, S., Blazevich, A. J., Martínez-Pascual, M., Pérez-Gómez, J., Luque, A. J., López-Román, F. J., \& Alcaraz, P. E. (2013). Effects of highresistance circuit training in an elderly population. Experimental gerontology, 48(3), 334340.

Schwanbeck, S., Chilibeck, P. D., \& Binsted, G. (2009). A comparison of free weight squat to Smith machine squat using electromyography. The Journal of Strength \& Conditioning Research, 23(9), 2588-2591.

Shaner, A. A., Vingren, J. L., Hatfield, D. L., Budnar Jr, R. G., Duplanty, A. A., \& Hill, D. W. (2014). The acute hormonal response to free weight and machine weight resistance exercise. The Journal of Strength \& Conditioning Research, 28(4), 10321040.

Silva-Grigoletto, D., Viana-Montaner, B. H., Heredia, J., Mata Ordóñez, F., Peña, G., Brito, C. J., . . . García-Manso, J. M. (2013). Validación de la escala de valoración subjetiva del esfuerzo OMNIGSE para el control de la intensidad global en sesiones de objetivos múltiples en personas mayores.

Studenski, S., Perera, S., Patel, K., Rosano, C., Faulkner, K., Inzitari, M., . . . Connor, E. B. (2011). Gait speed and survival in older adults. Jama, 305(1), 50-58.

Thomas, J. R., Nelson, J. K., \& Silverman, S. J. (2009). Métodos de pesquisa em atividade física: Artmed Editora.

Wirth, K., Hartmann, H., Sander, A., Mickel, C., Szilvas, E., \& Keiner, M. (2016). The impact of back squat and leg-press exercises on maximal strength and speed-strength parameters. The Journal of Strength \& Conditioning Research, 30(5), 1205-1212. 


\title{
Effects of resistance exercise on posterior muscles of rats chronically treated with dexamethasone
}

\author{
Andressa Pâmela Pires de Siqueira ${ }^{1}$, Jymmys Lopes dos Santos ${ }^{1}$, Silvan Silva de Araújo ${ }^{1}$, \\ Emerson Ticona Fioretto ${ }^{1}$, Vera Lúcia Corrêa Feitosa ${ }^{1}$, Anderson Carlos Marçal ${ }^{1 *}$

\begin{abstract}
In order to minimize the deleterious effects caused by Diabetes Mellitus, physical exercise has been used as an alternative non-pharmacological treatment. To assess the effect of resistance exercise on posterior muscles of rats chronically treated with low doses of dexamethasone. Twenty-Four Wistar rats were separated into four groups: saline trained (ST), saline sedentary (SS), dexa trained (DT), and dexa sedentary (DS). Based on the squatting protocol, rats from the ST and DT groups were attached to equipment where they were trained in three series with ten repetitions each, using an exercise load corresponding to $70 \%$ of maximum repetition (RM) during 12 weeks. After the experiment, the soleus, gastrocnemius and plantaris muscles were dissected and weighed. The resistance exercise led to an increase in body weight for SS and ST groups $(33.17 \%$ and $14.87 \%$, respectively), as well as in the weight of the soleus muscle for ST and DT groups $(28.33 \%$ and $25.29 \%$, respectively) and the plantaris muscle for ST group $(27.14 \%)$. Additionally, the percentage of perigonadal fat pad was decreased in DT and ST groups ( $24.0 \%$ and $26.6 \%$, respectively). The experimental protocol indicates that the resistance exercise improves the muscle quality, decreases fat mass, and increases the weight of some posterior muscles of the hind limbs.

Keywords: Glucocorticoids, resistance training, skeletal muscle, body weight.
\end{abstract}

\section{INTRODUCTION}

Resistance exercise (RE) is characterized by muscular tension, with or without joint movement, against muscular action (as a form of resistance). It improves physical aptitude, body composition, and disease prevention in several populations (Azevedo et al., 2007; Borges, Araújo and Cunha, 2010; Westcott, 2012). Among the functional benefits of practicing RE, the increase in muscle strength and endurance are the most prominent (Schoenfeld, Grgic, Ogborn, Krieger, 2017). Other authors have suggested beneficial effects on physiological parameters, such as improvements in cardiovascular and endocrine system, lipid profile, and body composition as well as increased insulin sensitivity, muscle mass, and bone density, and blood pressure control (American College Of Sport Medicine [ACSM], 2009; Faigenbaum et al., 2009; Westcott, 2012; Winnet and Carpinelli, 2001).

Attenuation of muscle atrophy has been observed in an experimental diabetes model following high-intensity (70\%-80\%) RE protocols (vertical climbing for 8 weeks) (Krug et al., 2016; Macedo et al., 2014). Different experimental models are used to evaluate the benefits of REs, such as climbing, running, and swimming, on the body; among them, squatting is an RE proposed by Tamaki, Uchiyama, and Nakano (1992). In this model, the execution of movements is at intervals and contraction is exerted by a particular muscle or muscle group opposed to a force, which in turn is contrary to the movements.

The beneficial effects of RE on the body have been evaluated under different metabolic conditions, such as obesity, type 1 diabetes (Moura et al., 2012), diet-induced obesity (Gamelin et al., 2016), monosodium glutamateinduced obesity (Andreazzi et al., 2009), and/or conditions after glucocorticoid treatment (Rodrigues, Abrahin, Sousa and Marcal, 2016). Dexamethasone is widely used for treating inflammatory and allergenic conditions, but its

\footnotetext{
${ }^{1}$ Universidade Federal de Sergipe, São Cristovão, Sergipe, Brasil

* Autor correspondente: Núcleo de Pesquisa em Sinalaização de insulina, Universidade Federal de Sergipe, Avenida Marechal Rondon, s/n - Rosa Elze, São Cristóvão/Sergipe, 49100-000 Brasil. E-mail: acmarcal@yahoo.com.br
} 
intake can cause muscle atrophy; it is also widely used for treating chronic conditions, resulting in weight loss (Caporali, Scire, Todoerti and Montrcucco, 2013; Rhen and Cidlowski, 2005). Therefore, RE is used as a non-pharmacological contribution to ameliorate or prevent these metabolic diseases (Ciolac and Guimarães, 2004).

Among the different benefits provided by physical activity, one of the most widely reported is weight loss (decreased body fat content) associated with an increase in muscle mass (Schoenfeld et al., 2017). Considering these findings, the present study aimed to evaluate the effect of RE on the posterior muscles of rats chronically treated with a low dose of dexamethasone.

\section{METHODS}

\section{Sample}

In this study, 40 Wistar rats (age, 7-8 weeks; weight, $250-300 \mathrm{~g}$ ) were used. The animals were housed in individual cages with controlled temperature ranging from $22^{\circ} \mathrm{C}$ to $24^{\circ} \mathrm{C}$, controlled brightness with a light-dark cycle of 12 $\mathrm{h}$, and free access to food and water (Nuvilab ${ }^{\circledR}$, Paraná, Brazil).

The animals were randomly divided into four groups of 10 rats each: the sedentary saline (SS) group comprising sedentary rats that received saline solution $(0.9 \%)$ intraperitoneally; the trained saline (TS) groups comprising rats following only to the RE protocol and receiving saline solution $(0.9 \%)$ intraperitoneally; the sedentary dexamethasone (SD) group comprising sedentary rats intraperitoneally administered with dexamethasone; and the treated dexamethasone (TD) group comprising rats following the RE protocol and intraperitoneally administered with dexamethasone.

\section{Procedure}

The animals of the TS and TD groups were familiarized to the squatting apparatus according to model proposed by Tamaki et al. (1992): for 1 week, three training sessions were conducted with a 48-h interval between sessions; each session contained two series of 10 repetitions, with a 1-min interval between the series. All groups were submitted to a maximum repetition test (1RM) to determine the workload. To readjust the workload and maintain the proposed intensity, new tests of 1RM were performed every 2 weeks.

The training protocol lasted 12 weeks. While the animals performed the series, electrical stimuli was applied ( $20 \mathrm{~V}$ for 0.3 -s durations at 3-s intervals) with electrodes (ValuTrode, Model CF3200, Axelgaard, Fallbrook, CA, USA) attached to their tail and to an electric stimulator (BIOSET, Physiotonus Four, Model 3050, Rio Claro, SP, Brazil) (Silva et al., 2013). The training was conducted thrice a week and comprised three sets of 10 repetitions ( $70 \%$ of the intensity load) with 60-s intervals of rest; it was conducted after the 1RM test (Rodrigues et al., 2016).

The dexamethasone treatment lasted 12 weeks and was performed once a week (0.2 $\mathrm{mg} / \mathrm{kg} /$ day Decadron ${ }^{\circledR}$, Prodome, Brazil) intraperitoneally and always at the same time (10:00) in the SD and TD group animals. According to Schneiter and Tappy (1998), the given dose is capable of inducing metabolic alterations. In the SS and TS group animals, saline solution (0.9\%) was injected intraperitoneally at the same time (10:00).

The animals were weighed prior to the initiation of the protocol and weighed again after 3 months. After the second weighing, a thiopental anesthetic $(80 \mathrm{mg} / \mathrm{kg}$ body weight of the animal) was applied before the animals were sacrificed; subsequently, the biological materials (the posterior muscles of the lower limb) were removed for analysis.

It should be emphasized that the procedures described in this study were previously approved by the Committee on Ethics in Research involving Animals of the Federal University of Sergipe (CEPA/UFS) under the protocol number $47 / 2016$.

\section{Data analysis}

For the analysis of the variables, Student's t-tests and one-way ANOVA were used with Bonferroni's post hoc test, and 0.05 was considered as the significance level. 


\section{RESULTS}

The total weight gain, from the first to the last day, of animals in all groups was analyzed. Figure 1A shows that body weight increased between the first and last day of the experiment in the SS and TS groups, and the increase was of $33.17 \%$ and $14.87 \%$, respectively. However, the groups treated with dexamethasone (SD and TD) showed no difference (Figure 1B).

A

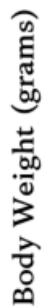
Strength Training

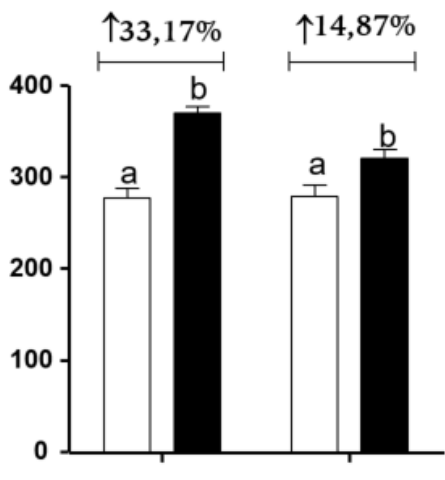

Dexamethasone

B

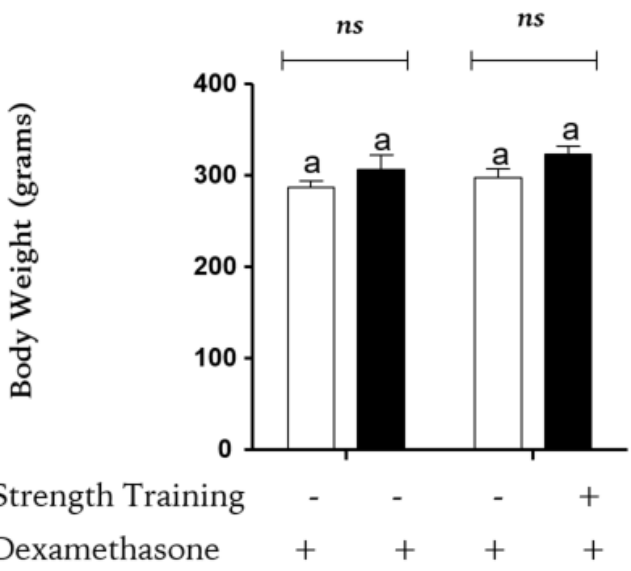

Figure 1. Evaluation of weight gain between the first weighing (" $\square$ ": blank bars) and after 3 months of training ("ø": filled bars). Figure 1A depicts the SS and TS groups. Figure 1B depicts the SD and TD groups. The body weight of each animal was represented by mean \pm standard error of the mean (one-way ANOVA, Bonferroni's post hoc test). The "-" sign indicates no application, and the "+" indicates application. Source: Siqueira et al., 2017

The gastrocnemius muscle presented no significant difference in mass gain among the groups (Figure 2A). The TS group presented mass gain of $28.33 \%$ in the soleus muscle compared with its control group (SS); the same was observed in the TD group, in which the increase in mass was $25.29 \%$ compared with its control group (SD) (Figure 2B). An increase of $27.14 \%$ in the mass of the plantar muscle was observed in the TS group compared with the SS group, whereas the SD and TD groups demonstrated no significant difference in mass gain (Figure 2C).

A

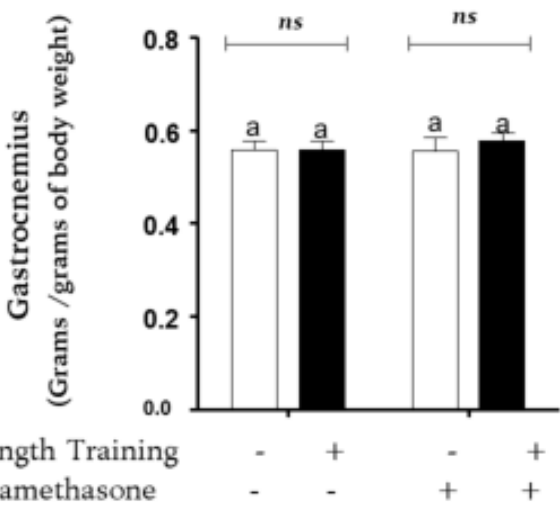

B

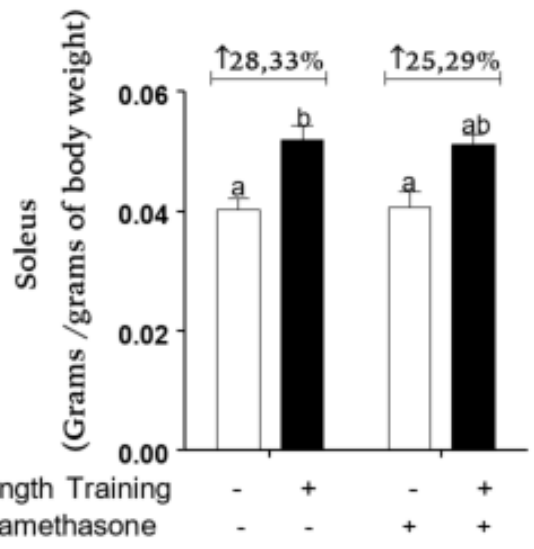

C

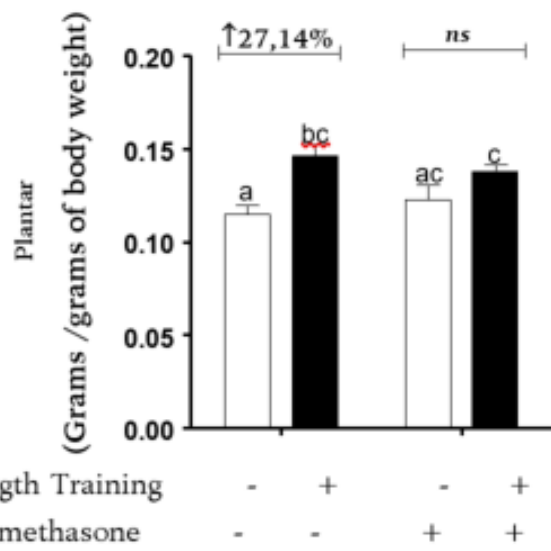

Figure 2. Evaluation of the mass of the gastrocnemius (2A), soleus (2B), and plantar (2C) muscles in the experimental groups SS, TS, SD, and TD. The values presented were corrected by the body weight of each animal and represented as mean \pm standard error of the mean (one-way ANOVA, Bonferroni's post hoc test). The “-" sign indicates no application, and the "+" sign indicates application. 
Regarding the evaluation of changes in fat percentage during the protocol, the TS group presented a $26.6 \%$ decrease in perigonadal fat compared with the SS group (3A). The same could be observed in the TD group, which showed a $24.0 \%$ reduction in perigonadal fat compared with the SD group (Figure 3B).

A

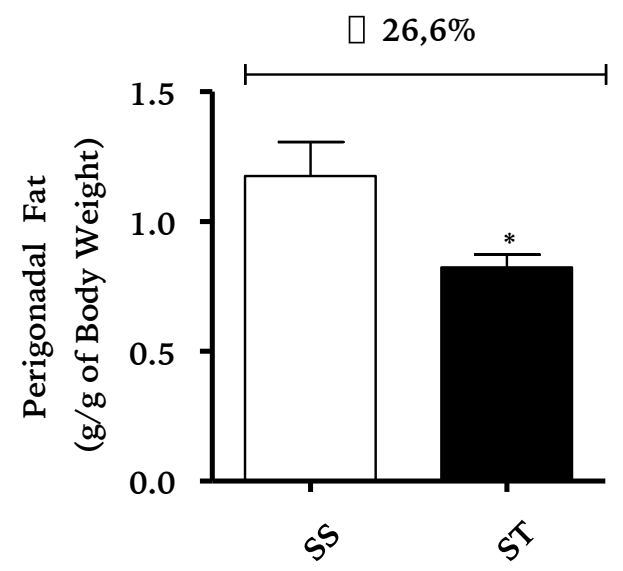

B

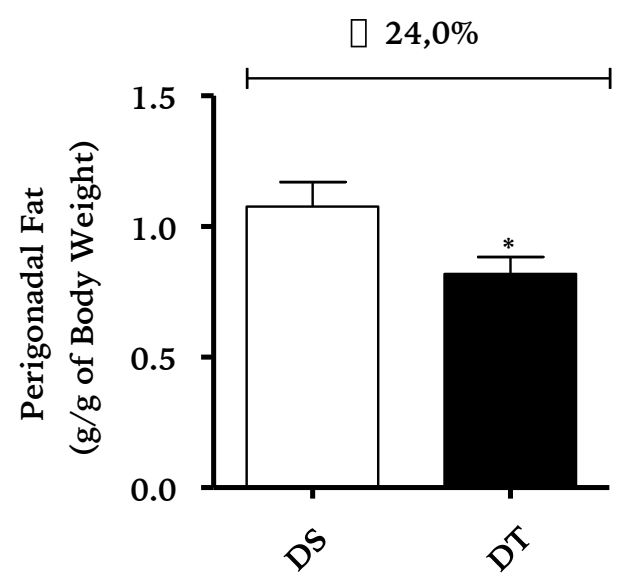

Figure 3. Evaluation of the perigonadal fat percentage between the SS and TS groups (3A) and between the SD and TD groups (3B). The fat weights were corrected by the body weight of each animal and represented as mean \pm standard error of the mean (Student's t-test, ${ }^{*} \mathrm{p}<0.05$ ).

\section{DISCUSSION}

Twelve weeks of high-intensity RE resulted in increased soleus muscle weight in saline- and dexamethasone-treated animals (TS and TD groups, respectively). Few studies have evaluated the soleus muscle using this type of protocol (Barel et al., 2010; Lee and Farrar, 2003).
However, they found no significant differences in the weight of the gastrocnemius muscle between the evaluated groups.

The use of glucocorticoids causes harmful effects to the skeletal muscles (muscle atrophy). An experimental study has indicated that the treatment of animals with dexamethasone while following RE protocols attenuates gastrocnemius muscle atrophy (Pinheiro et al. 2009); however, the training protocol used in that study included a pulldown exercise (running), suggesting that different RE protocols used in experimental animals present divergent effects.

A study by Tamaki et al. (1992) has shown an increase in plantar muscle mass and hypertrophy. A similar result was observed in the current study, in which the TS group presented a $27.14 \%$ increase in the muscle volume compared with the SS group; nevertheless, this effect was not observed in the animals belonging to the TD group. In a related study, using vertical climbing as a training protocol for 8 weeks, no difference was observed in plantar muscle weight in either the controls or the animals treated with dexamethasone (Lee and Farrar, 2003).

During the experiment, only the saline-treated groups (SS and TS) showed an increase in body weight on the last day of the protocol; this finding is corroborated by Macedo et al. (2014) who used a vertical climbing RE protocol. RE reduced the body weight gain in the TS group. However, no significant difference in body weight was observed in the SD and TD groups between the first and last day. These results were similar to those of Barel et al. (2010) who used the treadmill running model in animals and demonstrated that after 70 days of intervention, the training did not promote adjustments in the body weights of animals

In this study, the use of glucocorticoids was associated with increased fat mass and decreased lean body mass in the body composition (Bönisch et al., 2016; Hochberg et al., 2015). Physical exercise plays a role in minimizing these effects by reducing fat mass and increasing muscle mass (Eguchi et al., 2008). These findings are consistent with the findings of the present study regarding the reduction of perigonadal fat in the 
trained groups (TS and TD) compared with their respective controls (SS and SD).

According to Phillips and Winett (2010), RE is associated with improved plasma glucose concentration and insulin sensitivity. This is in part due to the increased muscle transverse area compared with lean body mass, as well as qualitative improvements in muscle metabolic properties, including increased GLUT4 density, glycogen content/activity synthesis, and insulin resistance. However, further studies on these pathways using the RE model proposed by Tamaki et al. (1992) are warranted.

\section{CONCLUSION}

The results of this study suggested that RE improves muscular quality, increases lean mass, and consequently decreases fat body mass. In addition, the main finding of this study was the hypertrophy of the soleus muscle, which requires further studies to elucidate the mechanism involved. The literature contains many studies involving RE, but the diversity of rodent-adapted equipment (for example, the Tamaki et al. (1992) model and the vertical climbing model) may demonstrate different outcomes, probably due to a greater or lesser extent of the recruitment of muscle groups involved in the execution of the movements.

\section{Acknowledgments:}

Nothing to declare

\section{Conflict of interests:}

Nothing to declare

\section{Funding:}

Nothing to declare

\section{REFERENCES}

AMERICAN COLLEGE OF SPORTS MEDICINE. (2009). American college of sports medicine position stand: progression models in resistance training for healthy adults. Medicine $\mathcal{E}$ Science in Sports \& Exercise, 41(3), 687-708. doi: 10.1249/MSS.0b013e3181915670

ANDREAZZI, A. E., SCOMPARIN, D. X, MESQUITA, F. P., BALBO, S. L., GRAVENA, C., DE OLIVEIRA, J. C., ... MATHIAS, P. C. F. (2009) . Swimming exercise at weaning improves glycemic control and inhibits the onset of monosodium l-glutamate-obesity in mice. Journal of Endocrinology, 201(3), 351-359. doi: 10.1677/JOE-08-0312

AZEVEDO, P. H. S. M., DEMAMPRA, T. H., OLIVEIRA, G. P., BALDISSERA, V., BÜRGERMENDONÇA, M., MARQUES, A. T., ... PEREZ, S. E. A. (2007). Efeito de 4 semanas de treinamento resistido de alta intensidade e baixo volume na força máxima, endurence muscular e composição corporal de mulheres moderadamente treinadas. Brazilian Journal of Biomotricity, 1(3), 76-85, 2007.

BAREL, M., PEREZ, O. A. B., GOIZZET, V. A., RAFACHO, A. BOSQUEIRO, J. R., AMARAL, S. L. (2010). Exercise training prevents hyperinsulinemia, muscular glycogen loss and muscle atrophy induced by dexamethasone treatment. European Journal of Applied Physiology, 108(5), 999-1007. doi: 10.1007/s00421-0091272-6

BORGES, G. A.; ARAÚJO, S. F. M.; CUNHA, R. M. (2010). Os benefícios do treinamento resistido para portadores de diabetes mellitus tipo II. Educación Física y Deportes, Revista Digital. 15(151). Recovered

from: http://www.efdeportes.com/efd151/treinament o-resistido-para-portadores-de-diabetes.htm

BÖNISCH, C., IRMLER, M., BRACHTHÄUSER, L., NEFF, F., BAMBERGER, M. T., MARSCHALL, S., ... BECKERS, J. (2016). Dexamethasone treatment alters insulin, leptin, and adiponectin levels in male mice as observed in DIO but does not lead to alterations of metabolic phenotypes in the offspring. Mammalian Genome, 27(1-2) 17-28. doi: $10.1007 / \mathrm{s} 00335-015-9616-5$

CAPORALI, R., SCIRE, C. A., TODOERTI, M. MONTRCUCCO, C. (2013). The role of low-dose glucocorticoids for rheumatoid arthritis in the biologic era. Clinical and Experimental Rheumatology, 31 (4 Suppl 78), 9-13.

CIOLAC, E. G.; GUIMARÃES, G. V. (2004) Physical exercise and metabolic syndrome. Revista Brasileira de Medicina do Esporte, 10(4), 319-324. doi: 10.1590/S1517-86922004000400009

EGUCHI, R., CHEIK, N. C., OYAMA, L. M., NASCIMENTO, C. M. O., MELLO, M. T., TUFIK, S. DÂMASO, A. (2008). Effects of the chronic exercise on the circulating concentration of leptin and ghrelin in rats with diet-induced obesity. Revista Brasileira de Medicina do Esporte, 14 (3) 182-187. doi: 10.1590/S151786922008000300004

FAIGENBAUM, A. D., KRAEMER, W. J., BLIMKIE, C. J. R., JEFFREYS, I., MICHELI, L. J., NITKA, M., ROWLAND, T. W. (2009). Youth resistance training: updated position statement paper from the national strength and conditioning association. Journal of Strength and Conditioning Research, 23(5), 60-69. doi: 10.1519/JSC.0b013e31819df407 
GAMELIN, F. X., AUCOUTURIER, J. IANNOTTI, F. A., PISCITELLI, F., MAZZARELLA, E., AVETA, T., ... HEYMAN, E. (2016). Effects of chronic exercise on the endocannabinoid system in wistar rats with high-fat diet-induced obesity. Journal of Physiology and Biochemistry, 72(2) 183-199. doi: /10.1007/s13105-016-0469-5

HOCHBERG, I., HARVEY, I., TRAN, Q. T., STEPHENSON, E. J., BARKAN, A. L., SALTIEL, A. R., ... BRIDGES, D. (2015). Gene expression changes in subcutaneous adipose tissue due to Cushing's disease. Journal of Molecular Endocrinology, 55(2), 81-94. doi: 10.1530/JME15-0119

KRUG, A. L., MACECDO, A. G., ZAGO, A. S., RUSH, J. W. E., SANTOS, C. F., AMARAL, S. L. (2016). High-intensity resistance training attenuates dexamethasone-induced muscle atrophy. Muscle Nerve, 53(5), 779-788. doi: 10.1002/mus.24906

LEE, S.; FARRAR, R. P. (2003). Resistance training induces muscle-specific changes in muscle mass and function in rat. Journal of Exercise Physiology Online, 6(2), 80-87. Recovered from: https://www.asep.org/asep/asep/Sukho.pdf

MACEDO, A. G., KRUG, A. L. O., HERRERA, N. A., ZAGO, A. S., RUSH, J. W. E., AMARAL, S. L. (2014). Low-intensity resistance training attenuates dexamethasone-induced atrophy in the flexor hallucis longus muscle. The Journal of Steroid Biochemistry and Molecular Biology, 143, 357364. doi: $10.1016 /$ j.jsbmb.2014.05.010

MOURA, L. P., GOMES, R. J., LEME, J. A., VOLTARELLI, F. A., RIBEIRO, C., MOURA, R. F., ... MELLO, M. R. (2012). Insulina pancreática de ratos diabéticos tipo 1 submetidos a um protocolo de treinamento físico individualizado. Revista Motricidade, 8(1), 23-32. doi: 10.6063/motricidade.8(1).234

PHILLIPS, S. M.; WINETT, R. A. (2010) Uncomplicated resistance training and health related outcomes: evidence for a public health mandate. Current Sports Medicine Reports, 9(4), 208-213. Doi: 10.1249/JSR.0b013e3181e7da73

PINHEIRO, C. H. J., FILHO, W. M. S., NETO, J. O., MARINHO, M. J. F., NETO, R. M., SMITH, M. M. R. L., SILVA, C. A. B. (2009). Exercise prevents cardiometabolic alterations induced by chronic use of glucocorticoids. Arquivos Brasileiros de Cardiologia, 93(4). Doi: 10.1590/S0066782X2009001000014

RHEN, T.; CIDLOWSKI, J. A. Antiinflammatory action of glucocorticoids-new mechanisms for old drugs. (2005). New England Journal of Medicine, 353(16), 1711-1723. doi: 10.1056/NEJMra050541

RODRIGUES, R. W. P., ABRAHIN, O., SOUSA, E. C., MARCAL, A. C. (2016). Efeitos do exercício resistido de alta intensidade em ratos que receberam dexametasona. Revista Brasileira de Medicina do Esporte, 22(3), 211-215. doi: 10.1590/1517-869220162203148503

SCHNEITER, P., TAPPY, L. (1998). Kinetics of dexamethasone-induced alterations of glucose metabolism in health humans. American Journal of Physiology, 275(5), 806-813.

SCHOENFELD, B. J., GRGIC, J., OGBORN, D., KRIEGER, J. W. (2017). Strength and hypertrophy adaptations between low- versus high-load resistance training: a systematic review and meta-analysis. The Journal of Strength $\&$ Conditioning Research. Recovered from doi: 10.1519/JSC.0000000000002200

BRAGA DA SILVA, T. L. T., MOTA, M. M., FONTES, M. T., SOARES, A. P. S., BARRETO, A. S., MARÇAL, A. C., SANTOS, M. R. V. (2013). Suplementação com L-arginina associada ao exercício resistido melhora a força muscular e impede o aumento da glicemia de ratos diabéticos. Revista de Ciências Médicas e Biológicas, 12,(1), 89-93. doi: 10.9771/cmbio.v12i1.6923

TAMAKI, T.; UCHIYAMA, S.; NAKANO, S. (1992). A weightlifiting exercise model for inducing hypertrophy in the hindlimb muscles of rats. Medicine \& Science in Sports \& Exercise, 24(8), 881886.

WESTCOTT, W. L. (2012). Resistance training is medicine: effects of strength training on health. Current Sports Medicine Reports, 11(4), 209-216. doi: 10.1249/JSR.0b013e31825dabb8

WINETT, R. A.; CARPINELLI, R. N. (2001). Potential health-related benefits of resistance training. Preventive Medicine, 33(5), 503-513. doi: 10.1006/pmed.2001.0909 


\title{
Evaluation of physical activity level, life quality and cardiovascular risk in amputees served in the basic health units of Aracaju-SE
}

\author{
Izabel Cristina de Oliveira Lima ${ }^{1}$, Mylena Maria Salgueiro Santana ${ }^{*}$, Marco Antonio Prado \\ Nunes ${ }^{3}$, Genilde Gomes de Oliveira ${ }^{4}$, Géssica Uruga Oliveira ${ }^{2}$, Luma Soares Lustosa ${ }^{4}$, Jader \\ Pereira de Farias Neto ${ }^{5}$, Walderi Monteiro da Silva Junior ${ }^{5}$
}

\begin{abstract}
Introduction: Amputation is the partial or total loss of a member, by surgery or traumatically, occurred by a diversity of etiologies. It is considered a health system issue due to the epidemiological growth and the physical, psychological and social impact. Objective: Evaluate the level of physical activity on quality of life and cardiovascular risk in amputees consulted at the basic health units from Aracaju-SE. Methodology: 60 amputees in inferior members were selected, of a total of 225, which answered the International Physical Activity Questionnaire (IPAQ), and questionnaire for evaluation of quality of life developed by the World Health Organization Quality of Life (WHOQL). Also, it was analyzed the type of physical exercise that they did and the risk of development of cardiovascular diseases by the criteria set in the Framingham Heart Study. Results: men showed highest incidence between the amputees. Only $23 \%$ of individuals studied were classified as active. According to the Framingham score no cardiovascular risk was observed. From the analysis of the WHOQL, the quality of life was better between active amputees. Conclusion: The prospect, based on the results, presents that the level of physical activity doesn't impact consistently in amputees' quality of life.

Keywords: Exercise, Amputation, Quality of life
\end{abstract}

\section{INTRODUCTION}

Amputation is the total or partial loss of a member, either surgically or traumatically way, caused by congenital or acquired changes, due to diseases such as: tumors, circulatory events, traumas, accidents at work and / or at traffic (Bello, Souza, Comassetto, \& Oliveira, 2014).

After amputation, it is required individual adaptations to new needs. An important factor related to quality of life (QOL) is the practice of physical activity. The prescription of physical exercise, based on the modality, intensity, duration, frequency and appropriate progression, may help improve quality of life, delaying harmful physiological changes, motor capacity and consequently, providing social, psychological and physical benefits (Alves, Leite, \& Machado, 2014).
In addition, physical activity has an important role in the treatment of diabetes mellitus (DM), as well as reduces possible complications, like blood glucose and cardiovascular risks, improves respiratory capacity and reduces blood pressure (D’Angelo, Leatte, \& Defani, 2015), besides reducing depression and anxiety (Peluso \& Andrade, 2005).

In Brazil, there are 13.9 cases of amputations for every 100,000 habitants per year, (Spichler et al., 2001), from 2013 to 2014 in Brazilian public health system (SUS), 36,451 amputations were performed only in lower limbs, and of these $34.9 \%$ were performed of the Northeast region (Ministério da Saúde, 2016). Only in Sergipe, of 109 admissions from diabetic patients, 56.1\% were submitted to amputations and $13 \%$ died. In addition, the annual cost of hospitalization for

\footnotetext{
${ }^{1}$ Programa de Pós-Graduação em Educação Física, Universidade Federal de Sergipe, Brasil.

${ }^{2}$ Programa de Pós-Graduação em Ciências da Saúde, Universidade Federal de Sergipe, Brasil.

${ }^{3}$ Departamento de Medicina, Centro de Ciências Biológicas e da Saúde, Universidade Federal de Sergipe, Brasil.

${ }^{4}$ Hospital Universitário de Sergipe, Universidade Federal de Sergipe, Brasil.

${ }^{5}$ Departamento de Fisioterapia, Centro de Ciências Biológicas e da Saúde, Universidade Federal de Sergipe, São Cristóvão, Sergipe, Brasil.

* Corresponding Author: Hospital Universitário de Sergipe (Unidade de Reabilitação), Rua Cláudio Batista, s/n -

Cidade Nova. Aracaju - Sergipe. CEP: 49060-118 E-mail: ftmylenasantana@gmail.com
} 
amputations was estimated at US \$ 264 million, proving that the impact of DM is high in the social and economic scope (Rezende et al., 2009).

As amputation process is growing every year in Brazil, it is important to evaluate quality of life in amputees, in this study, in Sergipe. So, it is necessary to evaluate questions such as: Is physical activity present in amputee's life? What is the perception of quality of life of these individuals? Have physical activity and quality of life influenced cardiovascular risk factors in the amputee population?

Thus, it is believed that amputees do not practice physical activity, increasing the clinical complications due to comorbidities and sedentary lifestyle. Therefore, the objective of this study was to evaluate the level of physical activity, quality of life and cardiovascular risk in amputees attended at the basic health units of Aracaju-SE.

\section{METHODS}

Descriptive cross-sectional study, carried out through a previous census of patients with lower limb amputations in the city of Aracaju, Sergipe.

\section{Sample}

Random sample with the present study approved by Ethics Committee of Federal University of Sergipe (protocol number: CAAE: 45313415.9.0000.5546). It was requested the release of the Municipal Secretary of Aracaju for access to medical records of patients with amputations in lower limbs, who should agree with their participation through the agreement recognized by the Term of Free and Informed Consent- TCLE.

At the time of the interview, the participants were informed about the purpose of the study, the benefits and the risks, having been assured of confidentiality, the privacy of the information provided and the non-use of the diagnosis and identification with their name or their general registration number.

\section{Instruments}

The variables were: sociodemographic and clinical data, physical activity level, quality of life and cardiovascular risk classification. Such measures were carried out through the following questionnaires:

- Demographic and clinical characteristics of the population: age, sex, level of amputation, associated disease (diabetes mellitus and systolic hypertension), if you have a prosthesis, participate in physiotherapeutic treatment, time since amputation and systolic and diastolic blood pressure

Physical activity: International Questionnaire of Physical Activity (IPAQ), in its short form, composed of eight open questions. Their information allows estimating the time spent per week in different dimensions of physical activity (moderate physical and vigorous walking and physical exertion) and physical inactivity (sitting position). Thus, the correlation between the physical activity performed (minutes / day), as well as its frequency (days / week) (Guedes, Lopes, \& Guedes, 2005). IPAQ allows to estimate the weekly time spent in physical activities of light intensity, moderate and vigorous, classifying the level of physical activity: sedentary; irregularly active; active; and very active (Malta \& Junior, 2013). Due to the sample size, in this study, IPAQ categories were grouped into active and non-active.

- Quality of life: A short-term Quality of Life Assessment Tool (WHOQOL-Bref), a short version, is composed of 26 questions that assess the quality of life in four domains: physical, psychological, social and environmental. This tool was adapted and translated in Brazil (Fleck et al., 2000).

Cardiovascular risk: Criterion of the Framingham Heart Study, which are assigned numerical values, according to the risk attributed to the values of age, blood pressure, smoking and diabetes. Each score obtained corresponds to a percentage of the probability of occurrence of a cardiovascular event (Cesarino, Borges, Ribeiro, Ribeiro, \& Kusumota, 2013). Due to the sample size, in this study, categories were grouped in high and not high risk. 


\section{Statistical analysis}

Descriptive analysis was used, with absolute and relative frequencies, in the case of categorical variables, and measures of central tendency and variability, in the case of numerical variables. The association between the variables and the differences between proportions were analyzed using the Pearson and chi-square test. In the comparisons of two independent samples, Student's t-test was used, with significance level of $p \leq 0.05$. The risk factors for the population were also analyzed using the chi-square test. Statistical analyzes were performed using program $\mathrm{R}$ version 3.3.2.

\section{RESULTS}

Sixty individuals with lower limb amputations had participated: $52 \%(31 / 60)$ males and a mean age of 59.9 years. Only 12 subjects underwent physiotherapy and had prosthesis, regardless of the level of physical activity found. A total of $23 \%$ $(14 / 60)$ of these were considered active, with smaller amputations being the most frequent in this group, also presenting an important predictor factor $(\mathrm{PR}=2.86)$. no statistically significant differences were found when comparing the epidemiological aspects between the active and non-active groups, as demonstrated in Table 1.

Table 1

Epidemiological Aspects of Amputees in Relation to Physical Activity.

\begin{tabular}{|c|c|c|c|c|c|c|c|c|c|}
\hline \multirow[b]{2}{*}{ Variáveis } & \multicolumn{2}{|c|}{ Active } & \multicolumn{2}{|c|}{ Not active } & \multicolumn{2}{|c|}{ Total } & \multirow[t]{2}{*}{$\mathrm{P}$ value } & \multirow[t]{2}{*}{ PR } & \multirow{2}{*}{$\begin{array}{c}\text { IC } 95 \% \\
\text { (Min, Máx) }\end{array}$} \\
\hline & $\mathrm{N}$ & $\%$ & $\mathrm{n}$ & $\%$ & $\mathrm{n}$ & $\%$ & & & \\
\hline \multicolumn{10}{|l|}{ Gender } \\
\hline Female & 5 & 35 & 24 & 52 & 29 & 48 & 0.4391 & 0.59 & $(0.23,1.56)$ \\
\hline Male & 9 & 65 & 22 & 48 & 31 & 52 & & & \\
\hline \multicolumn{10}{|l|}{ Amputation } \\
\hline Minor & 10 & 71 & 18 & 39 & 28 & 47 & 0.039 & 2.86 & $(1.01,8.11)$ \\
\hline Major & 4 & 29 & 28 & 61 & 32 & 53 & & & \\
\hline \multicolumn{10}{|c|}{ Physiotherapy } \\
\hline Yes & 3 & 21 & 9 & 20 & 12 & 20 & 0.819 & 1.09 & $(0.36,3.31)$ \\
\hline No & 11 & 79 & 37 & 80 & 48 & 80 & & & \\
\hline \multicolumn{10}{|l|}{ Prosthesis } \\
\hline Yes & 3 & 21 & 9 & 20 & 12 & 20 & 0.819 & 1.09 & $(0.36,3.31)$ \\
\hline No & 11 & 79 & 37 & 80 & 48 & 80 & & & \\
\hline Total & 14 & 100 & 46 & 100 & 60 & 100 & & & \\
\hline
\end{tabular}

Table 2

Risk Factors for Cardiovascular Diseases according to Physical Activity.

\begin{tabular}{|c|c|c|c|c|c|c|c|c|c|}
\hline & \multicolumn{2}{|c|}{ Active } & \multicolumn{2}{|c|}{ Not active } & \multicolumn{2}{|c|}{ Total } & \multirow[t]{2}{*}{$P$ value } & \multirow[t]{2}{*}{ PR } & \multirow{2}{*}{$\begin{array}{c}\text { IC 95\% } \\
\text { (Min, Max) }\end{array}$} \\
\hline & $\mathrm{n}$ & $\%$ & $\mathrm{n}$ & $\%$ & $\mathrm{n}$ & $\%$ & & & \\
\hline \multicolumn{10}{|c|}{ Normal glicemia } \\
\hline Yes & 4 & 29 & 21 & 46 & 25 & 42 & 0.134 & 1.53 & $(1.06,2.21)$ \\
\hline No & 10 & 71 & 25 & 54 & 35 & 58 & & & \\
\hline \multicolumn{10}{|l|}{ SAH descomp } \\
\hline Yes & 3 & 21 & 13 & 28 & 16 & 27 & 0.613 & 0.87 & $(0.25,2.29)$ \\
\hline No & 11 & 79 & 33 & 72 & 44 & 73 & & & \\
\hline \multicolumn{10}{|c|}{ Diabetes melitus } \\
\hline Yes & 12 & 86 & 29 & 63 & 41 & 68 & 0.204 & 1.36 & $(1.00,1.85)$ \\
\hline No & 2 & 14 & 17 & 37 & 19 & 32 & & & \\
\hline \multicolumn{10}{|l|}{ Smoking } \\
\hline Yes & 1 & 7 & 2 & 4 & 3 & 5 & 0.674 & 1.64 & $(0.28,7.76)$ \\
\hline No & 13 & 93 & 44 & 96 & 57 & 95 & & & \\
\hline \multicolumn{10}{|l|}{ Framigham } \\
\hline High & 5 & 36 & 18 & 39 & 23 & 38 & 0.818 & 0.91 & $(0.41,2.01)$ \\
\hline Not high & 9 & 64 & 28 & 61 & 37 & 62 & & & \\
\hline Total & 14 & 10 & 46 & 100 & 60 & 10 & & & \\
\hline
\end{tabular}


Regarding cardiovascular diseases, 35 subjects had altered glycemia, considered a predictive risk by the chi-square test $(\mathrm{PR}=1.53)$, as well as the presence of diabetes mellitus $(\mathrm{PR}=1.36)$ and smoking $(\mathrm{PR}=1.64)$.

Comparing the cardiovascular risk according to the Framingham Heart Study Criterion, between active and non-active amputees, there was a statistically significant difference when the time since amputation $(\mathrm{p}=0.024)$ was observed, as described in table 03 .

When the WHOQOL-Bref domains were evaluated for quality of life, there was a statistically significant difference in the overall score $(\mathrm{p}=0.038)$. The results of the domains and the general score are described in table 04 .

Table 3

Cardiovascular risk among amputees

\begin{tabular}{lccccc} 
& Active & Active & Not active & Not active & P value \\
& Mean & SD & Mean & SD & \\
\hline Age & 58.8 & 15.6 & 59.9 & 15.7 & 0.822 \\
Elapsed time since amputation & 3.3 & 2.0 & 5.9 & 6.8 & 0.024 \\
Systolic pressure & 145.7 & 25.3 & 138.9 & 22.0 & 0.347 \\
Diastolic pressure & 85.0 & 9.4 & 84.2 & 13.0 & 0.791 \\
Framigham - amount & 9.6 & 5.6 & 8.9 & 5.8 & 0.705 \\
Framigham - risk & 17.5 & 10.3 & 18.4 & 12.1 & 0.779 \\
\hline
\end{tabular}

Note: $n=$ sample; Student's t test: significant $<0.05$

Table 4

Relationship between Physical Activity Level and Quality of Life

\begin{tabular}{lccccc}
\hline & Active & Active & Not active & Not active & P value \\
& Mean & SD & Mean & SD & \\
\hline Physical Domain & 13.2 & 1.8 & 11.9 & 3.5 & 0.064 \\
Psychological Domain & 15.0 & 1.8 & 13.6 & 3.5 & 0.058 \\
Social relationship & 14.3 & 3.5 & 12.1 & 3.7 & 0.056 \\
Environment & 12.8 & 1.6 & 12.2 & 3.6 & 0.325 \\
General & 13.7 & 1.4 & 12.4 & 2.9 & 0.038 \\
\hline
\end{tabular}

Note: $n=$ sample; Student's t test: significant $<0.05$

\section{DISCUSSION}

The study revealed that most the amputees treated by the BHU of Aracaju are male (52\%), with a higher prevalence of lower amputations among the assets. The presence of decompensated glycemic, diabetes mellitus and smoking were considered predictive risks in this population. Regarding the time of amputation and the value of the general quality of life score, there was a statistically significant difference between the active and non-active groups.

The quality of life of the active amputees was significantly higher than in the group of nonactive amputees; there was a statistically significant difference in the overall value of the score given by the WHOQOL, despite the homogeneity in the scores of each domain of the questionnaire. This could be explained by a lower impact of the level of amputation on the limitations experienced by this population, considering that, in the group of active amputees, minor amputations predominated. In addition, the effects provided by physical activity are reported in literature as beneficial mainly for physiological adaptations and return to daily activities, favoring social participation to the amputee (Chin et al., 2002; Quigley \& Dillon, 2016).

Relating to cardiovascular risk factors, the presence of diabetes and altered glycemic indices were considered preponderant between active and inactive. DM is a frequent comorbidity in individuals with amputations (Maluf, Barreto, Reis, \& Vidigal, 2016; Pickwell et al., 2016; Spreen et al., 2016). 
This is due to DM presenting as a chronic exacerbation, which may trigger serious cardiovascular damage in its patients, being associated with vascular complications of high morbidity and mortality, requiring continuous care, permanent education and support to prevent complications (Cesarino et al., 2012).

Regarding to level of physical activity in this population, it was demonstrated that active individuals were minority in the group followed by the BHUs. It should be emphasized that the time spent since amputation was higher for the active group, which could explain the possible involvement of these subjects in activities and physical exercise, thus altering the expectation regarding their conditioning and quality of life (Chin et al., 2002).

Despite the sedentary lifestyle and the high rate of diabetics and hypertension, active or nonactive amputees had similar cardiovascular risk factors, in conforming with Framingham index. It seems that monitoring these patients by the Basic Health Units has contributed to control of several other comorbidities. However, the present study has limitations, as it does not investigate how UBS may be controlling such risk factors in amputees, which limits our explanation regarding this phenomenon.

\section{CONCLUSIONS}

In the light of data collected, the amputees of the city of Aracaju accompanied in the Basic Units of the city considered active obtained better values of quality of life. Also, observing the main predictive factors, it was verified that diabetes mellitus and altered glycemic indexes in both groups were considered high in this population.

\section{Acknowledgments:}

Nothing to declare

\section{Conflict of interests:}

Nothing to declare

\section{Funding:}

Nothing to declare

\section{REFERENCES}

Alves, L. C., Leite, I. d., \& Machado, C. J. (2014). Fatores associados à incapacidade funcional em idosos brasileiros. Revista de Saúde Pública, 46878 .

Bello, E. F., Souza, E. M., Comassetto, I., \& Oliveira, J. M. (2014). Vivência do idoso institucionalizados com membros inferiores amoutados decorrentes de complicações do diabetes mellitus. Revista de Enfermagem, 8(1), 44-55. doi: 10.5205/reuol.4843-39594-1-SM.0801201407

Cesarino, C. B., Borges, P. P., Ribeiro, R. d., Ribeiro, D. F., \& Kusumota, L. (2013). Avaliação dos fatores de risco para doença arterial coronariana em pacientes de São Caetano do Sul segundo o Escore de Framingham e sua relação com a síndrome metabólica. Acta Paulista de Enfermagem, 101-107.

Cesarino, E. J., Vituzzo, A. L., Sampaio, J. M., Ferreira, D. A., Pires, H. A., \& Souza, L. d. (2012). Assessment of cardiovascular risk of patients with arterial hypertension of a public health unit. Einstein (São Paulo), 10 (1), 33-38.

Chin, T., Sawamura, S., Fujita, H., Nakajima, S., Oyabu, H., Nagakura, Y., Nakagawa, A. (2002). Physical fitness of lower limb amputees. American Journal of Physical Medicine \& Rehabilitation, 81 (5), 321-325.

D’Angelo, F. A., Leatte, E. P., \& Defani, M. A. (2015). O exercício físico como coadjuvante no tratamento do diabetes. Saúde e Pesquisa, 8(1), 157-166.

doi: http://dx.doi.org/10.17765/19831870.2015v8n 1p157-166

Fleck, M. P., Louzada, S., Xavier, M., Chachamovich, E., Vieira, G., Santos, L., \& Pinzon, V. (2000). Aplicação da versão em português do instrumento abreviado de avaliação da qualidade de vida "WHOQOL-bref". Revista de Saúde Pública, 34(2), 178-183. doi: http://dx.doi.org/10.1590/S003489102000000200012

Guedes, D. P., Lopes, C. C., \& Guedes, J. E. (2005). Reprodutibilidade e validade do Questionário Internacional de Atividade Física em adolescentes. Revista Brasileira de Medicina do Esporte. Revista Brasileira de Medicina do Esporte, 11(2), 151-158. doi://dx.doi.org/10.1590/S15178692200500020 0011

Malta, D. C., \& Junior, J. B. (2013). O Plano de Ações Estratégicas para o Enfrentamento das Doenças Crônicas Não Transmissíveis no Brasil e a definição das metas globais para o enfrentamento dessas doenças até 2025: uma revisão. Epidemiologia e Serviços de Saúde, 22 (1), 151164. doi: 10.5123/S1679-49742013000100016

Maluf, C. B., Barreto, S. M., Reis, R. C., \& Vidigal, P. G. (2016). Platelet volume is associated with the Framingham risk score for cardiovascular disease 
in the Brazilian Longitudinal Study of Adult Health (ELSA-Brasil). Clinical Chemistry and Laboratory Medicine , 54 (5), 879-87. doi:10.1515/cclm-2015-0686

Ministério da Saúde. (2016). Portal do Departamento de Atenção Básica. Fonte: Ministério da Saúde: http://dab.saude.gov.br/portaldab/smp_ras.php. Peluso, M. A., \& Andrade, L. H. (Janeiro/Fevereiro de 2005). Physical activity and mental health: the association between exercise and mood. Clinics, 60 (1): 61-70. doi: /S1807-593220050001

Pickwell, K., Siersma, V., Kars, M., Apelqvist, J., Bakker, K., Edmonds, M., .. . Schaper, N. (2016). Minor amputation does not negatively affect health-related quality of life as compared with conservative treatment in patients with a diabetic foot ulcer: An observational study. Diabetes Metabolism. 33(3),doi: 10.1002/dmrr.2867.

Quigley, M., \& Dillon, M. P. (2016). Quality of life in persons with partial foot or transtibial amputation: A systematic review. Prosthetics and Orthotics International, 40 (1),18-30. doi: $10.1177 / 0309364614546526$
Rezende, K. F., Ferraz, M. B., Malerbi, D. A., Melo, N. H., Nunes, M. P., Pedrosa, H. C., \& Chacra, A. R. (2009). Predicted annual costs for inpatients with diabetes and foot ulcers in a developing country - A simulation of the current situation in Brazil. Diabetic Medicine, 27(1), 109-112. doi:10.1111/j.1464-5491.2009.02871.x.

Spichler, E. R., Spichler, D., Lessa, I., Forti, A. C., Franco, L. J., \& LaPorte, R. E. (2001). Capturerecapture method to estimate lower extremity amputation rates in Rio de Janeiro, Brazil. Revista Panamericana de Salud Pública, 10(5), 334-340.

Spreen, M. I., Gremmels, H., Teraa, M., Sprengers, R. W., Verhaar, M. C., Eps, R. G., .. . Overhagen, H. v. (2016). Diabetes Mellitus Is Associated With Decreased Limb Survival in Patients With Critical Limb Ischemia: Pooled Data From Two Randomized Controlled Trials. Diabetics Care, 39 (11) 2058-2064. doi:10.2337/dc16-0850 


\title{
Anthropometric evaluation, BMI and Physical Fitness in different levels of maturation in scholars from the Jequié's City - BA, Brazil
}

\author{
Carlos Alberto de Oliveira Borges ${ }^{1}$, Martha Maria Viana de Bragança ${ }^{2,3,4,5}$, Alfonso Salguero \\ del Valle ${ }^{6}$, Olga Molinero González ${ }^{6,7}$, André Luiz Carneiro ${ }^{8}$, Dihogo Gama de Matos ${ }^{10}$, \\ Marcelo Danillo Matos dos Santos ${ }^{10,11}$, Raphael Fabrício de Souza ${ }^{2,10}$, Andres Armas Alejo \\ 10,11, Felipe J. Aidar2,10,11
}

This study aimed to evaluate the anthropometric variables BMI and physical fitness in the different maturation levels of schoolchildren from the city of Jequié-BA. Thirty-seven students of both sexes, aged between 8 and 10 years old, participated in the study, using the model of Gallhue and Ozmu, self-evaluation of sexual maturation according to Tanner's classification, anthropometric variables (body mass and height) and BMI. The test battery used in physical fitness testing was analysis of upper and lower limb strength (Horizontal Jumping, Medicine ball Throwing); speed (30m race); agility (Shutle Run); general coordination (Burpee) and aerobic endurance (6-minute running). In the Shuttle Run, Medicine Ball and Burpee tests, no significant differences were found between boys. However, there were significant differences in Tricipital Skinfold and in fat percentage of the boys, and those classified at maturational level "2" presented higher levels. Significant differences were observed in height between girls and boys, and in both cases, those classified as maturation level "2" were taller. The results tend to help the training more appropriate to the stage of maturation in the prepubescent.

Keywords: Child Development, Physical Fitness, Child, Students.

\section{INTRODUTION}

It is by means of the motor exploration that the child develops the consciousness of himself as well as of the external world, thus emphasizing the importance of motor activity for the overall development of the child. Motor skills also assist in the achievement of their independence, in their games and in their social adaptation, important in the construction of the basic notions for their intellectual development (Rosa Neto, 2002).

Changes in motor behavior tend to reflect maturational changes in the central nervous system. However, the development process occurs dynamically and is it susceptible to being shaped by innumerable external stimuli, such as environment, stimulation, among others (Tecklin, 2002).

According to Malina, Bouchard and Bar-Or (2004), the characteristics of child motor performance are in part related to their growth, development and maturation. Growth would begin with conception and finish by the end of adolescence. The growth and development phase therefore tends to include changes in size and functional capacity (Haywood \& Getchell, 2004; He \& Sutton, 2004).

Another endogenous factor that can influence physical growth is the hormonal aspects, which, when interacting with genetic load and environmental conditions, reflect the final

\footnotetext{
${ }^{1}$ University of the Tras-os-Montes e Alto Douro, Vila Real, Portugal;

${ }^{2}$ Department of Physical Education, Federal University of Sergipe, UFS, São Cristóvão, Sergipe, Brazil;

${ }^{3}$ Research Nucleus in Physical Fitness, Health and Performance of Sergipe, NUPAFISE, UFS, Sergipe, Brazil;.

${ }^{4}$ Research Laboratory of Human Cognitive Development, LADEC, UFS, São Cristóvão, Sergipe, Brazil;.

${ }^{5}$ Doctorate Program in Physical Activity and Sport Sciences, Universidad de León, León, España

${ }^{6}$ Faculty of Physical Activity and Sports Sciences and Institute of Biomedicine, IBIOMED, León University, León, España.

${ }^{7}$ Faculty of Education, Autonomous University of Chile, Chile.

${ }^{8}$ State University of Montes Claros, UNIMONTES, Montes Claros, MG, Brasil.

${ }^{10}$ Performance Study Group, Sports, Paralympic Sports and Health - GEPEPS, UFS, São Cristovão, Sergipe, Brazil.

${ }^{11}$ Graduate Program in Physical Education, Federal University of Sergipe, São Cristóvão, Sergipe, Brazil

* Corresponding author: Department of Physical Education, Federal University of Sergipe, São Cristóvão, Sergipe, Brazil. E-mail: fjaidar@gmail.com
} 
situation of each individual (Malina, 1990, 1994, 1996). Thus, conditioning motor capacities identify attributes associated with resistance, strength, velocity, and their combinations. In this sense, the objective of the present study was to evaluate the BMI anthropometric variables and physical fitness in the different maturation levels of schoolchildren in the city of Jequié / BA.

\section{METHOD}

The State of Bahia possesses an area of $564,830,859 \mathrm{~km} 2$, in which 417 are found municipalities, having the city of Salvador as capital. The state is in the south of the northeast region, this unit of the federation is limited with Alagoas, Sergipe, Pernambuco, besides the Piauí to the north, Minas Gerais and Espírito Santo to the south, Goiás and Tocantins to the west and the east to the ocean Atlantic. Jequié is a municipality in the state of Bahia, located $365 \mathrm{~km}$ from the capital Salvador, in the southwest of Bahia, in the limitrophe area between the caatinga and the forest area (Instituto Brasileiro de Geografia e Estatística/IBGE, 2011)

\section{Sample}

The reference population for this study was 127 subjects from both genders, aged 8 to 10 years, using the model of Gallhue and Ozmu (2005), in the The Specialized Stage Phase of Motor Development. The subjects were selected in the teaching network of Jequié-BA. The sample was divided into two groups by gender and maturation level. The adopted procedures follow ethical norms in research with humans, according to resolution 466 of October 12 $2^{\text {th }}, 2012$, of the National Health Council (CNS), for research involving human beings, in accordance with the ethical principles contained in the Declaration of Helsinki (1964, reformulated in 1975, 1983, 1989, 1996, 2000, 2008 and 2013) of the World Medical Association.

The parents or guardians were informed about the study and signed the term of free and clarified consent.

For the development of the study the procedures of selection of the sample obeyed a sequence of steps, the intentional nonprobabilistic sampling, that could effectively represent the school population considered. For that purpose, one (1) primary schoolchildren of the public (municipal) and two (2) private schools from urban area of the municipality of Jequié-Ba were chosen, they were classified separately by sex, age, series and according to the school in which were enrolled in the 2011 school year.

The criteria adopted as exclusion criteria were: (a) refusal to participate in the study; (b) prohibition of parents or guardians; (c) absence to classes on the day scheduled for data collection; (d) one skipped self-evaluate in relation to Tanner's scale (1962); and, (e) any physical problem that would prevent them, temporarily or permanently, from performing the anthropometric measurements and the motor tests. Due these criteria, 127 students from the city of Jequié / BA remained in the study.

\section{Instruments}

For measurement of weight and height, one being evaluated in inspiratory apnea and with the head oriented in the Frankfort plane parallel to the ground, where the patterns of the collected measurements were obtained according to the determinations suggested by the International Society of Advance of The Kinesiantropometric ISAK (2001). To verify the Body Mass Index (BMI = weight $(\mathrm{kg}) /$ height $^{2}(\mathrm{~m})$, weight and height were measured.

Measurements of the body composition check followed the protocols suggested by ISAK (2001). Which determines the use of the Skinfold Triciptal (ST) and Subscapular (SB).

The percentage of fat $(\% \mathrm{G})$ was estimated using the regression equation proposed by Lohman (1986), which proposes the use of tricipital and subscapular skinfolds for children aged 6 to 16 years. The intermediate constants by sex, age and race, as suggested by Pires-Neto and Petroski (1996), were used.

In the evaluation of the basic physical qualities were used: 1) horizontal impulse test (Johnson \& Nelson, 1979); 2) throwing Medicine Ball (Gaya, 
2002); 3) 30-meter sprint test (Popov, 1986 apud Christodoulos, Douda, Polykratis \& Tokmakidis, 2006); 4) Shuttle Run Test (Johnson \& Nelson, 1979); 5) Burppe test (Johnson \& Nelson, 1979), and finally, 6) Six minute walk/jog test. Maturity was determined through the Tanner scale (1962), and the maturation levels were evaluated in the "1" and "2" scales.

\section{Procedures}

The team of evaluators was composed of three Physical Education teachers and four contributors. Prior to the beginning of the data collection, the evaluators responsible for taking the information, performing the anthropometric measurements and administering the motor tests were submitted to a training period, in an attempt to minimize the influence of intra-rater errors ( $r$ $=0.916)$ to its maximum. In addition, each of the evaluators performed the same function throughout all the data collection process.

All data collection was performed in schools. In order to collect data, it was initially requested from the direction of the schools' authorization to allow the study to be carried out in both public and private schools of the municipality of Jequié. After obtaining the document, the first contact between the team of evaluators and the teachers responsible for Physical Education sessions was established, when the objectives, methodology and strategies to be adopted in the study were presented.

Regarding the protocol adopted, it was initially to determine the maturational level and sex. Sexual age was determined using a Tanner scale (1962), using a graduation based on items 1 and 2. Afterwards, the anthropometric measurements were performed, and, in the sequence, the motor tests were applied in a single evaluation session.

\section{Statistical Analysis}

Descriptive statistics were measured using the central tendency measures (mean \pm standard deviation), normality test was used, using the Shapiro-Wilk test according to the sample size and according to normality, the independent ttest or the Mann-Whitney were done test to verify assumed differences between observed maturation levels. Statistical procedures were performed using the statistical package SPSS for Windows 22.0.

\section{RESULTS}

The results of the evaluated students in relation to age can be observed in Table 1, the results concerning anthropometric variables in relation to maturation are shown in Table 2, regarding the fat percentage relative to maturation are shown in Table 3, the results of the relative to the six-minute run, horizontal jump and 30-meter speed in relation to maturation are in Table 4 and Shuttle Run, Medicine Ball, and the results of the Burpee tests on maturation are given in Table 5.

Table 1

Reference values of the evaluated scholars age values according to maturation level, by gender.

\begin{tabular}{lccc}
\hline Gender & $\begin{array}{c}\text { Maturation } \\
\text { level }\end{array}$ & $\mathrm{n}$ & $\begin{array}{c}\text { Age } \\
\text { (Average } \pm \text { DP) }\end{array}$ \\
\hline Female & 1 & 37 & $9.16 \pm 0.69$ \\
Female & 2 & 34 & $9.53 \pm 0.51$ \\
Male & 1 & 28 & $9.10 \pm 0.86$ \\
Male & 2 & 28 & $9.41 \pm 0.50$ \\
\hline
\end{tabular}

Note: $\mathrm{n}=$ sample

Table 2

Result of the anthropometric variables of the evaluated scholars in relation to the level of maturation, by gender.

\begin{tabular}{lcccc}
\hline Gender & Maturation & Mass & Height & BMI \\
\hline Female & 1 & $31.87 \pm 4.71$ & $1.35 \pm 0.55$ & $17.46 \pm 1.73$ \\
Female & 2 & $37.25 \pm 9.45 \#$ & $1.41 \pm 0.71 \#$ & $18.50 \pm 3.21^{*}$ \\
Male & 1 & $30.02 \pm 4.85$ & $1.35 \pm 0.54$ & $16.53 \pm 1.89$ \\
Male & 2 & $32.32 \pm 8.85 \# \#$ & $1.35 \pm 0.11$ & $17.44 \pm 2.61$ \\
\hline
\end{tabular}

Note: $\mathrm{BMI}=$ Body Mass Index; ${ }^{*} \mathrm{p}<0.05$ (independent test t) Female, $\# \mathrm{p}<0.05$ (Mann-Whitney) Female, ${ }^{* *} \mathrm{p}<0.05$ (independent test t) Male, \#\# p $<0.05$ (Mann-Whitney) Male. Significant differences were found in height between girls and boys, and in both cases those classified at maturity level "2" presented higher stature 
Table 3

Result of the fat percentage of the evaluated ones in relation to the level of maturation, by gender.

\begin{tabular}{lcccc}
\hline Gender & Maturation & TS $(\mathrm{mm})$ & SS $(\mathrm{mm})$ & \% Gordura \\
\hline Female & 1 & $10.64 \pm 3.64$ & $8.72 \pm 2.94$ & $19.00 \pm 4.80$ \\
Female & 2 & $11.92 \pm 8.78$ & $9.87 \pm 7.70$ & $18.27 \pm 5.32$ \\
Male & 1 & $8.31 \pm 1.98$ & $7.06 \pm 1.94$ & $13.35 \pm 3.50$ \\
Male & 2 & $11.29 \pm 5.74 \# \#$ & $9.32 \pm 4.83$ & $16.96 \pm 7.86 \# \#$ \\
\hline
\end{tabular}

Note: $\mathrm{S}=$ Skinfold; $\mathrm{T}=$ Tricipital; $\mathrm{SE}=$ Subscapular; ${ }^{*} \mathrm{p}<0.05$ (independent test $\mathrm{t}$ ) Female, $\# \mathrm{p}<0.05$ (Mann-Whitney) Female, ${ }^{* *} \mathrm{p}<0.05$ (independent test t) Male, \#\# p $<0.05$ (Mann-Whitney) Male. Significant differences were found in Triciptal skin fold and fat percentage only for boys, and those classified at maturational level "2" presented higher fat levels

Table 4

Results of the six-minute run, horizontal jump and 30-meter speed in relation to maturation level, by gender.

\begin{tabular}{lcccc}
\hline Gender & Maturation & Six-minute run & Horizontal Jump & Thirty-meter sprint \\
\hline Female & 1 & $874.49 \pm 129.27$ & $1.20 \pm 0.16$ & $4.93 \pm 0.89 \#$ \\
Female & 2 & $855.94 \pm 102.42$ & $1.22 \pm 0.11$ & $4.50 \pm 0.68$ \\
Male & 1 & $903.04 \pm 92.19$ & $1.37 \pm 0.17$ & $4.56 \pm 0.68 \# \#$ \\
Male & 2 & $845.14 \pm 153.66$ & $1.25 \pm 0.12$ & $4.13 \pm 0.60$ \\
\hline
\end{tabular}

Note: ${ }^{*} \mathrm{p}<0.05$ (independent test $\mathrm{t}$ ) Female, \# $\mathrm{p}<0.05$ (Mann-Whitney) Female, ${ }^{* *} \mathrm{p}<0.05$ (independent test $\mathrm{t}$ ) Male, \#\# $\mathrm{p}$ $<0.05$ (Mann-Whitney) Male. Significant differences were found in speed for both boys and girls, and in both cases, those classified at maturity level "1" were faster.

Table 5

Results of the Shuttle Run, Medicine Ball and Burpee tests in relation to maturation level, by gender.

\begin{tabular}{lcccc}
\hline Gender & Maturation & Shuttle Run & Medicine Ball & Burpee \\
\hline Female & 1 & $12.32 \pm 0.84$ & $1.69 \pm 0.33$ & $17.76 \pm 2.94$ \\
Female & 2 & $12.74 \pm 0.90 \#$ & $2.03 \pm 0.29 \#$ & $16.44 \pm 4.25$ \\
Male & 1 & $12.12 \pm 0.64$ & $2.38 \pm 2.66$ & $18.39 \pm 2.82$ \\
Male & 2 & $12.27 \pm 1.20$ & $2.08 \pm 0.56$ & $19.54 \pm 3.01$
\end{tabular}

Note: ${ }^{*} \mathrm{p}<0.05$ (independent test $\mathrm{t}$ ) Female, \# $\mathrm{p}<0.05$ (Mann-Whitney) Female, ${ }^{* *} \mathrm{p}<0.05$ (independent test $\mathrm{t}$ ) Male, \#\# $\mathrm{p}$ $<0.05$ (Mann-Whitney) Male. In the Shuttle Run, Medicine Ball and Burpee tests, no significant differences were found among those evaluated for males

\section{DISCUSSION}

The information on growth variables constitute an important indicator of the health status of a young population (Guedes, 1994; Guedes \& Barbanti, 1995; Guedes \& Guedes, 1995, 2002).

When comparing the mass parameter among the studied males belonging to the two maturation levels (with values of $31.87 \pm 4.71$ and $37.25 \pm 9.45$, respectively for "1" and "2" maturity levels). A minimal significant difference was noticed, fact also verified among the scholars (with $30.02 \pm 4.85$ and $32.32 \pm 8.85$ values, respectively for maturation levels 1 and 2), when the Mann-Whitney test was applied at $5 \%$ of probability according to Table 2 .

Among the male students $(1.35 \pm 0.54$ and $1.35 \pm 0.11$, respectively for maturity "1" and "2" levels) there was no statistical difference; however, for the female gender $(1.35 \pm 0.55$ and $1.41 \pm 0.71$, respectively for maturation levels " 1 " and "2"), there was a statistically significant difference in the Mann-Whitney test (Table 2, p $<0.05)$.

Nevertheless, according to data from Table 2, for the Body Mass Index (BMI), only the female had a significant difference in the independent $t$ test $(p<0.05)$, a fact considered biologically compatible with the observed differences between the sexes related to prepubertal development, where girls develop and mature earlier than boys (Gallahue \& Ozmun, 2005).

Thus, it is perceived that monitoring growth can be a indicative tool of the physical fitness and quality of life of the young population, and it also permits analyzing the distortions involved in this population, especially regarding to aspects related to maturation and nutritional status (Martorell, Martorell, 1975; Martorell, Lechtig, Habicht, Yarbrough \& Klein, 2001; Martorell, Malina, Castillo, Mendoza \& Pawson, 1988). 
Epidemiological studies in several countries have sought to highlight the fundamental characteristics in the early stages of child and adolescent growth, as well as their level of maturation. According to Butte, Garza and Onis (2007), body size and proportions, the physical, the maturation and the body composition are important factors in physical performance and physical fitness (Malina, 1995).

The evolution of motor performance in childhood and adolescence would be strongly associated with growth and maturation processes (Farias \& Petroski, 2003; Filardo, Pires Neto \& Rodriguez-Añez, 2001; Flegal 1999). Due to this relationship of interdependence in the evaluation of motor performance, aspects of physical growth and chronological and biological ages should be considered (Böhme, 1995, 1996, 1999; Fonseca, Sichieri \& Veiga, 1998; França Junior \& Monteiro 2000; Fredriks et al., 2000).

The variations in body fat evidenced in Table 3 for stages "1" and "2" maturation in both boys and girls presented significant differences for the mean values.

Among girls, no statistically significant variation was observed for the parameters of Table 3, which refer to Tricipital Fold, Subscapular Fold and Fat Percentage. However, among boys in maturity stages 1 and 2, significant variation $(p<0.05)$ was observed by the MannWhitney test, in the male Tricipital Fold and Percentage of Fat questions. Regarding the equations of skinfolds, it is interesting to emphasize that its use should be attentive to the adequate knowledge of the standardization used and if the equation is specific or generalized.

Petroski (2003) and Petroski and Pires Neto (1993), specific equations are those that have been validated for a given population and depart from a linear model. The generalized ones can be used in several populations, because, in its validation, a heterogeneous sample was used, and for its validation, a quadratic model was used.

According to Malina (1996), among those indicators, the most commonly used for children and adolescents are the skinfold equations and the BMI (1996), because the distribution of adipose tissue in this range varies according to the maturational stage and it is not well defined, which makes it difficult to use the Waist/Hip Ratio (WHR) for the focus group of this research (Guedes \& Guedes, 1997; Malina, 1996).

As for Brazil, regional and cultural variations can be added, which may interfere with density and, consequently, tissue values, when compared with studies in other countries, which suggests that studies are validated and developed for our reality (Guedes \& Guedes, 2002).

The process of growth, development and biological maturation, as well as body composition, influence physical fitness. The higher maturational level, the better the performance of the children and in tests that depend on body weight, such as displacement tests, the lighter the child is more likely to perform better (Freitas Junior \& Barbanti, 1993; Frisancho, Guire, Babler, Borkan \& Way, 1980; Fulton, McGuire, Caspersen \& Dietz, 2001; Glaner 2002, 2003, 2005).

There were significant differences in speed for both male students $(4.93 \pm 0.89$ compared to $4.50 \pm 0.68$ for maturation level 2$)$ and for female students $(4.56 \pm 0.68$ compared to $4.13 \pm 0.60$ for level "2" of maturation level). In both cases, those classified as maturation level "1" presented the fastest Mann-Whitney test at $5 \%$ of probability.

It is worth noting the performance of female students of the level "1" of maturation for the running, which may be related to the lower stature and Body Mass Index (BMI), which could give them more agility and speed.

Physical fitness has been defined as the ability to perform physical activities in a satisfactory manner, without any abnormal fatigue, and with sufficient energy reserve to enjoy leisure activities and be able to respond adequately to any unexpected obstacle, being physical fitness dependent on inborn and/or acquired characters (Caspersen, Powell \& Christenson, 1985; Pate, 1985).

On the other hand, the physical fitness of a child or adolescent is related to his / her health, constituting a dynamic process/state of energy 
and vitality that would allow each individual to perform daily tasks and hours of leisure. In addition to enable conditions to face unforeseen emergencies without excessive fatigue, thus providing protection against the appearance of hypokinetic dysfunctions (Alfaro, Bejarano, Dipierri, Quispe \& Cabrera, 2004; Alison, Fontaine, Manson, Stevens \& Vanitallie, 1999; Aminorroaya, Amini, Naghdi \& Zadeh, 2003; Bouchard, Shephard, Stephens, Sutton \& McPherson, 1991).

In the horizontal jump test, according to gender or maturation, statistically significant variations ( $p<0.05)$ were found by the MannWhitney test and independent t-test used in the present study (Table 4).

In the horizontal jump, in which the force component exerts great influence, the tendency of increasing with the advancement of maturation is expected for individuals who are going through puberty, when there is an increase in the secretion of sexual steroids. However, it was not possible to perceive significant statistical differences possibly because they are prepubescent (Anjos, 1989; Armstrong, Welsman \& Kirby, 2000; Macêdo \& Fernandes Filho, 2003; Erikseen et al., 1998).

As it is known, androgens are responsible for a large part of the physical changes observed at puberty, in which acceleration of linear growth is accompanied by muscle gain, increase in connective tissue and, as a consequence, positive nitrogen balance. Macêdo and Fernandes Filho (2003) found a relationship between a major level of strength measured by vertical jump and the advancement of sexual maturation (Fleck \& Kraemer 1999; Janz \& Mahoney, 1997; Linhares et al., 2009).

Thus, significant differences were found in speed for both boys and girls, and in both cases, those classified at maturity level " 1 " were faster.

When analyzing the results in relation to the Shuttle Run, Medicine Ball and Burpee tests in regarding maturation, it was evident the influence in some analyzed parameters of the level of maturation of female scholars (Table 5).
For the Shuttle Run, Medicine Ball and Burpee tests, no significant differences were found among those evaluated for males, a fact supported by the available scientific literature, since among prepubescent males, substantial anatomical-morphological variations become more evident from puberty, by the marked and increasing production of testosterone.

In agility, no significant difference was found between the pubertal stages, although it is possible to perceive tendency to progression. For this test, there is a need for strength, since velocity is involved, and, at the same time, good coordination is required so that changes in position and direction of the body are made satisfactorily (Linhares et al., 2009).

In boys, from puberty to adolescence, there is direct influence of testosterone. And after puberty, for example, strength training may increase muscle mass beyond normal growth (Bouchard et al., 1991).

It is known that it is not possible in children to grow beyond normal muscle mass (Immature System Hormonal). It is common to notice among boys from 7 to 13 years of age a certain physical stability in muscular development compared to young people at puberty (from 14 to 17 years old). As they grow and pass through puberty, muscle increases become biologically plausible (Linhares et al., 2009).

In adolescence, it is verified that sexual maturation exerts effects on growth and development, since large maturational variation can be found among adolescents of the same chronological age. This divergence between maturation and chronological age is more pronounced when comparing boys with the latest and the most advanced contrasting pubertal stages. However, prepubertal males may not present clear and definite variations to pubertal individuals due to endogenous factors such as hormonal and physiological accommodations (Linhares et al., 2009).

Among the girls, the Shuttle Run test evidenced the influence of maturational status on performance (maturation stage "1" with $12.32 \pm$ 0.84 and maturation stage " 2 " with $12.74 \pm 0.90$ ), 
with statistical difference by the Mann-Whitney test $(\mathrm{p}<0.05)$.

According to Fleck and Figueira Júnior (1997), when the child approaches puberty, "the increase in muscle mass due to weight training may present better results than in other periods of life," suggesting that this is a good period for the work of increasing muscle mass.

From the point exposed, it can be noticed that the work of strength and agility in girls can be worked earlier, whose reflex in physical conditioning is expected to be more intensified (Linhares et al., 2009).

Oliveira and Gallagher (1997), complement these situations affirming that there is an increase of strength with increase of stature in both sexes during the childhood, as after puberty it tends to be faster in the boys due to hormonal action. These authors also report that when compared with older age groups, pre-teens tend to have greater trainability on strength development (Macêdo \& Fernandes Filho, 2003).

During childhood some variables of physical fitness are similar between boys and girls. For example, muscle strength is similar between the sexes. Only with the onset of puberty, boys acquire superior values compared to girls. There is a tendency to maintain this characteristic between childhood and adolescence, especially for lower limb strength (Malina, 1996), that is, children who obtain higher values of strength when prepubescent may be those who in adolescence will have the best performance. This tendency is also found for agility (Malina, 1996).

\section{CONCLUSION}

Testing tends to be an excellent mean of accompaniment in terms of adolescent growth and development, as well as helping to define the best strategies for adolescent planning in terms of sports training aimed at this segment.

\section{Acknowledgments:}

Nothing to declare
Conflict of interests:

Nothing to declare

Funding:
Coordenação de Aperfeiçoamento de Pessoal de Nível
Superior (Capes), sob processo número AUXPE
PROCAD/NF 110/2010

\section{REFERÊNCIAS}

Alfaro, E., Bejarano, I., Dipierri, J., Quispe, Y., \& Cabrera, G. (2004). Percentilos de peso, talla e índice de masa corporal de escolares jujeños calculados por el método LMS. Archivos Argentinos de Pediatria, 102(6), 431-439.

Alison, D. B., Fontaine, K. R., Manson, J. E., Stevens, J., \& Vanitallie, T. B,. (1999). Annual deaths attributable to obesity in the United States. JAMA, 282(16), 1530-1538

Aminorroaya, A., Amini, M., Naghdi, H., \& Zadeh, A. H. (2003). Growth Charts of Heights and Weights of Male Children and Adolescents of Isfahan, Iran. Journal of Health, Population and Nutrition, 21(4), 341-346.

Anjos, L. A. (1989). Growth, physical fitness, and maximal mechanical aerobic and anaerobic power output on a bicycle ergometer of schoolchildren aged 8-9 years living in underprivileged environments in Rio de Janeiro, Brazil (Thesis Doctoral). University of Illinois, Illinois.

Armstrong, N., Welsman, J. R., \& Kirby, B. J. (2000). Longitudinal Changes in 11-13 year Old's Physical Activity. Acta Paediatrica, 89, 775-780.

Bergman, P., \& Goracy, M. (1984). The Timing of Adolescents Growth Slurps of Ten BodyDimensions in Boys and Girls of the Workday Longitudinal Twin Study. Journal Human Evolution, 13, 339-437.

Böhme, M. T. S. (1995). Aptidão física e crescimento físico de escolares de 7 a 17 anos de Viçosa - MG. Revista Mineira de Educação Física, 3(1), 34-42.

Böhme, M. T.S. (1999). Aptidão física de jovens atletas do sexo feminino analisado em relação a determinados aspectos biológicos, idade cronológica e tipo de modalidade esportiva praticada (Tese Livre Docência). Universidade de Sâo Paulo, São Paulo.

Böhme, M. T. S. (1996). Aptidão física e crescimento físico de escolares de 7 a 17 anos de Viçosa - MG. Revista Mineira de Educação Física, 4(1), 45-60.

Bouchard, C., Shephard, R. J., Stephens, T., Sutton, J.R., \& McPherson, B. D. (1991). Exercise, fitness, and health: the consensus statement. In: C. Bouchard, R. J. Shephard, T. Stephens, J. R. Sutton \& B. D. McPherson (orgs.). Exercise, Fitness, and Health: A Consensus of Current 
Knowledge. Champaign, Human Kinetics (pp. 328).

Butte, N. F., Garza, C., Onis, M. (2007). Evaluation of the Feasibility of International Growth Standards for School-Aged Children and Adolescents. Journal of Nutrition, 137, 153-157.

Caspersen, C. J., Powell, K. E., \& Christenson, G. M. (1985). Physical activity, exercise and physical fitness: definitions and distinctions for healthrelated research. Public Health Reports, 100(2), 126-131.

Christodoulos, A. D., Douda, H. T., Polykratis, M. \& Tokmakidis, S. P. (2006). Attitudes towards exercise and physical activity behaviours in Greek schoolchildren after a year long health education intervention. British Journal of Sports Medicine, 40(4), 367-371.

Erikseen, G; Liest, K., Bjornholt, J., Thaulow, E., Sandvik, L; \& Erikssen, J. (1998). Changes in Physical Fitness and Changes in Mortality. Lancet, 352, 759-762.

Farias, E. S., \& Petroski, E. L. (2003). Estado nutricional e atividade física de escolares da cidade de Porto Velho-RO. Revista brasileira de cineantropometria \& desempenho humano, 5(1), 27-38.

Filardo, R.D., Pires Neto, C. S., \& Rodriguez-Añez, C. R. (2001). Comparação de indicadores antropométricos e da composição corporal de escolares do sexo masculino participantes e não participantes de programas de treinamento. Revista Brasileira de Atividade Física e Saúde, 6(1), 31-37.

Fleck, S., \& Figueira Júnior, A. J. (1997). Riscos e benefícios do treinamento de força em crianças: novas tendências. Revista Brasileira de Atividade Física e Saúde, 2(1), 69-75.

Fleck, S. J., \& Kraemer, W. J. (1999). Fundamentos do treinamento de força muscular ( $2^{\mathrm{a}}$ ed.) São Paulo: Artmed.

Flegal, K. (1999). Curve smoothing and transformation in the development of growth curves. American Journal of Clinical Nutrition, 70(suppl.), S162165.

Fonseca, V. M., Sichieri, R., \& Veiga, G. V. (1998). Fatores associados a obesidade em adolescentes, Revista de Saúde Pública, 32(6), 541-549.

França Junior, I., Silva, G. R., \& Monteiro, C. A. (2000). Tendência secular na altura adulta de crianças nascidas na cidade de São Paulo entre 1950 e 1976. Revista de Saúde Pública, 34(6 supl.), 102107.

Fredriks, A. M., Van Buuren, S., Burgmeijer, R. J. F., Meulmeester, J.F., Beuker, R. J., Brugman, E., ... \& Wit, J. M. (2000). Continuing Positive Secular Growth Change in the Netherlands 1955-1997. Pediatric Research, 47(3), 316-323.

Freitas Júnior, I. F., \& Barbanti, V. J. (1993). Comparação de índices de aptidão física relacionada à saúde em adolescentes. Revista da
Associação dos Professores de Educação Física de Londrina, 7(14), 42-46.

Freitas, R. T. (1997). Indicadores antropométricos e de aptidão física de crianças entre 7 a 10 anos em diferentes níveis socioeconômicos de Ijuí, RS (Dissertação de Mestrado). Universidade Federal de Santa Maria, Santa Maria.

Frisancho, A. R., Guire, K., Babler, W., Borkan, G., \& Way, A. (1980). Nutritional influence on childhood development and genetic control of adolescent growth of Quéchuas and mestizos from the Peruvian Lowlands. American Journal of Physical Anthropology, 52(3), 367-375.

Fulton, J. E., McGuire, M. T., Caspersen, C. J., \& Dietz, W. H. (2001). Interventions for weight loss and weight gain prevention among youth: current issues. Sports Medicine, 31(3), 154-165.

Gallahue, D. L., \& Ozmun, J. C. (2005). Compreendendo o desenvolvimento motor: bebês, crianças, adolescentes e adultos ( $3^{\mathrm{a}} \mathrm{ed}$.). São Paulo: Phorte.

Gaya, A. C. A. (2002). Projeto Esporte Brasil. Indicadores de saúde e fatores de prestação esportiva em crianças e jovens. Manual de Aplicação de Medidas e testes somatomotores. In: Desporto, actividade física e saúde. Porto. Desporto Actividade Física e Saúde. Porto: FCDEF-UP.

Glaner, M. F. (2002). Crescimento físico e aptidão física relacionada à saúde em adolescentes rurais e urbanos (Tese de Doutorado). Universidade Federal de Santa Maria: Santa Maria.

Glaner, M. F. (2003). Referenciais para o crescimento físico de adolescentes gaúchos e catarinenses. Revista Brasileira de Cineantrometria e Desenvolvimento Humano, 5(1), 17-26.

Glaner, M. F. (2005). Crescimento físico em escolares adolescentes do norte gaúcho e oeste catarinense. Revista Brasileira de Ciência e Movimento, 13(2), 15-20.

Guedes, D. P. (1994). Crescimento, composição corporal e desempenho motor em crianças e adolescentes do município de Londrina (PR), Brasil (Tese de Doutorado). Universidade de São Paulo: São Paulo.

Guedes, D. P. \& Barbanti, V. J. (1995). Desempenho motor em crianças e adolescentes. Revista Paulista de Educação Física, 9(1), 37-50.

Guedes, D. P., \& Guedes, J. E. R. P. (1995). Aptidão física relacionada à saúde de crianças e adolescentes: avaliação referenciada por critério. Revista Brasileira de Atividade Física e Saúde, $1(2), 27-38$.

Guedes, D. P., \& Guedes, J. E. R. P. (1997). Crescimento, composição corporal e desempenho motor de crianças e adolescentes. São Paulo: Balieiro.

Guedes, D. P., \& Guedes, J. E. R. P. (1998). Controle do peso corporal: composição corporal, atividade física e nutrição. Londrina: Midiograf. 
Guedes, D. P., \& Guedes, J. E. R. P. (2002). Crescimento, Composição Corporal e Desempenho Motor de Crianças e Adolescentes (2a ed.). São Paulo: CLR Balieiro.

Guedes, D. P., \& Guedes, J. E. R. P. (2003). Intensidades dos esforços físicos nas atividades cotidianas de adolescentes. Revista Brasileira de Ciência e Movimento, 3(suppl.), 49.

Guedes, D. P., Guedes, J. E. R. P. (2006). Manual Prático para Avaliação em Educação Física (1 ${ }^{\mathrm{a}}$ ed.). São Paulo: Manole.

Haywood, K. M., \& Getchell, N. (2004). Desenvolvimento motor ao longo da vida ( $3^{\mathrm{a}}$ ed.). São Paulo: Armed.

Instituto Brasileiro de Geografia e Estatística/IBGE. (2011). Censo Populacional 2010. Obtido 23 de Setembro de 2017, de https://biblioteca.ibge.gov.br/visualizacao/perio dicos/93/cd_2010_caracteristicas_populacao_do micilios.pdf

International Society for the Advancement of Kinanthropometry/ISAK. (2001). International Standards for Anthropometric Assessment. Sydney: ISAK.

Janz, K. F., \& Mahoney, L. T. (1997). Three-year follow-up of changes in aerobic fitness during puberty: The Muscatine Study. Research Quarterly for Exercise and Sport, 68(1), 1-9.

Johnson, B. L., \& Nelson, J. K. (1979). Practical Measurements for Evaluation in Physical Education. Minnesota: Burges Publishing Company.

Linhares, R. V., Matta, M. O., Lima, J. R. P., Dantas, P. M. S., Costa, M. B., \& Fernandes Filho, J. (2009). Efeitos da maturação sexual na composição corporal, nos dermatóglifos, no somatótipo e nas qualidades físicas básicas de adolescentes. Arquivos Brasileiros de Endocrinologia \& Metabologia, 53(1), 47-54.

Lohman, T. G. (1986). Applicability of body composition techniques and constants for children and youths. Exercise Sports Science Reviews, 14, 325-357.

Macêdo, M. M., \& Fernandes Filho, J. (2003). Estudo das características dermatoglíficas, somatotípicas e das qualidades físicas básicas nos diversos estágios de maturação sexual. Fitness \& Performance Journal, 2(5), 315-320.
Malina, R. M. (1990). Crescimento de crianças latinoamericanas: comparações entre os aspectos socioeconômicos, urbano-rural e tendência secular. Revista Brasileira de Ciência e Movimento, 4(3), 46-75.

Malina, R. M. (1994). Physical Growt hand Biological Maturation of Young Athletes. Exercise and Sport Science Reviews, 22, 389-433.

Malina, R. M. (1996). Regional body composition: age, Sex, and ethnica variation. In: A. F. Roche, S. B. Heymsfield \& T. G. Lohman (Eds). Human body composition. Champaign: Human Kinetics.

Malina, R. M., Bouchard, C., \& Bar-Or, O. (2004). Growth, maturation and physical activity ( $2^{\mathrm{a}} \mathrm{ed}$.). Champaign: Human Kinetics Books.

Malina, R. M., \& Buschang, P. H. (1985). Growth, strength and motor performance of Zapotec children, Oaxaca, Mexico. Human Biology, 57(2), 163-181.

Martorell, R. (1975). Normas Antropometricas de Crecimiento Físico para Países en Desarrollo? Nacionales o Internacionales? Boletín de la Oficina Sanitaria Panamericana, 79(6), 525-529.

Martorell, R., Lechtig, A., Habicht, J. P., Yarbrough, \& C., Klein, R. E. (2001). Normas antropométricas de crescimento físico para países en desarollo? Acta Sanitária Panamericana, 82(10), 87-92.

Martorell, R., Malina, R. M., Castillo, R. O., Mendoza, F. S., \& Pawson, I. G. (1988). Body proportions in three ethnic groups: childrens and youths 2-27 years in NHANES II AND HHANES. Human Biology, 60(2), 205-222.

Pate, R. R. (1985). Aptidão física. In: N. J. Dougherty. Educación Física y deportes: para el alumno de la escuela secundaria. Barcelona: Reverté.

Petroski, E. L., \& Pires Neto, C. S. (1993). Composição Corporal: modelos de fracionamento corporal. Comunicação, Movimento e Mídia na Educação Física. Caderno II, Santa Maria: Imprensa Universitária/UFSM.

Petroski, E. L. (2003). Antropometria: Técnicas e padronizações ( $2^{\mathrm{a}}$ ed). Porto Alegre: Pallotti.

Rosa Neto, F. (2002). Manual de Avaliação Motora. Porto Alegre: Artmed.

Tanner, J. M. (1962). Growth at adolescence (2 ${ }^{\mathrm{a}}$ ed.) Oxoford: Blackwell Scientific.

Tecklin, J. S. (2002). Fisioterapia pediátrica ( $3^{\mathrm{a}}$ ed.) Porto Alegre: Artmed. 


\title{
Influence of biological maturation on the body mass index of young soccer players
}

\author{
Wallas Carlos Silva Oliveira ${ }^{1 *}$, Alan Navarro Couto ${ }^{2}$, Matheus Henrique Fonseca Santos ${ }^{3}$, \\ Valdicleide Teixeira Santos ${ }^{4}$, Fabiana Medeiros de Almeida Silva ${ }^{5}$
}

ORIGINAL ARTICLE

\begin{abstract}
To definition, growth is the process resulted to the cellular multiplication and differentiation that determinate progressive change in the all body dimension or in parts and in specific segments, in respect to time, from the birth until the adult age. Objective: To analyze the sexual maturation by way of draft and pictures and corporeal mass in children and teens that practice football. Method: The study consists in domain research, with transversal character, done with 19 masculine people, between 10 and 16 years old, participating of the Football Sporting Association, in Aracaju (SE). To evaluate the sexual maturation stage, it was used the method described for Tanner, by way of self- examination protocol legitimized by Matsudo e Matsudo. Results: The pupil majority are classified in the stages P4 and P5 of maturation and the CMI $53 \%$ down, $42 \%$ ideal weight and 5\% excess weight. Conclusion: It is fundamental, then, doing periodically physical evaluation, phycology, physiologic and sociological, as with techniques abilities analysis, considering the maturation stage and the MCI to prescribe certainly and efficiently the training for this people.

Keywords: Body Mass Index; Soccer; Adolescent Health; Human Development.
\end{abstract}

\section{INTRODUCTION}

The evolution of the individual has characteristics that are repeated in all, but occurring at rates sometimes different and for various reasons (BÖHME, TEIXERA \& BOJIKIAN, 2005). Within this evolutionary period, puberty is the phase where it is easily possible to observe changes that will significantly affect life in adulthood (RÉ, TEIXERA, MASSA \& BÖHME, 2003).

These changes influence in such a way that the characteristics of strength and physical performance in sports or non-sports activities, within the school environment, can be easily observed (BÖHME, BOJIKIAN, MARTIN \& ARENA, 2001). The motor performance of young people in this phase, and the phenomena called growth spurts in height and weight, together with sexual maturation, can be understood and analyzed along with several aspects such as: body composition, growth and motor performance (BÖHME, BOJIKIAN, MARTIN \& ARENA, 2001).

From the perspective of Physical Education, it is important that the professional knows how to use maturational evolution tests to identify the characteristics of students and, based on the results and analyses, to work in the correct way for a good use of them within their biological age and age group (GUEDES, 2011). The most used evaluation methods to identify the level of biological maturation are: somatic evaluation, performed through the use of anthropometric measurements; skeletal maturation, dental

\footnotetext{
${ }^{1}$ Tiradentes University, Aracaju, Brazil

${ }^{2}$ Physical Education Degree, Tiradentes University, Aracaju, SE, BRAZIL.

${ }^{3}$ Academic in Physical Education Bachelor's Degree, Research Group in Gymnastics and Expressive Rhythmic Activities (GPGARE-LABIMH), Tiradentes University, Aracaju, SE, BRAZIL.

${ }^{4}$ Academic in Physical Education Bachelor's Degree, Research Group in Gymnastics and Expressive Rhythmic Activities (GPGARE-LABIMH), Tiradentes University, Aracaju, SE, BRAZIL.

${ }^{5}$ Master's Degree in Physical Education, Group of Research in Gymnastics and Expressive Rhythmic Activities, GPGARELABIMH, Tiradentes University, Aracaju, SE, BRAZIL.

* Corresponding Author: Physical Education Degree, Research Group in Gymnastics and Expressive Rhythmic Activities, GPGARE-LABIMH, Tiradentes University, Aracaju, SE, BRAZIL. E-mail:
} wallas.carlos@souunit.com.br 
maturation and sexual maturation (GUEDES, 2011).

The period of adolescence attracts the attention of researchers in the area of Physical Education and Sport, especially with regard to the biological changes of puberty. Thus, it is of fundamental importance the use of evaluation techniques that allow estimating the biological maturation of these individuals, in order to minimize this type of error of interpretation. These evaluation resources can help Physical Education and Sports professionals working with individuals who are at puberty (GUEDES, 2011).

By definition, growth corresponds to the process resulting from cell multiplication and differentiation that determines progressive changes in whole body dimensions or specific parts and segments, relative to the time factor, from birth to adulthood. On the other hand, development is characterized by the sequence of evolutionary changes in organs and systems of the human body that induce the improvement of its complex functions (ROCHE \& SUN, 2003). Thus, growth essentially refers to quantitative transformations, while development includes both quantitative and qualitative transformations and is the result of aspects associated with the process of physical growth, biological maturation and experiences in the following aspects: motor, emotional, social and cognitive performance, among others (ROCHE \& SUN, 2003).

In view of the above, this work aims to analyze sexual maturation through drawings and photos and the Body Mass Index (BMI) in children and adolescents practicing soccer in a Sports Association.

\section{METHODS}

This work consists of a cross-sectional field survey, carried out with 19 male subjects aged 1016 years, participants of the Sports Association registered in the Sergipe Soccer Federation, in Aracaju (SE), whose purpose is to promote the sport for children of a needy community.

For the evaluation of the stage of sexual maturation, the method described by Tanner (1962) was used through the self-evaluation protocol validated by Matsudo and Matsudo (1991).

\section{Tanner's stages}

1 Stage I (P1): Absence of pubic hair.

2 | Stage II (P2): Sparse growth of long, thin, discreetly curly hair along the base of the penis or large lips.

3 | Stage III (P3): More pigmented, thicker and curlier hair, extending into the pubic symphysis.

4 | Stage IV (P4): Adult-type hair, but in smaller amount than in adults.

5 | Stage V (P5): Hair in amount and type as in adults.

Prior to the beginning of the procedure, the subject entered a reserved room, where the characteristics that should be observed on the boards (photographs), the purpose and importance of the evaluation, and the guarantee of confidentiality of the results were explained. After the initial orientations, there was the presentation of boards and a card was delivered, in which the evaluated marked the number of the photograph that best represented his current stage of maturation. After evaluation, the participant was taken to a reserved place and had no contact with individuals who had not yet undergone the maturational test. This has prevented constraints and possible fraud in results. Weight and height were evaluated using electronic Welmy scale (Electronic of Welmy Indústria e Comércio, São Paulo - Brazil), with capacity of $300 \mathrm{~kg}$ and accuracy of $50 \mathrm{~g}$, and an anthropometric ruler coupled to the scale measuring between 1.00 and $2.00 \mathrm{~m}$ and accuracy of $0.1 \mathrm{~cm}$.

The answers were recorded by the examiner in a specific table with age, height, body mass index (BMI) and sexual maturation evaluation, as well as self-evaluation. For BMI, the criterion of classification for risk of overweight and thinness was used.

The Extension Board of Tiradentes University, Aracaju / SE approved this research as 
Extension Project. When selecting the sample, subjects aged less than 10 years and those above 16 years were excluded. Participation in evaluations was only performed after parents' or guardians' permission, through the signing of the Informed Consent Form (TCLE), the Clarified Assent Form (TAE) and the Clarified Institutional Form (TIE).

Data were tabulated and analyzed in the Microsoft Excel 2016 software through descriptive analysis (mean for classification of variables and frequency for prevalence).

\section{RESULTS}

Table 1 shows information on sex, age, body weight - BMI, Health risk and maturational stage in the development of pubic hair of students classified at P1 to P5 were presented, which characterized the sample selected for the study.

Table 1

Sample characteristics $(n=19)$

\begin{tabular}{ccccccc}
\hline Name & Sex & Age & Bmi & Classification & $\begin{array}{c}\text { Health } \\
\text { Risk }\end{array}$ & $\begin{array}{c}\text { Maturation } \\
\text { Stage }\end{array}$ \\
\hline$\# 1$ & M & 13 & 16.3 & low weight & high & P3 \\
$\# 2$ & M & 16 & 19.29 & ideal weight & absent & P5 \\
$\# 3$ & M & 10 & 14.11 & low weight & high & P2 \\
$\# 4$ & M & 13 & 17.24 & low weight & high & P4 \\
$\# 5$ & M & 14 & 20.06 & ideal weight & absent & P4 \\
$\# 6$ & M & 13 & 17.55 & low weight & high & P4 \\
$\# 7$ & M & 12 & 14.04 & low weight & high & P2 \\
$\# 8$ & M & 13 & 20.59 & ideal weight & absent & P4 \\
$\# 9$ & M & 14 & 20.52 & ideal weight & absent & P5 \\
$\# 10$ & M & 12 & 19.59 & ideal weight & absent & P4 \\
$\# 11$ & M & 14 & 15.11 & low weight & high & P3 \\
$\# 12$ & M & 10 & 14.7 & low weight & high & P1 \\
$\# 13$ & M & 16 & 20.75 & ideal weight & absent & P5 \\
$\# 14$ & M & 12 & 24.51 & ideal weight & absent & P3 \\
$\# 15$ & M & 10 & 15.54 & low weight & high & P1 \\
$\# 16$ & M & 14 & 16.17 & low weight & high & P4 \\
$\# 17$ & M & 14 & 28.8 & overweight & high & P4 \\
$\# 19$ & M & 14 & 18.71 & ideal weight & absent & P5 \\
\hline
\end{tabular}

BMI is recognized by the WHO (World Health Organization) as the main reference for the classification of weight ranges. People with BMI lower than 18.5 are classified as underweight; with BMI from 25 to 30 , as overweight and; with BMI above 30 , as obese. BMI considered as being adequate is from 18.5 to 25 . Figure 1 shows that, $53 \%$ of athletes were classified as BMI below the level considered ideal for their age and height.

This result can significantly contribute to the low performance of a student at the time of performing his sport activities and provide a high degree of risk to his health in general. Other consequences of this problem are: presentation of low bone mineral density values and small amount of muscular mass allied to a less impact with the ground during physical activities, which does not provide a healthy maintenance for dense bones.

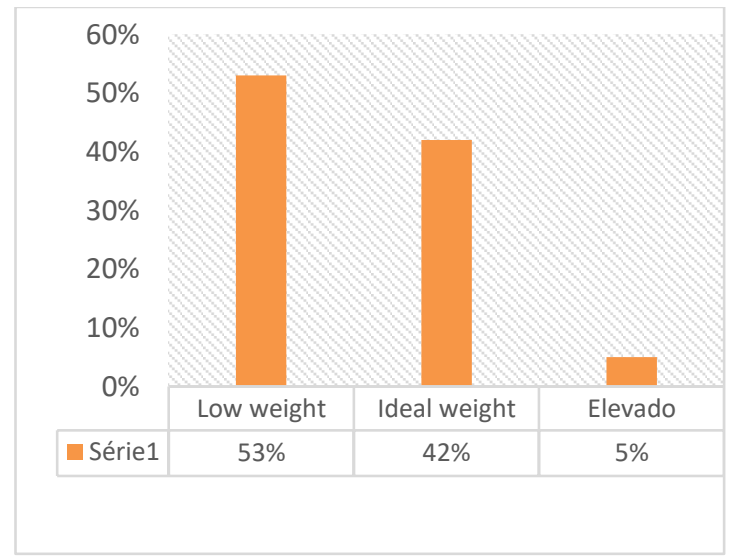

Figure 1. Body Mass Index 


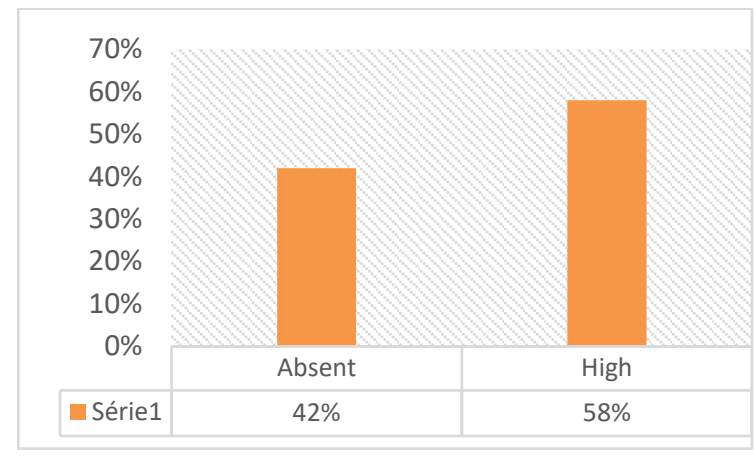

Figure 2. Health risk

Although athletes had BMI scores lower than desirable standards, the Association achieved a good performance in the championships in which it participated, exceeding expectations. The above-expected performance may have occurred due to the broad motor repertoire and the individual abilities of athletes, since only $42 \%$ of them, as shown in the chart, were within ideal body mass.

According to the acceptable BMI level, the majority of students, exactly $58 \%$, are in the high risk zone for their age group, as can be seen in Figure 2.

Thinness, when indicated by BMI, is a risk factor that shows that people generally are malnourished, have reduced immune resistance and are at high risk for respiratory, bone and infectious diseases. Overweight and obesity indicated by BMI are risk factors for diseases such as hypertension, coronary artery disease and diabetes, among other conditions considered to be of high risk for health.

It is worth mentioning that one should measure the BMI of children entering puberty with caution because the body is intelligent and at this stage, it accumulates more energy to aid growth. Therefore, before the growth spurt, girls aged 9-11 years and boys aged 10-15 years usually become fatter. This fat accumulation is normal in the development of children.

According to Figure 3, there is a prevalence of P4 and P5 stages, in which $33 \%$ of students are at P4 stage and $24 \%$ at P5, in which we can observe that most students are at the final stages of biological maturation.

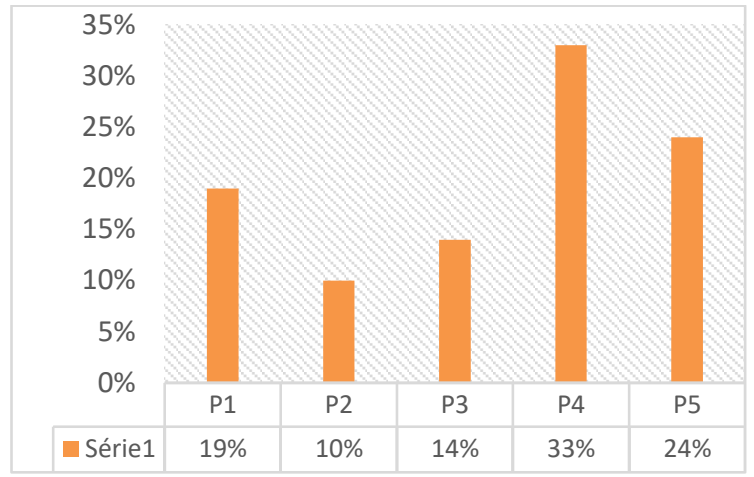

Figure 3. Maturation stages

\section{DISCUSSION}

One of the relevant points of this study is the data obtained on the BMI of athletes, where $53 \%$ are below ideal weight, $42 \%$ are ideal weight and $5 \%$ are overweight. It was also observed that $58 \%$ of individuals presented high risk to develop the aforementioned pathologies and $42 \%$ showed no risk, it is therefore necessary to reduce the problems that can lead to diseases related to obesity and thinness. Another important point is the classification of individuals at stages $\mathrm{P} 4$ and P5 of maturation, which characterizes that most are at the final stages of sexual maturation. The biological maturation rate together with the body mass index results in a great variability in the performance of sports practice.

In boys, the growth peak in height occurs around the age of 14 years, with great individual variations, being common its occurrence between the age of 12 and 16 years. Approximately six months after such an event, peak muscle gain occurs, which is directly related to the rise of the hormone testosterone in the body (Beunen et al., 1988; Rogol et al., 2002). This mass gain and maturation of muscle functions provide an increase in metabolic capacity, which in turn tends to increase strength, speed, and endurance indexes, especially if proper motor stimuli are worked (Jones, Hitchen, \& Stratton , 2000; Ré, Bojikian, Teixeira, \& Böhme, 2005; Stodden et al., 2008).

Thus, biological maturation has a great relationship with dexterity at the moment of physical and sports activity in adolescence and in later years, contributing to the formation of 
future athletes and to the health of the population in general.

According to Meylan et al. (2010) and Williams and Reilly (2000), studies have shown that elite young soccer players have higher biological age, that is, they are physically more mature than those who are not part of that group and, at the time of selection, students with momentary accelerated morphological growth are favored.

Mendez and Villanueva (2011) reported that the factors related to maturity influence the performance of soccer players. These effects of maturity on performance may be related to factors such as improvement of the neural function, greater rigidity of the musculature and increase of the testosterone concentration, among other hormones. There is a relationship between athletic performance and sexual maturation, including strength capacities. In boys, variations associated with maturation are more significant for 10-16 years (Figueiredo et al., 2009), that is, they are expressive when analyzed over a wide age range.

According to Pittoli et al. (2010) and Malina et al. (2004), within a chronological age group, boys with higher levels of maturational stage, when compared to others less mature, use their physical abilities better. This type of maturational characteristic, together with the specialization and sportivization of students, has a positive influence on their performance, since the specialization in sport can contribute to the improvement of the speed to make decisions during the sport activity, which in general requires accurate logical reasoning of practitioners.

The acquisition of motor abilities and capacities, as well as the improvement in sports performance, occurs due to the interactions between biological factors of the individual, being important to emphasize that this process can be determinant so that the quantity and quality of the stimuli present in that phase directly influence in development at later ages. In adolescence, the biological maturation rate, together with previous experiences, results in great variability in motor performance. Thus, in this age group, training programs should consider the factors mentioned above. Ideally, in the postpubertal period, adolescents should have an excellent coordinative pattern, so that, strength, speed and resistance training is prioritized, taking into account the specificity of a particular sports modality.

\section{CONCLUSION}

Based on the results of the present study, it could be concluded that the majority of students are classified at stages P4 and P5 of maturation and $53 \%$ have BMI corresponding to low weight, $42 \%$ to ideal weight and $5 \%$ to overweight. This means that in this category, there are pubertal and post-pubertal students and in boys, the P4 classification of pubic hair development predominates, which shows that in this Sports Association, students are at the final stages of pubertal development and almost reach adult maturation.

These results are a reflection of training and experience in soccer, since the high level of practice is a critical factor in the development and acquisition of specific motor skills, causing athletes to present good levels of ability, which is acquired during the time of practice of the athlete.

Physical, psychological, physiological and sociological assessments, as well as analyses of technical skills, should be carried out periodically, and the maturational stage and BMI should be taken into account in order to safely and efficiently prescribe training protocols for these individuals.

\section{Acknowledgments: \\ Nothing to declare}

\section{Conflict of interests:}

Nothing to declare

\section{Funding:}

Nothing to declare 


\section{REFERENCES}

Böhme, M.T.S.; Arena, S.S.; Kiss, M.A.P.D.M. (2013) Testes de campo em jovens atletas. In: Kiss, M.A.P.D.M (Orga.). Esporte e atividade física: avaliação e prescrição. São Paulo: Roca.

Böhme, M.T.S.; Bojikian, L.P.; Martin, R.H.C.; Uezu, R.; Massa, M.; Silva, L.R.R.; Parra, S.; Teixeira, C.P. (2003) Influência da maturação biológica associada ao crescimento físico, adiposidade subcutânea, muscularidade e treinamento sobre cada componente da aptidão Física de adolescentes do sexo feminino. In: congresso brasileiro do colégio brasileiro de ciências do esporte. 14., 2003, Caxambú. Anais. Caxambú: CBCE.

Böhme, M.T.S.; Bojikian, L.P.; Uezu, R.; Ré, A.H.N.; Sandoval, M.C. (2005) Growth and body composition of brazilian adolescents as a function of age, training, gender and time of measurement. In: annual congress of the european college of sport science, 10., 2005, Belgrado. Abstract Book... Belgrado: ECSS.

Guedes, D.P. (2011) Crescimento e desenvolvimento aplicado à Educação Física e ao Esporte. Revista. Brasileira de Educação. Física. 25(spe), 127-140.

Figueiredo, A. J., Gonçalves, C. E., Silva, M. J. C. \& Malina R.M. (2009) Characteristics of youth soccer players who drop out, persist and move up. Journal of Sports Sciences; 27(9), 883-91.

Linhares R. V, Matta M. O, Lima J. R, Dantas P. M, Costa M. B, Filho J. F. (2009) Effects of sexual maturation on body composition, dermatoglyphics, somatotype and basic physical qualities of adolescents. Arq Bras Endocrinol Metabol. 53(1), 47-54. .
Matta M.O. (2014) Morfologia, maturação biológica e aptidão física e técnica. Estudo em jovens futebolistas brasileiros. Porto: Horizonte.

Malina R.M. Bouchard C. (2002) Atividade física do atleta jovem: do crescimento à maturação. São Paulo: Roca.

Malina R.M. Eisenmann JC, Cumming SP, Ribeiro B, Aroso J. (2004) Maturity--associated variation in the growth and functional capacities ofyouth football (soccer) players 13-15 years. European Journalof Applied Physiology, 91 (5-6), 555-62.

Matsudo S., Matsudo V. (1991) Validade do auto avaliação na determinação da maturação sexual. Revista Brasileira de Ciência do Movimento, 5(2), 1835.

Mendez - Villanueva, A., Buchheit, M., Kuitunen, S. (2011) Age-related diferences in acceleration, maximum running speed, and repeated-sprint permormance in young soccer player. Journal of Sports Sciences. 29(5), 477-84.

Meylan, C., Croin, J., Oliver, J., \& Hughes, M. Talent identification in soccer: the role of maturity status on physical, physiological and technical characteristics. International Journal of Sports Science E Coaching; 29(5), 477-84.

Paoli P., Silva C., Soares A. (2008) Tendência atual da detecção, seleção e formação de talentos no futebol brasileiro. Revista Brasileira de Futebol, $01(2), 38-52$

Roche, A.F.; Sun, S.S. (2003) Human growth: assessment and interpretation. Cambridge: University Press.

Tanner JM. (1962) Growth at adolescent. 2ed. Oxford Blackwell Scientific.

All content of Journal Motricidade is licensed under Creative Commons, except when otherwise specified and in content retrieved from other bibliographic sources. 


\title{
Association of instruments of functional evaluation of the lumbar spine with the international classification of functioning, disability and health
}

\author{
Luana Caroline Dantas Pereira ${ }^{1 *}$, Saulo da Cunha Machado ${ }^{1}$, Mylena Maria Salgueiro \\ Santana ${ }^{2}$, Géssica Uruga Oliveira ${ }^{2}$, Luma Soares Lustosa ${ }^{1}$, Walderi Monteiro Da Silva \\ Júnior $^{3}$, Marzo Edir Da Silva Grigolleto ${ }^{4}$, Jader Pereira de Farias Neto ${ }^{3}$
}

\begin{abstract}
For evaluation of the lumbar spine dysfunctions, routinely utilize instruments little contacts among themselves, that little cover the overall concept of functionality. The aim was to establish an association between the theoretical aspects involved in the various instruments of evaluation of the lumbar spine and the categories and qualifiers of the International Classification of Functioning, Disability and Health (ICF). The items of the questionnaire were associated to the codes contained in the ICF price, as well as the levels of severity of the instruments with the qualifiers of ICF. The instruments used were: The Visual Analogue Scale of pain, Roland Morris Disability Questionnaire, Patient-Specific Functional Scale, Fear Avoidance Beliefs Questionnaire and Global Perceived Effect Scale. Next, the analysis of content, to survey the areas and categories of the ICF found inside of each instrument. The main items of the ICF related with the questionnaires were those related to mobility. Was not found, any item that could be associated with aspects of body structure and social aspects of ICF. Only one item of one of the questionnaires evaluated environmental factors. The assessment instruments selected point their ratings to aspects linked to mobility; yet, they do not cover all the biopsychosocial aspects of individuals with a disability related to lumbar spine.

Keywords: Lumbosacral region; low back pain; International Classification of Functioning, Disability and Health.
\end{abstract}

\section{INTRODUCTION}

The lumbar spine plays a vital role in sustaining loads resulting from body weight, muscle action and forces applied externally. This segment should be stable to keep the intervertebral anatomical relations and to allow the movement, besides protecting the adjacent structures (Almeida, Barbosa, Araujo, \& Braga, 2006).

The main complaint related to lumbar region is the pain associated with a tissue, actual or potential injury which etiology involves multiple risk factors. The pain in this segment is considered a major public health problem. It is the health condition that causes more years lived with disability, more than pathologies as diabetes, chronic obstructive pulmonary disease, depression, osteoarthritis, asthma, neck pain, among others (Global Burden of Diase Study, 2015).

This symptomatology is characterized by the reduction of ROM, muscle spasms, postural changes, reduction of muscle strength, and increasing of radiating or localized fatigue and pain (Dionne et al., 2008).

Since the low back pain is a biopsychosocial phenomenon, the differential diagnosis and evaluation are difficult and needs to be comprehensive (Delitto et al., 2012). In addition, there are validated and recommended

\footnotetext{
${ }^{1}$ Programa de Pós-Graduação em Educação Física, Universidade Federal de Sergipe, Brasil.

2 Programa de Pós-Graduação em Ciências da Saúde, Universidade Federal de Sergipe, Brasil.

${ }^{3}$ Departamento de Fisioterapia, Centro de Ciências Biológicas e da Saúde, Universidade Federal de Sergipe, São Cristóvão, Brasil.

${ }^{4}$ Departamento de Educação Física, Centro de Ciências Biológicas e da Saúde, Universidade Federal de Sergipe, São Cristóvão, Brasil.

* Corresponding author Email: luana_caroline12@hotmail.com
} 
instruments that are used for assessment of incapacity generated by the pain of the lumbar spine such as the Roland Morris Disability Questionnaire (RMDQ); the Patient Specific Functional Scale (PSFS); the Fear Avoidance Beliefs Questionnaire (FABQ), the Visual Analogue Scale (VAS); the Global Perceived Effect Scale (GPES); and others (Clement et al., 2015; DELITTO et al., 2012; Lewis et al., 2012; Kamper et al., 2010; Waddell, Newton, Henderson, Somerville \& Main, 1993).

Considering this biopsychosocial context, in 2001 the World Health Organization (WHO) adopted the International Classification of Functioning, Disability and Health (ICF) that incorporates the components of health in body and social levels. The evaluation of an individual with disabilities using the model proposed by this classification stands out from the biomedical model and expands the concept of health. It allows the professionals do the appropriate formulation for the relevant problems, the specific objectives, the identification of factors that cause and/or contribute to these problems, the planning of more appropriate interventions and a clearer vision of the functional picture of patients (Steiner, 2002). In addition, this classification provides a standardized language that enable the comparison of data between countries, services, health care sectors as well as the monitoring of the patient evolution (World Health Organization, 2001).

Aiming the easy application of the ICF, some instruments were created to summarize it as, for example, the 'Core Set' which can be defined as a set of categories of the ICF that describes the functionality of people in certain health conditions, such as low back pain, osteoporosis, gonarthrosis, among others (Riberto, 2011). Ibsen et al. (2016) observed in their study that the 'Core Set' prepared for low back pain presents low correlation with the RMDQ questionnaires, SF-36 and the pain scores. They conclude that there are limitations regarding the use of this instrument in this health condition. This reinforces the necessity of integration of different instruments in the process of evaluation of this population through the ICF for both a greater breadth of language and a more reliable overview of the functional framework of the individual.

With this in mind, the objectives of this study were to establish an theoretical association between the items of the lumbar spine functional evaluation instruments and the ICF, check the frequency of occurrence of the categories through a content analysis and establish a relationship between the qualifiers of this classification and the scores of the items of the instruments for determination of severity.

\section{METHOD}

It is a descriptive transversal study that follows the coding protocol proposed by Farias Neto et al. (2016) and it was performed in three stages: association of items of questionnaires to codes of ICF; content analysis; and determination of the severity assessed by the instruments from the qualifiers of ICF.

\section{Evaluation Instruments}

It has made a review in the databases Pubmed, Scielo and Bireme about the instruments considered the gold standard for evaluation of the lumbar spine, in respect to pain, psychosocial aspects, functionality and perception of their health condition.

\section{Assessment of pain}

The Visual Analogue Scale is a validated and recommended instrument for measuring pain in individuals with the most varied health conditions, including the low back pain (Clement et al., 2015). The patient is requested in order to measure the intensity of pain on a scale of 11 points, in which 0 indicates that there is no pain and 10 indicates the worst pain imaginable.

\section{Evaluation of functionality}

The questionnaire Roland Morris Disability Questionnaire (RMDQ) was proposed and validated by Roland \& Morris (1983), it was adapted to Brazil by Nusbaum et al., (2001), and it's recommended with strong level of evidence to identify changes in relation to the pain, function and disability in individuals with low back pain (Delitto et al., 2012). 
This instrument consists of 24 items with statements about the impact of the pain in daily life activities such as, for example, dress, climbing stairs, lifting, standing, eating, sleeping, cycling, among others. The interviewee should mark the items that represent his condition and the result is the number of items marked, and may vary from 0 (without disability) to 24 (severe disability).

The Patient Specific Functional Scale (PSFS) was developed by Stratford et al. (1995) to evaluate the functional incapacity and any changes in the performance of daily living activities of the patients suffering from clutter musculoskeletal. The PSFS is considered reliable and responsive in populations with chronic low back pain and acute and subacute conditions (Horn et al., 2012).

The interviewee is instructed to identify five activities or tasks of daily life that have difficulty or cannot perform. The degree of difficulty should be indicated by a scale ranging from 0 (unable to perform) to 10 (capable of performing the activity in a pre-injury level). A lower score indicates greater functional limitation.

\section{Evaluation of the psychosocial aspect}

The literature suggests that the fear, the beliefs and behaviors of avoidance are predictors for the development of chronic low back pain (George; Fritz \& Childs, 2008). As a form of assessment of these variables, it was developed the Fear Avoidance Beliefs Questionnaire (FABQ), which in turn is an assessment tool developed under cognitive behavioral models, translated and validated for Brazil, and commonly used for assessing individuals with chronic low back pain (Waddel et al., 1993; Abreu Faria, Cardoso \& Teixeira-Salmela, 2008). It is composed of 16 self-reported items, divided into two subscales: The FABQ-Work that addresses the fears and beliefs related to work and the FABQ-Phys that addresses the fears and beliefs related to physical activities. Among the items, statements such as "I can not perform physical activities that would make my pain worse", "My work can hurt my back" and "I shouldn't hold my normal work with my current pain" are made.
Each item is graded on a Likert scale of seven points, which varies from 0 (strongly disagree) to 6 (totally agree). In the isolated analysis of items, the numbers 13, 14 and 16 were considered redundant, and the numbers 1 and 8 showed a low correlation with the others (Waddel et al., 1993). In this way, these items were excluded from the sum of the final score, despite still being part of the questionnaire. It urges noted that the score must be obtained separately in each of the subscales, the score greater than 15 for physical activity and greater than 34 to work are powerful indicators for the belief of fear and avoidance for exercises and activities.

In addition, the individual's perception regarding their health condition and the treatment to which it is being submitted should be evaluated (Dworkin et al., 2005). For this reason, it was proposed Global Perceived Effect Scale (GPES) which consists of a scale of five points that varies from less than five points (much worse), zero (no change) and five points (completely recovered) whose reliability for evaluation of individuals with low back pain is considered high (Kamper et al., 2010).

The participants are asked in the following way for all the measures of the overall effect perceived: "Compared with the beginning of the episode, how do you describe your spine today?". Positive scores represent better recovery and negative scores indicate a worsening of symptoms.

International Classification of Functioning, Disability and Health (ICF)

The ICF is a classification of functionality and the conditions related to health, divided into two parts:

- Part 1: "Functionality and incapacity" that presents the following categories: "functions (b) and structures (s) of the body" and "Activity and Participation (d)".

- Part 2: "context factors" that presents the following category: "personal and environmental factors (e)".

This classification has an alphanumeric system in which the letters $b, s, d$ and $e$ are used to indicate Body Functions, Structures of the Body, Activity and Participation and 
Environmental Factors, respectively. These letters are followed by a numeric code that begins with the chapter number (one digit), followed by the second level (two digits) and the third and fourth levels (one digit each one).

In addition, there is a number separated from the code by a point called qualifier, which records the presence and degree of severity of a problem of functionality to the levels of the body, of the person and of the society (World Health Organization, 2001).

For the classifications of the function and structure of the body, the first qualifier indicates the presence of a disability according to a scale of five points (Table 1).

In the case of areas of Activity and Participation, there are two qualifiers, the first is related to performance (what the individual does in your environment) and the second refers to the capacity (the ability of the individual to perform a task or activity). In the field of Structures of the Body, a second qualifier will be used to indicates the extent of disability and a third indicating the nature of the same (World Health Organization, 2004).

Table 1

Qualifiers of ICF and percentage of corresponding limitation

\begin{tabular}{cccc}
\hline & No Disabilities & $\begin{array}{c}\text { (No, absent, } \\
\text { scarce...) }\end{array}$ & $0-4 \%$ \\
\hline xxx.1 & $\begin{array}{c}\text { Slight } \\
\text { Disabilities } \\
\text { Moderate }\end{array}$ & $($ Light, small...) & $5-24 \%$ \\
xxx.2 & Disabilities & $($ Mean...) & $25-49 \%$ \\
& Serious & (Large, & $50-95 \%$ \\
xxx.3 & Disabilities & extreme...) & $96-$ \\
& Complete & $100 \%$ \\
xxx.4 & Disabilities & \\
xxx.8 & Not specified & \\
xxx.9 & Not applicable & \\
\hline Source: (World Health Organization, 2001)
\end{tabular}

\section{Association of ICF with the assessment instruments}

The encodings of variables were carried out in a systematic way using the full document of ICF and the mobile app "Crefito Mobile Physio" respecting the ultimate goal of the results and the variables of each evaluation, using the methodology of the "linking rules" (Cieza et al., 2005).

Two evaluators conducted the encodings of all items and variables of each questionnaire individually and then the results were compared among themselves, in order to obtain a greater coding reliability. For the items in disagreements, a third reviewer was consulted with the purpose of deciding the most appropriate code.

Regarding the qualifiers, researchers have respected the percentages established by the ICF for each level of limitation (Table 1).

It is worth mentioning that for those instruments that do not have reference values for stratification, the classification was adapted considering $\mathrm{xxx} .0$ from ICF as a positive response, and xxx.4 as a negative response. In the questionnaire, the RMDQ positive response in terms of functionality is "no" to the inquiries. Since the ICF does not have a method of stratification of the total result, only the score of the items were coded and not the total score on the questionnaire.

\section{Analysis of the content of instruments}

The aim of this step was to analyze the frequency of occurrence of the terms contained in the ICF categories in accordance with the assessment instruments. For this, we carried out an approximation of the terms with the ICF code that had more similarity. The same researchers who established the codes association with the variables performed this procedure.

\section{Statistical analysis}

A descriptive analysis was performed for the variables in accordance with the ICF codes. In addition, quantify the frequency (\%) with which the codes were identified in the assessment tools.

\section{RESULTS}

The association between the "Visual analogue scale" and ICF, was established the component "back pain" (code b.28013), described as "an unpleasant sensation felt in the back which indicates actual or potential injury in some body structure including pain in the trunk and pain in the lumbar region".

The theoretical association of Roland Morris Disability Questionnaire (RMDQ) as well as the issues that composes it are presented in table 2. In Issue 8 "Because of my back, I try to get people to do things for me", two codes were used to describe 
the issue since "doing things for $m e "$ is something subjective.

In Issue 11 "Because of my back, I don't bend or squat", were adopted two codes since the ICF does not contain a unique code which covers "bend yourself" and "squat". In questions 15 and 18 were used the codes that most closely approximate the motion of the item since that the ICF does not have a specific code to "appetite" or "sleeping with the belly upwards." Already in item 23 "For the sake of my back, I climb stairs slowly than usual" was used only one code, however, the ICF does not include speed of climbing stairs.

Regarding the PSFS, it is known that the interviewee raises by himself the activities that implementation is hampered due to injury. In this way, it was not possible to establish the theoretical association of its items with the ICF.

Regarding the relation between the FABQ and ICF, it was observed that the ICF does not contemplate the relations established between the pain and physical activity or even pain and work. In view of it, the selected codes were that most closely approximate of the content of the questions as described in table 3.

In the theoretical association of Global Perceived Effect scale two codes were selected. The first is the b1568 that concerns the "functions of perception, others specified", which description of the category is "specific mental functions related to the recognition and interpretation of sensory stimuli." The second is the code b28013 that concerns the "back pain" already described earlier in the association of EVA.

The justification of the choice of these two codes is that the GPES affects the perception that the individual has about their health condition, the low back pain in this case.

The relationship between the assessment instruments discussed in this study and the qualifiers of ICF for the severity determination are presented in table 4 .

The obtained results with the content analysis showed that the higher frequency was of composite codes in the component "Disabled" (code $d 4$ ), which appeared 16 times (32.00\%); followed by the items present in the component "sensory and pain functions" (code B2), which appeared 15 times (30.00\%).

The component of "major areas of life" (code d8) which appeared nine times $(18,00 \%)$; the component of"self-care" (code d5), which appeared five times (10.00\%). The components of "functions of perception" (code B1), "Tasks and general requirements" (code $d 2$ ), "domestic life" (code d6), "Interactions and interpersonal relationships" (code d7) and "services, systems and policies" (code e5) appeared only once each $(2.00 \%)$ as shown in table 5 .

Table 2

Theoretical association of Roland Morris Disability Questionaire

\begin{tabular}{|c|c|c|}
\hline Question & $\begin{array}{l}\text { The ICF } \\
\text { Code }\end{array}$ & Description of the code \\
\hline Q1 & $\mathrm{d} 4601$ & $\begin{array}{l}\text { Move within buildings other than } \\
\text { the house itself }\end{array}$ \\
\hline Q2 & $\mathrm{d} 4159$ & $\begin{array}{l}\text { Maintain a position of the body, } \\
\text { not specified }\end{array}$ \\
\hline $\mathrm{Q} 3$ & $\mathrm{~d} 4508$ & Walk, another specified \\
\hline Q4 & d649 & $\begin{array}{l}\text { Domestic tasks, other specified } \\
\text { and not specified }\end{array}$ \\
\hline $\mathrm{Q} 5$ & $\mathrm{~d} 465$ & Move using any type of equipment \\
\hline Q6 & d4159 & $\begin{array}{l}\text { Maintain a position of the body, } \\
\text { not specified }\end{array}$ \\
\hline Q7 & $\mathrm{d} 4104$ & Put yourself in the foot \\
\hline Q8* & $\begin{array}{l}\mathrm{d} 599 \\
\mathrm{~d} 649\end{array}$ & $\begin{array}{l}\text { Self-care, Domestic tasks, other } \\
\text { specified and not specified }\end{array}$ \\
\hline Q9 & $\mathrm{d} 5409$ & Dress up, not specified \\
\hline Q10 & $\mathrm{d} 4154$ & Stand up \\
\hline Q11* & $\begin{array}{l}\mathrm{d} 4105 \\
\mathrm{~d} 4101\end{array}$ & $\begin{array}{l}\text { Bend yourself } \\
\text { Squat }\end{array}$ \\
\hline Q12 & $\mathrm{d} 4104$ & Put yourself in the foot \\
\hline Q13 & b2801 & Localized pain \\
\hline Q14 & $\mathrm{d} 4108$ & $\begin{array}{l}\text { Change the basic position of the } \\
\text { body, other specified }\end{array}$ \\
\hline Q15* & $\mathrm{d} 550$ & Eat \\
\hline Q16 & $\mathrm{d} 613$ & Shim \\
\hline Q17 & $\mathrm{d} 4501$ & Walk long distances \\
\hline Q18* & d4109 & $\begin{array}{l}\text { Change the basic position of the } \\
\text { body, not specified }\end{array}$ \\
\hline Q19 & $\mathrm{d} 5409$ & Dress up, not specified \\
\hline Q20 & $\mathrm{d} 4154$ & Stay standing \\
\hline Q21 & $\mathrm{d} 2101$ & Perform a complex task \\
\hline Q22 & d7202 & $\begin{array}{l}\text { Regulate the behaviors in } \\
\text { interactions }\end{array}$ \\
\hline Q23* & $\mathrm{d} 4551$ & Rise/Down \\
\hline Q24 & d44154 & Stand up \\
\hline
\end{tabular}

Legend: $\mathrm{Q}=$ Question of the RMDQ; $\left({ }^{*}\right)=$ The ICF does not contemplate the theme addressed the issue in a single code and, therefore, the closest to the same codes were listed. 
Table 3

Theoretical Association of the questionnaire FABQ

\begin{tabular}{|c|c|c|c|}
\hline & Question & The ICF Code & Description of the code \\
\hline & 1. My pain was caused by physical activity & b28013 & Back pain \\
\hline & 2. The physical activity makes my pain worse & DL8013 & \\
\hline & 3. Physical activity can affect my back & * & $*$ \\
\hline & $\begin{array}{l}\text { 4. I should not perform physical activities that } \\
\text { could make my pain worse }\end{array}$ & & \\
\hline & $\begin{array}{l}\text { 5. I can't perform physical activities that could } \\
\text { make my pain worse }\end{array}$ & b28013 & Back pain \\
\hline & 6. My pain was caused by my work or by an & b28013 & $\begin{array}{l}\text { Back pain } \\
\end{array}$ \\
\hline & 7. My work has aggravated my pain & d859 & $\begin{array}{l}\text { JoD and Employment, otner specined or } \\
\text { not specified }\end{array}$ \\
\hline & 8. I have a pension claim by virtue of my pain & e5750 & $\begin{array}{c}\begin{array}{c}\text { Services related to social support in } \\
\text { general }\end{array} \\
\end{array}$ \\
\hline & 9. My work is very heavy for me & d859 & $\begin{array}{l}\text { Job and Employment, other specified or } \\
\text { not specified }\end{array}$ \\
\hline & 10. My work is or could make my pain worse & & \\
\hline & 11. My work can hurt my back & & \\
\hline & $\begin{array}{l}12 \text { I shouldn't do my normal job with my current } \\
\text { pain }\end{array}$ & b28013 & $\begin{array}{c}\text { Back pain } \\
\end{array}$ \\
\hline & $\begin{array}{l}\text { 13. I can't perform my normal work with my } \\
\text { current pain }\end{array}$ & d859 & not specified \\
\hline & $\begin{array}{l}\text { 14. I can't perform my normal work until my pain } \\
\text { is treated }\end{array}$ & & \\
\hline & $\begin{array}{l}\text { 15. I don't think I will be back to normal work } \\
\text { within three months }\end{array}$ & & $\begin{array}{l}\text { Keep a job, perform the tasks related to } \\
\text { the work to maintain an occupation, }\end{array}$ \\
\hline & $\begin{array}{l}\text { 16. I don't think that someday I'll be able to } \\
\text { return to my job }\end{array}$ & d8451 & $\begin{array}{c}\text { business, profession or another form of } \\
\text { employment }\end{array}$ \\
\hline
\end{tabular}

Legend: $\left(^{*}\right)=$ The ICF does not address the issue raised in the question.

Table 4

Association between the qualifiers of the ICF with the variables of assessment

\begin{tabular}{cccccc}
\hline Qualifier & VAS & RMDQ & PSFS & FABQ & GPES \\
\hline $\mathbf{0}$ & 0 & Do not & 10 & 0 & 5 \\
$\mathbf{1}$ & 1 and 2 & & 6 to 9 & 1 & 4 to 1 \\
$\mathbf{2}$ & 3 to 5 & & 3 to 5 & 2 & 0 to -2 \\
$\mathbf{3}$ & 6 to 9 & & 1 and 2 & 3 to 5 & -3 and -4 \\
$\mathbf{4}$ & 10 & Yes & 0 & 6 & -5 \\
\hline
\end{tabular}

Legend: VAS = Visual Analogue Scale; PSFS = Patient Specific Functional Scale; RMDQ = Roland Morris Disability; FABQ = Fear Avoidance Beliefs Questionnaire; GPES $=$ Global Perceived Effect Scale.

\section{DISCUSSION}

The objective of this study was to establish an association between theoretical instruments for lumbar spine functional evaluation and the ICF, check the frequency of occurrence of the categories through a content analysis and establish a relationship between the qualifiers of this classification and the scores of instruments for determination of severity.

In faced of the need to study the functionality from the ICF and the complexity of using the codes and aspects discussed there, the number of studies that have aimed to establish the association between evaluation instruments and classification has been increasing in several clinical groups. Among them, we can cite elderly individuals, with AVE sequelae and temporomandibular disorders (Coelho de Morais, Silva, Corrêa, Laurentino and TeixeiraPrincipe, 2012; Farias Neto, Souza, Machado, Santana \& Silva-Grigoletto, 2016; Albuquerque de Oliveira et al., 2017).

In the theoretical association proposed in this study, both in the RMDQ and FABQ and GPES there were items that the ICF does not contemplate, a fact which prevented the use of only one code for association and culminated in the choice of those it more approached. The relationship between pain and work or physical activity, and the relationship between perception and the health condition are examples of items for which it was established more than one code. 
Table 5

Analysis of the content of instruments of evaluation of individuals with low back pain

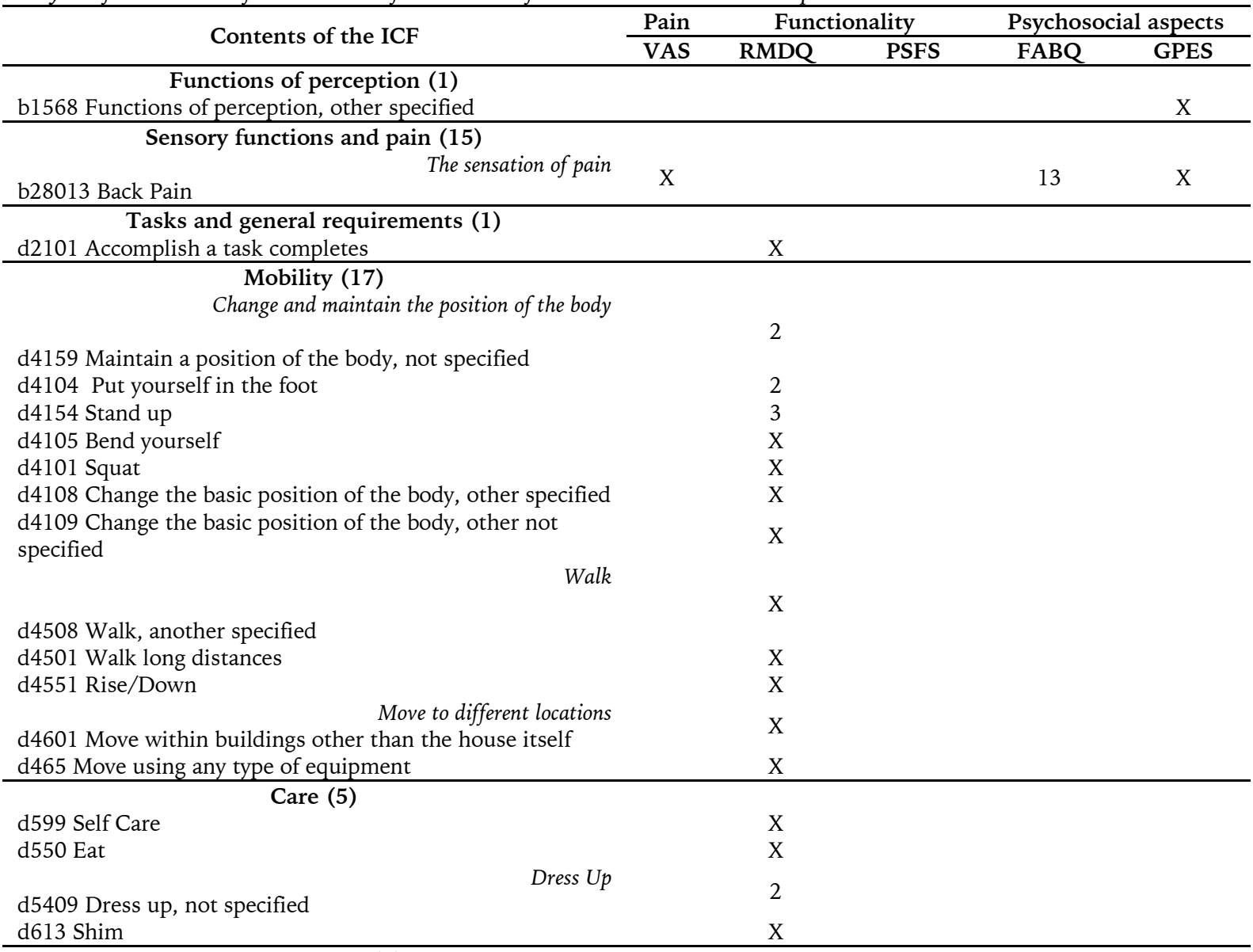
d613 Shim

\section{Domestic life (1)}

d649 Domestic tasks, other specified and not specified

Housework $\quad \mathrm{X}$

Interactions and interpersonal rel
7202 Regulate behaviors in interactions Main areas of life (9)

d8451 Keep a job

Job and Employment

d859 Job and Employment, other specified and not specified

$\mathrm{X}$

Services, systems and policies (1)

e5750 Services related with social support in general

$\mathrm{X}$

Legend: VAS = Visual Analogue Scale; PSFS = Patient Specific Functional Scale; RMDQ = Roland Morris Disability; FABQ = Fear Avoidance Beliefs Questionnaire; GPES = Global Perceived Effect Scale.

Only one question of the FABQ was not possible to establish the association with ICF because the codes that establish the discriminated relationship of the item were not identified. Albuquerque de Oliveira et al (2017) conducted a similar study for association between the categories of ICF, and the items of Research Diagnostic Criteria for Temporomandibular Joint Disorders (RDC/TMD) and observed that some codes of classification feature a certain variety for a same condition and others have become so comprehensive. This justifies the necessity to use more than one code performed in the present study as a way to enable the assessment of the relationship between variables through the ICF. Nicol, Robinson Nicol, Hopfe \& Newell (2015) proposed in their study an association between Bournemouth Questionnaire for low back pain and the ICF. From the results observed, it was suggested that the association between this evaluation instrument and the International Classification of Functionality enables both a comparison with other tools as a clearer understanding of the content addressed in them. 
The content analysis based on the ICF provides information about the concepts covered and enables the selection of the most appropriate tool for a given health condition, mapping important biopsychosocial concepts (NICOL et al., 2015). In the present study, the content analysis highlighted the prevalence of domains related to "Mobility" (code $d 4$ ), "sensory functions and pain" (code B2) and "major areas of life" (code d8) which corroborates with the study of Ibsen, SchiÃ, ttz-Christensen, Melchiorsen, Nielsen \& Maribo (2016), in which the pain and functional limitation were considered the main manifestations in individuals with low back pain.

According to the World Health Organization (2001), the functionality is defined as a result not only of individuals' health/disease but also in the context of the physical and social environment, of the different cultural perceptions, the availability of services and legislation. That is, the functionality encompasses functions of organs or systems and structures of the body, limitations of activities and social participation. From the content analysis it was possible to observe that the instruments selected for this study did not include the aspect of body structure and only one item proposed to assess environmental factors.

Weigl et al. (2008) observed that there is an import role of environmental factors on the functionality of patients with lumbago, often acting as risk factors for chronicity of symptoms, such as the family and interpersonal relationships, for example. In this way, the instruments that assess functional aspects related to low back pain should contemplate the environmental and social aspects to be performed a complete evaluation and the decision-making be appropriate to the actual proportion of functional impact of the disease. Urges emphasized that the present study proposed a determination of severity assessed by the instruments to the qualifiers of the International Classification of Functionality based on the percentages proposed by the classification.

Second Stier-jarmer, Cieza, Borchers \& Stucki (2009), the qualifiers operationalization can contribute to the management of health based on the classification since it promotes a universal understanding about the multidisciplinary rehabilitation. In addition, since the ICF is a neutral classification, qualifiers give meaning to the impact of the disease on a specific category (Sabino, Coelho \& Sampaio, 2008). In this way, it is possible to observe more clearly the functional framework and the patient's evolution over time and the effectiveness of interventions.

\section{Limitations}

Among the limitations of this study, it is the amount of instruments used for the analysis of content. It is suggested that other instruments recommended by the scientific community, to evaluate this population, should be associated with the ICF as a way to increase the scope of the concept of functionality, in accordance with what is proposed by the WHO.

\section{CONCLUSION}

It is concluded that the evaluation of individuals with low back pain, using the instruments recommended by the literature in this population, is more related to mobility, pain and major areas of life. Before the impact of physical, psychological and social health condition it is expected that it implies functional limitations and present impact on key areas of life including working life.

In addition, the categories content analysis included in these instruments reveals the necessity to incorporate in to assessment items related to structural and environmental factors in order to make it more complete.

\section{Acknowledgments:}

Nothing to declare

\section{Conflict of interests:}

Nothing to declare

\section{Funding:}

Nothing to declare

\section{REFERENCES}

Abreu, A., Faria, C., Cardoso, S., \& teixeira-salmela, L. (2008). The Brazilian version of the Fear Avoidance Beliefs Questionnaire. Cadernos de Saúde Pública, 24(3), 615-623. http://dx.doi.org/10.1590/s0102$311 \times 2008000300015$. 
Albuquerque de Oliveira, F., Conrado da Silva, V., Elpídio de Sá, F., Oliveira Brazil de Araújo, A. Leo Almeida, G., \& Viana-Cardoso, K. (2017). Proposal for use of the International Classification of Functioning, Disability and Health in the evaluation of the temporomandibular

dysfunction. Physiotherapy Brazil, 18(3), 294-305.

Almeida. (2006). Thoraco-lumbar fascia and active lumbar stabilization mechanism relation. Revista Brasileira de Ciência e Movement, 14(3), 105-112.

Barros, S. Angelo, R., \& Uchôa, yeah. (2011). Occupational back pain and the sitting posture. Pain Magazine, 12(3), Chatou. http://dx.doi.org/10.1590/s180600132011000300006

Cieza, A., Geyh, S., Chatterji, S., Kostanjsek, N., Üstün, B., \& Stucki, G. (2005). ICF linking rules: an update based on lessons learned. Journal of Rehabilitation Medicine, 37(4), 212-218.

Http://dx.doi.org/10.1080/1650197051004026 3

Clement, R., Welander, A. Stowell, C., Cha, T., Chen, J., \& Davies, M. et al. (2015). The proposed set of metrics for standardized outcome reporting in the management of low back pain. Acta Orthopaedica, 86(5), 523-533. http://dx.doi.org/10.3109/17453674.2015.1036 696

Coelho de Morais Faria, C., Silva, S., Ferrari Corrêa, J., Mutton Laurentino, G., \& fuscaldi teixeirasalmela, L. (2012). Identification of ICF participation categories in quality-of-life instruments utilized in cerebrovascular accident victims. Revista Panamericana de Salud Pública, 31( 4). http://dx.doi.org/doi:10.1590/S102049892012000400011

Delitto, A., George, S. Van Dillen, L., Whitman, J., Sowa, G., \& shekelle, P. et al. (2012). Low Back Pain. Journal of Orthopaedic and Sports Physical Therapy, 42(4), A1-A57. http://dx.doi.org/10.2519/jospt.2012.42.4.a1

Dionne, C., Dunn, K., Croft, P., Nachemson, A., Buchbinder, R., \& Walker, B. et al. (2008). The Consensus approach toward the standardization of Back Pain Definitions for use in Validation Studies. Spine, 33(1), 95-103. http://dx.doi.org/10.1097/brs.0b013e31815e7f 94

Dionne, C., Dunn, K., Croft, P., Nachemson, A., Buchbinder, R., \& Walker, B. et al. (2008). The Consensus approach toward the standardization of Back Pain Definitions for use in Validation Studies. Spine, 33(1), 95-103. http://dx.doi.org/10.1097/brs.0b013e31815e7f 94

Dworkin, R., Turk, D., Farrar, J., Haythornthwaite, J., Jensen, M., \& Katz, N. et al. (2005). Core outcome measures for chronic pain clinical trials: Immpact recommendations. Pain, 113(1), 9-19. http://dx.doi.org/10.1016/j.pain.2004.09.012
Farias Neto, J., Souza, E., Machado, S., Santana, M., \& Silva-Grigoletto, M. (2016). Association of function, health and disability with functional evaluation in the elderly in two different types of training. Drivability, 12(2).

Farias, N., \& buchalla, C. (2005). The International Classification of Functioning, Disability and Health of the World Health Organization: concepts, uses and perspectives. Revista Brasileira de Epidemiologia, 8(2), 187-193. http://dx.doi.org/10.1590/s1415$790 \times 2005000200011$

Global Burden ofF Disease Study. (2015). Global, regional, and national incidence, prevalence, and years lived with disability is 301 acute and chronic diseases and injuries in 188 countries, 1990-2013: a systematic analysis for the Global Burden of Disease Study 2013. Lancet, 386(99995), 743-800.

Horn, K., Jennings, S., Richardson, G., van Vliet, D., Hefford, C., \& Abbott, J. (2012). The patientspecific Functional Scale: PSYCHOMETRICS, Clinimetrics, and Application to Clinical Outcome Measure. Journal of Orthopaedic and Sports Physical Therapy, 42(1), 30-D17. http://dx.doi.org/10.2519/jospt.2012.3727

Ibsen, C., SchiÃ'Ttz-Christensen, B., Melchiorsen, H., Nielsen, C., \& markaryd, T. (2016). The patientreported Outcome Measures describe functioning in patients with low back pain, using the Brief International Classification of Functioning, Disability and Health Core Set the reference?. Journal of Rehabilitation

Medicine, 48(7),

618-624. http://dx.doi.org/10.2340/16501977-2100

Kamper, S., Ostelo, R., Knol, D., Maher, C., Vet, H., \& Hancock, M. (2010). Global Perceived Effect scales provided reliable assessments of health transition in people with musculoskeletal disorders, but ratings are strongly by current status. Journal of Clinical Epidemiology, 63(7), 760766.e1 http://dx.doi.org/10.1016/j.jclinepi.2009.09.009

Nicol, R., Robinson Nicol, M., Hopfe, M., \& Newell, D. (2015). Linking the Bournemouth Questionnaire for low back pain to the International Classification of Functioning, Disability and Health. Disability and Rehabilitation, 38(11) 10891096.

http://dx.doi.org/10.3109/09638288.2015.1090 484

Nusbaum, L., Natour, J., Ferraz, M., \& Goldenberg, J. (2001). Translation, adaptation and validation of the Roland-Morris Roland-Morris questionnaire - Brazil. Brazilian Journal of Medical and Biological Research 34(2), 203-210. http://dx.doi.org/10.1590/s0100$879 \times 2001000200007$

Pereira, N, Ferreira, L., \& Pereira, W. (2010). Effectiveness of segmental Stabilization exercises on chronic lumbar pain posturalmechanical. Physiotherapy In Motion, 23(4), 605- 
614.

http://dx.doi.org/10.1590/s010351502010000400011

Riberto, M. (2011). Core sets of the International Classification of Functioning, Disability and Health. Revista Brasileira de Enfermagem, 64(5), 938-946. http://dx.doi.org/10.1590/s003471672011000500021

Roland, M., \& Morris, R. (1983). A Study of the Natural History of Low-Back Pain. Spine, 8(2), 145-150. http://dx.doi.org/10.1097/00007632198303000-00005

Sabino, G., Rabbit, C., \& Sampaio, R. (2007). The use of the International Classification of Functioning, Disability and Health in the physical therapy assessment of individuals with musculoskeletal disorders of the lower limbs and lumbar region. Acta Fisiátrica, 15(1), 24-30.

Steiner, W. (2002). Use of the ICF Model as a Clinical Problem-Solving Tool in Physical Therapy and Rehabilitation Medicine. Physical Therapy. http://dx.doi.org/10.1093/ptj/82.11.1098

Stier-Jarmer, M., Cieza, A., Borchers, M., \& Stucki, G. (2009). How to Apply the ICF and ICF Core Sets for Low Back Pain. The Clinical Journal Of Pain, 25(1), 29-38. http://dx.doi.org/10.1097/ajp.0b013e31817bcc 78

Stratford, P. (1995). Assessing disability and Change on Individual Patients: A Report of a Patient Specific Measure. Physiotherapy Canada, 47(4), 258-263. http://dx.doi.org/10.3138/ptc.47.4.258

Waddell, G., Newton, M., Henderson, I., Somerville, D., \& Main, C. (1993). The Fear-Avoidance Beliefs Questionnaire (FABQ) and the role of fear-avoidance beliefs in chronic low back pain and disability. Pain, 52(2), 157-168. http://dx.doi.org/10.1016/03043959(93) $90127-b$

Weigl. (2008). Determinants of disability in chronic musculoskeletal health conditions: a literature review. European Journal of Physical And Rehabilitation Medicine, 1(44), 67-79.

World Health Organization (2001). International Classification of Functioning, Disability and Health: ICF. World Health Organization.

World Health Organization (2005). The WHO Family of International Classifications. World Health Organization. 


\title{
Relationship between personality and pre-competitive cortisol level in bodybuilding athletes
}

\author{
Licia Cerqueira Ferreira', Felipe J. Aidar1,2,3,4,5, Dihogo Gama de Matos ${ }^{1,4^{*}}$, Mauro Lucio \\ Mazini Filho ${ }^{6}$, Gabriela Rezende de Oliveira Venturini ${ }^{7}$, Nelson Sousa ${ }^{1,8}$
}

\begin{abstract}
Objective: To correlate personality indicators with pre-competitive Cortisol levels in male bodybuilding athletes. Methods: Participated in the study 12 federated athletes, aged between 20 and 35 years. The questionnaire, Factorial Personality Inventory (IFP) was used and it was applied during the weigh-in for the Paraense Championship of Bodybuilding and Fitness of 2015. Cortisol was collected and analyzed through the Coat-A-Count kit (DPCMedlab®, Brazil). Cortisol collection used venous blood, which remained at rest for 30 minutes at room temperature for coagulation. Thereafter, the blood was centrifuged for 10 minutes at $800 \mathrm{rcf}$ (relative centrifugal force) for serum separation. Biochemical measurements were performed by the Vitros ${ }^{\circledR} 5600$ film system (Ortho-Clinical Dianostics, Johnson \& Johnson Company, Rochester, NY, USA). The statistical treatment was performed using the Statistical Package for Social Science (SPSS), version 22.0. Results: There was a high correlation between cortisol and exposure (0.669) and performance (0.742) and an intermediate correlation between cortisol and persistence (0.539), cuddle (0.553) and intraception (0.544), in the other items the correlation was low. Conclusion: The correlation of personality and cortisol, tends to help in the control of the emotional and hormonal state favorable to the performance of the athlete.

Key-words: Personality, cortisol, bodybuilding athletes.
\end{abstract}

\section{INTRODUCTION}

The personality has been the subject of many studies, according to Samulski (2002), several theories of motivation that can influence the practice of physical activity and sports of the athletes. The personality would be the integration of these parts that interacting, tends to form the whole (Rey \& Martinez, 1989). According to Allport (Pervin \& John, 2004), there are personality traits that express a marked disposition in a person's life and that influence all the actions performed by him.

On the other hand, other studies have evaluated the presence of some hormones as indicators of stress, where cortisol plays an important role in the electrolyte balance and metabolism of carbohydrates, proteins and lipids and has a potent anti-inflammatory effect (Goldfien, 1998) an indicator of inflammatory response (Kraemer and Ratames, 2005; Mastorakos, Pavlatou, Diamanti-Kandarakis, Chrousos, 2005).

In this sense, some studies have referred to the anxiety presented by bodybuilding athletes in the moment before the competition, and it was shown that this moment provided additional anxiety to this population (Ferreira, Novaes, Rodrigues Neto, Costa Silva, Aidar \& Sousa,

\footnotetext{
${ }^{1}$ Department of Sports Science, Exercise and Health of the Trás-os-Montes e Alto Douro University, Vila Real, Portugal

${ }^{2}$ Department of Physical Education, Federal University of Sergipe, São Cristóvão, Sergipe, Brazil

${ }^{3}$ Graduate Program in Master's level in Physical Education, Federal University of Sergipe, UFS, São Cristovão, Sergipe, Brazil

${ }^{4}$ Group of Studies and Research of Performance, Sport, Health and Paralympic Sports, GEPEPS, the Federal University of Sergipe - UFS, São Cristovão, Sergipe, Brazil

${ }^{5}$ Graduate Program in Master and Doctorate's level in Physiological Science, Federal University of Sergipe, UFS, São Cristovão, Sergipe, Brazil

${ }^{6}$ Graduate Program in Master and Doctorate's level in Physical Education, Federal University of Juiz de Fora, UFJF, Juiz de Fora, Minas Gerais, Brazil.

${ }^{7}$ Graduate Program in Master's level in Exercise Science and Sports, State University of Rio de Janeiro, UERJ, Rio de Janeiro, Rio de Janeiro, Brazil.

${ }^{8}$ Research Center in Sports Sciences, Health Sciences \& Human Development, CIDESD, Vila Real, Portugal

*Corresponding author: Dihogo Gama de Matos, Department of Sports Science, Exercise and Health of the Trás-osMontes e Alto Douro University, Vila Real, Portugal. E-mail: dihogogmc@hotmail.com
} 
2015). However, there are few studies that have evaluated the relationship between personality and pre competitive cortisol levels in athleticism. In this sense, the present study aimed to correlate the personality indicators with the levels of Cortisol, pre competitive, in athletes of bodybuilding collected a day before the Paraense Championship of Bodybuilding and Fitness 2015, in the act of weighing the athletes.

\section{METHODS}

\section{Sample}

The sample consisted of 25 athletes, however, during the collections there were 12 subjects, aged between 20 and 35 years. Only federated athletes who provided informed consent were included in the study. The adopted procedures followed the norms of ethics in researches with human according to the resolution $\mathrm{n}^{\circ} 466$, of $12 / 12 / 2012$ of the National Council of Health, normative of research involving human beings, in agreement with the ethical principles contained in Declaration of Helsinki ( 1964, reformulated in 1975, 1983, 1989, 1996, 2000 and 2008) of the World Medical Association. The research project was approved by the Ethics Committee of the State University of Pará, as protocol CAAE: 0007.0.412.000-10.

\section{Instruments}

\section{Factorial Personality Inventory (IPF)}

The Factorial Personality Inventory (FPI) is based on the assumption of Murray's Basic Needs Theory, and presents some conceptual differences, since it considers that people have several needs, which function as important elements in motivational processes, since they mediate acts and behaviors throughout the life, referring to the readiness or the facility of each individual to react of certain form to specific situations (Murray, 1962). These psychological reasons would be expressed through 15 needs (Assistance, Intraception, Cuddling, Deference, Affiliation, Denial, Denial, Performance, Display, Aggression, Order, Persistence, Change, Autonomy and Heterosexuality) evaluated in Brazil through an instrument with a long tradition of use FPI (Pasquali, Azevedo, \& Ghesti, 1997).

Thus, the Factorial Personality Inventory (Pasquali et al., 1997), is an objective inventory of personality, based on Murray's basic needs theory, composed of 135 items, aimed at evaluating the normal individual (not being advised for use in Intraception, Cuddling, Deference, Affiliation, Dominance, Denial, Performance, Display, Aggression, Order, Persistence, Change, Autonomy, and Heterosexuality. In addition to the cited dimensions, the test has a social desirability scale (12 items) and a lie or validity scale (8 items), so that in all, the test contains 155 items, which must be answered within one a Likert-type scale composed of seven points. The FPI is composed of 15 Personality Traits, using a Likert scale, consisting of seven points, ranging from one (1) $=$ None characteristic to seven $(7)=$ Totally characteristic. Each Personality Trait includes nine statements making up a range of variability of scale type ratio from zero (0) to sixty-three (63).

Murray (1962) developed a list of needs that characterize the personality of an individual, as described:

Assistance - Show great desires and feelings of pity, compassion and tenderness, need to give solidarity to helpless, helpless people; give emotional support and comfort in sadness, illness and other misfortunes.

Intraception - Let yourself be led by diffuse feelings and inclinations. Be dominated by the pursuit of happiness, fantasy and imagination. At a higher stage, conceptualize facts of inner life and make judgments, sometimes without paying attention to the concrete facts. To judge the other by his real or supposed intentions, not so much by the acts in itself, taking immediately attitudes of affection or rejection.

Cuddling - Seeking support and protection. Expect to have your wishes satisfied by loved ones. Desiring to be caressed, supported, protected, loved, oriented, forgiven and comforted. Constantly need someone who understands 
and protects you. Feelings of anxiety, abandonment, insecurity and despair.

Deference - To have as main characteristics: respect, admiration and reverence. Express the desire to admire and support a superior; like to praise and honor their superiors, as well as imitate and obey them.

Affiliation - Desire to give and receive affections. Have characteristics like: trust, goodwill, love, attachment and loyalty to friends.

Dominance - Express feelings of self-confidence and a desire to control others, influence or direct the behavior of others through suggestion, seduction, persuasion, and command.

Denial - Surrender to resignation. To submit to submission and the passive surrender of external forces, to accept disgrace, punishment and guilt; resign themselves to fate, admit inferiority, error and failure; confessing mistakes and desiring selfdestruction, pain, punishment, disease and disgrace.

Performance - Be ambitious and committed; expressing the desire to accomplish something difficult, such as mastering, manipulating and organizing objects, people and ideas. Like to do things independently and as quickly as possible, stand out, overcome obstacles and maintain high standards of achievement.

Display - Be conceited, express the desire to impress, be heard and seen. Like to fascinate people and even shock them; enjoy dramatizing the facts to impress and entertain.

Aggression - The main characteristics are: anger, anger and hatred; express the desire to overcome with vigor and opposition. Like to fight, to fight, to attack and to insult others, to censor and ridicule.

Order - The main features are: order, cleanliness, organization, balance and precision.

Persistence - Finish any started task, however difficult it may seem. Being obsessed with seeing the end result of a job, forgetting the time and rest needed, occurring complaints about insufficient time, tiredness and worries.
Change - Want to get away from everything that is routine and fixed. Enjoy novelty, adventure, not having permanent connection with places, objects or people, change habits, places and food.

Autonomy - Tend to feel free, get out of confinement, resist coercion and opposition. Not liking to perform tasks imposed by authority, acting independently and free, following their impulses. Challenge conventions.

Heterosexuality - Desire to have sexual and romantic relationships with individuals of the opposite sex. The higher the score, the greater the fascination for sex and related matters.

\section{Cotisol concentration}

In order to determine plasma cortisol concentration the commercial kit Cortisol CoatA-Count (DPCMedlab ${ }^{\circledR}$, Brazil) was used. This is a solid phase radioimmunoassay procedure in which a gamma counter, Automatic Gamma Counter Wallac Wizard from Perkin Elmer (Waltham, USA) was used.

\section{Procedures}

The data collection was based on Barbacena and Grisi (2008) and was performed about 24 hours before the 2015 Para-Bodybuilding and Fitness Championship, Pará/Brazil, between the hours of 16 and 18 hours the day before the competition for occasion of weighing in male athletes. During the technical congress the authorization was obtained and the explanations were made about the procedures and during the weighing the athletes were called for the blood to be collected and the questionnaire filled out.

The questionnaire was completed by an evaluator with a minimum of 20 applications and an intra-rater correlation higher than 0.954. Data collection was completed in same place where the competition occurred. The chairs were available to the athletes so they could fill out the questionnaire. Any questions they might have were answered, and the length of time to complete the was about 15 minutes. 
Cortisol collection was performed using venous blood, which remained at rest for 30 minutes at room temperature for coagulation. Thereafter, the blood was centrifuged for 10 minutes at $800 \mathrm{rcf}$ (relative centrifugal force) for serum separation. Biochemical measurements were performed using the Vitros ${ }^{\circledR} 5600$ film system (Ortho-Clinical Dianostics, Johnson \& Johnson Company, Rochester, NY, USA).

\section{Statistics}

The statistical treatment was performed using the Statistical Package for Social Science (SPSS), version 22.0. The central tendency measures, mean \pm standard deviation $(X \pm S D)$, were used. To verify the normality of the variables, the Shapiro Wilk test was used, considering the sample size. To verify the possible differences between groups divided by age group, the ANOVA (one-way) test, Bonferroni's Post Hoc, was used for the CSAI-2 indicators. In order to verify the size of the effect, the Cohen $\mathrm{f} 2$ test was used, in addition to the cut points 0.02 to 0.15 with small effect, from 0.15 to 0.35 as median and greater than 0, 35 large ones (Grissom and Kim 2005). Pearson's $r$ was used to verify the correlations, and a $\mathrm{p}<0.05$ was considered.

Table 1

Correlation between Personality indicators through FPI and pre-competition cortisol levels (mean \pm standard deviation)

\begin{tabular}{lccc}
\hline Needs & FPI value & Cortisol & "r" Pearson \\
\hline & & $16,90 \pm 4,74$ & \\
Assistance & $48,09 \pm 6,63$ & & 0,146 \\
Intraception & $45,55 \pm 11,26$ & & 0,544 \\
Cuddling & $38,82 \pm 8,62$ & & 0,553 \\
Deference & $48,55 \pm 9,47$ & & 0,211 \\
Affiliation & $48,27 \pm 9,83$ & & 0,144 \\
Dominance & $40,46 \pm 9,49$ & 0,406 \\
Denial & $41,18 \pm 9,29$ & 0,029 \\
Performance & $51,55 \pm 8,64$ & 0,742 \\
Display & $43,36 \pm 8,27$ & 0,669 \\
Agression & $39,64 \pm 17,81$ & 0,142 \\
Order & $50,55 \pm 9,02$ & 0,322 \\
Persistence & $51,09 \pm 7,26$ & 0,539 \\
Change & $46,09 \pm 12,27$ & 0,161 \\
Autonomy & $47,73 \pm 9,18$ & 0,181 \\
Heterosexuality & $47,73 \pm 7,59$ & 0,389 \\
\hline
\end{tabular}

\section{RESULTS}

Table 1 shows the level of correlation between the personality indicators according to the FPI and Cortisol.

\section{DISCUSSION}

In our study there was a high correlation between cortisol and exposure (0.669) and performance (0.742) and an intermediate correlation between cortisol and persistence (0.539), cuddle (0.553) and intraception (0.544), in the other items the correlation was low.

Blood cortisol levels vary during the day because they are related to daily activity and serotonin, being higher in the morning. In the afternoon, as in the case of our collection (16.90 \pm 4.74 ) values between 16 and 17 hours tend to be between 2.4 and $13.6 \mu \mathrm{g} / \mathrm{dL}$ (Kraemer and Ratames, 2005).

There is no doubt that the personality of the athletes would be a determinant dimension in the performance, and some studies related the psychological antecedents regarding the injuries in the sport, where personalities more susceptible to the stress tend to present greater risk of injury in the sport (Chalmers, 2002; Brewer, 2003; Junge, 2000).

On the other hand, the results of the present study also reinforce the affirmations that the survey of psychological characteristics of the personality is of fundamental importance for the development of practical actions such as prognosis, diagnosis and psychological interventions in the sport (Weinberg \& Gould, 2001; Bara \& Ribeiro, 2005). Piffaretti (1998) suggests the tendency of some problems related to sports would be more related to the personality of each individual.

In the same direction in assessing the question of personality, Murray (1938) explains that needs would be the results of experiences assimilated by the individual through parental relationships and the environment. They would then be a force that has to order the perception provoked by internal processes and by the forces of the environment, leading the individual to a certain behavior.

In this sense, the needs of the individual described by the same author (Murray, 1938), would be formed from the beliefs acquired by the subjects throughout life and that are added by the lived events. 
The Cognitive Therapy theory organized by Aaron Beck (Beck, 2000), mentions that beliefs appear in childhood as the child interacts with people and confronts them with situations that confirm these ideas, end up giving meaning to their environment, organizing the experience to adapt. Beck (2000) postulates that people emotions and behaviors are influenced by the interpretation given to events.

Thus, stress would be related to depersonalization, emotional exhaustion and low achievement (Nogueira-Martins, 1989; Katz, Sharp \& Ferguson, 2006; Rosen, Gimotty, Shea \& Bellini, 2006). It has been demonstrated that the process of exhaustion tends to appear when the difficulties can not be overcome in a certain period or occasion, making the subjects more vulnerable to possible mental disorders (Dyrbye et al., 2010; Esquivel, Nogueira-Martins \& Yazigi, 2009; Benevides-Pereira \& Gonçalves, 2009; Gonçalves \& Benevides-Pereira, 2009).

On the other hand, although personality traits are relatively stable over time (Hall, Lindzey \& Campbell, 2000), the results obtained in some studies have demonstrated important psychological changes in some situations, including changes in defined personality traits \& Baldin, 2007). Other characteristics, such as the typical way of coping with difficulties and the ability to recognize one's own emotions, have also been altered in individuals who have been subjected to certain specific situations (Oliveira \& Yoshida, 2009). In this sense, it can be verified that the correlations found are supported by other studies, which can be neither in terms of preparation nor even in terms of determining the best form of personality in terms of sports, such as bodybuilding.

On the other hand, some studies verified the responses of salivary cortisol and testosterone concentrations, the psychological variables verified through the Variation of States of Mood (POMS) and sports performance questionnaire at different times of a competitive season (Filaire, Bernain, Sagnol \& Lac, 2001).

\section{CONCLUSION}

In our study, we can verify the importance of this personality and cortisol correlation in the pre competitive phase, especially in the case of bodybuilding sport, because, because it is a sport of high muscular definition requirement, any internal or external factor that can take physical balance or mental health of the athlete, could put everything to waste moments before a competition. High cortisol, can cause some factors that would be quite harmful to the athlete in pre competition, such as; loss of muscle mass, weight gain, decreased testosterone, etc. Which would probably leave him with a lot of fluid retention, damaging his physique in visualizing his muscular definition in the desired competition. Know the personality of the athlete, study their points to be worked for the improvement of their performance, such as: state or trait anxiety, would differentiate if the athlete is anxious, or if it is part of their personality the anxious state, being necessary, seek subsidies so that it can seek a control in its anxiety, that allows to be favorable to its sporting performance.

We believe that more in-depth studies of this personality and cortisol correlation in bodybuilding sport athletes is important to support a better emotional and hormonal control that contributes positively to the athlete's performance, as well as new studies that can correlate these two variables with the variation of mood states (POMS) in competitive seasons and in the daily scope of the athlete, for a more individualized context of the athlete and therefore a better performance in competitive seasons.

\section{Acknowledgments:}

Nothing to declare

Conflict of interests:

Nothing to declare

Funding:

Nothing to declare 


\section{REFERENCES}

Bahr R, Holme J. (2003) Risk factors for Sports Injuries - a methodological approach. $\mathrm{Br} J$ Sports Med. 37(5), 384-92.

Bara MGF, Ribeiro LCS. (2005) Personalidade e esporte: uma revisão. R Bras Ci e Mov. 13(2), 10110.

Barbacena MM, Grisi RNF. (2008) Level of anxiety precompetitive in athletes in swimming. Conexões. 6(1), 31-9.

Beck AT. (2000) O poder integrador da Terapia Cognitiva. Porto Alegre: Artes Médicas.

Benevides-Pereira AM, Gonçalves MB. (2009) Transtornos mentais e a formação em medicina: um estudo longitudinal. Rev Bras Educ Med. 33(1) 10-23

Brewer BM. (2003) Developmental Differences in Psychological Aspects of Sport - Injury Rehabilitation. J Athl Train. 38(2), 158-62.

Carazzato JG. (1996) Manual de medicina do esporte. São Paulo: Sociedade Brasileira de Medicina do Esporte.

Chalmers DJ. (2002) Injury prevention in sport: not yet part of the game? Inj Prev. 8 (Suppl 4), IV22-5.

Dyrbye LN, Power DV, Massie FS, Eacker A, Harper W, Thomas MR, et al. (2010) Factors associated with resilience to and recovery from burnout: a prospective, multi-institutional study of US medical students. Med Educ. 44(10), 1016-26.

Esquivel DA, Nogueira-Martins LA, Yazigi L. (2009) Is medical internship emotionally deleterious? A study on burnout and personality characteristics of first-year orthopaedic interns. Psico-Usf. 14(3), 261-74.

Fahrenkopf AM, Sectish TC, Barger LK, Sharek PJ, Lewin D, Chiang VW. (2008) Rates of medication errors among depressed and burnout out residents prospective cohort study. BMJ. 336(7642), 488-91.

Ferreira LC, Novaes J, Rodrigues Neto G, Costa Silva EG, Aidar FJ, Sousa NJ. (2015) Association between levels of precompetitive anxiety in bodybuilding athletes. Med Sport. 68(1), 91-8.

Filaire E, Bernain X, Sagnol M, Lac G. (2001) Prelimanary results on mood state, salivary testosterone:cortisol ratio and team performance in professional soccer team. Eur J Appl Physiol. 86, 179-84.

Goebert D, Thompson D, Takeshita J, Beach C, Bryson P, Ephgrave K. (2009) Depressive symptoms in medical students: a multischool study. Acad Med. 84(2), 236-4.

Goldfien A. (1998) Adrenocorticosteróides e antagonistas corticossupra-renais. In: Katzung BG (Ed). Farmacologia básica e clínica. Rio de Janeiro: Guanabara Koogan.

Gonçalves MB, Benevides-Pereira AM. (2009) Considerações sobre o ensino médico no Brasil: consequências afetivo-emocionais nos estudantes. Rev Bras Educ Med. 33(3), 493-504.
Hall CS, Lindzey G \& Campbell JB. (2000) Teorias da Personalidade. Porto Alegre: Artes Médicas Sul.

Junge A. (2000) The influence of Psychological factors on sports injuries: review of the literature. $A m \mathrm{~J}$ Sports Med. 28(5 Suppl), S10-5.

Katz ED, Sharp L, Ferguson E. (2006) Depression among emergency medicine residents over an academic year. Acad Emerg Med. 13(3), 284-7.

Kraemer W, Ratames N. (2005) Hormonal responses and adaptations to resistance exercise and training. Sports Med. 35(4), 339-361.

Leal, C. W. \& Baldin, N. (2007). O impacto emocional da cirurgia bariátrica em pacientes com obesidade mórbida. Rev Psiquiatr Rio Gd Sul. 29(3), 324- 327.

Magdaleno Jr., R., Chaim, E. A. \& Turato, E. R. (2009). Características psicológicas de pacientes submetidos à cirurgia bariátrica. Rev Psiquiatr Rio Gd Sul. 31(1), 73-78.

Mastorakos G, Pavlatou M, Diamanti-Kandarakis E, Chrousos GP. (2005) Exercise and the stress system. Hormones (Athens). 4(2), 73-89.

Murray HA. (1938) Explorations in personality: a clinical and experimental study of fifty men of college age. New York: Oxford University Press.

Murray, H. (1962). Explorations in personality. New York: Science Editions.

Nogueira-Martins LA, Botega NJ. (1998) Interconsulta Psiquiátrica no Brasil: Desenvolvimentos recentes. Rev ABP-APAL. 20(3), 105-11.

Nogueira-Martins LA. (1989) Consultoria psiquiátrica e psicológica no hospital geral: a experiênc ia do hospital. Rev ABP-APAL. 11(4), 160-4.

Oliveira JHA \& Yoshida EMP. (2009) Avaliação psicológica de obesos grau III antes e depois de cirurgia bariátrica. Psic Ref e Crít. 22(1), 12-19.

Pasquali L, Azevedo MM \& Ghesti I. (1997) Inventário fatorial de personalidade: manual técnico e de avaliação. São Paulo: Casa do Psicólogo.

Pervin LA \& John OP. (2004) Personalidade: Teoria $e$ pesquisa. Porto Alegre: Artmed.

Piffaretti M. (1998) Role of psychology in a multidisciplinary model of prevention and rehabilitation of sports injuries. Rev Med Suisse Romande. 118(5), 497-503.

Rey FG, Martinez AM. (1989) La personalidad: su educación y desarollo. Cuba: Editorial Pueblo y Educación.

Rosen IM, Gimotty PA, Shea JA, Bellini LM. (2006) Evolution of sleep quantity, sleep deprivation, mood disturbances, empathy, and burnout among interns. Acad Med. 81(1), 82-5.

Samulski D. Motivação.(2002) Psicologia do esporte: um manual para a educação física, fisioterapia e psicologia. São Paulo: Manole.

Sanches GD, Gazoni FM, Konishi RK, Guimarães HP, Vendrame LS \& Lopes RD. (2007) Cuidados intensivos para pacientes em pós-operatório de cirurgia bariátrica. Rev Bras Ter Intens. 19(2), 205209. 
180 | LC Ferreira, FJ Aidar, DG Matos, et al.

Tyssen R, Vaglum P, Gronvold NT, Ekeberg O. (2005) The relative importance of individual and organizational factors for the prevention of job stress during intership: a nationwide and prospective study. Med Teach. 27(8), 726-31.
Weinberg RS, Gould D. (2001) Fundamentos da psicologia do esporte e do exercício. ( $\left.2^{\mathrm{a}} \mathrm{ed}\right)$. Porto Alegre: Artmed.

(c) (i) (8) All content of Journal Motricidade is licensed under Creative Commons, except when otherwise specified and in content retrieved from other bibliographic sources. 


\title{
Effects of high-intensity functional and endurance training on neuromuscular performance and body fat of young individuals with overweight and obesity
}

\author{
Marta Silva Santos ${ }^{1,2^{*}}$, Antônio Gomes de Resende Neto ${ }^{1,2}$, Gilmar Werber Senna ${ }^{3}$, Jeferson \\ Viana $^{4}$, Raquel Simões Mendes Netto ${ }^{1}$, Marzo Edir Da Silva-Grigoletto ${ }^{1,2}$
}

\begin{abstract}
The aim of the present study was to analyze the effects of High-Intensity Functional Training (HIFT) and Endurance Training (ET) on lower limb muscular strength-endurance, agility, velocity, dynamic postural balance, cardiovascular resistance and body fat percentage. Fifty-five subjects were divided into two groups, HIFT (32.82 \pm 10.8 years) and ET (30.68 \pm 10.4 years), and each group performed 12 weeks of their respective training programs. Subjects from the HIFT group performed a linear periodization model in relation to the complexity and intensity of exercises. In the ET group, the continuous method was performed with a linear periodization relative to intensity. For all subjects, the 505 Agility, 20-foot Sprint, 6-minute walk, OctoBalance, and bioimpedance tests have been implemented. ANCOVA showed that both groups achieved a significant improvement in all variables analyzed after intervention (intra-groups, $\mathrm{p}<$ $0.005)$. However, there were no statistically significant inter-group differences in variables velocity ( $\mathrm{p}=$ $0.09)$, body fat percentage $(p=0.593)$ and cardiovascular endurance $(p=0.597)$. Thus, it was concluded that high-intensity functional training is more effective than endurance training in improving strength, endurance, and dynamic postural balance.
\end{abstract}

Keywords: exercise, physical activity, physical fitness.

\section{INTRODUCTION}

Functional training has been gaining prominence in the scientific community, being considered as an alternative to traditional endurance training (Pacheco, Texeira, Franchini, \& Takito, 2013). According to Da SilvaGrigoletto et al. (2014), functional training consists of a methodology that must be understood from the perspective of the functionality principle, which prioritizes the performance of integrated and multiplanar movements. These movements imply acceleration, stabilization and deceleration aiming at improving movement ability, stability of the trunk region (median zone / core) and neuromuscular efficiency (Distefano et al., 2013).
However, in addition to the definition of functional training, there are several methodological aspects that need to be systematized, such as, adequate frequency of stimulation, volume, intensity, density (exercise / interval ratio) and session organization, as well as the execution speed of exercises (Da Silva Gricoletto; Brito; \& Heredia, 2014).

Although publications investigating the standardization of functional training and its effects on performance have been found, the majority of these studies have compared functional training with strength training and were mainly performed with older adults, who due to sarcopenia, showed decreased neuromuscular and cardiovascular power, with

\footnotetext{
${ }_{1}^{1}$ Programa de Pós Graduação em Educação Física, Universidadde Federal De Sergipe

2 Scientific Sports/ Brasil

${ }^{3}$ Programa de Pós-Graduação em Enfermagem e Biociência, PpgEnBio, Doutorando pela Universidade Federal do Estado do Rio de Janeiro, UNIRIO, Rio de Janeiro, Brasil

${ }^{4}$ Universidade Federal de Juíz de Fora, Juíz de Fora, Brasil

* Autor correspondente: Programa de Pós Graduação em Educação Física, Centro de Ciencias Biológicas e Da Saúde, Universidade Federal de Sergipe, Campus Universitário - São Cristóvão. Caixa Postal 476. CEP: 49000100 F São Cristóvão/SE, Brasil. E-mail: martasilvaedf@gmail.com
} 
consequent functional impairments (LohneSeiler, Torstveit, Anderssen, 2013, Pacheco et al., 2013). This condition may enhance the responses to protocols being tested, making the results likely to be more noticeable, which also suggests methodological limitations. Thus, the literature lacks studies that investigate the effects of functional training on the performance of young adults.

It is known that obesity is associated with a number of comorbidities, as well as with increased risk of premature death (Xiao, Fu, 2015). Lagally et al. (2009) studied the physiological and metabolic responses to functional training in young adults and found that the exercise program used promoted caloric expenditure at levels equivalent to those related to health maintenance, considering the current recommendations of the American College of Sports Medicine (ACSM, 2007). However, observing the specific characteristics of functional training, it is necessary to evaluate the chronic adaptations, characterized by variables that reflect adaptations specific to this activity such as strength-endurance, speed, agility, dynamic postural balance and cardiovascular resistance.
Unlike functional training, endurance training promotes chronic adaptations in functional capacity and fat percentage reduction (Swift et al., 2014). However, to our knowledge, no previous study has compared the effects of both types of training on neuromuscular variables, fat percentage and cardiovascular resistance. The results of the present study will provide subsidies to health professionals from the understanding of the effects of both types of training for the most appropriate prescription of exercises for a young population with overweight or obesity.

Therefore, the aim of the present study was to analyze the effects of high- intensity functional training (HIFT) and endurance training (ET) on lower limb muscular strength-endurance, agility, velocity, dynamic postural balance, cardiovascular resistance and body fat percentage.

\section{METHOD}

\section{Experimental design}

This is a quasi-experimental study of quantitative approach and applied nature, in which two experimental groups were evaluated before and after a 12-week intervention period (Thomas, Nelson \& Silverman, 2007).

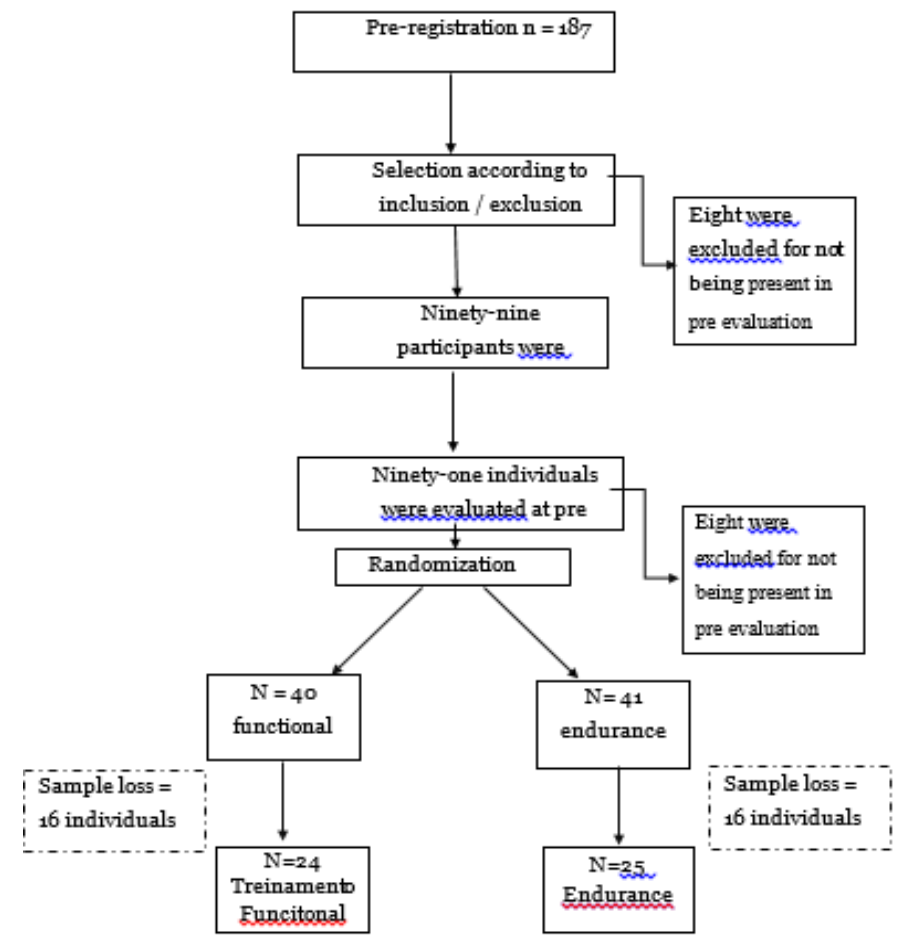

Figure 1. Diagram describing study procedures. 


\section{Participants}

The sample consisted of 55 individuals of both sexes (26 men and 23 women), who were randomly assigned into two groups: Highintensity functional training (HIFT, $\mathrm{N}=24$, $32.83 \pm 10.8$ years) and Endurance Training (ET, $\mathrm{N}=25,30.68 \pm 10.4$ years). The sample calculation was performed using the $G *$ Power software version 3.1.9.2 (Erdfelder, Faul, \& Buchner, 1996; Kiel, Germany). Statistical power was set at $80 \%$.

Sampling was randomized block type, in which participants were equally distributed in both groups according to age, sex and BMI. The steps of selection and randomization of participants are described in Figure 1.

Inclusion criteria in the present study were: (a) to be a student or employee of the Federal University of Sergipe; (B) to have body mass index (BMI) between 25.0 and 35; and (c) to have no orthopedic, cardiorespiratory or musculoskeletal problems that would prevent participation in the study. Characterization data of participants are shown in Table 1.

All participants were informed about ethical standards, objectives, procedures and risks related to the study and signed the free informed consent form. Data were kept anonymous and the present study was submitted to and approved by the Ethics Research Committee of the Federal University of Sergipe.

\section{Procedures}

All anthropometric measurements followed the International Anthropometric Assessment Standards (Marfell-Jones et al, 2006). For body mass and height measurements, a clinical scale (Filizola ${ }^{\circledR}$, São Paulo, Brazil) with scale of $0.1 \mathrm{~kg}$ and capacity of $150 \mathrm{~kg}$, equipped with stadiometer with scale of $0.5 \mathrm{~cm}$ was used.

Body composition assessment was performed using bioelectrical impedance (Biodynamics ${ }^{\circledR}$, BIA 310, New York, United States), and all volunteers followed the following guidelines: (a) 12-hour fasting; (b) not to perform physical exercise in the 24 hours prior to the test; (c) to ingest $2.0 \mathrm{~L}$ of water in the 24 hours prior to tests; (d) not to ingest alcoholic beverages and sources of caffeine on the day before evaluation.

Agility was analyzed using the 505 Agility test. For this, three cones (A, B and C) were arranged at A-B distance of 10 meters and B-C distance of five meters. A couple of photocells (Muscle-lab ${ }^{\mathrm{TM}}$, Standart, Porsgrun, Norway) were coupled to cone B (start / end position). Each participant left point $\mathrm{A}$ to point $\mathrm{C}$ at the highest possible speed, touching both feet on the line corresponding to point $\mathrm{C}$, returning at full speed to point $\mathrm{A}$. Two attempts were performed, with two minutes of interval between them. For analysis, the shortest time to travel the B-C-B distance (Chatzopoulos et al., 2014) was selected.

Speed was evaluated by means of the $20-\mathrm{m}$ running test. Each participant ran the distance of 20 meters as fast as possible. Time was recorded by photocells (Muscle-labTM, Standart, Porsgrun, Norway) placed at the beginning and end of the 20-m running test. In order to avoid participants to reduce speed before finalizing the test, a cone was placed after the last photocell so that the individual only reduced the speed after passing it, as referred by Kibele \& Behm (2009).

The strength-endurance of lower limbs was assessed by the sitting-rising adapted test. The test started with participant sitting in a chair with seat at a height of $40 \mathrm{~cm}$ from the ground and feet resting on the floor. Before beginning the test, the participant sat and stood once as a way of familiarizing with the task. At the signal from the evaluator, the participant sat up and got up from the chair as quickly as possible in a one-minute period. The participant was then encouraged to complete as many repetitions as possible. A repetition was only made possible when the participant, from the seated position, performed a complete hip extension and returned to the initial position, touching the buttocks on the chair again (Roldán-Jiménez, Benett, \& CuestaVargas, 2015).

In order to evaluate the dynamic postural balance, the adapted Star Excursion Balance Test (Gribble, Hertel, \& Plisky, 2012), called OctoBalance Low Body Test was performed (Marin et al., 2015), which uses four 
displacements for the right and left lower limbs: Anterior, Medial, Postero-Medial and PosteroLateral. Four attempts for familiarization were made for each limb (left and right); after that, 30 seconds of rest were given, and three more attempts were made, which were recorded for statistical purposes. All results of each displacement were adjusted by limb size and multiplied by 100 . The mean of these values was summed and the result was established as the measure of the dynamic postural balance.

Subsequently, cardiorespiratory endurance was assessed by the six-minute walk test. Each participant walked as fast as possible in a rectangular path $(45.72 \mathrm{~m}$, demarcated by cones every $4.57 \mathrm{~m}$ ), for six minutes (Beriault et al., 2009) (ATS, 2002).

Immediately after arrival at the evaluation site, participants remained in rest for five minutes and then performed the anthropometric measurements and the bioimpedance assessment and were encouraged to consume approximately $40 \mathrm{~g}$ of carbohydrates, $8 \mathrm{~g}$ of protein, $6 \mathrm{~g}$ of fat and $5 \mathrm{~g}$ of fiber in a total of $256 \mathrm{kcal}$. The meal suggestion was performed to provide the recommended macronutrient amounts according to ACSM on nutrition and athletic performance (ACSM, 2009). This feeding procedure was followed by experienced nutrition professionals and adopted by all participants both in pre- and post-test.

All tests (pre- and post-intervention) were performed in the morning shift (between 8 am and noon) and applied by the same evaluator. Subjects were instructed to keep the sleep schedule and to attend evaluations appropriately dressed for the tests. They were also advised not to perform exhaustive physical activities within 24 hours prior to data collection, to abstain from the consumption of products containing caffeine and to remain fasted until the performance of the bioimpedance test.

All tests (pre- and post-intervention) were performed in the morning shift (between 8 am and noon) and applied by the same evaluator. Subjects were instructed to keep the sleep schedule and to attend evaluations appropriately dressed for the tests. They were also advised not to perform exhaustive physical activities within 24 hours prior to data collection, to abstain from the consumption of products containing caffeine and to remain fasted until the performance of the bioimpedance test.

All evaluation procedures were performed in the same way in the pre- and post-test. After the pre-test, all subjects completed two weeks of familiarization with the treatment protocols and then performed 12 weeks of intervention. The weekly frequency was three sessions lasting 50 minutes each. The first and second weekly sessions were conducted with the presence of experienced Physical Education professionals (Table 2 and Table 3). The third weekly visit was performed with proper prescription and professional guidance (Table 3 and Table 4). The third session was held in a place of preference of the volunteer, which allowed greater adherence to the program. The periodization followed the Linear model, following a progression by density and choice of exercises that evolved from less complex to more complex.

The HIFT group performed a training protocol that was divided into six blocks in the following sequence: joint mobility, core muscle activation, coordination, two circuits called neuromuscular 1 and 2 and cardiometabolic

Briefly, the joint mobility block lasted about five minutes. In this part of the session, exercises of dynamic mobility of the cervical, glenohumeral, thoracic, hip and ankle joints were performed, performing a dynamic warm-up, with 10 executions per joint. The core pre-activation block lasted about 5 minutes with the performance of three exercises: frontal board, hunting dog and unilateral pelvic elevation. During exercises, bracing-type breathing was used, thus providing greater activation of the middle zone (Imai; Kaneoka; Okubo; Shiraki, 2016).

Soon after, the coordination block, lasting about 10 minutes, in which gait coordinates were applied in the sagittal and frontal planes with displacements in the anterior-posterior and lateral-lateral directions, respectively. 
Neuromuscular blocks 1 and 2 were composed of twelve minutes and six stations each. Stations included lower and upper limb power exercises, agility, and coordination. In the neuromuscular block 2, exercises that referred to functional actions of crouching and pulling, pushing and carrying were performed, as well as specific core exercises. Finally, the cardiometabolic block was composed of two distinct games: tug of war and interminable race.

Thus, all subjects of this group were encouraged to perform maximum effort in a certain period of time (duration of each game), after which a rest period was given. This part of the session lasted about ten minutes. Table 2 clearly demonstrates the study procedures. In the prescription of intermittent training of the third day, the neuromuscular phase 1 and 2 of Table 2 was mixed in Table 3, so the volunteer was able to carry out pulling, pushing, jumping and squatting activities, performing five exercises for each movement in order to include strength and power exercises. For the cardiometabolic block, running test was used according to methodological parameters previously mentioned.

Table 2

Periodization over 12 weeks of HIFT

\begin{tabular}{cccccc} 
Weeks & $\begin{array}{c}\text { Density } \\
\text { (seg) }\end{array}$ & $\begin{array}{c}\text { Activation and } \\
\text { Coordination } \\
\text { No. of } \\
\text { exercises / time }\end{array}$ & $\begin{array}{c}\text { Neuromucular 1 } \\
\text { Number of } \\
\text { exercises / time / } \\
\text { \% HR }\end{array}$ & $\begin{array}{c}\text { Neuromuscular 2: } \\
\text { : Number of } \\
\text { exercises / time / } \\
\% \text { HR }\end{array}$ & $\begin{array}{c}\text { Cardiometabolic: } \\
\text { Number of games / } \\
\% \text { HR }\end{array}$ \\
\hline $1-2$ & $20-40$ & $11 / 15$ & $5 / 10 / 75$ & $5 / 10 / 75$ & $1 / 85$ \\
$3-5$ & $25-40$ & $12 / 20$ & $5 / 10 / 80$ & $5 / 10 / 80$ & $1 / 90-95$ \\
$6-7$ & $25-35$ & $13 / 20$ & $5 / 10 / 85$ & $5 / 12 / 85$ & $1 / 90-95$ \\
$8-9$ & $30-30$ & $14 / 20$ & $6 / 10 / 88$ & $6 / 12 / 88$ & $1 / 90-95$ \\
10 & $35-30$ & $15 / 20$ & $6 / 10 / 90$ & $6 / 12 / 90$ & $1 / 90-95$ \\
11 & $35-20$ & $15 / 20$ & $6 / 10 / 90$ & $6 / 12 / 90$ & $1 / 90-95$ \\
12 & $40-20$ & $15 / 20$ & $6 / 10 / 90$ & $6 / 12 / 90$ & $1 / 90-95$ \\
\hline
\end{tabular}

Tabela 3

Periodization over 12 weeks of ET

\begin{tabular}{ccccc}
\hline Weerk & $\begin{array}{c}\text { Intensity (\% HR } \\
\text { max) }\end{array}$ & $\begin{array}{c}\text { Training session 1 } \\
\text { (duration min) }\end{array}$ & $\begin{array}{c}\text { Training session 2 } \\
\text { (duration min) }\end{array}$ & $\begin{array}{c}\text { Training session } 3 \\
\text { (duration min) }\end{array}$ \\
\hline 1 & 65 & 20 & 25 & 30 \\
2 & 65 & 25 & 30 & 35 \\
3 & 65 & 30 & 35 & 40 \\
4 & 65 & 35 & 40 & 35 \\
5 & 70 & 20 & 25 & 35 \\
6 & 70 & 25 & 30 & 40 \\
7 & 70 & 30 & 35 & 45 \\
8 & 70 & 35 & 40 & 30 \\
9 & 75 & 20 & 25 & 35 \\
10 & 75 & 25 & 30 & 40 \\
11 & 75 & 30 & 35 & 45 \\
\hline
\end{tabular}

In each session, the TE group performed two distinct moments: (a) dynamic warm-up and coordination, which were performed in the same way as the functional training; (b) aerobic, having running as main exercise, in which target intensities and volumes were selected (Table 4) to be maintained during the training. In addition, steps and elastic beds were also used, allied to running (when necessary), with the objective of increasing the cardiac frequency, when this did not correspond to the prescription for a given individual.

\section{Statistical analysis.}

Data were expressed according to their mean and standard deviation. Data normality was 
verified through the Shapiro-Wilk test. In order to compare intra-group and inter-group means, ANCOVA $2 \times 2$ was performed, including training type and time factors, as well as age as covariable. Bonferroni post-hoc was used for multiple comparisons. In addition, to determine the magnitude of results, the Effect Size (difference between pre-test and the post-test, divided by the standard deviation of the pre-test) was also calculated. The limits proposed by Cohen (1988) were applied to determine the magnitude of the treatment effect. In all cases, the significance level was set at $\mathrm{p} \leq 0.05$, and calculations were done using the SPSS software (Version 20.0, IBM, INC).

\section{RESULTS}

Regarding the strength-endurance of lower limbs (HIFT, $\mathrm{p}=0.001$; ET, $\mathrm{p}=0.011$ ), agility (HIFT, $p=0.022$, ET, $p=0.005$ ) significant intra-groups (post-intervention) improvements were observed. In addition, statistically significant differences between groups were identified for these variables (strengthendurance of lower limbs, $\mathrm{p}=0.037$, agility, $\mathrm{p}=$ 0.004).

For variables speed (HIFT, $\mathrm{p}=0.000 ; \mathrm{ET}, \mathrm{p}=$ 0.000 ) and cardiothoracic resistance (HIFT, $\mathrm{p}=$ 0.05; ET, $\mathrm{p}=0.04)$, significant intra-group improvements were observed. However, no statistically significant difference between groups was identified for these variables (velocity, $\mathrm{p}=$ 0.09 , cardiorespiratory resistance, $\mathrm{p}=0.597$ ). Specifically, for variable Dynamic Postural Balance, significant difference was observed for the HIFT group $(p=0.025)$, which did not occur for ET group $(\mathrm{p}=0.237)$. In addition, $\mathrm{a}$ statistically significant inter-group differences for this variable were identified $(p=0.03)$.

For variable fat percentage, both groups improved significantly after the 12-week intervention (HIFT: Pre $=33.8 \pm 3.8$; Post $=$ $29.8 \pm 4.4 ; \Delta=33.3 \% ; \mathrm{p}=0.036)$; (ET: Pre $=$ $34.0 \pm 5.9 ;$ Post $=31.7 \pm 6.6 ; \Delta=7.25 \% ; \mathrm{p}=$ $0.593)$

The Effect Size (ES) showed a large magnitude of intra-group values for variables strengthendurance, agility, speed, and cardiorespiratory resistance for both groups. However, large magnitudes were observed in the ET group for variables fat percentage and dynamic postural balance in the HIFT group, which did not occur for the ET group. Specifically, the fat percentage in the TE group showed moderate magnitude reductions, and for dynamic postural balance, small elevations were observed. Table 4 shows the mean and standard deviation descriptive values as well as intra-group ET comparisons (pre and post) for each variable.

Table 4

Behavior of strength-endurance variables of lower limbs, speed and agility, cardiorespiratory resistance and dynamic postural balance in HIFT and ET groups over the 12 weeks of intervention.

\begin{tabular}{ccccccc}
\hline \multirow{2}{*}{ Variables } & \multicolumn{3}{c}{ HIFT $(\mathrm{n}=24)$} & \multicolumn{3}{c}{ Groups } \\
& Pré & Pós & $E F$ & Pré & Pós & $E F$ \\
\cline { 2 - 7 } & $39.7 \pm 7$ & $48.1 \pm 7.5$ & 1.2 & $40.3 \pm 8.5$ & $46.4 \pm 8.3$ & 0.7 \\
SLL (rep) & $3.4 \pm 0.3$ & $3.2 \pm 0.2$ & 1.0 & $3.5 \pm 0.4$ & $3.3 \pm 0.2$ & 1.0 \\
Agility(seg) & $4.4 \pm 0.4$ & $4.04 \pm 0.3$ & 1.2 & $4.8 \pm 1$ & $4.3 \pm 0.6$ & 0.8 \\
Speed. (sec) & $674 \pm 50.6$ & $755.4 \pm 55.6$ & 1.6 & $611 \pm 48.3$ & $758 \pm 53.1$ & 3.0 \\
CE (m) & $72.2 \pm 1.4$ & $75.2 \pm 1.4$ & 2.1 & $72.1 \pm 73.7$ & $73.7 \pm 1.5$ & 0.02 \\
DPB & &
\end{tabular}

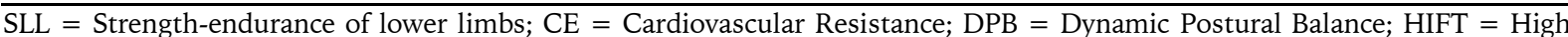
Intensity Functional Training; ET $=$ Endurance Training. EF $=$ Effect Size. ${ }^{*}$ Represents statistically significant inter-group difference for $\mathrm{p}<0.05$

\section{DISCUSSION}

The main finding of this study is that the effect of HIFT has a more positive impact on neuromuscular parameters than ET. Another relevant aspect is that body composition, speed and cardiovascular resistance improved for both groups without any difference between them. However, when comparing both training 
sessions, only HIFT was effective in improving dynamic postural balance.

There are different types of protocols for the application of functional training, but most use two tools as a means of applying training: the use of exercises with free weights and / or equipment that generate instabilities (García-Órea, Elvar, Santos, Da Silva-Grigolettoeto, 2016). In addition to the fact that there are different possibilities of tools for the application of functional training, there is a difficulty in systematizing the method due to the lack of control of training variables such as: speed of exercise execution, adequate stimulus frequency, training volume, adequate density, and methodological organization (Da Silva-Grigoletto et al., 2014). This range of methodological variables hinders comparative analyses between studies regarding the method used.

The present study sought to control all these variables and respected the basic method premise, i.e., the principle of functionality using movements that are most used in the daily life of any individual, such as pulling, pushing, crouching and carrying. In addition, there was a progression with regard to intensity, volume and density. All this may lead to conclude that there was no stagnation in relation to the effects of this type of training during the intervention period. Among the variables evaluated, strengthendurance of lower limbs increased in both groups after intervention, with a greater improvement in the HIFT group. In this group, exercises were used for lower limbs such as squatting, which are more specific in relation to movements of the daily living (Fleck, \& Kramer, 2006). In addition, the overload stress on the muscle is essentially linked to the promotion of neuromuscular adaptations (ACSM, 2009). Some authors have reported that the optimal intensity in training programs aiming at promoting muscle strength must provide endurance intensity of approximately $65 \%$ to $100 \%$ of one maximal repetition (Fry et al., 2004). Recent research has shown that lower intensities, such as $40 \%$ of maximal repetition, are as effective as high intensities for muscle hypertrophy if exercises are performed until exhaustion, but not for strength (Schoenfeld et al. 2015). Thus, as expected, the muscle tension produced in the lower limbs by endurance training was not enough to cause adaptations similar to functional training. In addition, different studies have suggested that the reduction of time interval between series (density, relevant parameter of functional training) can intensify exercise regardless of intensity (Senna et al., 2016), generate hormonal changes (Scudese Et al., 2016) and modifications of the immunological response (Gerosa-Neto et al., 2016). These methodological characteristics of intermittence that occurred in the HIFT group approached their results to those found in strength training.

In addition, recent evidence shows that muscle is also an endocrine organ secreting a number of hormones such as interleukin-6 (IL-6), tumor necrosis factor alpha (TNF- $\alpha$ ), and leptin, which have been associated with obesity, insulin resistance and endothelial dysfunction (Lambert et al., 2008). Both training groups decreased fat percentage and there is a significant number of studies in literature regarding the influence of aerobic physical training on systemic inflammation in the obese population (Arika-wa, et al., 2011). However, muscle contraction during strength exercises is also capable of releasing various cytokines into the bloodstream, such as interleukins IL-6, IL-10, IL-15, which exert protective and anti-inflammatory effects at many levels, including in adipose tissue (Arikawa, et al., 2011).

The ET applied in the present study was performed continuously, being characterized by a protocol with predominance of the aerobic system. On the other hand, HIFT has features of strength training (especially in the part of the session called Neuromuscular 2). Thus, based on the results of articles referring to strength and endurance training (aerobic) previously mentioned, it could be inferred that both types of training influenced the anti-inflammatory profile, which allowed the decrease in fat percentage (Arikawa, et al., 2011). Skeletal muscle is the main receptor and a modulator of insulin action, 
so that loss of muscle tissue is associated with loss of strength, which predisposes to the development of certain metabolic diseases (dyslipidemia, insulin resistance, Type 2 diabetes mellitus, metabolic syndrome and cardiovascular diseases). Thus, functional training seems to be a more effective proposal against obesity than endurance training, since it had a significant improvement in muscle strength, which leads to believe that an "ideal" level of strength may be linked to many metabolic and endocrine benefits that are responsible for protection against morbidity and mortality that threaten the effects of current lifestyles (Phillips et al. Al., 2012).

Few studies have evaluated the dynamic postural balance in young adults in functional training. Among them, the majority evaluate the static balance (Amar, \& Kadyan, 2014), which from the functional point of view does not seem to have relevance for the approximation of training results to actions of the daily living, since they are performed dynamically, using the neuromuscular interaction between lower and upper limbs and the core instability (mean trunk area) (Santos et al., 2011). The concept of core instability depends that external disturbances destabilize the passive, active and neural system of this middle zone of the body, and that during these perturbations, the trunk is able to return to the initial position, maintaining the stability of the entire spine and consequently the whole body (Garcia et al., 2015). This aspect is extremely relevant for the individual to perform harmonic tasks of the daily living without compromising the lumbar-pelvic region, thus reducing the risk of injury (Segarra et al., 2014).

Thus, in the present study, we chose to use movement patterns that are used in the Star Excursion Balance Test (SEBT), which evaluates the dynamic postural balance, seeking to verify the interaction between the core and the upper and lower limbs. These movements have been studied for more than two decades by the scientific community, and there is a correlation with possible lesions (Delahunt, Chawke, \& Kelleher, 2013) in lower limbs (Gribble, Hertel, \& Denegar, 2007). The sum of the movement patterns allowed us to evaluate the dynamic postural balance of the whole body, which has a greater transference to activities of the daily living, in which dynamic actions are performed. The HIFT group achieved a higher improvement in dynamic postural balance compared to the ET group. In the HIFT group, multi-joint exercises were prioritized, with the use of free weights and that did not activate the muscles of the lower and upper limbs in isolation.

One of the main roles of core is to minimize the burdens common to all sorts of activities, ranging from running to hurling (Kibler, Press, \& Sciascia, 2006). In addition, the pushing, pulling, carrying, and throwing actions that were used in the HIFT group seem to have generated greater activation in the core than the continuous running action of the ET group. This can be explained by the fact that these functional actions when carried out in a multi-joint manner provided greater activation of the trunk muscles (Mok et al., 2015). Higher core activation, coupled with greater gains in lower limb strength in functional training, may have provided an improvement in neuromuscular connections between core and limbs, thus reflecting a better dynamic postural balance.

Regarding agility, there was a significant difference between groups, with a prevalence of HIFT group in relation to ET group, which corroborates the results of Behn (2009) and Weiss et al. (2010). The same did not occur with variable speed. It is important to emphasize that activities with change of direction were developed in the HIFT group, which may justify the improvement in this variable. However, in the ET group, sessions were performed continuously and without change of direction. That is, in all training sessions, the volunteers ran in a straight line (without change of direction), which may explain the significant improvement of this group in relation to speed.

Initially, there was a hypothesis that the ET group improved more significantly than the HIFT group in relation to cardiovascular endurance due to its aerobic component. However, for this variable, no significant inter-group differences 
were found, that is, both groups improved. Although the influence of aerobic exercise on cardiovascular capacity is well documented in literature, other factors also influence performance in running. For example, Tong et al. (2016) have recently shown that there is an association between core strength and running economy and performance in meters in the $1-h$ treadmill run performance test, thus demonstrating that resistance of this muscle is important for the action of running.

The multi-joint exercises used by the HIFT group provided trunk activation (Mok et al., 2015) and consequently its training over time. Trunk training added to the significant increase in strength and endurance of lower limbs in the HIFT group may have influenced the increase in the distance of the 6-minute test. However, more specific tests that directly evaluated maximum $\mathrm{VO}_{2}$ could identify a sensitive improvement for ET.

The main aim of the present study was to add to the growing body of knowledge in the specific area of HIFT and its chronic comparisons to other activities, such as ET. Some limitations were found during the process of experimental planning, such as not having evaluated the maximum $\mathrm{VO}_{2}$ and the muscular strength through a direct test (gold standard). However, the study population was composed of sedentary, overweight / obese individuals, and both the cardiovascular test and the strength test could cause effects of contamination of data due to additional gains of specificity in the case of the ET group for the cardiovascular test and in the case of the HIFT group for the strength test.

\section{CONCLUSIONS}

It could be concluded that high-intensity functional training is more effective than endurance training in improving lower limb strength, agility and dynamic postural balance, but there is no difference between the two types of training regarding variables fat\%, speed and cardiovascular resistance.

Based on the results found in the present study, professionals can decide which type of training (HIFT or ET) should be used to improve physical fitness variables, since both HIFT and ET can be prescribed to improve cardiovascular condition, speed and fat percentage in overweight and obese individuals. However, when the aim is to prioritize the development of lower limb strength and endurance and dynamic postural balance, FT is more effective than ET.

Acknowledgments:

Nothing to declare

Conflict of interests:

Nothing to declare

Funding:

Nothing to declare

\section{REFERENCES}

Amar, A. K., \& Kadyan, G. (2014). Comparison of instability resistance training, traditional resistance training and plyometric training effects on strength, balance and functional performance on lower limb in normal collegiate male student. International Journal of Physical Therapy \& Rehabilitation Sciences, 1(1), 10-25.

Arikawa, A. Y., Thomas, W., Schmitz, K. H., \& Kurzer, M. S. (2011). Sixteen weeks of exercise reduces C-reactive protein levels in young women. Medicine and Science in Sports and Exercise, 43(6), doi.org/10.1249/mss.0b013e3182059eda.

ATS Committee on Proficiency Standards for Clinical Pulmonary Function Laboratories. (2002). ATS statement: guidelines for the six-minute walk test. American Journal of Respiratory And Critical Care Medicine, 166(1), 111. doi.org/10.1164/ajrccm.166.1.at1102.

Behm, D.G. Neuromuscular implications and applications of resistance training. (1995). Journal of Strength and Conditioning Research, 9(1), 264274.

doi.org/10.1519/15334287(1995)009<0264:naa or $>2.3 . \mathrm{co} ; 2$.

Beriault, K., Carpentier, A. C., Gagnon, C., Menard, J., Baillargeon, J. P., Ardilouze, J. L., \& Langlois, M. F. (2009). Reproducibility of the 6-minute walk test in obese adults. International Journal of Sports Medicine, 30(10), 725-727.

Chatzopoulos, D., Galazoulas, C., Patikas, D., \& Kotzamanidis, C. (2014). Acute effects of static and dynamic stretching on balance, agility, 
190 | MS Santos, AGR Neto, GW Senna, JViana, RSM Netto, ME Silva-Grigoletto

reaction time and movement time. Journal of Sports Science \& Medicine, 13(2), 403.

Cohen J. (1988). Statistical Power Analysis for the Behavioral Sciences. Hillsdale, NJ: Lawrence Erlbaum.

Da Silva-Grigoletto, M., Brito, C. J., Heredia, J. R. (2014) Funcional para que e para quem? Revista brasileira de Cineantropometria e Desenvolvimento Humano, 16(6), 714-719.

Delahunt, E., Chawke, M., Kelleher, J., Murphy, K., Prendiville, A., Sweeny, L., \& Patterson, M. (2013). Lower limb kinematics and dynamic postural stability in anterior cruciate ligamentreconstructed female athletes. Journal of Athletic Ttraining, 48(2), 172-185. doi.org/10.4085/10626050-48.2.05.

DiStefano, L. J., DiStefano, M. J., Frank, B. S., Clark, M. A., \& Padua, D. A. (2013). Comparison of integrated and isolated training on performance measures and neuromuscular control. The Journal of Strength \& Conditioning Research, 27(4), 10831090. doi.org/10.1519/jsc.0b013e318280d40b.

Fleck, S. J., \& Kraemer, W. J. (1999). Fundamentos do treinamento de força muscular. Artmed.

Fry, A. C. (2004). The role of resistance exercise intensity on muscle fibre adaptations. Sports Medicine, 34(10), $663-$ 679.doi.org/10.2165/00007256-20043410000004.

García-Orea, G. P., Elvar, J. R. H., Santos, M. S., SilvaGricoletto, M. E (2016). Efeitos agudos da utilização de dispositivos geradores de instabilidade externa sobre o desempenho neuromuscular. Revista Brasileira De Cineantropometria e Desenvolvimento Humano, 18(5), $1-14$.

Gerosa-Neto, J., Rossi, F. E., Campos, E. Z., Antunes, B. M., Cholewa, J. M., \& Lira, F. S. (2016). Impact of short and moderate rest intervals on the acute immunometabolic response to exhaustive strength exercise: Part II. The Journal of Strength \& Conditioning Research,30(6), 1570-1576. doi.org/10.1519/jsc.0000000000001413.

Gribble, P. A., Hertel, J., \& Plisky, P. (2012). Using the Star Excursion Balance Test to assess dynamic postural-control deficits and outcomes in lower extremity injury: a literature and systematic review. Journal of Athletic Training, 47(3), 339-357.

Gribble, P. A., Hertel, J., \& Denegar, C. R. (2007). Chronic ankle instability and fatigue create proximal joint alterations during performance of the Star Excursion Balance Test. International Journal of Sports Medicine, 28(03), 236-242. doi.org/10.1055/s-2006-924289.

Haskell W. L et al. (2007). Physical activity and public healt: updated recommendation for adults from the Americam College of Aports Medicine and the American Heart Association. Medicine and science in sports and exercise, 39(8), 1423-34.
Imai, A., Kaneoka, K., Okubo, Y., \& Shiraki, H. (2016). Immediate Effects of Different Trunk Exercise Programs on Jump Performance. International Journal of Sports Medicine, 37(03), 197-201. doi.org/10.1055/s-0035-1559714.

Kibler, W. B., Press, J., \& Sciascia, A. (2006). The role of core stability in athletic function. Sports Medicine, 36(3), 189-198. doi.org/10.2165/00007256-200636030-00001.

Kibele, A., \& Behm, D. G. (2009). Seven weeks of instability and traditional resistance training effects on strength, balance and functional performance. The Journal of Strength \& Conditioning Research, 23(9), 2443-2450. doi.org/10.1519/jsc.0b013e3181bf0489.

Lagally, K. M., Cordero, J., Good, J., Brown, D. D., \& McCaw, S. T. (2009). Physiologic and metabolic responses to a continuous functional resistance exercise workout. The Journal of Strength $\mathcal{E}$ Conditioning Research, 23(2), 373-379. doi.org/10.1249/01.mss.0000274173.13679.56.

Lambert, C. P., Wright, N. R., Finck, B. N., \& Villareal, D. T. (2008). Exercise but not diet-induced weight loss decreases skeletal muscle inflammatory gene expression in frail obese elderly persons. Journal of Applied Physiology, 105(2), 473-478. doi.org/10.1152/japplphysiol.00006.2008.

Lohne-Seiler, H.,Torstveit, M. K., Anderssen, S. A. (2013). Traditional versus Functional Strength Training: Effects on Muscle Strength and Power in the Elderly. Journal of Aging and Physical Activity, 21 (1), 51-70. doi.org/10.1123/japa.21.1.51.

Mok N. W., Yeung E. W., Cho J. C, Hui S. C., Liu K.C., Pang C.H. (2015). Core muscle activity during suspension exercises. Journal of science and medicine in sport, 18(2), 189-94. doi.org/10.1249/01.mss.0000479041.15861.b0.

Oppliger, R. A., Case, H. S., Horswill, C. A., Landry, G. L., \& Shelter, A. C. (1996). ACSM position stand: Weight loss in wrestlers. Medicine $\mathcal{E}$ Science in Sports $\quad \mathcal{E} \quad$ Exercise, 28(10), 135-138. doi.org/10.1097/00005768-199610000-00049.

Pacheco, M. M., Teixeira, L. A. C., Franchini, E., \& Takito, M. Y. (2013). Functional vs. Strength training in adults: specific needs define the best intervention. International Journal of Sports Physical Therapy, 8(1), 34.

Phillips, M. D., Patrizi, R. M., Cheek, D. J., Wooten, J. S., Barbee, J. J., \& Mitchell, J. B. (2012). Resistance training reduces subclinical inflammation in obese, postmenopausal women. Medicine and Science in Sports and Exercise, 44(11), 2099-2110. doi.org/10.1249/mss.0b013e3182644984.

Plisky, P. J., Gorman, P. P., Butler, R. J., Kiesel, K. B., Underwood, F. B., \& Elkins, B. (2009). The reliability of an instrumented device for measuring components of the star excursion 
balance test. North American Journal of Sports Physical Therapy: NAJSPT, 4(2), 92.

Ratamess, N. A., Alvar, B. A., Evetoch, T. K., Housh, T. J., Kibler, W. B., \& Kraemer, W. J. (2009). Progression models in resistance training for healthy adults [ACSM position stand]. Medicine and Science in Sports and Exercise, 41(3), 687-708. doi.org/10.1249/mss.0b013e3181915670.

Roldán-Jiménez, C., Bennett, P., \& Cuesta-Vargas, A. I. (2015). Muscular Activity and Fatigue in Lower-Limb and Trunk Muscles during Different Sit-To-Stand Tests. PloS one, 10(10), e0141675. doi.org/10.1371/journal.pone.0141675.

Santos, M. (2011). Estabilização Segmentar lombar. Sociedade Brasileira de Medicina Física e Reabilitação, 30(1), 14- 17.

Scudese, E., Simão, R., Senna, G., Vingren, J. L., Willardson, J. M., Baffi, M., \& Miranda, H. (2016). Long Rest Interval Promotes Durable Testosterone Responses in High-Intensity Bench Press. The Journal of Strength \& Conditioning Research, 30(5), 1275-1286. doi.org/10.1519/jsc.0000000000001237.

Segarra, V., Heredia, J. R., Peña, G., Sampietro, M., Moyano, M., Isidro, F., ... \& Da Silva-Grigoletto, M. E. (2014). Core y sistema de control neuromotor: mecanismos básicos para la estabilidad del raquis lumbar. Revista Brasileira de Educação Física e Esporte, 28(3), 521-529. doi.org/10.1590/s180755092014005000005.

Senna, G. W., Willardson, J. M., Scudese, E., Simão, R., Queiroz, C., Avelar, R., \& Dantas, E. H. M. (2016). Effect of Different Interset Rest Intervals on Performance of Single and Multijoint Exercises With Near-Maximal Loads. The Journal of Strength \& Conditioning Research, 30(3), 710-716. doi.org/10.1519/jsc.0000000000001142.

Schoenfeld, B. J., Peterson, M. D., Ogborn, D., Contreras, B., \& Sonmez, G. T. (2015). Effects of low-vs. high-load resistance training on muscle strength and hypertrophy in well-trained men. The Journal of Strength \& Conditioning Research, 29(10), 29542963.doi.org/10.1519/jsc.0000000000000958.
Stone, M. H., Plisk, S. S., Stone, M. E., Schilling, B. K., O'Bryant, H. S., \& Pierce, K. C. (1998). Athletic Performance Development: Volume Load-1 Set vs. Multiple Sets, Training Velocity and Training Variation. Strength \& Conditioning Journal, 20(6), 22-

31.doi.org/10.1519/10736840(1998)020<0022: apdvls $>2.3 . c 0 ; 2$.

Swift, D. L., Johannsen, N. M., Lavie, C. J., Earnest, C. P., \& Church, T. S. (2014). The role of exercise and physical activity in weight loss and maintenance. Progress in cardiovascular diseases, 56(4), 441-447.

Tarnanen, S. P., Siekkinen, K. M., Häkkinen, A. H., Mälkiä, E. A., Kautiainen, H. J., \& Ylinen, J. J. (2012). Core muscle activation during dynamic upper limb exercises in women. The Journal of Strength \& Conditioning Research, 26(12), 32173224. https://doi.org/10.1519/jsc.0b013e318248ad54.

Tan, B. (1999). Manipulating Resistance Training Program Variables to Optimize Maximum Strength in Men: A Review. The Journal of Strength \& Conditioning Research, 13(3), 289-304. doi.org/10.1519/00124278-199908000-00019.

Tong T. K, McConnell A. K, Lin H., Nie J., Zhang H., Wang J (2016). Functional' inspiratory and core muscle training enhances running performance and economy. Journal of strength and conditioning research, 30(10), 2942-51. doi.org/10.1519/jsc.0000000000000656.

Thomas, J., Nelson, J. K., Silverman, S. J. (2007). Métodos de pesquisa em atividade física. 5. ed. Porto Alegre: Artmed.

Weiss, T., Kreitinger, J., Wilde, H., Wiora, C., Steege, M., Dalleck, L., \& Janot, J. (2010). Effect of functional resistance training on muscular fitness outcomes in young adults. Journal of Exercise Science $\quad \mathcal{E} \quad$ Fitness, 8(2), 113-122. doi.org/10.1016/s1728-869x(10)60017-2 .

Xiao, T., Fu, YF (2015). Resistance training vc aerobic training and role of the factores on the exercise effects on visceral fat. European Review For Medical And Pharmacological Sciences, 19(10), 1779-84. 


\title{
Cardiorrespiratory tests of field in elderly: a systematic review
}

\author{
Gabriela Rezende de Oliveira Venturini ${ }^{1 *}$, Paulo de Tarso Veras Farinatti ${ }^{1,2}$, Nádia Souza \\ Lima da Silva ${ }^{1}$
}

\begin{abstract}
The assessment of the physical capacity to perform is relevant to the efficacy and safety of physical exercises, especially cardiorespiratory exercise. Because laboratory cardiorespiratory capacity tests are costly, daily field tests are developed for being simple, cheap, and current capacity to reach large portions of the population. However, there is still the need to investigate its validation processes. The objective of the present study was to analyze the validation process of field tests in the literature that evaluated the cardiopulmonary capacity of the elderly. A search was performed on Pubmed, Sportdiscus and Sci-elo databases, as well as manual searches on lists of articles references. The descriptors used from Decis, both plurally and singular, were: a) validation studies; B) physical fitness test and its results. The filters used were: species (human) and type of study (validation studies). After the selection of the studies, the final sample consisted of seven articles. After analysis it was concluded that all tests can be considered valid, although not all of them have gone through all the procedures desirable for a validation process and / or have not been validated with the elderly.

Keywords: Validation process, Field Tests, Cardiorespiratory Capacity, Elderly.
\end{abstract}

\section{INTRODUCTION}

Through the biological perspective, the human's aging process is featured by several physiological changes (Farinatti, 2002), which directly affect the physical capacities (Mazini Filho, et al., 2013), negatively impacting the ability to perform daily life activities (Guadagnin, et al., 2015), reducing functional autonomy (Martinho, et al., 2013).

The regular practice of physical exercises has been widely recommended as a strategy capable of inducing favorable adaptations in the structure and function of different organic systems, as opposed to the deleterious effects of aging (ACSM, 2009), contributing to the promotion of health and autonomy in advanced ages (Nicolau, et al., 2015). Therefore, the physical capacities evaluation of the participants is important, especially the cardiorespiratory, since it has a direct relation with the work capacity and the cardiac risk (Mazini Filho et al., 2013).

Considering that laboratorial cardiorespiratory capacity tests are expensive, different field tests have been developed because they are simple, cheap, and capable of reaching large portions of the population. However, there is still the need to investigate their validation processes, in order to assist the professionals in the area in choosing the test to be used. Thus, the objective of the present study was to analyze the validation processes of field tests in the literature which evaluate the elderly's cardiorespiratory capacity.

\section{METHOD}

The study is characterized as a systematic review, where the following inclusion criteria were adopted to select the studies for analysis: a) validation studies of field tests to evaluate the elderly's cardiopulmonary capacity; B) studies carried out with 60 year-old-human beings or older, healthy and of both sexes; C) studies that presented the methodology of the test in a detailed way; D) studies that presented a test validation strategy in a detailed way.

\footnotetext{
${ }^{1}$ Postgraduate Program in Exercise and Sport Sciences, Rio de Janeiro State University, UERJ, Rio de Janeiro, Brazil

${ }^{2}$ Postgraduate Program in Physical Activity Sciences, University Salgado de Oliveira, Niterói, Rio de Janeiro, Brasil.

* Corresponding author: Postgraduate Program in Exercise and Sports Sciences, Physical Education and Sports Institute, Rio de Janeiro State University (Universidade do Estado do Rio de Janeiro - UERJ) - Rua São Francisco Xavier, 524, João Lira Filho Pavilion, 9th floor, F Block, Maracanã, Rio de January / RJ, Brazil. CEP: 20550-900. Email: gabriela-venturini@hotmail.com
} 
The databases used in the search for the studies were: Scielo, Medline and Sport Discus. Manual searches were also conducted on lists of articles references in order to track potentially important studies to be included and, for some reason, were not shown in the electronic search.

The following search descriptors were used, in the singular and plural, with the recognition of specialized literature: a) validation studies (and its synonyms according to the Mesh terms); B) physical fitness test (and its synonyms according to the Mesh terms). The filters used were: species (human) and type of study (validation studies).

This way, the following search phrase was used: ("validation studies" [Title / Abstract] OR "validation" [Title / Abstract] OR "comparison" "Investigative Technique" [Title / Abstract] OR "Investigative Technique" [Title / Abstract] OR
"Technique, Investigative" [Title / Abstract] ] OR "Technic, Investigative" [Title / Abstract] OR "Technics, Investigative" [Title / Abstract] OR " [Title / Abstract] OR "cardiopulmonary capacity test" [Title / Abstract] OR "exercise test" [Title/Abstract]).

Figure 1 and frame 1 illustrates the selection process of the studies included in the systematic review.

Among the seven selected studies, the following data were analyzed: a) sample - number of individuals, age, clinical status; B) test evaluation criteria; C) validation strategy; D) result of the validation.

The evaluation of the validity and tests reproducibility was done through the correlation table for validation and reproducibility of the measure proposed by Triolla (1999).

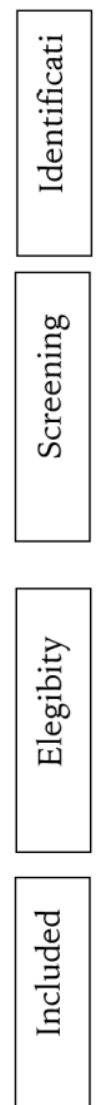

Studies identified in the search database Pubmed $(n=56)$, Sportdiscus $(n=100)$, Scielo $(n=0)$

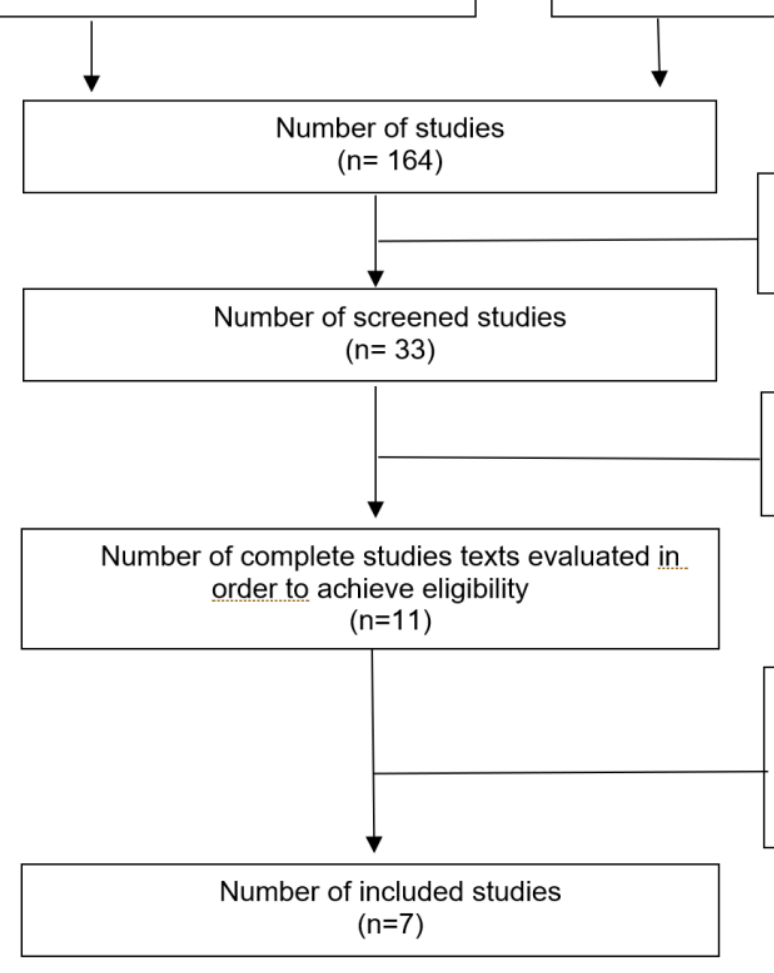

Studies identified in other sources $(n=8)$

Studies excluded after title / abstract reading $(n=131)$

Studies excluded after reading the full text $(n=22)$

Studies excluded after inclusion criteria:

1 - diferent population 3 - non-validated studies

Figure 1. illustrates the selection process of the studies 
Table 1

Value " $r$ ", and validty and objectiviness

\begin{tabular}{lll}
\hline \multicolumn{1}{c}{ Value of "r" } & Validty & Trustworthiness and objectiviness \\
\hline$+0.95-0.99$ & - & Excellent \\
\hline$+0.90-0.94$ & - & Very good \\
\hline$+0.85-0.89$ & Excellent & Acceptable \\
\hline$+0.80-0.75$ & Very good & Acceptable \\
\hline$+0.75-0.79$ & Acceptable & Weak \\
\hline$+0.70-0.74$ & Questionable & Questionable \\
\hline$+0.65-0.69$ & Questionable & Questionable \\
\hline
\end{tabular}

\section{RESULTS}

Table 1 shows the test data included in the present review. Among the seven studies found, three used the walk, one the stationary gait, two the bench, and one the walk or race in order to evaluate the elderly's cardiopulmonary capacity (Frame 2).

\section{DISCUSSION}

The first test presented in Table 1, the 1-Mile Test, aims to evaluate cardiorespiratory capacity through the time spent walking at a distance of 1600 meters and it was developed with 174 young and elderly (30 to 69 years old). In its validation process, Kline et al. (1987) proposed two equations: one used the absolute VO2max (L.min-1) and the second one the relative (mL.kg-1.min-1). The variables selected by Kline et al. (1987), using regression analysis for the elaboration of prediction models, were: age, sex, body weight (BW), heart rate (HR) in the last 15 seconds, and test run time.

One of the analysis used by Kline et al. (1987) to validate the 1-Mile Test was the correlation of VO2max predicted by its models with VO2max measured directly on the treadmill. The authors found for the general prediction equation of absolute VO2max $r=0.93$ and a standard error of 0.3251 .min- 1 . On the other hand, the equation of the prediction of the relative $\mathrm{VO} 2 \mathrm{max}$ obtained a $\mathrm{r}=0.88$ and a standard error of $5.0 \mathrm{~mL} . \mathrm{kg}$ 1.min-1. The author emphasized that the best formula was the absolute VO2max because it showed the smallest standard error. The standard error is the amount of error expected in the prediction, so the lower the error, greater the validity of the formula will be (Thomas, Nelson, Silverman, 2012).

The correlation coefficient values ( $r$ ) indicate the strength of relation between the investigated variables. They range from -1 to +1 . The closer the number 1 to the " $r$ " is, the greater the correlation will be (Mukaka, 2012). In the case of the study by Kline et al. (1987), r values above 0.85 were found, which for Triolla (1999) they are classified as "excellent" for validation studies.

In order to reinforce the validation of the general equation in 1.min-1, the authors used cross-validation in a sample containing 169 individuals and obtained $\mathrm{r}=0.92$ and a standard error equivalent to $0.3351 . \mathrm{min}-1$. No significant differences were found between the mean values observed (2.66 \pm 0.94 l.min-1) and estimated $(2.67 \pm 0.87$ l.min-1). This demonstrates that the equation can be used because it allows reaching very closed values to the observed ones. In general, the data found suggest that the test is valid, however, the author did not test its reproducibility, which may be considered a flaw in its validation process, since testing it is a way to evaluate its consistency (Thomas, Nelson, Silverman, 2012).

Despite the lack of data on its reproducibility, the 1-Mile Test, in general, has been considered safe and applicable as a form of submaximal assessment of cardiorespiratory capacity (Kline et al., 1987), which encouraged other studies to adopt it to validate different evaluation possibilities, such as the ones by Seneli et al. (2013), Mailey et al. (2010) and Jurca et al. (2005), which corroborated its validation. 
Table 2

Presentation of the studies evaluated

\begin{tabular}{|c|c|c|c|c|c|c|}
\hline \multirow{2}{*}{$\begin{array}{c}\text { Study } \\
\text { Test }\end{array}$} & \multirow{2}{*}{ Sample } & \multirow{2}{*}{ Evaluation Criteria } & \multirow{2}{*}{ Validation Strategy } & \multirow{2}{*}{ Prediction Equations of VO2max } & \multicolumn{2}{|c|}{ Triolla's Classification (1999) } \\
\hline & & & & & Validity & Reproducibility \\
\hline $\begin{array}{l}\text { Kline et al. } \\
\text { (1987) } \\
\text { 1-mile test }\end{array}$ & $\begin{array}{l}\mathrm{N}=174 \\
\text { Age: } 30 \text { to } 69 \\
\text { years old } \\
\text { Relatively } \\
\text { healthy }\end{array}$ & $\begin{array}{l}\text { Time spent to walk the } \\
\text { distance of } 1600 \mathrm{~m} \text {. }\end{array}$ & $\begin{array}{l}\text { Multiple regression for model } \\
\text { definition; } \\
\text { Concurrent validity; } \\
\text { Cross-validation; } \\
\text { Calculation of the standard error. }\end{array}$ & $\begin{array}{l}{\left[\mathrm{VO}_{2_{\text {max }}}\left(\mathrm{L} \cdot \mathrm{min}^{-1}\right)=6,9652+0,0201(\mathrm{BW})-0,0257(\mathrm{AG})+0,5955(\mathrm{SEX})-0,2240(\mathrm{~T} 1)-0,0115(\mathrm{HR})\right]} \\
{\left[\mathrm{VO}_{\text {max }}\left(\mathrm{mL} \cdot \mathrm{kg}^{-1} \cdot \mathrm{min}^{-1}\right)=132,853-0,1692(\mathrm{BW})-0,34(\mathrm{ID})+6,315(\mathrm{SEX})-3,2649(\mathrm{~T} 1)-0,1565\right.} \\
(\mathrm{HR})] \\
\mathrm{BW}=\text { body weight; } \mathrm{AG}=\text { Age; } \mathrm{SEX}=\text { men }-1 \text { woman }-0 ; \mathrm{T} 1=\text { route time; } \mathrm{HR}=\text { heart rate in the last fourtl } \\
\text { part of a mile }\end{array}$ & Excellent & 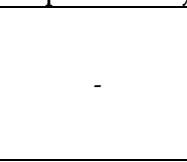 \\
\hline $\begin{array}{l}\text { Oja et al. } \\
(1991) \\
2 \mathrm{~km} \text { test }\end{array}$ & $\begin{array}{l}\mathrm{N}=159 \\
\text { Age: } 20 \text { to65 } \\
\text { years old } \\
\text { Relatively } \\
\text { Healthy }\end{array}$ & $\begin{array}{l}\text { Time spent to walk the } \\
\text { distance of } 2 \mathrm{~km} \text {. }\end{array}$ & $\begin{array}{c}\text { Multiple regression for model } \\
\text { definition; } \\
\text { Multiple correlation between } \\
\text { VO2max and combinations of } \\
\text { predictive variables; } \\
\text { Concurrent validity; } \\
\text { Cross-validation; } \\
\text { Calculation of the standard error. }\end{array}$ & 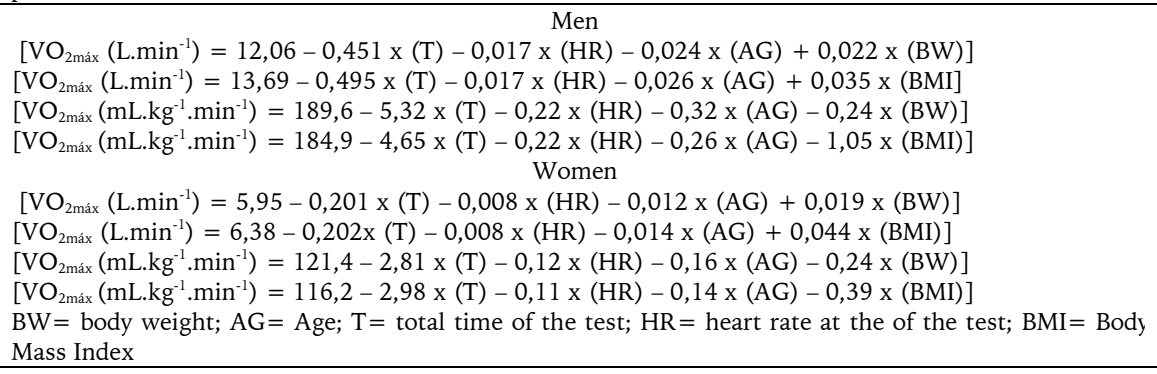 & $\begin{array}{c}\text { Very good; } \\
\text { Excellent }\end{array}$ & $\begin{array}{l}\text { Excellent; } \\
\text { Very good; } \\
\text { Acceptable }\end{array}$ \\
\hline $\begin{array}{l}\text { Rikli,e Jones } \\
\quad(1998) \\
\text { 6WMT }\end{array}$ & $\begin{array}{c}\mathrm{N}=77 \\
\text { Age: } 60 \text { to } 87 \\
\text { years old } \\
\text { Relatively } \\
\text { healthy } \\
\end{array}$ & $\begin{array}{l}\text { Maximum distance } \\
\text { traveled in } 6 \text { ', in a } \\
\text { course of } 46 \text { meters }\end{array}$ & $\begin{array}{l}\text { Validation as to content, criteria } \\
\text { and construct; } \\
\text { Reliability. }\end{array}$ & ( & Acceptable & Excellent \\
\hline $\begin{array}{l}\text { Johnston } \\
\text { (1999) }\end{array}$ & $\begin{array}{l}\mathrm{N}=25 \\
\text { Age: } 60 \text { to } 89 \\
\text { years old; } \\
\text { Relatively } \\
\text { healthy } \\
\end{array}$ & $\begin{array}{l}\text { Maximum number of } \\
\text { right knee elevations } \\
\text { that the individual } \\
\text { performs for } 2 \text { minutes } \\
\text { in stationary gait } \\
\end{array}$ & $\begin{array}{c}\text { Reliability; } \\
\text { Concurrent validity. }\end{array}$ & I & Acceptable & Very Good \\
\hline $\begin{array}{l}\text { Petrella et al. } \\
\quad(2001) \\
\quad \text { SPBT }\end{array}$ & $\begin{array}{c}\mathrm{N}=240 \\
\text { Age } \geq 65 \text { years } \\
\text { old } \\
\text { Relatively } \\
\text { healthy }\end{array}$ & $\begin{array}{l}\text { Time taken to go up and } \\
\text { down two steps }(20 \mathrm{~cm} \\
\text { each), for } 20 \text { times, in } \\
\text { self-selected rhythm }\end{array}$ & $\begin{array}{l}\text { Multiple regression for model } \\
\text { definition; } \\
\text { Reliability; } \\
\text { Concurrent validity; } \\
\text { Cross validation }\end{array}$ & 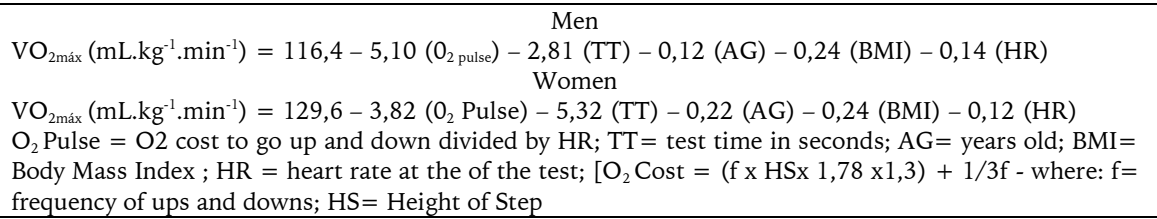 & Very Good & $\begin{array}{l}\text { Excellent; } \\
\text { Very Good }\end{array}$ \\
\hline $\begin{array}{l}\text { Cooper } \\
(1968)\end{array}$ & $\begin{array}{c}\mathrm{N}=115 \\
\text { Age: } 17 \text { to } 52 \\
\text { years old } \\
\text { Healthy } \\
\text { Military }\end{array}$ & $\begin{array}{c}\text { Distance traveled in } 12 \\
\text { minutes }\end{array}$ & $\begin{array}{l}\text { Regression of distance in } 12 \\
\text { minutes according to VO2max; } \\
\text { Concurrent validity; } \\
\text { Reliability }\end{array}$ & $\begin{array}{c}\text { VO2máx }(\mathrm{mL} \cdot \mathrm{kg}-1 \cdot \min -1)=\mathrm{m}-504,9 / 44,73 \\
\qquad \mathrm{M}=\text { traveled distance }\end{array}$ & Excellent & Excellent \\
\hline $\begin{array}{l}\text { Jetté et al. } \\
\text { (1976) }\end{array}$ & $\begin{array}{l}\mathrm{N}=59 \\
\text { Age: } 15 \text { to } 74 \\
\text { years old } \\
\text { Relatively } \\
\text { Healthy }\end{array}$ & $\begin{array}{l}\text { HR } 5 \text { to } 15 \text { seconds after } \\
\text { going up and down the } \\
\text { bench for three minutes }\end{array}$ & $\begin{array}{l}\text { Multiple regression for model } \\
\text { definition } \\
\text { Concurrent validity. }\end{array}$ & VO2máx (mL.kg-1.min-1) =42,5 + 16,6 (VO2) - 0,12 (M) - 0,12 (HRpost) $-0,24$ (AG) & Excellent & - \\
\hline
\end{tabular}


The second test presented in Table 1 is the " 2 km test" of the Urho Kaleva Kekkonen Institute (UKK). It was developed by Oja et al. (1991) to evaluate the cardiopulmonary capacity of young and not-very-old-elderly (20 to 65 years), through the time spent to walk the distance of $2 \mathrm{~km}$. With a sample of 159 individuals, different prediction models were proposed by the authors, who took into consideration different variables selected through a regression analysis. The variables were: age, Body Mass Index (BMI), body weight, total walking time and heart rate (HR) collected at the end of the test.

One of the ways used to validate the $2 \mathrm{~km}$ test was its correlation with the VO2max measured directly on the treadmill. According to the classification proposed by Triolla (1999), the formulas developed by Oja et al. (1991) who presented "excellent" correlation were: the absolute VO2max which considered Body Weight (BW) for men; The relative VO2max which considered BW for women; and those who considered BMI for both, once they had a correlation coefficient above 0.85 . The other formulas were classified as "very good" because they presented the correlation coefficient between 0.80 and 0.84 . In general, all formulas presented a good correlation. The model that adopted the BW produced correlation coefficients between the measured absolute VO2max and the estimated equivalent to 0.85 for males and 0.82 for females and, respectively, 0.81 and 0.87 for the relative. The model that adopted BMI generated coefficients of 0.81 for men and women when correlated with absolute $\mathrm{VO} 2 \mathrm{max}$ and 0.86 for relative VO2max.

Standard error values equivalent to 0.46 for men and 0.19 for women were found in the absolute VO2max and 6.2 for men and 3.0 for women in the VO2max relative formulas that used BW. For the formulas that used BMI, 0.51 were found for men and 0.20 for women, regarding absolute VO2max; and 5.1 for men and 3.3 for women, related to the relative VO2max. These data show that the formulas that had the least prediction error were those referring to absolute VO2max for women.
Another strategy used by the authors was the test-retest of men and women to obtain correlation coefficients of, respectively, $r=0.95$ and $\mathrm{r}=0.93$ for $\mathrm{T} ; \mathrm{R}=0.89$ and $\mathrm{r}=0.84$ for $\mathrm{HR} ; \mathrm{R}=0.98$ and $\mathrm{r}=0.91$ for absolute VO2max; $R=0.98$ and $r=0.94$ for the relative. These results indicate that the reproducibility of the $2 \mathrm{Km}$ Test may be considered acceptable. Considering that most of the variables obtained values above 0.94 (classified as "very good", according to Triolla, 1999), it can be said that such measures were reliable.

Oja et al. (1991) also used a cross-validation, using only the formula that used the BMI, which occurred through the correlation between estimated VO2max in the $2 \mathrm{~km}$ test and the one measured directly on the treadmill, where the results varied according to the characteristics of the individuals. The proposed model yielded reasonable accuracy in obese men and women and in moderately active men (0.69-0.84) and lower precision in moderately active and highly active men (0.29-0.56).

As with the 1-Mile Test, the results presented by the 2-km Test boosted other experiments, such as Laukkanen's (2000), who sought to investigate the accuracy of the test developed by Oja et al. (1991), concluding that the UKK Institute Test fairly estimates aerobic power.

It is worth noting that, despite the fact that the 1-mile and 2-km tests are considered adequate, both were not validated with older individuals, which may be a limitation for their application in the general elderly population, which is getting older and older as time passes by.

Differently from the tests developed and validated by Kline et al. (1987) and Oja et al. (1991), Rikli and Jones (1998) proposed the "6-Minute Walk Test" (6MWT) exclusively for the elderly (60-87 years), which takes into consideration the maximum distance the individual can walk for 6 minutes.

For Thomas, Nelson and Silverman (2012), the validity of measurements shows in which degree the test or the instrument measures what it is intended to be measured; and it can be 
categorized as logical validity, content, criterion, or construct. The validities used by the authors in the 6MWT with 77 individuals were criterion, content and construct.

Based on Thomas, Nelson and Silverman (2012), criterion validity is understood as the degree in which the test scores relate to some recognized standard. Content validity shows the degree in which the test exemplifies or applies to what it is intended to be evaluated, while the construct validity shows the degree in which the test measures a hypothetical construct, regarding presented results.

In the case of the 6MWT, the validity of the content was determined through the definition of physical fitness as a theme and the criterion validity through the correlation between the distance walked on the 6MWT and the submaximal treadmill walk time through the Balke protocol, when it was up to $85 \%$ of predicted HRmax $(r=0.78)$; This correlation value is considered "acceptable" according to the classification of validity proposed by Triolla (1999) and indicates good criterion validity. The submaximal physical performance was chosen as a criterion measure due to its great relevance to the functional capacity of the elderly.

Regarding the construct validity, it was tested through self-report about the physical fitness of the elderly, using a simple questionnaire about frequency and intensity of the exercises performed. This validity was determined by the group differences method and demonstrated by the ability of the test to detect differences in performance from one age group to another and from highly active versus non-active people.

The reproducibility of the 6MWT was established by calculating the interclass correlation coefficient, using a one-way analysis of variance (anova), obtaining $r=0.94$, being characterized as "excellent". The test also detected declines in expected performance by age group and differentiated high and low levels of physical activity from individuals.

It must be said that 6MWT did not undergo cross-validation (which helps estimate the retraction of predictive validity) and that, more recently, Gobbi et al. (2012), analyzed the validity of the 6MWT in relation to the fatigue time and, consequently, the aerobic capacity, concluding that the test has only moderate validity when the criterion fatigue time is used. In spite of these facts, the study by Rikli and Jones (1998) presented a detailed validation strategy and was validated exclusively with elderly individuals aged from 60 to 87 years, thus reaching older individuals.

With similar aim to the studies presented here, Johnston (1999) validated the "2-minute Stationary Gait Test" (2SGT) with 25 elderly (6089 years old) using the same strategies of the 6MWT and was included in the "Physical Fitness Test For the Elderly "by Rikli and Jones (1998), as an alternative test to be used when time, space, or climate precludes the application of the $6 \mathrm{MWT}$. Their classification is given by the number of times the right knee reaches a level previously determined according to the midpoint of the thigh of the assessed person. The scores for this test were correlated with Rockport's 1-mile walk and treadmill walk for the elderly, using the Bruce protocol, and presented a $r=0.74$, considered "acceptable" for validation studies as well as the reliability test-retest showed a $\mathrm{r}=$ 0.90, considered "very good" for its reproducibility (Triolla, 1999).

It should also be highlighted the fact that 2SGT, as well as the MWT, was validated exclusively with elderly individuals aged from 60 to 87 years old and could be applied in older individuals.

The fifth test presented in Table 1 is the "SelfPaced Bank Test" (SPBT), which considers the time taken to go up and down two $20 \mathrm{~cm}$ steps each, 20 times, in a self-selected rhythm. It was validated by Petrella et al. (2001) with 240 elderly people older than 65 years old, proposing different equations for men and women due to the fact that the execution time was higher in the women's test. The variables selected for the elaboration of the prediction models through the regression analysis were: $\mathrm{O} 2$ pulse (ratio of $\mathrm{O} 2$ cost to go up and down the steps and heart rate), 
test time, age, body mass index (BMI), heart-rate (HR) and height of the step (HS).

For validation of the SPBT, a correlation between the VO2max observed in the maximum treadmill test and the proposed test was obtained, in which $r=0.93$ in women and $r=0.91$ in men; Which suggests a high degree of validity (Triolla, 1999). However, the standard error was not calculated. The test also presented a testretest correlation coefficient for the test time of 0.90 for men and 0.93 for the women; 0.96 for men and 0.92 for women for HR; and 0.97 for man and 0.98 for woman for the estimated VO2max, presenting values classified as "very good" and "excellent" for reproducibility, respectively (Triolla, 1999).

Cross-validation of SPBT was performed in order to test the accuracy of its predictive models with 70 individuals, 30 hypertensives and 40 hip arthroplasty patients. There was a slight underestimation tendency of the $\mathrm{VO} 2 \mathrm{max}$ observed directly in the groups, however, these differences were small: $3 \%$ in the hypertensive group and $7 \%$ in the arthroplasty group. The correlation coefficients ranged from 0.75 to 0.80 in the hypertensive group and 0.82 and 0.94 in the arthroplasty group. These results did not show significant difference for the main group using the predictive model. However, the group that presented the best values was the arthroplasty one, as it revealed a correlation coefficient above 0.80 ; The other group showed lower but acceptable values (Triolla, 1999).

As with other tests, different authors also tried to verify the effectiveness of SPBT, demonstrating contradictions in their conclusions. Hansen et al. (2011), for example, compared HR and VO2max in SPBT with those found in maximal cardiopulmonary test, finding significant differences in the responses of the two tests $(\mathrm{p}<0.01)$ and also suggested that the test should always be applied in the presence of a doctor, questioning its safety. Contrary to Hansen et al. (2011), in the defense of SPBT, Stuckey et al. (2012) report that the test has been used with relative safety with patients who have cardiovascular diseases, but emphasize the importance of the accurate compliance of the validated protocol, as well as the self-collecting variables control.

The 12-minute test (CT12), validated by Cooper (1968) with 115 military people with the age of 17 to 52 years old, used a unique formula, which its proposed model adopted the distance variable, based on the study of Balke (1952). For the prediction of the VO2max, a regression of the traveled distance in 12 minutes (walking or running) was performed in function of the oxygen consumption. For its validation a correlation was calculated between the VO2max observed in the treadmill test and the predicted one in the test created, presenting $r=0.897$. Although the value of the correlation coefficient was classified as "excellent" (Triolla, 1999), a multiple regression analysis was not performed to analyze whether other variables had a relation or strength to be included in the formula. It is worth mentioning that the author also did not perform the calculation of the standard error, in order to check the amount of error.

The CT12 had its reliability tested in 149 different young individuals of the original sample, and obtained $r=0.976$, indicating "excellent" reproducibility (Triolla, 1999), however, no cross-validation was performed.

Although not validated with the elderly, this test was included in our analysis because the author proposed values of cardiovascular capacity for individuals over 60 years old (Cooper, 1982) and because of that it has been used by several authors as a tool to evaluate the cardiorespiratory capacity of this population.

Emtner et al. (2014), for example, carried out a study to verify changes in fat-free mass after the physical abilities training of 27 elderly people with chronic obstructive pulmonary disease (COPD) and CT12 was used to verify functional exercise capacity. Silva and Maranhão Neto (2006) used CT12 to evaluate 135 women (21-84 years) practicing water aerobics. The proposal was to adapt such a test to the shallow pool, given the lack of specific tests for water aerobics.

The last test presented in Table 1 is the Canadian Home Fitness Test (CHFT) by Jetté et 
al. (1976). The CHFT was developed as a motivational tool to improve the cardiorespiratory capacity of Canadians, in a selfmanageable way, making their adherence easier. The test is based on the HR found at 5 and 15 seconds after the assessed individual go up and down from a two-step bench $(20.3 \mathrm{~cm}$ each) to the sound of a progressive rhythm song (preestablished according to gender and age), during seven sessions for men and six for women. It was elaborated and marketed in a CD that has a manual of explanation and songs suitable for the ages and sexes, as well as the classification of the cardiorespiratory capacity by age and sex. This test was validated with 59 subjects aged from 15 to 74 years and proposed a general equation, obtaining $\mathrm{r}=0.905$ between the predicted VO2max and the one observed on a treadmill, being classified as "excellent"; However, it presented a standard error of $4.08 \mathrm{~mL} . \mathrm{kg}-1 . \mathrm{min}$ 1, considered high for validation studies (Triolla, 1999). A multiple regression equation was defined for a proposal to estimate the classification of the cardiorespiratory capacity level; the model considered age and sex. It should be emphasized that the standard error, the crossvalidation test, or its reproducibility were not calculated, which suggests a questionable validity.

In 1980, Roy Shepard published an opinion piece advocating CHFT, claiming that it was designed to mass-serve the population, as well as stimulate the practice of physical activity at home. In his text, he mentioned several studies that reproduced the test and obtained results similar to those in the original study, defending its validation, highlighting that 500,000 copies of the CD had been sold.

Weller et al. (1993) developed a study to increase the precision of CHFT prediction, modifying the protocol and developing a new equation.

A group of 129 individuals (from 15 to 69 years old, both sexes) underwent CHFT-modified and a maximum treadmill test. The modification of the protocol was to allow each individual to complete the number of sessions required to achieve $85 \%$ of the maximum predicted HR for the age. This required the addition of one session for men and two for women.

Later, Weller et al. (1995) evaluated the CHFT-modified predictive capacity in a sample of 154 individuals (from 15 to 69 yearsold, both sexes) comparing it with the original test and relating both to the treadmill maximum test. The results showed that the strength of the linear relationship between predicted and observed values would be the same for both CHFTmodified $(r=0.88)$ and original CHFT $(r=$ 0.89). No further studies were found using CHFT with the elderly.

\section{CONCLUSION}

We conclude that all the different field tests that evaluate the cardiorespiratory capacity in the elderly found in our search can be considered valid. However, through a more detailed analysis it was possible to identify that not all have gone through all the desirable procedures for a validation process, such as the calculation of the standard error, the cross-validation test, and the reproducibility, which suggests a questionable validity by some studies.

Likewise, not all of them were validated with elderly and younger elderly, which makes it difficult its application in this population, which is increasingly frequent in physical exercise spaces.

Acknowledgments:

We thank our translator, Lucas de Assis Borges, for the translation of this article from Portuguese to English

Conflict of interests:

Nothing to declare

Funding:

Nothing to declare

\section{REFERENCES}

American College Of Sports Medicine Position Stand. (2009). Exercise and physical activity for older adults. Sport Med Sci Exer, 41(7), 1510-30. doi: 10.1249 / MSS.0b013e3181a0c95c 
Cooper, KH (1968). A means of assessing maximal oxygen uptake. Jama, 203(2), 201-204. doi: 10.1001 / jama.1968.03140030033008

Cooper, GE (1982). Aerobic capacity and oxygen debt related to canoe racing performance. Brit $J$ Sport Med, 16, 111-112. doi: 10.1136 / bjsm.16.2.111-a

Emtner, M .; Hallin, R .; Arnardottir, R .; H. Janson, C. (2015). Effect of physical training on fat-free mass in patients with chronic obstructive pulmonary disease (COPD). Upsala J Med Sci, 120(1), 5258. doi: 10.3109 / 03009734.2014.990124

Farinatti, PTV (2002). Biological theories of aging: from the genetic to the stochastic. Bras Med Sport Journal (Rev Bras Med Esporte) 8 (4), 129-138. doi: 10.1590 / S1517-86922002000400001

Gobbi, S .; Oliani, MM; Lopes, AG; Coutinho, GF; Bucken, LT; Costa, JLR (2012). Validity of the 6 minute-march test for the elderly in relation to the time of fatigue. Bras Journal Phys Activ Health Journal (Rev Bras Ativ Fis Saúde), 11 (1), 1318. doi: 10.12820 / rbafs.v.11n1p13-18

Guadagnin, EC; Da Rocha, ES; Mota, CB; Carpes, FP (2015). Effects of regular exercise and dual tasking on spatial and temporal parameters of obstacle negotiation in elderly women. Posture Gait, 42 (3), 251-256. doi: 10.1016 / j.gaitpost.2015.05.012

Hansen, D .; Jacobs, N .; Bex, S .; D'haene, G .; Dendale, P .; Claes, N. (2011). Are fixed-rate step tests medically safe for assessing physical fitness? Eur J Appl Physiol, 111 (10), 25932599. doi: 10.1007 / s00421-011-1886-3

Jette, M .; Campbell, J .; Mongeon, J .; Routhier, R. (1976). The Canadian home fitness test as a predictor of aerobic capacity. Can Med Assoc J, 114, 680-682.

Johnston, J. (1999). Validation of a 2-minute step-inplace test realist to treadmill performance in older adults. Unpublished master's thesis. California State University, Fullerton.

Jurca, R .; Jackson, AS; Lamonte, MJ; Morrow, JR; Blair, SN; Wareham, NJ; Haskell, WL; Van, MW; Church, TS; Jakicic, JM; Laukkanen, R. (2005). Assessing cardiorespiratory fitness without performing exercise testing. Am J Prev Med 29 (3), 185-93. Doi: 10.1016 / j.amepre.2005.06.004

Kline, GM; Porcari, JP; Hintermeister, R .; Freedson, PS; Ward, A .; Mccarron, RF; Ross, J .; Rippe, JM (1987). Estimation of VO2max from a one-mile track walk, gender, age and weight bogy. Exer Sport Med Sci, 19, 253-9.

Mazini Filho, ML; Matos, DG; Rodrigues, BM; Aidar, FJ; VenTurini, GRO; Salgueiro, RS; Hickner,
RC; Lima, JRP (2013). The effects of 16 weeks of exercise on metabolic parameters, blood pressure, body mass index and functional autonomy in elderly women. SportMed International Journal, 14 (2), 86-93.

Mailey, EL; White, SM; Wojcicki, TR; Szabo, AN; Kramer, AF; Mcauley, E. (2010). Construct validation of a non-exercise measure of cardiorespiratory fitness in older adults. BMC Public Health, 8 (10), 327-345. doi: 10.1186 / 1471-2458-10-59

Nicolau, S .; Maecenas, AP; De Freita, CMSM (2015). Elderly practitioners of physical activity: perspectives on the aging of the population. Sci Helth Files (Arq Ciênc Saúde), 22 (2), 69-74. doi: 10.17696 / 2318-3691.22.2.2015.146

Oja, P .; Laukkanen, M .; Pasanen, T.; Tyry, I. (1991). A $2-\mathrm{km}$ walking test for assesing the cardiorespiratory fitness of healthy adults. Int $J$ Sports Med, 12, 356-362. doi: 10.1055 / s-20071024694

Petrella, RJ; Koval, JJ; Cunningham, DA; Paterson, DH (2001). A self-paced test to predict aerobic fitness in older adults in the primary care clinic. $J \mathrm{Am}$ Geriatr Soc, 49, 632-638. doi: 10.1046 / j.15325415.2001.49124.x

Rikli, RE; Jones, CJ (1998). The validity and reliability of a 6-minute walk test as a measure of physical endurance in older adults. $J$ Phys Activ Aging, 6, 363-375. doi: 10.1123 / japa.6.4.363

Triola, MF (1999). Introduction to statistics. 7. ed. Rio de Janeiro: LTC.

Weller, IMR; Thomas, SG; Corey, PN; Cox, MH (1993). Prediction of maximal oxygen uptake from a modified canadian aerobic fitness test. Can J Appl Physiol 18 (2), 175-188. Doi: 10.1139 / h93-014.

Seneli, RM; Ebersole, KT; O'connor, KM; Snyder, AC (2013). Estimated v (o2) max from the rockport walk test on a nonmotorized curved treadmill. J Strength Cond Res, 27 (12) 3495-505. Doi: 10.1519 / JSC.0b013e31828f04d8

Silva, MHA; Maranhão Neto, GA (2006). Proposed test run in shallow pool for women practicing water aerobics: reliability and classification of traveled distance. Bras Med Sport Journal (Rev Bras Med Esporte), 12 (4), 206-210. doi: 10.1590 / S151786922006000400008

Stuckey, M .; Knight, E .; Petrella, RJ (2012). The step test and exercise prescription tool in primary care: a critical review. Physical Medicine and Rehabilitation, 24, 1-2. doi: 10.1615 / doi: 10.1615/CritRevPhysRehabilMed.2013006823 


\section{UINURSIDADE BEIRA INTERIOR \\ http://http://www.ubi.pt

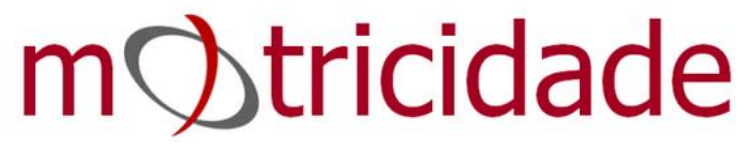

http://revistas.rcaap.pt/motricidade 